

\section{Suburban Urbanities}





\title{
Suburban Urbanities
}

Suburbs and the Life of the High Street

\author{
Edited by \\ Laura Vaughan
}

UCLPRESS 
First published in 2015 by

UCL Press

University College London,

Gower Street,

London WC1E 6BT

Available to download free: www.ucl.ac.uk/ucl-press

Text (C) Contributors 2015

Images (C) Contributors and copyright holders named in the captions

A CIP catalogue record for this book is available

from The British Library

This book is published under a Creative Commons Attribution Non-commercial Non-derivative 4.0 International license (CC BY-NC-ND 4.0). This license allows you to share, copy, distribute and transmit the work for personal and non-commercial use providing author and publisher attribution is clearly stated. Further details about CC BY licenses are available at http://creativecommons.org/licenses/by/4.O

ISBN: 978-1-910634-14-1 (Hbk.)

978-1-910634-13-4 (Pbk.)

978-1-910634-17-2 (PDF)

978-1-910634-15-8 (epub)

978-1-910634-16-5 (mobi)

DOI: 10.14324/111.9781910634134 
To Neil and Daniel from ' $U$ ' 



\section{Foreword}

In recent years there has been much debate within urban studies as to which came first in the evolution of human settlements, the countryside or the city. There was always a third context to this discussion, however, and that was the suburb. Life beyond the city walls was a distinctive feature of ancient urban civilisations from Persia to Minoan Crete, and today in the Anglophone world the suburban population is a majority. How surprising, then, that few scholars have attempted to understand the nature and agency of suburban living as a dominant characteristic of human settlements. This was symptomatic of a wider academic indifference and even hostility towards 'the suburban' which has only (ridiculously) recently been challenged by a new generation of scholars who take suburbs seriously.

Suburban Urbanities is a hugely important contribution to understanding our suburban world. Drawing upon scholarship within the now rapidly expanding field of suburban studies, synthesising historical geography with space syntax theories and methods, and the sociology of everyday life, it sheds new light on the historic and spatial evolution of the city. It shows that suburbia is not a synchronic caricature of a life-less-lived, but a dynamic context of metropolitan agency and creativity. As an historic process, suburbanisation is not something that evolved beyond the city to suck the life out of it, but was intertwined with trajectories of growth, with the socioeconomic patterning and structuring of cities large and small. It is impossible to grasp the meaning of class relations, of gendered lifestyles, of ethnic segregation and integration, of urban economies and patterns of mobility and communications, without placing suburbia at the forefront of the analysis. The universality of the themes of Suburban Urbanities is obvious: the dynamics of growth are significant historically because suburbs are starting points in change over time, not the end of the line. Old suburbs were once new, and today's new suburbs, springing up rapidly across the world, will one day be old. As dynamic environments they continue to act as vectors of social, economic and political development, locally, nationally and globally.

The book is timely in another important sphere, and that is the personal subjectivity of suburbanites. To those who live in them, suburban lives 
have meaning. Back in 2013, I went for a walk in Fort Totten, an AfricanAmerican suburb of Washington, DC. On a sweltering August lunchtime, as I took photographs of the comfortable suburban homes of middle-class black people in roads that were empty except for flowering trees and parked cars, a woman's voice called out to me with a gentle but audible 'good afternoon'. Across her neatly trimmed front lawn I began chatting with a woman in her sixties who was taking tea with a friend on her veranda. She had left downtown DC in 1976 and as she stated with some passion, 'I couldn't wait to get out'. Fort Totten had its problems, but it was an attractive and spacious place to raise children, and well connected to the city. Her story is an important one because it is one of millions of inconvenient truths being ushered out of view by the current urban policies that demonise suburbia, and by the retro-fitting of suburbs that were, until very recently, doing just fine. Myriad examples of successful suburban living and suburban happiness and of triumph over social exclusion can be found if academics want to look for them. Suburban Urbanities looks for them, and understands that they are part of an ongoing pattern of human settlement that stretches from the ancient past to the present, and will persist long into the future.

\author{
Mark Clapson \\ Reader in History \\ University of Westminster
}




\section{Preface}

This book has taken shape over many years, as part of an ongoing consideration of the way in which society and urban form interact over time. My research focus on the suburbs was first sparked by Professor Bill Hillier, who liked to tease me, as his student on the Bartlett's MSc Advanced Architectural Studies, as being 'just a girl from Edgware' (despite my having spent much of my life till then in the suburbs of Jerusalem). This very much echoes the experience of my predecessor at the Bartlett, Ian Davis, almost exactly forty years earlier. In 'Dunroamin', Davis describes his own first day at the Bartlett School of Architecture in 1953, putting down 'Edgware' as his address and being advised by his tutor that he should make rapid plans to move from there to a more 'civilised address, such as Camden Town'.' Subsequently, my reading of Mark Clapson's essential histories of the working-class suburb opened my eyes up to alternative narratives of the twentieth-century suburban experience. I should also mention the series of exchanges with Vesna Goldsworthy, whose 'The Good Life' conference at Kingston University in 2004 formalised suburban studies as a field of academic research in its own right. Shortly after the conference Vesna and I wrote a proposal for a multidisciplinary book on suburban studies, which, although never realised, helped seed the idea for this book in its current guise.

The urban theories of Bill Hillier, Julienne Hanson and Alan Penn at the UCL Space Syntax Laboratory, Bartlett School of Architecture, have deeply influenced my thinking about how cities grow and change. Amongst many of my other colleagues elsewhere at UCL I would like to particularly mention the work on high streets by Matthew Carmona of the Bartlett School of Planning. Last, but not least, I would like to mention the vital contribution that my research colleagues Muki Haklay and Sam Griffiths have made to the creation of this book. Our weekly discussions over coffee and cake influenced my own reflections of the suburbs as being as complex as the city itself. Essential to this understanding was Muki's thinking regarding interdisciplinary research and the nature of space in geography, as well as Sam's urban historian's conception of the temporality of urban form. 
The financial support from the UK research councils transformed what had started off as old-fashioned scholarship - carried out alongside the myriad responsibilities of a busy academic - into two vast enterprises of scientific research. I close by acknowledging and expressing my gratitude for this support. ${ }^{2}$

\section{Notes}

1 Oliver et al. (1981: 27).

2 The two research projects in question were: Funded by UK EPSRC Grant no. EP/ Do6595X/1 (2006-9) 'Towards Successful Suburban Town Centres: a study of the relationship between morphology, sociability, economics and accessibility'. Project team: Laura Vaughan and Muki Haklay with Sam Griffiths and Catherine (Kate) Emma Jones.
Funded by UK EPSRC/ESRC Grant no. EP/loo1212/1 (2010-13) 'Adaptable Suburbs: a study of the relationship between networks of human activity and the changing form of urban and suburban centres through time'. Project team: Laura Vaughan, Claire Ellul, Muki Haklay, Sam Griffiths and Victor Buchli with Patrick Rickles, Ashley Dhanani and David Jeevendrampillai. 


\section{Contents}

List of Figures and Plates xiii

List of Tables $\quad x x$

List of Contributors $\quad$ xxii

Introduction Suburbs are as Old as the City Itself 1 Laura Vaughan

Part A: Theoretical Preliminaries 9

$\begin{array}{lll}\text { Chapter } 1 \text { The Suburb and the City } & 11\end{array}$ Laura Vaughan, Sam Griffiths and Muki Haklay

Chapter 2 The High Street as a Morphological Event Sam Griffiths

\section{Part B: Suburban Centralities 51}

Chapter 3 Suburban Continuity and Change

Ashley Dhanani

Chapter 4 Spatial Memory and Shifting Centrality

Nadia Charalambous and Ilaria Geddes

Chapter 5 Street Quality, Street Life, Street Centrality

Adel M. Remali, Sergio Porta, Ombretta Romice and Huyam Abudib

Chapter 6 Beyond Lively Streets

Borja Ruiz-Apilánez, Mayte Arnaiz and José M. De Ureña 
Part C: High Street Diversity 151

Chapter 7 High Street Diversity

Laura Vaughan

Chapter 8 High Street Transactions and Interactions

Garyfalia Palaiologou

Case Study 1 High Street Productivity

204

Fiona Scott

Case Study 2 High Streets and the Pedestrian Realm

Yodan Rofè, Galit Yerushalmi, Moshe Margalith and Ahuva Windsor

Part D: Everyday Sociability 237

Chapter 9 Street Interaction and Social Inclusion

Ann Legeby, Meta Berghauser Pont and Lars Marcus

Chapter 10 Sociability and Ethnic Identity

Angela Piragauta

Chapter 11 Being Suburban

287

David Jeevendrampillai

Glossary of Space Syntax

References

Index 


\section{List of Figures and Plates}

*Plates refer to images in case studies.

Figure 1.1: Relief of the Elamite city of Madaktu, Persia showing suburban growth beyond the walls (668-627 BCE)

Figure 1.2: $\quad$ Sir Richard Steele's Cottage, Hampstead by John Constable (1831-2) 5

Figure 2.1 (a): Villages to the north-west of Sheffield c.1795 35

Figure 2.1 (b): Villages to the north of London c.1820 35

Figure 2.2: Montage view of Willesden High Road c.1920s and $c .2010$

Figure 2.3 (a): High Street, South Norwood c.1905 38

Figure 2.3 (b): High Street, South Norwood 1956

Figure 2.3 (c): High Street, South Norwood 2015

Figure 3.1: London-wide street network dataset with $\mathrm{M}_{25}$ ring-road overlaid highlighted in red 60

Figure 3.2: Street network evolution of High Barnet and Loughton 62

Figure 3.3: Street network evolution of Surbiton and South

Norwood 62

Figure 3.4: Maps showing constraints to growth; Epping Forest adjacent to Loughton and Hampton Court Palace and Hampton Court Park adjacent to Surbiton

Figure 3.5: $\quad$ Street network density $\left(\mathrm{km} / \mathrm{km}^{2}\right)$ from 1880 to 2013 in each case study

Figure 3.6: Map showing analysis subdivisions of London street network

Figure 3.7: Historical network density changes in case studies in comparison to contemporary London network subdivisions 
Figure 3.8: Comparison of junction density change in four case study areas in comparison to contemporary London network subdivisions

Figure 3.9: Comparison of junction to dead end ratio change in case studies in comparison to contemporary London network subdivisions

Figure 3.10: Map showing the development of dead ends during network growth and parcel subdivision in South Norwood 69

Figure 3.11: Transformation of Kingston By-Pass junction in Surbiton study area showing maps of the highlighted area for 1880, 1910, 1960 and 2013

Figure 3.12: First section of the Kingston By-Pass is opened to the public in 1927

Figure 4.1: Tourist map of Limassol during the Colonial period from Mangoian and Mangoian (1947)

Figure 4.2: Diagram of Limassol's main routes, zones and car parks, 2011

Figure 4.3: Admiralty chart of Limassol, 1849, drawn by Lieut. Lord John T. Browne 82

Figure 4.4: Map of Limassol in 1883 from Rodney (2001) 83

Figure 4.5: $\quad$ Map of Limassol (detail) from 2011 Selas (2011) 84

Figure 4.6: Characteristics of Anexartisias street 86

Figure 4.7: Characteristics of Makriou street 87

Figure 4.8: Multi-scale accessibility core of Limassol 92

Figure 4.9: Distribution of land uses in the area of Anexartisias 95

Figure 4.10: Distribution of land uses in the area of Makariou 96

Figure 4.11: Proportion of land uses on Anexartisias and Makariou 97

Figure 4.12: Average pedestrian and vehicular movement per hour in the surveyed areas

Figure 4.13: Distribution of land uses and pedestrian movement peak (12:00-14:00) on the two high streets 98

Figure 5.1: The three character areas in Tripoli's city centre: Old Town, Italian Quarter and Garden City

Figure 5.2: The MCA analysis of street centrality over Tripoli city centre 
Figure 5.3: $\quad$ The three case studies are $400 \mathrm{~m} \times 400 \mathrm{~m}$ areas centred on highly central streets in the three character areas $\quad 115$

Figure 5.4: Street centrality in the three case studies 115

Figure 5.5a: Old Town: street front quality map 117

Figure 5.5b: Italian Quarter: street front quality map $\quad 118$

Figure 5.5C: Garden City: street front quality map 119

Figure 5.5d: Old Town, Italian Quarter and Garden City: overall quality

Figure 5.6: Old Town, Italian Quarter and Garden City: quality amount per class of quality

Figure 5.7: Old Town, Italian Quarter and Garden City: human activities and street quality at peak and non-peak times 126

Figure 6.1: $\quad$ Map of the contemporary city of Toledo

Figure 6.2: The study area, showing Zocodover Square, Town Hall Square, and the high street linking them

Figure 6.3: Total pedestrian volumes on Wednesday (08:00-20:00) in the study area

Figure 6.4: Total pedestrian volumes on Saturday (09:00-21:00) in the study area

Figure 6.5: Percentage of visitors from total pedestrian volume on Wednesday (08:00-20:00) in the study area

Figure 6.6: Percentage of visitors from total pedestrian volume on Saturday (09:00-21:00) in the study area

Figure 6.7: Average pedestrian volume per hour in the high street and its side streets on Wednesday

Figure 6.8: Average pedestrian volume per hour in the high street and its side streets on Saturday

Figure 6.9: Distribution of stationary activities in Town Hall Square, the high street and Zocodover Square

Figure 6.10: Town Hall Square from the high street

Figure 6.11: The high street. Comercio Street towards Town Hall Square

Figure 6.12: Zocodover Square from the north entrance

Figure 6.13: Distribution of ground-floor land uses in 1995 and in 2014 
Figure 6.14: Distribution of the retail sector in 1996 and 2014

Figure 6.15: Percentages of visitor customers in ground-floor units 144

Figure 6.16: Distribution of frontages according to the visitor-/ non-visitor-oriented image

Figure 6.17: Evolution of normalised angular integration (NAIN) for four different time periods for the city of Toledo

Figure 7.1: Non-domestic land uses in Surbiton in 1880, 1910, 1960 and 2013

Figure 7.2: Weighted counts of land uses in the four study areas across time

160

Figure 7.3: Non-domestic land uses around Surbiton town centre in 1880, 1910, 1960 and 2013

Figure 7.4: Pie charts showing average building area by use class for Surbiton in 1880, 1910, 1960 and 2013

Figure 7.5: Traffic on South Norwood high street $c .2008$ 165

Figure 7.6: Line chart showing overlap between radius $400 \mathrm{~m}$, 800m, 1200m, 1600m, 2000m, 3000m and 4000m

Figure 7.7: Contemporary map of South Norwood street layout surrounding the town centre overlaid with segment angular integration $800 \mathrm{~m}$

Figure 7.8: Non-domestic land uses, Victoria Road, Surbiton in 1880, 1910, 1960 and 2013

Figure 7.9: Axonometric projection of the built form changes over time on the north side of Victoria Road, Surbiton 169

Figure 7.10(a): Victoria Road, Surbiton 1907

Figure 7.10(b): Victoria Road, Surbiton 2014

Figure 8.1: Islington, London: Upper Street and surroundings (c.2013)

Figure 8.2: Islington, London, c.1805. A plan of Islington and its environs

Figure 8.3: $\quad$ Section of Charles Booth Maps Descriptive of London Poverty 1898-99 showing Islington, London, c.1898-9 181

Figure 8.4: $\quad$ Upper Street and surroundings. Showing segment length weighted measures for choice and integration, C.2013 183

Figure 8.5: $\quad$ Upper Street and surroundings. Showing segment angular analysis for the measure of combined integration and choice, for radius 2,500m, c.2013 
Figure 8.6: $\quad$ Upper Street and surroundings. Showing building entrances and associated land use classified as domestic or non-domestic, c.2013

Figure 8.7: $\quad$ Upper Street - west and east street sides. Showing building entrances and associated land use, c.2013

Figure 8.8: $\quad$ Upper Street - northern, middle and southern sections. Showing visibility fields and community buildings, c. 2013

Figure 8.9: Islington, London: historical street network, c.1910, c.1965. Showing grid transformations and segment angular analysis for the measure of combined integration and choice, for radius $2500 \mathrm{~m}$

Figure 8.10: Islington, London: historical street network, c.1910, c.1965. Showing segment angular analysis for the measure of normalised choice, for radius $n$

Figure 8.11: Upper Street - historical built form transformations. Showing building footprints for $c .1875,1910,1965$ and 2013

Figure 8.12: 133 Upper Street

Plate 1.1: $\quad$ Map showing network of over 600 London high street locations

Plate 1.2: Hand sketch illustrating high street urban blocks on Roman Road (A1818), Redbridge, London: a spiritualist church, a tile wholesaler, a Caribbean restaurant and a Punjabi bakery, amongst other uses

Plate 1.3: Hand sketch illustrating high street urban blocks on Roman Road (A1818), Redbridge, London: a recycling centre, learning centre and crèche, café, amongst other uses

Plate 1.4: Hand sketch illustrating high street urban blocks on Roman Road (A1818), Redbridge, London: Seven Kings parade of shops including mosque, nightclub and other uses

Plate 1.5: $\quad$ Aerial view showing extent of employment study areas in the Upper Lea Valley

Plate 1.6: Cox Workshop, Tottenham

Plate 1.7: Rosamanda Pleaters, Tottenham

Plate 1.8: $\quad$ 'From Around Here Shop' exhibition of locally produced goods, on High Street Tottenham 
Plate 1.9: $\quad$ Existing industrial buildings, Blackhorse Lane, Waltham Forest

Plate 1.10: $\quad$ Plan showing suite of project proposals for Blackhorse Lane Outer London Fund (Round 2) bid

Plate 1.11: Blackhorse Lane shop-front improvements

Plate 1.12: Blackhorse Lane public realm and trading estate improvements

Plate 1.13: $\quad$ Blackhorse Lane public realm and trading estate improvements

Plate 1.14: $\quad$ Blackhorse Workshop building devised, designed and implemented by Assemble and London Borough of Waltham Forest

Plate 1.15: Blackhorse Workshop building devised, designed and implemented by Assemble and London Borough of Waltham Forest

Plate 1.16: Artwork at Blackhorse Lane and Forest Road junction, by Chris Bracey (London Borough of Waltham Forest)

Plate 2.1: The modernist paradigm - the functional hierarchy of urban street design and its relationship to traditional major urban streets

Plate 2.2: $\quad$ Case study streets in the metropolitan context

Plate 2.3: $\quad$ Typical view of Sokolov Street, Ramat Hasharon

Plate 2.4: $\quad$ Typical view of Ahuza Street, Ra'anana

Plate 2.5: $\quad$ Typical view of Weizmann Street, Kfar-Saba

Plate 2.6: $\quad$ Pavement on Sokolov Street; note raised planting box meant to direct pedestrians to painted crossing at intersection

Plate 2.7: $\quad$ Crossing between intersections on Weizmann Street 229

Plate 2.8: $\quad$ Lively pedestrian realm on Weizmann Street

Plate 2.9: $\quad$ Extended and well-managed pedestrian realm on Ahuza Street

Plate 2.10: An arcade allows the extension of the pedestrian realm and creates a protected walking and sitting area on Weizmann Street

Plate 2.11: Combining modes of movement on suburban high streets increases their viability 
Figure 9.1: Correlation between degree of 'integration interface' and degree of incoming people to squares in Stockholm $\quad 248$

Figure 9.2: The location of the studied neighbourhoods and squares in Gothenburg 250

Figure 9.3: Network integration at city scale (radius 50) 251

Figure 9.4: Distance to home addresses of co-present people 254

Figure 9.5: Catchment area of the squares: the home addresses of co-present people 255

Figure 9.6: Minimum distance to urban amenities, access to urban amenities and aspects important for opportunities in the labour market

Figure 9.7: Line analysis east-west section in Bergsjön illustrating topography, betweenness, constitution and mix between residents and non-residents 258

Figure 9.8: Proposed interventions in Bergsjön 259

Figure 9.9: Increase of access to workplaces before and after the proposed interventions 260

Figure 10.1: $\quad$ Ordnance Survey maps for Seven Sisters area. 266

Figure 10.2: $\quad$ Land use map of Seven Sisters Market 267

Figure 10.3: Ethnic ownership map of Seven Sisters Market 268

Figure 10.4: Seven Sisters Market, entrance from High Road 270

Figure 10.5: Seven Sisters Market, Pueblito Paisa Café 270

Figure 10.6: House in Pueblito Paisa, Medellín, Colombia 27

Figure 10.7: Stalls decoration inside the market 272

Figure 10.8: Direct references to Latin-America 272

Figure 10.9: Restaurant inside the market 273

Figure 10.10: Stationary activities in the market on a Saturday, from 8.00 to 9:00 p.m. 276

Figure 11.1: Seethinger wearing an 'I live in Seething' T-shirt 296

Figure 11.2: Making a giant wicker lamp 297

Figure 11.3: The Annual Lefi Parade fronted by Thamas Deeton, the giant of Seething 299

Figure 11.4: The Sardine Parade stopping traffic whilst moving from the river to a local park 


\section{List of Tables}

Table 3.1 Size of $3 \mathrm{~km}$ analysis and $6 \mathrm{~km}$ reconstruction areas for each study area

Table 3.2 Network length and subdivision area for whole London street network

Table 3.3 Network densities for London street network subdivisions $\quad 65$

Table 3.4 Junction density change through time in study areas 67

Table 4.1 Comparison of choice values for the six study periods

Table 5.1 Street front length according to the street type for the three study areas

Table 5.2 Quality measures according to street type for the three study areas

Table 5.3 Activity figures split by centrality and quality of streets for the three study areas

Table 5.4 Activity figures split by type and quality of streets for the three study areas

Table 5.5 Activity figures split by type and quality of streets

Table 7.1 Non-domestic frontage length and building area

Table 7.2 Highest correlation between integration and choice at the same radius

Table 8.1 Islington, London - building entrances and associated land use for the two main streets and surroundings (c.2013)

Table 8.2 Islington, London - door encounter rate for the two main streets and surroundings (c.2013)

Table 8.3 Islington, London - Upper Street: door encounter rate (c.2013) 
Table 8.4 Islington, London - Upper Street: building entrances and land use (c.2013)

Table 8.5 Historical map: segment angular analysis showing mean values for the measure of combined integration and choice, for different radii (c.1910)

Table 8.6 Historical map: segment angular analysis showing mean values for the measure of combined integration and choice, for different radii (c.1965)

Table 8.7 Contemporary map: segment angular analysis showing mean values for the measure of combined integration and choice, for different radii (c.2013)

Table 8.8 Temporal shifts in network, c.1910-2013

Table A Frequency of activities along case study high streets

Table B Relation between physical aspects of the streets and the sense of safety and well-being of people on them

Table 9.1 Spatial conditions and access to people

Table 9.2 Co-presence study: results from interviews and observations 


\section{List of Contributors}

Huyam Abudib is an architect and urban designer. She graduated from Tripoli University, Libya and has recently gained an MRes in Architecture from the University of Strathclyde. Her research work mainly focuses on traditional urban fabric and courtyard houses of the Old Medina. Prior to attaining her post-graduate studies she designed numerous projects for private and governmental clients in Libya. She aims to manifest the philosophy of traditional courtyard houses into contemporary residential developments in Tripoli / Libya, supported by her theoretical research and design skills.

Mayte Arnaiz holds a Master's degree in Architecture from the Polytechnic University of Madrid and a Master's degree in Territory, Transport and Environment from the University of Castilla-La Mancha, where she currently is a PhD candidate. Working on her thesis, she studies the social, economic and spatial evolution of World Heritage cities in the metropolitan area of Madrid.

Meta Berghauser Pont is Senior Lecturer in Urban Design at Chalmers University of Technology. Her work has its base in urban morphology with a focus on quantitative spatial analysis. The development of tools and methods such as Spacematrix, supporting both research and urban design practice, is central to her work. With Spacematrix, urban form can be quantified using a set of density variables and related to a range of urban performances from air pollution to land use diversity. The method has recently been integrated with space syntax to arrive at a measure of perceived density.

Nadia Charalambous is an assistant professor of Architecture at the Department of Architecture, University of Cyprus. Underpinning all research and professional activities is a continuous interest in the relationship between spatial configuration and social phenomena approached from a variety of analytical perspectives, including both quantitative as well as qualitative research tools. Recent research work investigates the complex relationship between urban form, segregation and conflict through time. 
José M. De Ureña is full professor in Urban Design and Regional Planning at the University of Castilla-La Mancha in Toledo, Spain. His research has focused on territorial transport implications, management of floodplains, metropolitan reorganisation and the design of urban public space. His publications and those of the research group he leads on the territorial implications of high-speed rail are particularly well known. His most recent research interest is on historic/heritage urban areas, and their role in the overall urban morphology, in improving metropolitan peripheries and in attracting knowledge-intensive activities.

Ashley Dhanani is a research associate at the Bartlett School of Architecture at the Space Syntax Laboratory, UCL. He holds a PhD in Architecture and Urbanism, and a Master's degree in Geographic Information Science from UCL. His PhD research involved modelling and analysing the spatial and architectural development of outer London from the late nineteenth century up to the present day. His current research forms part of an interdisciplinary project studying community severance, where he is developing a model of urban mobility patterns, with a particular focus on walking and active travel.

Ilaria Geddes holds a Master's degree in GIS and Spatial Analysis in Archaeology and a Master's degree in Housing Futures from UCL. She is currently a PhD candidate at the University of Cyprus, working on the urban development of Limassol from the end of the Ottoman period to the present day. Her research focuses on diachronic analysis of city development, morphogenetic theories and the integration of space syntax and social sciences methodologies.

Sam Griffiths is Lecturer in Spatial Cultures in the Space Syntax Laboratory at UCL's Bartlett School of Architecture. His PhD was on the historical relationship between the built environment and emergent patterns of socio-economic and cultural practice in Sheffield. His research focuses on the built environment as an aspect of the social and cultural life of cities in a range of historical and contemporary contexts, including industrial cities and small town centres. He is co-editor with Alexander von Lünen of Spatial Cultures: new perspectives on the social morphology of cities past and present published by Ashgate.

Muki Haklay is a professor of Geographic Information Science at UCL. His research interests include public access to environmental information and the way in which the information is used by a wide range of stakeholders, 
citizen science and in particular applications that involve community-led investigation, development and use of participatory GIS and mapping, and Human-Computer Interaction $(\mathrm{HCl})$ for geospatial technologies. Over the past fifteen years, he has been involved in a range of projects about suburban town centres, including a project developing town centre statistics in the UK. He has published widely in these areas.

David Jeevendrampillai is an anthropologist at UCL. His current research explores the relationship between transformations of the built environment and social life in suburbs. He has a particular interest in practices of knowing and representing place including mapping, walking, parading and 'local' carnivals. He is interested in how contestations over representing the material environment intersect with different practices of knowing and showing, such as when indigenous or 'local' claims are incommensurate with planning policy, academic research or systems analysis. Overall his interests include body-land relations, material culture, the politics of affect, geographies of knowledge, GIS, phenomenology and spatial thinking in anthropology.

Ann Legeby is a researcher in urban design at the School of Architecture at KTH, The Royal Institute of Technology in Stockholm. Her research is focused on the social dimension of urban design, and how urban design enables or inhibits certain urban processes. The research includes for example a development of methods and tools for analysing urban segregation and how urban life may be affected by urban form. In addition, Ann lectures at $\mathrm{KTH}$ and works part time as an urban design practitioner.

Lars Marcus is an architect and Professor in Urban Design at Chalmers University of Technology, where he is research leader for a new research group in Spatial Morphology. The focus here is theories and methods in the analysis of spatial form but also its application in relation to social, economic and ecological urban systems and how this may generate new knowledge that can inform professional practice. He is also founder and partner in the consultancy firm Spacescape, performing spatial analysis, design support and policy development in architectural and urban projects for architects, municipalities and real estate companies.

Moshe Margalith has been combining architectural practice with academic teaching and research since the establishment in 1979 of Moshe Margalith Architects \& Urban Planners Ltd. Former head of the Azrieli School of Architecture at Tel Aviv University, he now heads the Tel Aviv Institute of 
Architecture: Environment, Culture and Community, and holds the UNESCO Chair on Modern Heritage. Professor Margalith has organised seminars and workshops on Modernism and Urban Transformations of the built heritage of Tel Aviv, and has conducted research on the built heritage of Jaffa-Tel Aviv, Nicosia, the Jewish Ghetto of Shanghai, on pedestrians in urban centres, and on land policies and environmental protection.

Garyfalia Palaiologou is a researcher at the Space Syntax Laboratory, Bartlett School of Architecture, UCL. She holds an EPSRC- funded PhD in Architectural and Urban Morphology, and a Master's degree in Advanced Architectural Studies from UCL. Her PhD research investigated the micromorphology and urban transformation of the London terraced house and the Manhattan row house from the late nineteenth century till the present. Garyfalia is now working on a new EPSRC- funded post-doctoral research project studying urban conservation, where she is using space syntax tools to develop novel methods for delineating historical urban landscapes.

Angela Piragauta completed a Bachelor in Architecture degree at the National University of Colombia, Bogotá, in 2005. From 2005 to 2012 she worked as a designer in private architectural firms in the development of numerous institutional projects, her area of expertise being the design of educational buildings. She completed her Master of Science degree in Advanced Architectural Studies at the Bartlett School of Architecture, UCL in 2013. Currently she is working at the National University of Colombia as the coordinator of the local architecture team for the Postgraduate Building for the schools of Economic Sciences, Law, Social and Political Sciences, designed by Steven Holl Architects.

Sergio Porta is Professor of Urban Design, Director of the Urban Design Studies Unit and former Head of Department at the Department of Architecture, University of Strathclyde, Glasgow. Dr Porta is a member of the Environmental Structure Research Group, the Academy of Urbanism and of the editorial boards of leading international journals such as Environment and Planning B, Urban Design International and Urban Studies Research. Dr Porta is peer reviewer for Nature Scientific Reports, Environment and Planning $B$, Urban Studies, Urban Design International and others. He has published roughly forty international peer-reviewed papers.

Adel M. Remali is an architect and urban designer and a member of the Urban Design Studies Unit (UDSU) at the University of Strathclyde. Initially, his work covers and manages building typology and morphological change 
and growth in Libyan towns and cities from the sub-regional level down to block scale. Recently, his interdisciplinary research has been in two main areas: urban morphology and street network analysis where street front quality, constitutedness and street life that is based on street centrality play a major role in understanding the interaction between city form and city life.

Yodan Rofè is Senior Lecturer in Urban Planning and Design at Ben-Gurion University in Israel. He was also a Founder and Board Member until 2013 of the Movement for Israeli Urbanism (MIU). His research interests include neighbourhoods in urban theory and city planning, cognition and feeling in the built environment, urban space and street design, and the connection between transportation and land use. Together with Allan Jacobs and Elizabeth Macdonald he authored The Boulevard Book: History, evolution, design of multi-way boulevards published in 2002 by MIT Press.

Ombretta Romice is Senior Lecturer in Urban Design at the Department of Architecture, University of Strathclyde in Glasgow, and Fellow of the Higher Education Academy. She is a past President of IAPS, the International Association for People-Environment Studies. Her teaching and research work focuses on urban design, environmental psychology and user participation in design. She holds a PhD in urban design and a Post Doctorate in housing and neighbourhood regeneration sponsored by the European Union.

Borja Ruiz-Apilánez is a Lecturer in Urban Design at the School of Architecture at the University of Castilla-La Mancha in Toledo, Spain. His research is focused on public space at different scales - from the single street to the street and public space network as a whole - and from different perspectives - space configuration, urban form, use, social, performance, materials, heritage, design, economy, ecology - in order to better understand the relation between human activities and the built environment.

Fiona Scott is an architect and a founding director of London architectural practice Gort Scott. She studied architecture at Cambridge University and the Royal College of Art. Fiona was appointed to the London Mayor's Design Advisory Group in 2013. She was also an Urban Design Scholar and Design Advisor in 2009 for Design for London. Gort Scott is known for its varied portfolio ranging from urban strategy to different scales of buildings and streetscape design. Their urban design research includes detailed observational and analytical studies of London's high streets and industrial areas. 
Laura Vaughan is Professor of Urban Form and Society and Director of the Space Syntax Laboratory at the Bartlett School of Architecture, UCL. Her research expertise lies in the multi-scale relationship between urban form and society and she has led a series of UK government funded projects on a range of critical aspects of urbanism today. She is currently working with public health experts and transport engineers to conduct research into community severance and walkability. She is also collaborating on research into the role of political, spatial and social factors in shaping urban segregation in ethnically mixed cities.

Ahuva Windsor is an environmental psychologist who lives and works in Tel Aviv Jaffa, Israel. She teaches at the Max Stern Yezre'el Valley College on the social facets of environmental issues, among them environmental justice and participatory planning, waste-related behaviour and sustainable management. Her research is focused on public space users, and on environmental attitudes and behaviour. She also provides consulting and research services to local authorities mainly on community participation in urban planning, and to the business sector on improving work environment design.

Galit Yerushalmi is a Landscape Architect, and holds an MA from the Porter School of Environmental Studies at Tel Aviv University. She currently manages a planning department at the Jewish National Fund (JNF), Israel. For her thesis Galit conducted field research on the views and rights of pedestrians with regards to day-to-day movement in city centres. Throughout her career, Galit has been an award-winning leader in pursuing 'walkability' related aspects of urban planning. She initiated various planning processes for several municipalities in Israel that promoted walking, cycling and public transit within city centres. 



\title{
Introduction: Suburbs are as Old as the City Itself
}

\author{
Laura Vaughan
}

While both urban and rural studies have long thrived, the academic study of suburbs is still a relatively new field - despite the fact that, as Peter Ackroyd has said - suburbs are as old as the city itself (Ackroyd 2000: 727). Taking just one example from the historical record, the carved stone relief of the ancient Persian city of Madaktu in Figure 1.1, dating from the seventh century $\mathrm{BCE}$, shows suburban villas situated in an array surrounding the city walls. It is remarkable to see how the image presents a contrast between the city itself, with its neatly arrayed buildings, and the suburban villas dispersed outside the wall, each with its own palm tree. This image of city contrasted with suburb, whether it reflects reality or not, is a commonplace visual and conceptual trope that has continued to emerge, especially in the past century and a half.

Even when they are studied, suburbs tend to be considered separately from the city or as an undefined mass within a chaotic peri-urban landscape at the city edges (Vaughan et al. 2010a). Rather than taking the city out of the suburb or the suburb out of the city, the intention of Suburban Urbanities is to consider the two together: the suburb as a continuum of the city's spatial-social complexity. It is therefore intended to make the case for the suburbs' (however defined) urbanity. The book contains a range of cases: from an old city which has become a touristic outpost of the new city centre, to one where the old centre has grown to encompass what used to be its periphery. These examples demonstrate that attempting to define an urban particularity entirely without reference to the suburban is almost certain to fail. Instead, using spatial analysis, and historical and ethnographic perspectives, the book will counteract the binary opposition between city and suburb and challenge the perception that urbanity only exists in the city. The case will be made instead that urbanity is an issue of degree rather than a binary choice between suburb and city, or suburban versus urbane. 


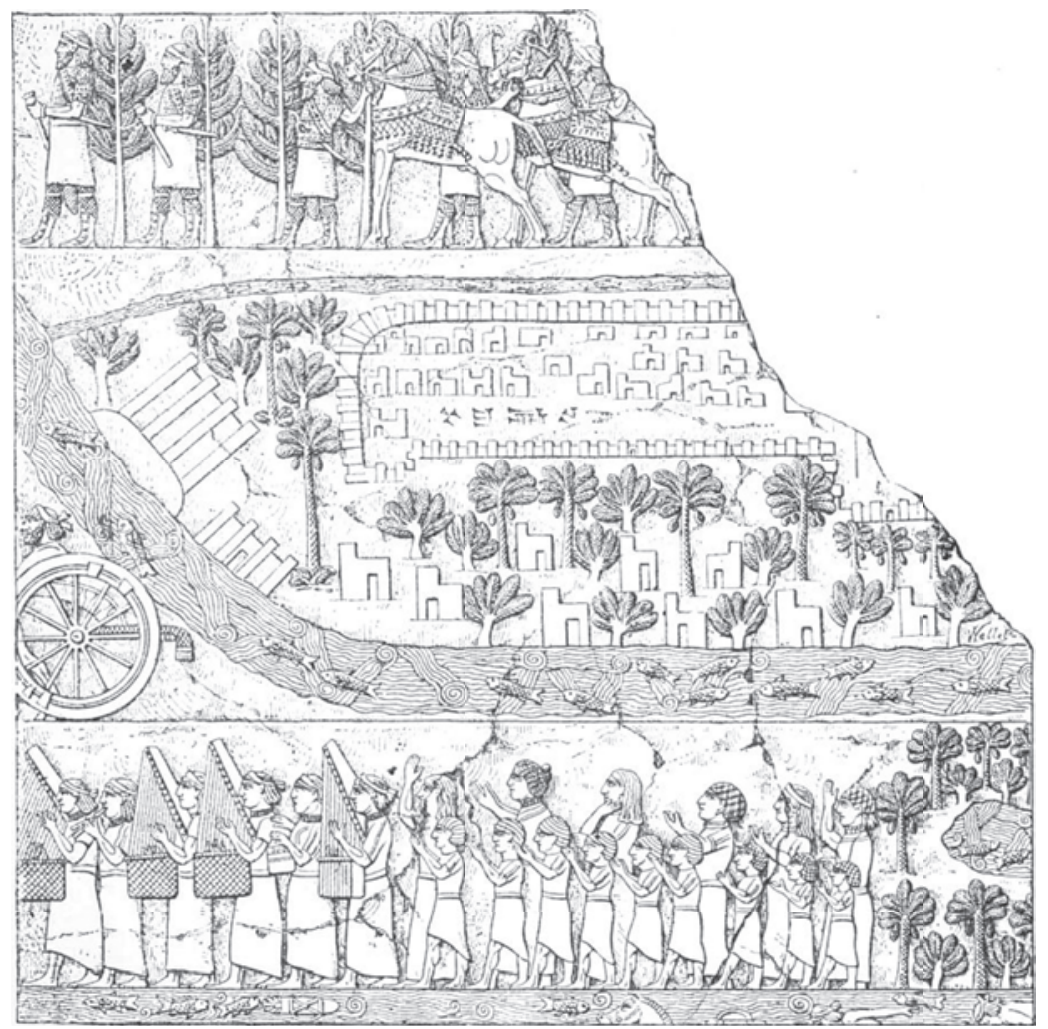

Figure 1.1

Relief of the Elamite city of Madaktu, Persia showing suburban growth beyond the walls $(668-627$ BCE)

From The Project Gutenberg ebook of 'A History of Art in Chaldæa \& Assyria', v. 1, by Georges Perrot and Charles Chipiez (1884), p. 332.

In considering suburbs as a continuum of the city, this book focuses on metropolitan suburban centres: both in their relation to other centres elsewhere in the city, and in the role they play in relation to their locality. This approach stems from a desire to capture the full spectrum of nondomestic activity: people working from home, start-up businesses selling on the internet, weekly markets, informal labour and so on, as well as the similarly diverse range of leisure activities that take place outside of the home. For example London, like most large urban spatial systems, consists of an interdependent network of linked centres (Hillier 1996) which, when studied in detail on the ground, reveal a level of detail and complexity more normally attributed to cities. Taking the suburban built environment as a 
subject of enquiry in its own right and as a distinctive aspect of the spatiotemporal process growth of cities, Suburban Urbanities presents the high street, the core of suburban non-domestic activity, as a special kind of space with demonstrable potential for creating the living heart of the suburb. Griffiths' take on the high street as a 'morphological event' in this volume provides a useful counterweight to those who claim that the high street is dead (or dying). Local suburban centres can provide a rich diversity of experience for an area's inhabitants, in many ways offering a more sustainable lifestyle than in the inner city.

When considered in fields such as cultural geography or literary studies, the study of suburbia has determinedly focused on the suburb as the place of the 'other', the 'wild' or the wilderness (Wunsch 1995). In spite of (or perhaps because of) the fact that the majority of people in English-speaking countries live in it, suburbia has remained 'the love that dares not speak its name' (Goldsworthy 2004): it is all too frequently despised and easily patronised. Critics maintain that suburbs lead to alienation, that they are homogenous breeding grounds for apathy, yet suburbia is nonetheless the place many people aspire to live. Another difficulty is the tendency to view suburban social networks either as spatially bounded home communities or as non-existent, with the common perception being of widespread anomie. The view of the US writer Robert Putnam, that we are all 'bowling alone', has been picked up with glee by critics as another stick with which to flog suburban life (Putnam 2000). Notwithstanding the continuing influence of these ideas, several scholars have sought to refute Putnam's findings: with Miles Hewstone, for example, arguing that the study 'conflated opportunity for [social] contact and actual contact' (Hewstone 2009: 284) and Jan Bruekner and Ann Largey showing that social interaction is less related to the density of residential areas than to the life situation of the people living within them (Brueckner and Largey 2008). Yet the myth of suburban anomie continues. Without a combined effort from the spatial and social disciplines together, studies of suburbs, suburban history or suburban life end up focusing on snapshots of information, rather than appreciating the cumulative effect of small-scale changes over time or the influences of wider spatial change (such as a new motorway drawing away traffic from a centre) or social change (such as new work patterns) on the locality itself. This book aims to fulfil this ambition by asserting how city or regional spatial change and micro-anthropological phenomena come together to implicate the suburban scale of social life. It shows that to attribute a lack of social engagement purely to a crude residential typology ignores the variability of suburban environments and the messiness of modern life, in which people travel in, around and between suburban and urban locations. 
The term suburb is trapped by an historical legacy of aesthetic distaste from the cultural elite, such as the declaration of the International Congress of Modern Architecture in 1933 that the suburb is 'a kind of scum churning against the walls of the city' and that it is 'one of the greatest evils of the century' (cited in Oliver et al. 1981). From an architectural point of view there are some good reasons why the suburbs are considered a poor solution to mass housing. With the widespread use of cars and low densities, contemporary thinking would suggest that suburbia represents an inefficient use of natural resources and an unsustainable approach to planning. Whilst there are undoubtedly valid criticisms to be made of suburbia, the point this book makes is different: it offers an alternative conceptualisation of suburbs and proposes that suburbs are shaped by a generic spatial process that appears in many different contexts. This process is spatial as well as temporal and many of the examples illustrated here will show the manner in which the built environment adapts to changing socio-economic conditions by maintaining a balance between stability of the street network over time with a degree of adaptability of the shape and pattern of buildings themselves. A wide range of socio-economic and built environment factors influence this process, and issues of social and cultural context are accounted for when interpreting the analytical results of the studies in question.

In planning studies the focus is on the suburb's spatial position in relation to the centre and the notion that suburban centres are simply an extension of the city is the orthodoxy in most treatments of the subject (Bourne 1996). One criticism of this approach is that centre-periphery models only make sense at an observer-agreed scale of what constitutes a region. Instead, it could be argued that spatial relationships repeat and overlap at many different scales and are not inherently stable. The conventional, hierarchical view downplays both suburbs and their centres and therefore ignores the essential role the street network plays in linking between places, as well as shaping the potential for places to work in their own right. This book will show that urban growth that follows the spatial logic of the existing network is a pattern that has worked well for centuries. Indeed, suburban growth has been a positive solution for inner-city crowding, albeit reinforcing social class divisions in some instances. History shows how the spread of the railways not only shaped the spatial patterning of class in cities such as London or Brussels, but also helped ameliorate the severe deprivation, overcrowding and disease of the inner city (see Pollins 1964; Polasky 2001). The development of transport technologies shaped the lines on the ground but also shaped social change along those lines. As early as 1770 eight coaches a day left from central London to suburban locations, and by 1809 Camberwell in south London was seen as within 
reach as 'a pleasant retreat for those citizens who have a taste for the country' (Pricilla Wakefield, Perambulations, 1809, in Bullman et al. 2012: 299). As Nick Barratt shows in his Greater London: the story of the suburbs, by the eighteenth century 'it became increasingly possible ... to commute daily from nearby suburbs or to commute weekly from ones further away' (Barratt 2013: 105). The subsequent development of the railways in the nineteenth century and the twentieth-century growth of private motor car ownership (and the subsidy of road building by governments in the USA) had equally important impact both spatially and socially.' Existing settlements such as Hampstead, although originally outside of the urban conurbation, helped to mitigate the rawness of London's suburban development, so that main roads which formerly might contain linear developments of coaching inns, shops and villas, subsequently were in an ideal position to develop as London's network of high streets (Griffiths et al. 2008; Carmona 2015). This process is illustrated by a painting from $c .1830$ by John Constable (Figure 1.2). The painting shows Sir Richard Steele's cottage, Hampstead in the foreground on the main road to London from suburban Hampstead (now Haverstock Hill), with St Paul's Cathedral and the City of London in the distance. A pub was situated opposite the cottage that had taken the place of a much older inn, which would have served wayfarers travelling

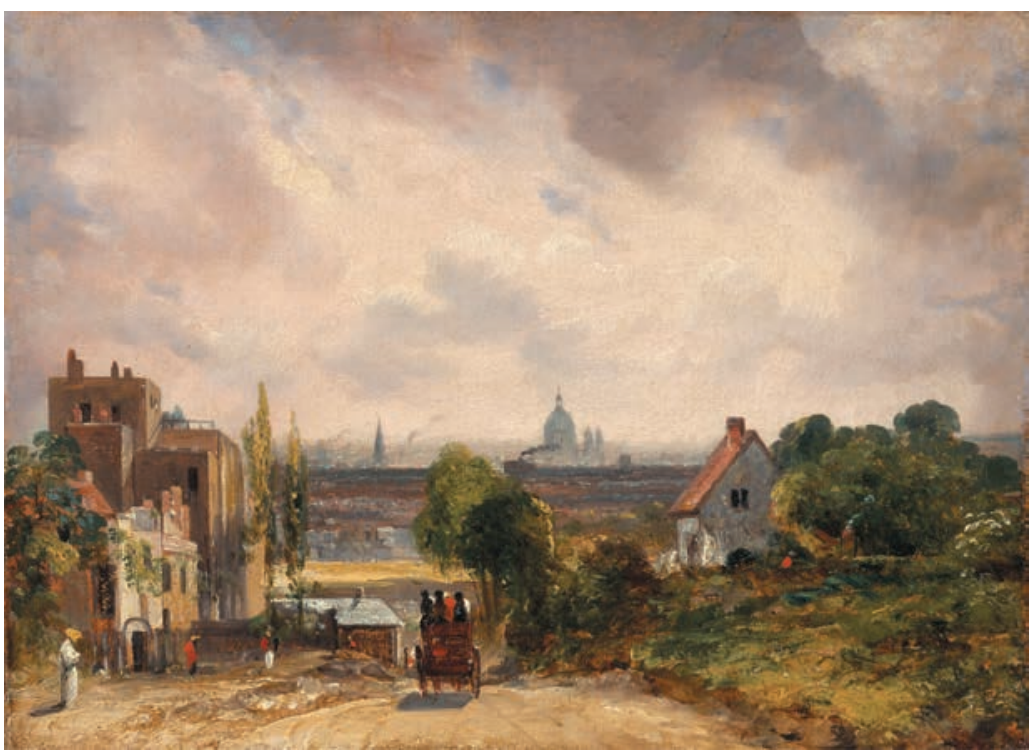

Figure 1.2

Sir Richard Steele's Cottage, Hampstead by John Constable (1831-2)

Image: Yale Center for British Art. Distributed under a CC-BY 2.0 licence. 
from afar into London. The pub continues to serve passers-by to this day, despite the transformation of Hampstead from a suburb outside of the urban conurbation to being an integral part of it. Not only has the same road alignment continued to carry shorter and longer journeys alike to this day, the continuity of use of the pub building itself signals a kind of path dependency that is one of the ways in which cities such as London have managed to adapt to change.

Multi-scale pathways and adaptation to change are at the heart of much of the research described here. Many of the empirical chapters use space syntax theories and methods that, due to their ability to analyse spatial systems at multiple scales and in relation to socio-economic factors, allow for this complex issue to be addressed. The theory and methods of space syntax, integrated with those of urban anthropology, are a useful combination for studying the dynamic processes described in this book. Over the past three decades space syntax research has developed mathematical (latterly computerised) urban models to help assess patterns of land use and economic viability in relation to urban form (Hillier 1996). The methods of space syntax are now well established in many fields, such as design, urban geography and planning. Rather than burdening the reader with lengthy technical explanations of the methods, those chapters which use space syntax provide information on the particular techniques used, supported by the book's Glossary which explains the key terms used.

This book's theoretical position has been shaped by ideas developed on two research projects at University College London (UCL), both of which took a cross-disciplinary approach to bring methods from architecture, anthropology, history and geography to inform research into London's suburban evolution since the nineteenth century. The contributions from the London project are interwoven with contributions by scholars from a variety of suburban settings across Europe and elsewhere, which serve to provide contrasting perspectives on the findings of the research undertaken at UCL. In selecting a number of cases from outside of the UK it demonstrates how many common features can be identified across the varied sample.

Cities are routinely acknowledged as complex and dynamic built environments but this description is rarely extended to the suburbs, which are generally regarded as epiphenomena of the urbs and therefore of little intrinsic theoretical interest in themselves. Chapter 1 presents a detailed critique of this widely held assumption by showing how the idea of 'the suburb' as an essentially non-problematic domain has been perpetuated from a range of contrasting disciplinary perspectives, including those which directly address suburban subject matter. The result has been that attempts to articulate the complex social possibilities of suburban space are easily 
caught between theories of urbanisation that are insensitive to suburban specificity, and competing representations of the suburb that rarely move beyond the culturally specific to consider their generic significance. It makes the case for a more substantive theory of the suburban built environment as constituting a distinctive field of practice in which socio-economic processes and cultural identities can be contested and negotiated over time. Such a theory, it is argued, would acknowledge the generic significance of suburban space as the dynamic, generative, principle in the historical differentiation of complex built environments undergoing processes of change and continuity. Chapter 2, the second of the pair of theoretical preliminaries, presents the suburban high street as a complex socio-spatial 'event' that is at once historical and morphological. It draws attention to the contribution of high streets to the emergence of diverse suburban socialities in successive historical periods.

Whilst research broadly recognises the complex interrelatedness across scales that is the essence of urban systems, the particularities and similarities between the spatial structure of the suburb and that of its host city are rarely examined in any great detail. Chapters 3, 4, 5 and 6, which form the book's 'Suburban Centralities' section, take the reader from London to Limassol, Toledo and Tripoli, showing that local places are shaped and formed over time according to their accessibility to long-term patterns of human, social and economic networks of activity across scales. By combining detailed spatial analysis with careful use of economic data and observation of behaviours, the four cases demonstrate how centrality can shift as the city grows and how the shape and form of individual places contribute to their ability to adapt (or not, as in the last case in this section) to social and economic change.

The 'High Street Diversity' collection of chapters goes down a scale to focus on the high street, the active centre of urban and suburban centres. This focus on the suburban pathways of socio-economic activity, what is termed in the UK as the 'high street' (broadly equivalent to the US 'main street') has many cultural resonances that flow from its functioning as a complex and dynamic entity within both the urban and the suburban streetscape. The first two chapters consider cases located in London. Chapter 7 sets the scene of this section, by proposing that diversity of uses and users is a key factor in the long-term adaptability of smaller town centres. It argues that the mixing of different people carrying out different activities makes for the rich experience of encounter and daily routine. Chapter 8 goes as far back as the early nineteenth century to show how Islington, considered today to be part of urban London, was originally a suburb. Its subsequent development along historic road alignments helped sustain its long-term 
success, but also shaped its particular pattern of land use diversity. These two chapters are followed by two shorter case studies, which provide some urban design practice-based context to the empirical work presented in the book. Case Study 1 focuses particularly on the high street realm as being a place of socio-economic productivity in London and Case Study 2 considers how the pedestrian realm of Greater Tel Aviv is shaped by the way in which local main streets have been integrated into the metropolitan road network.

The last section of the book is called 'Everyday Sociability'. Here the trio of chapters moves the focus onto the people inhabiting suburban space. Gothenburg is the subject of Chapter 9, where the authors provide a theoretical overview and empirical analysis of how the design and layout of public spaces such as streets, squares and parks contribute to daily social interaction and help to overcome social exclusion, especially of ethnic minorities. Chapter 10 also considers ethnicity, in this case the often overlooked Latino minorities of contemporary London. Chapter 11 takes an ethnographic perspective on everyday life in the suburb, investigating ways in which local residents and business owners have created a new vision for Surbiton, situated in outer London. Reinforcing similar points made elsewhere, this chapter illustrates how social productivity in the suburban centre has generated new forms of economic productivity. Just as the suburbs are as old as the city itself, there is no reason to suppose that cities will not continue to grow and adapt to change in similar ways to those which have occurred in the past. The suburbs are an important part of that story.

\section{Note}

1 An important feature of the impact of transport infrastructure on social change was in the growth of independent private transportation, which led to a culture of motoring where car ownership was possible financially. See Law, Michael John. 2012. 'The car indispensable': the hidden influence of the car in inter-war suburban London. Journal

of Historical Geography 38 (4):424-33. In a similar vein Rubinstein has written how the invention of the bicycle in the nineteenth century 'provided not only a practical means of transport but [became] a symbol of emancipation' (Rubinstein, David. 1977. Cycling in the 189os. Victorian Studies 21 (1): $47-71)$. 


\section{PART A \\ Theoretical Preliminaries}
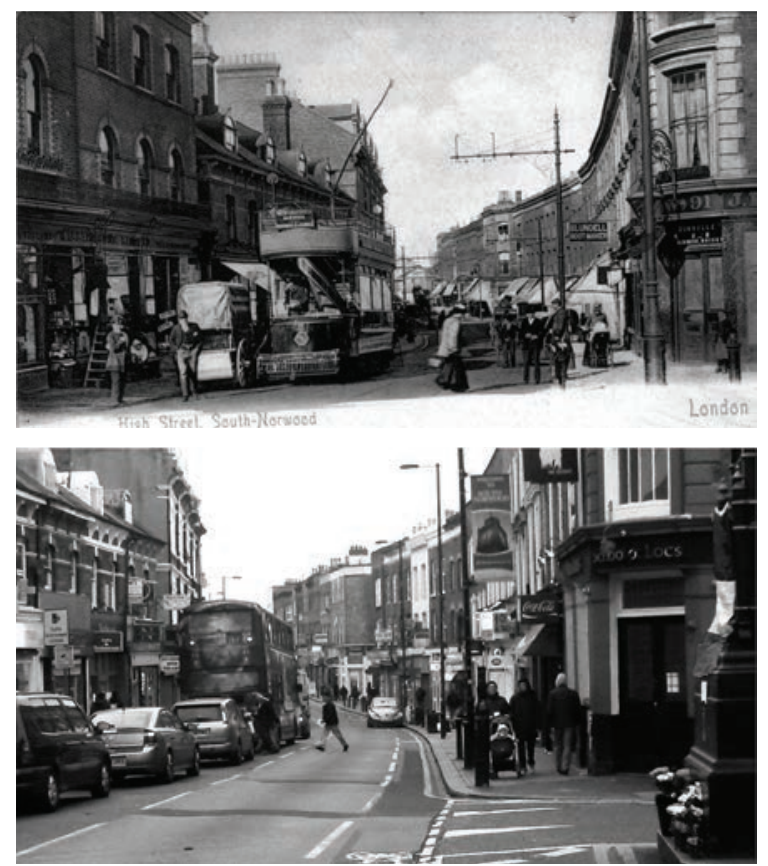

High Street, South Norwood c. 1905 (top) and 2015 (bottom) 



\title{
Chapter 1
}

\section{The Suburb and the City}

\author{
Laura Vaughan, Sam Griffiths and Muki Haklay
}

\section{Introduction}

A 2009 article co-authored by the present authors posed the question of 'whether the suburbs exist' (Vaughan et al. 2009a). The question was posed rhetorically - but not facetiously. An increasingly large academic literature across a wide range of disciplinary fields strongly suggests that they do indeed exist, and it is probably true to say that there are few people in the developed and developing worlds who would not claim to know a suburb when they saw one. If further reassurance were needed it can be found statistically: for example by 2000 the UK had 84 per cent and the USA (on a narrower definition) 50 per cent of its population classified as resident in suburbs according to government data (ITC 2004; Pacione 2005: 87). The question then, is not metaphysical; we are content with widespread scholarly and common-sense agreement that suburbs are characteristic aspects of the built environment. Rather, it is intended to draw attention to the epistemological fragility of the term 'suburb'. Beyond the most perfunctory level of definition, it is far from clear as to what this term actually means or indeed, whether it can be thought to possess meaning at all. A pronounced tendency to neologism in suburban studies highlights the underlying theoretical weakness. This justifies the original question: if there is widespread agreement that suburbs exist, a fog of competing representations tends to obstruct the possibility of meaningful generalisation. All too often it seems as though the language of the suburban floats free from the suburban streets and the people who live in them. This disjunction means that a particular focus on the suburbs can appear as a distraction, rather than an essential bearing, for research into the relationship of the built environment with everyday social practices. Given the ubiquity of suburban living in contemporary society, this seems an undesirable state of affairs. This chapter 
revisits many of these ideas, originally laid out in our 2009 article, in order to set them within the context of this book's consideration of the suburb as a long-standing and essential part of the city. This chapter is accordingly updated both to reflect recent scholarship in the field, but also to position the piece within a more explicitly international context than in the original journal article.

Growth at the urban periphery has in recent times assumed whole new patterns in South America and southern Asia. Brazilian favelas, for example, and similar forms of informal settlement elsewhere in the global south, with their emergent patterns of economic activities, give a whole new meaning to Garreau's (1992) notion of edge city. Indeed, they have given rise to whole new socio-spatial shapes on the ground, such as the 'spatial segregation of peripheral neighbourhoods' (Monteiro 2008). Whilst the phenomenon of suburbanisation extends world-wide, it can fairly be said that its contemporary origins lie in the UK, North America and Australia. It makes sense, therefore, that a large proportion of the academic literature which provides the basis for the critique advanced in this chapter is drawn from the Englishspeaking countries where suburban topics have generated the most debate. This de facto emphasis notwithstanding, the wider aim, both of this chapter and of the collection as a whole, is to contribute to the development of suburban studies as a coherent research domain in human geography and urban studies. Indeed, since we started work in this domain, several major research projects have sprung up, such as 'Re-imagining the Australian Suburb' project at RMIT University, Melbourne, Australia and Roger Keil's international comparative study at York University, Toronto, Canada. Each has its own emphasis, with the former primarily focused on housing and the latter on development and economics. Our approach differs from these. It stems from a proposition inherent to our specialist field of research, space syntax, that the specificity of suburban space and the complexity of its historical development need to be the starting point in understanding the nature of the suburb. Acknowledging the great variety of ways in which the suburbs have been addressed in the academic literature means challenging, in a more fundamental sense, conventional descriptions of the urban fringe as tabula rasa. We propose that the key theoretical significance of suburban space lies in its potential to undermine dominant historical-geographical narratives of city and periphery, which are premised on a series of fixed, culturally specific, representations where the suburb is typically viewed as an entity distinctly and measurably different from the city. Such images are essentially static and militate against the asking of important questions, such as what happens to an edge city when it is no longer at the edge, and what is it like to live in one over an extended period of time? We propose 
therefore to articulate the dynamic spatio-temporal principle through which built environments become differentiated and adapt to changing socioeconomic conditions over time, suggesting that suburbanisation is a process, rather than a fixed state. Moreover, exactly because they do not receive the close attention of the centre, suburbs have their own dynamic scope in which ideas, forms and practices can evolve and become part of new urban futures. Massey (2005) argues that space constitutes interconnected and open-ended space-time trajectories of social relations, so events in a suburb create the opportunity of social interaction which might shape future events in and around the area. From an architectural perspective, this broad socio-spatial perspective allows one to consider how a generic description of suburban built form might serve as a prelude to the development of a more effective theory of the suburbs; one articulated in terms of the relationship between the emergence of suburban space in particular socio-cultural contexts and the range of social practices that are reproduced there over time. To explore this proposition further, this chapter reviews a wide range of research into suburban subjects in order to examine the different ways in which the relationship between suburban space and society has been represented in the literature. Four such 'suburban imaginations' are identified, which are then discussed in the following sections. The chapter concludes with the proposition that the suburb should be considered as a distinctively dynamic domain that shapes and is shaped by society over time.

\section{Suburban imaginations}

Definitions of the suburbs abound in the academic and policy literature. However, these provide little indication as to how the suburban built environment should be approached conceptually as a particular category of inhabited space. In a review of suburban literature, Hinchcliffe has argued:

The literature on suburbs is extensive, yet the subject always seems elusive. For some the suburb is a geographical space; for others, a cultural form; while for others still it is a state of mind. (Hinchcliffe 2005: 899)

Hinchcliffe's observation echoes Connell (1974: 78), who criticised the 'elusive' and 'partial' nature of definitions. In a similar vein, Nicolaides and Wiese (2006: 7) argue that, when it comes to defining the suburbs, 'consensus seems unlikely to emerge any time soon'. While it is, of course, the case that the quest for definitions of urban environments can prove no less 
contentious, it is the sense of suburban space as peculiarly intangible that emerges from the literature. When Hubbard (2006: 7) argues for a 'reassertion' of urban theory, he is arguing that we need to go beyond seeing the city as a container for urban life; rather we should examine its role in shaping economic and social relations (Hubbard 2006: 2). Here he is making the valid point that the specific nature of cities is frequently undervalued in geographical theory, but it could hardly be claimed that the subject of the city is 'elusive' in the sense Hinchcliffe uses this term. The reason perhaps lies in the origins of urban centrality at critical historical-geographical nexus, meaning the city occupies the privileged analytical position in geographical and urban studies at the expense of suburbs, which end up being effectively pushed to the periphery of research.

Four tacit conceptions that inform much of the historical and geographical literature serve to obstruct a fuller conceptualisation of suburban space. The first is a general sense that the suburb is a straightforward geographical concept that ought not to be seen as a matter of concern in its own right; this we refer to as the assumption that suburbs are onedimensional. The second is a tendency to consider urbanisation as a process which somehow produces the suburb as an end-point or outcome, regardless of the suburb's own history of spatial transformation as a settlement in its own right. The third is the belief that, as a powerful site of social reproduction, suburban space is adequately described simply in terms of its multiple cultural constructions, such as depictions of the suburbs in literature, film, art and so on. Such culturally based approaches are often accompanied by the implication that by focusing on the specifics of suburban built form, one is somehow implying that spatial layout causes a particular social outcome. The fourth engages with the suburban domain as a powerful imaginary place of otherness, away from mainstream society. The accumulative effect of these assumptions is that the alleged elusiveness of suburbs becomes self-fulfilling. The inhabited space of the suburban built environment itself seems insubstantial in comparison to the weight of geographical representations that it bears. We argue that this under-theorisation and over-representation of suburban space have effectively taken away any substantive discussion of suburbs within urban theory. The following three sections discuss this proposition in further detail.

\section{The one-dimensional suburb}

The majority of British-based studies tend to define suburbs according to a range of planning, socio-economic or cultural criteria. Thorns (1972) 
differentiates between suburbs according to social class, land use and development type; whilst Gwilliam et al. (1999) find it useful to distinguish by dominant mode of transport. More comprehensively, Bourne (1996) identifies ten different perspectives on the suburbanisation process, from an expression of rural nostalgia to the so-called rational decisions by developers in choosing the urban periphery for its cheap land and the way in which consumers prefer a suburban lifestyle. While these systems of suburban classification go some way to recognising the range of suburban built environments, they are unsatisfactory in the sense that most actual suburbs invariably contain elements that cut across many of the categories they describe. Such schemes seem to bear limited, or very reductive, relation to actual places. They also overlook the fact that many suburbs have undefined borders, so could fit into any one of these category labels. All too often the suburb is assumed to be one-dimensional in comparison with the city.

A powerful tradition in Western thought defines the city in terms of the rural world it appears to negate (Williams 1975). In North America the notion of the suburb may also imply a distinct community identity associated with a specific spatial district often embodied in local governments (Harris and Larkham 1999: 14). Whether the contrast is viewed positively or negatively, the sheer scope and depth of work exploring the specific nature of the urban experience in human society demands that the complex, multi-faceted nature of city life does not go unacknowledged - meaning there is less urgency to resolve underlying theoretical difficulties about the relationship of society and space. However, when the subject being addressed is specifically suburban, this theoretical difficulty becomes more pronounced, since it reveals the absence of a general agreement about specifically what kind of space, if any, is actually at issue. Indeed it is a case in point that the numerous introductions to rural and urban geography have few equivalents in suburban studies. The geographical transition from the urban nucleus to rural patterns of settlement is relative and variegated rather than absolute, especially in the case of the radically decentralised regions. Recognising this fact, scholars have generally preferred to adopt functional definitions of the suburb that are adequate for the task at hand despite having little theoretical value. The difficulty is that such definitions have proliferated but have not challenged the common assumption that suburban space can essentially be reduced to a simple working definition. For example, in 1961 Dyos advanced the notion that:

In essence, a suburb is a decentralized part of a city with which it is inseparably linked by certain economic and social ties. (Dyos 1961: 22) 
This definition would still be widely accepted as a description of the most basic properties of traditional suburban settlements (Connell 1974; Hinchcliffe 1999; Pacione 2005). The difficulty is that it assumes suburbs are essentially residential - and dependent on the city. Yet long before the accelerated decentralisation of employment to what Garreau (1992) has termed 'edge city', suburbs had always served as places of work, especially where the pollution caused by industry or cost of urban space recommended a peripheral location. For example, studies have shown that contemporary patterns of industrial suburbanisation were well under way in North American cities by the late nineteenth century (Harris and Lewis 2001). There is plenty of other evidence showing that at least in the past, if less so at present, suburbs are places of work and of production, as will be seen in several chapters of this book. In fact, recent research shows that the trend is for suburban centres to be situated in a network of relationships with other places, rather than solely in a bi-lateral relation with the metropolitan centre (see e.g. Masucci and Rodgers 2008).

The need for a pluralistic approach to suburban history and geography is becoming more common. Bourne (1996: 163-4), for example, argues for a 'diversity of perspectives' and a comprehensive survey of suburban research by Harris and Larkham (1999: 20) also proclaims a multidisciplinary approach as a hallmark of the subject area, highlighting the 'surprising complexity' of the topic. Similarly, Nicolaides and Wiese (2006: 8) celebrate the multiplicity of suburban definitions as being a virtue rather than a problem. Certainly, it is proper that the extent of scholarly activity in suburban studies since the 1950 s should lead to an acknowledgement of the breadth and depth of the research in this area. If that is the case, the complexity of the suburb should surely require a theoretical engagement with the subject. Instead, attempts to approach the suburban realm as a general research domain are consistently undermined by definitions derived from the particular geographical, social-economic, technological or cultural characteristics that recommend them at a given time. Such a model does not make adequate allowance for the diversity of existing suburbs or for the multiple social possibilities of their future evolution.

Research which focuses on the characteristics of the suburban built environment meets with a recurrent challenge in the literature, in the tendency for suburban space itself to effectively disappear when considered conceptually. In his classic urban history of the London suburb of Camberwell, Dyos (1961) notes how changes in demographics, building legislation and urban development mean that what appears urban in one period or culture, may appear relatively suburban in another and vice versa. He quotes Defoe's description of early eighteenth-century Epsom to make 
the point that this settlement functioned as spa, market town and commuter outpost of London all at the same time and that suburban boundaries could therefore be blurred by changing transport technology and seasonal patterns (Dyos 1961: 26-7). It is notable that Dyos' wish to identify essential suburban characteristics at a conceptual level repeatedly conflicts with his historical knowledge of London's suburbs, undermining his attempts at straightforward classification. Ultimately, the difficulty of establishing a satisfactory geographical definition leads Dyos to prefer a more amorphous category based upon attitudes and behaviours:

... the modern suburb is clearly less of a geographical expression than it is an attitude of mind and a species of social as well as economic behaviour. (Dyos 1961: 26)

Many authors since have come to similar conclusions in viewing the suburb mainly through a primary interest in particular socio-economic or cultural processes, rather than in suburban places themselves - a point recognised by Harris (1996: 18, 2004: 13). Accounts of suburbanisation in terms of race are particularly prominent in the American literature. For example, the intimate relationship between the suburb, the inner city and its slums was characterised in post-war United States in terms of 'white flight' from the inner city and an increase in racial segregation (Massey and Denton 1993; Kruse 2005). Widespread academic interest in this process contributed to the construction of a powerful image of the traditional American suburb as white, wealthy and middle class (Jackson 1985; Fishman 1987). This stereotype has since been revealed as just one among diverse suburban identities in which the working class, as well as immigrant and non-white populations, feature strongly (Harris 1996; Nicolaides 2002; Wiese 2004). In a British context Clapson (2003) and Phillips et al. (2007) have emphasised the distinctive suburban experience of ethnic minorities. A recurrent theme in both British and American literature is the role of the suburb in defining social aspiration amongst different social groups. Studies of earlier periods in cities including Brussels and London have also shown how suburbanisation promised a solution to the perceived problem of the concentration of the urban poor (Young and Willmott 1957; Polasky 2001). The powerful critique of stereotyped representations of 'typical' suburban demography offered by this research is undoubted, yet there is still a need for greater theoretical clarity as to the role of spatial form in influencing dynamics of social change and reproduction in suburbs over time.

Since Dyos many urban historians and historical geographers have considered the particular complexity of suburban built environments 
(Jackson 1973; Warner 1978 (1962); Carter 1983: 130-48; Stilgoe 1989; Dennis 2008: 179-205; Barratt 2013). The historical work of Kelly (1993) on the rebuilding of Levittown and Archer's (2005) architectural perspective on the suburban 'dream house' are comparatively unusual in directly addressing the potential of suburban built form to adapt over time in relation to the development of communal and individual identities in a suburban context. The most systematic contribution in this respect has been made by urban morphologists working in the tradition of plan analysis (Conzen 1960). Whitehand's subsequent work on the suburban fringe belt has revealed how the distinctive structuring of suburban space is related to building cycle periods. During economic downturns large areas of land on the urban periphery remain relatively undeveloped as land uses are assigned to institutional or recreational use; subsequent development then 'leapfrogs' the fringe belt (Whitehand 1967). At the scale of the individual suburb, Whitehand and colleagues have shown how suburban growth is negotiated through the economic cycle between the state, planners, architects, developers and the owners of individual residences (Whitehand et al. 1992; Whitehand and Carr 2001). Far from being the timeless retreats of the Arcadian imagination, the suburbs of Birmingham are shown to be evolving over time in response to a wide range of factors, including society itself.

Yet the wider significance of research into the social morphology of the suburban built environment is undermined where the theoretical implications of Dyos' argument - that the suburb are less of a geographical than socio-economic or psychological entity - are still commonly accepted at face value. Silverstone's (1997: 13) discussion of the 'suburban imaginary' suggests how the suburban cultural domain risks becoming increasingly detached from the everyday experience of suburban space itself. Silverstone argues that globalisation has had the effect of marginalising ordinary everyday suburban spaces. Yet in a manner similar to Dyos, his response to the theoretical problem presented by suburban space is to accept its dematerialisation within a socio-cultural discourse in which 'suburbia is a state of mind', ubiquitous and pervasive; no longer an actual space but a 'virtual space' (Silverstone 1997: 13).

The theories of Lefebvre (1991 (1974)), Harvey (1989) and Soja (1990) have contributed significantly to our understanding of how social systems produce space in their image. However, other scholars in human geography have tended to emphasise the importance of space itself as a factor in society's organisation, for example the effect of one's location in the city on the way in which information is disseminated (Hägerstrand 1967, 1982; Pred 1990), and everyday social interaction becomes implicated in 
the reproduction of social structures (Giddens 1984). In a development of Giddens' theory, Hillier (2008) has argued that there is a tendency in social theory to prioritise the social production of space at the cost of a fuller consideration of the fundamentally spatial nature of human social organisation. The effect is that the built environment is reduced to being simply a passive stage on which society is enacted. The pervasive nature of this assumption is indicated in the introduction to A Suburbs Reader edited by Nicolaides and Weise (2006) in which suburban space is twice referred to as a 'backdrop' (2006: 1, 6). Taking issue with this approach, Hubbard (2006: 7) argues that there is a need to take spatiality 'seriously' if the contribution of the urban built environment to geographical theory is to be understood. Such seriousness would involve acknowledging the suburb as a particular kind of locale in which many different socio-economic processes and cultural identities are negotiated over time.

The morphological approach is important not only for the way in which it has identified the distinctive configuration of suburban built form but also in showing how this form adapts over time to different social, cultural and economic contexts. However, we propose that a further theoretical-methodological step is required to balance the emphasis on deliberate interventions in suburban morphology to acknowledge the significance of everyday social practices in this adaptive process. Where this dialogue between society and space is insufficiently understood theoretically, the range of competing suburban definitions available seems unlikely to lead to an enhanced understanding of the specificity and complexity of suburban places. The consequence, as Harris and Larkham (1999: 8) have argued, is that the term 'suburb', like the suburbs themselves, 'often seems formless' because 'to most people, suburbs are characterised along more than one dimension'. This point has been noted by the historians McManus and Ethington (2007) who draw on morphological approaches to argue for an 'interactive ecology' of suburban built environments and the life-cycles of different suburban communities. The authors' belief that suburban history needs to focus on the processes through which suburban life adapts to changing socio-cultural dynamics over time complements the case for a distinctively suburban theory of social organisation that is advanced in this chapter. To conceive of suburbs as multi-dimensional is to recognise their complexity as social spaces beyond the reductive categories so frequently applied to them, whether in terms of socio-economic processes or exclusive cultural affiliation. To understand that suburbs are evolving entities shaped over time by external forces is another essential aspect all too frequently overlooked in traditional historical studies. 


\section{Suburban trajectories}

The assumption of suburban one-dimensionality is deep-seated and perpetuates itself in a variety of ways. One recurrent theme views suburbs as an outcome of the urbanisation process (or an 'excrescence', as Silverstone 1997: 4, puts it). This process can involve both centripetal suburban development at the urban fringe or centrifugal dispersion of urban activities over a wider area, but in both instances suburbs are conceptualised relative to the urban centre. Suburban growth trajectories have traditionally been described negatively, in terms of the 'assault', 'conquest' and 'invasion' of the country by the city (Dyos 1961: 31, 33 passim). Mumford (1940: 472) gave expressive voice to this discourse in which suburbs are contaminated and ultimately destroyed by the 'spreading mass' of the devouring city. Within this teleology the possibility for suburban space to sustain difference - its own sources of meaning - is diminished by being reduced to a point in the trajectory of the urbanisation cycle.

The historical relationship of the suburb to the city is evidently key, but the point of view is inevitably urban and typically this view is that of the privileged, educated individual. One consequence is the imposition of a powerful narrative of 'rise and fall' on the history of the suburb in which the latter is denied agency except in terms of the relative proximity or distance of the city. To historians of English suburbs such as Dyos (Camberwell London), Cannadine (Edgbaston - Birmingham) and Spiers (Victoria Park - Manchester) it seems that the 'golden age' of the suburb existed from the early to mid-nineteenth century when the cost of transport meant suburban development could be socially exclusive (Dyos 1961; Spiers 1976; Cannadine 1977). Dyos argues that by the end of the nineteenth century, with increasing densification of both people and buildings, 'the great days of Camberwell as a suburb were over' (Dyos 1961: 193). In a similar vein, Nicolaides (2002) has documented how the desire for suburban exclusivity led residents of working-class suburbs in Los Angeles to fear the arrival of urban nuisances such as dirty industry, juvenile delinquents and transient renters that threatened their expectations of the suburban 'good life'. Indeed, the fear of their suburban neighbourhood going 'down in the world' is a staple theme in English culture. Similarly, the traditional view of the design elite has been for a long while one of derision towards the suburb, so eloquently described in 'Dunroamin' (Oliver et al. 1981), where the 1933 declaration of the International Congress of Modern Architecture is quoted as stating that the suburb was 'a kind of scum churning against the walls of the city' and that it is 'one of the greatest evils of the century'. Currently the narrative of suburban decline and fall is unfolding in reverse in North 
America where it is distance from, rather than proximity to, the urban centre that seems to threaten the suburban way of life and the return of young couples pushing baby carriages on the city centre streets is viewed as a thoroughly positive progression (Florida 2013).

If, as this chapter argues, suburban space represents the possibility of spatial-social change over time and the pervasiveness of diverse activities within an extended urban region, it follows that the urbanisation of a suburb should not be regarded as synonymous with the total erasure of its suburban identity. The densification associated with urbanisation is often accompanied by the persistence of village-like elements characteristic of the earlier phases of growth. Connell (1974), for example, refers to these as metropolitan villages. Similarly, some regular features of suburban morphology, for example their forming nuclei on pre-urban road networks, will often anticipate their later identity as a so-called suburban settlement. This is a feature well documented in the UK as well as in the USA and Canada (Griffiths 2009; Hallowell and Baran 2013). In this respect there is some ambiguity in Bourne's statement that:

... the attributes of suburbs that we want to emphasize [are] their relative newness, separateness and location. It is also suggestive of the obvious but often overlooked fact that suburbs are evolutionary or transitional states: yesterday's new suburbs are today's mature suburbs and tomorrow's older suburbs or inner city. (Bourne 1996: 165)

While Bourne notes the adaptability of suburban space he also implies this quality means it is ephemeral since, as suburbs cease to be new, as he describes it, they seem to become less suburban. The narrative of suburban rise and fall endorses representations of the suburb as essentially indistinguishable from the history of the city. Yet, as mentioned in this book's Introduction, many suburbs have their own histories within a geographical region that, while not ignoring the urban perspective, should not privilege it uncritically. London, just as much as older parts of the USA and Canada, has grown in line with existing road alignments, field boundaries and other such physical elements that have helped shape its pattern of growth.

A perspective on the suburb as essentially devoid of form is consistent with the schematic models of urban structure provided by the Chicago School in which the more affluent sections of the population are said to move outward through a series of transitional zones projected onto an undifferentiated spatial surface (Burgess 1967 (1925)). Similarly, central place theory views regional urban systems as if they are simply arrangements of town centres, seldom taking account of the fact that those centres 
are interconnected through regional networks of streets. Likewise, the 1969 Greater London Development Plan illustrates the growth of the city in time bands, representing the city's notional phases of growth, but the overall impression is of an explosion of matter moving from centre to edge to fill a spatial vacuum.

Alternative models of urbanisation that ignore the common currency of growth from centre to edge provide other conceptualisations of the relationship of city and suburb. Harris and Lewis (2001), for example, have shown how, in North America, some multinucleated suburban regions have their origins in clusters of nineteenth-century employment centres. Following the Second World War, mass car ownership, coupled with deindustrialisation and subsequent mass communication, had a profound effect on the economies of traditional urban concentrations. Castells has said of this process:

... it relies on the formation of relatively dense business and commercial sub-centres, transforming the metropolitan areas into multinuclear, multifunctional spatial structures, organized around ... new 'urban villages.' (Castells 1989: 156)

Recognising this transformation, Marshall has argued for a change from the hierarchical view of suburban centres to one where the urban core is viewed as just one of many centres within a region, since 'the urban gravitational pull is more truly said to be from everywhere to everywhere else' (Marshall 2006: 274). He prefers the term 'semi-urban' to 'suburb' as being more appropriate for this type of built environment - suggesting how, even in a polycentric system, suburban space remains essentially formless, defined negatively in terms of its urban or rural characteristics. Moreover, current approaches to polycentricity tend to be principally concerned with the organisation of major centres into mega-city regions (Hall and Pain 2006); these are hardly concerned with the question of suburban space as such. Sieverts (2003) comes closer to capturing the complexity of extended decentralised built environments in the regions he calls Zwichenstadt (the term Sieverts coined in 1997 for what we would call 'sprawl' in English). He argues that putting the urban centre first is an unhelpful barrier to innovative thinking about how to develop areas with more diffuse patterns of settlement, in which rural and urban forms are intermingled.

Indeed, the one-sided love for the historical city is the main reason for our repression of the challenge presented by unloved suburbia.

(Sieverts 2003: 17) 
Sieverts' contention that the suburbs are unloved can be easily refuted by the extensive literature that expresses the contrary. This chapter does not seek to promote either the loveliness of suburbia or indeed its hatefulness, but instead to challenge the notion that the only way of defining suburban space is in the negative: as being neither urban nor rural.

\section{Suburban identities}

Cultural geographers and literary scholars have, in many ways, been more successful in establishing the suburbs as important loci of socio-cultural identity. Goldsworthy (2004), for one, shows that suburbs help to define an important aspect of Englishness, with their secluded quiet living; whilst Silverstone (1997) describes the emergence of a particularly recognisable (at least in English-speaking cultures) middle-class way of living. Others show how the suburb is a highly significant domain for women's engagement with urban modernity and the major social (and to an extent emancipatory) developments of the twentieth century (Giles 2004). However, theoretical difficulties arise when making the connection back from the cultural representation of the suburbs in terms of a particular social group to the materiality of the suburban built environment. Such a connection is necessary to prevent a powerful cultural representation, for example that of the 'feminine domestic sphere', becoming clichéd when projected uncritically onto suburban space; this would risk eliding the differences in women's experiences, such as those of the housewife and her domestic help. Clearly the experience of the working-class woman in the move out from the city was not the same as that of her middle-class counterparts. Anthropological investigations of suburban life have made useful contributions to the discipline, with the work of Hecht (2001) on the material culture of suburban home life shedding new light on how suburban incomers relate to their past lives elsewhere. One of the first such studies was that by Michael Young and Peter Willmott, who famously compared the street-based life of inner-city Londoners with their patterns of friendship after a move to the outer London suburbs. Theirs was one of the first to turn the ethnographic eye on the British suburb (see also Willmott and Young 1960). Another important suburban ethnography from this period is Herbert Gans' study of Levittown (1967), which concluded that suburban character was shaped more by the background of the incomers than the new surroundings within which they settled. His study raises pertinent questions about the relationship of society and space that are a primary concern of this collection, describing, for example, the importance of community facilities, such as school meeting rooms, to help ameliorate feelings of isolation 
during the initial period of settling in. Nevertheless, we argue that there is an absence of a more generic conceptualisation of suburban space in such sociological studies, as well as a lack of a rigorous approach to analysing differences between suburban settings, which means that considerations about class, gender or ethnicity cannot be properly set against their spatial contexts. The physicality of the suburb becomes simply a scene-setting for the social experience: it is usually 'leafy' or 'green' - to follow the cliché to its common conclusion - and thus it is amorphous and undefined. The consequence, we argue, has been the tendency among researchers in suburban studies to imply that the sheer range of perspectives and case studies available to them somehow constitutes a theoretical position in itself. Although suburban variety is indeed an obvious and important aspect of their character, it leads to a similarly varied set of representations that remain essentially self-contained. Three of these representations, the dystopian suburb, the realist suburb and the idealist suburb, are discussed below.

Suburban dystopian theorists are likely to be urban-rural idealists. In other words they believe the suburban to be synonymous with the degradation of the city, the loss of the rural and a challenge to civilised society. Suburbanisation in England in the second half of the nineteenth century was experienced as trauma by the cultural elite - typified by John Ruskin who were horrified by the terraces of monotonous suburban housing they believed to be literally and figuratively philistine (Hapgood 2005). An example of the response to the apparent horror of suburban growth can be seen in this extract from the Westminster Review:

It is curious to remark the various gradations by which London fades into the country, or, as we should more accurately say, by which the country is gradually swallowed up in London. The main army is preceded by an advance of villas, thrown out like skirmishers. They begin by seizing a few picked positions, but are to be found, as their numbers increase, wandering off into the fields, where they can only be approached along muddy and unlighted lanes. Then come the more solid ranks of the semi-detached, forming in continuous lines along the high roads and in the neighbourhood of railway stations. They are followed by rows of shops. Generally headed by an enterprising gin-palace, which bind together the more irregular forces and complete the army of occupation. We find some morning that a town has grown up which has a physiognomy peculiar to these suburban districts. For it is evidently no articulate whole, but a mere fragment, which will soon be assimilated by the advancing mass behind ... (Westminster Review, April 1866) 
The apparent degradation of suburban life is captured in this quote by the reference to gin-palaces, the epitome of social decline in the nineteenth century. Indeed, Hunt (2005) argues in this tradition that the growth of suburbia in the UK was frequently associated with the decline of Victorian civic pride.

A century later, McLuhan (1951) and Whyte (1956) writing in post-war America, describe the suburbs as places of consumerist-inspired social conformity. From the start, the long commute and low densities associated with 'sprawl' have been widely blamed for the supposed demise of community life, political engagement and lack of contact across ethnic groups (Riesman et al. 1950; Duany et al. 2000; Putnam 2000), despite widespread criticism that such studies tend to overlook new patterns of socialisation that may not be captured by their studies and that they typically hark back to halcyon days of chats over white picket fences, overlooking the messy reality of suburban life that is easily forgotten. In Britain, the aforementioned Young and Wilmott (1957) study set the tone for criticism of suburban life. Their book, which has never been out of print since its first publication, describes in great detail the densely overlaid networks of contacts supported by the pattern of the inner-city street. The subsequent dispersal of the working-class population to a suburban estate in north-east outer London is portrayed as destructive of traditional communal structures. Mark Clapson's unpacking of the reality of this story - that for many, the move to the suburbs was generally positive - refutes much of this criticism (Clapson 1998, 2012). In a different vein Harvey (1989: 122) has characterised suburbanisation as the means by which capitalism ensures a market for consumer products and the nourishment of an anti-communitarian ideology of 'competitive individualism'. Other critiques focus on the way in which suburban growth trajectories or de facto racialised planning decisions have cemented class or racial divides, such as in Silicon Valley, California (Cutler 2015). Yet the geographical tradition which views the suburb as representative of fragmented, stratified society, denying the right to the city (Soja 2010) and in a fundamentally destabilised, capitalistic system can overstate their case. They frequently overlook the fact that it is not the suburbs themselves that are the root of the problem, but a lack of access to facilities (as explained by Urry 2002 and Legeby et al. in this volume). The value and integrity of this research are not disputed as much as the ease with which such representations come to be considered as axiomatically suburban.

The representation of suburban space in terms of communal atrophy is associated with an assumption of its essential formlessness. In 1955 the editor of Architecture Review, Ian Nairn, produced a monograph entitled 'Outrage' to rail against: 
... the creeping mildew that already circumscribes all of our towns.

This death by slow decay is called subtopia ... the world of universal low-density mess. (Nairn 1955: 365)

Nairn's anti-sprawl polemic, along with his Counter-Attack Against Subtopia (1956), can be highlighted as the precursor to modern antisuburbanism (Bullard et al. 2000). Amongst these, the sober 'post-modern' re-examination of suburbia by Anderson (2006) in Australia, who describe the particularly complex diversity of ethnicities and identities both in Australia and elsewhere. Amanda Wise's detailed ethnography of a Sydney suburb confirms Anderson and colleagues' findings, where she shows how multiculturalism takes shape in the form of cross-cultural interaction, a 'multiculturalism of inhabitance' (Wise 2006). The point here is not the legitimacy or otherwise of the dystopian view. Rather it is to argue that representations in these terms are easily divorced from the historical realities of the suburbs as places to which people aspire to live and are happy to do so. Instead, they become fixated on the symbolic value of the suburb as a cipher for what is perceived to be wrong in the urban and rural spheres.

The historian Clapson $(1998,2003)$ belongs to what could be termed a nascent 'realist school' of contemporary history on the English suburb. Its roots are in the ground-breaking work of an earlier generation of American sociologists who saw in post-war suburbia nothing more than the rise of a modern, affluent and more mobile society (Gans 1967; Berger 1968) as opposed to rural atavism (Glass 1989). Clapson's research suggests that there are grounds for thinking that English suburbanites of the post-war generation were not so different from their American counterparts (Clapson 2003: 52). What the theorists of the realist school have in common is a belief that the popularity of the suburbs as places where many people choose to live and work means they need to be taken seriously as a distinctive category of settlement, typically associated with liberal-democratic values such as individualism and lifestyle choice (Marshall 2006). From this perspective sprawl is an expression of the power of suburban aspiration over urban living and a socio-economic success story in its own right (Garreau 1992; Gordon and Richardson 2000; Couch and Karecha 2006).

The realists have played an important part in establishing the suburbs as a credible field of academic study. Some might be criticised as portraying the suburban as intrinsically progressive, in an emancipatory if not overtly political sense. This comes close to endorsing a deterministic view of the suburbs as the 'natural' product of advanced phases of urbanisation, and therefore entitled to some higher moral legitimacy. Of course not all movements to the suburbs are out of choice, for example, the movement of 
miners to the suburbs following the restructuring of the coal industry from the 1950s onwards (Evans and Larkham 2004). Despite this, the realists are probably most open to acknowledging suburban space as a distinctive field of social practice than other dominant representations because they are less likely to marginalise or mythologise them. Their difficulty lies in acknowledging the sheer number of ways in which people engage with the suburbs, not all of which may be consistent with the model of the suburbanite as a rational consumer or social aspirant.

On the other hand, idealist representations of the suburb differ from the dystopian and realist in symbolising the possibility of reclaiming the lost (rural) past and through this redeeming the city and its population from degradation. The modern idealist tradition can trace its roots back to Ebenezer Howard's notion of the Garden City, with its idea to combine the perfect mix of town and country qualities as a remedy both to the dire social problems of the late nineteenth-century city and the cultural sterility and economic decline of the countryside (Miller 1992). With its emphasis on relatively low-density housing, gardens and village greens, the idealist approach has been highly influential in the emergence of 'garden suburbs' and new towns both in the UK and throughout the world (Whitehand and Carr 1999c). Whereas the Garden City movement targeted the human consequences of unregulated building, the economics of 'slumification' and urban unemployment, the New Urbanists in the United States argue that very low-density suburban living is environmentally and socially unsustainable (Calthorpe 1993; Tiesdell 2002). Despite their apparent differences, advocates of the New Urbanism share their idealism with the proponents of the Garden City. Both approaches contain strong communitarian prescriptions for social reform and put their faith in the planning process to effect social and environmental change.

Idealist representations of the suburb lend themselves to powerful cultural stereotyping in terms of the 'typical' family life. In the UK the highly popular 1970s BBC television situation comedy The Good Life was one of many which presented suburbia sentimentally but positively as a place where eccentricity prospered quietly behind the privet hedge, and social discord could be resolved over a cup of tea and a biscuit. In the USA the nostalgic suburban image of the television sitcom has been remorselessly parodied in films such as Pleasantville (1998) and American Beauty (1999). Both fantastic and dystopian images resonate throughout contemporary popular culture, as apparent in television series such as Desperate Housewives (Muzzio and Halper 2002). The appropriateness of these images to articulate the complex socio-economic and cultural diversity of contemporary suburbs is doubtful but it is undeniable that they constitute a powerful imaginary in 
which the suburban built environment is an important agent - the nature of that agency, however, remains relatively unexplored.

\section{Suburban otherness}

'Suburban otherness' refers to the tendency for the suburbs to be mythologised as places that exist somewhere else and are inhabited by people unlike ourselves. The idea of the suburb as the place where the waste of the city (both human and otherwise) is disposed of is not without basis in fact, as dirty trades, such as leather tanning, and institutions, including hospitals for the mentally ill and prisons, have traditionally been located beyond the urban periphery (Sinclair 2002). Mumford alludes to this tradition in one of his few relatively positive comments about the mid-twentieth-century suburb - although one might be forgiven for hearing an ironic tone in his comment:

... in the crowded, modern city, the first general exodus to a more desirable dwelling place in the country was the migration of the dead to the romantic Elysium of a suburban cemetery. (Mumford 1961: 15)

Consistent with this view of the suburb as an earthly limbo, Webster argues that it is the perceived insubstantiality of suburbia, 'devoid of cultural and aesthetic value so that the very absence of signification becomes a haunting presence' (Webster 2000: 2), that has come to be almost the default manner of depicting suburbs in the written and visual arts. Typically rendered in a heavily stylised fashion, the vacuity of suburban life portrayed in films such as The Time Bandits (1980) or Edward Scissorhands (1991) creates the dramatic potential for the fantastic events to unfold. Graphic artists such as Richard McGuire in Here (newly issued, December 2014) depict the suburban living room as the point of reference for thousands of years of North American life, using the very mundanity of the setting as a contrast with apocalyptic events from the past and the future. Other suburban imaginaries feature in the psychogeography of London's outer suburbs. Commenting on the life of the M25's executive villages Sinclair writes that:

The suburb is no longer a suburb, it's a denial of the motorway - on which it depends for its future survival. (Sinclair 2002: 310)

Augé (1995) would characterise such locations as 'non-places' in which historical identity and centrality are gradually eroded by the social and 
technological forces that strip them of their local contexts. This theorisation renders suburban space perfectly textureless, defined by easy accessibility to places elsewhere in what Castells (1989) refers to as the 'space of flows'. In contrast, Massey (2005) contends that such global connections must play out locally as well as vice versa. In effect, such discourses render suburban space as marginal, ephemeral, inert and essentially other to everyday experience.

The assumption of suburban otherness can be identified in futurist representations of the suburb. The novelist J. G. Ballard has commented that he moved to the outer London suburb of Shepperton in the $1960 \mathrm{~s}$ because he thought:

... the future isn't in the metropolitan areas of London. I want to go out to the new suburbs, near the film studios. (Campbell 2008)

The association of the suburbs with creative high-technology industries fuels much of the current interest in decentralised development in locations such as Silicon Valley, California that constitute Garreau's 'edge cities'. The aspatial social networks and high disposable incomes of (some) people working and living in these environments have contributed to representations of the suburb as a non-place. However, they also serve as reminders that the suburbs are as much about commerce as about consumption, and that suburban life includes poverty and environmental pollution as well as wealth and clean air (Pellow and Sun-Hee Park 2002). Indeed, suburban life can in certain circumstances reinforce racial divisions, such as can be seen in the history of the formation of what would become Silicon Valley, where de facto housing segregation continued well into the 1970s (Cutler 2015).

The fecundity of vocabulary for contemporary suburban built environments is impressive. A selection includes: 'outtowns' (Goldberger 1987), 'technoburbs' (Fishman 1987), 'exopolis' (Soja 2000), 'superburbs' (Bourne 1996: 173), 'ethnoburbs' (Li 1998), 'edgeless cities' (Lang 2003), 'Zoomburbs' (Hayden 2004) and 'boomburbs' (Lang et al. 2008). These settlement forms, associated with radical decentralisation and the expansion of urban 'sprawl', have been classified by Phelps et al. (2006) as the 'post-suburban'. Such interesting suburban developments certainly merit serious academic consideration. However, we suggest that this festival of neologism is indicative of an underlying theoretical weakness that inhibits comparative research into suburban space. In these futurist representations of the suburbs, novelty is perpetual; there is no time for a past to accumulate at locations where social and economic energy will soon move onto the next frontier. Ironically, this renders them incapable of adaptation or 
change since such 'strange' built forms are devoid of historical continuity with existing, or indeed pre-existing, built environments and landscapes. In the absence of a more substantive conceptual framework, too exclusive a focus on suburban novelty avoids sufficient discussion of suburban persistence in time.

\section{Conclusion}

This wide-ranging literature review was originally designed to lay the groundwork for our research, which began studying the morphological, social and economic evolution of London suburbs in 2006. 'This review has shown that while both urban and rural studies have long thrived, suburban studies are generally neglected as a distinctive field and the inherent needs and problems of suburban living remain unaddressed. Scholars researching suburbia in the framework of different disciplines still have no easy overview of what the different areas of their subject have in common. Whilst cities are routinely acknowledged as complex and dynamic built environments, we have shown that this description is rarely extended to the suburbs, which are generally regarded as epiphenomena of the urbe and therefore of little intrinsic theoretical interest in themselves. We have critiqued this widely held assumption by showing how the idea of 'the suburb' as an essentially non-problematic domain has been perpetuated from a range of contrasting disciplinary perspectives, including those which directly address suburban subject matter. The result has been that attempts to articulate the complex social possibilities of suburban space are easily caught between theories of urbanisation that are insensitive to suburban specificity and competing representations of the suburb that rarely move beyond the culturally specific to consider their generic significance.

Although we posed the question of whether the suburbs exist, they do, of course, exist. Increasingly they are a theme of universal significance, implicated in the growth of globalised 'world cities' and the rapid development of the built environment in emerging economies. However, the argument advanced in this chapter is that until the agency of suburban space as a distinctive domain of social organisation is acknowledged, the notion of the 'suburb' remains too epistemologically fragile to carry the burden of representation that it currently bears.

The consequence of this fragility is that research in the field of suburban studies risks being undermined by an enduring legacy of widely held assumptions regarding the 'essential' nature of the suburb. Yet such suburban imaginations tend to be derived from historically particular instances, 
rather than from a consideration of the type of generic problem that the suburb represents. This chapter, therefore, has sought to make the case for a theoretical consideration of suburban space on its own terms as a specific and complex field of social practice. Rather than tacitly conceiving of suburban space as formless, timeless and 'other', it is equally possible to think of it as dynamic, persistent and familiar. We propose that the significance of suburban theory lies in its potential to undermine one-dimensional approaches to the built environment by refocusing attention on the generic significance of suburban space as the dynamic, generative, principle in the historical differentiation of complex built environments undergoing processes of change and continuity. As we will show in the remainder of this book, examples from a large array of different urban settings show suburbs to be part of a network of smaller and larger settlements that operate differently through space and time. They also provide substance to the assertion made over two decades ago that the 'deep structure' of the street network (Hillier 1989) has a significant role in shaping potentials for the daily rhythm of life to take place. We will show how in the suburbs, even more so than in the city, the opportunities for encounter, rest and play are vital to daily lives.

This chapter is based on the article 'Do the Suburbs Exist?' published in 2009 in the journal Transactions of the Institute of British Geographers by the authors along with Catherine (Kate) Emma Jones. We are grateful to John Wiley \& Co for their giving us permission to produce an updated version of the article for this book. (C) 2009 The Authors. Journal compilation (c) Royal Geographical Society (with The Institute of British Geographers).

\section{Note}

1 For details on the grants in question, see the Preface to this book. 


\title{
Chapter 2 \\ The High Street as a Morphological Event
}

\author{
Sam Griffiths
}

\section{Introduction}

The high street has long been a near ubiquitous feature of British towns, cities and suburbs. The dual role of high streets as signifiers of communal identity and as subsidiary nodes in economic topography means a comprehensive account must contend with both the tangibility of what high streets do in socio-economic terms, as well as the intangibility of what they mean to local people. Acknowledging both these qualities, the approach taken here is to frame the traditional British high street as a phenomenon exhausted neither by the metrics of central place analysis nor by its representation in popular culture, whether as a metaphor for the retail sector as a whole or as a (quite possibly the) dominant urban trope in stories aimed at very young children. Rather, it is claimed that the high street requires serious conceptualisation as a distinctive mode of social time-space organisation that in many cases emerged historically and in relation to persistent morphological structures that might pre-date the built environment itself. In this sense both the functional attributes and symbolic resonance of high streets are said to arise from their quality as interfaces generative of everyday sociality; a process that, for reasons that will be explained, has the effect of extending the presence of the community backwards and forwards in time. The high street therefore appears here as a key site for the realisation and perpetuation of locality, not least through the ongoing local negotiation of social change. In proposing the high street as a site through which community is performed rather than operationalised and represented, the intention is to contribute to the lively debate about the future of a very familiar but also poorly understood feature of the British built environment. 
While noting that the suburb has no unique claim to the high street, a research focus on suburban high streets is justified by the fact that the suburbs are still overwhelmingly conceived as exclusively residential locations. A body of empirical work, some presented in the current volume, has revealed that this picture is misleading, if not downright inaccurate (for example, Gort Scott and UCL 2010; Vaughan et al. 2010b; Urban Design 2013). These studies highlight the capacity of high streets and their environs to sustain a broad base of socio-economic, cultural and community activities. In this sense the high street serves as an apposite illustration of the theme of Suburban Urbanities. It is true, however, that such attributes of the suburb may be regarded as peculiarly British, in that British suburbs tend to be extensions to historically nucleated settlements. While, to a greater or lesser extent, this pattern of suburban growth is common in European contexts, it is much less the case in North America where a combination of low-density car-based development and strict zoning combine to give greater credence to the identity of the suburb as residential sprawl. Nevertheless, those familiar with 'Main Street' and even 'edge city' might expect to find some parallels with the parochial debate over the fate of British high streets, which also serves to highlight several broader themes about the built environment as an aspect of 'community'.

A wave of contemporary interest in the fate of the British high street raises the interesting question of how the past of a town, city or suburb relates to its future. Paradoxically, however, this debate is often couched in rather ahistorical terms, pitching the economic realism of the 'moderns' (the high street is dead, long live the shopping mall/internet!) against the atavism of the 'ancients' (the high street is dead, long live the high street!). ${ }^{1}$ While the former are quick to invoke what I have referred to elsewhere as the narrative of historical high street 'decline' in order to shift the terms of the debate onto a less parochial footing, the latter identify something of intrinsic social value in the historic built environment, but rarely go beyond rather eulogistic descriptions of the imagined virtues of medieval urban centres under threat of becoming 'clone towns' (NEF 2005; Griffiths et al. 2013). The irony is that both positions broadly concur in defining the high street as a 'problem', differing only in the extent to which they think this matters. The terms of this rather emotive debate were anticipated by the advocate of 'non-plan' (Barker 1999). Barker, at that time a critic of restricting the development of economically dynamic out-of-town shopping centres, argued that the traditional high street had reached the end of its life expectancy. There is further irony in the fact that the out-of-town shopping centres that once fascinated Barker are no less, and in some senses much more, exposed to the competition of internet shopping. ${ }^{2}$ 
The tacit agreement that there is a 'crisis' amounts to little more than counsel of despair. I wish to take issue with this pessimistic position by drawing attention to the rather simplistic way in which it invokes history. Both the ancients and moderns in the high street debate tend to endorse the modernist framing of the historical past as a 'foreign country' where things are 'done differently'. ${ }^{3}$ Now, of course, there is an important sense in which this is true, but a thorough knowledge of context is essential to avoid anachronism in historical accounts. When one is dealing with the built environment, however, it is often far from clear what temporal arc is most appropriate to express the historical qualities of a particular context. A general lack of clarity on this question helps explains why so much of current policy debate is premised on a kind of 'end of history' argument, in which the 'traditional' high street is rendered as a vestige of a past civilization that has increasingly little in common with our own. It also explains the apparent paradox in Barker's argument that a highly programmed environment such as a shopping mall appears to be a better example of 'non-plan' than high street environments that have sometimes been the site of continuous socio-economic activity over centuries.

The argument developed here is not intended to dismiss legitimate concerns about the fortunes of the contemporary high street in the name of an updated theory of non-plan. Quite the contrary, it is acknowledged that many high streets in Britain are suffering and could benefit from appropriate policy regimes to support the important services they offer local communities. At the same time it should be acknowledged that many others are weathering change and even prospering during periods of economic transition. In either case the merit of taking an historical perspective to the high street is that it serves to highlight their long-term durability as places frequently capable of reproducing socio-economic activity of one kind or another over successive generations. The evidence-based perspective that needs to inform the current debate should not exclude the historical built environment itself as one possible source of this resilience.

\section{High street temporalities}

It would clearly be erroneous to assert that the high street describes some kind of universal condition of life in the built environment. Indeed, the high street (in the sense of the main shopping street) has a number of different histories. In England, for example, it is associated with the eighteenth-century appetite for leisured urban consumption and public displays of sociability, the nineteenth-century conversion of stalls into 
shops for the sale of everyday foodstuffs as a consequence of rapid urbanisation, and the contemporary phenomenon of coffee culture. Acknowledging its role in successive phases of social history, however, does not in itself explain how in many ways British high streets escape definition in terms of conventional historical periods altogether. They are often as much a feature of the Victorian and inter-war periods as the post-war years and internet age; a source of communal continuity proudly illustrated in any number of local history publications and school history projects. The high street as a site of historical continuity with a capacity for negotiating social change in a local context is insufficiently addressed on the conceptual level by accounts organised by the conventional periods of social history, since the built environment history of the high street typically extends beyond these.

This argument is consistent with historical-geographical accounts that note how many suburban high streets emerged in an unplanned way along roads that connected to the original marketplace or centre of the nucleated settlement (Griffiths et al. 2010). Figure 2.1(a) shows a section of a map covering an area to the north-west of the built-up area of the English city of Sheffield in 1795 and Figure 2.1(b) shows the area to the north of London in the 1820 s. Both maps depict these areas before sustained suburban development in the later nineteenth century. It is immediately notable to anyone familiar with these places how the historical road network had already 'seeded' a number of localities now recognisable as suburbs

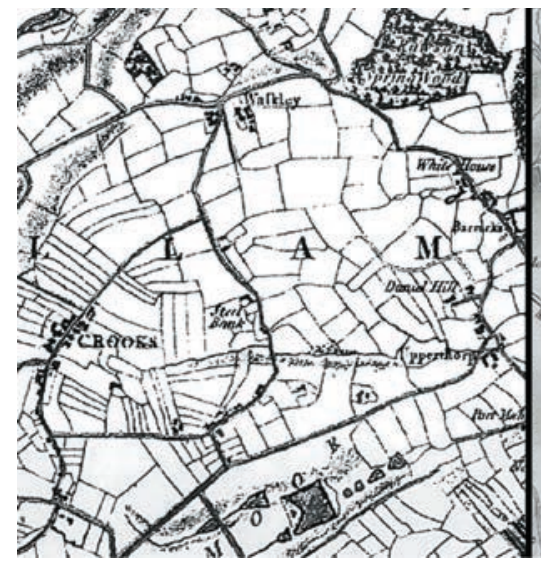

(a)

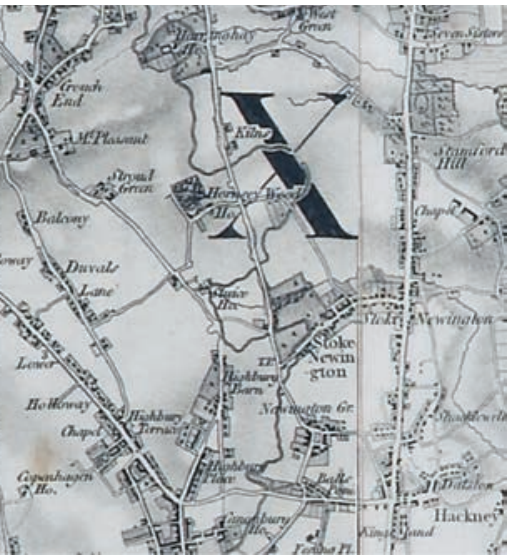

(b)

Figure 2.1

(a) Villages to the north-west of Sheffield c.1795 By permission of Sheffield Archives.

(b) Villages to the north of London 6.1820 (c) The British Library Board: Cartographic Maps CC.1.t. 
or urban villages with their own high streets. In Sheffield, these include Crookes, Upperthorpe and Walkley. In London, Newington Green, Stroud Green and Crouch End, and also Hackney and Stoke Newington are identifiable along the route of the old Roman Road heading north-south.

Of course, there are other place names on the map that have less contemporary resonance, nor is the subsequent development of these settlements absolutely equivalent to their historical starting points. The point that the historical maps are intended to illustrate is how historical road networks might be described as significant 'morphological events', that is, as spatial entities that continue to happen. These networks are not, in other words, static and eternal features of the landscape but realise complex time-space trajectories that unfold from the past into the present and future (see also Griffiths 2009). Conceiving of high streets in this sense as particular kinds of morphological event arising from the network qualities of roads implies the inadequacy of the popular discourse of the high street in terms of its imminent death or life. The idea of morphological events will be explored in greater depth in Section III.

Sensitivity to the extended temporalities of the built environment is perhaps intensified at the scale of the high street, with its functional and symbolic importance to the everyday practice of community. Perhaps that explains the widespread popularity of the web-based art form which involves positioning photographs or paintings of particular urban locations in the past in the equivalent contemporary location, capturing the resulting montage as a photograph and posting online. The work of Halley Docherty is exemplary in this respect. His preference is for placing well-known paintings in iconic central locations in major cities. For example, William Logsdail's 1888 painting of a girl selling flowers inserted into the contemporary setting of St Martin-in-the-Fields church in central London.4 But just as interesting are crowd-sourced history projects such as the BBC's Turn Back Time Flickr group for the history of the high street (BBC 2010). Of the hundreds of photographs of local high streets past and present posted by participants, many chose this method of montage. Figure 2.2 gives the representative example of High Road, Willesden, a suburb of north-west London, showing a photograph of the 1920 s superimposed onto the contemporary scene.

What fascinates us in such pictures is how evidence of even a relatively small degree of continuity in the built environment, especially a built environment of which one has personal experience, serves to bring the lives of the past, their actuality as agents of movement and encounter, into our framing of the present. Whereas a view of the past 'as a foreign country' might produce an expectation of juxtaposition in these montages, 


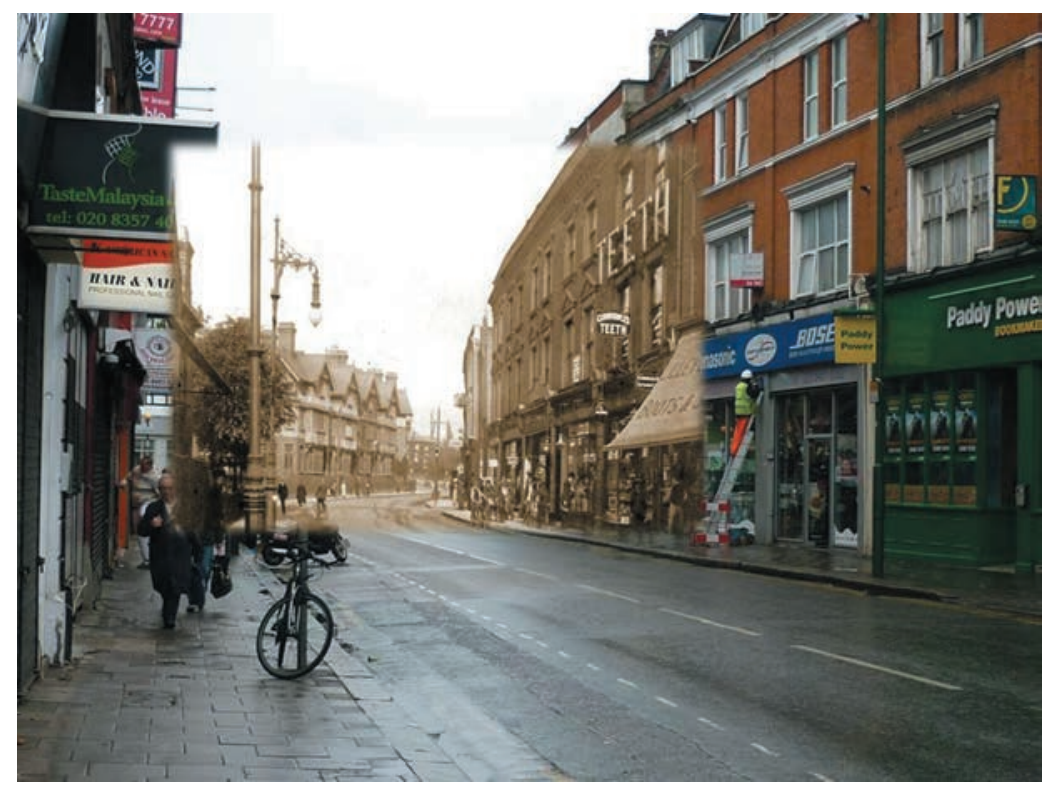

Figure $\mathbf{2 . 2}$

Montage view of Willesden High Road c.1920s and c.2010

(C) Brent Archives.

it is surprising to find instead an unexpected orientation of the past towards the present and indeed, of the present towards the past (note, for example, the contemporary figures to the left of Figure 2.2). If some aspects of the historical period are clearly distinct from our own, for example clothes, shop fronts, the vehicles, there is evident continuity in the built form of the high street itself. The local history of the High Street in South Norwood, south-east London, shown in a series of historical photographs in Figure 2.3 , illustrates how in many respects the study of the past indeed reveals discontinuities. ${ }^{5}$ For example, the awnings, the hats, the higher density of people on the street and the lower density of vehicles seem to come from another time and in that sense are inaccessible. Yet in each photograph parents are also seen walking and pushing their children, along the same pavement, past the same buildings opening onto the same streetscape. This description recalls Jacobs' (1961: 65) notion of the 'intricate ballet' of urban life and Seamon's (1980: 163) phenomenological conception of 'place ballet' in which 'human and material parts' are said to 'unintentionally foster a larger whole with its own special rhythm and character'. In South Norwood one might reflect on how the 'ballet of the high street' extends in time such that distinctive signifiers of historical periods are no 
(a)

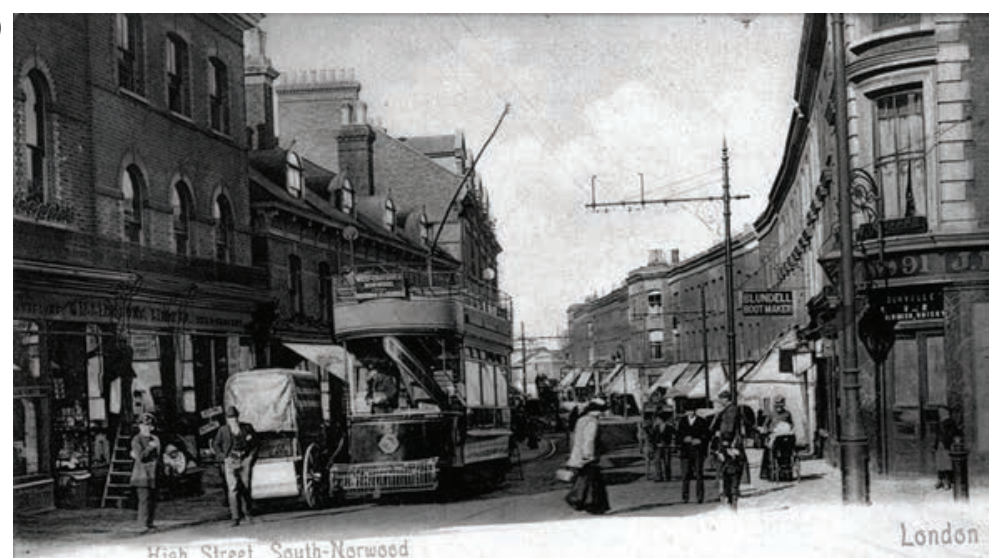

(b)

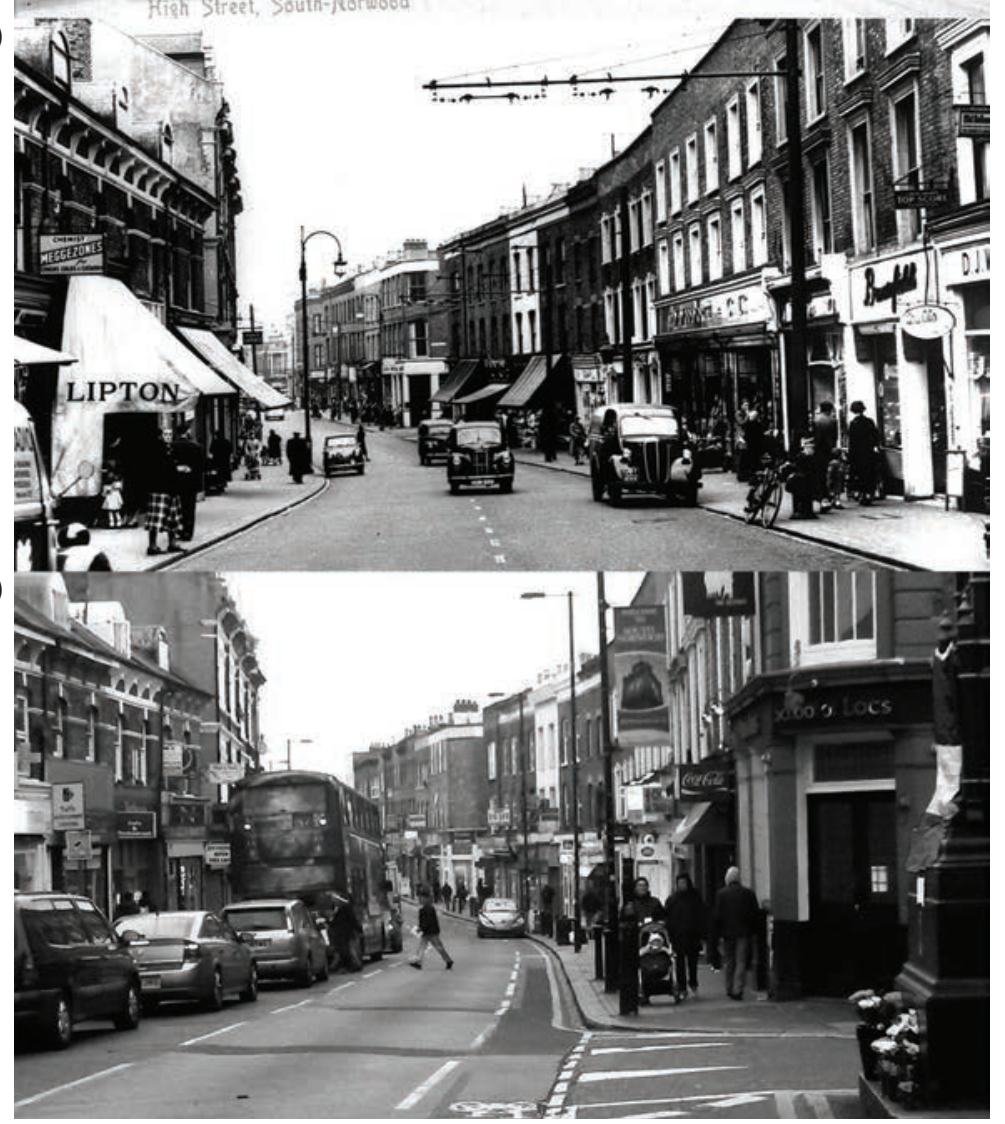

Figure 2.3

(a) High Street, South Norwood C.1905 Image courtesy of the Museum of Croydon, John Gent collection.

(b) High Street, South Norwood 1956 Image source as above.

(c) High Street, South Norwood 2015 Sam Griffiths. 
more symbolically potent than the fact of the 'dance' itself. In acknowledging the high street as a dynamic agent of continuity, against which the staccato of discontinuity is revealed, as it were, in relief, we become aware that we inhabit a material realm that is not entirely of our own making but through which we are bequeathed the capacity to make the world meaningful.

The question that is difficult for historians to pose in relation to such photographs regards the appropriate description of a particular builtenvironment temporality that is implied in the contemporary resonances of what might otherwise be conceived as the material backdrop to a scene rich in signifiers of historical difference. Importantly it is this distinctive temporality that imparts a certain agency to the high street environment as something not entirely equivalent to (though certainly not entirely distinct from) the particular social-historical context it depicts. Unlike the practice of scholarly history, which develops the intellectual methods needed to recover the past, these photo-montages highlight the possibility of a more spontaneous, everyday sense of temporality through which the past permeates the present. In Figure 2.2 and through a comparison of the images in Figure 2.3 it is not so much a question of us, as observers, accessing the past as it is the people of the past entering into the present.

Research done by the Adaptable Suburbs project at UCL has shown how both building stock and land uses have continually adapted to each other in London's outer suburbs over the past century, while maintaining a great deal of continuity overall (Vaughan et al. 2015; Vaughan in this volume). For example, the data shows how successive historical periods witnessed the expansion of 'third place' locations, that is, places of social meeting and interaction that are neither places of home nor work (Oldenburg 1997). In South Norwood a late-Victorian flourishing of pubs, dining rooms and tearooms was followed by growth in the popularity of the café and snack bar in the 1960 s and a more recent explosion in takeaways (of many different types). By contrast, the Jolly Sailor pub has been a licensed premises for over a century. In other suburbs, churches and chapels have become pubs as part of a 'night-time' economy that would have been almost unimaginable several generations before. In this way the high street continues to re-invent itself. A recent UK Channel 4 reality television series The Fried Chicken Shop depicts the social life of a community through the customers at a fast-food venue in Clapham, London (Channel 4 2013). Although many policy makers associate such venues with high street decline, the programme reveals this as a strongly normative - arguably middle-class - position, by documenting how the social opportunity the takeaway offered was valued by its clientèle. The argument is not that communities do not have the right to debate the kind of high street they would like, but to emphasise that such normative 
discussions would benefit from a greater understanding of high streets as socially productive built environments. Achieving such an understanding requires an improved conceptualisation of the high street as an historically emerging social space.

\section{Morphological history and morphological events}

The Durkheimian idea of social 'effervescence' is evoked by Liebst (2014) to describe the co-presence of people in urban space as a source of social energy. Whereas Durkheim primarily identified collective forms of social action with the performance of religious ritual, Liebst draws on micro-sociology to make the point that social energy is also characteristic of everyday practices. This formulation, as Liebst knows, resonates with Hillier's theory of the 'virtual community' that proposes how readily intelligible street networks impart an intuitive expectation of likely patterns of spatial co-presence between people which, he argues, is a condition of community, although not in itself sufficient for a community to exist (Hillier 1996: 212-14). Co-presence for Hillier, therefore, refers to the possibility of social interaction, not an actual social interaction. He has in mind the sense an urban walker might have that one area is likely to be occupied by 'locals' while another is likely to be more socially heterogeneous, or that a certain street feels 'unsafe' because it is likely to be empty while another feels safer because it is likely to be busy. Unlike the codes of ritual, the codes of such everyday performances are unlikely to be inscribed in texts but exist embodied in routines. Of course, a sense of safety has much to do with the age and gender of the walker, and the governance of the urban area, but it makes sense that street morphology is also a factor in the different ways in which people inhabit urban space. Yet, it is argued, there is a missing element in Hillier's theory, namely an acknowledgement that the temporal intuition of co-presence is no less necessary than spatial intuition to the notion of the virtual community - for example, the sense that people were here yesterday and are likely to come again tomorrow. In this sense the idea of co-presence as an elementary social energy extends in both space and time.

This temporalised notion of virtual community helps us to understand the high street as a source of communal continuity. It has been noted how an examination of historical road networks can identify the nucleus of urban sites in and around which much contemporary community life takes place. As complex morphological events, these networks have a history that does not map neatly onto the conventional periods of local social history. This offsetting of different temporalites (for example, those associated 
with the material built environment, a particular socio-economic epoch and everyday routines) is not, of course, unique to the British context but is common to all historical societies. Acknowledging temporal offsetting forces a reconsideration of the traditional 'palimpsest' analogy of urban form, which all too easily reduces the overlapping temporal trajectories at play into equivalent 'layers' integrated into a GIS platform - note the problem here is not with the method as such but with the conceptualisation of time it enforces. Academic historians have a similar tendency to serve up the past in well-defined temporal packages that are likely to repress the long arc of built-environment temporality. Possibly as a consequence of this temporal foreshortening, urban design consultants often struggle to define precisely what 'history' has to do with their pressing contemporary concerns. Certainly the historical and design disciplines tend to converge on issues of 'preservation', 'conservation' and 'heritage' rather than the exploration of design possibilities as such. Yet a more sophisticated articulation of built-environment 'diachromesh' - Corfield's (2007) term for the interlocking of different temporal scales or 'frames' - could reveal the historical potential of a high street to generate patterns of social co-presence, encounter and engagement in relation to an expanded range of normative agendas and design scenarios. For example, a given high street might be designated as a site of special 'social and economic interest' with a range of accompanying incentives for investment in community and commercial infrastructure, including that of the road network itself. Such an initiative would offer a different (one hopes complementary) emphasis to that of the urban conservation area, with its proper concern for the preservation of historical buildings.

Given that the history of most high streets in Britain extends over many lifetimes, we should take seriously the question of its temporal framing, which demands increased sensitivity to the way built environments evolve in relation to the communities they support. In the extended temporal frame that the built-environment history of the high street requires, contemporary problems can be properly contextualised as a particular phase in an ongoing history, rather than as a relic worthy of preservation. Acknowledging this might enable designers and policy makers to focus more clearly on the generative qualities of the high street as a source of social life. For example, before commenting on whether particular phenomena - such as charity shops or takeaways - are indicative of decline, it might first be better to acknowledge the agency of the built environment in simply continuing to make things happen, in Durkheimian terms: to produce a social energy. A concentration on short-term concerns risks allowing the potential of high streets for self-regeneration to be overlooked. 
Acknowledging these arguments still leaves open the question of the extent to which the morphological history of the built environment, as a persistent site of everyday community life, can have anything to do with the social construction of community as an entity with a past and a future. In her unpublished PhD thesis Hanson (1989a: 13 and passim) makes the interesting distinction between a morphological history and the history of events and asks: 'what is the relationship between them?' (1989a: 383). For Hanson 'morphological history' means the evolution of the street plan conceived as a configuration or network of space. 'Event history', by contrast, refers to myriad localised interventions in the network, such as road widening or encroachments. Hanson uses space syntax analysis to describe the spatialmorphological properties of the street network of the City of London, since she argues that its morphological description as a complex system of space is only accessible through formal analysis. What distinguishes Hanson's thesis is the use of formal analysis in conjunction with a forensic study of the 'history of events' in the City of London since the Roman period, insofar as these have a demonstrable effect on the network. Hanson's innovative approach makes it possible to think in terms of the built environment possessing a 'network history' (1989a: 395).

Hanson's intensive analytical work on the historical grid of the city notes the continuing importance of the Newgate-Cheapside axis and the contours of the Roman wall in the history of the City of London over two millennia. It leads her to argue that in the urban grid 'history does not go away' but is, in some sense, projected into the present. The dynamic relationship between the network and events arises from the nature of the urban interface - which serves to bring people together and keep them apart in different ways, consistent with the social mores of a given period. Hanson concludes that a durable urban grid is a source of 'historical memory' in the sense that it is able to absorb more change, while effectively staying the same, than a pristinely preserved utopian planned city (1989a: 396; see also Griffiths 2012). On the basis of this network history, Hanson argues that her analysis 'lends a new meaning to conservation: that of conservation through morphology' (Hanson 1989a: 398).

Hanson's argument that the urban grid serves as a source of historic memory though, requires further consideration. Her priority to note the distinction between morphological history (as structure) and morphological events (as ordering) compromises this task since, I would argue, her analytical emphasis has the secondary effect of over-differentiating between the 'deep' synchronic structures of morphological history accessible through formal analysis and the social history of (diachronic) morphological 'events'. The effect is to flatten out the trajectories of different 
historical periods into a single transhistorical pattern. Methods of spatial analysis necessarily shoehorn our thinking into layers, yet conceptually this 'flattening' should be resisted since Hanson's proposition of the urban grid as a form of historical memory necessarily invokes the temporal dimension. 6

Hanson's distinction between morphological and event history has its origins in Hillier's notion of cities as comprising a configurational description (network layer), a socio-economic description ('contextualizing social forces') and a layer that refers to the everyday nature of urban practices (events) (Hillier 1996: 339). Hillier contends that deep urban structures create initial grid conditions that have a strong bearing on what comes next but, equally, that very different cities are able to discover different cultural possibilities in urban space. Nevertheless, Hillier's preference for theorising historic urban structures in terms of generic function presents a rather static model, as I have argued elsewhere (Griffiths 2011).

There is a notable parallel between Hillier's three-tiered notion of cities and Braudel's (1975) well-known tripartite scheme of historical method which suggests how the analytical binary of network synchrony and event diachrony might be better recast as a question of contrasting temporal scales. This involves rethinking the network as a (temporal) 'event' and rethinking the event in terms of the (spatial) 'network'. Braudel famously divided historical narrative into three temporalities: environmental history - 'a history whose passage is almost imperceptible'; social history - 'the history of groups and groupings'; and the history of events, which refers to daily life at a scale most comprehensible to the individual (Braudel 1975: 20-1). We might think of Hanson's morphological history as existing somewhere between Braudel's first and second layers, occupying neither the pre-social world of geological time nor the temporal rhythms of social and cultural organisation per se but rather the materiality of social organisation conceived in terms of its socio-spatial morphology. It is interesting from this perspective to note how Braudel's chapters on towns and cities are included at the end of Part 1 of his three-part history of the Mediterranean world (on the fold of environmental and social history). Appropriately enough, Braudel's starting point is the deep structures of urban life such as the position of towns on key roads and river crossings.

In the spirit of Hanson's (1989a) diachronically sensitive application of space syntax analysis in her morphological history of the City of London, it is possible to propose the network as a morphological event made up of many smaller events (including, for example, high streets), rather than as a generic or transcendent structure. This conceptual move helps to reveal the particular temporal description of the built environment, that is, the temporal 
rhythms that pertain to its morphological organisation. Considered in this light, the virtual community (to use Hillier's term) sustained by the high street becomes something recognisable not only in synchronic terms, as a node in a spatial network generating intensified patterns of movement and encounter, but also in diachronic terms, since the everyday performance of the virtual community serves to extend communal co-presence back in time while projecting it into the future. Note that this description of temporal co-presence is not to be confused with a sense of local history; rather, the argument goes, it a precondition for something like 'local' history to exist.

Whitehead's (2006: 90-1) philosophy of science helps to justify a rethinking of the deep network structure of the built environment as a morphological event (and therefore temporal). For Whitehead, scientific method necessarily aims to articulate a simplicity of relation in order to formulate general laws. The effect of this reduction is to restrict the time-space extension of an object such that it becomes comprehensible from a particular observational perspective. Yet, whatever reductions may be required for particular analytical exercises, the nature of any concrete 'event' is both spatial and temporal - and highly complex - meaning that any label we attach to it (for example, 'high street') is necessarily a simplification. With regard to the built environment, while network analysis using space syntax and other methods has made progress in helping to improve our formal understanding of the complexity of spatial relations, the temporalities of these relations are still difficult to articulate - perhaps because of their intuitive nature.

In his reflection on the well-known example of Cleopatra's Needle on London's Victoria Embankment that Whitehead used to illustrate his ideas, Steven Shaviro (2012) notes how the Needle has a conventional history that describes its fabrication, its movement from Heliopolis to Alexandria to London and, in the future, its eventual fate. But he also notes how Whitehead does not regard the needle as an 'impassive' entity on which history inscribes its narratives but rather it is itself 'eventful at every moment ... even as it stands seemingly motionless' (2012: 17). Whitehead therefore sees no clear distinction between material object and immaterial relation but rather a complex structuring of time-space 'events'. These events are continually occurring at any number of spatial-temporal scales from those imperceptible to humans - for example, at the atomic level - to those which may be perceived - for example, relations of heat, colour (or even co-presence) - to those belonging to the historical narrative of 'events' that might be read about in a newspaper or history book.

For Whitehead then, the idea of the 'event' articulates something like the world's 'temporal grain' (Carr, referred to in Bentley 2006: 360), which 
complements the spatial notion of the built environment, itself possessing an historical 'grain' or 'tissue' that becomes the object of conservation (Griffiths et al. 2010). From this perspective the traditional British high street resembles a morphological event that creates the intensification of co-presence which affords different social possibilities over time. In this sense it is right to speak of 'temporal intelligibility' as a built environment quality no less than spatial intelligibility - indeed the two can hardly be separated in perpetuating a sense of locality or 'place'. The idea of temporal intelligibility proposes a process through which the structure of the urban grid has mnemonic affordance to human beings in time. No more than spatial intelligibility can orientation to temporality be thought of as equivalent to or mappable onto any specific semantic content. Meaning in this sense is afforded by, not derivative of, the time-space intelligibility of the event.

This theoretical discussion has aimed to develop Hanson's (1989a) notion of the relation of morphological history and the history event, and to show how temporal description is implicit in the notion of 'morphological events' as Hanson describes them in her case study of the City of London. It has been proposed that the network itself can legitimately be described as an 'event', and in that sense an intrinsically temporal phenomenon. Such a network history does not lend itself to metaphors of layers and palimpsests so much as knots in timber that describe processes of growth and decay. The spatial configuration of the grid is reticulated in space and time, a materialisation of Corfield's (2007) 'diachromesh'.

\section{High streets as network topoi}

It is now possible to extend Hanson's (1989a) notion of the urban grid as a source of historical memory from an observer perspective to consider the temporal description of the network as a source of social memory from an embodied, performative perspective. This is because it has been shown how the 'events' that, in a conventional sense, comprise social history do not have to be categorically separated from the history of the network. Intelligible temporality is not a staccato time-series, nor is it a purely psychological state; rather it is a social state that arises somewhere and some-when and is ongoing until its material conditions cease to exist. This allows us to conceive of 'temporal co-presence' - implying what Hillier (1996: 187) might call the 'raw material' of social memory - meaning not actual social memories but a quality without which such a notion becomes untenable. The idea of collective or social memory was first proposed in sociological terms by Maurice Halbwachs (1992), who argued that the idea of memory 
was only meaningful if conceived of as socially constructed in relation to the spatial-temporal reality. Interestingly, one of his key works explores the topography of pilgrimage routes in the Holy Land, in which he shows how this topography was a key agent in the ability of successive generations of pilgrims to discover and rework biblical narratives consistent with their own reading.

Michael Hebbert, one of the relatively few historians to specifically address the role of the history of street plans in urban design practice, has argued that the urban landscape becomes a repository for social, or 'collective', memory (2005b, 2014). Hebbert claims, in an echo of Hanson, that 'collective memory can be found as much in the street plan as its landmarks' (2014: 297). He proposes a fundamental link between the street plan and collective memory, noting that the streets themselves are neglected aspects of our built environment inheritance. Building on the previous discussion, one might augment this notion of collective memory as being predicated on an intensification of temporal co-presence (i.e. connecting past, present and future) realised through intensification of spatial co-presence (i.e. the everyday performance of community) in local places. If the street plan is indeed a source of temporal intelligibility as has been proposed here then, arguably, it helps to explain why discussion of high street spaces can evoke such strong feelings - it is not simply the personal recollections of community that are at issue but rather the possibility of communal remembering itself, which is intimately connected with the spaces we inhabit.7 It is the possibility of a maimed built environment sundering this sense of extension between past, present and future under the dislocating conditions of modernity that so worries Connerton in How Modernity Forgets (2009). But while we may agree with him that modern urban development is destructive of urban heritage, we should also be careful not to focus on particular images of the historic city to make this point - collective memory may have deeper roots than he suspects in Hanson's morphological sense of history.

Despite the efforts of thinkers such as Hanson, Hebbert, Connerton and others (e.g. Crang and Travlou 2001; Rose-Redwood et al. 2008), the theoretical underpinnings of the relationship of street plan and social memory remain underdeveloped. It is possible to understand how a prominent street such as a high street might acquire a collective importance de facto in any given period but it is harder to see how that significance might transcend the collection of buildings that constitute the plan at any given time. Inevitably, when thinking of cultural significance of the built environment, we resort to the semiology of building typologies, largescale planning interventions or associations with historical events of note. High streets, unlike major public buildings or ceremonial thoroughfares 
generally, emerged 'messily' in Britain without architectural design or formal social programmes; therefore, the process of translating between architectural intention, plan and meaning is far from clear theoretically. The consequence is a default to reading 'the city as a text' in a rather academic sense, obscuring everyday associations and rendering quotidian places such as high streets relatively invisible in these terms. Now that some of the conceptual ground has been cleared, it is worth considering concepts that can help frame research in this area.

In referring to the high street as a morphological event I have described it as a particular kind of node and used the metaphor of knots in wood to describe the time-space reticulation of a street plan that produces such nodes. Preferable to 'node' is Ethington's conceptualisation of 'topoi' (Ethington 2007). 'Topoi', meaning 'places' in Greek, is also used in rhetoric to suggest a commonplace or conventional device. For Ethington topoi are the places of past and continuing human action the mapping of which comprises history (2007: 465). Ethington argues that a spatialised notion of topoi is present in Heidegger for whom being in time is always 'located' - that is, it takes place somewhere. From this Heideggarian perspective on space and place, the question of history becomes one of the extent to which the past is available to us in the world - that is, the extent to which it is 'ready to hand' in everyday life as distinct from being 'present to hand', and thus requiring more intellectual effort to access. In claiming that history is a 'map', Ethington therefore advances a radical spatiality which evokes an intuitive, spontaneous historical sense of the built environment - for example, one might think of the past of the high street as being 'ready to hand' on an everyday basis that could not easily be said of, perhaps, the history of science.

Ethington's conceptualisation of topoi is a powerful argument for the spatiality of history but, lacking Hanson's distinctive sense of a networked morphological history, his necessary focus on the 'history of events' leads him to collapse time absolutely into his spatial cartographic compass. A theoretical difficulty is that he takes a largely phenomenological route to social space via Bergsonian time that tends towards the psychological and aspatial (see Massey 2005), to Heidegger and Edward Casey's (1997) work on place. Ironically, the rather static implications of place as 'dwelling' favoured by the latter render these kinds of topoi rather easily named and represented and, in that sense, limited for the purpose of morphological history. As Michael de Certeau (1984) has argued - this mapping of language onto place (topoi) is a strategy to be contrasted with the tactics of the urban walker, in which movement as wandering upsets such neat correspondences and brings forth new possibilities for meaning while subverting tired linguistic motifs. A networked approach to topoi 
makes it possible to dispense with the limitations of the topos - that, as Thrift (2004) points out, imply a static, rather than an enclosed or a background space - and propose, after Hanson, a topoi in which everyday sites of spatial practice are acknowledged as places we keep coming back to - or in the parlance of phenomenology, open places that escape fixed representation and keep becoming.

Despite the radical ontological implications of his historical topology, the epistemology of Ethington's mapping method seems incomplete. For example, photographs of historical urban spaces are an important source for his innovative multimedia website of Los Angeles in which many different sources are linked online via hypertext (Ethington 2000) ${ }^{8}$ Yet his account of the mapping process lacks a convincing theorisation of the time-space rationality that associates the various topoi represented in the photographs. Interestingly, in this context, Ethington argues that hypertext environments are largely indistinguishable from cities in supporting linkages between topoi. He may have a point, yet it is questionable whether urban networks resemble the same kind of hierarchy that he notes on his website (Alexander 1966). In any case, without some more substantive account of network agency, Ethington's mapping method remains problematic theoretically since its focus on representation means it is unable to articulate the qualities of temporal-spatial co-presence that are implicit in (for example) the photograph of an historical street scene but are not explicitly represented. This is precisely the epistemological gap that the montage method discussed in Section II is able to expose. For Ethington the portrayal of the past in photographs is prima facie a question of representation, but this approach seems to be reductive with regards to the temporality of everyday places like high streets. We might be acutely conscious of the otherness of the scene in the photograph but still experience it intuitively, in terms of its non-representational description of a region of time-space - as a kind of spatial-temporal co-presence with the scene represented.

Co-presence as a diachronic as well as a spatial phenomenon might be thought of as reducing, though without entirely collapsing, the temporal distance between a community's (imagined but not in an arbitrary sense) past, present and future. In this sense, it is proposed, the meaning of the high street is less the point than the affordance it sustains for the social performance of 'being-in-memory'. The possibility of social memory from this networked perspective is not evenly distributed in urban space but is intensified at particular places where we expect other people to be, to have been or to be in future. A research focus on the quotidian routines of the street plan, such as those that may take place on the high street rather than the semiology of landmark buildings, reveals a fascinating and shifting, but 
far from chaotic mix of instrumental and symbolic affordances for social life. As a condition of, rather than simply a repository for, collective memory, they invoke a temporality that is not easily bracketed as 'the past' but is open and ongoing, a temporality of historical presence that is re-embodied with each trip to the shops or the doctor's surgery.

In the topos then, the past becomes implicated in the present and the future through the co-incidence of temporal and spatial virtual communities. Without a theory and method able to give formal description to the non-representational qualities of historical street systems, the temporal and spatial scope of built environment history is likely to be restricted to the conventional brackets of historical context - to the detriment of understanding the everyday built environment of community. Similarly, however, without a good knowledge of the history of events, the epistemology of networks becomes detached from its temporal moorings and abstracted as a perfectly synchronic system.

Space syntax as initially developed by Hillier and Hanson (1984) and their colleagues is a good starting point for exploring high street topoi from a networked perspective. It provides a theory and method for describing formal qualities of a street plan rendered as 'spatial configuration' and linking these to observed or recorded patterns of movement and encounter (Hillier 1996). The agency for the production of such patterned phenomena is said to lie with the spatial configuration, which shapes patterns of movement and, in turn, the patterns of land use and their concomitant social encounters, as much as the 'pull' of particular attractors. Yet, as has already been discussed, the social temporality implicit in these networks has been relatively marginalised in space syntax research with its strong analytical focus premised on a privileged observer (see Griffiths 2011). Conceived as a topos in this configurational sense, it is clear how the everyday 'high street' touches on fundamental time-space arrangements in British society, not least as an agent of social memory. The network-topos, therefore, is a place, such as a high street, where a community might expect to encounter itself in space and also in time. This emphasis on the performativity, not only of spatial co-presence but also of social memory, suggests how the typical high street resembles what Michel de Certeau refers to as a kind of 'practised place' (de Certeau 1984: 117).

\section{Conclusion}

None of this makes it easier for built-environment professionals to draw 'lessons from history' but certainly learning from the past should not entail 
an indulgent 'trip down memory lane'. Nor should history only be of interest to the heritage community. There is an important role for architects and urban designers to play in understanding how the complexity of apparently quotidian places such as high streets not only creates conservation responsibilities but also presents opportunities for design that can take this complexity into account. The high street is not a repository of static meanings to be toyed with but rather a source of time-space orientations towards the world that afford social memory. Rather than present the high street as a passive object - derivative of a given phase of the 'history of events' - we might instead, following Hanson, view it as an agent of morphological or network history, a history which touches on the 'history of events' by bringing people, development and commercial activity together in ways that are not entirely predictable. High streets can then be regarded as special kinds of 'morphological events', historical sites of heightened temporal-spatial co-presence. To recall Jane Jacobs (1961: 65): 'time is constructive quality in cities, it is the indispensable factor'. By seeking to better understand high streets as loci of continuity and change, particularly suburban high streets in their deep residential hinterlands, it is possible to gain a better sense of their contribution to built environments that are both resilient and adaptive to social change.

\section{Notes}

1 Emma Duncan (Deputy Editor of The Economist at the time of writing) is certainly a modern, see: 'Death of the high street? Hurrah ... Move with the times. Turn empty shops into much needed housing' in The Observer, 27 April 2014; the ancients view of the traditional high street is more pervasive in British culture but the battle lines are well defined by the terms of the media debate over the value of Mary Portas's High Streets Review and the popular Channel 4 series 'Mary Portas: Queen of the High Street' (2013) - of course no one likes being accused of nostalgia. For a more open-minded though still critical view see Hugo Rifkind, 'Don't mourn for the old High Street. It was awful', The Times, 11 October 2014.

2 David Boyle (ex New Economics Foundation campaigner): 'In Britain, like the US, the outof-town shopping giants are dying: I campaigned against clone towns but I needn't have bothered. After all, who wants to spend hours in a slip-road traffic jam?' The Observer, Sunday, 22 June 2014. http://www. theguardian.com/commentisfree/2014/ jun/22/britain-us-out-of-town-shopping-isdying, accessed 19 December 2014.

3 Paraphrased from L. P. Hartley, The Go-between (1953). The original quotation reads: 'The past is a foreign country: they do things differently there.'

4 http://www.theguardian.com/cities/gallery/ $2014 / \mathrm{feb} / 25 /$ london-paintings-googlestreet-view-canaletto-1\#img-4, accessed 19 December 2014 - Halley Docherty, also known as Shystone-commissioned by The Guardian.

5 I am grateful to Mr John Hickman for his help in sourcing original images for Figure 2.3.

6 This theme is explored empirically in Ashley Dhanani's chapter in this volume in which he offers an analysis of London's built form evolution.

7 David Jeevendrampillai's chapter in this volume comments on the uses of memory both real and mythologised - in creating community in Surbiton.

8 A version of Ethington's multimedia website is available at http://www.usc.edu/dept/ LAS/history/historylab/LAPUHK/index. html, accessed 18 February 2015. 


\section{PART B \\ Suburban Centralities}
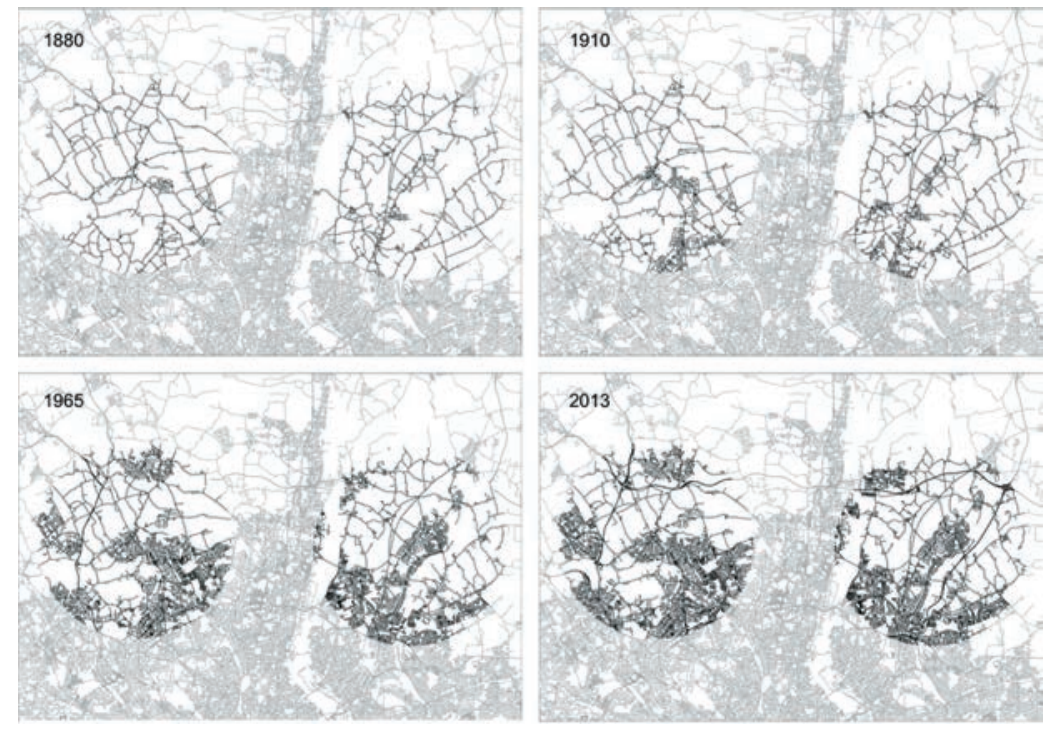

Street network evolution of High Barnet (left-hand circle) and Loughton (right-hand circle) 



\title{
Chapter 3
}

\section{Suburban Continuity and Change}

\author{
Ashley Dhanani
}

\section{Introduction}

The peripheries of urban areas have been the focus for varied discourses within academic studies and representations within popular culture, ranging from the utopian to the dystopian (Vaughan et al. 2009a, 2010a). Previous studies have tended to situate this discourse in the present, rather than taking an historical view of how the peripheries of urban areas function in relation to the whole city, and how they have developed over time. This ignores the complex processes that occur on the fringes of cities, and their dynamic relationship with the rest of the city (Griffiths et al. 2010; Vaughan et al. 2010b). Despite efforts to create typologies of suburban form, primarily relating to the residentially focused periphery of the city (e.g. Gwilliam et al. 1999), the suburb is seen as neither universal nor fixed in time-space. In this chapter I propose that it may be more appropriate to assess what suburbs are in the context of how they develop over time, taking into account local and city-scale spatial relationships as illustrated by infrastructural developments. This will allow for a more nuanced reading of the place and role of the suburb within the city system and an acknowledgement of its inherent symbiosis with the wider city.

Previous applications of space syntax analysis methods and land use analysis in suburban areas have shown that complex structures of centrality are expressed in the network structures of suburban areas and the land uses associated with them relate to this complex ordering. This indicates that different functional qualities are expressed morphologically and that suburban areas are not homogeneous, but potentially express the same properties of differentiation and scaling as the urban whole, only on a smaller scale (Vaughan et al. 2010b). 
Peripheral urban areas are some of the most contested areas of the city in terms of the range of competing land uses: from industrial and distribution to residential and leisure. The conflict is not due just to competition for space, but also to contrasting social and political opinions on what the city edges are for, whether they should be urbanised, or conserved for their openness and green space and indeed who should determine their future. These are also the locations where there is significant potential and capacity for change (Stanilov and Scheer 2004). The research reported here focuses on this aspect of the urban landscape of London.

This study considers the changes and continuity that occur in the spatial development of suburban areas over time. Historically, many parts of London that are currently considered to form central areas were what would now be called suburban, but have been subsumed and urbanised to an extent that they are no longer recognised as such. This highlights the importance of suburban research for both an understanding of the urban growth process, and planning future urban development. Aiming to highlight the principal forms that the street network takes both locally and in relation to the wider city, the aim of this research is to understand the suburban as a relational entity that changes and persists through time, and forms an intrinsic part of the city and its growth process.

Suburban development can be considered as part of a wider process of peri-urban expansion that is occurring globally (Stanilov and Scheer 2004). Analysing the ways in which urban areas develop and change is vital for uncovering the driving forces behind their development; it will allow a better understanding of urban growth processes as a whole, particularly those which occur at the urban edges. Discovering those aspects of urban areas that are persistent over time will reveal the underlying adaptable nature of the urban fabric alongside the requirements of human settlement, which remain constant.

As has been explained in the opening chapter of this book, the meaning of suburban as a concept can be traced back to the earliest spatial arrangement of settlements. The term suburban is derived from the Latin sub urbe, meaning beneath or below the focus of the settlement, the urbs. Predominantly the spatial arrangement was such that the sub urbe was situated beyond the walls that defined the centre of the settlement (Harris and Larkham 1999). The employment of this terminology to describe the relationship between the periphery and the core continues today in the use of the term suburban, still connoting an inferior position of the periphery relative to the centre (Vaughan et al. 2010a). The contemporary differentiation between the urban and suburban is more complex, relating to multiple social and economic factors (Harris 2010) beyond simple spatial 
arrangements. Central to this is the perceived inter-relationship between the urban and suburban. Even though the populations of peripheral areas often commute to the centre of the city for employment purposes (Van der Laan 1998) and in some cases in the opposite direction (Glaeser and Shapiro 2001), the social and economic life of the city are intertwined across the spectrum of urban spaces that are spoken of as supposedly separate or different. The spatial notion of the urban or suburban can thus be seen to be a continuum of a diverse set of social and economic relationships occurring across space. Creating definitions of suburbs is not necessarily useful, and a better approach is to generate local understandings of places and their relationships across all spatial scales, from their hinterland to the wider urban region, and over time (Vaughan et al. 2009a).

The English suburb is a particularly heavily studied urban form that has elicited multiple opposing viewpoints. Whilst there is widespread criticism of the problems of urban sprawl, certainly in the case of London, suburban developments have been argued to have the potential to enable a diverse public life, allowing suburbs to adapt to change and become part of the urban fabric over time as the urban area expands and further develops. It is through the relationship between the suburb and the city, and the internal relationships in the local area, that the role of the suburb can be understood from the viewpoint of its inhabitants (Vaughan et al. 2010a). A particularly crucial aspect of the discussion of the perceived nature of suburbs is their historical development. A great body of literature has been written that has explored the sociology and history of the development of suburbs, primarily focused on the expansion of the railways (Jackson 1978; Weightman and Humphries 1984; Wolmar 2013) and the social improvement that they aimed to bring about by depopulating poorer areas in the centre of the city, widely regarded as undesirable. During London's most recent suburban growth, developments in transport infrastructure allowed for increasing mobility that played a vital role in the rapid expansion of its built-up area, with similar trends in other major cities. In London the extension of the railway systems to the urban fringe has been said to have dissolved the boundaries of the urban area historically imposed by travel time and cost constraints (Hebbert 1998). Although the work of Hebbert provides a much needed insight into the dynamics between the railways and urban growth, other research in this area tends not to fully account for the significance of older settlements in shaping the way in which cities grow at their edges. Instead, the urban edge is frequently seen as a tabula rasa for growth. Similarly, the role of pre-existing older street networks in influencing patterns of suburban expansion or densification is often overlooked. Indeed, the commonly repeated notion of the suburbs arising out of 
new forms of mobility in the city (see Gwilliam et al.'s 1999 definitions of suburbs according to modes of transport, for example) is problematic in itself, as it tends to focus the view on suburbs as dating from the first innovations in mechanised transport, when the reality is that suburbs have a history dating back thousands of years (Simon 2008). Understanding suburbs not as something new but as an inherent part of the urban structure, whatever particular local form they may take, is important in reconceptualising the role and function of the urban periphery within the overall urban assemblage. Whilst historical studies of particular epochs in city/suburban development abound (e.g. Hebbert 1998), an historical perspective of a city's change over time is a quite different aspect that this research aims to address by empirically studying the spatial and architectural development of peri-urban London over 130 years.

Similarly, the role of local, smaller suburban centres tends to be overlooked in conceptualisations of suburbia. The commonly accepted thinking that local centres primarily function as retail locations is slowly being overturned by studies which explore their wider spatial, economic and social role (Vaughan et al. 2009a; Vaughan et al. 2013), and new studies of changes in consumption patterns brought about by internet shopping are starting to assess whether local centres within areas considered to be suburban can provide useful economic drivers both locally and for a wider region.

Aside from the social and spatial aspects of the development and functioning of English suburbia, there is a corpus of work that analyses residential built form and the way in which its architecture has been developed and adapted to the social demands of the time. The work of Whitehand and colleagues at Birmingham University (1975, 2001b; Whitehand and Larkham 1991; Whitehand and Carr 1999a, 1999c) has shown how changes in and adaptation of suburban architecture reflect social processes and change. The built form of suburbia is proposed by the Whitehand school of urban morphology to have the capacity to adapt over time through accretive extension and additions, as well as developing new forms such as garages in response to the rise of the personal motor vehicle. This has also been noted by writers such as Paul Barker, who has shown how the supposedly prosaic nature of suburban architecture reflects its inherent adaptability (Barker 1999). Whilst these nuanced accounts capture the evolution of suburban built form at the finest architectural scale, their focus is less relevant to the broader understanding of suburban/urban growth patterns.

This chapter presents an analysis of the changing network properties of four case study areas over a 130-year period, set within and compared to the whole of London's street network. The selection of the case studies 
required the identification of town centres within the London city-region, but outside the inner London boundary as defined by the Greater London Authority (GLA), that have experienced significant urbanisation over a 130year period. This allowed for analysis of the characteristics of change in the street network that occurs during urbanisation. The area that is considered to be London for the purposes of this research is the area bounded by the M25 orbital motorway, which is the most significant physical-spatial network feature that bounds and delineates the area of London. Detailed historical maps were studied for the earliest 1880 period to find areas that were not part of the continuous urban fabric at that time and which therefore had low or non-existent urbanisation. In subsequent mapping from the later time periods of 1910 and 1960, the same areas became enmeshed in the continuous urban fabric, grew significantly locally or became highly connected to the wider urban area due to the development of other transport links. The sample for this research was drawn from an earlier study which focused on a sample of twenty smaller town centres from around London's periphery, ' selected in order to study cases which have existed since the late nineteenth century and have survived social, economic and physical change whilst maintaining a mix of commercial and other town centre related activities. The earlier study found that these smaller centres are a vital background of activity to the larger outer London centres, forming part of an interdependent network (Griffiths et al. 2008). The final criterion for choosing the four cases was that they should be distributed across the London city-region so that they would be representative of urban growth occurring in all directions away from the centre of London and so help to identify any differences this may have brought to their developmental trajectories. The four case studies that were found to satisfy these criteria were Surbiton, South Norwood, High Barnet and Loughton.

Surbiton is located in the south-west of London within the Royal Borough of Kingston upon Thames. The main high street runs along a northeast-south-west axis parallel to the railway line. Surbiton itself is a product of the development of the railways. When the London to Portsmouth railway line was proposed, the town of Kingston upon Thames, located north of present-day Surbiton, rejected the plan to locate a station there due to the belief that it would damage the coaching trade that was important to the area. Instead, the railway station was located close to the centre of present-day Surbiton. The station opened in 1838 and was initially called Kingston-Upon-Railway. Surbiton as a named area came into existence in 1855 when it was named as a local government district. The development of the area following the construction of the railway station was driven by businessman Thomas Pooley, who saw the potential for the area to be 
developed as a location where commuters into the city of London could live. He purchased the land around the station in 1839 and began a project of residential development in the area after the local farmer who owned the land died. This was the first development in the built form of the area. Since then Surbiton has grown and continued to be a major residential area with good transport links to the centre of London used by residents to commute to their places of work. The importance of the railway and the conflicting interplay with new forms of transport technology, namely the railways and coach services in the development of the area, is significant and relates to the contestation that occurs during urban development and growth mentioned at the start of this chapter.

South Norwood is located in the south-south-east of London, almost due east of Surbiton, in the London Borough of Bromley. The town centre is located adjacent to the north-west of the railway station. This railway line and station also play an important role in the history of South Norwood. The station opened in 1839 under the name of Jolly-Sailor Station due to the proximity of a pub by the same name. This station lay on the London to Brighton railway line. Prior to the opening of the station and the urban development of the area, it was covered by oak forest. The forest covered much of the area around South Norwood, its name deriving from its location within the wooded area, called the Great North Wood. The Croydon Canal also featured prominently in the development of the area with housing and businesses developing along the section of the canal that ran through South Norwood. Brick manufacturing was a significant local trade throughout most of the eighteenth and nineteenth centuries; the location of one of these areas is now a park named Brickfields Meadows. Following the construction of the railway, the area gradually became residential with direct links to London for commuters. It is also close to the site of the Crystal Palace, the location of the Great Exhibition in 1851, destroyed by fire in 1936.

The town of Loughton is located in the north-west of London and is situated just outside the administrative boundary of London, within the county of Essex. Once again the town is situated close to a railway line, providing links to the centre of London. Loughton as a named place appears in records dating back to 1062. A settlement in the same location as present-day Loughton is also mentioned in the Doomsday Book of 1086 as Lochintuna. To the north-west of Loughton is Epping Forest, awarded Royal Forest status in the twelfth century and used as a royal hunting ground. Nowadays the forest falls under the governance of the City of London and is a protected area that cannot be built upon. Throughout the forest's history it has been used for the manufacture of charcoal through the pollarding of trees, evidence of which can still be seen today. The first significant development of 
the town came in the seventeenth century when the road through Epping Forest was built; this turned the town into a stopping point for coaches travelling between London and Cambridge and other points northwards in East Anglia. The subsequent development of the area occurred when the railway line was constructed close to the town and the station opened in 1856 . From this period onwards the town grew slowly until the 1930 s when the suburban development of London reached its fastest pace. The railway line was electrified in 1948 and became part of the London Underground Central Line rail network. Following this integration with the Underground network, the town has continued to grow slowly, constrained by the presence of the protected area of Epping Forest at its north-western edge.

High Barnet, known previously as Chipping Barnet, is located in the north of London within the London Borough of Barnet. It has been a London borough since 1965; previously it was part of the county of Hertfordshire. Settlement in this area can be traced back to the twelfth century when records of a settlement named Barnet can be found. The town centre is located on the historic Great North Road linking London to York and Edinburgh. The most significant architectural landmark in the area is St John the Baptist church to the south of the town centre that was erected in 1560 and remains to this day. To the south-east of the town centre is the London Underground Northern Line terminus station of High Barnet. There has been a station in the vicinity of the town centre since 1872 when it was the end point of the line between Finsbury Park and Edgware. The line and station were then incorporated into the London Underground network and the Underground station in the same location was opened in 1940. Today High Barnet is primarily a residential area on the edge of the administrative boundaries of London, bordering Hertfordshire.

Comparative analysis looks at the different network characteristics of the four case studies as they have evolved over time, using a variety of measures. This is then set against the whole London street network to place these developments in a wider context and illustrate how they have developed and currently sit within the context of the whole city. There then follows a discussion of the specific transformations that have occurred in the road network in the case study areas. Understanding the relative network properties of peripheral locations in relation to the network within which they are situated is vital to understanding how they function in the context of London as a whole. This is particularly important when considering different scales of movement between a suburb and its wider surroundings.

The highly detailed Integrated Transport Network (ITN) road network model produced by the UK national mapping agency, the Ordnance Survey, is used as the basis for the analysis presented here. The standardised 
practices in the dataset production and the interoperability with other standard UK mapping datasets made it the most desirable from the perspective of both highly detailed analytical results and data integration. Furthermore, the standardisation makes the process of cartographic redrawing that is employed for historical reconstruction of the four case studies street networks simpler and more reliable (Dhanani et al. 2012).

\section{The case studies}

Figure 3.1 shows the London-wide network. This network covers $2,932 \mathrm{~km}^{2}$ and contains a total of $26,011 \mathrm{~km}$ of street network. The boundary that was chosen for the London-wide analysis, shown in blue, is larger than the official boundaries of inner and outer London as defined in the 2011 London Plan created by the GLA. The reason for using an enlarged area for the street network model is two-fold; first, three of the four

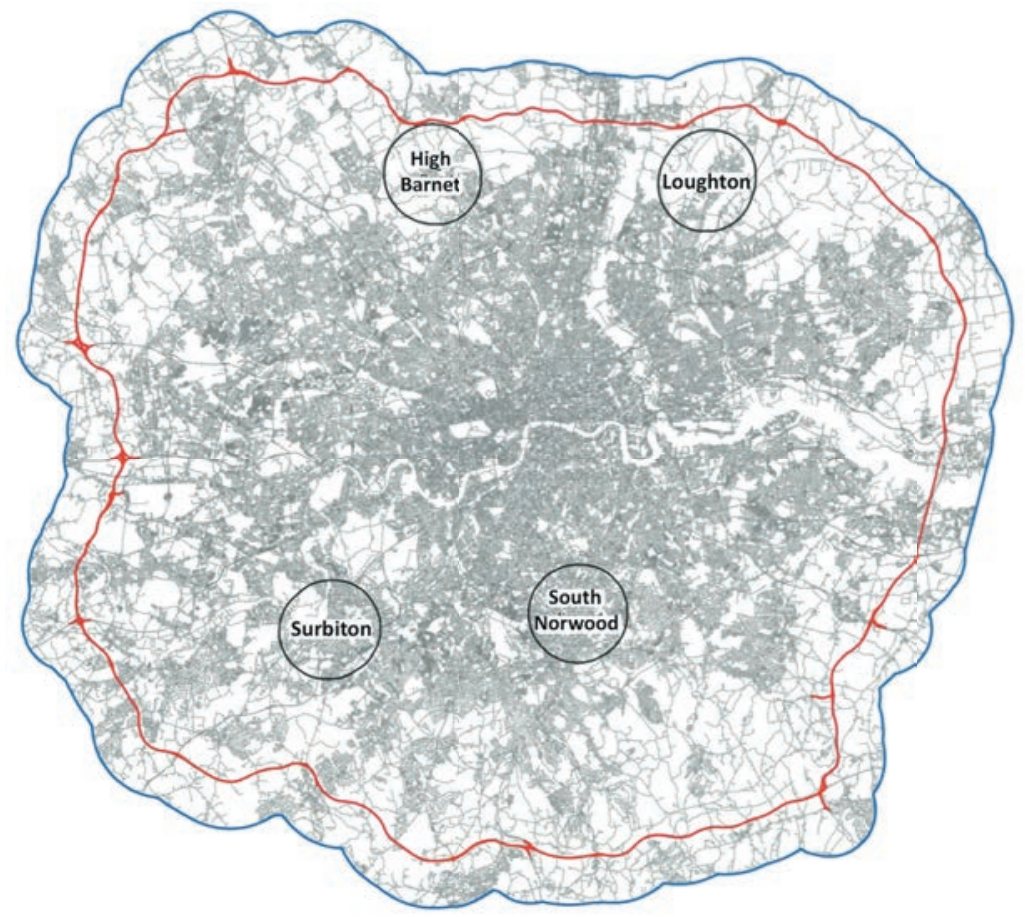

Figure 3.1

London-wide street network dataset with $\mathrm{M}_{25}$ ring-road overlaid highlighted in red Contains Ordnance Survey data (C) Crown copyright and database right 2014. 
peripheral case studies fall partially outside the largest official boundary of London and, secondly, in network terms the M25 orbital motorway is the most clearly defined continuous boundary (shown in red in Figure 3.1). The latter boundary was then extended by $3 \mathrm{~km}$ outwards to capture the network that is adjacent to, but outside, this network structure. Modelling this wider spatial context is essential for evaluating a largely continuous structure such as a road network.

Figure 3.1 also highlights the four case study areas: High Barnet, Loughton, South Norwood and Surbiton. These four case studies were reconstructed and analysed in order to understand their spatial evolution over time. In Figures 3.2 and 3.3 the reconstructed networks for the four periods of analysis are shown respectively for High Barnet and Loughton, and South Norwood and Surbiton. In Table 3.1 the size in square kilometres is given for each of the case study areas, showing the $6 \mathrm{~km}$ contextual area (captured to avoid edge effect) within which a $3 \mathrm{~km}$ area was analysed. All further analysis uses the $3 \mathrm{~km}$ boundary. The difference in area size between the case studies is due to the way in which they were determined, which was by using a fixed distance from each place's town centre outer boundaries which themselves varied in size. The town centre boundaries are determined by the UK Department of Communities and Local Government and define the area of a notional central core of high street functions (see ODPM 2004), drawn in relation to the commercial and office space contained within each town centre. ${ }^{2}$

Initial observation of the network in Figures 3.2 and 3.3 of development over the 130-year period shows that there has been dramatic development of the network across all the four case study areas. In South Norwood and Surbiton there has been more even and continuous growth of the network compared to Loughton and High Barnet, where the network is still very fragmented with large areas remaining undeveloped. Their locations within the London network may also relate to this difference, as South Norwood is closer to the centre of the urban area (Figure 3.1) and is therefore more likely to have been urbanised at an earlier period, as the city and its environs grew.

There are also other factors that limit even growth, such as protected areas, as in the case of Epping Forest to the north-west of the Loughton study area, and Hampton Court Palace and Gardens to the north-west of the Surbiton study area (Figure 3.4).

The chart in Figure 3.5 shows the development of the network for each of the four study areas. The values presented in the chart show the density of the network in kilometres of network per square kilometre of land area in 2013. These figures are normalised for the differing areas, so 

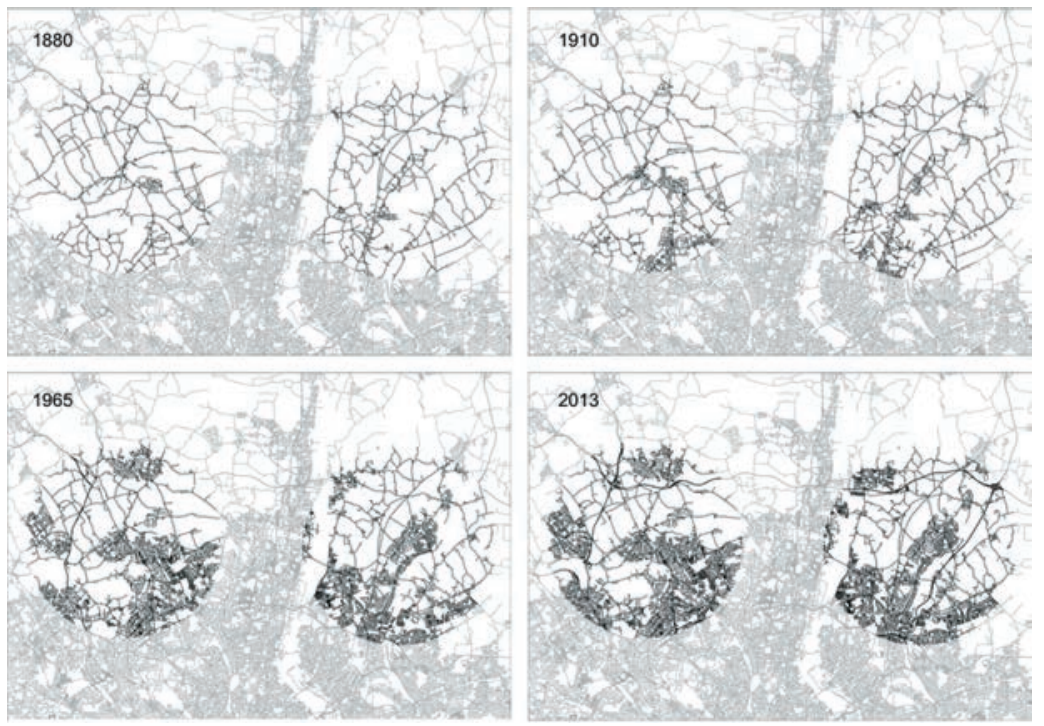

\section{Figure 3.2}

Street network evolution of High Barnet (left-hand circle) and Loughton (right-hand circle). Historical network in black and contemporary network in grey Contains Ordnance Survey data (c) Crown copyright and database right 2014.
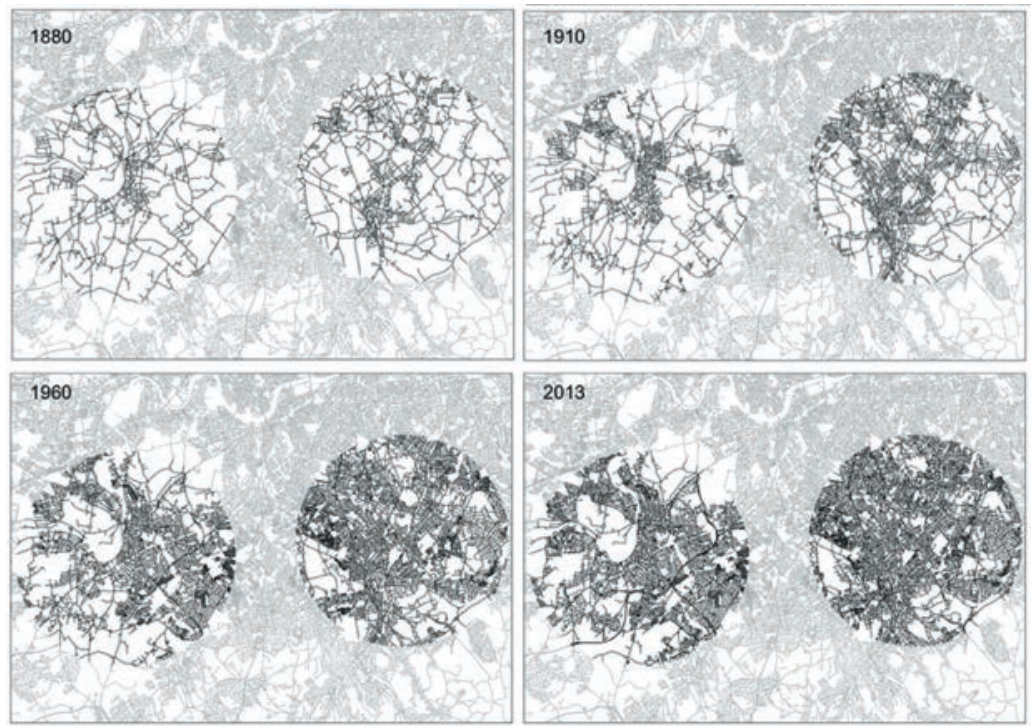

\section{Figure 3.3}

Street network evolution of Surbiton (left-hand circle) and South Norwood (righthand circle). Historical network in black and contemporary network in grey Contains Ordnance Survey data (c) Crown copyright and database right 2014. 
Table 3.1 Size of $3 \mathrm{~km}$ analysis and $6 \mathrm{~km}$ reconstruction areas for each study area

\begin{tabular}{lll}
\hline & $\mathbf{3 k m}$ analysis area & $\mathbf{6 k m}$ reconstruction area \\
\hline High Barnet & 34.36 & 124.96 \\
\hline Loughton & 34.46 & 125.21 \\
\hline Surbiton & 34.45 & 125.15 \\
\hline South Norwood & 31.66 & 119.74 \\
\hline
\end{tabular}
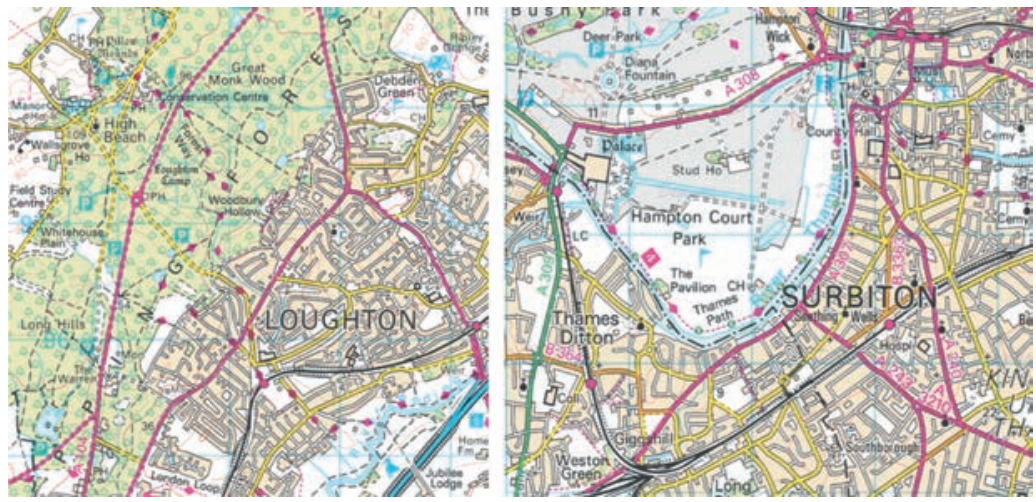

Figure 3.4

Maps showing constraints to growth; Epping Forest adjacent to Loughton (left) and Hampton Court Palace and park adjacent to Surbiton (right)

Contains Ordnance Survey data (c) Crown copyright and database right 2014.

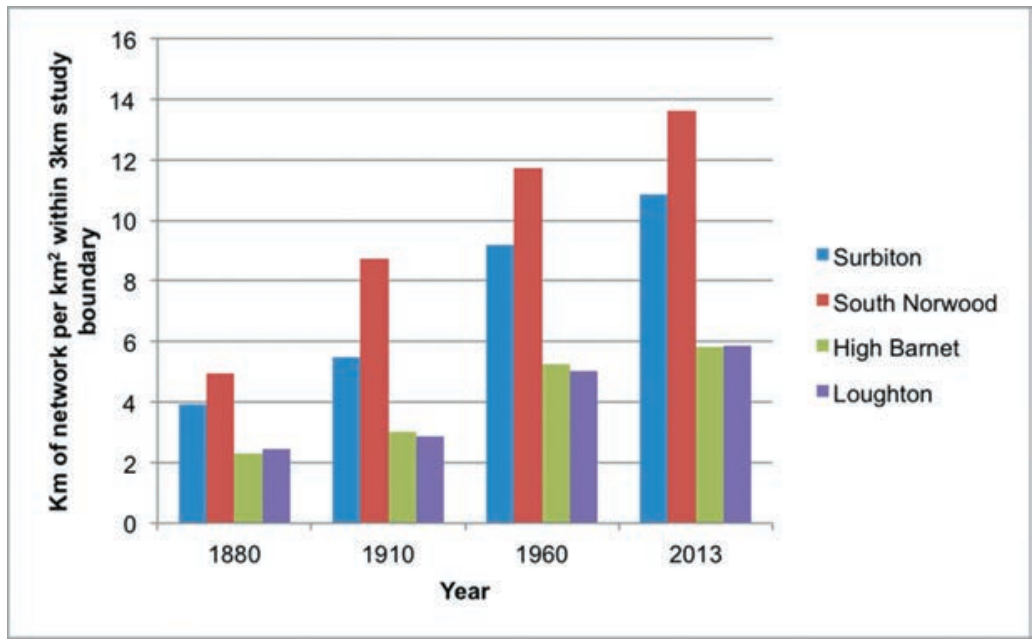

Figure 3.5

Street network density $\left(\mathrm{km} / \mathrm{km}^{2}\right)$ from 1880 to 2013 in each case study Ashley Dhanani. 
that they are directly comparable (Table 3.1). From this the initial observation of the development of greater network density in Surbiton and South Norwood is confirmed, with South Norwood having a density more than twice that of Loughton. Strikingly, the density of the network in Loughton in 2013 is comparable to that of Surbiton 100 years earlier. There is also a clear linear progression through time as the network develops in all four cases. The chart also shows that in 2013 High Barnet had approximately half the density of Surbiton, as was also the case in 1880 . In fact, all the case study areas retain proportional relationships that are roughly constant across the four periods. This suggests that the development that we see in the contemporary city has its roots in the initial structure and topology of development that began centuries ago; the relationship between streets in the network is a temporal constant. This confirms the necessity of an appreciation of the historical process in understanding both the present and future planning of cities.

\section{The London-wide context}

Whilst this introductory analysis of the network and its development in the four case study centres captures the basic network development of the four areas, it is useful to contextualise the development in relation to the network characteristics of London as a whole. In order to do this, a model of the London-wide street network is compared with the historical development of the network within the case study areas. Figure 3.6 shows the divisions of the London network that were used. The Inner, Outer and M25 boundary lines demarcate the three areas compared (i.e. the M25 area is that which lies between the green and the blue lines): Table 3.2 shows the total network length and the corresponding area for the four centres along with the values for All London (i.e. the entire area contained within the blue line). ${ }^{3}$

Table 3.3 shows the network density values for each of the London network divisions. The 'All London Network' is the average value for the whole network. The density of the network in the Inner London region is the highest, with a value of $15.4 \mathrm{~km} / \mathrm{km}^{2}$ and then Outer London is second, whilst the M25 Outer area is the lowest. When this is considered in relation to the four case study areas and their historical development in Figure 3.7, their developmental trajectory shows a trend of increasing density to levels that are in line with their spatial positioning within the subdivisions of London, with the exception of High Barnet. South Norwood sits mostly outside of the Inner London area and has a density value of $13.6 \mathrm{~km} / \mathrm{km}^{2}$, that is, just below the Inner London average density. Surbiton, which straddles the 


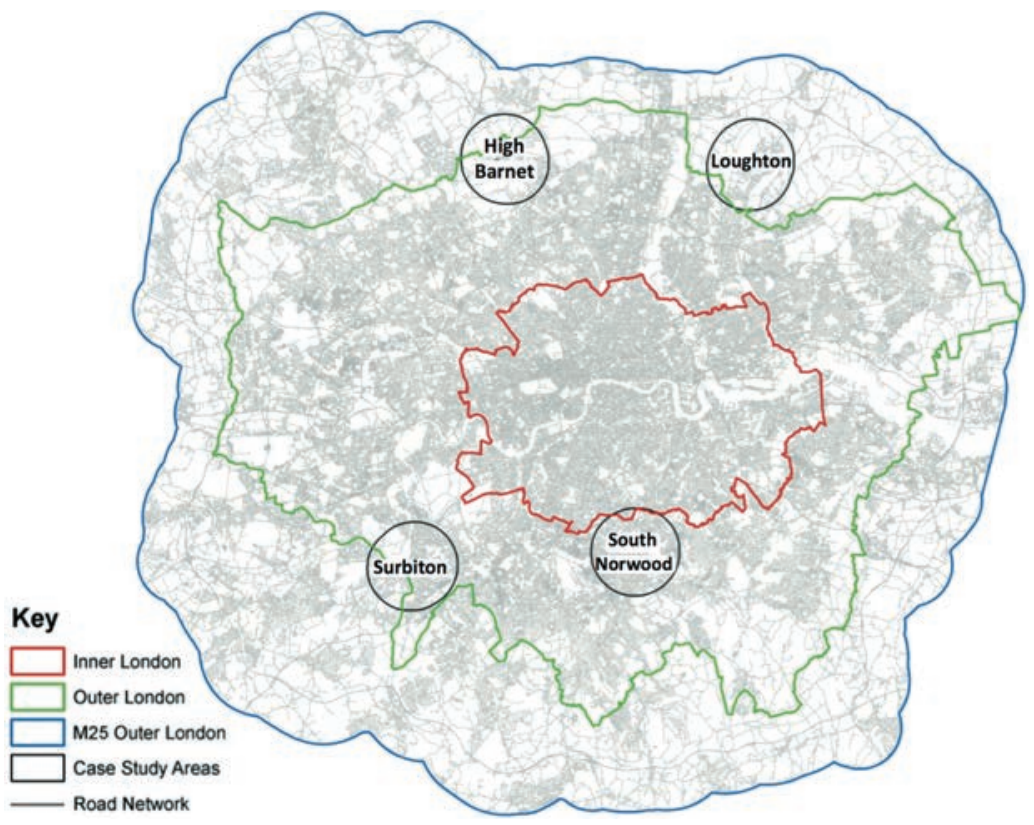

Figure 3.6

Map showing analysis subdivisions of London street network

Contains Ordnance Survey data (c) Crown copyright and database right 2014.

Table 3.2 Network length and subdivision area for whole London street network

\begin{tabular}{lccl}
\hline & Length of network $(\mathbf{k m})$ & Area $\left(\mathbf{k m}^{2}\right)$ & Density $\left(\mathbf{k m} / \mathbf{k m}^{2}\right)$ \\
\hline Inner London & 5382.48 & 348.63 & 15.44 \\
\hline Outer London & 12982.27 & 1246.07 & 10.42 \\
\hline M25 Outer & 7685.66 & 1337.76 & 5.75 \\
\hline All London Network & 26011.30 & 2932.24 & 8.87 \\
\hline
\end{tabular}

Table 3.3 Network densities for London street network subdivisions

\begin{tabular}{lc}
\hline & Kilometres of network per square kilometre \\
\hline All London Network & 8.8 \\
\hline Inner London & 15.6 \\
\hline Outer London & 10.3 \\
\hline M25 Outer & 5.8 \\
\hline
\end{tabular}




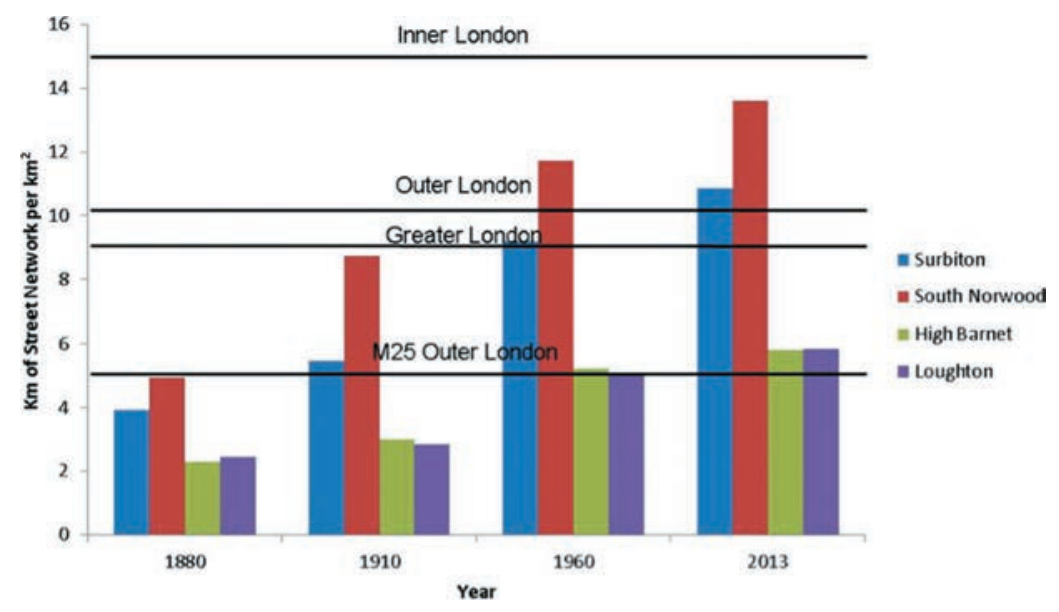

Figure 3.7

Historical network density changes in case studies in comparison to contemporary London network subdivisions

Ashley Dhanani.

Outer London and $\mathrm{M}_{25}$ Outer boundaries, has a value just above the Outer London average whilst Loughton and High Barnet have very similar density levels that are just above the M25 Outer average. High Barnet stands out in this comparison due to its density being significantly lower than the Outer London average, but within a similar range of values as Surbiton. It is clear that whilst Surbiton and High Barnet share similar spatial positioning in relation to the official Outer London boundary, they have very different network densities.

\section{Spatial network evolution}

Analysis of the changing density of the street network across the four case studies allows an understanding of the extent to which the network has grown over time, but it does not capture the nature and development of the pattern of connections that form the network. In order to understand the structure of street network development, the density of junction points in the network and the ratio of junctions to dead ends were analysed. Junction density was used as an approximation for the density of street network connectivity, whilst by examining the ratio between junctions and dead ends in the network, the balance between connectivity and exploratory network growth could be examined. Amongst other things, this analysis tested the conception that suburban growth typically corresponds to an increase in cul-de-sacs 


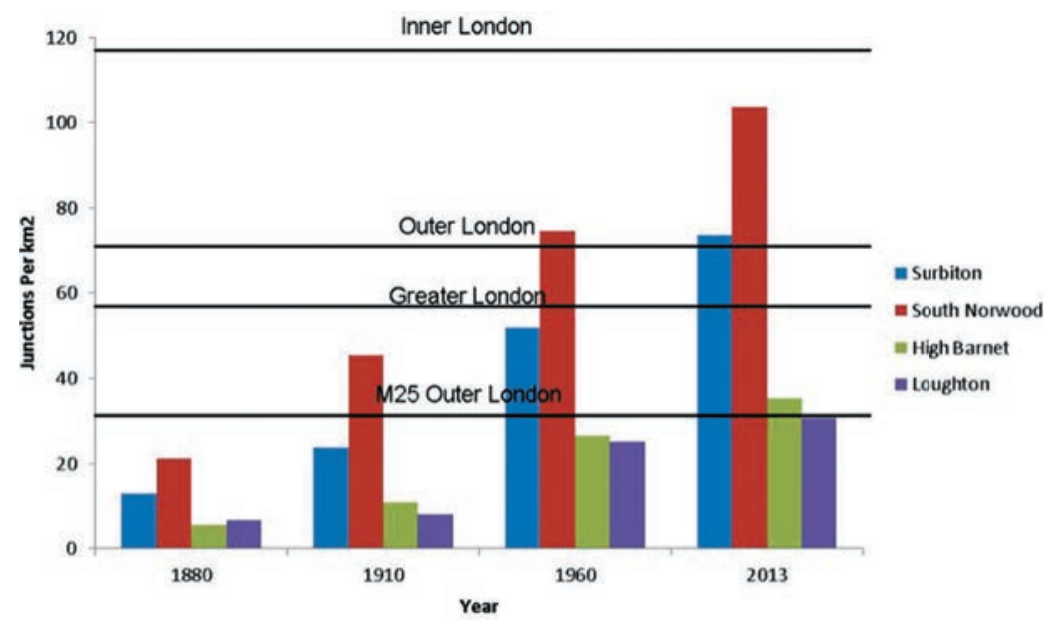

Figure 3.8

Comparison of junction density change in four case study areas in comparison to contemporary London network subdivisions

Ashley Dhanani.

(dead ends) in the network. The following time-series analysis of the four case study centres looks at the type of growth that occurred in each period.

Figure 3.8 shows a comparison of the changing junction density for the four case study areas over time with that of London overall in 2013. (The boundary areas are the same as described earlier and shown in Figure 3.6.) A similar trend to that observed in Figure 3.7 is evident, with a linear progression of the development of junction density over time across the four case studies, with the more central suburbs of South Norwood and Surbiton having the greatest density, and the more peripheral High Barnet and Loughton having significantly lower densities. As before, all cases maintain roughly proportional junction densities over time (see Table 3.4).

The ratio of junctions to dead ends captures the balance between exploratory growth in the network (a greater increase in dead ends than in junctions over a period of time) and consolidation (a greater increase of junctions than

Table 3.4 Junction density change through time in study areas

\begin{tabular}{lcccr}
\hline Junction density & $\mathbf{1 8 8 0}$ & $\mathbf{1 9 1 0}$ & $\mathbf{1 9 6 0}$ & $\mathbf{2 0 1 3}$ \\
\hline Surbiton & 12.92 & 23.80 & 51.99 & 73.53 \\
\hline South Norwood & 21.13 & 45.51 & 74.60 & 103.72 \\
\hline High Barnet & 5.41 & 10.65 & 26.52 & 35.25 \\
\hline Loughton & 6.53 & 7.98 & 25.01 & 30.73 \\
\hline
\end{tabular}




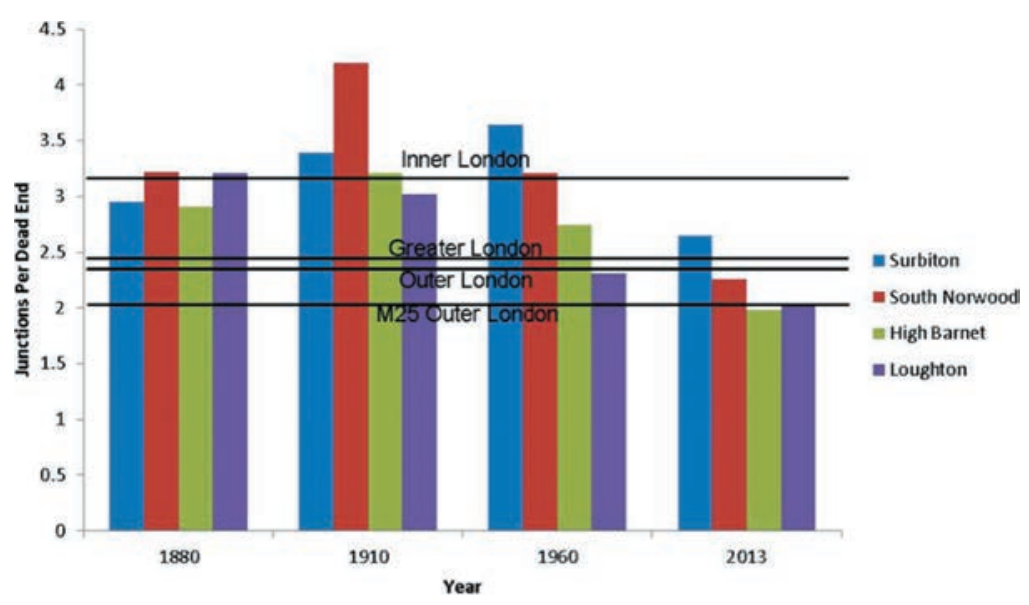

Figure 3.9

Comparison of junction to dead end ratio change in case studies in comparison to contemporary London network subdivisions

Ashley Dhanani.

dead ends). Figure 3.9 charts the results of this analysis and shows that the trend in street network development that has been observed so far in the other measures of development do not continue here. Instead there is an initial increase in junction to dead end ratios for all four places between 1880 and 1910, followed by a decline in subsequent periods. Notably, in all the case studies this measure reaches (and in the case of Surbiton and South Norwood exceeds) that of central London today. This can be understood as showing an early stage of connective development consolidating the area and developing a more connected local grid. Having established this steady state, we can see that from 1910 onwards there is a decline in the ratio in all cases with the exception of Surbiton, as the development pattern of the network changes. This can be attributed to the way in which exploratory growth in the network occurs to provide more space for residential developments. This is achieved through the splitting of land parcels as network elements branch off pre-existing network structures. This is illustrated in Figure 3.10, which shows a portion of the 1960 South Norwood network overlaid on the 1910 map.

It is also interesting to note that although South Norwood has the highest network density and junction density once dead ends are taken into consideration, Surbiton has the most connective network of the four case study areas. This indicates that whilst connectivity as measured by junction density is important, a consideration of disconnection is also important for an understanding of the overall character of the network, its development trajectory and the underlying nature of the street network. 


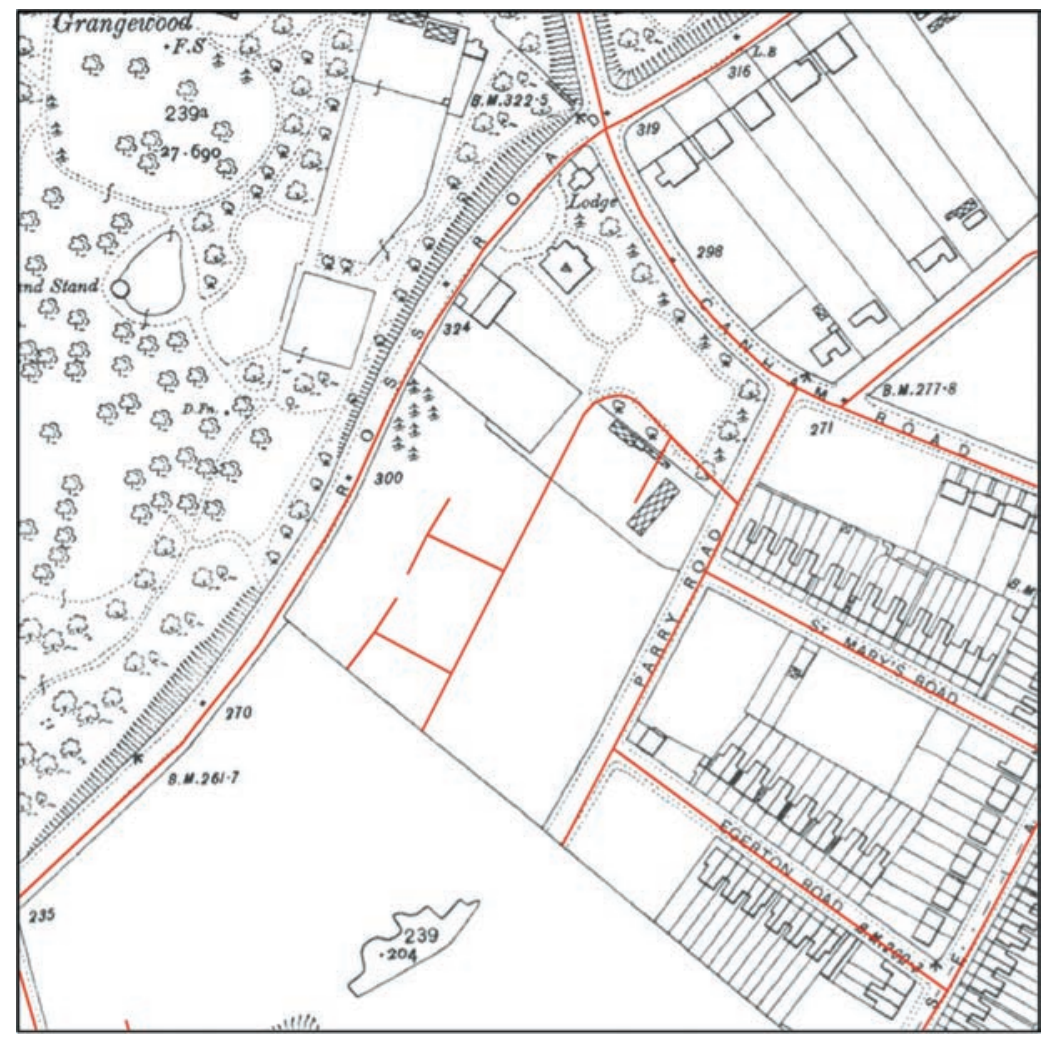

Figure 3.10

Map showing the development of dead ends during network growth and parcel subdivision in South Norwood. 1960 network (red) overlaid on 1910 base map Contains Ordnance Survey data (c) Crown copyright and database right 2014.

\section{Interventions in the network}

When moving from looking at the local-scale road network development to developments in macro-scale road network structures over time, two types of intervention and development are typical of the studied period: motorways and road by-passes, and examples of both can be observed in close proximity to three of the four case study areas: High Barnet, Loughton and Surbiton. The M25 orbital motorway was constructed to the north of High Barnet and Loughton between 1960 and 2013, whilst the Kingston By-Pass (one of earliest large-scale road projects in the UK) was constructed near to Surbiton from 1910 onwards, opened in $1927^{4}$ and was further developed in subsequent periods through road widening and the introduction of an overpass roundabout system. 
In Figure 3.11 the present-day junction of the Kingston By-Pass is highlighted on a map showing the street network. Below this map are four closeups of the highlighted junction, one from each of the time periods analysed, showing the detail of the changes that took place. In 1880 there is simply a kink in a small road, also present in 1910, but by 1960 the original multi-lane by-pass that was opened in 1927 has been constructed. By 2013 multiple levels have been introduced and the road has undergone further widening. Figure 3.12 shows aerial images from 1928 of the newly constructed by-pass. The transformations on the ground shown in Figure 3.11 highlight the changes that took place between these periods that have important implications in relation to both connectivity between local centres and the city-region, and to the lived experience of the local area at ground level. The relationship between local centres is directly affected by the barrier that the by-pass forms between places on either side of the road, creating an infrastructure biased towards car travel. Whilst these large-scale changes occurred, smaller changes in the road network also took place. This was particularly a feature of change in the Surbiton case study area, where many of the smaller changes to the street network occurred in close proximity to the new large-scale road infrastructure. This is likely to have affected the flows in the existing street network and will have contributed to shifts in accessibility (Griffiths et al. 2013). It is evident how large infrastructural interventions have the potential to transform spatial relationships between and within local centres, as well as their relationships to the city overall in terms of mobility. Faster access to the wider city region is a likely result, but also the dependence and dominance of the car as the means for doing so. In relation to the experience on the ground of pedestrians navigating the area in 1960 all the junction's structures are at the level of the street, with pedestrian crossing provision. However, by 2013 the infrastructure gives primacy to the car, and pedestrian pathways are structured beneath the roundabout via suspended walkways. Whilst historical development in street networks around town centres has been shown to be accretive and very much at the same scale, providing for both pedestrians and non-pedestrians together, the by-pass and motorway forms of road infrastructure are far removed from this. The consequences are the creation of space that is not equitable to all forms of movement and are likely to act as a barrier to non-motorised traffic, with subsequent change in how the local environment shifts from providing local land uses and a pedestrian-friendly environment to a setting which is hostile to both.

If we contrast the Kingston By-Pass setting with that of the M25 orbital road, the differences are clear. Taking High Barnet and Loughton, the M25 is present on the fringe of both areas but it is evident that their local road network structures are not directly impacted, since the M25 is not directly 

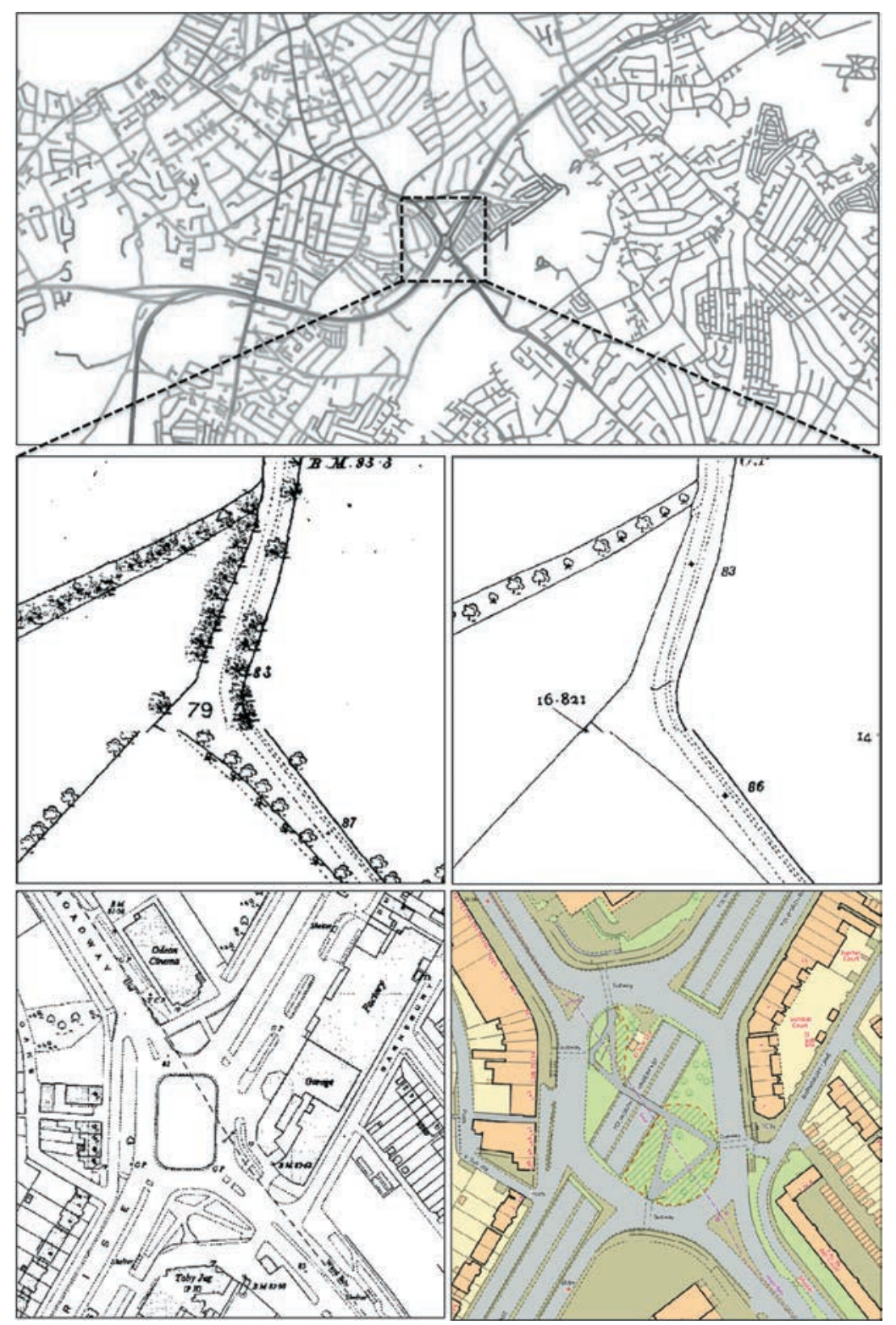

Figure 3.11

Transformation of Kingston By-Pass junction in Surbiton study area showing maps of the highlighted area for 1880, 1910, 1960 and 2013

Contains Ordnance Survey data (c) Crown copyright and database right 2014. 

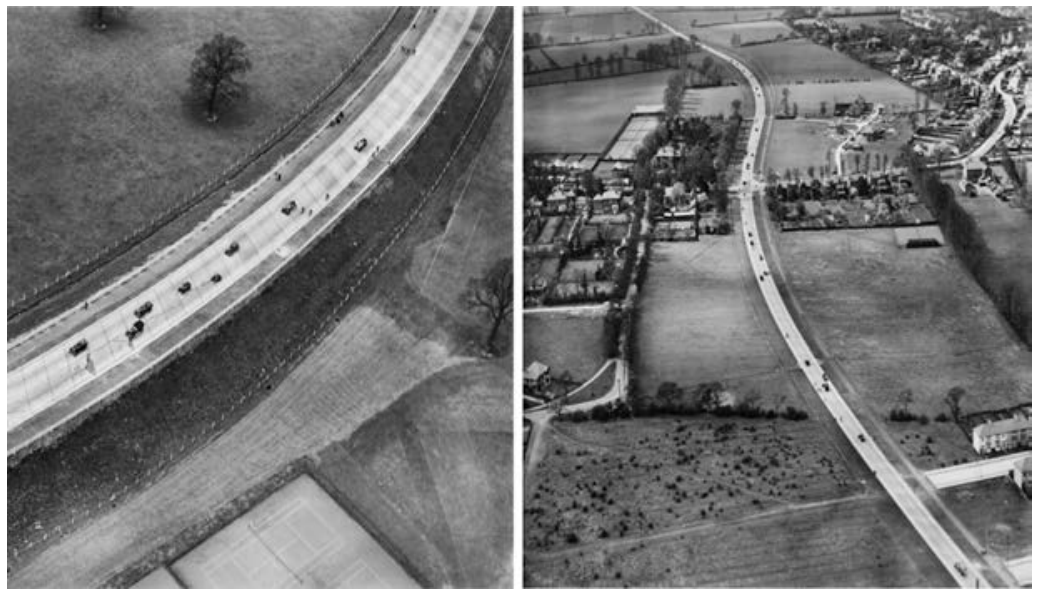

\section{Figure 3.12}

First section of the Kingston By-Pass is opened to the public in 1927

(c) Historic England. Licensor www.rcahms.gov.uk.

adjacent to either town centre. This lack of direct impact on local morphology indicates that the building of this form of road network infrastructure designed to serve city-scale movement is doing just that: by not integrating with the local network it does not greatly affect the road network development. The new network interacts at a larger scale, moving traffic around the city, rather than through the centres, in order to alleviate congestion. However, in Surbiton, the Kingston By-Pass does have an impact. It is more closely interlinked with the local network, integrating the new configuration with the old. It is also likely that the gradual development of the By-Pass allowed the new network structures to integrate slowly into the local grids. The M25 in High Barnet and Loughton was built rapidly, creating the typical urban fringe scenario of large-scale road infrastructure flowing in proximity to an area, without integrating or relating to the local street network morphology.

In the spatial development of the four case study areas discussed here, local development in the street networks shows the local accretive process of peripheral urban growth, gradually blending into part of the sometimes (semi) continuous urban fabric, while the large-scale road infrastructures such as the Kingston By-Pass and M25 illustrate a vital alternative dynamic process between the urban periphery and the core. These observed developments resonate closely with the readings of peripheral areas of cities, often characterised by the awkward confluence of different scales of movement and seemingly contradictory uses (Garreau 1992), as seen in the case study 
areas. They are frequently characterised as involving the coming together of diverse land uses such as distribution centres, industrial parks and residential areas, criss-crossed by local roads and remnants of a rural past. Elevated, multi-lane motorways pass through and pay little attention to historical, local network structures - which are likely to have developed over centuries and gradually adapted to the advent of new mobility technologies; these enable faster access to the core of the urban area and are often highlighted as typifying the periphery of the city, effects which were observed in this study (Sheller and Urry 2000). This messiness in the urban fabric and the diverse uses and relations that each one signifies is at the heart of the ambiguous and contested image of suburbia, and peripheral urban areas more generally. In the analysis of the case studies that was presented, the coming together of radically different, and sometimes conflicting features in the urban fabric were found to be present: the mixing of historical road networks that have developed and grown slowly over time, embedded within the new large cityscale infrastructures, serving different purposes but impacting on both the local area and its development, as well as the city-region.

To better understand the processes in the spatial development of suburban London that have been observed, the concepts of edge city (Garreau 1992) and the dynamics of the rural-urban interface (Keil and Shields 2013) are useful to consider and have been applied numerous times. However, these discursive approaches situate the discussion largely within the spatial confines of the suburban and urban periphery. The analysis in this chapter indicates that in order to understand the suburban, a wider spatial frame of reference is necessary, taking into account both local and city-scale urban development. Central to the development of peripheral urban areas in London has been the development of new forms of transport, such as trains and automobiles, and their associated infrastructures, such as railways, the Kingston By-Pass and $\mathrm{M} 25$, which are city-scale processes that manifest themselves in particular ways on the fringes of the city. Whilst they may coalesce in the centre, on the outskirts of the urban area, as in the case study areas considered here, they manifest themselves in specific ways, particularly in relation to their relative dominance of the local spatial relations and implied potential future local development trajectories that will be heavily framed by these large infrastructures. To be able to fully conceptualise and understand the suburban, approaches that take into consideration city-wide processes are necessary. Both micro and macro perspectives should be considered, since the suburban is a manifestation of a certain form of urbanisation that arises from the totality of the urban development process with a particularly strong relation to transport developments. 


\section{Conclusion}

The analysis of suburban spatial network development as presented in this chapter has shown that the four case study areas considered individually, as well as London considered in its entirety, have a diverse range of network characteristics that were revealed through different methods of network analysis. South Norwood and Surbiton have the densest networks of the four case study centres, while High Barnet and Loughton have significantly lower densities. The four areas studied have network densities in line with their spatial positioning in the overall London network. When the network density of the four centres is evaluated over time, from 1880 to 2013 , a steady increase is observed in all four cases, with the four areas maintaining their relative levels of density in relation to one another. This highlights the stability and continuity in the growth of the areas over the 130 -year period. Taking into consideration junction density, both in comparison to the whole London network and through time, the same trend of steady densification over time and maintenance of relative density between cases is observed.

Examining the ratio of junctions to dead ends revealed a different pattern of development over time. This analysis assessed whether connective or exploratory growth was predominant in each period. It found that in the earliest stage of development (from 1880 to 1910), the network became more connective as grid intensification took place and the ratio of junctions to dead ends increased. In the subsequent periods - 1910-60 and 19602013 - the trend reversed and the ratio fell significantly. This change in the network development trajectory is likely to have been due to changes in the role of these locations in the context of London as a whole. With the expansion of networks of public transport and the desire to develop away from the centre of the city, rapid residential expansion took place on the periphery. As this occurred, the network grew in an exploratory fashion, primarily through the subdivision of pre-existing land parcels as was shown in the chapter. This in turn created a network with many dead ends in relation to junction points, leading to the changes observed in the analysis.

The examples of large road network infrastructure developments illustrate that the hierarchy and relationship between mobility networks that serve different purposes are important for understanding the spatial relationship between the suburban case study areas on the urban periphery, and the wider urban area. The development of these large-scale infrastructures, implemented from a macro view of city-wide and regional road network development, interact in particular ways on the urban periphery, where they do not always directly integrate with the local road systems. By understanding the interaction, both spatially and historically, between the 
development of large-scale transport infrastructures and local areas, a better appreciation of the nature of the spatial relationships and hierarchies that exist within a city can be achieved. This is particularly important in any discussions regarding sustainable urban development and sustainable transport planning, where evidently the spatial characteristics of existing street networks are likely to determine the types of mobility that they can provide for, or be adapted to.

The influence of the pre-existing street network structures on future development has been demonstrated in other urban regions (Pinho and Oliveira 2009; Serra and Pinho 2012) and was also seen in this analysis. In all the case study areas the majority of the network structures that were present in 1880 persist until the present day. This illustrates the pathdependence (Arthur 1988; Batty 2007) that occurs during urbanisation, influencing future growth patterns and potential. This in itself highlights the need for considered approaches to drastic urban planning intervention, due to the potential impact it has on possible future developments; this is particularly relevant in rapidly urbanising regions where whole cities are being reshaped. As a counterpoint to the continuing presence and influence of historical network structures, it was shown that completely new types of street network structures are introduced through large-scale interventions, such as the Kingston By-Pass in Surbiton and the M25 in Loughton. The confluence of the historical and the new in spatial infrastructure terms was found to be a defining feature of the case study areas, highlighting the periphery as a location for synergetic processes of urban development operating at both the local and city scale, but not necessarily coalescing together as an integrated whole. The development and persistence of the local street network structures of all four case studies, as well as the introduction of radically new structures in their vicinity, emphasise the duality of change and continuity that is found in the development of London's suburban landscape. Alexander's (1966) proposition that the structure of a city is not tree-like, but is a series of nested and overlapping structures working at different scales, corresponds strongly with the findings here, and the historical developmental perspective helps to substantiate this proposition that nested structures are more supportive of the complexity of modern societal structures where social connections may occur a distance away and where overlapping networks are essential to maintain this social-spatial complexity.

The importance of movement technologies in the spatial and architectural development of the urban periphery reinforces theories of the movement economy (Hillier 1996), which suggest that the flow of people through the urban system is paramount to their functioning and success. Whilst in 
London the railway system has been shown to have a significant impact on historical urban development patterns (Jackson 1978) and all the case study areas' development was seen to be reliant on the arrival of the railways at a given point in time, this research has shown that the motorised vehicle, and the associated infrastructures in the street network, have played a significant role in the forms of urbanisation seen in suburban London. All these technologies of mobility develop around the aim of allowing movement to occur more freely, quickly and easily across larger areas. The impacts on socio-spatial dynamics that these changes in mobility bring about is an important area that needs further research to enable an understanding of the particular socialities that different motilities engender.

\section{Notes}

1 The earlier research referred to here was the Towards Successful Suburban Town Centres project at UCL. The research reported in this study formed part of the subsequent Adaptable Suburbs study, for which the author was awarded a PhD studentship. For full details of both projects, see notes to this book's Preface.

2 The UK town centre boundaries exclude smaller non-domestic premises as well as industrial activity to define particular economic aspects of their functionality. In contrast, the Adaptable Suburbs research project intentionally captured a much wider area in order to analyse the spatial, social and morphological properties of an area of activity within walking distance from the centre.

3 Inner and Outer London are official boundaries, as defined by the 2011 London Plan produced by the Mayor's Office at the Greater London Authority; the M25 Outer London area was drawn to encompass a contextual area $3 \mathrm{~km}$ beyond the $\mathrm{M} 25$, as described earlier.

4 Putting aside sporadic cases such as this, Britain was quite late in adopting the practice of motorway construction, with the M1 opening only in 1958. A major catalyst for this was the highly influential Traffic in Towns report commissioned by the Ministry of Transport that suggested that the impending explosion in car ownership necessitated protecting town centres from over-congestion (Buchanan 1964). One proposed solution to this was to construct road infrastructures such as by-passes and orbital motorways. 


\title{
Chapter 4
}

\section{Spatial Memory and Shifting Centrality}

\author{
Nadia Charalambous and Ilaria Geddes
}

\section{Introduction}

Cities are complex entities, which are constantly changing in terms of their built form, their social and demographic make-up, and their street network and public spaces as well as the way in which they are used and lived in by their population. The study of their evolution requires the capability to link all these different elements, historical and geographical, and relate them to each other in a meaningful way, so as to draw inferences as to the nature of changes in each element and how these interact spatially over time. History, whether in terms of the evolution of architectural forms or the socio-economic and political context of a place, can be used as a background to inform the analysis of the urban form at any point in time. Researchers have approached the analysis of the evolution of the urban form from various viewpoints, by bringing the social context to the foreground, by focusing on settlement forms or by linking the built form with ideologies and historical events.

Many of these approaches focus on the social and economic dimensions with little attention given to the effect of space on the issues in question. Without seeking to undermine such histories, this chapter is concerned with urban phenomena and city evolution, whilst taking into consideration the discourse concerning the implications that are embedded in or are generated from spatial patterns. Such an approach treats cities as socio-spatial entities, as 'highly relational systems' with complex organisation (Hillier and Vaughan 2007) that are driven by evolutionary processes that might generate, reproduce and transform urban phenomena over time.

This chapter seeks to provide such an understanding of the evolution of the city of Limassol in Cyprus, as particular kinds of spatial environments characterised by both change and persistence over time can be identified. Limassol, one of the most significant cities in the modern history of 
urbanisation in Cyprus, experienced rapid growth throughout the twentieth century with significant spatial developments and transformations. Urban growth has affected the transformation of the historic centre resulting in a changing context where certain characteristics of the traditional high street changed, while others persisted through time, and the boundary of the former 'edge city' became the new high street.

As demonstrated by Hillier (1999a), centrality in a city is not a permanent, localised situation; rather it is a process which sees the shifting of centrality as the city grows or shrinks and as its spatial network changes. This process is formed according to the impact of spatial configuration on movement, which in turn influences the distribution of land uses. As cities grow, their choice values and their intelligibility tend to decrease, an effect which was shown to be particularly pronounced in Mediterranean port cities which have grown rapidly in recent years (Shpuza 2009). Centrality also tends to shift towards the edges of the city; this is because people's movement in cities has both a global and a local aspect, the one reflecting circulation in and out of the system, the other within the system. It is 'this tension between the internal and external movement economies of the settlement [that] is the fundamental reason why centrality tends to shift toward the edges of the settlement' (Hillier 2002: 176). As Hillier has noted (1999, 2009b), the dynamism of the 'edge city' is not restricted to the edge: he argues that it is the pervasive nature of centrality that allows cities to sustain themselves.

The question raised is how far can spatial configuration explain the historical pattern and sustained urban vitality and 'attraction' of the high streets under study? The idea that the spatial morphology of the urban grid itself creates movement attractors is an aspect of the space syntax theory of cities as 'movement economies' (Hillier 1996). Such an approach allows that 'attraction' might be implicit up to a point in the spatial configuration of the city itself (Griffiths et al. 2013). Griffiths et al. point out that we can then explore the potential of the high street to attract and facilitate co-presence as a result of its spatial configuration and its ability to sustain varied and mixed land uses, regardless of the presence of other, particular 'attractors'. The interaction between spatial configuration and land use distribution reflects social and economic activities that occur in the physical environment and possibly relate to urban vitality.

Within this framework the following analysis sets out to explore the development through time of the historic street network in the urban centre of Limassol, adding details of the complex historical processes which lead to changes and the persistence of some elements in its urban form. It focuses on the spatial properties of two main streets: Anexartisias, the traditional high street in the historical core of the city of Limassol, and a stretch 
of Makariou, the first inner ring-road of the city built just after the Second World War; Figure 4.1 shows a tourist map of Limassol from 1947 indicating the location of the newly built inner ring-road (labelled Bye-Pass) on the outskirts and Anexartisias, situated in the well-established historical core.

Historical analysis of the process of growth of Limassol, taking into account configurational changes and continuities together with land use and social data, will facilitate a better understanding of its contemporary urban form, spatial properties and the ways in which historical formations of urban configuration influence the present life of the city and its urban vitality. Such a perspective provides valuable evidence and facilitates an understanding of the ways a city or a street network grows and its capacity for resilience - its ability to adapt after experiencing multiple urban interventions, to accommodate change and to withstand the impact of economic cycles. With regard to the mechanisms of growth and the adaptability of cities, building on Hillier's proposition (1996, 1999a), research by Al-Sayed et al. (2012) has shown that centrality drives the generative process and

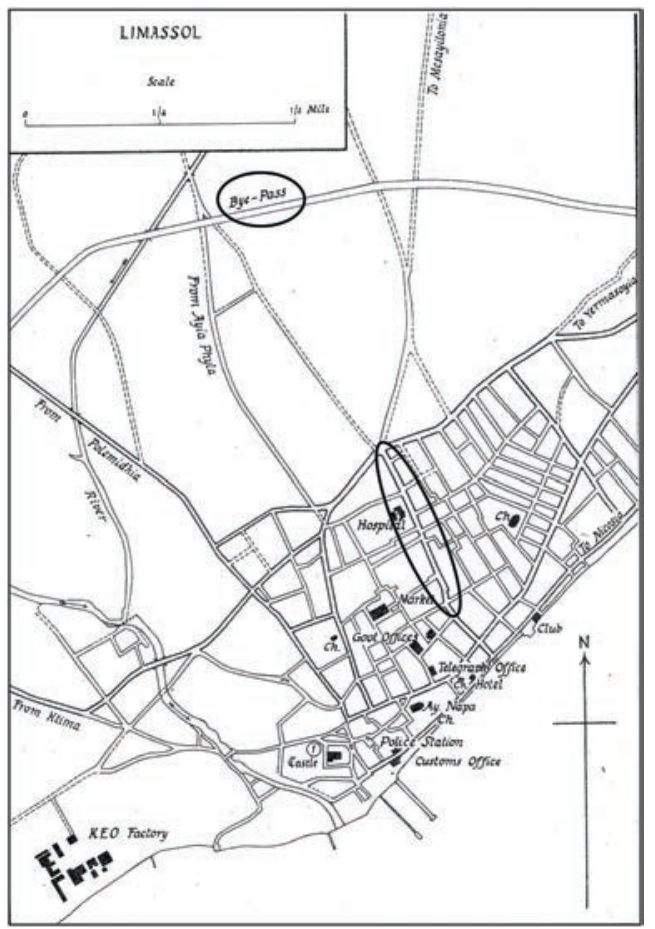

Figure 4.1

Tourist map of Limassol during the Colonial period from Mangoian and Mangoian (1947)

With permission (C) Mongoian Bros Ltd. 
precedes the emergence of densification - the intensification of the urban grid in areas which have seen high gains in centrality is identified as an adaptive process reflective of a form of intelligence.

Other recent research reveals morphological properties of the street network that in some cases seem to be distinct and persistent through time while in others they are continuously modified (Geddes 2014). While the processes of gaining centrality and densification suggest a form of intelligence, the persistence of certain spatial properties after a period of adjustment suggests a form of 'spatial memory', sustaining a mixture of land uses through time. Comparing the spatial features of the two streets at six points in time (1880s, 1930s, 1960s, 1980s, 2000s and 2010s) while assessing their contemporary situation through land use, pedestrian and vehicular movement analyses, the question is then raised whether there is such a thing as 'spatial memory'.

The focus of this study is therefore the application of a suitable methodology to assess the historic street network's patterns and process of growth and the ability of specific areas to adapt to multiple changes (Marcus 2012). The approach used here is the application of space syntax methodology coupled with land use and movement analysis. This approach is a spatial one: it directly links spaces with actual use and daily patterns of living, it has the ability to scale up and down from the particular to the general and vice versa and allows the investigation of a system as a whole or in its parts (Karimi 2012).

Historical maps are used to create spatial models of the city in the past, while contemporary land use and movement data and space syntax analysis form the basis for the methodological approach of this research. They are used in an attempt to explore whether contemporary spatial properties, distribution of land uses and movement patterns of the historic street network may have roots in the past, and may be better understood as being conditioned by the interaction between 'inherited' spatial configuration and contemporary life.

The historical evolution of the case studies is described in the following section, which is followed by a description of the research methods. Three sections of analysis are then presented focusing on how the spatial properties of the city and the two high streets changed over time, the contemporary land use distribution and the movement patterns in the two study areas.

\section{Limassol's urban development}

Limassol, whose metropolitan area has a population of 183,656 (as of 2011), is the second largest city in Cyprus. It occupies the southernmost point of 
the island, stretching from east to west while expanding across the low hills to the north as well. A highway running east-west and surrounding the city a few kilometres to the north of the coastline separates the city from the suburban villages to its north which have come to be part of the city conurbation. This highway and two ring-roads together form the main east-west circulation routes of the city. The old city centre and its southernmost limit, the coastline, are connected to the ring-roads and highway in the north by a number of radial streets running north-south. Town planning is still based on zoning, dedicating different areas of the city to specific uses, with the exception of the historical town centre, which grew organically as a mixeduse area comprising residential, commercial, retail and tourist activities. Development plans, including the recent regeneration of the old port and promenade and a new marina, have been designed with provisions for car use in mind. This has resulted partly in major vehicular routes linking ringroads to the town centre, and partly in a large number of car parks serving as access points to the old town centre, the few pedestrianised areas of the University of Technology (TEPAK) and the old port and promenade. The situation is illustrated in Figure 4.2.

At the beginning of the nineteenth century Limassol was a very small settlement, described as 'a miserable town consisting of 150 mud houses of which 100 are Greek and 50 Turks' (Turner 1820: 568). It developed substantially during the second half of the century when Agkyras Street was

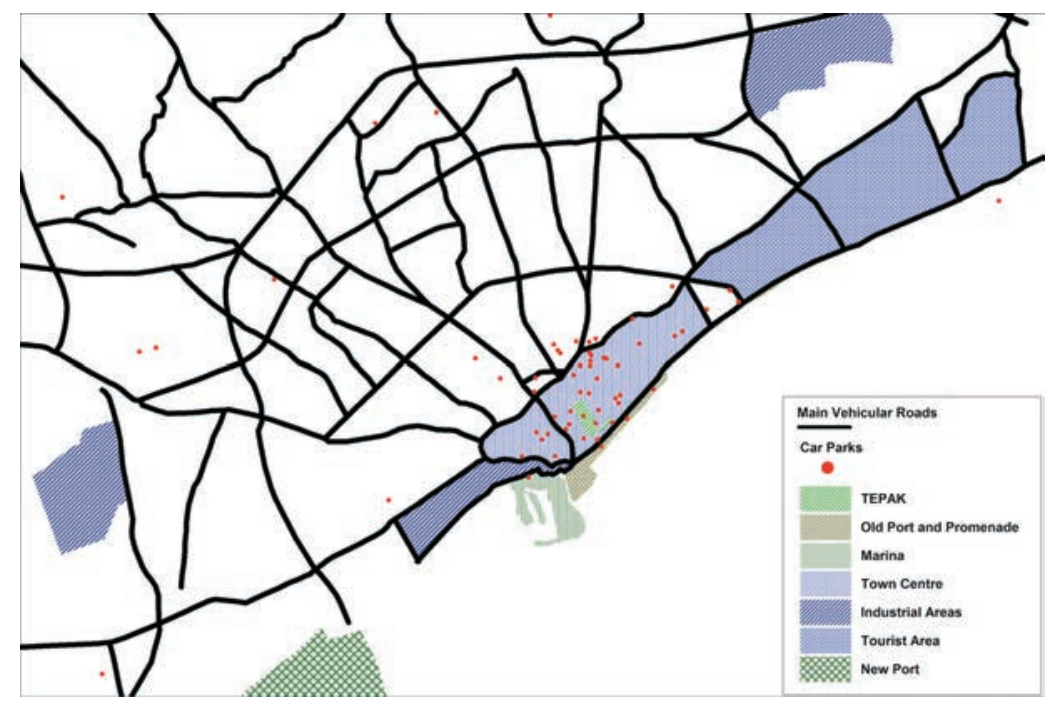

Figure 4.2

Diagram of Limassol's main routes, zones and car parks, 2011.

Nadia Charalambous and Ilaria Geddes. 
the main commercial street (Severis 2006: 98). A map of 1849 (Figure 4.3) shows the small town with the street of Agiou Andreou (still a popular commercial street today) intersecting with Anexartisias at its southern end parallel to the seafront and Agkyras, the western continuation of the same street curving towards the north.

Towards the end of the Ottoman period, Limassol developed as a city of proto-industrialisation, as the economy benefited from the stationing of British troops in the district, with consequent development of catering establishments and retail facilities in the town stocking a greater array of imported goods, meeting increased and changing demands due to ongoing social and historical changes, such as the change in the administrative bodies and the settling of a British population in the area (Katziaounis 1996).

However, during this time ethnic and social divisions started to become spatially apparent. Pivlakis (1977) describes how these divisions were becoming more accentuated, with the Turkish living to the east of the river, a poorer area developing alongside the port and castle, and the wealthier Greek community settling around the church of Katholiki. Moreover, other social problems, partly related to social division and partly to the

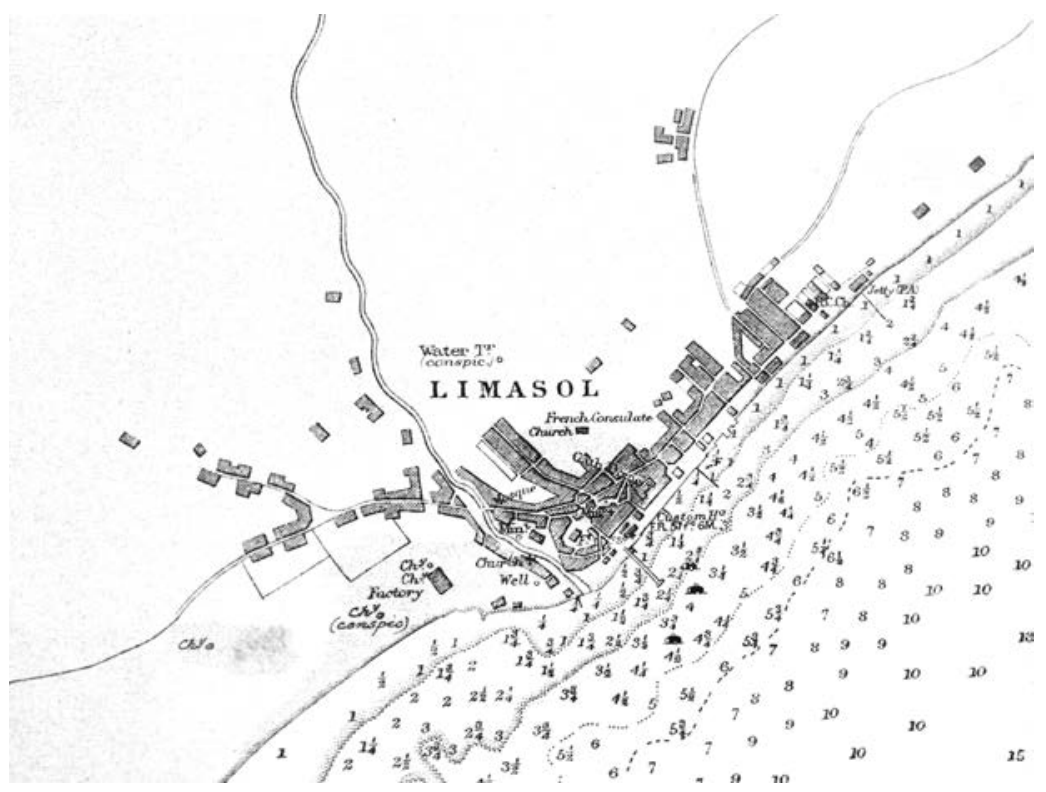

Figure $4 \cdot 3$

Admiralty chart of Limassol, 1849, drawn by Lieut. Lord John T. Browne (survey by Capt T. Graves. Admiralty Chart 2074. 3.5 sea miles to one inch)

With permission (CUK National Archives. 
nearby stationing of military troops, were evident, although they provided a demand for land for uses such as wine shops, cafés and even brothels in much of the city at the time (Katziaounis 1996). A map of 1883 highlighting the relevant areas is shown in Figure 4.4.

In the 1920s and 1930s the ethnic diversity of the city is evidenced by travellers' records, with the seafront, Agkyras and Agiou Andreou retaining their importance as part of the city core and commercial areas. Gladys Peto's description of 1927 also confirms that different groups lived to a great extent in separate areas (Severis 2006).

Previous analyses of Limassol's growth have pointed out that uncontrolled urban development led to an uneven expansion of the city, creating a fragmented structure and leaving many gaps in the urban fabric (Kritioti 1988). Limassol has now become a large and sprawling city, as the distribution of the population between the urban and the metropolitan areas has changed drastically. Whilst in 198270 per cent of the population was based in the urban area, this is true of only 52 per cent in the 2010 (Gerasimou and Georgoudis 2011). This process can be attributed, on the one hand, to suburban growth and, on the other hand, to development focused on providing vehicular access and parking while employment, services and

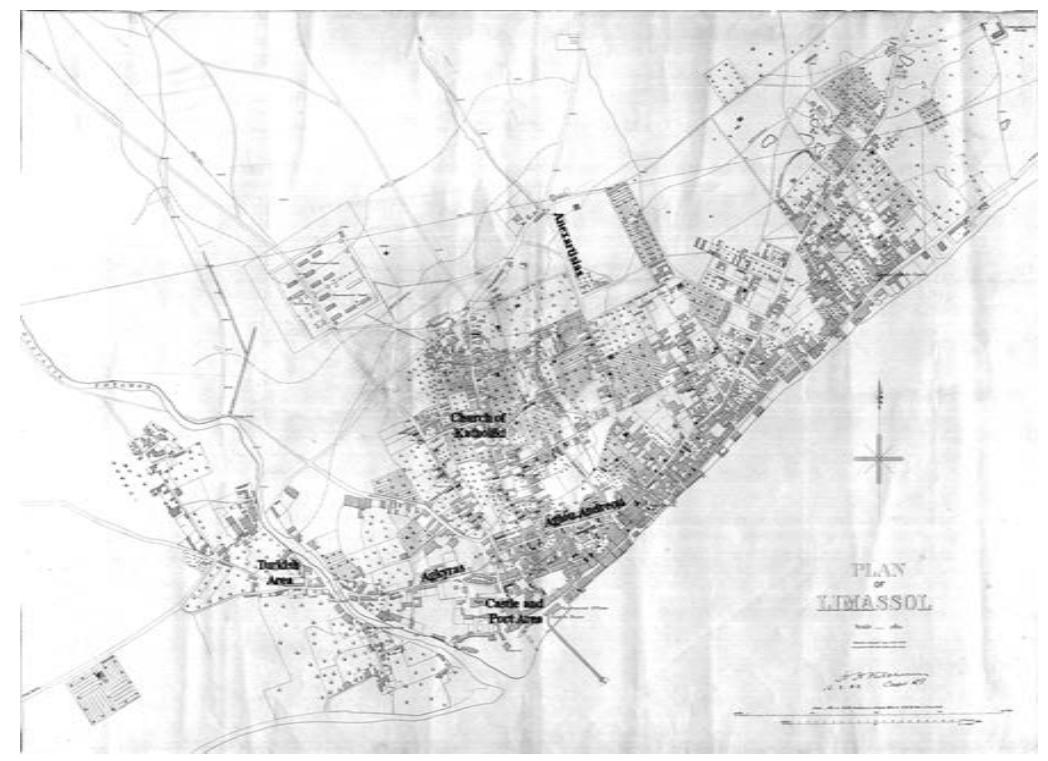

Figure $4 \cdot 4$

Map of Limassol in 1883 from Rodney (2001)

With permission (c) Bank of Cyprus Cultural Foundation. 
commercial activities as well as tourist services had been developed in the historic town centre and the coastal area.

The two streets selected for this study are Anexartisias and Makariou, both considered popular commercial high streets within the city centre today - a detail of a contemporary map of the city is presented in Figure 4.5. Anexartisias is located within the historical town centre, an area classified by the town planning department as a 'central commercial area', while Makariou is located at the northern edge of the city centre and classified as a 'secondary commercial area' (Town Planning Department 2013).

There is evidence that Anexartisias was already developed by 1883 (Figure 4.4). It runs north-south from the seafront to the end of the historic town centre, where it meets another four roads forming a major junction known as Pentadromos (five roads). At about two-thirds of its length from the seafront, there is a significant bend in the road forming a junction with the street of Athinon, along which many of the TEPAK buildings are found. The southern stretch of the road is crossed by Agiou Andreou, another main commercial street with tourist shops in the historic centre,

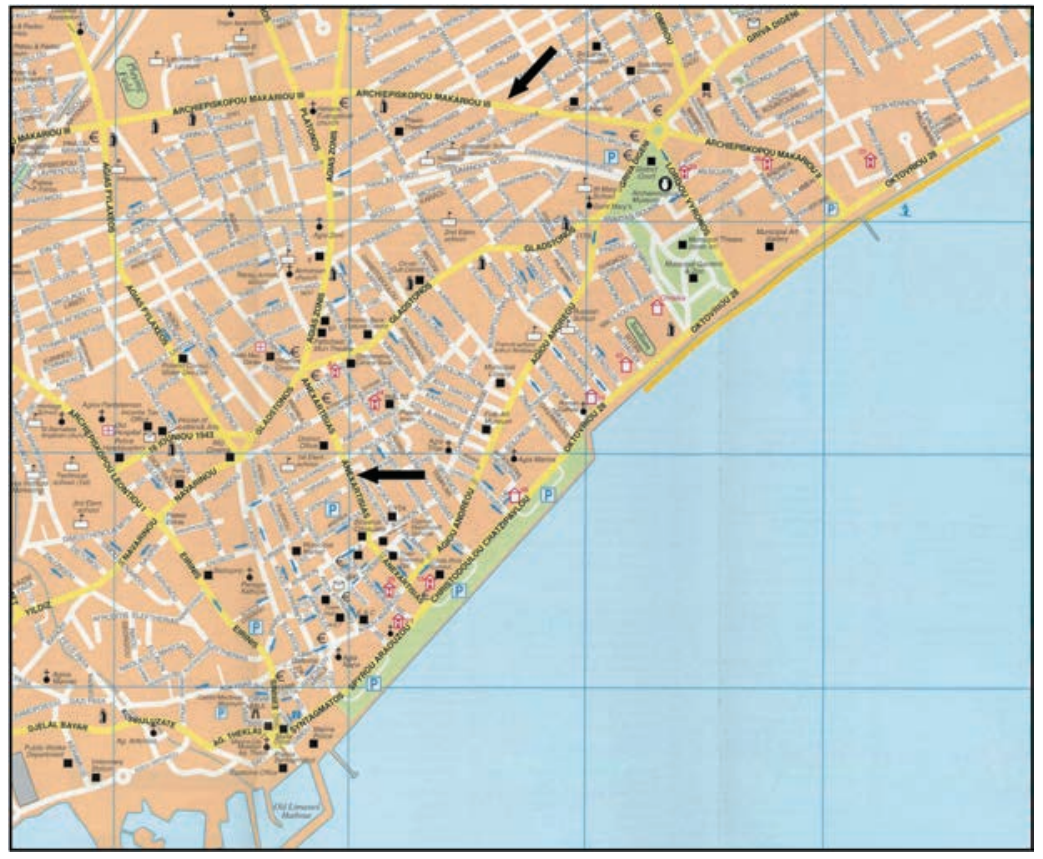

Figure 4.5

Map of Limassol (detail) from 2011 Selas (2011). Arrows indicate Makariou street (above) and Anexartisias street (below)

With permission (c) Selas Ltd. 
which leads all the way to the old castle where it joins the street of Agkyras, the commercial centre during the Ottoman period. The street does not appear on the map of 1849; however, this map may not be representative of the full extent of the city at the time - though accurate, it is an admiralty map concerned with representing visible landmarks from the water and the shape of the built form along the coast, rather than recording the built form of the city.

The section of the street under study is the northern section, from the junction with Athinon all the way to Pentadromos. The street is lined with shops, cafés and takeaway outlets. The street also has a public space opening from it (Gregori Afxentiou Square) - overlooked by the Municipality Offices building. Across the square two side roads lead to Iroon Square, a popular area, especially during the evenings with entertainment venues and restaurants, where many public events are held. The shops and cafés along the street comprise independent shops as well as popular brands such as Topshop, Bershka, Starbucks and Subway, although a number of outlets are currently empty following the economic crisis which came to a head in March 2013. The street was repaved in 2011 with a shared surface design. The design included separation of the pavement from vehicular traffic by posts rather than a step, and street furniture such as benches were also added along the street's length. Figure 4.6 summarises the visual characteristics of the high street.

Makariou was developed after the Second World War; it runs from the seafront towards the north and north-west at first, where it meets with another five major roads at a large roundabout; it then continues westwards around the whole city centre, forming the city's first inner ringroad. The section studied here runs from the roundabout to the west until the first major junction with the road of Agias Zonis, which leads south to Pentadromos and Anexartisias. This section was the first to be built along a pre-existing footpath along the ditch of the River Vathias, visible in the map of 1933 - although the eastern part of this section was realigned when the paved road was built; the footpath along the ditch is the street used in the spatial analysis of the 1933 map. Most of the street was in place by 1960 except for the eastern section running down to the seafront - we were unable to find information as to when this section was built, but it is present in a map of 1987, a time when the motorway was already in place, although the second ring-road between Makariou and the motorway had not yet been built.

This street is also a popular commercial area and it is where the yearly carnival parade runs, starting at the roundabout and heading westwards. Like Anexartisias it is lined with shops, cafés, restaurants and takeaways 

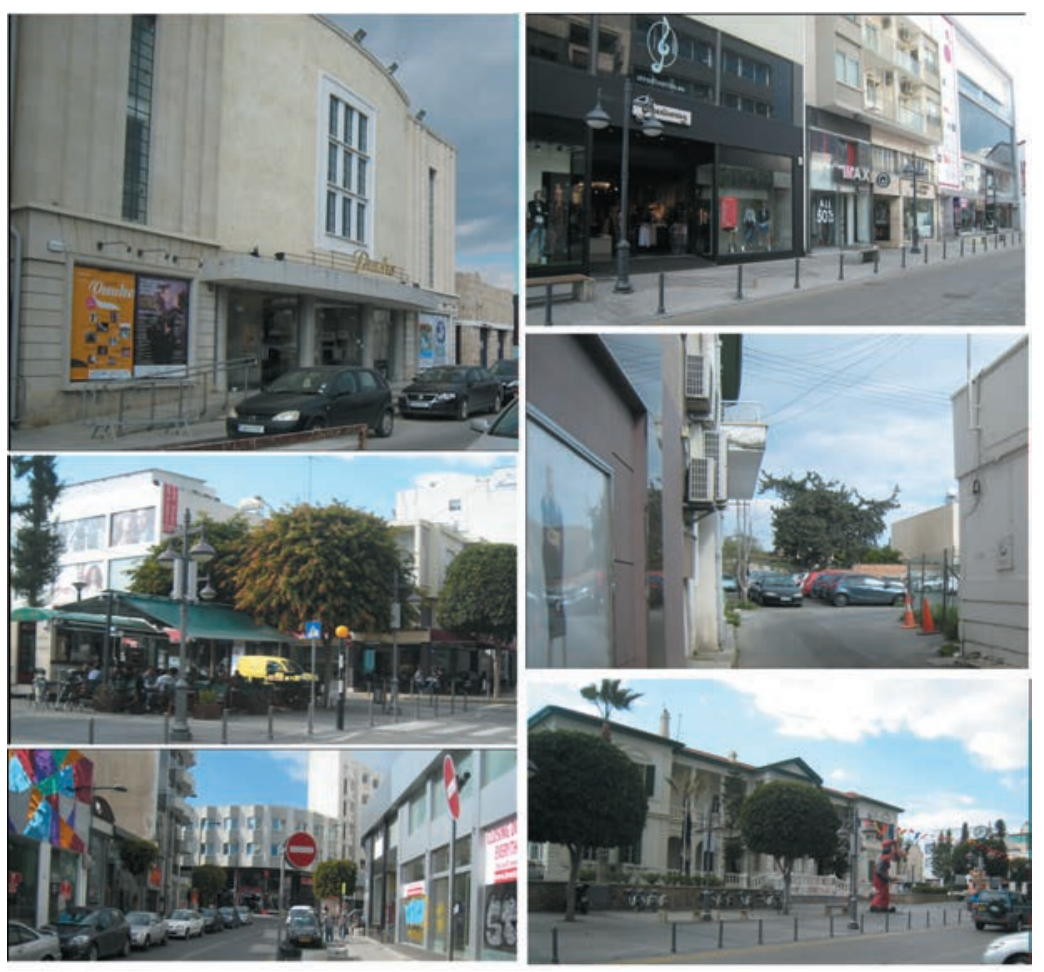

\section{Figure 4.6}

Characteristics of Anexartisias street, left to right and top to bottom: the Rialto Theatre on Iroon Square, built in the 1930s and a very popular venue until the late 1970s, when the area decayed and the theatre closed - it was reopened in 1999; popular shops along the street with a shared surface design and benches along the pavement; outdoor café seating on the corner of Gregori Afxentiou Square; parking area just off a side street; closed-down shops due to the economic crisis; public space in front of the Municipal Offices building Nadia Charalambous and Illaria Geddes.

(including closed-down shops affected by the economic crisis). A greater number of services are located here than on Anexartisias, particularly banks. Although the road is much wider than Anexartisias and has more of its original ring-road feel, here can be found not only popular brands, such as Calzedonia, Babylos, La Senza, KFC and Costa Coffee, but also more upmarket brand retailers (Fendi, Trussardi, Versace, La Perla), along with the local Marks \& Spencer, and the offices of major international companies such as Deloitte. The road is served by bus routes with two stops along the case study area, and fairly large car parks are also found along the road, as well as in the side streets and back streets. Just to the south of the roundabout 

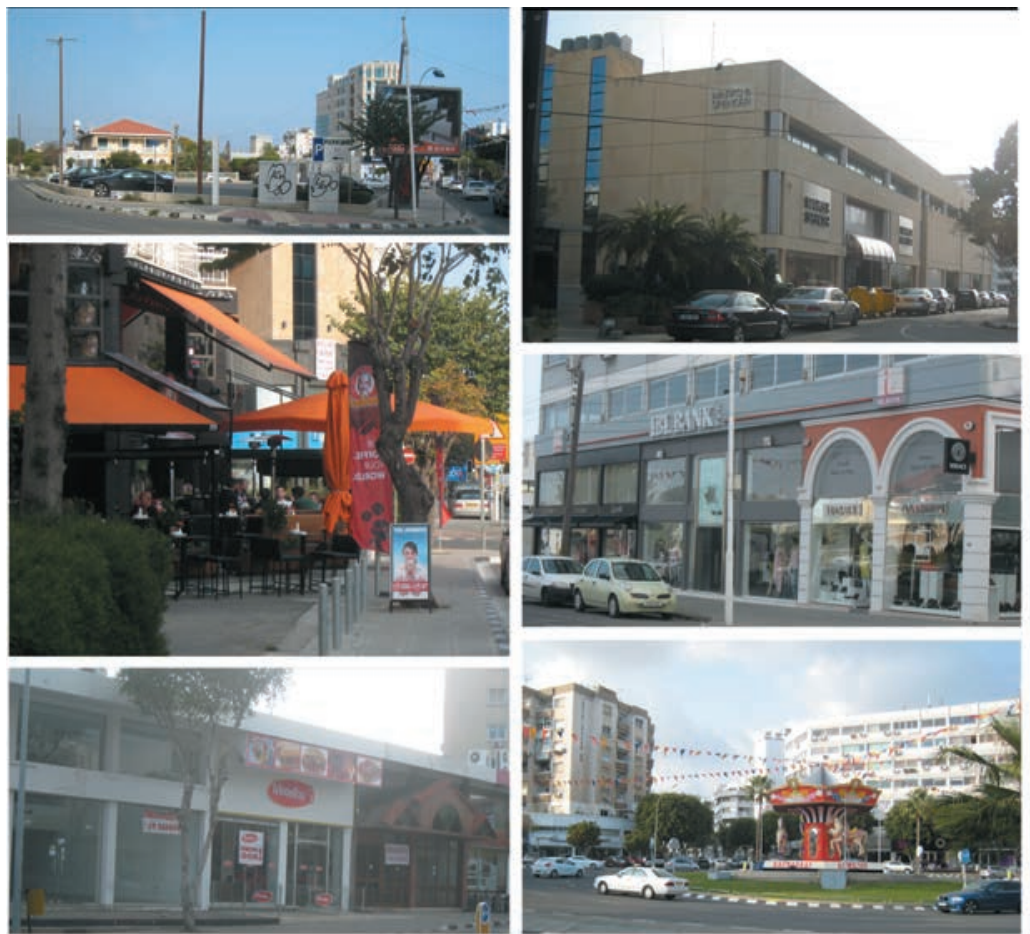

\section{Figure 4.7}

Characteristics of Makriou street, images from left to right, top to bottom: parking area along the street; the local Marks \& Spencer; outdoor café seating along the street; upmarket retailers and international banking services (Intercontinental Bank of Lebanon in this case); closed-down shops due to the economic crisis; the roundabout decorated for the upcoming carnival

Nadia Charalambous and Illaria Geddes.

are the law courts, the archaeological museum, the historical archives and the public gardens (this was the most popular area with British residents during the 1930s). The characteristics of the street are presented in Figure 4.7.

\section{Research methods}

Three sets of analyses were run for this study. The urban structure of Limassol - focusing on the two high streets - was analysed at six points in time $(1883,1933,1960,1987,2003$ and 2014); prior to 1933 the development of the city was analysed qualitatively through maps of 1849 and 1883 , as well 
as the existing literature and travellers' records from the nineteenth and early twentieth centuries. Further to the spatial analysis, a land use survey and movement observations were run in the two study areas in February 2014.

Six spatial models of Limassol were constructed using space syntax methodology. Space syntax is a method for quantitatively describing patterns of spatial layout; once the model is built, it can be analysed to provide various measures reflecting different properties of the urban configuration and of specific elements of the street networks, such as a street segment (the section of a street from junction to junction or from a bend in the street to a junction or another bend and vice versa). The most important measures of space syntax are integration, representing 'to-movement' or the accessibility of a specific element within the system, and choice, representing 'through-movement' or betweenness (the number of times a segment falls on the shortest route between all pairs of segments within a specified network distance, termed 'radius'). Both global and local measures can be calculated, the global measures taking into account all elements in the system - a city-wide level - and the local measures taking into account all elements within a given radius, such as a notionally walkable radius of around $800 \mathrm{~m}$ (here results for $400 \mathrm{~m}, 800 \mathrm{~m}$ and $1200 \mathrm{~m}$ are presented). Global measures tend to be representative of the whole-city structure and often correlate with vehicular movement; local measures tend to be representative of local neighbourhood structures within a city and often correlate with pedestrian movement (see this volume's Glossary for more information on space syntax).

The specific analysis used in this study is angular segment analysis, which takes into account the least angular deviation of each segment from all other segments (hence it takes into account the relative straightness of a route). The measure used is normalised angular choice (referred to as ' $\mathrm{NACH}$ ' in technical diagrams and 'choice' for short in the analyses presented in this chapter) - this measure was chosen because it allows for comparison between systems of different size and is thus the only reliable measure to compare a city diachronically where a city has grown significantly and the systems analysed are therefore of greatly different sizes. Furthermore, because of the mathematical way the measure of choice is normalised, it takes into account the depth of elements within the system (a proxy for integration) and so to an extent also combines a representation of to- and through-movement (see Hillier et al. 2012).

Choice values range between $\mathrm{o}$ and 2 , where values above 1.3 are considered to be in the top range of choice, and values of 1.5 or above being extremely high. All the segments in the system with values of 1.3 or above are considered to be part of the 'integration core' of the city - the global core 
when considering the whole system (the 'superstructure' of the city) or the local core when considering a specific local radius. The two cores can be matched to identify the multi-scale core of the city (Versluis 2013) - all the segments which have both the highest global and local integration values, constituting the centrality core of the city. The spatial models were drawn manually in MapInfo GIS using historical and contemporary maps as basemaps, which were geo-referenced manually using ten control points. The contemporary spatial model was constructed first by tracing onto the historical maps and then elements were removed and adjusted to construct the historical models. Some further adjustments of the historical models were also needed due to the errors caused by manual geo-referencing. The choice measures were calculated using the Depthmap Process tool in the Space Syntax extension for Maplnfo, developed and licensed by Space Syntax Ltd. $\mathrm{NACH}$ (choice) was then calculated automatically in GIS using the formula provided in Hillier et al. (2012), thematic maps were constructed and the global, local and multi-scale cores calculated and displayed in GIS using simple querying and visualisation tools.

The land use survey was run on the same day as the movement observations. Only the ground-floor land uses were recorded along the high street and in the side streets up to the first junction in each street. Digital parcel maps (digitised by T. C. Geomatics Ltd. from the cadastral maps of the Department of Lands and Surveys) were used as basemaps to record land uses. The parcels reflect land property and do not always match the building outlines and even less so any subdivision of buildings. In these cases the buildings/outlets were redrawn manually to match the observed number of outlets. Although the number of outlets recorded is accurate, and so is the analysis based on the proportion of different land uses, the maps presented in this chapter do not always accurately represent the size and outline of the buildings and outlets. As no data were available for historical land uses, thematic maps were produced by reporting the points of interest on the historical and contemporary maps and classifying them with the same categories as the contemporary land uses. These maps are by no means comprehensive, as they give us no clue as to the extent of retail, housing and businesses; however, they do give an indication of the variety of uses in each area as well as how the uses adapt through changing times.

Movement observations were run on two consecutive Mondays in February 2014 - the weather in both cases was fair and warm (around 20 degrees Celsius) during the day and fair and cool (around 12 degrees Celsius) during the evenings. Movement was recorded in ten locations along each high street and a selection of major and minor side streets by a single observer. The observation locations were placed between junctions 
and all vehicles, bicycles and pedestrians crossing an 'imaginary' line in front of the observer were recorded in five-minute slots twice during twohour periods; the observations were then processed to derive hourly rates. The observation periods included early morning (08.00-10.00), lunchtime (12.00-14.00), mid-afternoon (16.00-18.00) and evening (20.00-22.00); the categories observed were male and female adults, male and female young people (up to 25 years of age, as assessed by the observer), bicycles (including pedestrians pushing a bicycle) and total vehicles (including buses, trucks, vans, cars, motorbikes and scooters); only unaccompanied children were counted.

Beyond the methodological issues regarding the basemaps used to construct the spatial models described above, one of the main limitations to the study is the different time gaps between the models $(50,27,27,16$ and 11 years, respectively). However, the decreasing time gap between the maps is reflective of increasing rates of construction and swifter pace of change in more recent decades. Land uses are naturally bound to be changeable, and this is particularly true during recent economic upheaval. The land use picture is therefore prone to be a snapshot of a very specific point in time and likely to alter rapidly, in turn having an impact on the movement present on the high streets and the surrounding areas.

Regarding the historical land uses, these are necessarily dependent on what the maps report, which is changeable across time, especially when the maps come from different sources. Moreover, the 1960 map does not report the use of the points of interest; therefore, these were derived from a map of 1974 if the building still existed, or from the map of 1933 if the building was not present in the 1974 maps. This is of course a significant assumption, but proved the only way to produce a land use map for this period; in a few cases it was not possible to identify a use, so the building is reported on the map and classified as 'unknown'. As no map with points of interest was available for 2014, a map of 2011 (Figure 4.5) was used for comparative purposes.

Movement flows are dictated by socio-cultural patterns, day and season of observation. Though it was winter time during the observations, the weather was good for the time of year. However, it is likely that warmer weather might see higher movement flows - including more tourists, both pedestrian and vehicular - on both high streets, especially during the evening hours. This, though, is only true up to and after the very hot summers of Cyprus, when from lunchtime to the early afternoon hours most shops are closed and streets in cities are almost deserted (except for a few tourists). This is especially the case during the month of August, when movement peaks and pedestrian flows are likely to be high during the evening hours. 
The same is true for weekends, when greater numbers of people are likely to go out for shopping and meeting friends in cafés and restaurants. The picture of movement flows presented in this chapter is thus limited to a winter weekday picture - further observations during weekends and warmer seasons are planned for future research.

\section{Continuity and change}

This section presents the results of the space syntax analysis of the changing structure of the urban form as represented through space syntax normalised choice measures, used to find the multi-scale spatial core of the city. It also highlights the differences and similarities in the contemporary land use mix of the two high streets, as well as the different levels and patterns of movement which make up the social use of the two streets.

Over time the global (city-wide) integration core of the city shifts from the historical centre outwards. While in 1883 and 1933 the core comprises most of the historical centre, including the seafront - the streets of Agkyras, Agiou Andreou and Anexartisias - by 1960 the western side of the seafront is losing its importance at the city-scale and the global core includes fewer segments within the historical centre and more to its north, including much of Makariou. By 1987 the global core has shifted to the north of the historical centre, with global choice values decreasing even further between 2003 and 2014 .

Looking at the local choice at $1200 \mathrm{~m}$ radius, this changes far less over time and although choice values decrease slightly in the southern area of the city and increase in the area north of the historical centre, the difference is not significant, meaning that the development of the city to the north and the changes which have occurred over time have had only a very marginal impact on the functioning of the historical town centre at the local level.

When looking at the multi-scale analysis it is clear that the choice core of the city shifts northwards and eastwards as the global choice shifts; it becomes more scattered, shifts further towards the edge (the north side of the city) and includes more of the distant areas in the east and fewer of the areas than it used to in the west (Figure 4.8). Initially it comprises most major routes within the centre including most of the seafront - the streets of Angyras and Agiou Andreou - as well as most of Anexartisias. By 1933 the city seems to have strengthened the structure of its historical centre by having a high proportion of its global core matching the local core (33.6 per cent of the system has values of choice radius $n$ (global) and choice 1200 over 1.3, compared with 25.2 per cent in 1883). The core forms an almost 


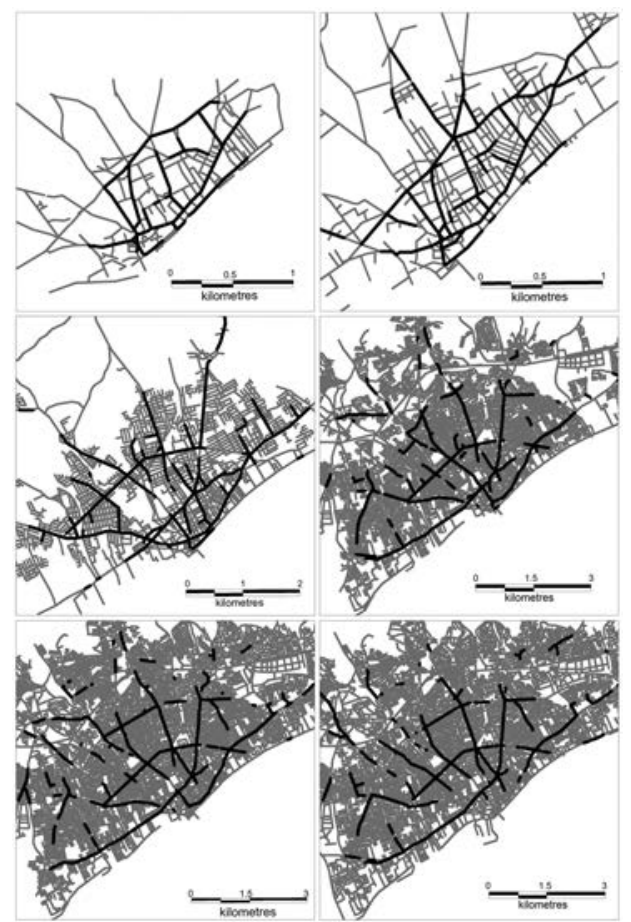

Figure 4.8

Multi-scale accessibility core of Limassol, left to right and top to bottom: 1883, 1933, 1960, 1987, 2003, 2014

Nadia Charalambous and Illaria Geddes.

continuous loop around the historical centre, but also includes much of the seafront and has started radiating out of the historical centre. However, the extent of the multi-scale core has by now decreased (22.6 per cent of the system compared to 25.2 per cent in 1883), probably due to the expansion of routes out of the centre towards the surrounding villages. While in 1933 various stretches of the seafront and the whole of Agiou Andreou and Anexartisias were part of the multi-scale core, by 1960 the seafront has decreased in importance and, though both Agiou Andreou and Anexartisias remain part of the core, fewer streets in the historical centre are part of it. At the same time the edges of the stretch of Makariou under study and in particular the roundabout at its south-eastern edge have become part of the multi-scale core, though most of the study area is still not included in this.

In the later periods the choice core becomes steadily more fragmented and focused to the north of the historical centre; this is also reflected in the decreasing proportion of the system forming the multi-scale core (27.3 per 
cent, 19.2 per cent, 15 per cent and 10.2 per cent for the town centre, and 14.7 per cent, 6.9 per cent, 6 per cent and 5 per cent for the whole city, in 1960, 1987,2003 and 2014, respectively. As we get to the present day the seafront and Agiou Andreou are no longer part of the city's multi-scale core, nor is most of the historical centre. Only the northern part of Anexartisias (the section under study) and the eastern part of Agiou Andreou remain within the core, while longer stretches of Makariou are now included.

The choice values of the two high streets show how the importance of Makariou grows both locally and globally over time; it has to be noted, however, that its global choice was at its peak in 1960 and has since decreased again, probably due to further expansion of the city towards the north and the building of the further ring-road and motorway. Anexartisias though, had fairly high global choice values from the start and still does today (the mean being always above 1.3 and nearly 1.5 in 1933), although it has gradually decreased its importance at the city-wide level.

Although Makariou has increased its local choice values, these frequently continue to fail to reach the 1.3 threshold, with the wider scale of $1200 \mathrm{~m}$ radius having higher values than the more local scale of $800 \mathrm{~m}$ radius. In contrast, despite the dramatic growth of the city and the significant changes to the surrounding spatial structure, since 1933 Anexartisias has had practically unchanged values at the local scales of $800 \mathrm{~m}$ and $1200 \mathrm{~m}$. The results are summarised in Table 4.1. An important finding from the spatial analysis is that, in both cases, the streets in the early years of their existence were more accessible at the global rather than the local level and so are characterised as carriers of through-movement. It seems that it is only when changes occurred in the surrounding and wider areas, coupled with densification of the street network over time, that they acquired their local importance. This process seems to confirm Hillier's propositions

Table 4.1 Comparison of choice values for the six study periods

\begin{tabular}{lllllll}
\hline & $\begin{array}{l}\mathbf{1 8 8 3} \\
\text { Mean }\end{array}$ & $\begin{array}{l}\mathbf{1 9 3 3} \\
\text { Mean }\end{array}$ & $\begin{array}{l}\mathbf{1 9 6 0} \\
\text { Mean }\end{array}$ & $\begin{array}{l}\mathbf{1 9 8 7} \\
\text { Mean }\end{array}$ & $\begin{array}{l}\mathbf{2 0 0 3} \\
\text { Mean }\end{array}$ & $\begin{array}{l}\mathbf{2 0 1 4} \\
\text { Mean }\end{array}$ \\
\hline Anexartisias 400m & 1.12 & 1.31 & 1.25 & 1.26 & 1.26 & 1.21 \\
\hline Makariou 400m & $n / a$ & 1.15 & 1.26 & 1.28 & 1.21 & 1.22 \\
\hline Anexartisias 800m & 1.24 & 1.35 & 1.34 & 1.36 & 1.34 & 1.34 \\
\hline Makariou 800m & $n / a$ & 1.18 & 1.25 & 1.29 & 1.25 & 1.24 \\
\hline Anexartisias 1200m & 1.33 & 1.42 & 1.41 & 1.41 & 1.39 & 1.39 \\
\hline Makariou 1200m & $n / a$ & 1.20 & 1.28 & 1.30 & 1.32 & 1.29 \\
\hline Anexartisias Global & 1.49 & 1.49 & 1.43 & 1.29 & 1.27 & 1.32 \\
\hline Makariou Global & $n / a$ & 1.22 & 1.56 & 1.53 & 1.51 & 1.51 \\
\hline
\end{tabular}


regarding spatial centrality being a temporal process, as described at the start of this chapter.

Historically, the 1883 map shows no particular landmarks on Anexartisias, its northern stretch still barely built up, with open fields and a garden featuring along the eastern side of the street. By 1933 the local hospital, the electric power station and two schools are recorded along the northern stretch, while four hotels are recorded along the southern stretch. The hospital is still recorded on the map of 1947 (Figure 4.1) but had become the Municipality Offices by 1960 . The map of 1960 does not report landmarks, although significant buildings are highlighted in black and comprise the hospital plus one other building on Anexartisias.

As shown in Figure 4.9, it is clear that in the vicinity of Anexartisias a variety of land uses had developed by 1933 with services concentrated to the south of the street; this variety is clearly retained throughout time, and by 1960 the area to the west had become a popular entertainment area and services, especially hotels and banks, have developed around the area. With the decline of cinemas in recent years, the level of land use for entertainment and service in this area had reduced by 2011 . However, the general variety in the area remains and adaptation of buildings over time is common. Examples of reuse and adaptation include a former cinema turned into a cultural centre, the hospital converted into the Municipality Offices and a school first turned into the law courts and then government offices, subsequently redeveloped as a university building, finally regaining its original educational use almost a century later.

Figure 4.10 shows that no buildings were present along the ditch and footpath of 1933. However, the map shows that two schools, three gypsum factories, a cemetery and a flour mill were in its vicinity. The Commissioner's house (already existing in 1883 and later to become the historical archives) and the public gardens found to the south of the roundabout were already present. Except for an educational complex, the area at this time is still dominated by industrial uses and public services requiring large spaces, such as the public gardens, athletic grounds and a cemetery, typically located at the edges of cities. No buildings of importance are highlighted along the street in the 1960 map. Nevertheless, a variety of land uses have developed in the area with further public and private services, educational and entertainment uses. By 1987 a concentration of educational uses has developed to the south of the street as well as a concentration of services at the western end of the area; both of these uses have continued to increase in number up to the present day. The map of 1987 by the Department of Lands and Surveys shows three banks, one hotel, one consulate, one post office box and one telephone box, along with the Municipality Offices along Anexartisias. The 


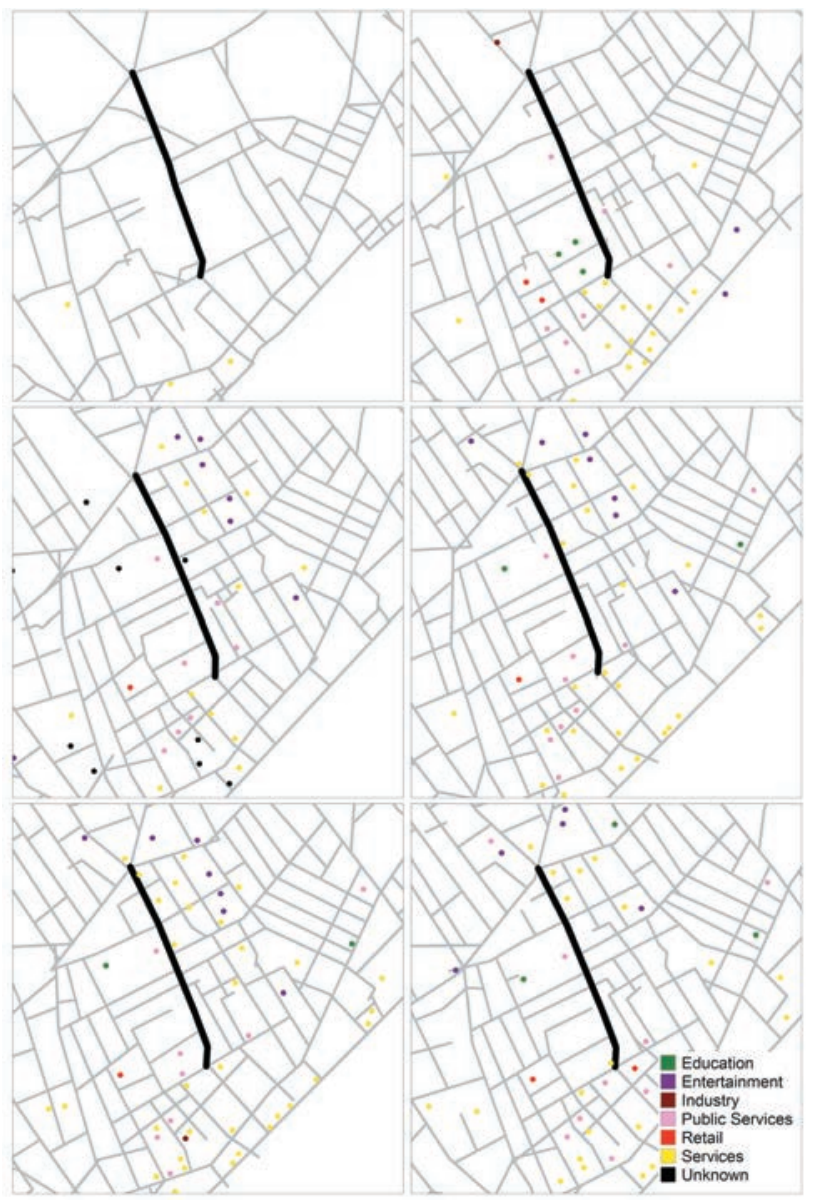

Figure 4.9

Distribution of land uses in the area of Anexartisias, left to right and top to bottom: 1883, 1933, 1960, 1987, 2003, 2014

Nadia Charalambous and Illaria Geddes.

same map shows a petrol station (still existing), a post office box and two guide posts along Makariou, as well as three banks around the roundabout and a cinema at the western junction with Agias Zonis. By 2003 three banks and a hotel were present on Anexartisias, uses which had by now given way to retail and catering; at this time the cinema was still present on Makariou, but was later converted to retail use.

The contemporary land use analysis shows that the two high streets now have a very similar make-up despite their different spatial characteristics: they are both dominated by retail outlets, which make up more than 


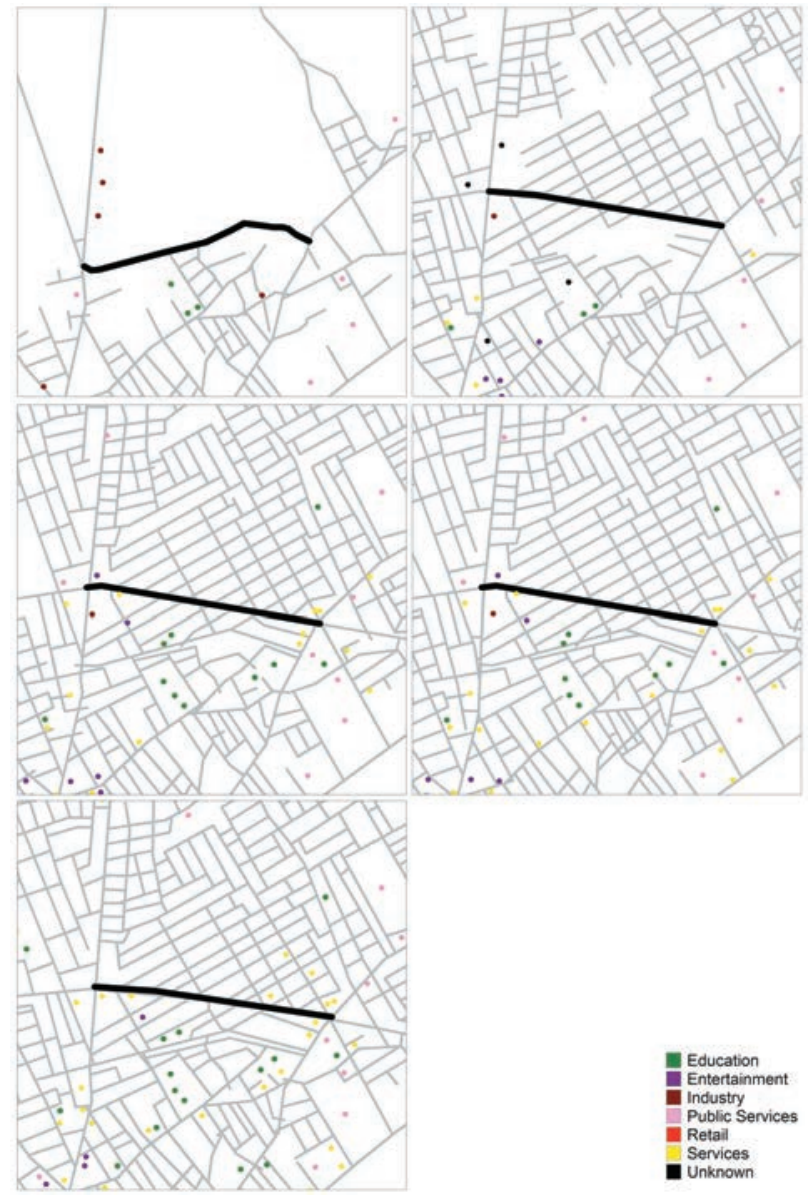

Figure 4.10

Distribution of land uses in the area of Makariou, left to right and top to bottom: 1933, 1960, 1987, 2003, 2014

Nadia Charalambous and Illaria Geddes.

half of the land uses in the surveyed areas. The main difference between the two is that Makariou has a greater proportion of services, while Anexartisias provides more catering outlets. Both high streets have suffered significantly from the economic crisis, with many shops, bars and restaurants having closed since March 2013 - they seem to have suffered almost equally if one uses the proportion of empty outlets as an indicator ( 11 per cent of commercial properties on Anexartisias are empty, compared with 12 per cent on Makariou). Figure 4.11 shows the proportion of each type of land use in the surveyed areas. 

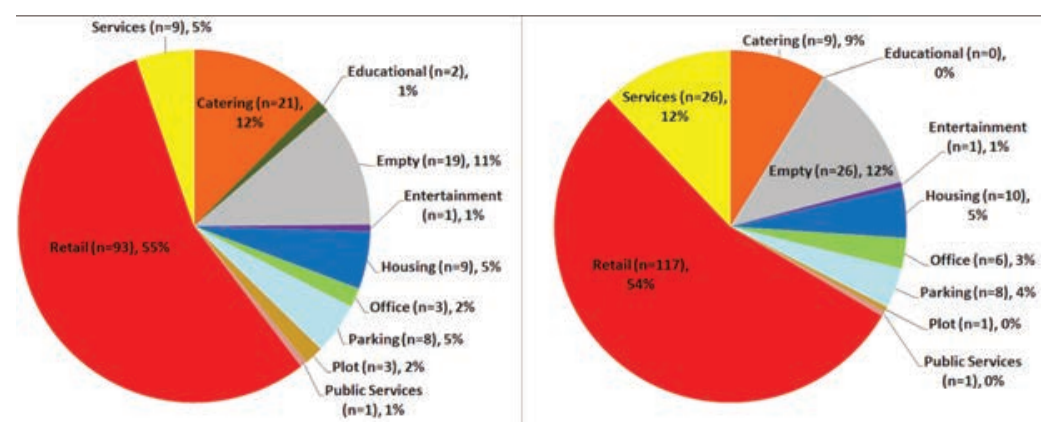

Figure 4.11

Proportion of land uses on Anexartisias (left) and Makariou (right)

Nadia Charalambous and Illaria Geddes.

Regarding the distribution of land use, there is not much difference between the two high streets. In both cases uses are mixed throughout the surveyed areas, with no particular concentration of one use or another in one specific area. However, it can also be noted that in both cases services tend to concentrate towards the edges of the high streets and in the side streets, particularly in the case of Anexartisias. Empty outlets are also more common towards the edges, although they can be found towards the middle of the streets. Dwellings are found almost exclusively on the side streets - only one case was found on the high street on Makariou (a large detached home from the late 1940s, dating from when the street was built). One main difference between the two streets is that parking areas can be found on Makariou, while in the case of Anexartisias parking is located on the side streets. The distribution of land uses is shown in Figure 4.12.

The analysis of pedestrian and vehicular movement reveals that pedestrian flows are generally very low and vehicular flows very high (Figure 4.9). Pedestrian movement levels were higher on Anexartisias, reaching almost double the number of pedestrians per hour in comparison to Makariou; in both cases peak pedestrian movements were found at lunchtime (12.00-14.00). Regarding vehicular movement, levels were higher on Makariou, with the peak found at lunchtime, although the difference compared to the afternoon rush hour was not great (less than 100 vehicles per hour). On Anexartisias the vehicular movement peak was during the afternoon rush hour (16.00-18.00), with a substantial increase when compared to the rest of the day. Figure 4.13 shows the average pedestrian and vehicular flows for the surveyed areas.

Bicycle use was very low, reaching 48 bicycles per hour in one location during the afternoon rush hour, but in most cases comprising between 0 and 24 bicycles per hour. The proportion of young people was much higher 


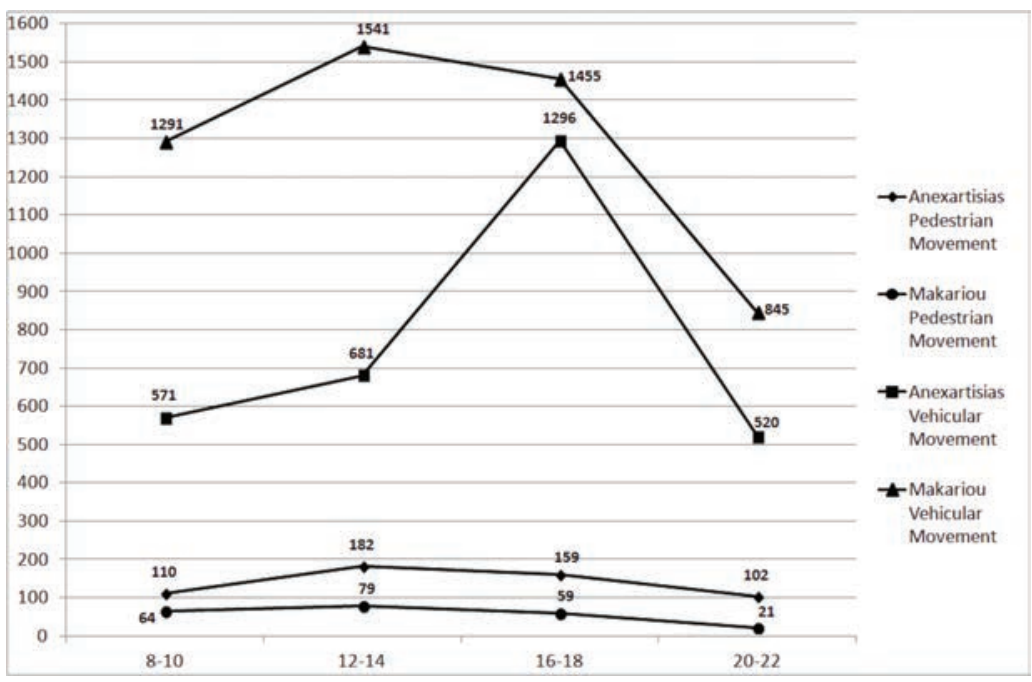

Figure 4.12

Average pedestrian and vehicular movement per hour in the surveyed areas Nadia Charalambous and Illaria Geddes.

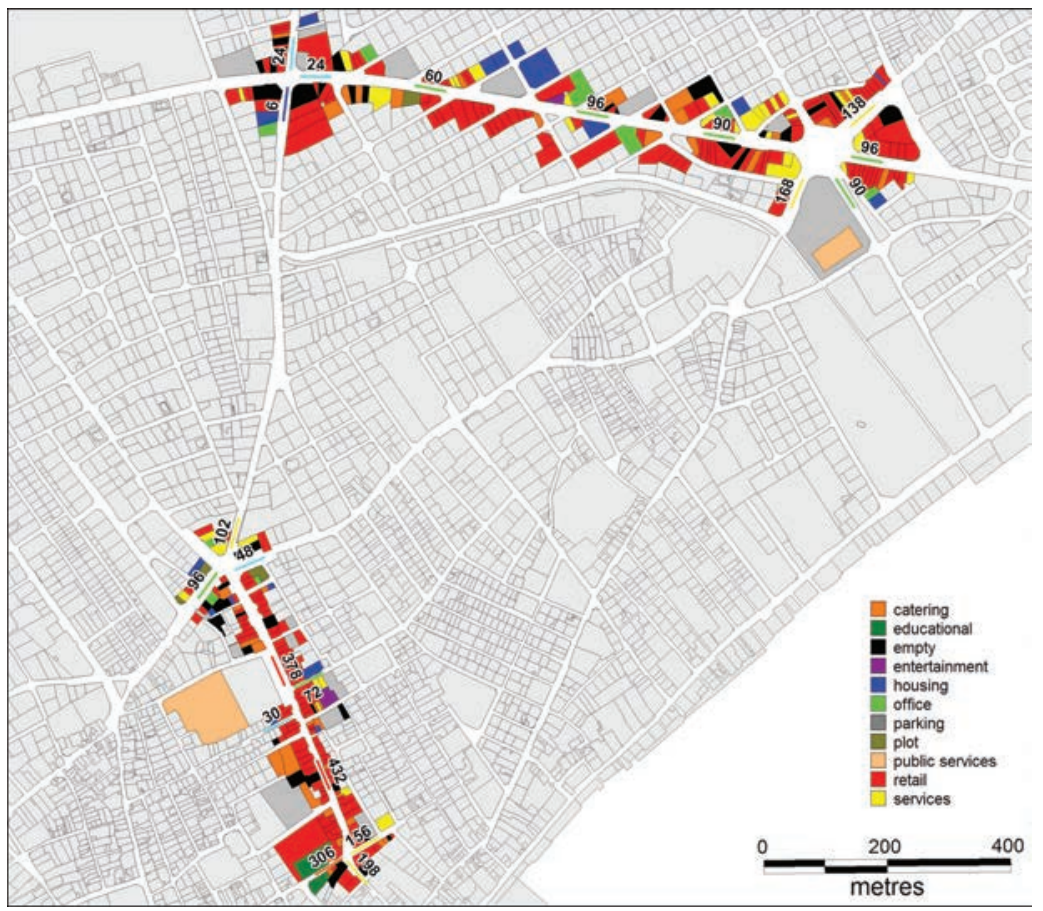

Figure 4.13

Distribution of land uses and pedestrian movement peak (12:00-14:00) on the two high streets, Makariou at the top, Anexartisias at the bottom Nadia Charalambous and Illaria Geddes. 
on Anexartisias, possibly due to the presence of the university campus nearby, while Makariou is located within the main business district and thus has a high number of offices and corporate companies in its vicinity. As shown in Figure 4.13, in the case of Anexartisias (bottom of the map) pedestrian movement tends to concentrate on the high street itself and to a certain extent on the southern edge nearer to the university and to the waterfront. On Makariou (top of the map) pedestrian movement focuses around the roundabout at it south-eastern edge, nearest to the courts of law, the public gardens and the archaeological museum. While on Anexartisias movement is fairly evenly spread out, on Makariou pedestrian rates tend to progressively decrease as one moves farther away from the roundabout, with the exception of the evening hours during which pedestrian numbers are slightly higher along the high street itself.

Vehicular flows tend to concentrate on the northern side of Anexartisias where the high street joins four other major roads. However, during the afternoon rush hour and during the evening vehicular flows are more evenly spread out and rates become significantly increased on the high street itself during the afternoon rush hour. On Makariou vehicular flows are more evenly spread out but tend to be slightly greater on the high street, in particular during the evening hours when rates around the roundabout on its south-eastern edge and at the junction on its north-western edge drop to a greater extent than on the high street itself.

\section{Shifting centrality}

This analysis has shown how in the changing context of Limassol's urban growth its integration core shifted towards the edge of the old city and then farther out into the contemporary city. The shift in centrality is mostly due to changes in the global choice values. The global integration core of the city shifted from the historical centre outwards: initially it comprised all major routes within the centre including the whole of the seafront, the street of Agiou Andreou and the whole of Anexartisias. By 1960 the western side of the seafront was losing its importance at the city-scale, and the global core included fewer segments within the historical centre and more to its north, including much of Makariou. Centrality has since shifted towards the north and the east, in particular the 'superstructure' has moved towards the former edge of the city centre, now a central area itself. At present the global core barely includes the northern stretch of Anexartisias, which has moved farther to the north and the west and comprises the whole of Makariou. 
The global-spatial properties that once belonged to Anexartisias were appropriated by Makariou, which became a new high street with some characteristics different from its older counterpart, for example the higher proportion of services it offers, and its higher vehicular and lower pedestrian flows. Over time Makariou has become a local high street over time with as great a variety of land uses as Anexartisias: it is not just a ring-road any longer, possibly due to its location near to historically popular areas with various uses in the vicinity, the fact that it was developed along an historic element of the city (the ditch/footpath alignment) and its significantly high choice value (reaching and at times higher than 1.3) at the medium-local scale of $1200 \mathrm{~m}$. This is probably also due to further expansion of the city to the north and the east, grid intensification in the surrounding areas and its position in the wider urban network that enabled its development as a successful high street at the edge of the historical core. As Vaughan et al. (2010b) point out, 'live' suburban centres are characterised by a relation to the wider active centre in terms of choice and the inter-relationship between a variety of activities fostered by mixed land use.

The local choice values have changed far less over time, with the historical centre, in particular Anexartisias, retaining its local historical values at the $800 \mathrm{~m}$ and $1200 \mathrm{~m}$ radii, while Makariou has increased its values at these radii, though not quite reaching the same values as Anexartisias. It is perhaps to be expected that local choice values of the historical town centre would change little after a certain time, as development and redevelopment would occur mostly in areas relatively far from it. This, however, is unlikely to be the cause given that many changes occurred within and near the town centre between 1933 and 1960. Moreover, a major development recently occurred within the historical town centre with the construction of the new marina at its western edge, which does not seem to have had a measurable impact on Anexartisias' local choice values. This raises the issue as to whether there is such a thing as 'spatial memory', whether once an element of the system has established a certain status, or perhaps an ideal level in the local spatial hierarchy, it then develops a resilience - an ability to retain some of its spatial properties in the face of significant growth and change. Such a concept could be key to further an understanding of urban development and of how high streets can have the ability to sustain a mixture of land uses and movement patterns through time.

Despite the differences between pedestrian and vehicular movement flows, both the studied cases are popular high streets with a very similar land use make-up. This may be related to the fact that Limassol has a car-based society and Makariou can function as a high street despite low levels of pedestrian movement. Again, despite lower levels of pedestrian movement, 
Makariou has not, to the present day, suffered much more than Anexartisias from the economic crisis.

As centrality shifted with city growth and planning developed to suit the post-war car-based society, Anexartisias retained high street characteristics typical of its former spatial properties, more suited to pedestrian use, while Makariou developed first to meet its requirements as a vehicular route improving long-distance connectivity within and through the city and later seems to have adapted to suit more diverse modes of use as densification made it part of a local network, and its requirements for through-movement decreased with the construction of the outer ring-road and motorway.

Historical spatial properties played an important part in the development of the function and role of the two high streets and despite the spatial changes, Anexartisias has retained the characteristics and functions of a high street, competing with and complementing its younger counterpart. The multiplicity of activities observed around the area may be a contributory factor in its ability to remain a lively area and to adapt to socio-economic changes over time.

\section{Conclusion}

This chapter has presented the findings of an exploration of the evolution of the spatial structure of Limassol's historic street network. More specifically, it focused on the spatial properties of Anexartisias, the traditional high street in the historic core of the city of Limassol, and a stretch of Makariou, the first inner ring-road of the city built just after the Second World War; once the edge of the city and now a central area, Makariou marks the boundary between the old historic core and the contemporary post-war city.

The historical analysis of the whole city has provided a detailed understanding of various processes that seem to contribute to the formation and development of the high streets, not just from a spatial point of view, but also in the context of demographic and social changes, highlighting how the commercial core of the city shifted: from the west where the ruling and trading Ottoman community lived; and to the east and north where the wealthier Greek community resided after the end of Ottoman rule. In subsequent years the first stretch of Makariou developed along a pre-existing physical alignment, supporting a then-suburban area where the newly arrived British community settled, and the formal government offices of the Commissioner's House were established. At the same time, the major services and infrastructure of the city (the hospital, the electric power station, 
the market and various schools) were located in the geographical centre of the city, along Anexartisias and its surrounding area.

The evolution of the city of Limassol and the tension between the newly developed areas and the historical core clearly affected the transformation of the historic centre and the traditional high street within it. In the context of urban growth, a shifting of centres was observed, indicating the tendency of local centrality to shift from traditional centres towards new areas where peripheral commercial streets emerge in relatively highly accessible locations.

Despite differences in the spatial morphology and choice values of the two high streets at various scales, the findings have revealed a similar process in their development with an initial role as through-movement carriers developing into important local destinations. This adaptability took place both through spatial changes and as a result of the provision, retention and adaptation of historical land uses. While spatial changes have occurred, after a time of adaptation both streets seem to have stabilised through time, fixing their choice values at certain medium-local scales, imbuing them with a kind of 'spatial memory' of their former local and global roles, as well as perhaps providing them with a certain level of resilience to changes both in their vicinity and at a wider whole-city scale. The maintenance of a variety of land use patterns over time seems to affect street vitality, indicating that the interaction between spatial structures and land use patterns facilitates social and economic development, which is important in understanding urban evolution.

Despite the perception that lively urban centres depend on commercial activities, the analysis has shown that the spatial configuration of the two high streets in the context of the wider area (high choice values at various scales, supporting a mixture of movement through and to the area) is a key factor in their ability to support a mixture of land uses through time, thus maintaining their vitality. This finding confirms research by Vaughan et al. (2010b) and Dhanani (in this volume) on the urban evolution of London over a similar historical period, and suggests that there are generic temporal processes occurring in both cases - and potentially elsewhere.

The value of Limassol as a case study is related to wider contemporary urban development issues around fast growth characterised by extensive and superficially inchoate sprawl and concurrent multiple developments, in particular in port cities of the Eastern Mediterranean area. Many such port cities have recently undergone rapid growth and redevelopment of their waterfront areas, turning former traditional ports into targets for urban renewal programmes; for example, the redevelopment of port areas and warehouses at the Ladadika quarter in Thessaloniki, the Solidere Project in Beirut and modern development projects in the former port areas of the 
Golden Horn and the Bosporus in Istanbul, to name just a few. This 'renaissance' of port cities and recent re-emergence of cultural pluralism in many parts of the Mediterranean calls for a careful analysis of how such changes to the urban space impact on the city and its society.

The outcomes of the methodology proposed in this chapter not only highlight the importance of considering historical-spatial properties and land uses when analysing contemporary space use in these cities, but also points to the relevance of diachronic analysis for understanding and assessing how streets at the edges of cities may have the potential to transform into vibrant central high streets through the process of adaptive centrality. It demonstrates that it is not just centrality that allows for transformations to take place but the adaptability of the network and the built form itself. Furthermore, it allows the exploration of the dimension of time and the role it plays in the way the street network and the built form itself react to change and development; in other words, the city's capacity for resilience, in particular the resilience of its high streets, and their ability to recover and accommodate change over time. 


\title{
Chapter 5 \\ Street Quality, Street Life, Street Centrality
}

\author{
Adel M. Remali, Sergio Porta, Ombretta Romice \\ and Huyam Abudib
}

\section{Introduction}

This chapter contributes to the debate on the role of urban form, and public space in particular, in meeting societal needs, a topic that has gained increasing attention in the discipline of urban design (Carmona 2014) as well as in the wider global debate on urban management and regeneration (Habitat 2013). In the UK, this debate has recently gained momentum in the context of a reconsideration of the social and economic potential of high streets in secondary urban and peri-urban centres (Vaughan et al. 2009b; Carmona 2014). In the Islamic urban context, this debate touches on the overarching cultural conflict between the global trends of Westernization and the preservation of local identity in the 'home environment' (Al-Naim 2006). In this sense, the Islamic versus Western dichotomy can be reinterpreted more appropriately as a deeper trans-cultural conflict between 'traditional' and 'modern', which operates equally in the Western and increasingly - the Islamic context, and indeed in other regions of the developing Global South. Accordingly, traditional urban and street structures are under a new wave of scrutiny in terms of their ability to 'make places' that better react to external challenges and are resilient - or adaptable - over time. This adaptability is bound in a higher capacity to support community identity, equity, accessibility to urban resources and quality of life. This shift has been described as a 'counter-revolution' against the modernist age, or 'one of the most significant reversals in urban design history' (Marshall 2005: 9). 
Other chapters in this book take account of the position of the high street within the wider street network in considering its capacity to adapt to change. In a similar fashion, we compare the street built form and network characteristics for three sample high streets in central Tripoli, Libya, but we focus on the scale of street characteristics, considering whether differing spatial/morphological starting points have influenced the subsequent adaptation of the street. The chapter looks into how urban areas generated under different historical conditions have inherited spatial configurations which exhibit not only a peculiar environmental quality, but also, and accordingly, peculiar patterns of social activities and behaviours.

The three case studies in this chapter span a period of time long enough to cover premodern as well as post-war developments. In so doing, we explore how the radical shift in city production which has accompanied modernisation across this period has contributed to societal impacts whose signature is recognisable all over the world.

Centrality, a product of the street network's configuration, has been identified as a significant driver of the ability of cities to support the development of diversity and intensity of city uses and users over time, thus reinforcing self-surveillance and community capacity. A fundamental feature in urban geography and urban systems analysis, centrality was developed as an urban design modelling tool by Bill Hillier (1996) from the mid-1980s. More recently, Porta et al. (2006) have explored the same subject, drawing on studies of the physics of complex networks, and ultimately from a grounding in post-war structural sociology. The two models, respectively space syntax and Multiple Centrality Assessment, share the same philosophy and serve the same purposes within the field of urban design. However, while the former is grounded in a representation of the street system based on visibility and accessibility, using sightlines and step-distance measurements, the latter utilises a conventional street network representation which is 'weighted by centrality values and economic activities' (Porta et al. 2012: 6). Despite its significance, centrality is just one side of the coin: local aspects related to the architecture of the street front, namely diversity, permeability and transparency of the building façade, have been extensively acknowledged as crucial components of street safety and sociability (Jacobs 1961; Appleyard 1969; Whyte 1980; Porta and Renne 2005). It is important to note that since the early 1960 s a series of studies has dealt with the observation and measurement of social life in cities, informing studies of urban regeneration and design (Whyte 1980; Project for Public Spaces 2000; Gehl and Svarre 2013). Notably Hillier (2004) has located 'street constitution' as a measurable element relating to the intervisibility of building entrances with street users. This conception is an important aspect of our own study. 
In this study we explore the relationship between street front quality and social life in streets, as characterised in streets with different degrees of centrality in the contemporary city centre of Tripoli. In Section II we briefly present the method of research for the measurements of street centrality, street front quality and street life. In Section III we present the three case studies and the selection criteria utilised. Section IV presents the findings, and subsequently Section $V$ sums up the potentials of street centrality and quality within the city centre of Tripoli and their contribution to street life in order to develop a more sustainable planning framework conducive to a different and more historically aware urban future in Libya.

\section{Research methods}

This chapter investigates three character areas of Tripoli city centre identified according to the distinctive historical origin of their urban form: the Old Town, the Italian Quarter and the Garden City. Their different historical origins are largely still reflected in the structure and character of their current urban form, which is illustrated in Section III. Within each of the three character areas, streets are classified on the basis of their degree of centrality in the broader urban network. Secondly, one $400 \mathrm{~m} \times 400 \mathrm{~m}$ edged, squared sample is extracted in each character area such that the centre of the sample lies on a highly central street; the three $400 \mathrm{~m} \times 400 \mathrm{~m}$ case studies are therefore identified. Thirdly, the street front quality of all streets is measured for each case. Finally, a direct survey of human activities is conducted on a sample of twenty-five streets over the three case studies.

\section{Measuring street centrality}

Since the mid-1980s street centrality has grown continuously as a subject for study in urban design (Hillier and Hanson 1984; Hillier 1996; Marshall 2005; Porta et al. 2010) and the science of complex networks (Barthelemy 2011). Central streets are identified as significant features in the evolution of the urban fabric (Conzen 1960; Caniggia and Maffei 2001), directly affecting in many ways its liveability (Jacobs 1961; Jacobs 1993; Newman and Kenworthy 1999).

Multiple Centrality Assessment (MCA) is a computer-operated procedure that allows the mapping and calculation of the centrality of street networks, where the streets are represented as network links, and the intersections between them as nodes. It applies a set of methods drawn from research into the physics of complex networks in nature, society, culture 
and technology to the analysis of street networks. MCA has re-interpreted urban street systems as a special class of complex networks, where centrality goes beyond proximity, dealing with how people experience and navigate the system of streets and intersections. Centrality can be measured according to different indices, for example 'straightness', 'closeness' and 'betweenness'; in this research we have only utilised betweenness centrality, which is effectively the same as the measure of 'choice' used in space syntax (see the Glossary). The betweenness centrality of an intersection is calculated as the number of shortest paths connecting all pairs of intersections in the system. The betweenness of a street is then measured as the average betweenness of its two defining intersections (namely, the intersections at either end of each of the streets). As such, the betweenness of a street expresses the general likelihood that movement over the network as a whole 'chooses' that street while going from any origin to any destination. Boyd (2010) states that places with higher betweenness are more likely to evolve into hubs of denser and more diverse economic and human activities. Therefore, routes with high 'betweenness' have the potential to support the active presence of people and the resultant urban economy (Porta et al. 2006).

\section{Measuring street front quality}

The space between the building façade and the public right-of-way is an essential part of the image and the character of a street, and is dependent on the positive interaction between ground-floor uses and the public pavement. Urban street fronts have to be integrated with their surrounding context in order to enhance the quality of streetscapes, where the relationship between a street and its buildings plays a major role in fulfilling and achieving this task. Rich, open and detailed building frontages are exciting and interesting for walkers, as they provide places where they can enjoy a complex sensorial experience (Gehl 2010). However, the extent to which these qualities of street fronts actually correspond to the social success of places remains more a matter of personal subjectivity than established, evidence-based knowledge. There is a clear need to extend the available evidence base on issues such as, for example, whether these patterns of correspondence would be culturally and geographically specific.

In this chapter, within the three selected case studies, main streets 'high centrality', connecting streets 'medium centrality' and cul-de-sacs 'low centrality' are our focus. Street fronts are identified and their metric lengths are measured. A quantitative analysis of the distribution of street fronts across the three types is undertaken in order to provide insight 
into the impact of different street network models on the structure of the urban form.

In each case study, a quality mark is attributed directly in the field, by visual survey, to the façade at ground floor only and on both sides of the street. The research team inspected $50 \mathrm{~m}$ of street at a time, using five indicators: number of visible units accessible from the street $(\mathrm{S})$; visible diversity of function (F); openness to the public street $(\mathrm{O})$; level of maintenance (M); and level of detail and quality of materials (D). Scores were assigned separately for the five indicators, ranging from 1 (lowest) to 7 (highest); street fronts with no building alignment are attributed a value of 1 (lowest) across all indicators. The subjective nature of this process was mitigated by preliminary discussion with the field surveyor who was additionally provided with a handbook that included a comprehensive atlas of exemplar cases in every category of quality for all types of street. Following Gehl $(1994,2002)$ and Hershberger (1969), the total of the values attributed to a homogeneous single street section for all five indicators generates a compound index of quality that we term Street Front Quality. This index ranges from a minimum of five (all five indicators are equal to one) to a maximum of thirty-five (all are equal to seven), and is classified in a six grade scale from 'unattractive' (values from five to ten) to 'exciting' (values from thirty-one to thirty-five). The Street Front Quality of a homogeneous single street section is then weighted by section length to determine a quality total for whole streets (calculated on both sides) and ultimately for classes of streets, for example all main streets. The idea of an 'amount' of quality that constitutes the contribution of whole streets to the overall quality of the place, independent of exceptional landmark buildings, comes from the tradition of evaluative image assessment proposed by Gehl (1994, 2002, 2010) and Nasar (1998). In the following sections we define and discuss the indicators used to assess the quality of street fronts, and provide a short link to their research background.

According to Gehl (1987), street frontages become more interesting and attractive when they exhibit a relatively high number of units with many entrances. More doors mean more visibility, and greater likely interaction between street and internal space (Gehl 2004). In addition, the number of units visible at eye level contributes to the density of activities taking place on the street and gives a good proxy for the 'granularity' of the streetscape (and the urban fabric alike).

Number of Units (S) is defined as the number of units that are visible and accessible from the street. A unit is defined as a functionally homogeneous and autonomous part of the building that is accessible from the street, for example a residential apartment, a shop or an independent storage 
space. Scores are assigned a mark between 1 and 7 according to the number of units per 100m: $0,1-9,10-14,15-19$ and 20 or more, respectively.

Since Jane Jacobs (1961) stressed the importance of diversity as a contributor to successful place-making, this factor has been extensively explored at various scales. At the street scale, diversity of land uses, particularly at the ground floor, significantly influences the ability of a place to attract a diverse population of city users and permanent inhabitants, thus expanding social control and enhancing the dynamics of synergy and innovation between people and ventures. Because of the varied nature of mixed-use environments, people tend to participate in community life by socialising at the edges of the pavement instead of just passing through to reach their destinations. In short, following Potschin (2009), enhancing the mixture of land uses at street level improves the quality of city life.

Diversity of Functions ( $F$ ) is defined as the number of different land uses that are visible from the street. Scores are assigned a mark of 1, 2, 3, 5 and 7 according to the number of uses per 10om: 1, 2, 3-4, 5-6 and 7 or more, respectively.

The 'transparency' of the street edge is regarded as conducive to more social interaction in a public space. An appropriate level of physical and visual openness between the inner spaces of buildings and the public realm contributes to a thriving social life and to safer outdoor spaces. Visual contact between indoor and outdoor spaces also improves the ability to navigate the street network and enriches movement behaviour in transitional spaces (Gibson 1950; Chang 2002).

Openness $(\mathrm{O})$ is defined as the percentage of windows (or shop windows) that are visible from the street, measured in metric length against the total length of the homogeneous street section. It should be noted that if windows are concealed from the street by, for example, walls or hedges or any other visual barrier, they are not taken into account. Scores are assigned a mark of 1, 2, 3, 5 and 7 according to the number of windows per 10om: o-19\%, 20-39\%, 40-59\%, 60-79\% and 80-100\%, respectively.

The conditions of preservation and maintenance of buildings, and the cleanliness and sense of care that they convey to the visitor and the resident alike, have been identified as the most significant factors in revealing and generating appreciation of place, a sense of belonging and street liveability (Francescato 1979; Darke 1982; Marcus and Sarkissian 1986; Kaplan et al. 1998). The visual measure of maintenance plays a pivotal role in shaping the patterns of integration between the spatial and social dimension of places (Giuliani and Wiesenfeld 2003).

Maintenance $(\mathrm{M})$ is defined as the level of maintenance of the façade's structures, materials and finish. Scores are assigned a mark of 1 , 
2, 3, 5 and 7 according to the level of maintenance: very bad, bad, average, good and very good, respectively.

Assessing the quality of street fronts is essentially related to the process of visual perception, which deals with the visual stimuli generated by the articulation, detailing and finishing of its architectural elements. It is also affected by physiological processes based on biological principles inherent to human beings (Weber 1995). Visual perception is dominant when compared to the other senses of hearing, smell and touch (Gehl 2010). The pattern, rhythm and proportion of elevations confer a degree of harmony to the edges of the public domain, where their materials, colours and details play a part in increasing and enriching the quality of the public space at pedestrian eye level (Bentley et al. 1985; Jacobs 1993; Davies 2007).

Details and Materials (D) is defined as the level of quality and intensity of architectural details and building materials. Scores are assigned a mark of 1, 2, 3, 5 and 7 according to the level of detail: very poor, poor, average, rich and very rich, respectively.

\section{Measuring street life}

In the street life survey we first simplify the Street Front Quality classification into: 'good', 'average' and 'poor'. The 'good' category includes all streets whose Street Front Quality was either 'exciting', 'attractive' or 'pleasant'; the 'average' category includes those previously classified as 'average'; and the 'poor' category includes those previously classified as 'dull' or 'unattractive'. We then conduct a survey of human activities in a total of twenty-five streets in the three selected cases: in the Old Town and Italian Quarter we pick up three 'good' (one main street, one connector and one cul-de-sac), three 'average' (same) and three 'poor' (same) streets (nine streets in each case), whilst in Garden City we can only identify two 'good' (one main street and one connector), two 'average' (one main street and one connector) and three 'poor' (one main street, one connector and one cul-de-sac) streets (seven streets in total because no 'good'/'average' streets are present in Garden City's cul-de-sacs). In every selected street the survey is conducted visually by establishing a survey point roughly in the middle of the street ('gate') and then proceeding in two different ways: walking activities are surveyed just by counting how many people pass through the gate in one hour in both directions; sitting and standing activities are surveyed by locating six researchers at strategic points along two successive $25 \mathrm{~m}$ sections of the street before the gate, and two corresponding sections after the gate, the counts being undertaken 
at the same time for one hour. Surveys are produced at both peak time, 11:00-14:00 and 18:00-20:00, and off-peak time, 08:00-10:00, 15:00-17:00 and 21:00-23:00.

The survey accounts for the number of people engaged in the activities of walking, standing and sitting, and distinguishing the nature of those activities based on Jan Gehl's (1987) terminology: necessary, optional or social. Necessary activities are undertaken individually by necessity in a certain space, typically including, for example, walking to the next rail station, shopping in a large store or fixing a lamppost. Optional activities include all those undertaken individually by choice in a specific place, for example having a rest on a bench, indulging in conversation with friends over a coffee, reading in a park, strolling around and walking the dog. Social activities are undertaken in a way that implies a significant amount of contact and exchange with others, either in a pair, trio or larger group. The quality of the public space has been found to exert a strong influence on optional activities, while having a minor influence on necessary activities, which by definition would be conducted in that place anyway (Whyte 1980, 1988; Gehl 1994; 2010; Marcus and Francis 1998).

- Walking is measured in people/hour: the number of people passing through the survey 'gate'.

- Standing is measured in people/hour: the number of people standing within the 10om street, centred on the 'gate'.

- Sitting is measured in people/hour: the number of people sitting within the 10om street, centred on the 'gate'.

\section{The case studies}

\section{Tripoli's districts}

Tripoli's city centre is made up of three distinct parts (Figure 5.1). The Old Town, originally established under the Roman Empire in $111 \mathrm{CE}$ and later transformed into an Islamic city after the Arab Muslims came to Libya in $642 \mathrm{CE}$, is located at the heart of the city and is characterised by the strong impact of Islamic spatial, organisational and formal principles. The Italian Quarter, developed after Italy invaded Libya in 1911, is located south and east of the Old Town and dominates most of the city centre with a colonial urban form and organisational distributional pattern. Finally, the Garden City, which was developed during the British military administration after the Second World War according to principles reminiscent of Ebenezer Howard, is at the southern fringe of the city centre. 


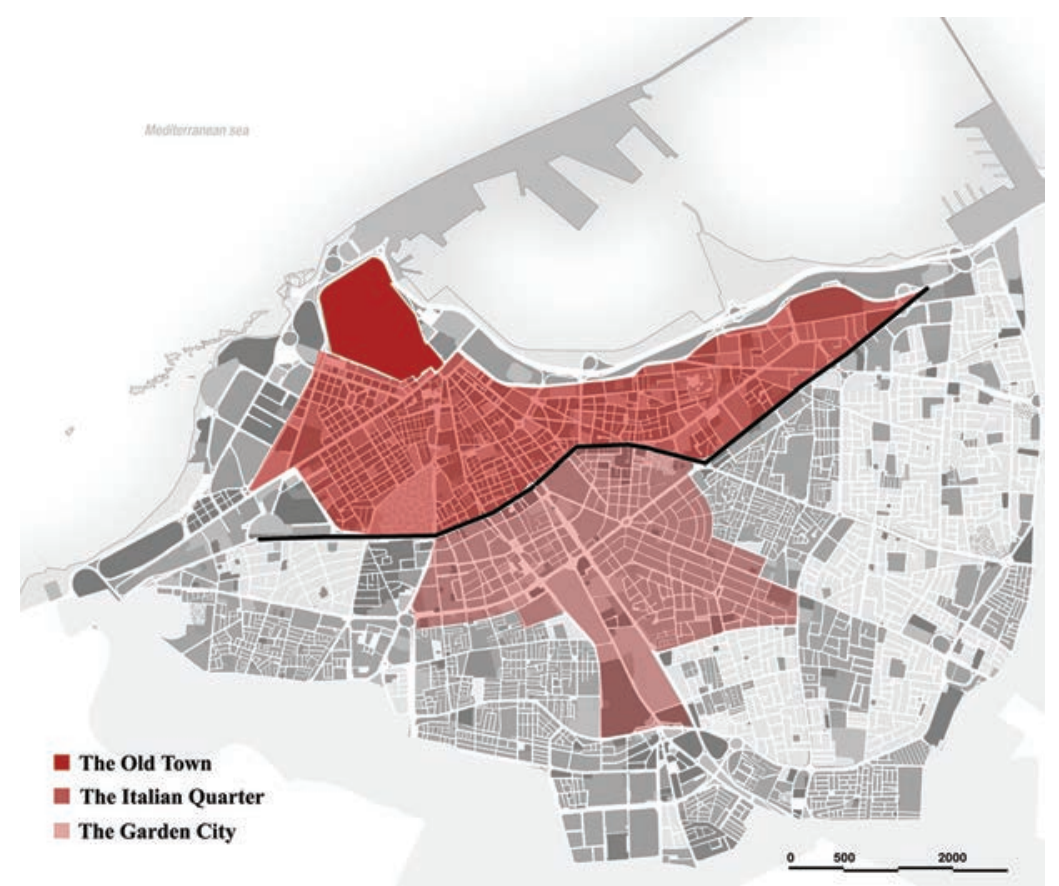

Figure 5.1

The three character areas in Tripoli's city centre: Old Town, Italian Quarter and Garden City

Images Adel Remali.

The Old Town is the main part of the city centre of Tripoli (see Figures $5.5 \mathrm{a}-\mathrm{d}$ ). This traditional urban fabric has witnessed the passage of several civilisations over time, including Phoenician, Roman, Carthaginian and Muslim, all of which left the city with the hallmark of its own physical characteristics. For hundreds of years, the town evolved incrementally to contain many residential quarters, with a single commercial area that still functions today as a commercial hub, not only at the urban scale but for the whole western region of Libya. The Old Town is typical of a traditional Islamic city where a large mixture of homogenous low-rise courtyard buildings form a hierarchical network of main streets, alleyways or connecting streets and cul-de-sacs. Here the main commercial activities take place within one central area: local non-residential land uses such as masjids (local mosques), shops and bakeries generally sit along the most central thoroughfares and alleyways, while land uses with lower movement sensitivity, such as private houses, are located on less central streets or cul-desacs. The Old Town is characterised by a modified orthogonal street layout, 
which is inherited from the ancient Roman routes organised around key locations and attractions. The traditional built environment is constructed at a pedestrian scale, which results in an extremely dense townscape with a high degree of complexity.

The Italian Quarter largely owes its spatial structure to the metropolitan masterplan that was designed by Italian architects during the colonial period in the 1920 s and 1930s. It is regarded as the most prominent area of Tripoli city centre today, accommodating a wide variety of services such as public institutions, banks, commercial stores and leisure facilities. Accordingly, a mixed land use is dominant in the area: here the residential units are normally accommodated on the upper floors, while the ground floor is occupied by commercial and leisure activities directly facing the main streets. Purely residential or manufacturing activities are located along less central streets. Streets and squares in the Italian Quarter are more active than those in the Old Town: commercial activities are located at the ground floor on both sides of the street and some are sheltered by arcades. The Italian Quarter is based on the masterplan of Italian engineer Luigi Luiggi a few months after the military invasion in 1911 (McLaren 2006). Essentially, the design of the quarter was influenced by the need to serve the requirements of pedestrians and vehicles. Its street network structure accommodates the most accessible thoroughfares within the city centre of Tripoli, successfully achieving a usable network. Since most of the properties on the ground floor are occupied by commercial functions, the shops are equipped with large windows that create a strong relationship between buildings and public streets.

The British Garden City, designed and built during the 1940s, provided new types of single family houses as an alternative to the urban residential blocks of the Italian Quarter and the courtyard houses of the Old Town. The urban fabric of the Garden City is a quiet, purely residential environment with the majority of plots interfacing with the street through blank walls or fences that conceal the private yards from passers-by. Streets in this neighbourhood are mainly designed for vehicular traffic, and their size differs from that of both the Old Town and the Italian Quarter. In the Garden City, the large mono-functional residential areas are served by commercial hubs located on the edge of the neighbourhood. This ultimately leads to car-dependent layouts that force people to travel by automobile to reach shops, services and mosques. Although the subdivision of the block is similar to that of the Old Town, in that each plot is occupied by one distinct single-family unit, the relationship between indoor and outdoor spaces is reversed, as buildings lie isolated within the plot and entirely separated from the street. This model reduces the compactness of the fabric, 
and the traditional identity that characterises both the Old Town and the Italian Quarter are lost in the Garden City.

\section{Three character areas sampled}

Because we want to explore the patterns of relations between social life and urban form in places that are characterised by clearly different morphological features, we identified three distinct portions in each of the three character areas that are comparable in terms of general structure. Of the three elements under scrutiny in this research - street centrality, street front quality and street life - we wanted in particular to determine whether the latter two are related to each other, and whether this relation varies according to the centrality of the streets. As a consequence it was important to include streets that fell into all classes of centrality. An MCA study of the whole city centre of Tripoli informed our choice of the case study areas. The resulting MCA map (Figure 5.2) clearly shows the structure of major urban streets, including both mid-range central streets and a 'background' set of minor local streets.

With reference to Figure 5.2, we identify as our case studies three $400 \mathrm{~m}$ areas centred on streets with the highest degree of centrality in each of the three character areas (Figure 5.3).

The classification of street centrality in the three cases is reduced to only three classes (Figure 5.4): highly central streets, named 'main streets'; streets of medium centrality, named 'connectors'; and finally, streets of low centrality, named 'cul-de-sacs'.

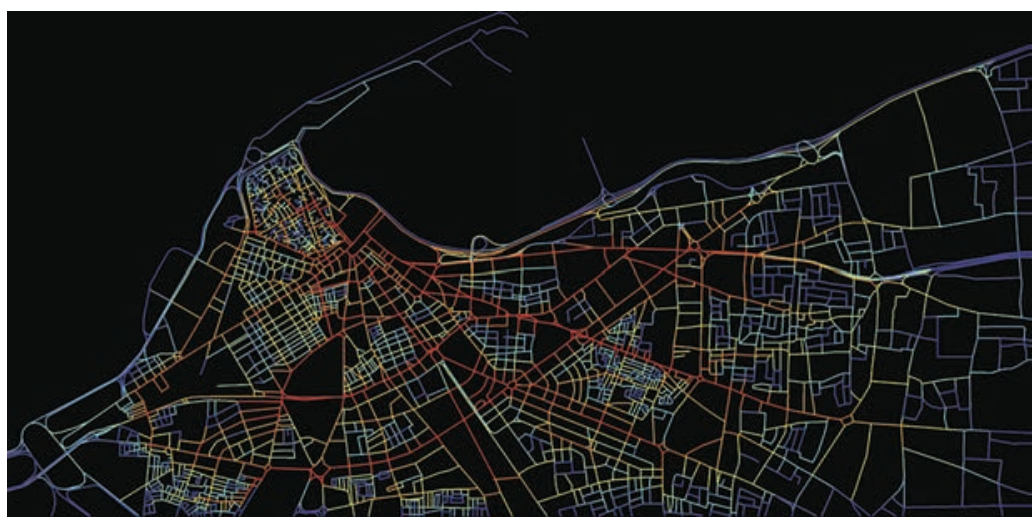

\section{Figure 5.2}

The MCA analysis of street centrality over Tripoli city centre. Values of betweenness centrality are visualised ranging from very high (red) to very low (blue)

Images Adel Remali. 

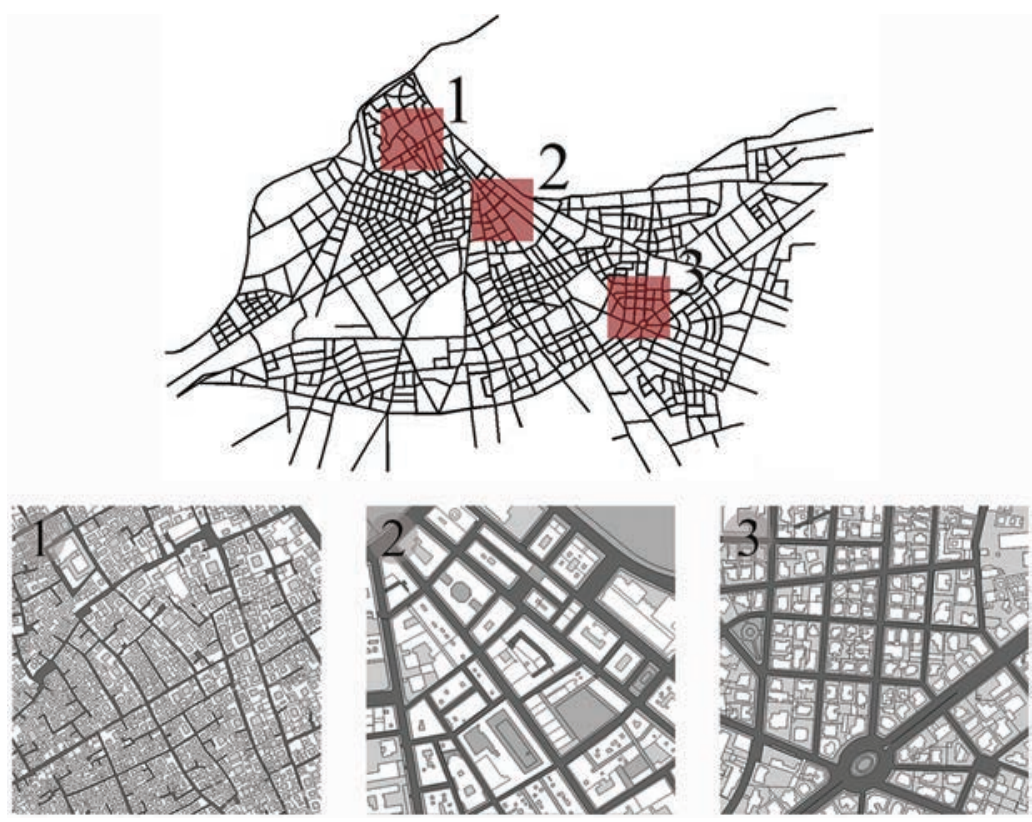

\section{Figure 5.3}

The three case studies are $400 \mathrm{~m} \times 400 \mathrm{~m}$ areas centred on highly central streets in the three character areas: Old Town (1), Italian Quarter (2) and Garden City (3) Images Adel Remali.
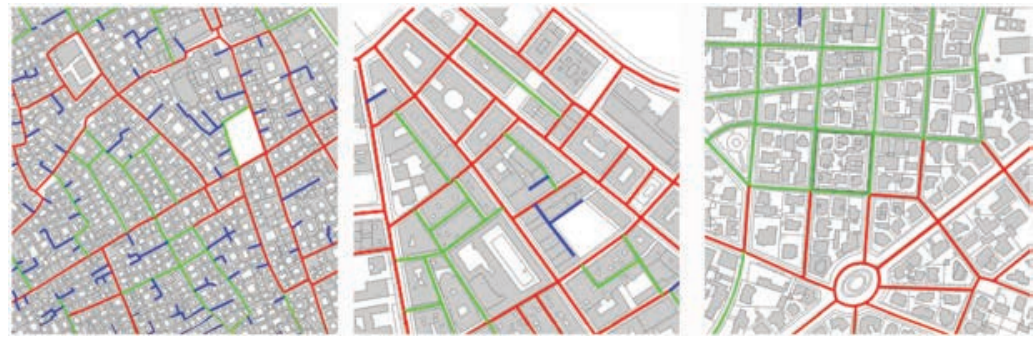

\section{Figure 5.4}

Street centrality in the three case studies, left: Old Town, middle: Italian Quarter and right: Garden City, according to the simplified classification of centrality: main streets in red; connectors in green; and cul-de-sacs in blue Images Adel Remali.

\section{Street structure}

Streets and street centrality

On the basis of the classification of streets into main streets, connectors and cul-de-sacs, the total length of street front per type is then calculated 
Table 5.1 Street front length according to the street type for the three study areas

\begin{tabular}{lcccc}
\hline Neighbourhood & Main streets & Connecting streets & Cul-de-sacs & Total street length \\
\hline Old Town & $5326 \mathrm{~m}$ & $3146 \mathrm{~m}$ & $3356 \mathrm{~m}$ & $11828 \mathrm{~m}$ \\
& $45.00 \%$ & $26.60 \%$ & $28.40 \%$ & $100 \%$ \\
\hline Italian Quarter & $5387 \mathrm{~m}$ & $2209 \mathrm{~m}$ & $344 \mathrm{~m}$ & $7940 \mathrm{~m}$ \\
& $67.80 \%$ & $27.80 \%$ & $4.40 \%$ & $100 \%$ \\
\hline Garden City & $2858 \mathrm{~m}$ & $3798 \mathrm{~m}$ & $5 \mathrm{~m}$ & $6709 \mathrm{~m}$ \\
& $42.60 \%$ & $56.60 \%$ & $0.80 \%$ & $100 \%$ \\
\hline
\end{tabular}

for the three case study areas, revealing profound differences between them (Table 5.1).

First, we find almost twice as many streets in the Old Town as in the Garden City (with the Italian Quarter roughly in between) in the same $400 \mathrm{~m} \times 400 \mathrm{~m}$ area. This difference in the urban model is taken into account below. Second, notwithstanding the relative difference in the total number of streets, the Old Town and the Italian Quarter exhibit a very similar absolute number of main streets, with slightly more in the Italian Quarter. But whilst the Italian Quarter has many fewer streets than the Old Town, a much larger proportion of them are highly central.

The Old Town has by far the most cul-de-sacs, but these account for a little over one-quarter of the total street frontage. Notably, whilst the traditional Islamic fabric of the Old Town includes a high proportion of culde-sacs, these exist at the expense of connectors, rather than main streets, which remain proportionally its backbone. Conversely, the Garden City is the only case study area where the largest network share is taken by connectors, not main streets.

We can thus see that the Garden City has a structure of street centrality that is the opposite of that found in the Old Town and the Italian Quarter: while the former pattern is dominated by connectors, the latter is structured around main streets. This is a significant difference in the way the inner structure of the two urban models work, which clearly sets apart the postwar Garden City from the other two studied areas.

\section{Street front quality}

Street front quality is measured on the street fronts of all streets included in the three $400 \mathrm{~m} \times 400 \mathrm{~m}$ cases (Figure 5.5a, b and c).

Table 5.2 shows that the Italian Quarter follows a similar pattern to the Old Town: the more central a street, the more likely it is to be of 'good' overall quality. However, percentages do not tell the real story: of the total 'good' 

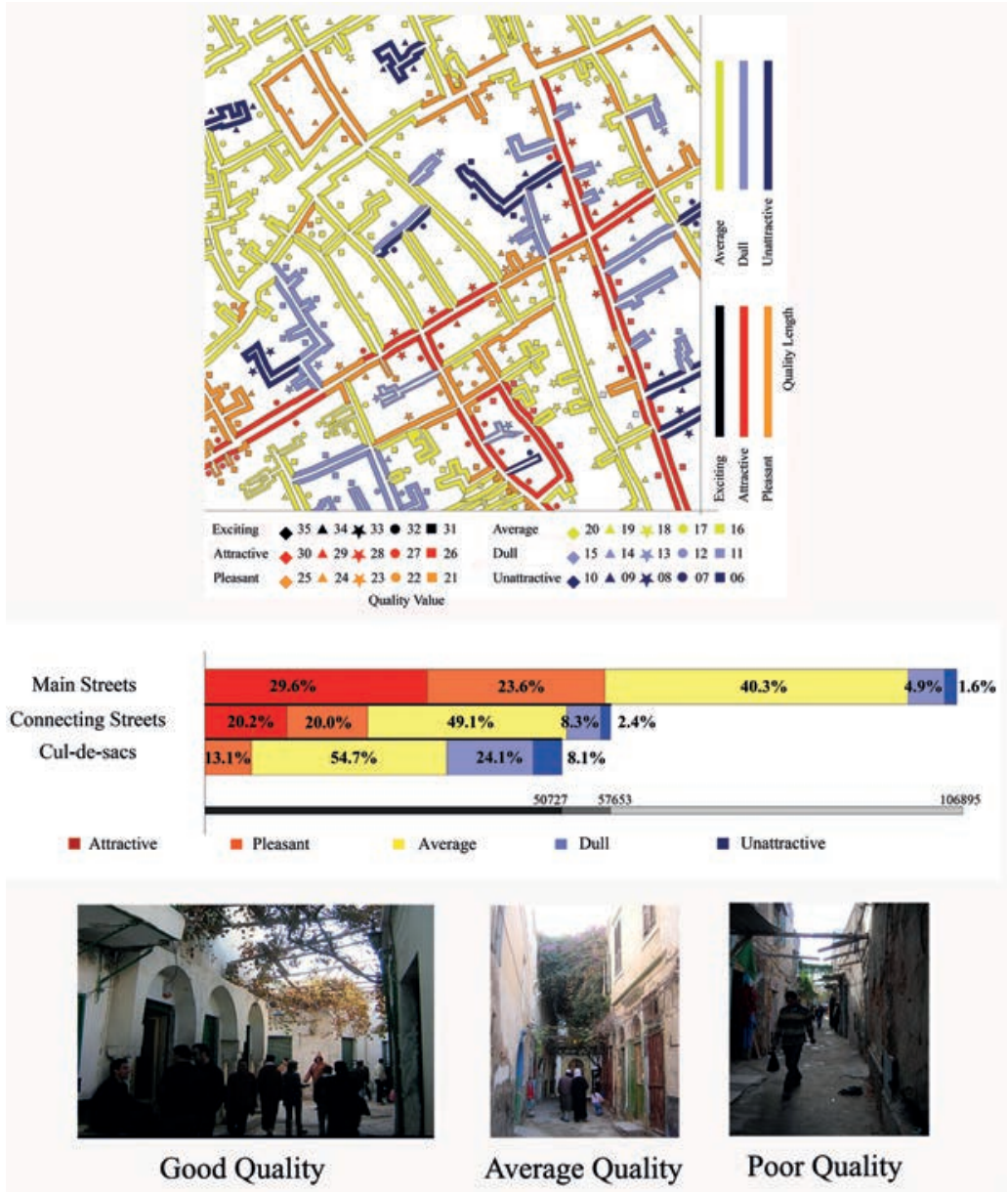

Figure 5.5a

Old Town: street front quality map

Images Adel Remali.

quality (red and orange) street fronts, more than 65 per cent are main streets, with around 8 per cent cul-de-sacs (Figure 5.5a). On the other hand, around 43.4 per cent of the 'average' street frontage quality is located along main streets while connectors and cul-de-sacs have the remainder of this assessment. Although connectors and cul-de-sacs are shorter than main streets, about 55.4 per cent of those with a 'poor' street frontage quality are located on cul-de-sacs, 23.6 per cent on main streets and 21.0 per cent on connectors.

The positive correspondence between street centrality and quality score found in the Old Town recurs in the Italian Quarter, reinforced by the high proportion of main streets (Figure 5.5b). Of these, 88.2 per cent are of 


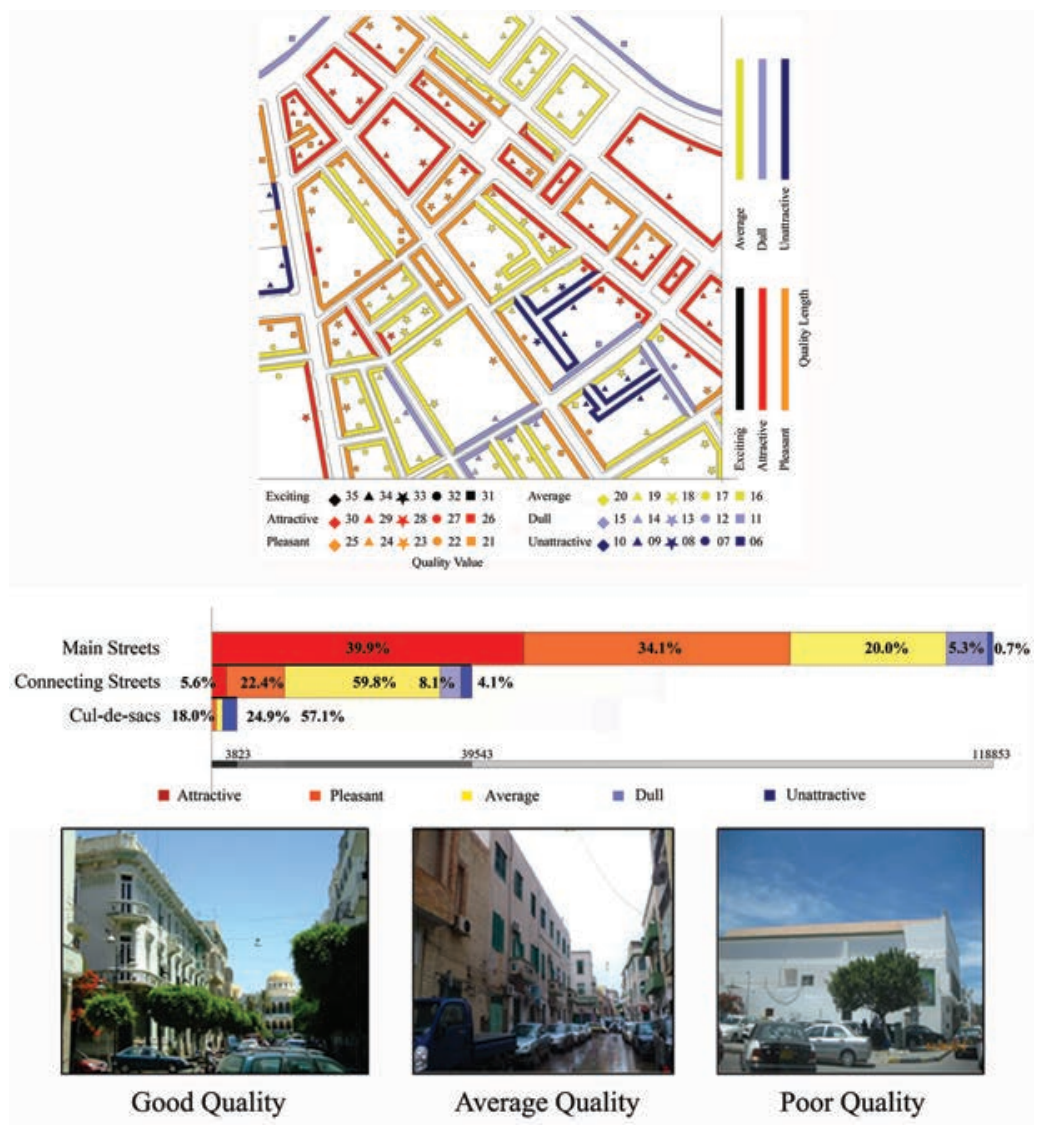

Figure $5.5 b$

Italian Quarter: street front quality map Images Adel Remali.

'good' quality. Cul-de-sacs sit at the bottom of the scale, but their impact is minimal, as there are only four short streets of this type.

Garden City has an interconnected and accessible street network. However, as described above, the street network is mainly designed for vehicular movement and most dwellings are concealed from street view by high walls or fences, even on main streets (Figure 5.5c).

As already seen, a peculiar feature of the Garden City is that main streets are not the largest part of the whole street network, a position taken up by connectors. Nevertheless, the pattern of positive correspondence observed in both the Old Town and the Italian Quarter emerges just as clearly in the Garden City (Table 5.2). Here, main streets contribute more than 66 per cent of the 'good' (red + orange) quality amount. 

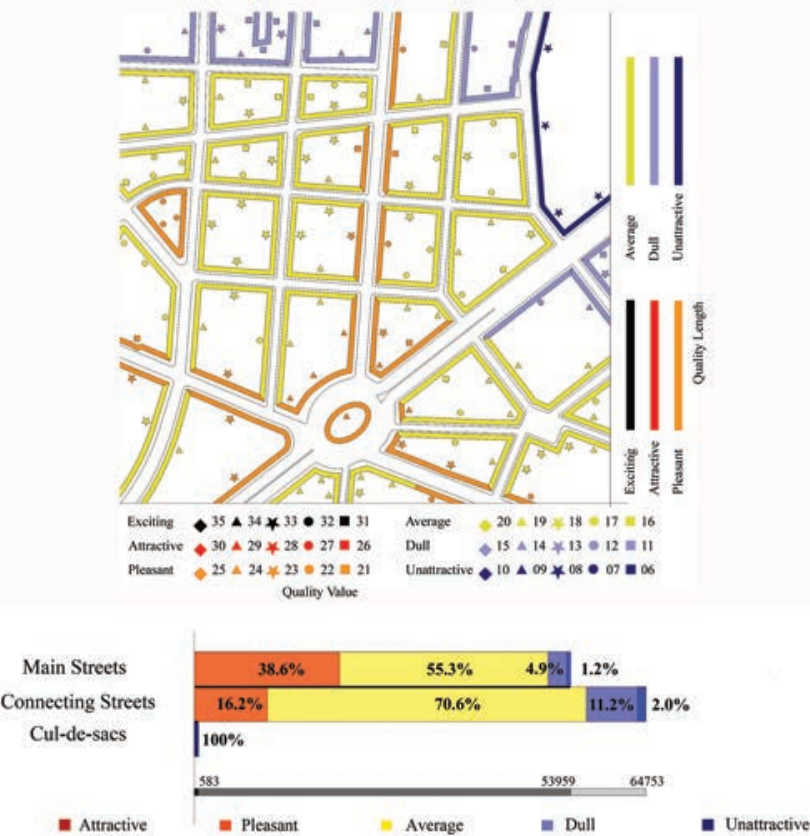

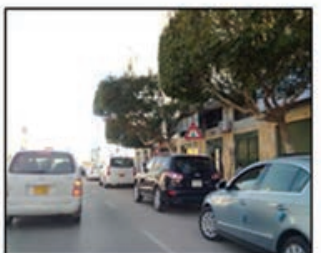

Good Quality

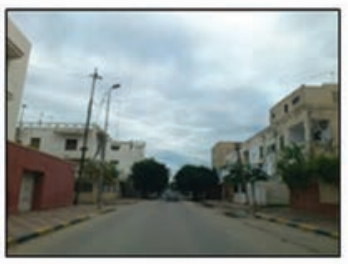

Average Quality

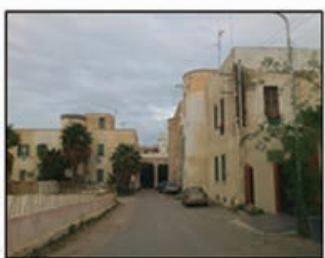

Poor Quality

\section{Figure 5.5C}

Garden City: street front quality map Images Adel Remali.

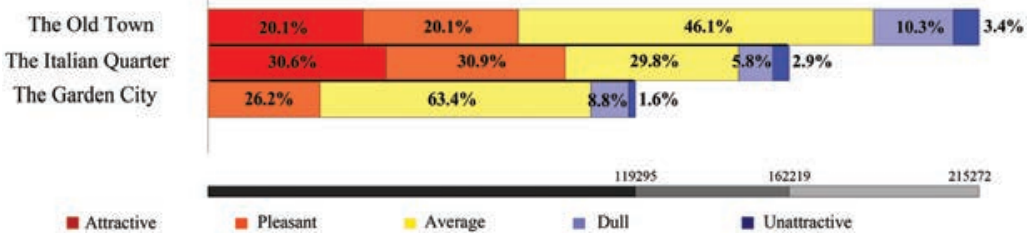

Figure 5.5d

Old Town, Italian Quarter and Garden City: overall quality Images Adel Remali. 
Table 5.2 Quality measures according to street type for the three study areas

\begin{tabular}{lccccccc}
\hline $\begin{array}{l}\text { Total length } \\
\text { of street } \\
\text { edges }\end{array}$ & Attractive & Pleasant & Average & Dull & Unattractive & $\begin{array}{l}\text { Total } \\
\text { quality } \\
\text { amount }\end{array}$ & $\begin{array}{l}\text { Average } \\
\text { quality }\end{array}$ \\
\hline $\begin{array}{l}\text { The Old } \\
\text { Town }\end{array}$ & 43277 & 43348 & 99165 & 22257 & 7228 & 215275 & 18.20 \\
$\begin{array}{l}11,828 \mathrm{~m} \\
\text { The Italian }\end{array}$ & $20.10 \%$ & $20.10 \%$ & $46.60 \%$ & $10.30 \%$ & $3.40 \%$ & $100 \%$ & \\
$\begin{array}{l}\text { Quarter } \\
7,940 \mathrm{~m}\end{array}$ & $30.60 \%$ & $30.90 \%$ & $29.80 \%$ & $5.80 \%$ & $2.90 \%$ & $100 \%$ & \\
\hline $\begin{array}{l}\text { The Garden } \\
\text { City }\end{array}$ & 0 & 31301 & 75608 & 10490 & 1896 & 119295 & 17.78 \\
$6,709 \mathrm{~m}$ & $0 \%$ & $26.20 \%$ & $63.40 \%$ & $8.80 \%$ & $1.60 \%$ & $100 \%$ & \\
\hline
\end{tabular}

Across the Garden City's sample area there are no streets of 'attractive' quality, but this category counts for around 20 per cent of the streets in the Old Town and 30 per cent of those in the Italian Quarter. From the analysis, we can see that the Italian Quarter is dominated by 'good' streets that represent over 60 per cent of the total quality score, while in the Old Town this proportion drops to 40 per cent and in the Garden City to 26 per cent. The category that prevails in the Garden City is 'average', which accounts for 63 per cent of all the streets. In the Old Town 46 per cent of streets are 'average', and in the Italian Quarter around 30 per cent.

In short, the results suggest that the Garden City is an urban model dominated by streets of medium centrality, which consequently lacks any strong potential to develop a robust and resilient system of non-residential activities (retail, services). This weakness is further confirmed by a surprisingly high share of streets in the middle range of quality; this rather middling urban environment typically serves a monoculture of dwellings that is unlikely to develop into anything different in the future.

In this research we can observe a combination of two emerging patterns: (a) of the overall street network, main streets account for the largest proportion of streets sampled in the Old Town and the Italian Quarter, but not in the Garden City; (b) accordingly, 'good' quality street fronts (combining 'attractive' and 'pleasant') are a considerable proportion of all street fronts in both the Old Town and the Italian Quarter (around 40 per cent), but a minor component of the Garden City, which is in fact largely dominated by 'average' quality streets (Figure 5.5d and Table 5.3). This combination, which we call a 'street structure divide', appears to reveal a very profound difference in the way cities have grown since the Second World War, 


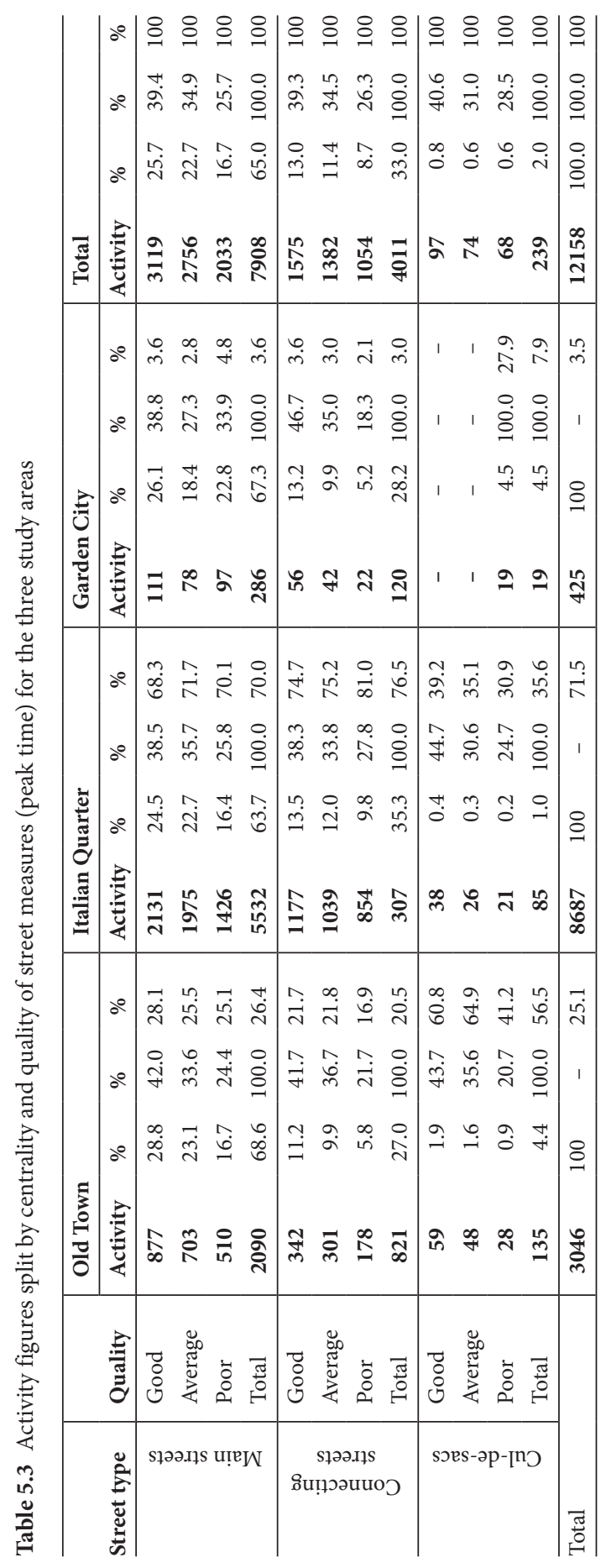




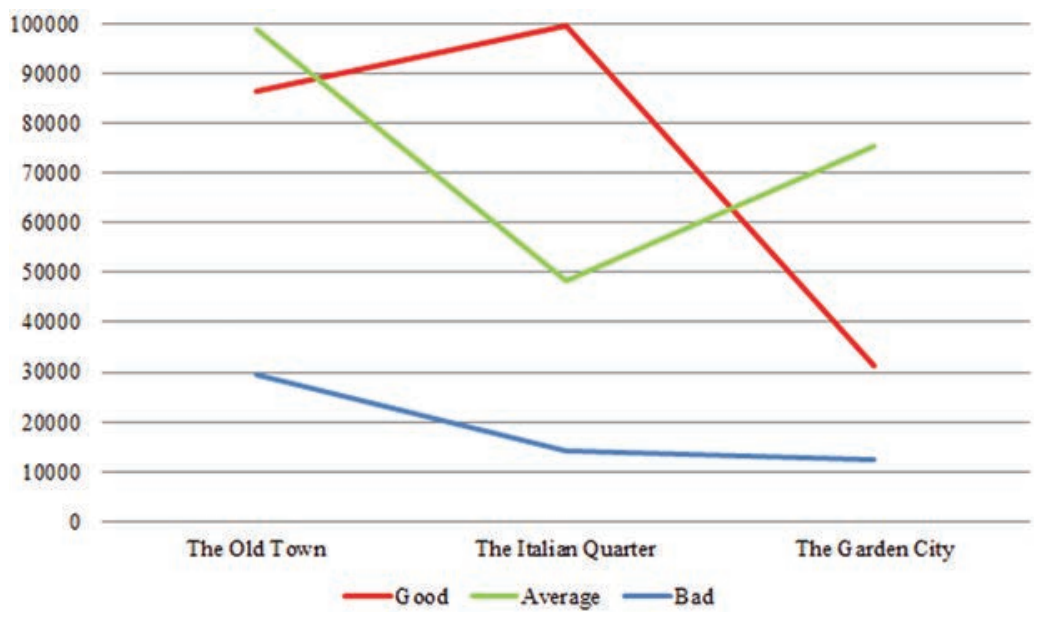

Figure 5.6

Old Town, Italian Quarter and Garden City: quality amount per class of quality Images Adel Remali.

when professional theories of urban design, developed in the decades before the turn of the twentieth century, finally became 'bricks and mortar', as described by Rofé elsewhere in this volume. These theories (Ebenezer Howard's Garden City, Clarence Perry's Neighbourhood Unit, and subsequently Le Corbusier's Radiant City and the post-Second World War UK New Town movement that spread from the UK to other countries under its influence) shaped many major processes of post-war urbanisation around the world and Libya is no exception. They brought about a major shift which is clearly evident in Tripoli in the way the planning approach of the Garden City departs from that of the other two cases, both of which are expressions of a more traditional culture of city building. The Old City exemplifies an unplanned tradition that has evolved over centuries, whilst the Italian Quarter illustrates an approach that precedes twentieth-century planning theories.

As has already been shown, compared to the Italian Quarter and the Garden City, the Old Town exhibits by far the greatest length of street fronts, with almost double the street frontage length of the Garden City, and over a quarter more than the Italian Quarter. Tripoli Old Town is in fact an interesting case that differs from the typical image of Islamic urban fabric where blank walls and cul-de-sacs commonly appear as features traditionally associated with privacy in the realm of the extended family. This example of Islamic urbanism has a clear backbone of well-connected main streets 
that is not dissimilar to many Western models. What differentiates the Old Town from the other two cases is therefore not so much the length of the main streets, which remains comparable across the board, but rather that it has many more connectors and cul-de-sacs than in the Garden City and the Italian Quarter.

Finally, we measure the amount of street frontage by quality classification in absolute rather than in relative terms. This is important in cities, because the quality of the street scene is a finite resource that is directly connected to the potential for supporting social and economic activities. Of the three studied cases (see Figure 5.6), the Old Town contains the highest number of 'poor' streets (dull and unattractive), followed by the Italian Quarter and then the Garden City (albeit balanced by a much higher number of 'good' streets). The most important finding here is the very low presence of 'good' streets in the Garden City, a feature particular to this urban model.

\section{Street life}

Due to adverse security conditions in the city of Tripoli at the time of the field survey, Street Life is measured only on a subset of streets, but nevertheless covers all the classes of street centrality available on the ground. Direct observation and the counting of activities were carried out on a total of nine streets each in the Old Town and the Italian Quarter, and seven streets in the Garden City.

A striking pattern emerges in the Old Town: the more central a street, the more overall human activity takes place on it. In addition, within each class of street centrality, the higher the frontage quality, the more activity was found to take place there. There are more people walking along main streets and connectors during peak times than off-peak times. Remarkably, however, cul-de-sacs revealed an inverse pattern, containing more people during off-peak times than peak times (Tables 5.3 and 5.4).

Optional activities tend to increase with the progression from 'bad' to 'good' street quality, while the contrary applies to necessary activities. This applies throughout the dataset irrespective of the type of activity, the centrality of streets or the time of day.

The Italian Quarter shows by far the greatest amount of street life compared to the other two case studies, especially on main streets and connectors. As in the Old Town, we observed a pattern for understanding the importance of streets in urban life: street life appears to correspond to street centrality on one hand and, on the other, when measured on streets that are equally central, it corresponds to street front quality. We have named this particular pattern, which applies consistently throughout our cases, the 


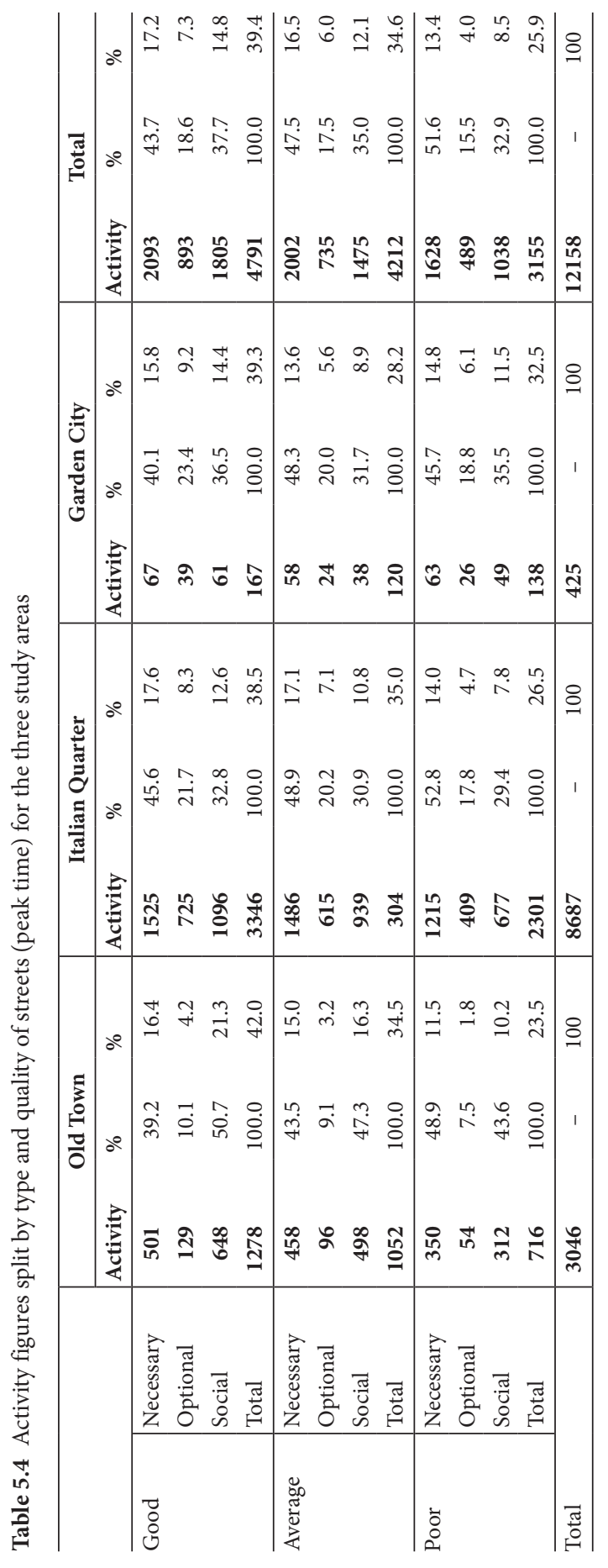


'street life double rule'. Similarly, walking is the most popular activity, and not surprisingly levels of street life in general are much higher at peak than at off-peak times. The same pattern of increased street life off-peak, noted in the Old Town, also applies to the Italian Quarter; however, in the Italian Quarter, unlike the Old Town, street life remains relatively low on cul-desacs compared to main streets and connectors.

Optional activities in the Italian Quarter tend to follow the same pattern as in the Old Town, that is, they increase in line with the quality of the street. However, there is an exception for the number of people sitting in cul-de-sacs, which in fact decreases with the quality of the street, especially at peak times.

The Garden City shows the lowest level of street life of the three case study areas examined in this research: 111 people were detected on main streets at peak times, 2,131 in the Italian Quarter and 877 in the Old Town. Remarkably, in the Garden City there was more street life at off-peak than at peak times, which represents a unique pattern that is, however, typical of a purely residential/commuting area (Tables 5.3 and 5.4).

In general, there is clear evidence that the 'street life double rule' applies, although with a minor exception in main streets during peak times where slightly more people were detected on 'poor' than on 'good' streets. Walking activities still prevail in the Garden City, but the gap between standing and sitting activities is greatly reduced (Figure 5.5C). The same pattern with regard to street quality applies in the Garden City, with optional activities corresponding to street quality and necessary activities following an inverse correspondence with street quality, with a few minor exceptions mainly concentrated off-peak.

Whilst further research is required to discover whether these results apply elsewhere, this study has shown a consistent pattern across three diverse case studies: the amount of human activity on streets increases with the centrality of streets, and also with the quality of their frontages. Each of these two aspects has been observed and measured in previous separate studies, but we aimed here to provide detailed and comprehensive evidence that these features tend to emerge in combination, across all types of streets, across all types of activities and throughout the day.

In terms of overall human activity (Table 5.5) the Italian Quarter clearly stands out as the most 'lively' of the three case study areas: more than 70 per cent of all activities were found in this case study area. The Old Town is the location for almost all the rest (25 per cent), and the Garden City for only 3.5 per cent. This alone is a very interesting result, revealing a lot about the different nature and potential for sociability of the three cases. We have also seen that the Italian Quarter is the case study area with the highest 
Table 5.5 Activity figures split by type and quality of streets (peak time)

\begin{tabular}{|c|c|c|c|c|c|c|c|c|c|c|c|c|}
\hline & \multicolumn{3}{|l|}{ Good } & \multicolumn{3}{|c|}{ Average } & \multicolumn{3}{|l|}{ Bad } & \multicolumn{3}{|l|}{ Total } \\
\hline & Activity & & $\%$ & Activity & $\%$ & $\%$ & Activit & & $\%$ & Activity & $\%$ & $\%$ \\
\hline Necess & 2093 & 36.6 & 43.7 & 2002 & 35 & 47.5 & 1628 & 28.4 & 51.6 & 5723 & 100 & 47.1 \\
\hline Optional & 893 & 42.2 & 18.6 & 735 & 34.7 & 17.5 & 489 & 23.1 & 15.5 & 2117 & 100 & 17.4 \\
\hline Social & 1805 & 41.8 & 37.7 & 1475 & 34.2 & 35 & 1038 & 24 & 32.9 & 4318 & 100 & 35.5 \\
\hline Total & 4791 & 39.4 & 100 & 4212 & 34.6 & 100 & 3155 & 25.9 & 100 & 12158 & 100 & 100 \\
\hline
\end{tabular}

proportion of main streets, equal to almost 70 per cent of its street network. The Italian Quarter not only has an internally interconnected street layout, but it also benefits from its central location within Tripoli, which gives its streets greater potential to develop active frontages and, consequently, become attractive places for people.

Whatever the reason for its high share of central streets, study of the Italian Quarter confirms that the more central the streets, the more likely they are to be populated and lively. This is confirmed for all three case studies taken together, where the figures for overall distribution of activities are striking (Table 5.5): main streets attract 65 per cent of all activities, connecting streets 33 per cent and cul-de-sacs only 2 per cent; in the Old Town alone, this pattern is even sharper.

A second observation (Figure $5.7 \mathrm{a}, \mathrm{b}$ ) suggests that the amount of street life increases with the quality of street fronts. Moreover, these percentages are remarkably similar in all three cases.

Finally, while the number of people observed carrying out necessary activities decreases with increasing quality, the contrary applies to optional and social activities. These actually increase with increasing quality. This suggests that the level of optional and social activity corresponds more closely to the quality of the surrounding environment than the level of necessary activity, that is, activities undertaken through need.

(a)

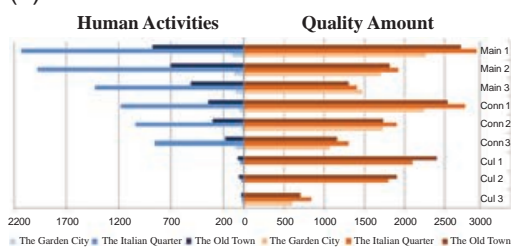

(b)

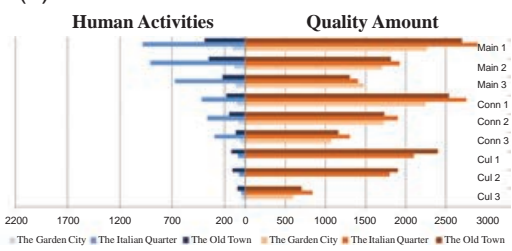

Figure 5.7

Old Town, Italian Quarter and Garden City: human activities and street quality at peak (a) and non-peak (b) times Images Adel Remali. 
An interesting pattern radically distinguishes the Garden City from the other two case study areas: here we observe more activities at off-peak times than at peak times, the opposite of both the Old Town and the Italian Quarter. We observe that the Garden City also shows lower levels of activity in general, which sets it apart from the other two cases, as well as a lower proportion of main streets. This clearly confirms the character of the area as a predominantly residential, dormitory quarter populated at a low level after work hours.

The normal pattern of street life highlighted above (the Italian Quarter being the liveliest followed by the Old Town and, far behind, the Garden City) is reversed in the cul-de-sacs of the Old Town, which in fact - at offpeak times - are more highly populated than those of the Garden City. This is mainly due to the fact that cul-de-sacs in the traditional built environment are seen as private open spaces effectively owned by the surrounding residential units. At off-peak times especially, these spaces become the stage for intense social life, thus extending the living room space of dwellings into their adjacent streets.

\section{Conclusion}

The three areas of Tripoli studied here serve to illustrate three shifts in urban design principles, demonstrating how the continuity of built form that existed for centuries was interrupted at key points in time, represented by the three studied areas, whose differing historical origins are revealed in contrasting physical forms.

This chapter has shown how street life corresponds with patterns of street centrality and street front quality in the three studied areas. The in-depth analysis of these three aspects of streets reveals interesting patterns that confirm several fundamental assumptions, and support previous research mentioned in the opening sections of this chapter. This study shows that these assumptions can be applied to the specific cultural and historical context of a Mediterranean Islamic city, and highlights the possibility that there are two patterns of broader importance for urban studies.

First, we observe that while in traditional urban fabrics (the Old Town and the Italian Quarter) main streets are the most common type within the street network, and tend to be characterised by being of good quality, this is not the case in the modernist fabric of the Garden City. This is arguably the mark of the historical shift to a profoundly different model of urbanism that intervened after professional theories of urban design took centre stage in the early twentieth century and began to be applied on a large scale after the Second World War. 
Second, a clear pattern emerges that closely links street life to two aspects of the built fabric: the degree of centrality of the streets and the quality of their building fronts. We have named this connection 'the street life double rule' because street life corresponds to two factors - quality as well as centrality - and it is the combination of the two that we believe makes the rule. Social interactions flourish along main streets and connectors, where streets are more accessible and better integrated into the street network. Our observations have shown clearly that as centrality increases, city life follows. One might think that this is caused by the colonisation of rapidly disappearing traditional lifestyles by Western social habits and cultural norms, but this research suggests the opposite: in the Old Town this pattern is in fact even sharper, with nearly 70 per cent of street life happening on main streets. Moreover, the same pattern links street life with the quality of the street scene. Here again, the numbers are very clear: of more than 12,000 people observed, 39 per cent were on 'good' streets, 35 per cent on streets of 'average' quality, and 26 per cent on 'poor' streets, with the same behaviour emerging across all the three areas.

A third, important general pattern emerges according to which optional and social activities tend to follow the quality of the street fronts, while necessary activities follow an inverse pattern and are found in greater quantity as street front quality decreases. This is a confirmation of Jan Gehl's (1987) observations, where he states that the good quality of public spaces is an important factor in settling high levels of optional and social activities and holds a vital role in improving life in cities, while a low-quality urban environment tends mostly to host activities that people need to do, and about which they have little choice. Overall, the traditional Islamic urban fabric appears to share a common structure with the traditional Western model: both are heavily based on highly central and densely social main streets, with a culturally specific culde-sac structure emerging only at the scale of the residential 'sanctuary area' (Porta and Romice 2014). The data show, in this respect, that the traditional model is still capable of supporting the life of contemporary communities: cul-de-sacs in the traditional Old Town are not only better quality than those in the Italian Quarter, but they also have a better social life.

It is important to highlight that all patterns linking street life with street centrality and street quality revealed in this research are subject to the limitations of the study. First of all, they are typical of three $400 \mathrm{~m} \times$ $400 \mathrm{~m}$ areas in the city centre of Tripoli, so they represent a tiny fraction of the Libyan capital; second, as extensive as this database is, it leaves out a number of important factors of a demographic, social, environmental, economic and historical nature, that should certainly be taken into account when investigating the causes and motivations behind our observations. 
Caution must therefore be exercised before drawing more general conclusions from the local patterns highlighted in this research. That applies first and foremost to the two general patterns we found in this study. The idea that these are general rules of urbanisation as a cultural human product is only a suggestion, which we leave to further research to either confirm or disprove.

In addition to the urban design properties of the three sample areas, it is possible to draw conclusions about the characteristics of their centrality in broader terms. We have shown how the two more traditionally laid-out districts had much greater proportions of streets with high centrality. The results confirmed other studies that have suggested that higher centrality goes hand-in-hand with greater movement flows and activity levels. It is interesting, though, to consider also the way in which these three areas have - or have not, in the case of the Garden City - adapted to the massive growth of the city of Tripoli around them (Azzuz 2000). The nature and level of the recorded activity is clear: whilst the Garden City has retained its original role as a residential quarter of the city, with only marginal non-domestic activity on its boundaries, the other two areas have continued to serve multifarious roles within the city, hosting a wide range of activities especially within streets of good visual quality.

This research has chosen to explore and assess three urban areas to re-establish an organic link with the past, not for the sake of nostalgia, but rather to direct future developments towards a more careful integration and consideration of that past. It has sought to identify essential structuring principles that can be revived, adapted and perpetuated to enhance social life in the contemporary built environment. 


\section{Chapter 6 Beyond Lively Streets}

Borja Ruiz-Apilánez, Mayte Arnaiz and José M. De Ureña

\section{Introduction}

Both urban and suburban high streets have historically been the locus for some of the highest levels of human activity and social interaction. Despite the constant changes that economy and lifestyles have been experiencing in recent years, the high street has continued to demonstrate a special ability to adapt to change, maintaining its socio-economic relevance.

The interest of geographers in English-speaking countries in the high street can be traced back to the mid-1950s, when a range of studies on 'the interactions and inter-linkages amongst land uses and their users took place in different countries' (Dawson 1988: 2). Similarly, in Spain, the analysis of two streets in Madrid by De Terán (1961) exemplifies this focus on land uses and activities.

The importance of mixed-use streets has recently been highlighted and they have been identified as a key component of sustainable urban communities. They encourage sustainable mobility, economically support their neighbourhoods, offer a safe public realm, facilitate social inclusion, enhance a local identity and encourage social life (Jones et al. 2007). However, as pointed out by Griffiths et al. (2008: 1158), both the academic and policy-oriented literature has conventionally measured the socio-economic health of traditional suburban centres based on their 'vitality' (pedestrian activity) and 'viability' (the ability to attract investment). Indeed, it is broadly assumed that lively streets and active ground-floor businesses are symptomatic of successful urban tissue. This chapter investigates the validity of this apparent relationship for the case of the historic centre of Toledo (Spain) and its high street, based on an analysis of its public life, local demography and economy, and the configurational evolution of the city. 


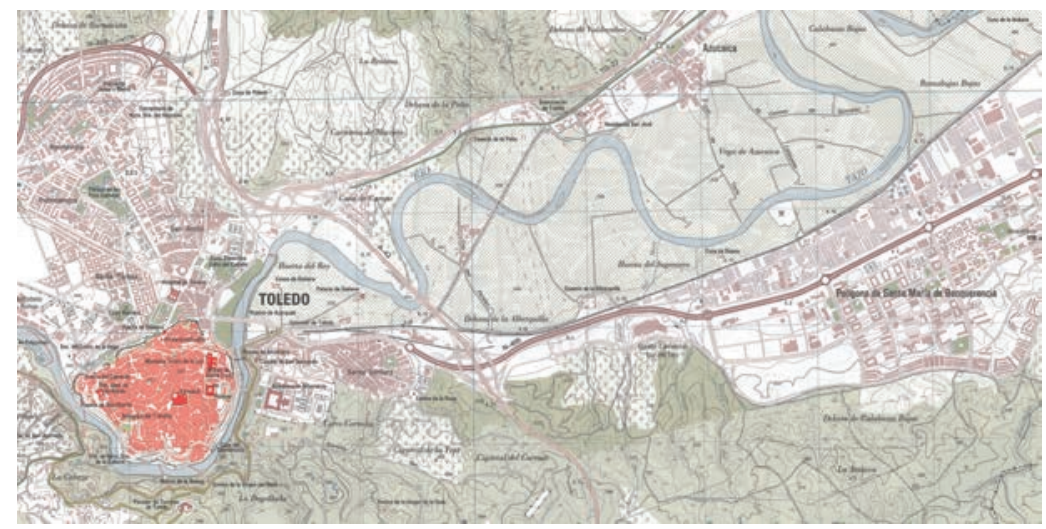

Figure 6.1

Map of the contemporary city of Toledo. The historic city is marked in red

(C) 2010 National Geographic Institute of Spain, with permission. Borja Ruiz-Apilánez over the 2010 National Geographic Institute of Spain 1:2500 Toledo Map.

Toledo has been the capital of Castilla-La Mancha since 1983. It was founded in pre-Roman times on top of a steep hill above the River Tagus (Figure 6.1). It has nearly 80,000 inhabitants, 11,000 of whom live in the historic city. This district has been suffering from a range of environmental, social, functional and demographic problems, which has meant that since the mid-twentieth century its population has steadily decreased, while the city has continued to grow well beyond the original historic core. In 1986 the historic city was listed as a UNESCO World Heritage Site due to its precious architectural heritage and long history. This listing, its imposing site at the top of a hill and its proximity to Madrid - only $70 \mathrm{~km}$ away and exceptionally well connected by two highways and high-speed trains since the 2000s have made it one of the main tourist destinations in Spain with about one and a half million visitors per year.

The most recent comprehensive study on the socio-economic situation of the historic city of Toledo dates back to 2000 and is based on data from 1995 and 1998. The study focus was on population, the built environment and the economic activity, with an emphasis on tourism. At the time of the report, the loss of population that had begun in the middle of the twentieth century was still ongoing: the historic city, having almost 30,000 inhabitants in the 1950s, contained less than 12,000 residents by the late 1990s. Despite some small signs of recovery, the population in the historic centre was ageing compared to the city as a whole. The report also noted a large number of decaying dwellings, whilst in the case of monumental buildings, although these had better legal protection and maintenance, a significant proportion needed 'urgent action'. The report shows that Toledo 
was receiving 1.7 million visitors per year and tourism was described as the fastest growing economic activity in the historic city. Nevertheless, the historic city was said to maintain important economic activity, although with a progressive increase and concentration of tourism and hospitality-type activities in the high street area. The continuing existence of the majority of the city's civic and administrative institutions was helping to maintain the functional vitality of the centre (Vázquez et al. 2000).

Since then, numerous functional, aesthetic and economic actions have been taken. The centre has been re-equipped with new infrastructure and major facilities, and a large number of built environment elements from single apartments to complete monumental buildings, from shops to streets and squares - have been renovated or, in fewer instances, built anew. Today, the improvement in the built environment is certainly impressive, but demographics have not followed a similar trajectory. Far from recovering, the current population is actually slightly smaller than in the late $1990 \mathrm{~s}$ $(10,800$ in 2013) and the proportion of people over 65 , although diminished from 26 per cent to 19 per cent, is almost double the proportion of those under 15 .

Surrounded by an extraordinary townscape, most visitors and even a good number of Toledans are likely to perceive the historic city as a socioeconomically healthy urban fabric as they walk through its lively streets, flanked as they are by active ground-floor businesses. However, further observations suggest a relatively fragile socio-economic condition, which was characterised in the 2000 study as a combination of demographic decay, spatial concentration of economic activity and a growing focus on tourism alongside the growth of the service sector associated with it. The report found that growth in a tourist economy had led to a decrease in local (i.e. non-tourist) shops, offices and professional services, with a subsequent specialisation in leisure-related economic activities. The transformation of ground-floor frontages to attract tourism was found to be a striking feature of these changes.

\section{Research methods}

Given the two contradictory, yet coexisting, perceptions of the current situation of the historic city of Toledo - its success as a tourist destination, yet also its fragile socio-economic situation - the main aim of this research is to shed light on the apparent paradox about the health of the city core, by obtaining new and updated data and carrying out a structured spatial analysis of the area. A second purpose of this investigation is to explore the 
roots of the historic demographic decline that has characterised the historic centre for more than half a century (Zárate and Vázquez 1983; Busquets 2000; Vázquez 2000).

The investigation of the present state of the historic centre was undertaken from two complementary perspectives: first, a study of public life on the streets of the historic city, and second, a building use study that mainly but not exclusively - focuses on ground-floor businesses. The methods in the first study consisted of systematic direct observations, while the second included surveying and interviewing. In both cases a distinction was made between visitors and locals in order to get to grips with possible ongoing socio-economic processes with regard to the functionality of the centre for locals.

Systematic direct observations included head counting and mapping, distinguishing between visitors and locals throughout two days in March 2014. This differentiation was based on the observer's perception of the appearance and behaviour of pedestrians, a relatively reliable method when applied by a trained observer. Hourly counts were used to determine pedestrian flows and the number of stationary activities observed in the area using standard methods (Gehl and Svarre 2013). The exercise distinguished between people shopping, standing or sitting. For the latter category, we distinguished between primary seating (public chairs or benches), secondary seating (other urban features, such as sculptures), and tertiary seating (chairs provided by cafés, restaurants and so on), using the method established in an earlier study (Ruiz-Apilánez et al. 2014).

A survey determined the land uses, vacancy rate and whether the ground-floor premises catered for tourists. Upper-floor vacancy rates were noted as well. In addition, short interviews with the owners or the managers of the ground-floor businesses provided information about the year the business was established, the percentages of local and visitor customers and, sometimes, the previous land use.

The study area included the two main squares in the old city - Plaza de Zocodover (Zocodover Square) and Plaza del Ayuntamiento (Town Hall Square) - the streets running between, and those connecting with this central urban axis (Figure 6.2). Zocodover Square is the former market square from the Muslim period, whilst Town Hall Square is surrounded by the main civic and religious institutions from the subsequent Christian period - the cathedral, the Archbishop's Palace, the court house and the town hall. The streets between the two squares comprise the historic high street, the longestablished retail backbone of the city which, together with the two plazas, has supported Toledo's public life for centuries. Today, the complex of squares and streets are central to tourist visits to the city. Finally, in order to 

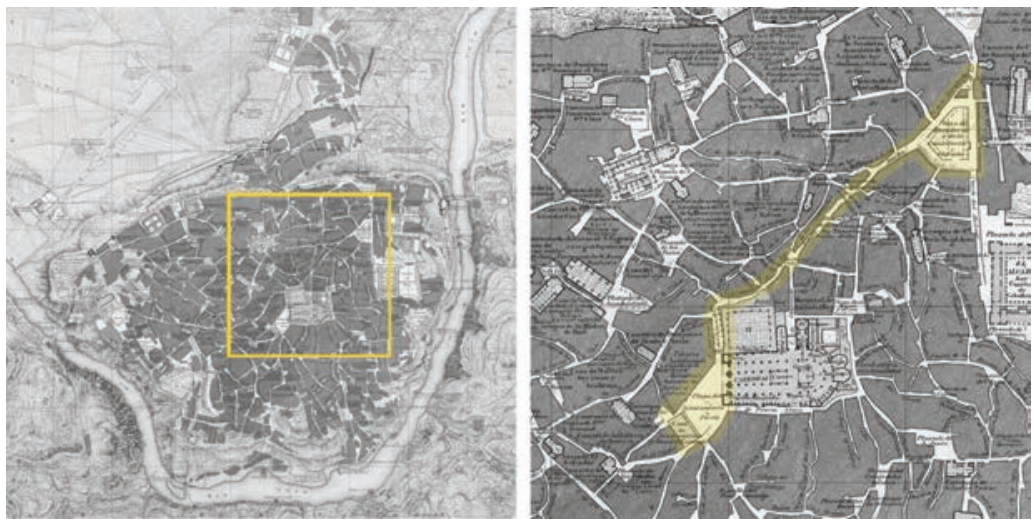

Figure 6.2

The study area (inset on the right), showing Zocodover Square (north-east), Town Hall Square (south-west), and the high street linking them

Source: http://www.ayto-toledo.org/archivo/imagenes/pym/ciudad/g/PI-1858.jpg. Borja Ruiz-Apilánez over the 1858 Toledo Map by F. Coello and M. Hijón.

search for the origins of the long-term loss of population, a configurational explanation is explored using space syntax methods and tools to analyse segment maps from Toledo's street and road network in four different time periods: 1950s, 1970s, 1990s and 2010s. They had been produced for an earlier study of the evolution of the distribution of spatial integration values in the last decades by Arnaiz et al. (2013).

This study shows how the growth of the city can generate a radical shift in centralities. According to our research, the case of Toledo exemplifies the way growth over decades has gradually led to the old city effectively losing its historic centrality. Demographic, social and economic data suggest a loss of the traditional urban functions from this part of the city, while analysis of the evolution and distribution of the choice and integration values throughout the historic city and city as a whole allows us to trace this socio-spatial shift.

\section{Observing street life}

Analysis of the data collected through systematic direct observations is quite revealing. They confirm the perceived lively atmosphere - especially in Zocodover Square and the high street - and, simultaneously, confirm that the majority of the side streets are not so animated. However, further 
examination of the pedestrian traffic and the stationary activities allows a better understanding of the social life of the historic city, according to their evolution throughout the day, their location (the high street, the side streets and the squares), the day of the week (weekday or weekend) and whether people are locals or visitors.

Regarding pedestrian movement, both the figures and the distribution of the total daily volumes on Wednesday and Saturday show two facts. First, there is a strikingly uneven distribution of pedestrians, with sharp differences between the high street and side streets; and second, there is an extraordinary increase of people in the area on Saturdays (Figures 6.3 and 6.4).

It is notable how the irregular distribution between the high street and side streets is almost the same on weekdays and weekends, when analysed in relation to the maximum daily gate volume registered on that day. The maximum flow is located where the high street meets Zocodover Square. Then, the number of pedestrians gradually decreases along the high street up to the entrance to Town Hall Square. The majority of the side streets show volumes that are less than 0.2 times the maximum daily gate flow, and none of the remaining streets exceeds 0.4 . Given this unbalanced distribution and the sudden drop towards the side streets, it is easy to imagine how the volumes rapidly decrease deeper inside the network. The only

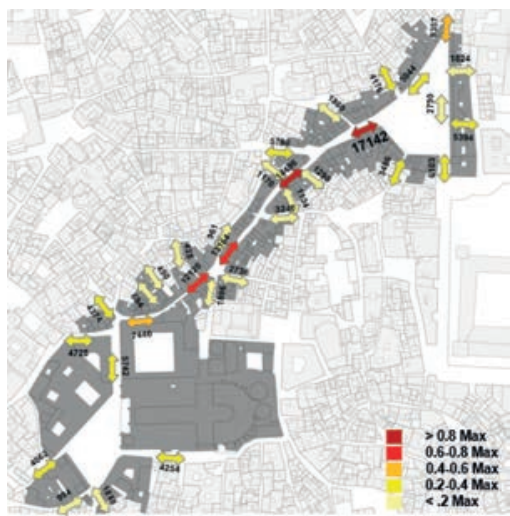

Figure 6.3

Total pedestrian volumes on Wednesday (08:00-20:00) in the study area. Colour gradient based on the proportion at each gate of the total pedestrian volume in the study area

Borja Ruiz-Apilánez and Inmaculada Mohíno.

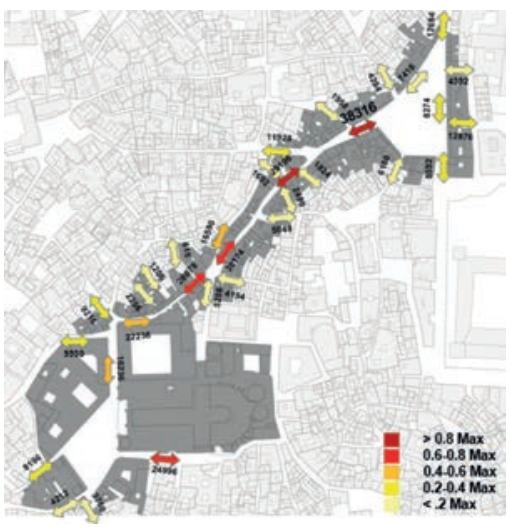

Figure 6.4

Total pedestrian volumes on Saturday (09:00-21:00) in the study area. Colour gradient based on the proportion on each gate of the total pedestrian volume in the study area

Borja Ruiz-Apilánez and Inmaculada Mohíno. 
exception can be found in the southern part of the Saturday map, in the street where the entrance to the cathedral is located, and is probably due to this being the highlight of tourist routes around the area. These differences between pedestrian volumes mean that there are empty streets one block away from an overcrowded high street. In fact, looking at Saturdays from 12:00 to 21:00, the high street constantly shows flows greater than twelve people per minute per metre $(\mathrm{p} / \mathrm{min} * \mathrm{~m})$, frequently exceeding the 'comfortable carrying capacity' limit of $13 \mathrm{p} / \mathrm{min} * \mathrm{~m}$ according to Jan Gehl's standards for public space (Gehl Architects 2004: 82). In the evening, when the central part carries its maximum flow $-19.4 \mathrm{p} / \mathrm{min} * \mathrm{~m}$ - thirteen other streets carry fewer than $2 \mathrm{p} / \mathrm{min}^{*} \mathrm{~m}$, and seem to be virtually empty. There is a similarly significant increase of pedestrians on Saturdays. On average, the streets are carrying twice the number of pedestrians than on weekdays, and the main cause of this growth is the influx of visitors: whereas locals are 1.35 times more abundant on Saturdays, visitors increase by 4.69 from their weekday baseline measure.

On weekdays, the average percentage of visitors per street is 26 per cent and three of them show measurements over 50 per cent (Figure 6.5). The rates observed in different streets are five to ten times higher than those registered by a 1994 study (Equipo de Técnicos en Transporte y Territorio). On weekends, the average visitor rate per street doubles and reaches 54 per cent (Figure 6.6). Both maps show a clear difference between the northern and southern part of the study area which can be observed

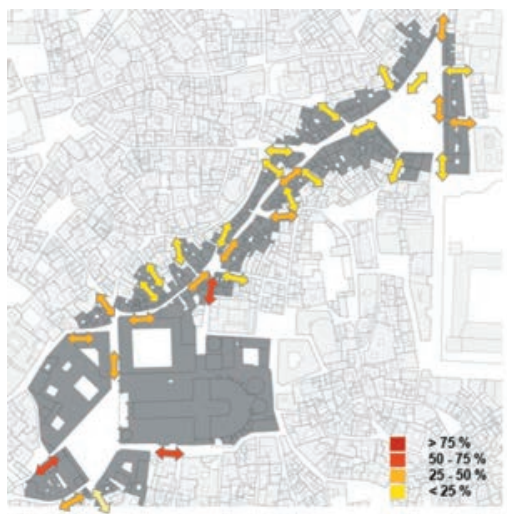

Figure 6.5

Percentage of visitors from total pedestrian volume on Wednesday (08:00-20:00) in the study area Borja Ruiz-Apilánez and Inmaculada Mohíno.

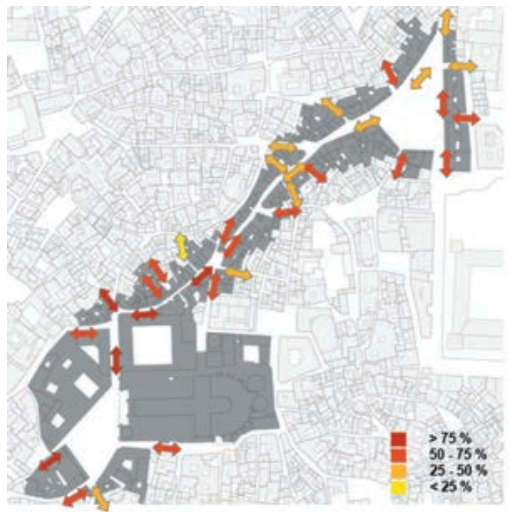

Figure 6.6

Percentage of visitors from total pedestrian volume on Saturday (og:Oo$21: 00$ ) in the study area Borja Ruiz-Apilánez and Inmaculada Mohíno. 
in the high street itself. The proportion of visitors is higher in Town Hall Square and decreases along the high street until it reaches Zocodover Square. This suggests locals are less likely to penetrate inside the historic centre and also illustrates differences in the use of both squares. The latter aspect is further explored in the subsequent analysis of stationary activities. Distribution throughout the day is also revealing, especially when comparing Wednesdays with Saturdays and distinguishing between locals and visitors. On weekdays, pedestrian traffic on the high street constantly grows during the morning and peaks twice before 12:00 and 14:00 (a pattern which differs from the typical Spanish practice of a late lunch taken between 14:00 and 16:00, see discussion below). Pedestrian traffic drops slightly and remains quite stable during the rest of the day, starting to fall late in the afternoon (Figure 6.7 below).

Pedestrian patterns can be better understood by analysing the local and visitor flows separately (Figure 6.8). The first peak is produced by locals (office workers on their coffee break, the users and clients of the existing administration offices and professional services, and unemployed people), whereas the second peak corresponds with the lunchtime period of visitors (mainly foreign tourists). In contrast on Saturdays, pedestrian traffic on the high street rises until noon, keeps growing more slowly during the afternoon, goes up sharply again and peaks before 19:00 to decrease slightly afterwards, which is quite uncommon for a high street in Spain. Local and visitor flows are quite similar until 19:00, although the latter start to arrive one hour later and at double the rate of locals after 12:00. This correspondence indicates similar behaviours, suggesting that locals use the area in a very similar way to visitors, as a leisure destination at weekends. After 19:00, visitors start leaving the area while locals continue to use this part of the city to go for a late walk, dine or have a drink, confirming the leisure-related role of the area for locals as well. Quite interestingly, on both days the side

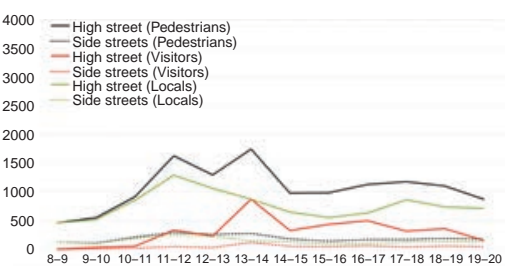

Figure 6.7

Average pedestrian volume per hour in the High Street and its side streets on Wednesday

Borja Ruiz-Apilánez.

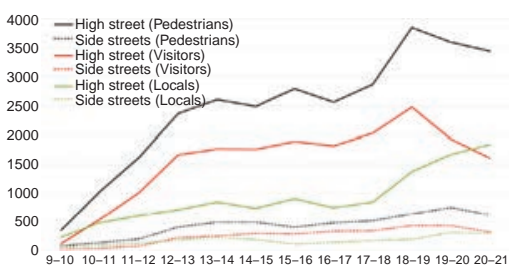

\section{Figure 6.8}

Average pedestrian volume per hour in the High Street and its side streets on Saturday

Borja Ruiz-Apilánez. 
streets, although carrying a fifth of the volume, replicate the same distribution over time, suggesting they play a tributary role.

Similar to the pedestrian traffic study, analysis of stationary activities illustrates that the three main public spaces of the study area - the high street and the two squares on either end (Town Hall and Zocodover) - show high percentages of visitors, a radical increase in numbers on Saturdays and clear differences in the distribution of activities among the three places, with different roles in the social life of this part of the city (Figure 6.9). Considering the whole area, the percentage of visitors involved in stationary activities is 50 per cent on weekdays and 65 per cent on Saturdays. The former is quite high - 1.72 times higher - compared to the 29 per cent of people observed on foot, whereas the latter is quite similar to the 60 per cent of Saturday's pedestrians. This suggests, again, that the way locals use the study area on weekends has certain similarities to that of visitors and is basically linked to leisure activities, whereas on weekdays the area must support other local activities related to different economic sectors.

The graphs in Figure 6.9 show a significantly different distribution of activities among the three places and a variety of percentages of visitors depending on the kind of activity, the place and the day of the week - but a similar distribution of activities on weekdays and Saturdays, especially in Town Hall Square and the high street. The comparative analysis of each place provides further information on the social dynamics of the area.

Town Hall Square (Figure 6.10) has a clear preponderance of visitors. Surrounded by the main façades of three magnificent buildings - the town hall, the cathedral and the Archbishop's Palace - but only two operating entrances - to the court house and a tourist information office - the square offers lots of things for visitors to see but very few things for locals to do. Among the numerous visitors taking pictures, listening to the explanations

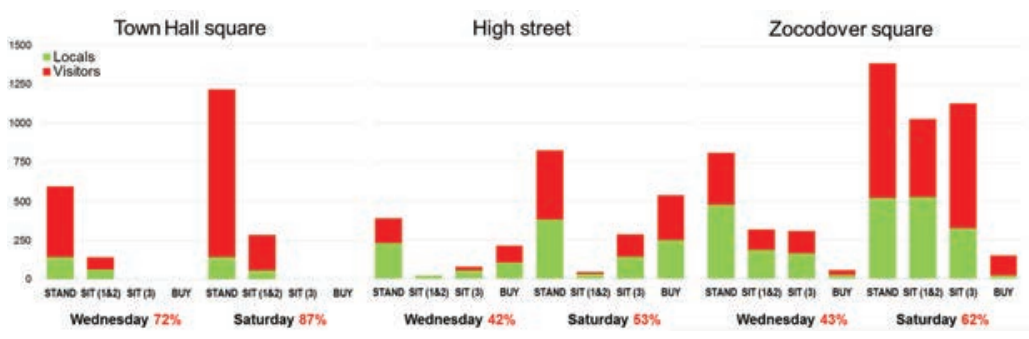

Figure 6.9

Distribution of stationary activities in Town Hall Square, the high street and Zocodover Square. Results from thirteen hourly headcounts per day Borja Ruiz-Apilánez. 


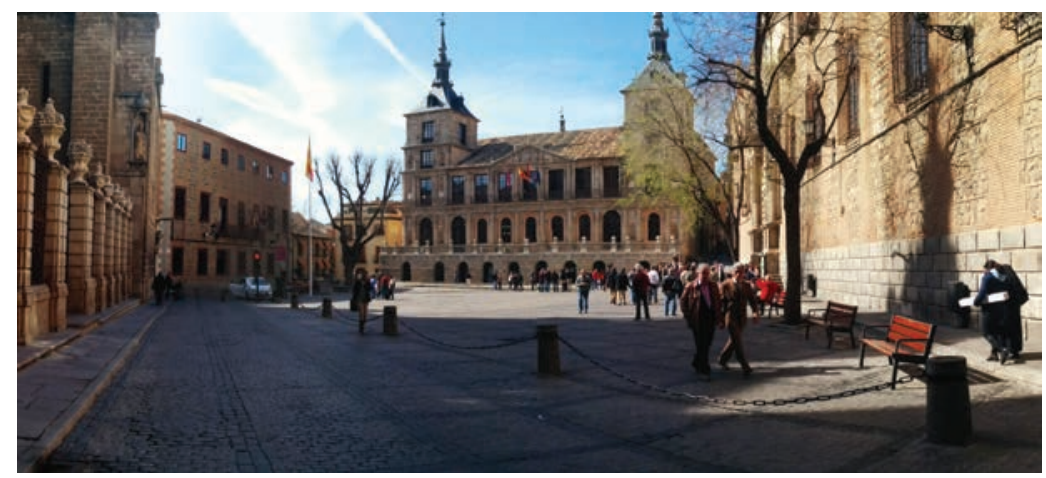

Figure 6.10

Town Hall Square from the high street. From left to right: the cathedral, the court house, the town hall and the Archbishop's Palace

Borja Ruiz-Apilánez and Mayte Arnaiz.

of a tour guide, admiring the architecture or resting from walks through the hilly historic city, it is hard to find any locals. The number of visitors in the square is 2.45 times greater on Saturdays whereas the low number of locals remains constant. It is paradoxical that one of the greatest urban settings of the city is not a place for its citizens - except for the few occasions the square holds a public event.

The high street (Figure 6.11) actually has a lower proportion of visitors, although the number of static visitors is similar to that of locals, especially on Saturdays. The majority of stationary activities are essentially linked to business activity because, aside from the many people shopping or eating outside, a good number of the people standing are actually window-shopping. The limited space and the immense pedestrian flows allow little room for other standing stationary activities, and very few sitting opportunities apart from those offered by the restaurants and cafés with chairs and tables outside. There are over twice as many stationary activities on Saturdays, but the percentages of people involved in each activity are very similar on both days, for both visitors and locals. This similarity points to the important leisure orientation that the high street has today. It is also significant that the percentages of locals and visitors shopping are almost equal, suggesting a similar dependence of those businesses on both groups, as confirmed by interviews with the shop managers.

Zocodover Square (Figure 6.12) is the place where people are more likely to stay for an extended period of time, either strolling, waiting to meet someone, chatting standing up or sitting on the abundant formal and informal seating, mostly fully occupied on Saturdays. These activities represent 


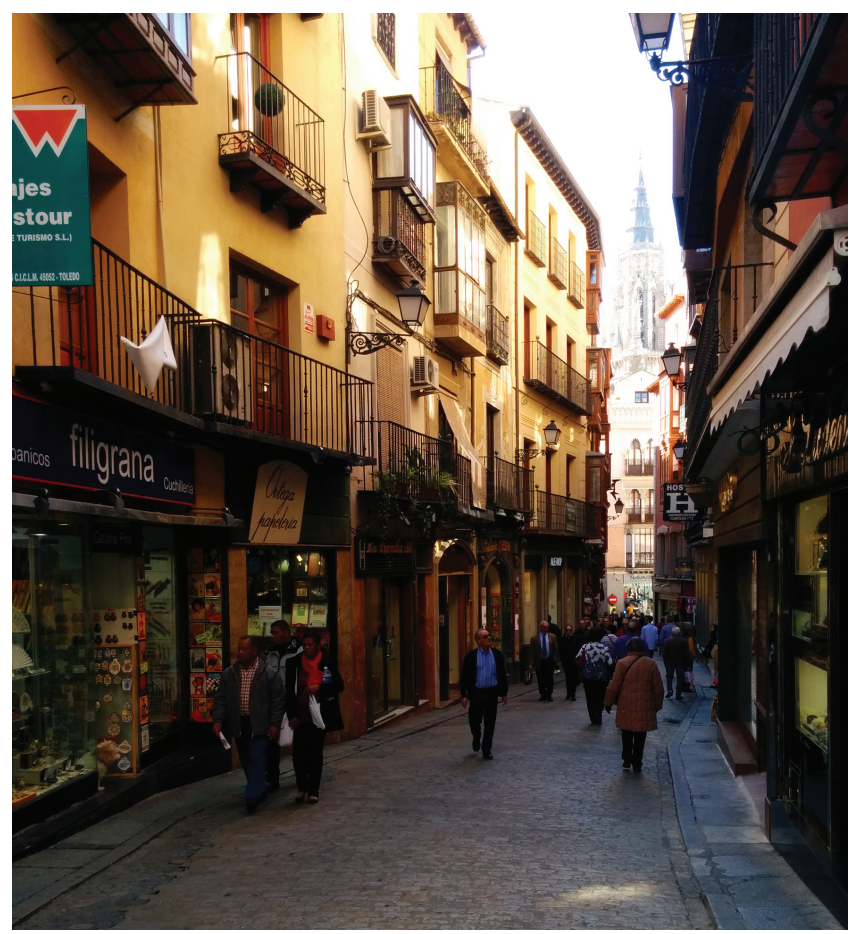

Figure 6.11

The high street. Comercio Street towards Town Hall Square. The cathedral's tower can be seen to the rear of the image Borja Ruiz-Apilánez and Mayte Arnaiz.

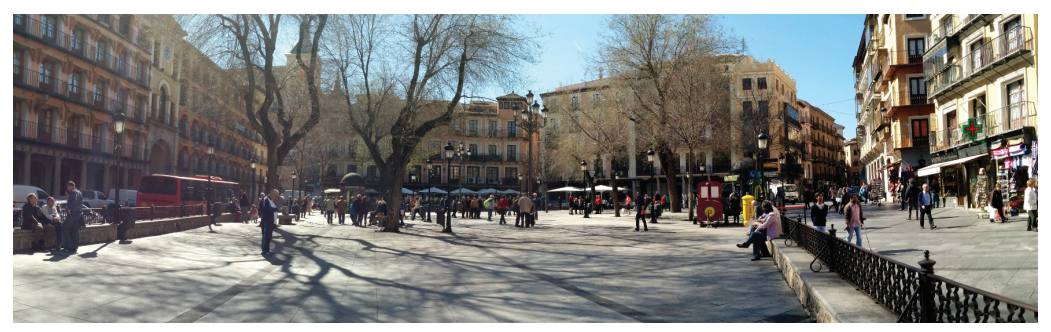

Figure 6.12

Zocodover Square from the north entrance. The high street begins at the back right Borja Ruiz-Apilánez and Mayte Arnaiz.

96 per cent of all stationary activities on both days. On Saturdays, there is a two-fold increase in stationary activities on the square - similar to that observed in the other two areas - and the overall percentage of visitors is also higher, increasing from 43 to 62 per cent. It is significant that the number of people sitting (locals and visitors) significantly increases on weekends, both 
in absolute and relative terms. More importantly, the percentage of locals in primary and secondary seating increases from 19 to 38 per cent, which is the greatest relative increase for activities in the three areas for both locals and visitors. It indicates that Zocodover Square is a place for longer and more relaxed stays, used for leisure by locals in the presence of visitors.

\section{Street frontage analysis}

The built environment surveys provide valuable data about the ground-floor land uses, the extent to which shop fronts are arranged to attract visitors and the upper-floor vacancy rate. Furthermore, the material gathered in short interviews with business managers - year of establishment, percentages of local and visitor customers and previous use of the premises - offers supplementary information to evaluate the stability and tourism dependency of ground-floor businesses. The resulting data suggest an ongoing process of change in the socio-economic aspects of the historic city.

The study area includes 127 buildings with 166 different properties on the ground floor. Eighty-eight per cent house economic activities and the remainder include residential, vacant premises and other singular uses such as the cathedral, the town hall, the courthouse or the Archbishop's Palace. A subsequent land use analysis shows that the retail sector (74.6\%) clearly dominates current economic activity in the area, followed far behind by the catering industry (18.3\%) and offices and professional services (5.6\%) (Figure 6.13). The low ground-floor vacancy rate $(5 \%)-$ which is in

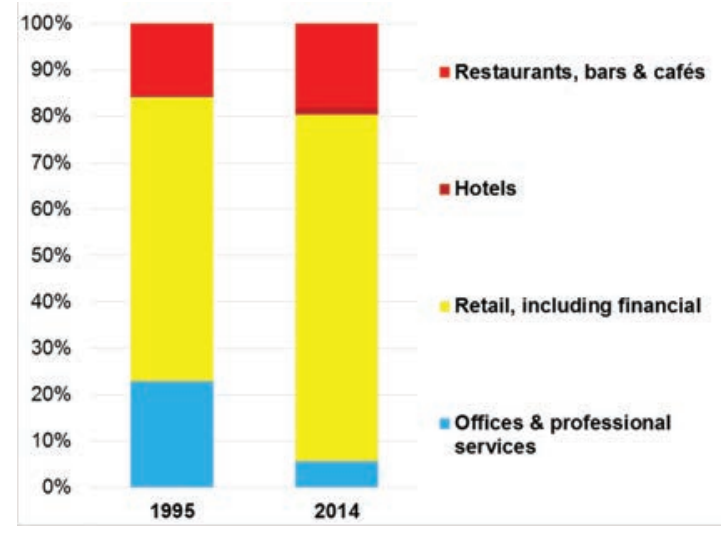

Figure 6.13

Distribution of ground-floor land uses in 1995 and in 2014. Percentages based on the number of units Borja Ruiz-Apilánez. 
fact lower than it appears in the analysis, as approximately half of the vacant units were being refurbished and were due to open soon for business - and the clear preponderance of retail and catering industries $(81.8 \%$ of all the 166 units in the area) do transmit the impression of a prosperous urban area. However, the imbalanced distribution of land uses, and the complete absence of other uses such as community uses that would typically serve a local population (Vaughan et al. 2013), suggest a possible socio-economic dysfunction for the town centre

The high street is mostly flanked by commercial-residential buildings. This building type has common attributes across cultures. Typically these are: a location on collector streets and commercial-residential boundaries, narrow frontages, maximization of retail frontage and maximization of openness at ground level (Davis 2009). However, detailed observation of ground floor premises shows that some buildings have access to the upper floors through the retail units on the ground floor, others use the upper floors as storage and some eliminate the stairs to basements to gain extra ground floor area. All of these practices, although not always new, are symptomatic of a potentially problematic retail intensification at the expense of the traditional pattern of living or working above (and below) the shop.

A comparison of land use distribution between the Busquets (2000) study and today (although absolute numbers are not comparable due to differences in the size of the area covered in each case) shows an increase of 20 per cent, indicating a change in the economic activity of this part of the city that is apparently becoming less diverse and more retail-focused (Figure 6.13). The detailed breakdown of the retail sector of the study area (139 units) shows a much greater emphasis today on shops catering to the tourist sector at the expense of provision for locals. Comparing the current distribution with the 1996 data by Troitiño et al. (1998) shows clear differences. The increments in the overall share of jewellery shops, etc. (+80\%), clothes stores $(+57 \%)$ and, of course, souvenirs and visitor focused stores $(+28 \%)$ suggest an ongoing process of reorientation of the retail sector towards the visitor customers (Figure 6.14).

Business managers provided estimates of the percentage of visitors among their customers: on average 56 per cent for all economic activities. However, there were wide differences across types of economic activity, ranging from less than 20 per cent to more than 80 per cent. Both the retail sector and the catering units have an identical estimated 59 per cent of visitor clients, suggesting a similar dependency of both sectors on tourism. The geographical distribution across the study area shows some spatial concentration in the central part of the high street for these two tourist-focused business types (Figure 6.15). 


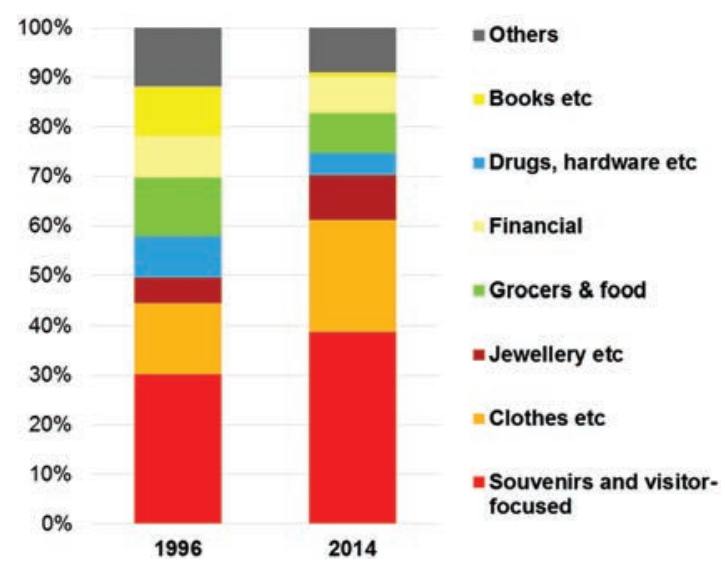

Figure 6.14

Distribution of the retail sector in 1996 and 2014 .

Percentages based on the number of units

Borja Ruiz-Apilánez.

The survey of the business frontages classifies all the ground-floor premises in the area into three categories: (a) visitor-oriented, (b) partially visitor-oriented and (c) others. Shops displaying Toledo T-shirts, caps and the like, swords, damascene ware and other such souvenirs all fall into the first group, whereas bars announcing 'Tourist Menu' and shops selling typical or regional products also consumed by locals, such as the famous Toledo marzipan or Manchego cheese, fall into the second category (Figure 6.16). Of all the shops surveyed, 45 per cent are fully visitor-oriented with an additional 11 per cent partially so. There is less of a focus on visitors, in particular in the case of restaurants, bars and cafés, where 20 per cent are fully visitor-oriented, 64 per cent are partially so and the remaining 16 per cent have no especial orientation towards visitors. These figures are to a certain extent confirmed by the business owners interviewed: both shop and catering establishment owners estimated their tourist customer base to be around 56 per cent.

There has evidently been an increase in the proportion of touristoriented shops in recent years, with businesses established in the 1980s, 1990 s and onwards having a proportionate increase of visitor-oriented units (for example, of businesses established in the 1980s, 55 per cent are visitor-oriented, whilst those established in the last decade constitute nearly 75 per cent). This supports the previously suggested ongoing process of reorientation of the retail sector towards tourists and implies a risk of losing authenticity, both due to the touristic nature of the businesses and due to the concomitant reduction in the local residential population - in fact the 


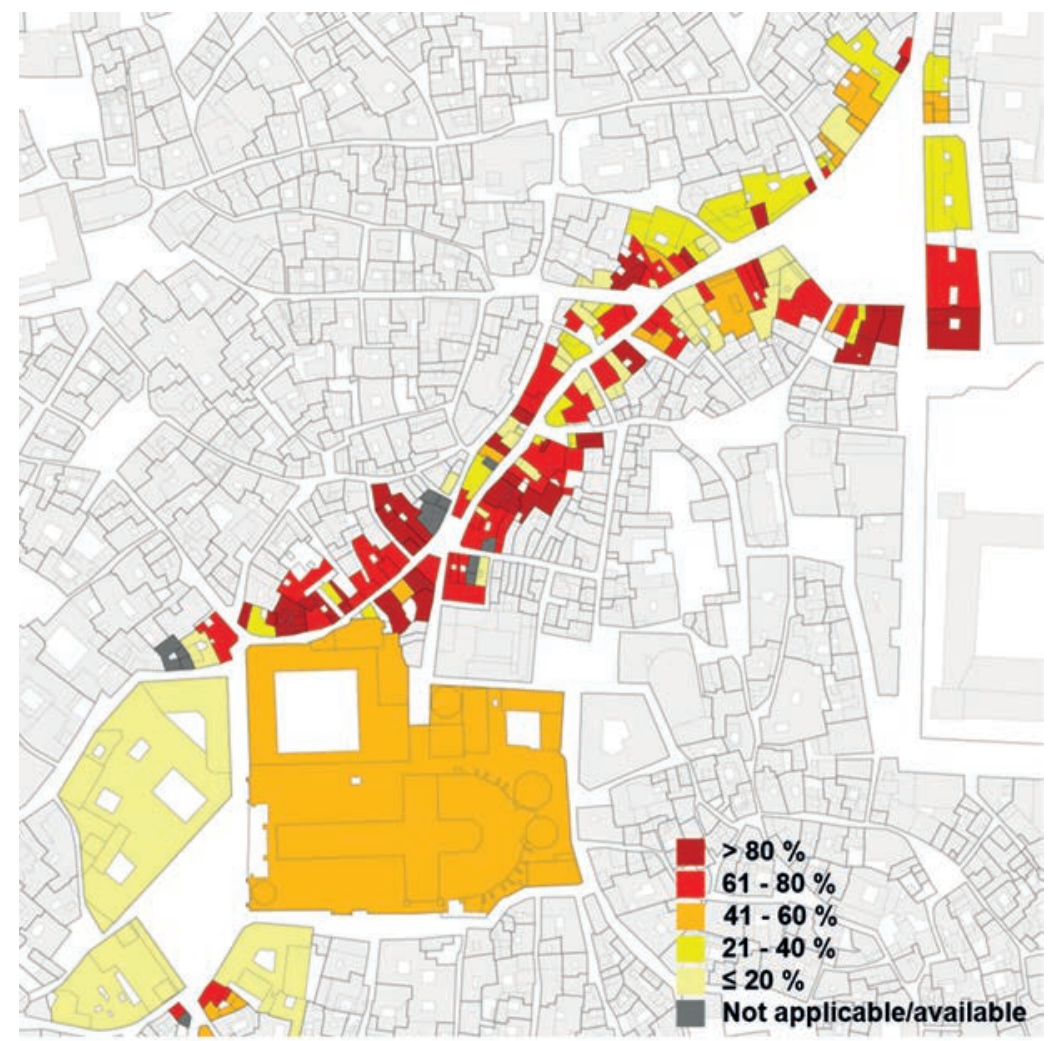

Figure 6.15

Percentages of visitor customers in ground-floor units

Borja Ruiz-Apilánez and Inmaculada Mohíno.

latter is a common risk amongst other World Heritage sites (Pendlebury et al. 2009).

The shift in orientation towards visitors corresponds to the loss of population within the historic city. This decline could be related to the decreasing average household size in Spain - from 4.22 in 1940 to 2.53 in 2014 - but the surveyed housing vacancy rate of 20 per cent in the area confirms the worrying demographics and changing socio-economic situation of the area. According to official statistics, this value is quite similar to the housing vacancy rate of the whole historic city in 1991 (22\%) and 1981 (18\%), although smaller than the rate provided by the study published in Busquets (2000: 137), which showed a 25 per cent vacancy rate for the whole neighbourhood and 26 per cent for the Zocodover district. In any case, it is certainly a high vacancy rate for a long-established area 


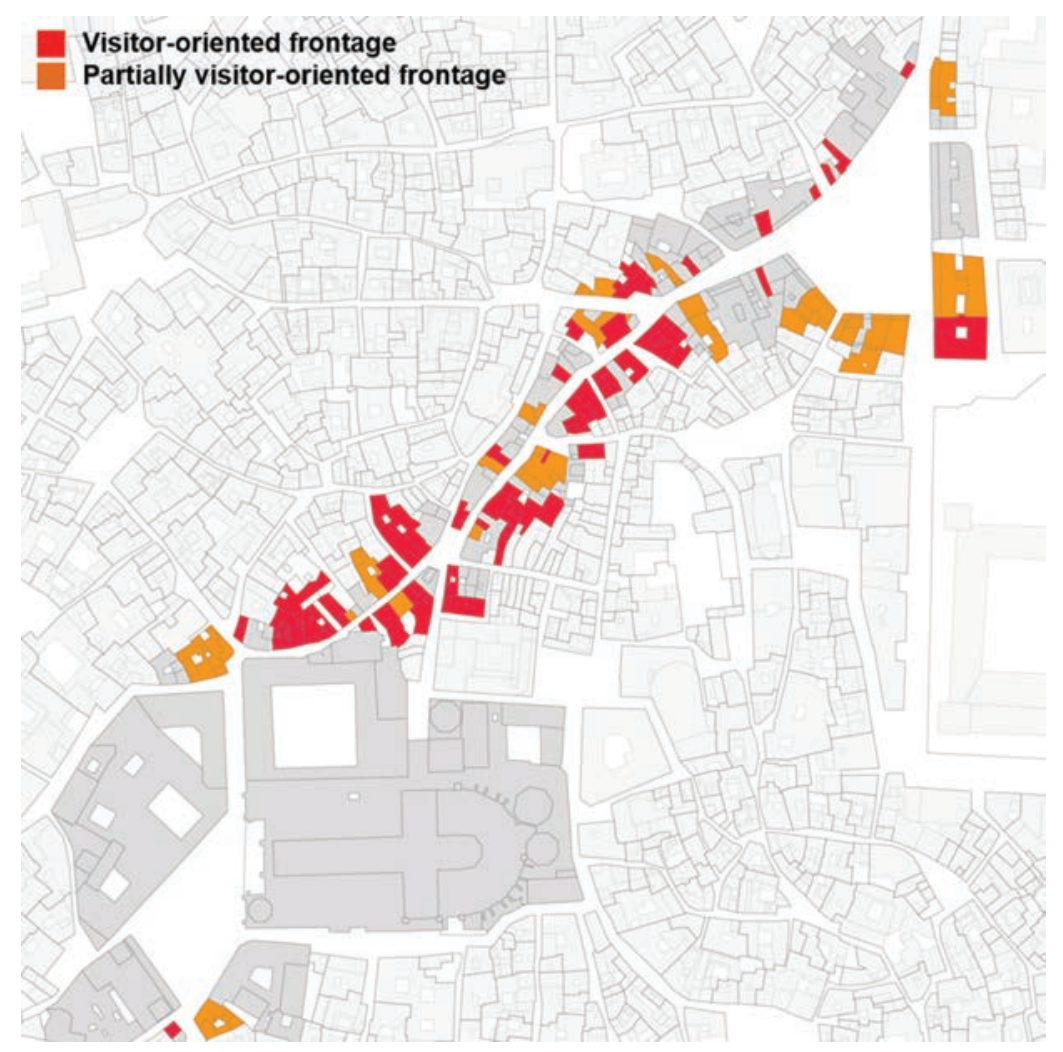

Figure 6.16

Distribution of frontages according to the visitor-/non-visitor-oriented image Borja Ruiz-Apilánez and Inmaculada Mohíno.

such as this one (rather than an area that has only recently been developed) and suggests a critical underlying dysfunction, especially when contrasted with the city overall, where vacancies have decreased over time from a high of 20 per cent in 1981 to 11 per cent in 2011. Indeed, the 20 per cent vacancy rate in the study area suggests its situation in comparison with the wider city might be the key to the socio-economic reality of the historic city.

\section{Street network configuration}

The preceding sections have suggested that the continuing loss of population in the historic city of Toledo is part of a wider socio-economic process. As first recognised by Zárate and Vázquez (1983), numerous problems 
of historic cities date back to the expansion of Spanish cities between the 1950 s and 1970s. Subscribing to this thesis, the following analysis suggests a spatial explanation based on the correspondence between the evolution of some syntactical variables of the street network of the historic centre and its demographics.

Space syntax tools were used to analyse the average values of the measures of integration and choice (see this volume's Glossary for a detailed explanation of space syntax) in four different time periods - 1950s, 1970s, 1990 s and 2010 - indicating the potential for spatial accessibility in and around Toledo's high street in each period. These four decades represent key phases of the socio-spatial development of the city. The analysis uses space syntax maps of Toledo's street and road network produced for an earlier study by the authors (Arnaiz et al. 2013) (Figure 6.17).

In the 1950 s the city was still mainly located within its original walls, although there were some extensions to the north along the road to Madrid. On the 1970s map, it is possible to identify the more regular grid of the pseudo-ensanche extension north-west, a small neighbourhood between the railway station and the Infantry Academy to the east, and the incipient Benquerencia industrial and residential estates further east, all built during the preceding dictatorial decades. The 1990 s map shows a small residential area in the north-west, the expansion of the railway station neighbourhood and the partial consolidation of the Benquerencia estates during the first urban cycle of the current democratic period. Finally, the 2010 s map shows the result of the last and most expansive cycle, with new residential developments in the north-east and further consolidation and extension of the Benquerencia estates.

The analysis of the evolution of integration values of the street and road network in the four stages shows a radical transformation of the spatial network, indicating how the historic city and the high street have been gradually losing their relevance and dominance in the system. Indeed the average normalised angular integration values for the high street segments drops from 1.01 in the 1950 s to 0.76 in the 2010 s (see Figure 6.17, where it is referred to as NAIN). See Hillier et al. (2012) for a full explanation of normalisation. It shows that as the city has grown beyond its walls, the dominance of the high street in relation to the wider city has become much reduced. Choice values similarly fall, from 1.37 in the 1950 s to 1.29 in the 2010s. It is interesting to note that this drop in spatial values corresponds to the proportional drop in the historic city's population when compared with the city overall in each decade.

The reasons for the loss of population in the historic city have commonly been associated with its own inner conditions such as lack of 


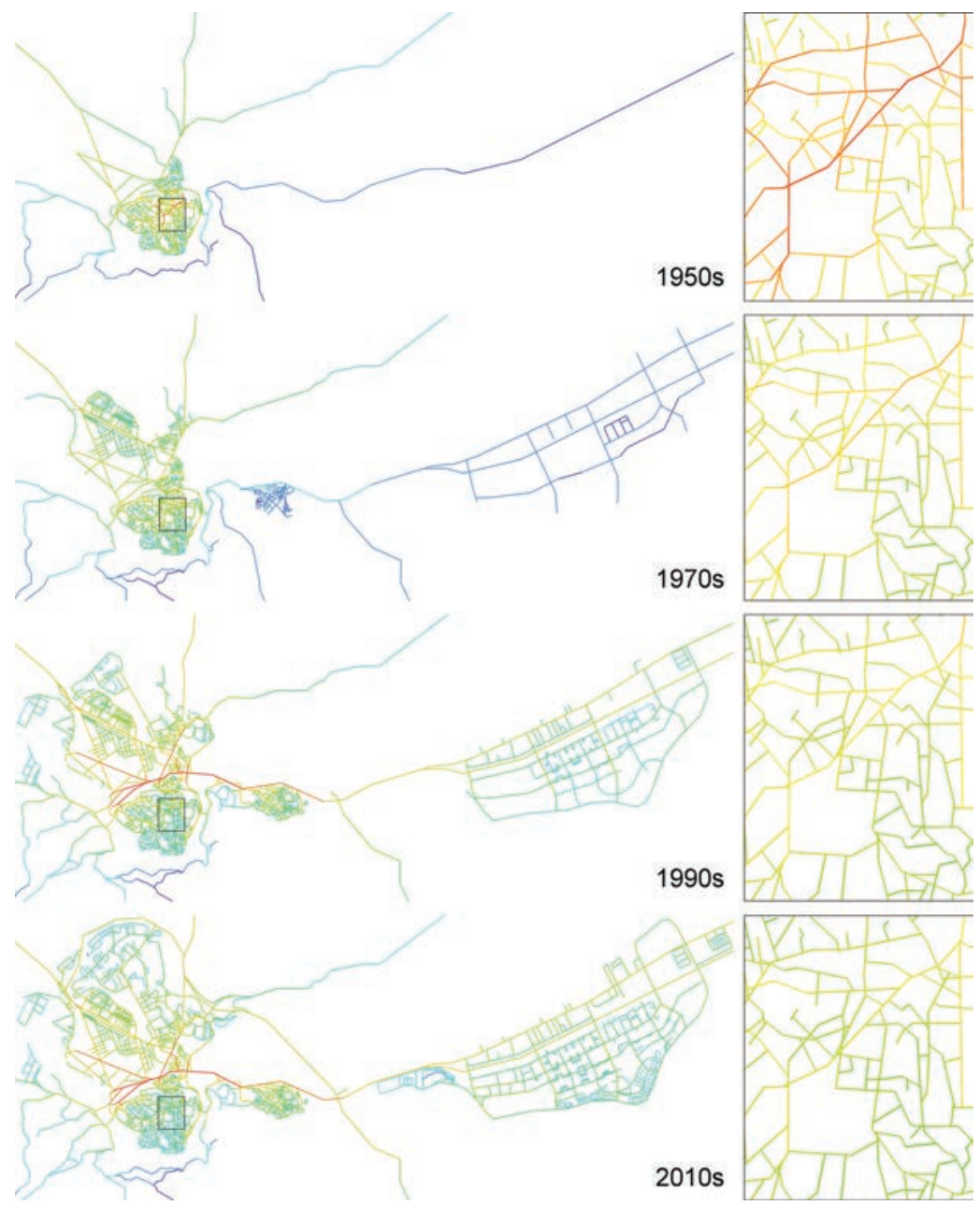

Figure 6.17

Evolution of normalised angular integration (NAIN) for four different time periods for the city of Toledo. On the right, the study area is shown in greater detail. The warmer the colour, the higher the integration value (ranging from deep blue to red) Borja Ruiz-Apilánez and Mayte Arnaiz.

facilities, traffic and environmental problems, and poor living conditions (Troitiño et al. 1998). However, most of these difficulties have been greatly attenuated and demographics have not improved significantly.

As has been illustrated here, the progressive loss of relevance of the historic city in the street and road network of the whole city can be seen to be related to another, external cause - in fact literally external, because it 
is the evolution of the city outside the walls that seems to have changed conditions within. Since the city of Toledo began to expand beyond its walls, its development has resulted in a loss of potential to attract movement to and through the historic centre (as indicated by the measures of integration and choice, respectively). As a result, the historic city has been progressively abandoned while other parts of the city, as they gained configurational status, have become more populated.

\section{Conclusion}

At the beginning of this chapter we showed how in previous decades corrective and preventative actions were considered essential in order to retain population and preserve the built heritage. Subsequent studies found the old city to still be 'the multifunctional centre of the city' (Troitiño et al. 1998) with an economic activity characterised by the predominance of basic everyday and occasional shops together with bars and cafés (Equipo de Técnicos en Transporte y Territorio 1994).

This study has investigated the current state of Toledo's historic centre, based on the examination of its core network of streets. Interviews, surveying and observation techniques have been used to research aspects of the socio-economic situation beyond the lively streets and active ground-floor businesses that characterise the main pedestrian thoroughfares. An effort has been made to compare the outcomes with data from preceding time periods.

The analyses show that almost two decades since it was last comprehensively studied (Troitiño et al. 1998; Vázquez et al. 2000; Busquets 2000), the situation is, at least, concerning. Despite intensive renovation of the built environment, investment in facilities for transportation, healthcare, education, culture, administration, etc., and progressive traffic reorganisation, the demographic decline has continued, albeit with a levelling-off in the past few years that could be due to the global economic recession. The analysis shown here has identified several other socio-spatial and socioeconomic processes that could be associated with this ongoing demographic change, as follows.

First, there is an extremely uneven spatial distribution of uses and activities producing spatial concentration and segregation. In the street network, the main streets carry five to ten times the pedestrians on other streets, causing serious congestion problems on a few streets while many remain almost empty, uninviting and, potentially, unsafe. Some squares are becoming scarcely used by locals and hold very few kinds of activities and people, and might progressively lose their role in the life and memory of Toledans, 
as detected in Town Hall Square, one of the most traditionally used and beautiful places in the city. That pattern of land uses shows touristic economic activities concentrated on the ground floors of buildings aligning the main routes, while upper floors suffer from a high 20 per cent vacancy rate and nearby streets have notably fewer economic activities.

Second, there is evidence of a functional restructuring of the historic city. During the 1980s and 1990s, the historic city absorbed a large number of headquarters and offices of public and private institutions and corporations, but the 2000 s have witnessed not only the relocation of many of the latter organisations and companies to newer buildings situated in other parts of the city, but also the opening of two shopping malls on the city outskirts. Toledo has not escaped from the effects of the rise of the network society (Castells 1996) and the old city centre is becoming less multifunctional. The survey has shown the current loss of offices and professional services and how economic activities are dominated by the retail and catering industries.

Third, the centre is no longer the shopping reference point for the rest of the city. Despite the previously described retail dominance, it is experiencing a sectorial specialisation with an emphasis on tourism and leisure. This is illustrated not only by the above-mentioned high share of the catering industry among the ground-floor premises, but - as shown in the detailed analysis of the retail sector - also by a clear preponderance of souvenir and visitor-focused businesses. Nevertheless, whilst the high number of people - both visitors and locals - sitting in Zocodover Square confirms the area as a leisure destination, with a busy nightlife that is primarily for locals, this is because only 27 per cent of the visitors spend the night in the city (Esteban et al. 2005) and many hotels are quite distant from the historic centre (Zárate 2007).

Fourth, the area shows a growing economic dependency on tourism. This and the above-mentioned sectorial specialisation have consequences that are unlikely to stimulate demographic recovery. The number and distribution of shops serving the needs of local residents has been decreasing over time. This offer reduction, and the increasing percentages of visitors among consumers, produce a rise in the price of goods that further discourages locals from shopping within the historic centre.

Fifth, there is a growth in businesses with a clear visitor-oriented image, presenting risks of a loss of authenticity for the historic centre. Lying beneath these last three evidenced processes are the astonishingly high number of visitors who stroll around the historic city daily - 29 per cent of the pedestrians on weekdays and 60 per cent on weekends - and the low number of residents who, being as few as they are, cannot rebalance the socio-economics of this part of Toledo. 
Lastly, it has been shown that in order to understand the demographics and socio-economics of the historic city it is essential to recognise the position of the old city in relation to the city overall. In this sense, the analysis of the spatial network evolution of the study area in relation to the entire city has demonstrated that as the city grew, the old city was left behind, playing a less relevant role in the network as a whole. Here, it is key to understand centrality as a process and, as Hillier (1999a: 107) has pointed out, to be aware that spatial factors are not only decisive in the 'formation and location of centres', but also in 'developing and sustaining their vitality'.

In the case of Toledo, it has been shown how the old city is shifting from being a multifunctional centre, serving a local population, to increasingly becoming a predominantly touristic and leisure centre, providing a showcase for Toledo's symbolic centre. In effect this symbolism and the apparent success of the old city in drawing visitors to its well-preserved architectural complex are masking a continuing demographic decline that seems to be irreversible, based on current trends.

Taken together, the study outlines the current socio-economic situation and reveals ongoing socio-spatial dynamics in the historic city. The analysis of the case of Toledo illustrates how urban centres - in general and not only historic ones - besides being affected by spatial transformations inside the district itself (Karimi 2000) can be significantly influenced by spatial transformations occurring within other parts of the city's street network (Perdikogianni 2003). The study also shows how lively streets can give the misguided impression of being active live centres, when the reality is entirely different: an urban fabric in serious decline. It shows how decisive reorganising of urban processes can cause change beneath the surface, emphasising the importance of research to reveal the reality underneath. 


\section{PART C \\ High Street Diversity}

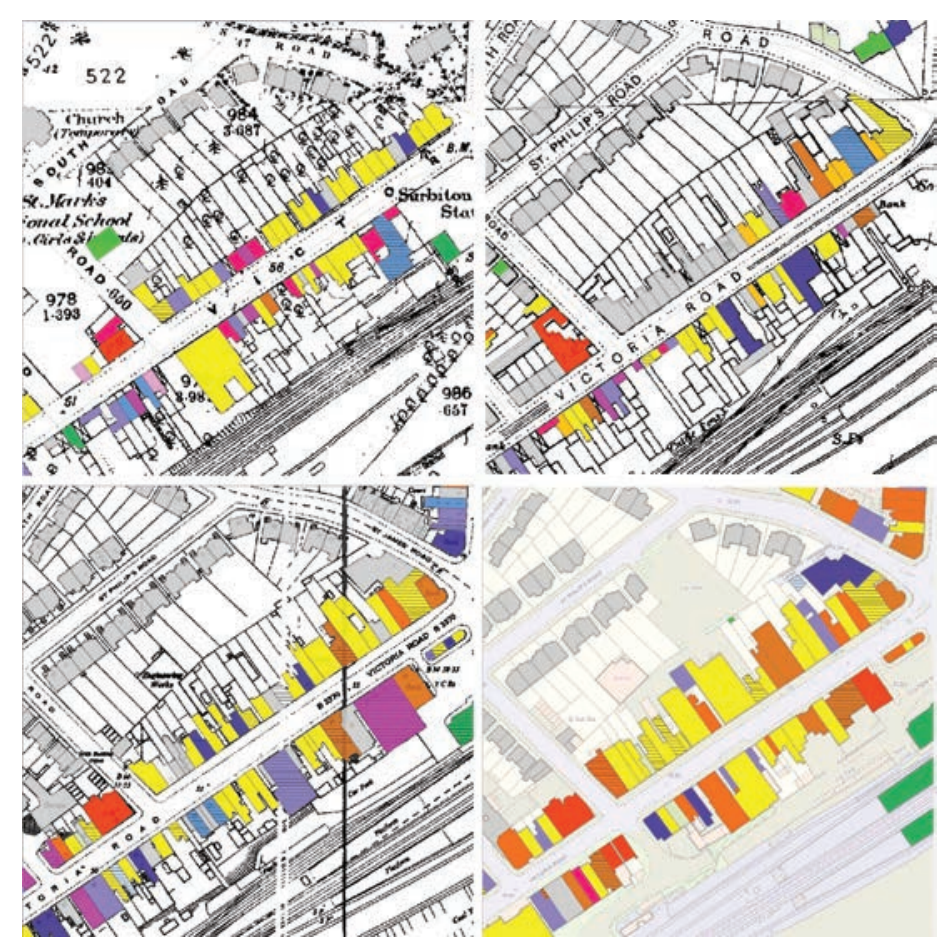

Non-domestic land uses, Victoria Road, Surbiton 



\title{
Chapter 7 \\ High Street Diversity
}

\author{
Laura Vaughan
}

\section{Introduction}

The nursery rhyme of the butcher, the baker and the candlestick-maker is increasingly used nowadays to emphasise the importance of diversity in the high street. Broadly equivalent to the main street in the USA, the high street is a common metonym used in public debate when discussing town centres and is frequently alluded to when discussing the apparent decline of smaller centres. As shown by Griffiths in his chapter for this volume, discussions of town centre decline typically manage to convey two messages at once: that the traditional town centre contains a variety of uses, and that those uses will include both shops and small-scale craftsmen or manufacturers. This is frequently set in contrast to cases where high streets are transforming into bland 'clone towns' comprised of large chains or where high streets are in decline, comprised of charity shops and shuttered business units. Or, alternatively, it is presented in contrast to the supposed move of retail online, with the 'death' of the high street approaching fast. Elsewhere in the world, particularly in North America, the death of suburbia's centres has apparently already occurred, despite strong evidence to the contrary from research conducted by, e.g. Keil and Shields (2013), and indeed the infinite variety of suburban life continues to spread world-wide.

One solution to the decline of some suburban centres is diversity. It is a measure of success increasingly cited in government reports and academic research alike, and earlier research has suggested how multifunctional town centres sustain adaptability over time: with evidence that centres are much more resilient if they are not reliant on just one form of activity (Vaughan et al. 2013). But the reality is that diversity is rarely measured with any great accuracy or detail and measures of diversity that take account of a spatial dimension are rarer still. After all, diversity has 
innumerable spatial variations. If we take land uses as an example, diversity can take the form of mixing at the scale of a block face, two sides of a street, around a corner or within a certain distance. Each of these has consequential social and economic relationships, so a mix of uses across a town centre does not necessarily mean that uses are mixed along a street alignment. The challenges of measuring diversity and its significance for suburban studies lie at the heart of the research described here.

In her influential book The Death and Life of Great American Cities, Jane Jacobs (1961) proposed four conditions for creating city diversity: a mixture of primary uses within each district and within each part of the district; short blocks and multiple intersections; a variety of buildings of different types and ages; and a dense concentration of people, including people resident in the district. Her ideas recur in every decade since - probably as they are such a powerful argument against mono-functional districts. For suburban settings such as those described in this book, Jacobs' description of the daily ballet of people as doing little more than coming and going is even more important, as it demonstrates how public life is comprised of the prosaic, small-scale activities that collectively make a trip into the local centre worthwhile. An understanding of the 'rhythmic landscape' of cities, comprised of differing intensities of activity, and different uses and people, has been taken up by more recent writers, including John Allen (see Massey et al. 1999), who emphasises how even changing patterns of light and smells recompose the city hour by hour. More recent research by Palaiologou and Vaughan (2012) on the evolution of Manhattan's row houses and Islington's terraced houses provides empirical evidence on how spatial boundaries between house and street and the street's own urban setting in turn, create shifting patterns where the individual is (successively or abruptly) transformed from inhabitant, to commuter and to citizen as they move from house, to local street, and to the city at large. The latter research shows how diversity of uses contributes to this shifting pattern, by bringing local and stranger into contact with one another. The diversity of uses creates a rhythm, where, as one walks down a street, a regular change in the visual landscape creates a natural setting for an intermingling of people on their daily perambulations.

It is interesting to continue the language of landscape and to consider an analogy between hedgerows and town centres. Ecological research proposes that hedgerows tend to have a much greater diversity of plants and animals and to be thicker, taller and more continuous as they increase in age (Hooper 1970). This chapter proposes that there is an analogous consideration of diversity and age that can be made by conceiving suburban high streets as 'hedgerows'. Beyond the rather neat association between leafy suburbs and green hedges, such a conception implies the emergence of 
distinctive, complex and stubbornly persistent material cultures over time. As Alan Penn and colleagues have pointed out, diverse areas are not formed randomly, but are the outcome of highly structured sets of related systems (social, economic and cultural) as well as physical (Penn et al. 2009). Also referring to ecological theory, they state how the outcome of the long-term formation of diversity is not a random mixing of uses, cultures and economies, but a distinct pattern that follows a spatial logic. Just as in ecological systems theory, where the richness and evenness of species in a community (i.e. the number of different types of species and the number of each species in the same area) are said to contribute to the overall resilience of the ecosystem, the following historical morphological analysis, together with an exegesis of historical business directories, explores the extent to which the diversity of suburban town centres is associated with their historical pattern of land use and habitation.

In one of the most famous studies in the field of urban morphology, Conzen (1960) showed how the mediaeval burgage plots of the town of Alnwick went through a cycle of continuity and change over time, with shifting patterns of plot sub-division into open-plan, multiple use, rear courtyard uses and partial consolidation. This is not a mere function of built form or urban tissue. The underlying land pattern that follows this pattern of continuity and change has its own life-cycle, but importantly, this life-cycle maintains certain generic spatial relationships. As was proposed so lucidly by the late architect Richard MacCormac in his Anatomy of London (1996):

there seems to be a pattern in the relationships which reoccurs over time though the functions change. For example, in the eighteenthcentury-city large houses on primary streets were inhabited by highincome families and the mews behind serviced them. Today the houses might be offices with the mews inhabited by businesses selling services - commercial or professional - like photocopying, printing or sandwich bars to the primary users.

According to MacCormac, such streets are 'like reinhabited coral reefs' (MacCormac 1996: 307). This built form, land use and spatial configurational interdependence are not trivial matters, since just as much as coral reefs constitute delicate ecologies that can weather minor changes in sea currents, predators and the like (and the reader can easily discern a similarly effective analogy to be made with regard to hedgerows), a major disruption to that ecology can be life-threatening. Understanding the nature of diverse ecology in the context of the suburban high street is considered in this chapter.

Another theoretical approach needs explaining at this juncture: the way in which the built environment is considered as a configurational network, one in which, rather than considering buildings, plots or streets in isolation, the relationship of a single street to its surroundings is measured 
using space syntax analysis. In this way, diversity is considered as a spatially related factor, rather than a random mixing of land uses (or people) within an area. As mentioned above, diversity can take different forms according to its spatial context (see also Marcus and Ståhle 2005; Sevtsuk and Mekonnen 2012). If one considers the differences in experience between, say, walking down a street with five different uses on both sides of the street, to that of a street where only a single use is observed on either side, but four others can be found round the corner, the importance of bringing the spatial detail into what would otherwise be dismissed as 'mixed-use' becomes evident. This is even more the case when one considers the way in which different uses set up different potential connections between building and street and the people using that street.

This chapter examines four periods of London's development to provide evidence for a new proposition on how high streets adapt to change.' It opens with a discussion of the need to distinguish between mixed-use in general and spatial diversity in particular: the fact that diversity has many dimensions that arguably work together to make for a rich ecology of the high street experience. Analysis of shifting diversity patterns over time is shown to correspond to the continuity and robustness of the street network. Seeing architecture as an object - where the mixing of different people carrying out different activities makes for the rich experience of encounter and daily routine - is shown to be a mundane but vital aspect of what makes high streets places that continue to be valued. A focus on building diversity ends the chapter, illustrating how the persistence of street form is tied up with how buildings and plots are arrayed along the high street.

\section{Concepts of diversity}

Notions of diversity cannot be separated from the phenomenological properties of urban and suburban built environments. These are consistent with claims made by Hillier et al. (1987) that the fundamental intelligibility of the built environment is an essential condition of bringing people together in public space and affording them encounter. In space syntax theory 'intelligibility' refers to the ability of certain configurations to allow for an overlap between people carrying out local activities on foot, alongside people passing through on their way to longer-distance trips. Other research by Penn et al. (2009) - building on Hillier's proposition regarding centrality being part of a spatial-temporal process (Hillier 1999a) - has shown for example that areas of the grid with a greater amount of land use diversity have spatial properties that allow for greater amounts of circulation, with a denser 
and more intensified local grid (Zhang 2005). ${ }^{2}$ Penn et al. point to another essential aspect of diversity: this is not purely an aspect of land use distribution, and in order to have land use diversity, they argue, an urban area must 'support a diverse social and economic life as well, with all the outward manifestations of that which are open to the sensory experiences of sound, sight and smell' (Penn et al. 2009: 220). They suggest that experiential diversity is formed by differentiating building shapes, land parcels and movement patterns, and consequently shaping the pattern of human encounters. The importance of the experiential dimension of the built environment, of 'human bodies in material space', has also been highlighted by the phenomenologist David Seamon, who maintains that the vibrancy of urban places is supported or stymied by the material or spatial qualities such as street configuration, population density and mix of activities (Seamon 2013: 143). This rich tapestry of the architectural-social morphology of town centres, alongside the importance of seeing such places as emergent - that is, as having developed their spatial/experiential qualities over time (as pointed out by Griffiths elsewhere in this volume) - is the approach used here: intending to refute the apparently conventional nature of these sites and enquire into the forces that help shape their inherent complexity.

\section{Land use diversity}

This chapter describes research that took place as part of a four-year study of a sample of London's outer town centres. This built on a previous threeyear study, which looked into the development of London's suburbs both spatially and economically to find the factors that make their town centres and surroundings successful and vibrant. The four cases were chosen from each of the outer London quadrants: north-west (High Barnet), north-east (Loughton), south-east (South Norwood) and south-west (Surbiton), and detailed data on historic and contemporary land uses, changes in street network configuration and built form were compiled into a large geographical information database to allow for detailed analysis of the factors that contributed to the centres' success. This was coupled with a contemporary ethnography of two of the cases.

The first project's research into London's historical growth found that its suburbs had a high degree of continuity in street networks over time, providing a relatively robust network. This can be seen on the sequence of maps of Surbiton's evolution since the 1820s (Figure 7.1). Whilst in the earliest period Surbiton was the name for the small junction of streets south of Kingston-upon-Thames, by 1880 , though still a semi-rural area, it had loci 


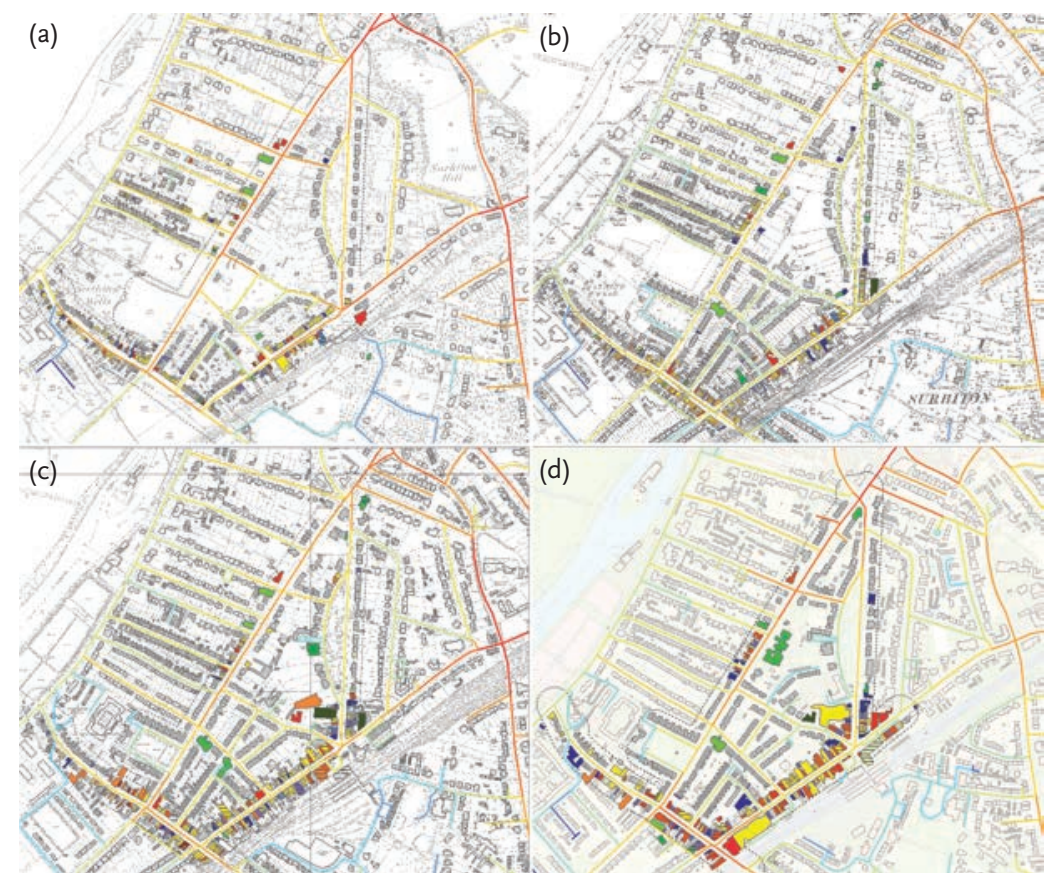

Figure 7.1

Non-domestic land uses in Surbiton (a) 1880, (b) 1910, (c) 1960 and (d) 2013, overlaid with segment angular integration at $800 \mathrm{~m}$. Refer to Fig. 7.4 for land use legend

Contains Ordnance Survey data (C) Crown Copyright/database right 2013.

of settlement that are recognisable today. The sequence of images shows intensification of the network, with particular building features (including garages) reshaping the network to accommodate new ways of living; it is only in the contemporary map that the planned interventions in the twentieth century are seen to have had a profound effect on the larger-scale connectivity of the area when the Kingston By-Pass enabled the creation of a focus of activities reliant on car travel and corresponding to wider patterns of accessibility, but not local ones at all, such as a traveller's hotel (see more on this in the chapter by Dhanani in this volume).

If we peel back to the past we can see how the availability of passing movement changes with the evolution of the street network; it in turn adapts its configuration to serve land uses of different types, according to the most beneficial catchment distances. Space syntax analysis considers the urban network as a spatial configuration, proposing a fundamental relationship between spatial morphology, movement patterns and the distribution of land uses as a 'movement economy'. The synergy of activities in and around 
suburban town centres has been shown to stem from the presence of overlapping movement flows of through-movement (represented by a statistical correspondence between the space syntax measures of choice and integration). This overlapping of different types of movement is proposed to create the conditions for local diversity in land use. So in Figure 7.1 we see that in 1800 the original settlement of Surbiton (on the north-western edge of the map) was connected to the larger-scale network through roads leading to the south-west (on the edge of the River Thames) and to the south-east. By the time the railway arrived in 1890, new connections had been created to serve a different set of scales of movement and activity.

In parallel to this shifting of scales, some sections of the network show features of a path dependency, with certain generic characteristics emerging, so that a particular trajectory of a business or industrial activity ends up persisting over time (Verburg et al. 2004; Page 2006; Griffiths et al. 2009). For example, Ewell Road in Surbiton served doctors and other such professional and commercial services in nineteenth-century Surbiton (Kelly's London Suburban Directory 1901) ${ }^{3}$ and today it serves a very similar range of activities and services, although with more restaurants than in the past.

In the case of the research described here, the relationship between the structure of the built environment and functional land use distribution in suburban town centres was associated with its spatial setting by recording all non-domestic land use and constructing a dataset in which all the street sections were listed, and then attributing the spatial unit to the buildings lying alongside it (or vice versa). Diversity was then modelled in differing ways: considering the relative concentration of non-domestic uses in particular streets, taking account of frontage length or building footprint area as well as the degree of land use mix street by street across the town centre - either according to land use group (of which there are five) or by the finer-detailed class (of which there are theoretically twenty-six, although none of the cases had more than twelve in any of the studied periods).

The first analysis looks at the pure mixing of activities across a large area of each of the four cases. The areas were determined by drawing a notional line around all the streets which had continuous non-domestic activity from 1890 to 2013 , so there might have been streets excluded from the analysis if their non-domestic uses did not exist in more recent periods. The distribution of the different classes of use over time was analysed by drawing bar charts of weighted counts of land uses in High Barnet, South Norwood and Surbiton (Figure 7.2). These graphs show an increase in the proportion of street segments with the maximum of four or five use classes in the latter two periods and a commensurate decrease in streets with only 
(a)

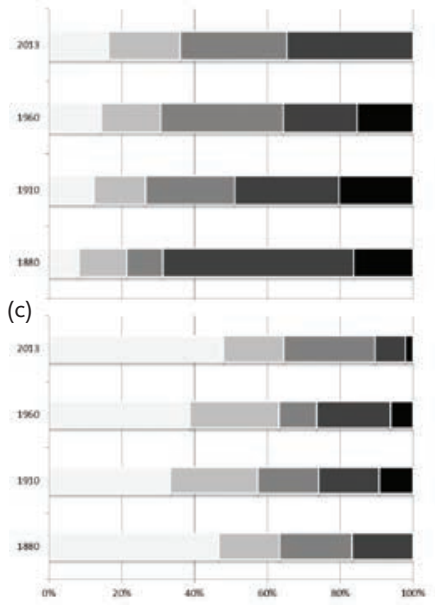

(b)

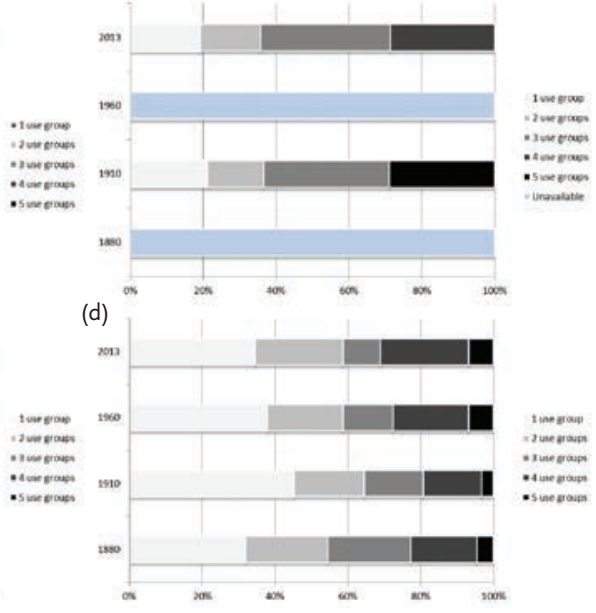

Figure 7.2

Weighted counts of land uses in the four study areas in (a) High Barnet, (b) Loughton, (c) South Norwood and (d) Surbiton across time Laura Vaughan.

one use. Notably, both High Barnet and Surbiton - the two centres with greater economic success today (not only by the subjective assessment of their more vibrant appearance, but also in their possessing a larger town centre area according to national town centre statistics) - also have an increase in the proportion of streets with a mixing of uses over time. We might conclude from this that diversity of use goes hand-in-hand with economic success over time.

The location of these streets with diverse uses is also important when taking account of the experiential dimension of land use mix. Taking Surbiton, for example (Figure 7.3), it is clear that non-domestic land uses are spread out through the area right from the earliest period, but mixing of uses occurs principally on Victoria Road and Brighton Road, the two streets which form a V to the south of the images, whilst a small section of Maple Road, running northeast, has a focus of activity through the period, but with a lower level of mixing.

In Table 7.1 the streets with the greatest concentration of non-domestic land use activity are separated from those with fewer such uses (so these might be streets with a church and a school, with the remaining buildings being purely residential). Evidently there is a big difference in building area between the two groups. Whilst frontage length becomes more even over time, we see the emergence of larger buildings overall, but also a focus on certain uses, such as retail. Surbiton, which of all the cases has the most varied and constant diversity of activity all the way through to 2013 (Figure 7.4), 


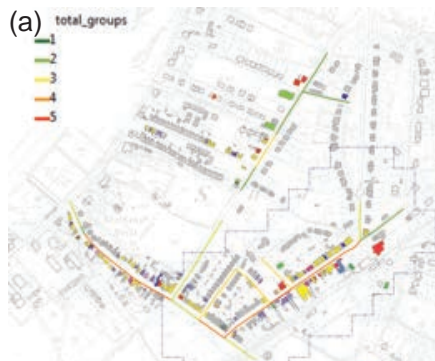

(c)

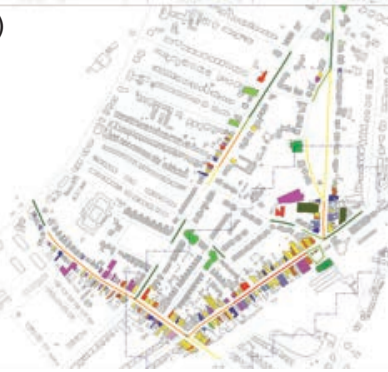

(b)

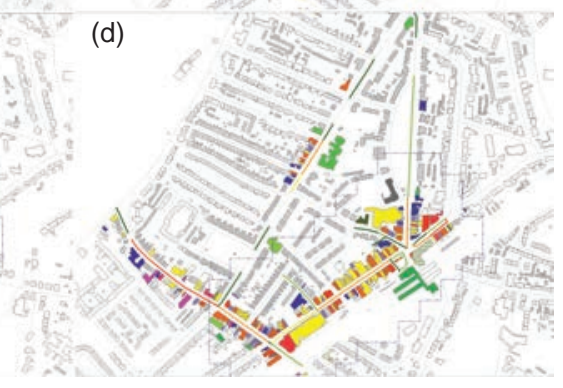

Figure 7.3

Non-domestic land uses around Surbiton town centre in (a) 1880, (b) 1910, (c) 1960 and (d) 2013, with road centrelines coloured to indicate the total number of land use groups in each street section. Refer to Fig. 7.4 for land use legend.

Laura Vaughan.

also has the most consistency in the width of frontages, an indication of the amount of potential for diversity available in the building alignment. These differences are picked up in the penultimate section.

\section{Movement interfaces}

Hillier et al. suggested in an early space syntax study that it is likely that a correlation between the mathematical values of spatial integration and choice might "index the degree of correlation between these two types of movement pattern ... the degree of "movement interface" between inhabitants and strangers' (Hillier et al. 1987: 237). However, it is only in recent years that the analytic capability has been developed to examine this relationship. Whilst choice approximates a measure of through-movement potential and integration approximates a measure of to-movement potential, the locations where the highest values for both measures overlap to the greatest degree will create, as termed by Hanson, 'different modes of spatial co-presence and virtual community' (Hanson 2000: 115). It could be 
Table 7.1 Non-domestic frontage length and building area

\begin{tabular}{|c|c|c|c|c|c|c|}
\hline \multirow[b]{2}{*}{$\begin{array}{l}\text { High } \\
\text { Barnet }\end{array}$} & \multicolumn{3}{|c|}{$\begin{array}{l}\text { Non-domestic frontage length (totals } \\
\text { in metres) }\end{array}$} & \multicolumn{3}{|c|}{\begin{tabular}{|l}
$\begin{array}{l}\text { Non-domestic building area } \\
\text { (average for each group in turn } \mathbf{m}^{2} \text { ) }\end{array}$ \\
\end{tabular}} \\
\hline & $\begin{array}{l}\text { Upper } \\
\text { intervals }\end{array}$ & $\begin{array}{l}\text { Lower } \\
\text { intervals }\end{array}$ & $\begin{array}{l}\text { All non- } \\
\text { domestic }\end{array}$ & $\begin{array}{l}\text { Upper } \\
\text { intervals }\end{array}$ & $\begin{array}{l}\text { Lower } \\
\text { intervals }\end{array}$ & $\begin{array}{l}\text { All non- } \\
\text { domestic }\end{array}$ \\
\hline 1880 & 744.17 & 506.11 & 1250.28 & 949.71 & 422.82 & 648.63 \\
\hline 1910 & 819.07 & 1351.78 & 2170.85 & 1178.14 & 645.69 & 785.86 \\
\hline 1960 & 1148.43 & 1466.27 & 2614.72 & 1157.87 & 1034.84 & 1079.85 \\
\hline 2013 & 830.77 & 1227.01 & 2057.77 & 1499.69 & 726.9 & 939.41 \\
\hline Loughton & \begin{tabular}{|l|} 
Upper \\
intervals
\end{tabular} & $\begin{array}{l}\text { Lower } \\
\text { intervals }\end{array}$ & $\begin{array}{l}\text { All non- } \\
\text { domestic }\end{array}$ & \begin{tabular}{|l|} 
Upper \\
intervals
\end{tabular} & $\begin{array}{l}\text { Lower } \\
\text { intervals }\end{array}$ & $\begin{array}{l}\text { All non- } \\
\text { domestic }\end{array}$ \\
\hline 1880 & $\begin{array}{l}\text { Data } \\
\text { unavailable }\end{array}$ & $\begin{array}{l}\text { Data } \\
\text { unavailable }\end{array}$ & $\begin{array}{l}\text { Data } \\
\text { unavailable }\end{array}$ & $\begin{array}{l}\text { Data } \\
\text { unavailable }\end{array}$ & $\begin{array}{l}\text { Data } \\
\text { unavailable }\end{array}$ & $\begin{array}{l}\text { Data } \\
\text { unavailable }\end{array}$ \\
\hline 1910 & 311.31 & 889.65 & 1200.95 & 663.56 & 552.3 & 575.48 \\
\hline 1960 & $\begin{array}{l}\text { Data } \\
\text { unavailable }\end{array}$ & $\begin{array}{l}\text { Data } \\
\text { unavailable }\end{array}$ & $\begin{array}{l}\text { Data } \\
\text { unavailable }\end{array}$ & $\begin{array}{l}\text { Data } \\
\text { unavailable }\end{array}$ & $\begin{array}{l}\text { Data } \\
\text { unavailable }\end{array}$ & $\begin{array}{l}\text { Data } \\
\text { unavailable }\end{array}$ \\
\hline 2013 & 1140.83 & 996.44 & 2137.27 & 2278.17 & 750.67 & 1181.5 \\
\hline $\begin{array}{l}\text { South } \\
\text { Norwood }\end{array}$ & $\begin{array}{l}\text { Upper } \\
\text { intervals }\end{array}$ & $\begin{array}{l}\text { Lower } \\
\text { intervals }\end{array}$ & $\begin{array}{l}\text { All non- } \\
\text { domestic }\end{array}$ & \begin{tabular}{|l|} 
Upper \\
intervals
\end{tabular} & $\begin{array}{l}\text { Lower } \\
\text { intervals }\end{array}$ & $\begin{array}{l}\text { All non- } \\
\text { domestic }\end{array}$ \\
\hline 1880 & 458.03 & 716.9 & 1174.93 & 789.48 & 281.23 & 348.68 \\
\hline 1910 & 1350.96 & 1198.48 & 2549.44 & 1070.82 & 455.92 & 626.73 \\
\hline 1960 & 1291.11 & 1242.76 & 2533.87 & 1286.56 & 510.68 & 716.53 \\
\hline 2013 & 810.6 & 1879.9 & 2690.5 & 1028.13 & 864.87 & 902.28 \\
\hline Surbiton & $\begin{array}{l}\text { Upper } \\
\text { intervals }\end{array}$ & $\begin{array}{l}\text { Lower } \\
\text { intervals }\end{array}$ & $\begin{array}{l}\text { All non- } \\
\text { domestic }\end{array}$ & $\begin{array}{l}\text { Upper } \\
\text { intervals }\end{array}$ & $\begin{array}{l}\text { Lower } \\
\text { intervals }\end{array}$ & $\begin{array}{l}\text { All non- } \\
\text { domestic }\end{array}$ \\
\hline 1880 & 742.48 & 413.59 & 1156.07 & 1349.03 & 389.66 & 578.58 \\
\hline 1910 & 825.43 & 597.96 & 1423.39 & 1452.16 & 325.36 & 579.8 \\
\hline 1960 & 803.71 & 892.68 & 1696.39 & 2277.45 & 626.85 & 968.35 \\
\hline 2013 & 950.75 & 1346.98 & 2297.73 & 2754.92 & 992.57 & 1357.19 \\
\hline
\end{tabular}

said that integration is a measure of exploratory movement, whilst choice is highly influenced by the scale (or distance) at which you are measuring and it will tend to highlight major road networks - the deep structure of the network. Here we repeat this analysis in greater detail by considering where peak correlations exist for each case and across the four periods. This analysis of co-presence is carried out through time to ascertain the changing peak locations of co-presence in the network.

As has been proposed in an earlier piece using this form of analysis (Vaughan et al. 2010b), the location of greatest overlap is likely to be where the qualities of centrality associated with suburban movement economies are most likely to be seeded. We termed this the 'spatial signature' of suburban town centres, suggesting that some centres operated best for a much more 

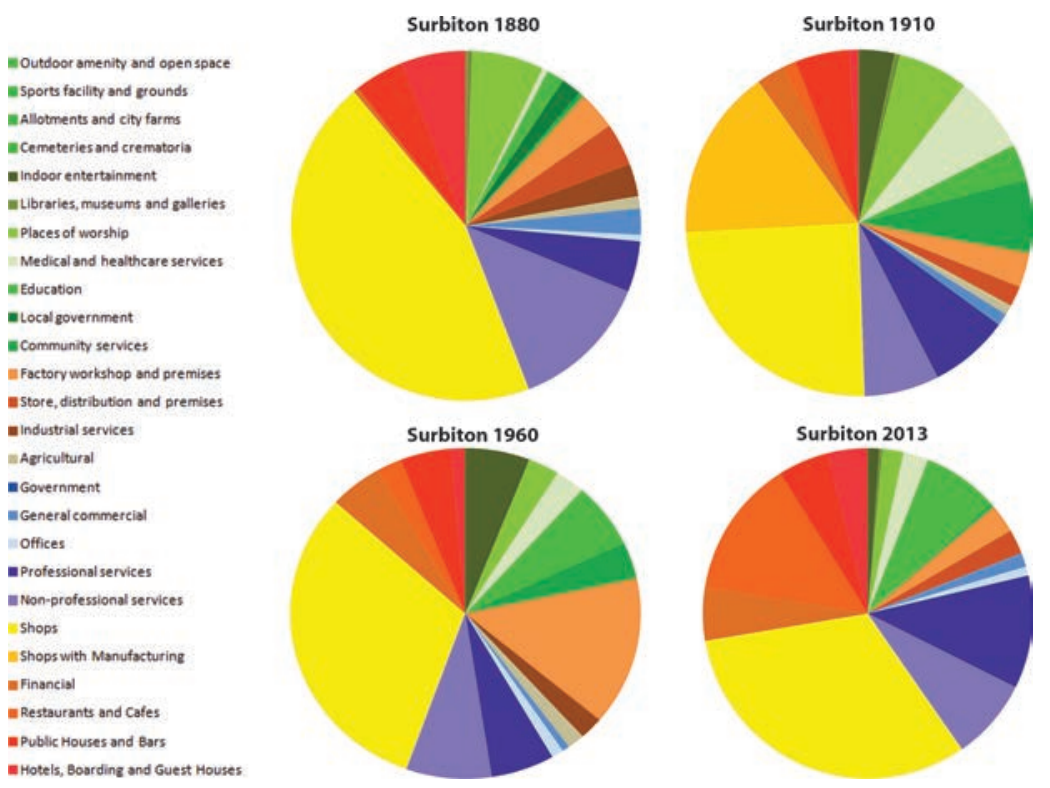

Figure 7.4

Pie charts showing average building area by use class for Surbiton in 1880, 1910, 1960 and 2013

Laura Vaughan.

localised network of connections, whilst others sustained connections both locally and more widely. Where the two correspond closely, two sorts of activities can easily coincide during the same trip: both moving from a particular origin to destination and en route doing other things, going different ways, depending on whatever combination of planned (and unplanned) activities is desired. In such a network, the same trip to the local supermarket can take a different route each time, depending on an individual's specific plans that week or indeed what the grid offers up opportunistically. A limited amount of redundancy means that pedestrian activity spreads out beyond a single street and, given the right conditions, enables interactions to flourish accordingly.

Bearing in mind that the following analysis focuses on the set of streets and their immediate environs that had continuous non-domestic inhabitation over the past 130 years, Table 7.2 shows the highest correlation 
between integration and choice at the same radius (e.g. choice 400 correlated with integration 400), selecting only the streets within the comparative boundary, highlighting the top three correlations for each epoch in bold. Two clear findings emerge: first, focusing on the figures in bold, with the exception of South Norwood, the cases have a distribution of high as well as low scales within which there is a correspondence throughout the periods (so for example, High Barnet has its top three correlations at scales of 3000 and 4000 as well as 800 or 1200 in any given period). If we then focus only on correlations above .750 , which are at the higher end, only High Barnet and Surbiton have any such cases. It might be said that this is a feature of these two centres, which are the more successful. The meaning of this on the ground is that there are two scales - one local and one wider-reaching at which the two networks of activity overlap. Less correspondence means that there are fewer opportunities for people carrying out varying journeys to intermingle - large-scale trips occur in parallel to people moving locally and the latter have less opportunity to explore beyond their immediate neighbourhood. Where they do intermingle with wider-scale trips, this occurs

Table 7.2 Highest correlation between integration and choice at the same radius, selecting only the streets within the comparative boundary, highlighting the top three correlations for each epoch in bold

\begin{tabular}{llllllll}
\hline High Barnet & $\mathbf{4 0 0}$ & $\mathbf{8 0 0}$ & $\mathbf{1 2 0 0}$ & $\mathbf{1 6 0 0}$ & $\mathbf{2 0 0 0}$ & $\mathbf{3 0 0 0}$ & $\mathbf{4 0 0 0}$ \\
\hline $1880(\mathrm{n}=47)$ & 0.610 & $\mathbf{0 . 8 1 7}$ & $\mathbf{0 . 8 3 1}$ & 0.724 & 0.741 & $\mathbf{0 . 7 9 6}$ & 0.750 \\
$1910(\mathrm{n}=57)$ & 0.487 & 0.695 & $\mathbf{0 . 7 5 1}$ & 0.692 & 0.704 & $\mathbf{0 . 8 4 0}$ & $\mathbf{0 . 8 2 0}$ \\
$1960(\mathrm{n}=60)$ & 0.318 & 0.643 & 0.616 & 0.641 & $\mathbf{0 . 7 0 0}$ & $\mathbf{0 . 8 0 8}$ & $\mathbf{0 . 8 1 3}$ \\
$2013(\mathrm{n}=68)$ & 0.435 & $\mathbf{0 . 7 3 2}$ & 0.727 & 0.680 & 0.726 & $\mathbf{0 . 8 3 7}$ & $\mathbf{0 . 8 4 6}$ \\
\hline Loughton & $\mathbf{4 0 0}$ & $\mathbf{8 0 0}$ & $\mathbf{1 2 0 0}$ & $\mathbf{1 6 0 0}$ & $\mathbf{2 0 0 0}$ & $\mathbf{3 0 0 0}$ & $\mathbf{4 0 0 0}$ \\
\hline $1880(\mathrm{n}=27)$ & 0.434 & 0.436 & 0.577 & $\mathbf{0 . 7 0 6}$ & $\mathbf{0 . 7 4 6}$ & $\mathbf{0 . 6 6 4}$ & 0.686 \\
$1910(\mathrm{n}=36)$ & 0.568 & 0.494 & 0.574 & $\mathbf{0 . 6 8 1}$ & $\mathbf{0 . 7 4 8}$ & $\mathbf{0 . 6 8 3}$ & 0.653 \\
$1960(\mathrm{n}=52)$ & 0.548 & 0.709 & 0.639 & $\mathbf{0 . 7 2 7}$ & $\mathbf{0 . 7 5 1}$ & $\mathbf{0 . 5 4 8}$ & 0.482 \\
$2013(\mathrm{n}=69)$ & 0.646 & $\mathbf{0 . 7 1 6}$ & 0.565 & 0.581 & 0.644 & $\mathbf{0 . 7 1 5}$ & $\mathbf{0 . 7 0 5}$ \\
\hline South Norwood & $\mathbf{4 0 0}$ & $\mathbf{8 0 0}$ & $\mathbf{1 2 0 0}$ & $\mathbf{1 6 0 0}$ & $\mathbf{2 0 0 0}$ & $\mathbf{3 0 0 0}$ & $\mathbf{4 0 0 0}$ \\
\hline $1880(\mathrm{n}=58):$ & $\mathbf{0 . 6 9 5}$ & $\mathbf{0 . 6 5 1}$ & $\mathbf{0 . 6 3 1}$ & 0.607 & 0.563 & 0.588 & 0.612 \\
$1910(\mathrm{n}=90):$ & 0.627 & $\mathbf{0 . 6 9 8}$ & $\mathbf{0 . 6 6 5}$ & $\mathbf{0 . 6 6 0}$ & 0.622 & 0.535 & 0.609 \\
$1960(\mathrm{n}=94):$ & 0.642 & $\mathbf{0 . 7 2 7}$ & $\mathbf{0 . 7 2 3}$ & $\mathbf{0 . 6 9 7}$ & 0.669 & 0.633 & 0.661 \\
$2013(\mathrm{n}=107):$ & 0.639 & $\mathbf{0 . 7 4 2}$ & $\mathbf{0 . 7 1 7}$ & $\mathbf{0 . 7 0 8}$ & 0.696 & 0.633 & 0.600 \\
\hline Surbiton & $\mathbf{4 0 0}$ & $\mathbf{8 0 0}$ & $\mathbf{1 2 0 0}$ & $\mathbf{1 6 0 0}$ & $\mathbf{2 0 0 0}$ & $\mathbf{3 0 0 0}$ & $\mathbf{4 0 0 0}$ \\
\hline $1880(\mathrm{n}=41):$ & 0.386 & 0.761 & 0.668 & $\mathbf{0 . 8 1 4}$ & 0.736 & $\mathbf{0 . 7 7 8}$ & $\mathbf{0 . 7 6 3}$ \\
$1910(\mathrm{n}=48):$ & 0.567 & $\mathbf{0 . 7 7 6}$ & 0.702 & $\mathbf{0 . 8 5 8}$ & $\mathbf{0 . 8 1 3}$ & 0.740 & $\mathbf{0 . 7 9 0}$ \\
$1960(\mathrm{n}=61):$ & 0.417 & $\mathbf{0 . 7 7 4}$ & 0.653 & 0.750 & 0.728 & $\mathbf{0 . 8 1 5}$ & $\mathbf{0 . 7 8 7}$ \\
$2013(\mathrm{n}=76):$ & 0.674 & $\mathbf{0 . 8 9 2}$ & $\mathbf{0 . 8 6 2}$ & $\mathbf{0 . 7 7 7}$ & 0.745 & 0.761 & $\mathbf{0 . 7 7 7}$ \\
\hline
\end{tabular}


in streets that were not intended for this purpose, such as in the high street, South Norwood, where on a typical day pedestrians can be overwhelmed by the volume of heavy goods vehicles and buses making trips across the city, polluting the atmosphere for people walking down the narrow pavements to the local café, office, high school or shops (Figure 7.5). In the following, the way in which the suburban centres are embedded in major road networks (many of which are historical) is studied by plotting the above values in line charts which show the shift in degree of overlap over time for each centre. Figure 7.6 shows the result of averaging the $\mathrm{R}^{2}$ value across the four periods.

We see that South Norwood has high path overlap only at the lower scales of 400-1600m - which may only be due to the effective walking distance from the station - with much less overlap at the larger scales. The segmentation of the centre by the railway line as well as by the major road network seems to have an effect on its grid, with no deformation or intensification around the main roads (Figure 7.7).

In contrast, High Barnet and Surbiton have a much greater grid deformation alongside large roads connecting onwards. In Barnet the live centre is actually on the big road and the circulation is across it, as well as circuitously around it in a form of centrality (as proposed in fact by Hillier as a function of larger, more urban centres; see Hillier 1999a). This is reflected in a strong peak

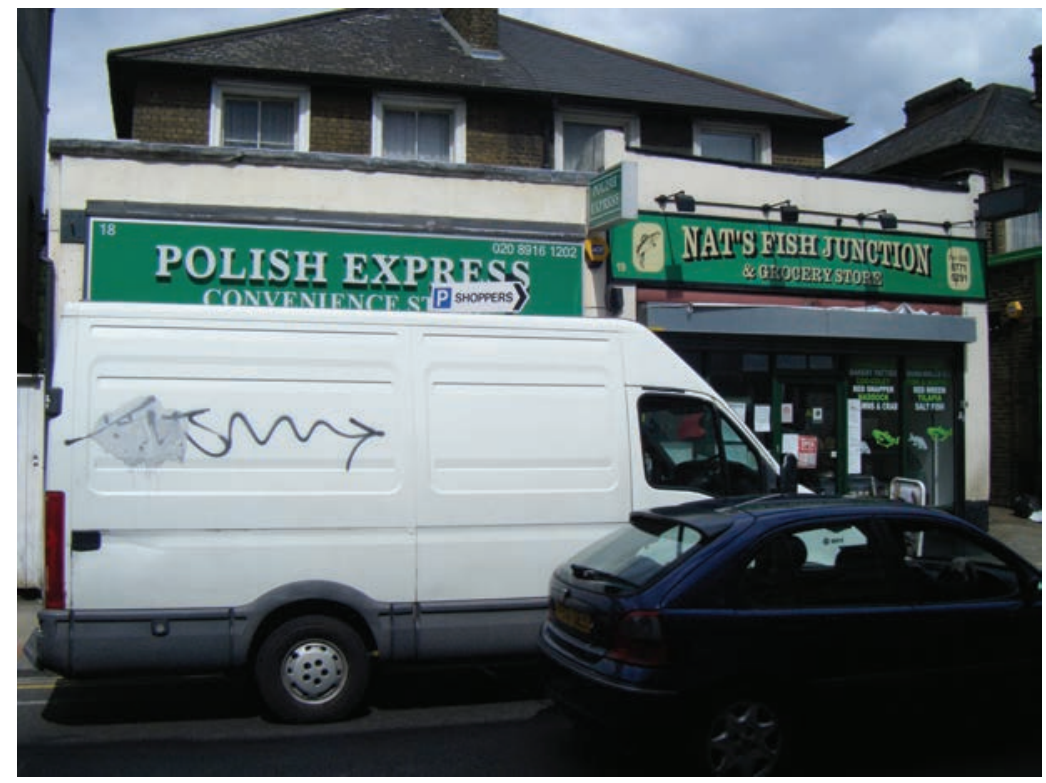

Figure 7.5

Traffic on South Norwood high street $c .2008$ Laura Vaughan. 


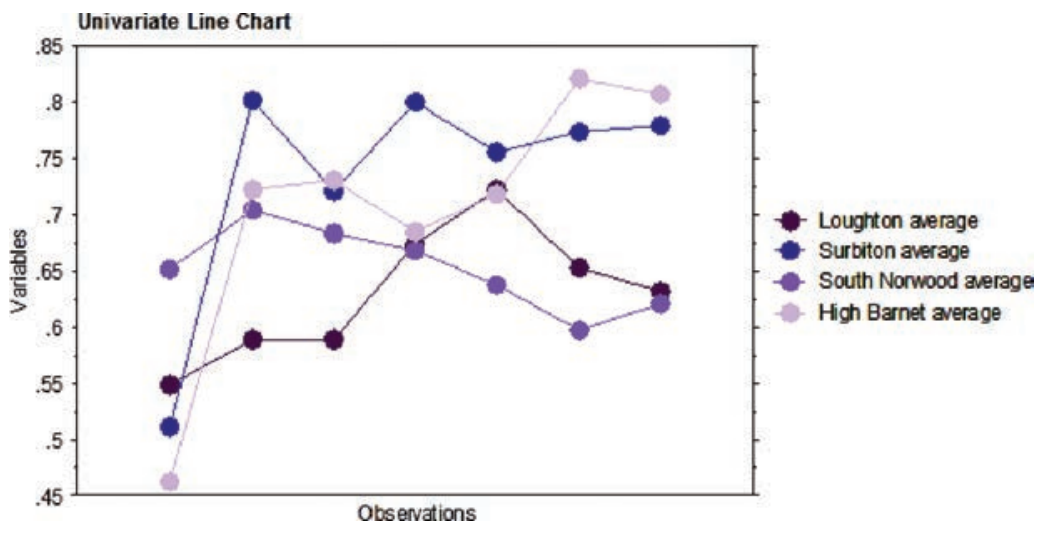

Figure 7.6

Line chart showing overlap between radius $400 \mathrm{~m}, 800 \mathrm{~m}, 1200 \mathrm{~m}, 1600 \mathrm{~m}, 2000 \mathrm{~m}$, $3000 \mathrm{~m}$ and $4000 \mathrm{~m}$ from left to right

Laura Vaughan.

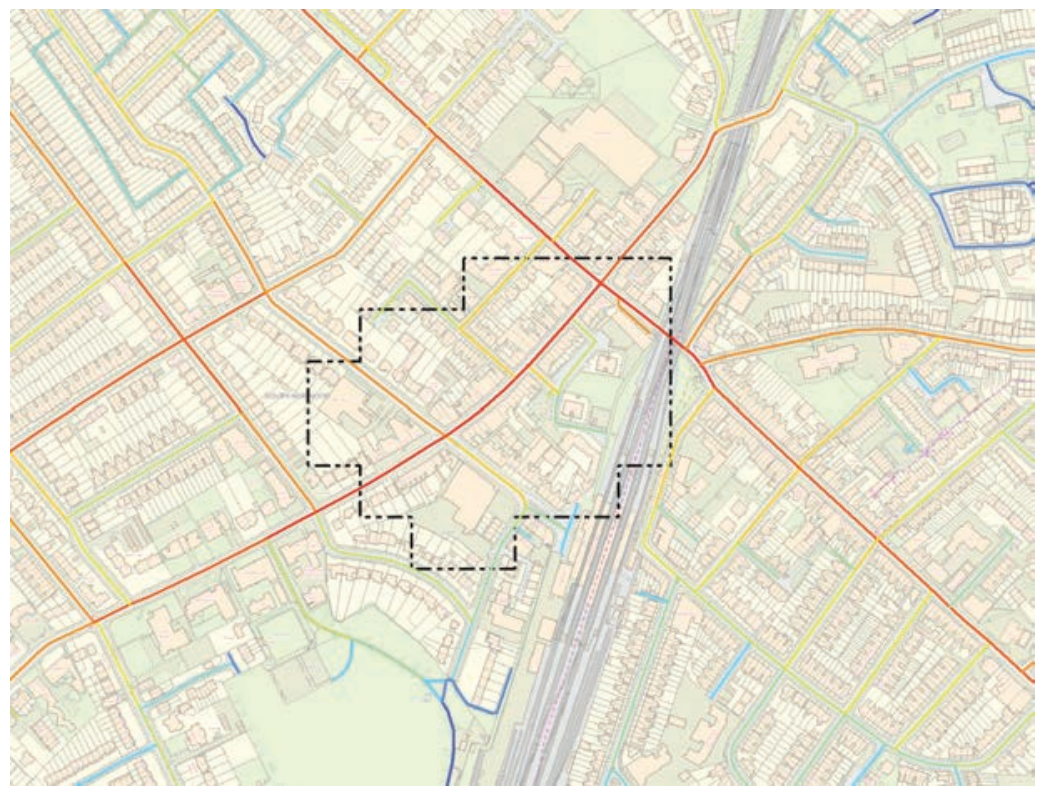

\section{Figure 7.7}

Contemporary map of South Norwood street layout surrounding the town centre (with peak activity area marked in black dashes) overlaid with segment angular integration $800 \mathrm{~m}$

Laura Vaughan. 
of correspondence of scales at the $800 \mathrm{~m}-1200 \mathrm{~m}$ range, but then again at what may be critical: the $3000 \mathrm{~m}-4000 \mathrm{~m}$ scales. Surbiton has a slightly different pattern on the ground: like South Norwood, it is segmented by the railway line and, at a very large scale, suffers to a certain degree from the Kingston By-Pass; yet possibly because the by-pass links back to historic road alignments, such as Ewell Road, it serves to reconnect what it divides elsewhere - it projects local connections at a higher scale. Like High Barnet it has a strong correspondence at 800 and also at 1600 and then exactly the same at $3000 \mathrm{~m}-4000 \mathrm{~m}$.

Putting aside the local differences, which add further veracity to the spatial signature argument mentioned above (Vaughan et al. 2010b), these averages are fair representations of all the different periods. They represent the structural continuity of the built form/movement interfaces in each of these places. By looking at the relationship between the two types of movement pattern, there is supporting evidence for structural continuity across the sample. Arguably this is a definition of structural resilience in terms of the way in which, despite the massive spatial change (consider the doubling and then half again in size of the network, for example - see also Dhanani's chapter in this volume), the fact is that the movement interface index remains consistent over time.

Whilst through-movement is restricted to only the one street in South Norwood, there is a degree of complexity in places such as High Barnet that provides enough local movement, without preventing people from making larger trips across and through it. Having the station situated on the edge rather than cutting through the centre perhaps helps in this instance; what also possibly helps is the fact that the main road runs through the high street without overwhelming it with heavy traffic. There are alternatives, turnings off, that allow for centrality to develop, or at least, the town centre can spread beyond the linear high street. Surbiton is another such case with its three 'high streets' - Brighton Road, Victoria Road and Ewell Road, (notwithstanding Maple Road with its secondary functions) - that allow the town centre to spill over and around the corner in a much more effective way. Loughton has some local centrality either side of its very strong spine of a high street, but despite a large number of pedestrian routes in and around it, it has not extended its growth that far beyond it. Nevertheless, the relatively large amount of non-domestic activity in and around its centre is a sign that, despite its relatively small size, it has sufficient adaptability to weather long-term change. South Norwood is effectively the worst-off of all four cases. It has not managed to adapt its network (or its uses) as well over time, evident in the fact that despite being the closest to the centre of London, and the most urban in its amount of building coverage, it has the least number of centrality features. 


\section{Building adaptability}

The above analysis has shown that the continuity of generic types of activity, despite major changes to the actual functions they maintain, seems to be a consequence of there being a variety of building types, sizes and street morphologies which together are more likely to propagate patterns of co-presence over time - providing the minimal but essential balance between stability of uses, on the one hand, and adaptability in building, as well as use class, on the other. MacCormac's 'reinhabited coral reefs' quoted above are essentially an observation of building scale adaptability, but this phenomenon also occurs at the urban scale. Arguably, neither a rigid structure that only allows (in the extreme case) for one use in a big box, nor a high turnover of businesses which creates an unstable system,

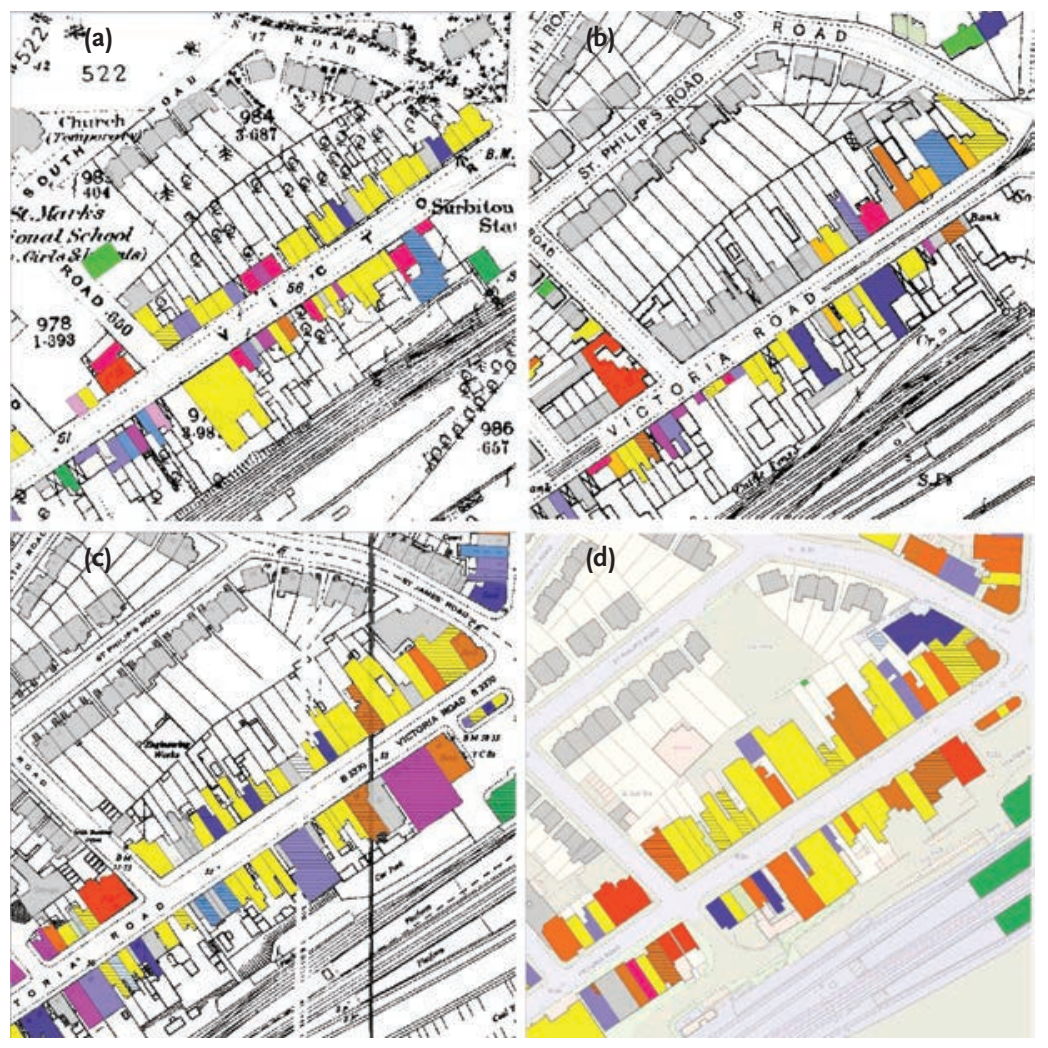

\section{Figure 7.8}

Non-domestic land uses, Victoria Road, Surbiton in (a) 1880, (b) 1910, (c) 1960 and (d) 2013. Refer to Fig. 7.4 for land use legend.

Laura Vaughan. 


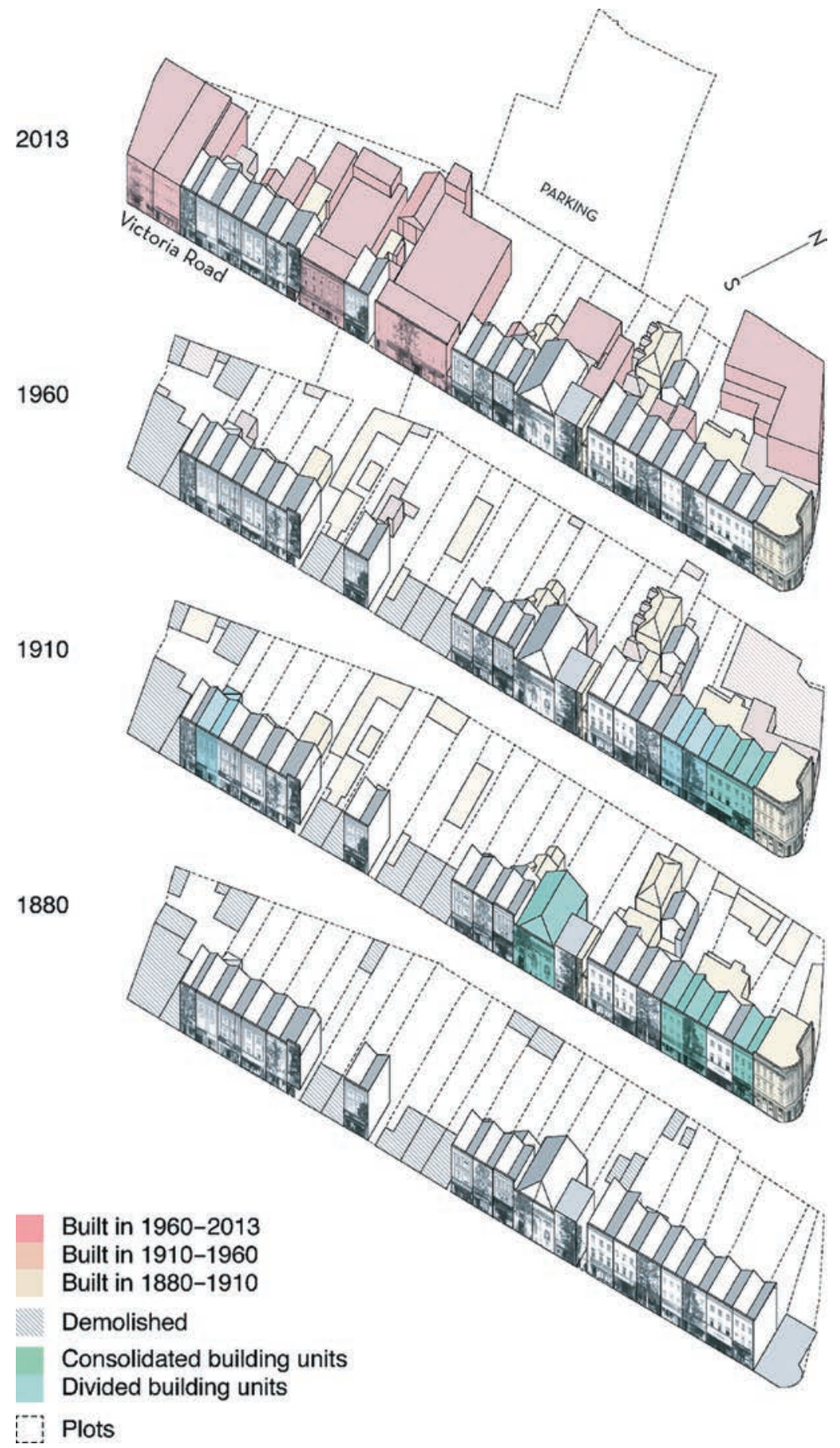

Figure 7.9

Axonometric projection of the built form changes over time on the north side of Victoria Road, Surbiton.

(C) Ilkka Törmä. 

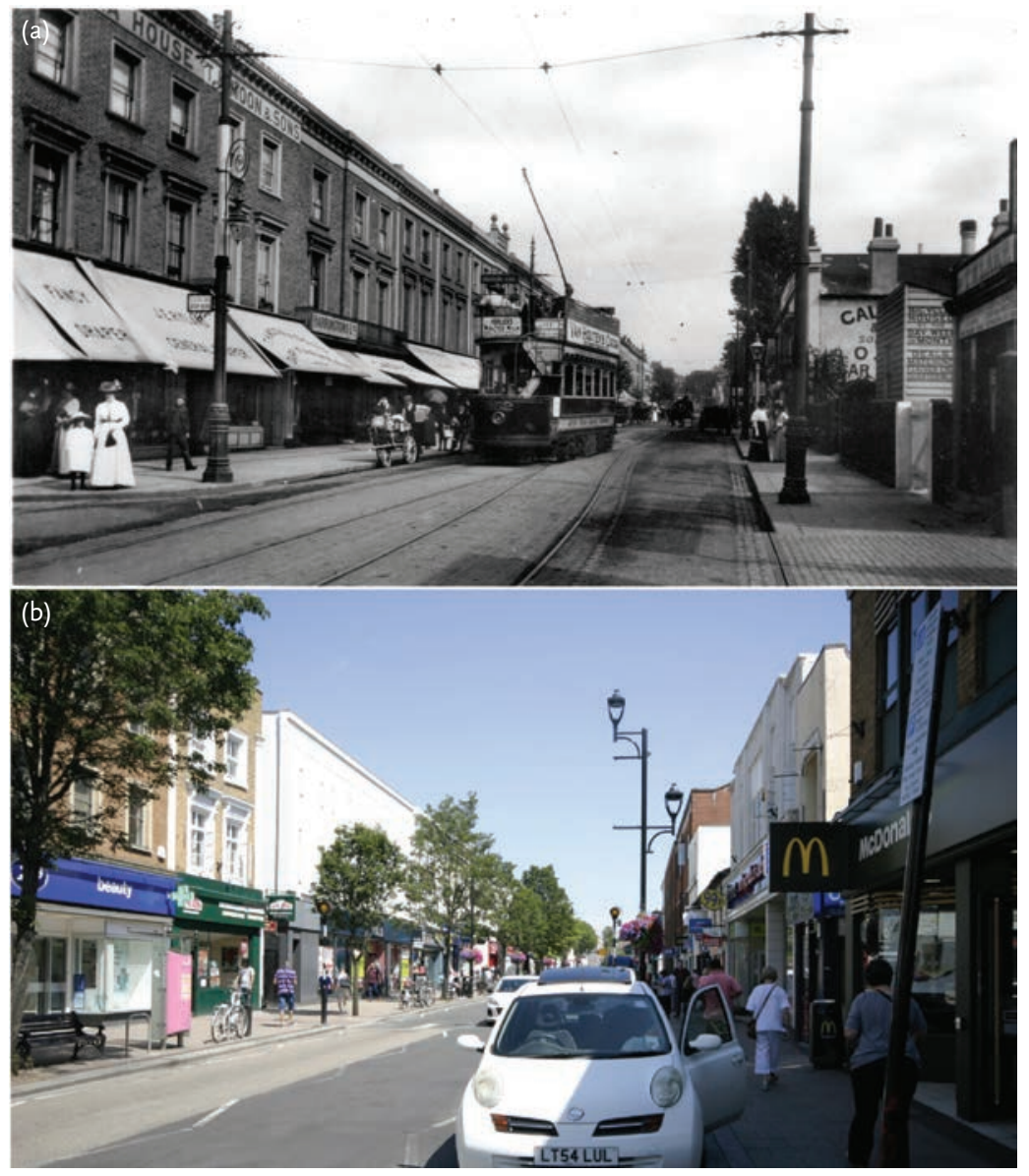

Figure 7.10

(a) Victoria Road, Surbiton, 1907 From the private collection of Dr Ruth Davies and

(b) Victoria Road, Surbiton, 2014 (c) Ilkka Törmä.

will develop a successful centre. Taking one of the more successful cases of street morphological adaptability outlined above, we can start to explore the built form and land adaptability in a couple of streets in the area.

First, considering a section of Ewell Road in Surbiton, where the highest concentration of changes of uses has taken place over the past 130 years (Figure 7.8), it is evident that the site pre-dates the railway development. Space syntax analysis shows it has one of the highest degrees of 'choice' in every period studied, suggesting it is likely to have benefited from high rates of through-movement throughout the period. Another aspect of its 
adaptability over time is the building survey undertaken by Ilkka Törmä for the Adaptable Suburbs project, which shows how most of the non-domestic premises are spatially constrained - small extensions to residential buildings, both to the fronts and backs, or small buildings on small plots - but manage to adapt their premises by a variety of means. This can be seen in the axonometric projections in Figure 7.9, which shows the shifting patterns of sub-division into open-plan, multiple-use, rear courtyard uses and partial consolidation, forming together a classic cycle of continuity and change (Whitehand et al. 2014). 4 Such streets are resilient across the scale and Törmä's (2014) study showed how a shorter frontage length, smaller building footprint, smaller plot size and higher plot efficiency typically predict use change. Figure 7.9 shows how the section of street went through the whole gamut of division, consolidation, demolition and extension, but also - alongside a high diversity of activity - a balance between constancy and change in land uses. This illustrates how the persistence of street form is tied up with how buildings and plots are arrayed along the high street. Indeed, if we look at the pair of images in Figure 7.10 of the same street section in 1907 and 2015, other than the greater presence of pedestrians in the earlier period and motor vehicles in the latter, the very persistence of the general ambience of the road is the most striking aspect that one observes.

\section{Conclusion}

Biological analogies proliferate in architecture. Perhaps this is because of the non-discursive nature of architectural space. Yet, in this case, the notion of a high street ecology stemmed from a real-life observation of the nature of historical town centres: that these seem to have a richer and more diverse mix of uses and that this diversity seems, on the one hand, to follow a spatial logic and, on the other, to be bound up with the social and economic vitality of these places. Such an ecological analogy to urban systems is effectively restating the proposition that diverse ecosystems are resilient and more able to adapt to change, as detailed in an earlier conference paper regarding this topic (Vaughan et al. 2015).

Bill Hillier has proposed in the past that there is 'a generic process of centre formation' whereby centres start with a spatial seed, such as an intersection or indeed a single road segment which will, by virtue of its spatial configuration, have particular spatial properties that shape its future growth (2009a: 42). This research has provided evidence to support Hillier's proposition that the subsequent growth of centres is dependent on the relative balance of the local and wider-scale ('global' scale) connections of the 
streets running through them which shapes their degree of interaction with neighbouring and more distant centres. We have seen evidence that the more successful of the four cases studied confirm his theory in the way in which they have evolved over the past 130 years.

The research presented here suggests that a shorter frontage length, smaller building footprint, smaller plot size and higher plot efficiency typically predict use change, but it does not necessarily follow that use change on its own is a measure of resilience, or the adaptability of the buildings to change. Whilst such streets or segments of streets can be active places like many of the twenty cases studied across our research projects - with continuous non-domestic activity, they are not necessarily resilient in the sense that the same use has been continuous over time. Instead, they are places where uses come and go. One weakness that can be observed is that there are some plots that have become consolidated over time to allow for larger buildings to be erected, which means that in the long term there will be less scope for diversity of uses than in the past. One conjecture that explains this process might be that the limitation in space does not allow for modification to changing needs. Whilst use change takes place at the highest rate in spatially constrained buildings, most distinctly in non-domestic buildings that are on efficiently built-up plots, the analysis also shows that small buildings situated on larger plots are more vulnerable to irreversible change. Overall, what is evident is that the overarching predictor of use change is the accessibility of the street itself as well as the flexibility of the street's area to adapt to changing scales of movement in and around it.

This research also indicates that street network complexity helps contribute to a town centre's resilience against external disruptive forces, such as economic downturns or social change (such as different populations moving into an area), although in comparison to city centres, smaller town centres are likely to be more vulnerable, given their relatively lower connectivity city-wide. In our cases this is characterised by connections via a small number of arterial roads alongside good public transport: over-ground trains and buses. Their lower population densities compared with urban centres means that suburban town centres somehow need to work harder to sustain themselves through economic downturns. At the same time, the long-term growth of cities towards their edges can cause a conflict between older pathways of local movement and an increase of traffic through the area (Jones et al. 2007; Gort Scott Architects and UCL Bartlett School of Planning 2010). Morphological diversity, it is argued, enables the development of niche markets in smaller centres which can support new forms of socio-economic activity. 
Notions of diversity cannot be separated from the social properties of urban and suburban built environments. Just as the fundamental intelligibility of the built environment is an essential condition of bringing people together in a public space and affording them encounter, it is a no less, possibly more, vital resource in the relatively sparse environment of the suburban town centre. Having a mix of smaller and larger buildings allows for a mix of businesses of various sizes as well as the array of activities that necessarily feed off each other within a town centre. This is why the study considered high streets within their wider context: land uses within a catchment of up to a kilometre away and built form and network connectivity within a radius of $3 \mathrm{~km}$. By taking account of the larger spatial ecology, we were able to explore the full extent of the interconnected relationships between land uses and the people who serve and use them.

Evidently diversity is not the same as 'mixed-use'. The spatial structure of the pattern of inter-relationships, from building to street, from street to neighbouring street and from local streets to the wider network, works to create an interdependence of activity much wider than that observed by MacCormac. The significance of this finding is greater still if we consider that the discussion of diversity has mainly focused here on land use diversity. We might legitimately propose and use diversity as a proxy for co-presence. It is easy to overlook this self-evident aspect of land use diversity: the greater the diversity of land uses, the more likely it is to generate different sorts of activity by different sorts of people.

If we consider for a moment social diversity, folklore has it that Paris organised social classes vertically in urban courtyards, from the bourgeois on the main floor to the poor in the upper garret (Bernard 2014). ${ }^{5}$ Berlin did it horizontally, with the rich at the front and the poor at the back, and London arranged classes turn-by-turn: linearly integrated, but marginally separated, as can be seen in the famous Booth map of poverty, where different street alignments each carried different poverty classes. As Hillier (1996: 166) has suggested, all of these are formulae for mixing uses without them getting in each other's way. In the case of London, street alignment, not the block, has tended to be the basic organising urban element. Different uses or grades of use are juxtaposed but on different streets, separated just enough to allow for the different grid conditions to play their part in generating higher amounts of movement on the main streets (where more public-facing activities can be located) and lower amounts of movement on the back streets. The process of the formation of these spatial patterns, even on the outskirts of the city, is evidently key to the continuity and robustness of London's town centres, as has been shown in this chapter. ${ }^{6}$ 


\section{Notes}

1 Some of the research contained in this chapter was presented as a paper at the 1oth International Space Syntax Symposium in July 2015 (Vaughan et al. 2015).

2 Interestingly, Penn et al.'s research on land use patterns in Clerkenwell points to the possibility that diversity could sometimes emerge as a result of economically marginal locations, allowing for places 'just off' the main throng to emerge as loci of specialist businesses. Historical analysis of longstanding market places such as Exmouth Market in Clerkenwell support this contention, showing that Exmouth Market used to be the main thoroughfare of the area and it is only when a new street alignment was inserted to its north-west to carry trams that the market street came to be cut off at one end and effectively receded into the background.

3 Kelly's directory (1901) lists the following, from the Surbiton Hill junction, southwards: wine \& spirit merchants, physicians \& surgeons, dentist, surgeon, ... physicians \& surgeons, Young Women's Christian Association, builder, decorator, cycle maker, oilman, saddler, stationer, ... linen draper, fruiterer, corn dealers, grocer, school, fancy repository, provision merchants, chemist, grocers \& provision merchants, Surbiton Hill Post \& Telegraph Office, baker, butcher, dairyman, fishmonger, dairyman, boot \& shoe warehouse, grocers \& provision merchants, ... girls' school, ... Urban District Council of Surbiton, Wesleyan Chapel, solicitor, veterinary surgeon, School of Art, Anchor Coffee Tavern, butchers, fly proprietor, Plough Public House, ironmonger, boot maker, milliner, beer retailer, plumber, builders, upholsterer, umbrella maker \& cutler, cycle company, newsagent, butcher, ... Victoria Public House, draper, coal merchant, London \& Provincial Bank Ltd., builders, South Down Farm Dairy ... etc.

4 The urban morphologist Jeremy Whitehand outlines two kinds of urban landscape change. 'One is the adaptation (in a broad sense) of existing forms: this includes, for example, the modification of a building, perhaps by adding rooms or changing the roof, or, in the case of a street, it might involve changing the relationship between the areas allocated to vehicles and those for pedestrian use only. Changes of this type may occur at various intervals over the lifespan of a plot, building, street, or other feature in the landscape. An example well known among geographical urban morphologists is the burgage cycle. In this cycle the "burgages" - the plots of land derived from those held by the enfranchised members of medieval boroughs - become progressively built up. Each plot has a building constructed at its head, usually early in the life of the plot, and this is followed by subsidiary buildings being added along the length of the plot over many decades, or sometimes over centuries ...

The other kind of change is the introduction of new types of buildings, streets or other features. In England, bye-law terraced houses introduced and reproduced in the Victorian and Edwardian periods, followed by semi-detached houses (of "universal" plan) in the interwar period, are well-known "period types", at least in that part of the world. The tower block and the expressway (to use the American term) were widespread introductions, essentially in the twentieth century, although introduced in different parts of the world at different times.'

5 Andreas Bernard (2014) argues that whilst in the nineteenth century the attic and basements of buildings attracted a stigma of abnormality, by the early twentieth century, the invention of the lift in fact 'freed the upper storeys [of hotels] from the stigma of inaccessibility and lent them an unheard-of glamour', meaning that the highest rental prices could be charged for penthouses.

6 Indeed, both clustering and separation can co-exist, as shown in historical research into immigrant settlement patterns (Gilliland et al. 2011: 493, 495). 


\title{
Chapter 8
}

\section{High Street Transactions and Interactions}

\author{
Garyfalia Palaiologou
}

\section{Introduction}

This chapter describes the long-term transformation of what started out as a suburban high street on the northern outskirts of London and subsequently became part of its urban heartland: Upper Street, Islington. The discussion focuses on the spatial and morphological properties that have allowed Upper Street to embrace aspects of both persistence and change over time without losing its historical references to the suburban retreat settlement that Islington once was. The analysis of Upper Street examines in particular whether there is anything spatially and morphologically inherent which has contributed to this process. With an examination of the historical spatial and functional dynamics that shaped Upper Street, the discussion examines the way local and city-wide forces have developed, evolved through time and brought about the 'spatial culture' (Hillier 1989) of Islington within its urban context.

Spatial cultures emerge from the way societies order their physical space, in order to organise 'the principles for ordering social relations' (Hillier 1989: 6). The concept of spatial cultures suggests that there is cultural symbolism embedded in space which is expressed through the way people's encounters and activities are organised, produced and reproduced within a given spatial setting. The discussion in this chapter aims to investigate the way streets, buildings and building uses bring together unique street profiles; and more particularly, high streets. It will describe how Upper Street comprises a unique 'morphological event' for Islington (see the chapter by Griffiths in this volume) which plays an important role in holding together the spatial culture of the historical settlement. In other 
words, it will show how Upper Street is distinctive both in terms of the way it is situated within its surroundings, and because of its building morphology and function. Upper Street will be shown to have been shaped by particular spatial transactions and interactions which are in turn subject to the wider London network forces as these form over time. Overall, the discussion comments on the potential role of high streets as intermediary urban configurations - spatially, culturally and socially; as urban units that comprise the socio-spatial thresholds between the local and the city-wide context.

To open the discussion, a basic idea that frames the explorations presented here is that the battle of the high street is one between scales: physical, social and time scales. In The Constitution of Society, Giddens (1984: 139-44) reflects on the schism between the 'micro' and 'macro' scales in sociological context (i.e. micro- and macro-sociology). His rationale exposes the reasons why the distinction of the micro and macro approaches is questionable. Giddens explains that both scales have their distinct structure, as well as presenting intersections - namely, they overlap - and are akin to different ways of measuring time (long term versus short term, for instance). He goes on to clarify that the macro scale is not merely the agglomeration of many 'micro-situations'. The author firmly asserts that there cannot be any question of either scale having priority over the other (Giddens 1984: 139) and suggests that the two should be approached in an integrated way. A basic feature of the high street is that it is a constitutive element of the local (micro-) and the city (macro-) scales. When high streets face urbanisation, a battle of dominance sets off between the city's tendency to dominate or overrule the high street's authority and the high street's primary responsibility to cater for the local area. In other words, the emerging debate around the nature of suburban urbanities might be said to hinge on whether the micro-scale street will continue to play a local role in its new positioning within the urban configuration, or will be absorbed and overtaken by the city.

Other issues of potentially equal importance are the cultural connotations of the high street. High streets are of cultural significance to local communities, and therefore the battle of the high street to not abandon its micro-scale references extends to a conceptual level of 'place identity'. Relph (1976: 45) suggests, 'the identity of something refers to a persistent sameness and unity which allows that thing to be differentiated from others'. On the other hand, Kirby (1996: 18) argues, 'a place persists only as long as the boundary creating it is deliberately maintained, and the spaces these boundaries encircle are subject to continual remodelling'. Both statements sound coherent and true, but also somewhat contradictory; the first implies that the context is what differentiates the object/system, and the second that differentiation comes through 
the maintenance of the object/system boundary, whilst the context stays liable to change. High streets are such instances within a city, and they can demonstrate different readings of whether a local place has a fixed boundary or whether it shifts over time, depending on how the street's surroundings grow and change, or indeed, according to a person's own experience of the place ('The Boundaries of Belonging' in Hall 2012). The example of Upper Street is of interest, as its longevity and special character are adherent to properties akin to both Relph and Kirby's understanding: the street has maintained aspects of its socio-economic value to the local area on the one hand, maintaining an ongoing spatial role within the local context; on the other hand, it has accommodated change, its boundaries have merged with the city but the street remains protected from high-maintenance urban flows.

In the following sections, the narrative unfolds the story of Upper Street starting from a historical overview of the growth of Islington and moving on to the investigation of the spatial culture of Upper Street and its role as a high street over time. The study focuses on the part of Islington surrounding Upper Street (see Figure 8.1; study area highlighted in dark grey), with the case study area covering approximately $1.45 \mathrm{~km}^{2}$.

\section{The growth of Islington}

This historical account summarises the area's rapid growth and highlights key features of its long-term profile. Figure 8.1 serves as a reference point to the discussion, showing key streets, the surrounding districts and landmarks of the area. Offering a 'mixture of town and country' (Inwood 1998: 570), Islington first flourished as an escape from the urban turmoil. The appeal and conflicts of the area have inspired descriptions of Victorian London in classic literature, exposing this mixture of urban and suburban qualities. To Noah Claypole, one of the characters in Oliver Twist (1837-9), the crowd and vehicles in Angel, Islington were the 'earnest' prelude to Charles Dickens's London of the Victorian era (Dickens 1837-9: 271). To Molly Hughes, writing of her experience as A London Child of the 1870s, the streets of suburban Canonbury were lingering in silence, only interrupted by '[a] tradesman's cart, a hawker or a hurdy-gurdy' (Hughes 1977: 49). These contrasting descriptions demonstrate very early a debate around scales (although not using those terms) in relation to Upper Street. Thomas Cromwell writes in 1835 prefacing his Walks through Islington, 'few are the suburban districts around the vast metropolis, which have been more fertile in changes, or are more inviting in their existing aspect, than that of Islington' (Cromwell 1835: iii). 


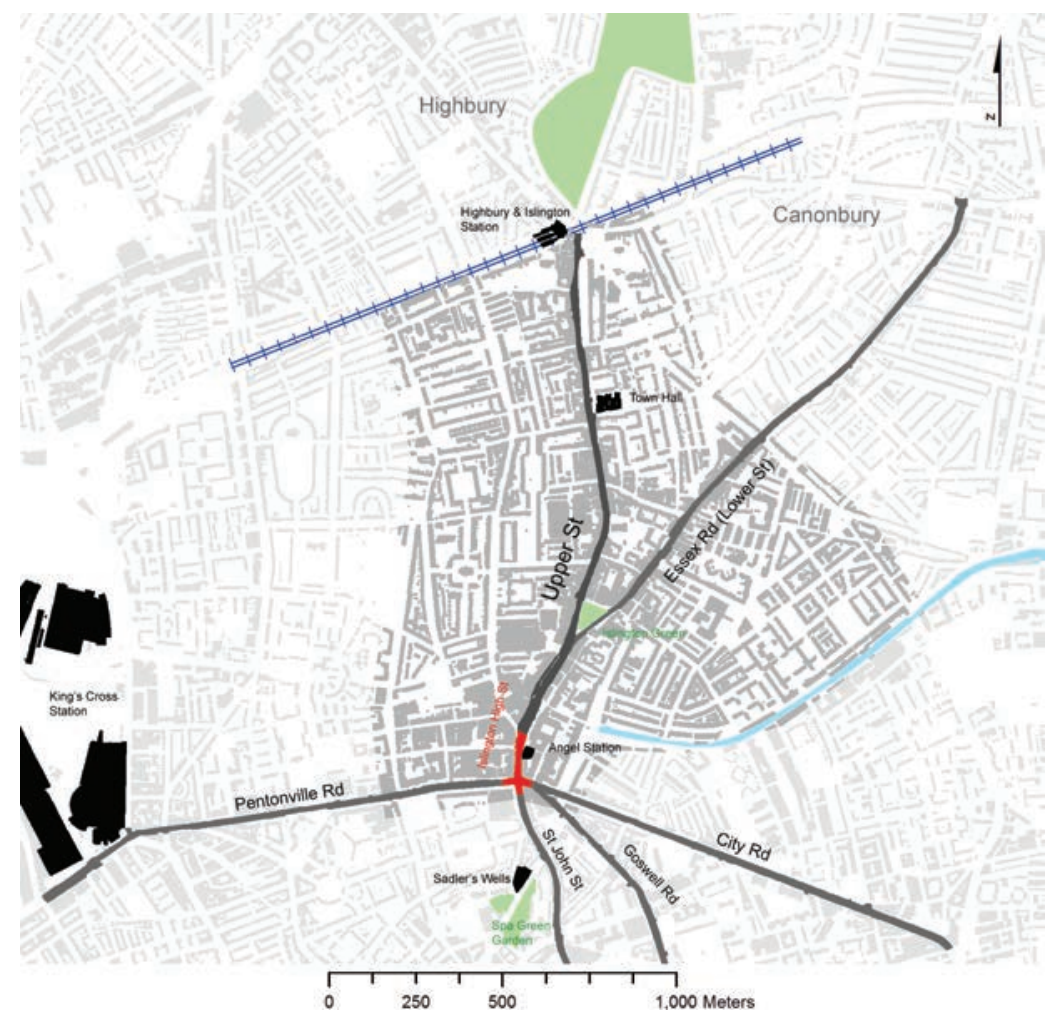

Figure 8.1

Islington, London: Upper Street and surroundings (c.2013)

Background map: (c) 2013 Crown Copyright. An Ordnance Survey/EDINA supplied service.

In the mid-sixteenth century Islington was known as a dormitory village, where inns and watering holes provided shelter to long-distance travellers. Islington High Street - the southern extension of Upper Street - has been an historical route for journeys to and from London since the Middle Ages, connecting Liverpool Road and Upper Street (north) with St John Street and Goswell Road (south) (Figure 8.2). By 1590 this short street had become the focus of the main building development in the area. Islington provided at that time the services of a collar-maker, a vintner, a glazier, a shoemaker, a tailor, a wheelwright, a weaver, a tanner and a brewer (Baker and Elrington 1985: 69-76). Being located close to the City of London, Islington gradually attracted rich and eminent Londoners and began to serve as an area of suburban retreat with springs and spas (McKellar 1999). Between the mid-seventeenth and mid-eighteenth centuries, London's expanding edge had reached the renowned gardens of Sadler's Wells (namely, the Islington 


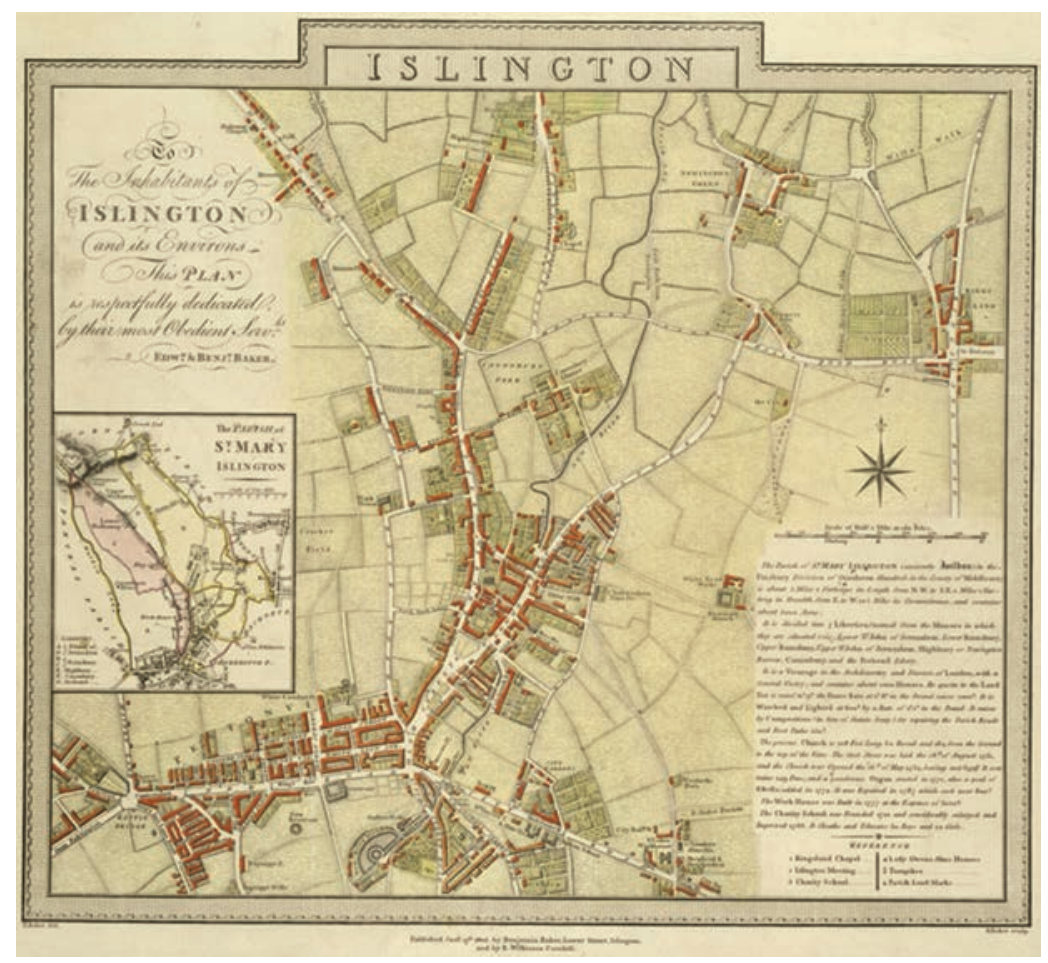

Figure 8.2

Islington, London, $c .1805$. A plan of Islington and its environs, originally published in 1805 by $\mathrm{E}$. Baker

Image from Wikimedia Commons.

Spa, formerly called New Tunbridge Wells; Thornbury 1878: 289-96), bringing the metropolitan area closer to Islington. For Londoners, the increasing density of the fast-growing city strengthened the appeal of suburban living for the middle classes.

During these years of early development, when Islington was becoming one of London's satellite towns (Baker and Elrington 1985), buildings clustered alongside the two historical main roads: Upper and Lower Street. Upper Street is the eastern branch at the north end of Islington High Street leading towards Holloway (with Liverpool Street extending to the west). A little farther north from Islington High Street lies Islington Green, where Upper Street meets Lower Street (Essex Road), the area's main connector to Newington. The first three decades of the nineteenth century found Islington increasing rapidly in population (10,000 to 37,000) and coverage. Villas and terraced houses started appearing in Canonbury and Barnsbury. 
In the years that followed, the parish was to face even more radical growth: the population rose from 37,316 in 1831 to 335,238 in 1901. The building boom sped up the process of turning Islington into a town in its own right, also attracting transportation links to the area. The first horse-drawn bus connections appeared in 1829 (replaced by motor buses by 1911) and such developments made daily trips to and from the city centre possible, intensifying Islington's attraction as a commuter suburb. An even stronger morphological imprint on the area's topology came from the tram and railway infrastructures; by the turn of the nineteenth century the majority of tramways had been electrified and by 1906 the area's underground railway stations had been built.' Inwood describes that '[o]f all London's satellites, the modest roadside town of Islington was the most vulnerable to suburban encroachment' (Inwood 1998: 582). Simultaneously, London continued to expand towards its fringes, reaching Islington High Street, and from that point onwards the suburban qualities of Islington began to be reshaped by the city's urban growth and the increasing numbers of new settlers: many of the middle-class single-family terraces in Barnsbury were sub-divided into multi-dwellings, and the older houses in Lower Street were replaced by rows of shops.

The rapid development led not only to physical changes, but also to a shifting social pattern as time went on. By the mid-nineteenth century, the forces of urban migration had brought into the area settlers from the lower rungs of the middle class, and from the working classes as well as artisans - leaving far in the past Islington's uniformly middle-class profile. Islington started to suffer from overcrowding and a deterioration of living conditions. Of the areas most affected $^{2}$ by poor housing conditions were those buildings clustered at the back of the main commercial alignments of Islington High Street, Upper Street and Essex Road - namely, the oldest streets of the area - rather than the more recent nineteenth-century developments of Canonbury and Barnsbury. Instead, in those latter districts, housing spread gradually in the form of estates which configured a network of residential garden squares. As it appears from the Charles Booth Poverty Map and Notebooks (Booth 1886-1903, 1898-9), the area's decay did not compromise the generally prosperous image of Upper Street (Figure 8.3). The high street remained a fashionable residence of the middle class and an attractive shopping destination from farther afield with drapers, outfitters and jewellers - particularly known in the 1880 s for trousseau shopping and underclothes (Adburgham 1964: 151).

Overall, Islington's profile follows the typical configuration seen in much of urban London, where the high street acts as the core of local social life (Jones et al. 2007; Dhanani and Vaughan 2013; Vaughan et al. 2013). The 


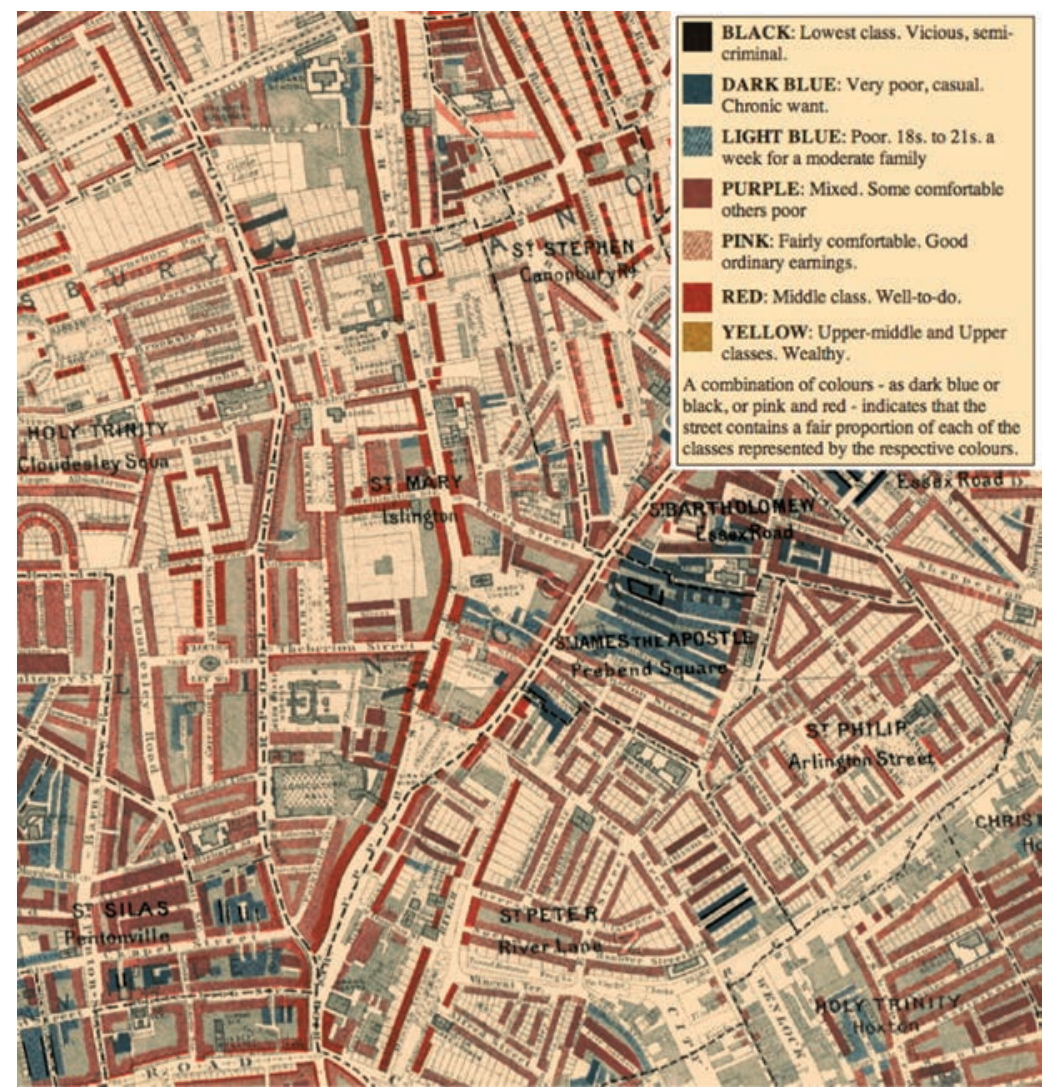

Figure 8.3

Section of Charles Booth Maps Descriptive of London Poverty 1898-9 showing Islington, London, c.1898-9

(c) LSE Library with permission (ref: UCL EPSRC Space and Exclusion project).

special role of Upper Street and its prosperity are evident up to the present, showing the street's ongoing importance. The possible reasons for this are explored in the following section.

\section{Spatial configuration}

As a preface to exploring the idiosyncrasies of Upper Street in detail, it is essential to understand the way the street is situated within its urban surroundings. Space syntax analysis reveals the spatial role of Upper Street within the wider London street network. Previous research suggests that its 
spatial properties, in terms of the way the street is connected to its surroundings, relate strongly to its socio-economic significance in serving local life and the wider urban context. This section presents the current character of Upper Street in light of spatial analysis alongside land use data. The analysis and discussion comment on the distinctive role of the high street in contrast with its residential hinterland, as well as the differing character of Upper Street when compared to the other main street of the area, Essex Road.

A substantial array of space syntax research and publications has confirmed that the configurational properties of street sections, in terms of spatial relations, play a significant role in shaping the socio-economic profile that streets develop over time. In the space syntax literature this is described as a process of 'movement economy' which is generated by the spatial layout of cities (c.f. Hillier 1996; Hillier and Vaughan 2007). This theory not only recognises the numerous and varying interrelated factors which influence one another in the urban realm, but is essentially an acknowledgement that urban places are the by-products of cumulative processes (multiplier effects) which act and become more complex over time. Space syntax (syntactical) analysis shows that these urban processes possess a 'hidden' spatial structure found in the properties of the city grid and, notably, that the way cities organise their spatial milieu has generic similarities across cultures, so that the urban core of a town in pre-modernised Iran will have similarities in its spatial patterning of central activities such as the market (c.f. Hillier et al. 1993; Hillier et al. 2012; Karimi 1997).

This theory of urban process stems from Bill Hillier's observations regarding the 'deformed wheel' model (Hillier et al. 1993). Hillier explains that there is a generic city form which is organised around a prominent foreground network of spatially integrated streets while quieter, primarily residential streets make up the urban background (Hillier and Hanson 1984: 115; Hanson 1989a: 20; Hillier 1989: 10; Hillier and Vaughan 2007: 217). This functional distinction across street networks derives from the way streets are embedded spatially in their surroundings, and relates in turn to a variety of socio-economic phenomena. Consider, for example, how commercial land uses are consistently found on main street arteries in different urban cultures around the world (Hillier 1999a, 1999b). The primacy of some streets over others signifies that those streets are well connected within the city network and are likely to be part of a high number of routes linking across the city. In turn, land uses requiring high footfall have been shown to follow this spatial logic (Hillier 1996).

The spatial significance of streets has a morphological and configurational basis. In the case of London, Hillier has observed that the foreground network is comprised of longer and straighter street alignments, which 
are in turn more accessible than is the case with the fragmented irregular background street pattern of the city grid (Hillier 2009b; Hillier et al. 2012). The foreground street network in London serves macro-economic performance, in contrast with the background network which supports local life and micro-economic activity.

Analysis of Islington shows that it has its own local 'deformed wheel' structure. The morphology of the area renders Upper Street and Essex Road as geometrically strong elements of the street layout. The orthogonal geometry of these two streets leads to their local spatial prominence within the area's overall network. Figure 8.4 shows two syntactical measures for the
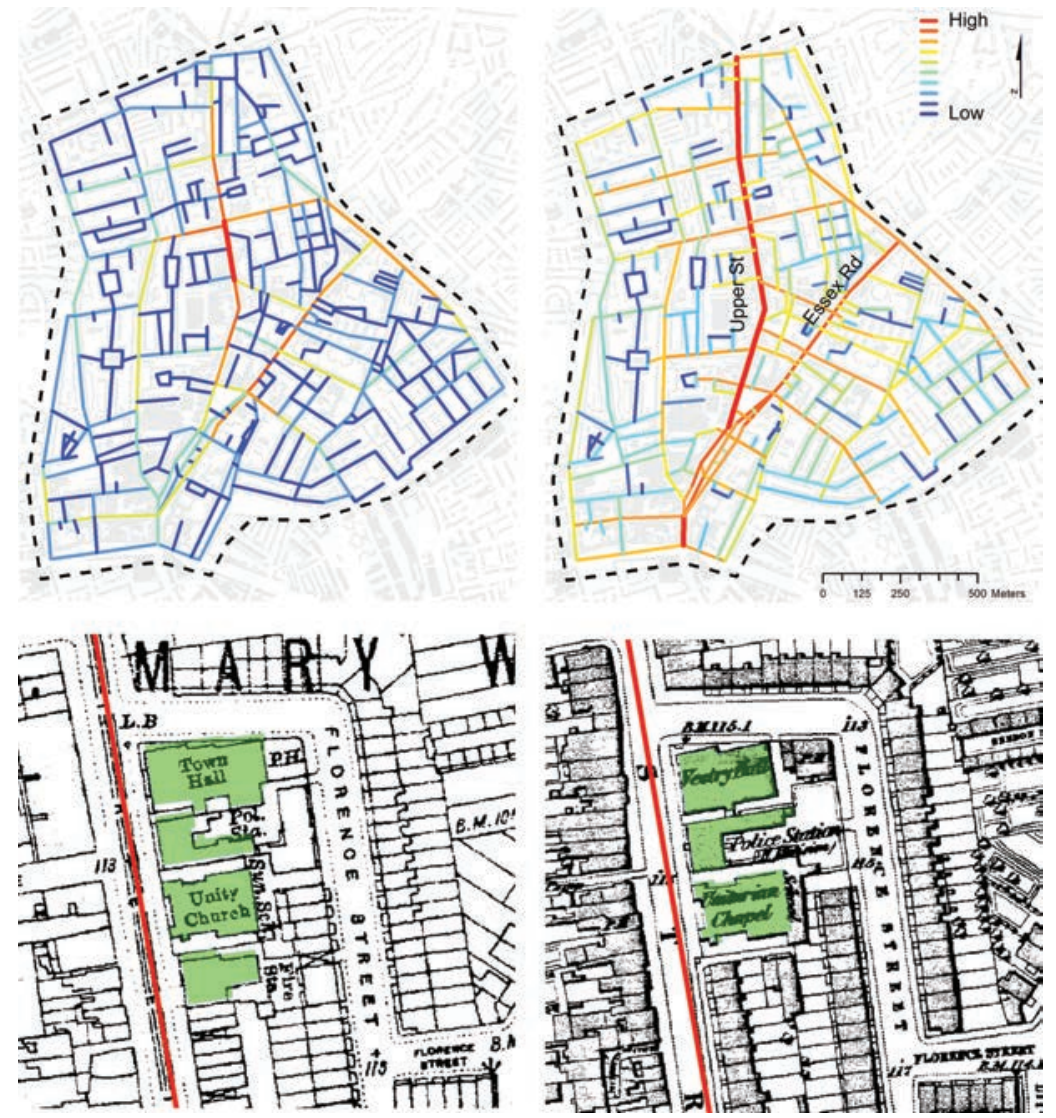

Figure 8.4

Upper Street and surroundings. Showing segment length weighted measures for choice (left) and integration (right), $c .2013$ set above Ordnance Survey maps $c .1875$ (left), c.1910 (right)

(C) Crown Copyright/database right 2013. 
local street segment map. The map represents streets as lines. For the purposes of the analysis, which aims to show the role of the street grid and geometry in the spatial properties of the network, the area is shown isolated from the wider London grid surroundings. The measures shown are the segment length weighted integration and the segment length weighted choice for radius $\mathrm{n}$ - each measure considers accessibility from each segment to all other segments in the map. ${ }^{3}$ The map illustrates the relation of the two main streets to their immediate surroundings. It is clear how the street segments comprising Upper Street are the most accessible in the area, followed closely by Essex Road. Interestingly a study of the nineteenth-century maps of the area shows that the street segments that possess the highest value for the measure of choice in the contemporary network (i.e. the stretch between Barnsbury and Cross Street) are where the most important community buildings were located in the area's suburban period: the chapel, the police station and the vestry in 1875; and the Union Church, still the police station and the Town Hall in 1910).

Previous research has described the urban growth process as being constituted by an emergent set of spatial rules that guided London's growth in the past century and a half, connecting the expanding urban realm with its suburban hinterland (Vaughan et al. 2010b; Dhanani's chapter in this volume). In this process, the numerous and diverse urban parts - configured to comply with the local landscape and the genius loci (Hebbert 1998) - were physically merged according to the city's spatial history (Hanson 1989a: 329). The morphological processes that turned the suburbs into urban components suggest that the growing city clasped itself along and around extensions of the main foreground lines of the London street network (c.f. Griffiths et al. 2008; Vaughan et al. 2009b; Vaughan et al. 2013).

It would be difficult to describe Islington today as a suburb. As discussed earlier in the historical overview, central London started to approach Islington High Street in the early years of the nineteenth century. By the beginning of the twentieth century, the city had already become intertwined with the two long-standing main streets of the area. In its present state, the mingling of the local with the city scale in Islington appears so complete as to be obscured from view. Besides their distinct role in the local scale, Upper Street and Essex Road also form part of the wider London network. Figure 8.5 illustrates the way these streets are embedded in the urban grid. The map extends approximately to a catchment of $3 \mathrm{~km}$ around Upper Street. Syntactical analysis brings to the fore the configurational significance of the two streets when considering the wider surroundings. The colours on the map reflect the segment values for the space syntax measure of combined 

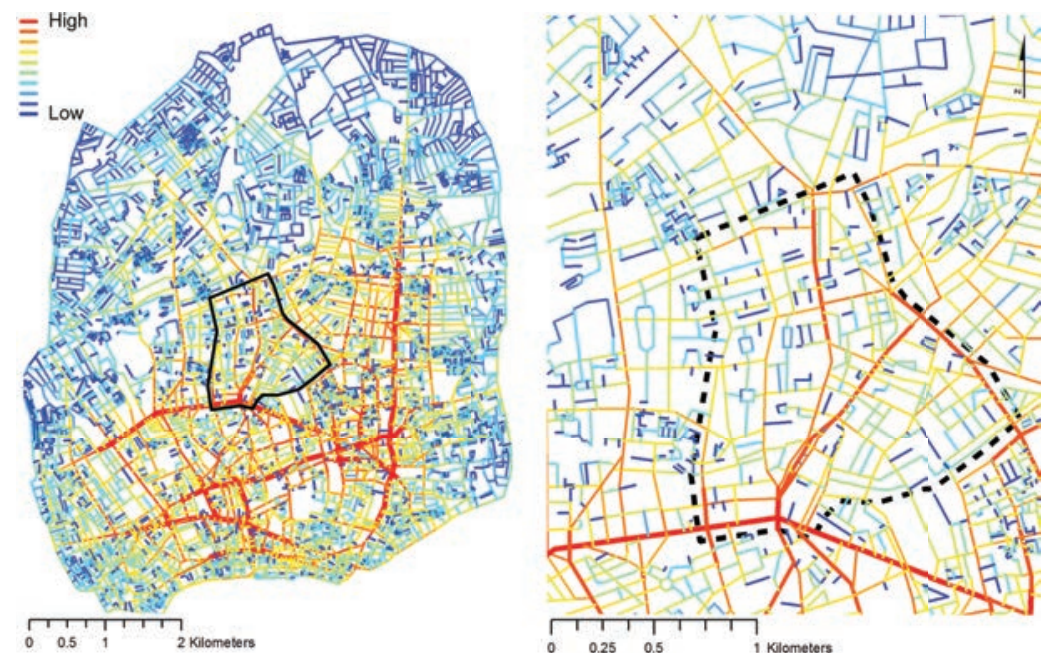

Figure 8.5

Upper Street and surroundings. Showing segment angular analysis for the measure of combined integration and choice, for radius $2500 \mathrm{~m}, \mathrm{c.2013}$

Garyfalia Palaiologou.

integration and choice 4 calculated for a radius of $2.5 \mathrm{~km}$ (chosen as a largescale analysis that avoids an edge effect).

The map in Figure 8.6 records building entrances in the area of study (marked as points on the map). Points are coloured according to the building's associated land use at ground-floor level: domestic or non-domestic. Data were collected in a survey conducted by the author in 2013. The map shows how the non-domestic profile of Upper Street and Essex Road stands out from their immediate, primarily domestic surroundings. In Upper Street 75.8 per cent of the buildings are non-domestic; in Essex Road nondomestic uses take up 66.8 per cent of the street (Table 8.1). These percentages are about four times higher than the average of those recorded for the surrounding streets (16.6\%).

The two main streets are socio-economically distinguished from the surrounding streetscape not only in terms of the type of uses they accommodate, but also in terms of the proximity of these uses; namely, in terms of the density of the activities taking place on the ground floor, alongside the street. To form a general idea of the density of building entrances we can measure the total length of building façades and divide this by the number of doorways; this gives an average estimation of the frequency with which a pedestrian is likely to encounter a building entrance. Table 8.2 shows the door encounter rate on average for the main streets and the remaining street sections. Particularly in the case of Upper Street, the street 


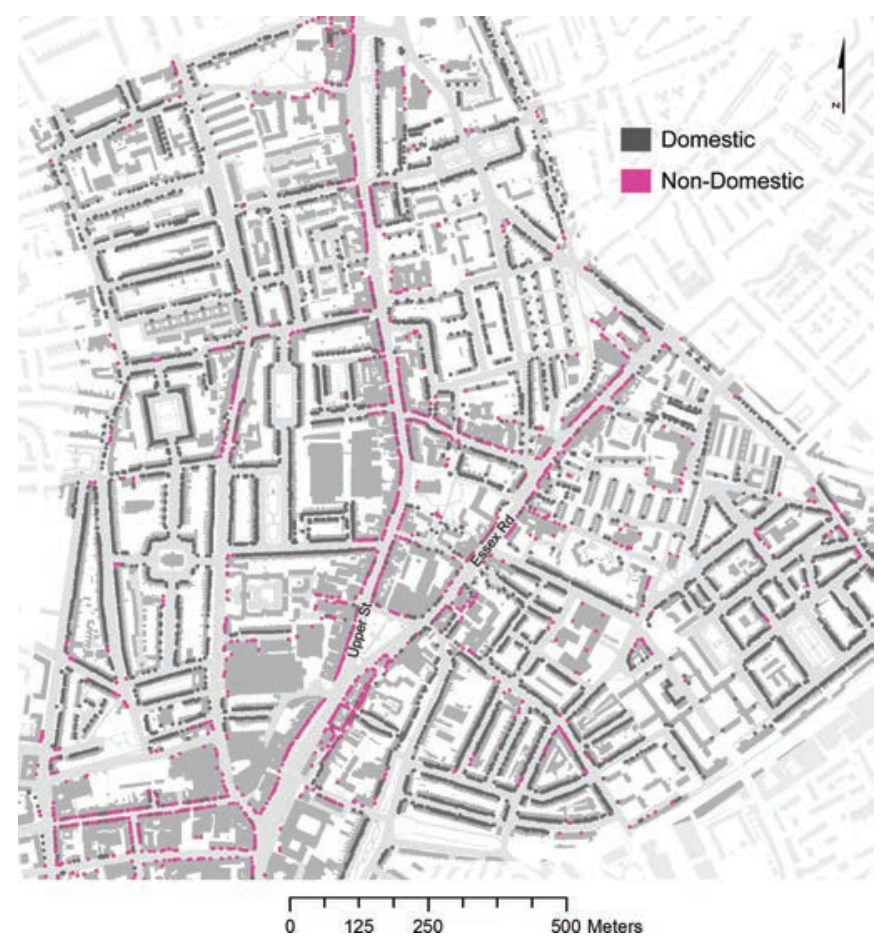

\section{Figure 8.6}

Upper Street and surroundings. Showing building entrances and associated land uses classified as domestic or non-domestic, c.2013

Background map: (C) 2013 Crown Copyright. An Ordnance Survey/EDINA supplied service.

Table 8.1 Islington, London - building entrances and associated land use for the two main streets and surroundings (c.2013)

\begin{tabular}{lcccc}
\hline & Façades & Doors & Domestic & Non-Domestic \\
\hline Surroundings & 5041 & 6713 & 5595 & 1118 \\
& & & $83.40 \%$ & $16.60 \%$ \\
\hline Upper Street & 282 & 434 & 105 & 329 \\
& & & $24.80 \%$ & $75.80 \%$ \\
\hline Essex Road & 139 & 205 & 68 & 137 \\
& & & $33.20 \%$ & $66.80 \%$ \\
\hline
\end{tabular}


Table 8.2 Islington, London - door encounter rate for the two main streets and surroundings (c.2013)

\begin{tabular}{lcccc}
\hline & Façades & Doors & Total façade length $(\mathbf{k m})$ & Door encounter rate $(\mathbf{m})$ \\
\hline Surroundings & 5041 & 6713 & 41.1 & 6.1 \\
\hline Upper Street & 282 & 434 & 2.1 & 4.9 \\
\hline Essex Road & 139 & 205 & 1.2 & 5.7 \\
\hline
\end{tabular}

interface appears denser: a pedestrian is likely to encounter a doorway every $5 \mathrm{~m}$, while this rate increases to every $6 \mathrm{~m}$ in the secondary streets. Notably, Essex Road is not as densely populated in terms of uses and doorways.

An interesting question arises at this point: since both Upper Street and Essex Road hold an important role in the socio-spatial functioning of the area, which are the distinct features that render Upper Street the core of local social life, as the high street? In order to investigate this query, the next section examines the street interface in greater detail, focusing on the way street life is articulated at the ground level.

\section{Life on the high street}

Much of the essence of urban living is arguably found in the street domain, in populated and vibrant sidewalks (c.f. Whyte 1980, 1993; Jacobs 1961; Gehl 1987; Appleyard 1981; Anderson 1986; Vidler 2011), where diverse activities are taking place and people randomly encounter one another, creating an 'urban buzz'. In Space is the Machine, Bill Hillier maintains that cities are 'mechanisms for generating contact' and moves on to describe how the urban buzz is a by-product of space and nourishing 'multiplier effects' which refer to the way the city works as a system to produce and reproduce everyday activity (Hillier 1996: 126). The syntactical analysis presented so far has highlighted the significance of the two historical thoroughfares for the heart of Islington, Upper Street and Essex Road. These streets would be expected to possess an urban buzz, being active routes within the wider London network.

High streets, however, are more than just routes busy with traffic and activities. On top of that, the high street is an incubator of local life, the socio-spatial highlight of a community, and as such it plays a conceptual as much as a functional role ('The Boundaries of Belonging' in Hall 2012, 2014; Carmona 2015). At a symbolic level, high streets are a material realisation of the special character, the unique identity of settlements and the 
physical, social and cultural features that enhance a sense of spatial bonding. Consider the experience of a trip around London as one moves between neighbourhoods. Whilst on the one hand there are cross-city similarities in the built form and function (for instance, across the many terraced housing blocks), nonetheless, when one reaches a high street, the local identity of the area is easily perceived.

For Islington, Upper Street is the area's social resource and signature. The following paragraphs aim to unfold the physical and spatial properties that generate and support the specific spirit that has permeated the street over time. Remarkably, throughout its processes of urban transformation, Upper Street has accommodated both local life and urban change while remaining at the same time faithful to Islington's historical ambience as an area of retreat. McKellar (1999: 191) notes in The Birth of Modern London that as early as the 1720s, Islington was a popular destination for 'taking the air and walking'. The author mentions the 'fashionableness of the visitors' dress'; the fact that entertainments were 'housed in adapted vernacular buildings'; and the variety of retreat activities offered in the Islington spas, such as taking coffee, gambling, games and concerts (McKellar 1999: 191). Recreation facilities, such as cultural venues (theatres, cinemas) as well as public houses, coffee shops, bars and restaurants, were prominent along Upper Street then just as much as today, where they stand side by side with local community services for the area.

The importance of Upper Street for Islington is easily demonstrated by considering a number of straightforward facts evident from a study of its building stock. In contrast to Essex Road, where the majority of nondomestic uses are commercial, Upper Street fosters functional variety along its length. The northern end of the street is marked by Highbury and Islington Station, serving both underground and over-ground lines. At its southern end, Upper Street ends at Islington High Street and Angel Station. Besides transportation links, the street has several significant administrative buildings: the London Borough of Islington main offices, Islington Town Hall, the police station and the fire station. Churches and educational buildings further establish the street as the locus of community activities. Finally, cultural premises are also present along Upper Street, including theatres, music venues and a cinema, alongside numerous restaurants, bars and pubs. Offices, shops, two post offices and several bank branches complete the range of building uses found in Upper Street, which collectively mark the existence of an organised community in its own right, rather than merely a passage into the city centre.

Building use diversity, in other words, is a feature that distinguishes Upper Street from Essex Road. Returning to Hillier's words on 
the generation of human encounter at the street domain, the mix of uses contributes to the attraction and co-incidence of journeys and activities. It is conjectured that the denser the uses that interface - and potentially interact - with the street domain, the higher the chances for a greater number of journeys and populated sidewalks. Fiona Scott discusses in the next chapter of this book how high-street diversity tends to be overlooked. Scott explains the extent to which the robustness of high streets is supported by a very wide range of activities, all of which are associated with high street economic productivity.

Analysis of the street interface micromorphology can shed further light on the structure of use diversity patterns in Upper Street. In the scholarly tradition of urban morphology, the study of a street's micromorphology refers to a micro-scale examination of built form properties at the level of the individual building (or plot) (c.f. Conzen 1960; Whitehand et al. 1999; Whitehand 2001a). The discussion here looks at the way diversity is articulated across the block fronts facing Upper Street, not so much to emphasise the economic micro-structure as to describe how the street interface is morphologically and functionally diverse.

The building footprints indicate that there is, first, a difference in the way either side of the street is composed in terms of building morphology and built form articulation (Figure 8.7, Table 8.3). The west side of the street appears more built-up than the east side, where the street interface looks fragmented in some locations and is interlaced with green spaces. Upper Street measures approximately $1.5 \mathrm{~km}$ in length. The total building façade length for each side $(1.3 \mathrm{~km}$ west, $0.8 \mathrm{~km}$ east) shows that building density is on average 34 per cent higher (86.7 per cent of the street is covered on the west side and 53.3 per cent on the east). A difference in building footprints is also observed. The mean building façade length for each side indicates that the building scale increases considerably on the east: building façades are wider on average by approximately $2 \mathrm{~m}$ (i.e. $7 \mathrm{~m}$ on the west as opposed to $9 \mathrm{~m}$ on the east, on average). The morphological distinction between the two sides, with bigger buildings and more open space on the east side, is strongly related to building use (Table 8.4). The east side includes 70.8 per cent of the administrative and community buildings of the street (whilst only 29.2 per cent lie on the west). The exact opposite ratio is recorded for commercial uses (both retail and entertainment): 70.9 per cent of the street's commercial activity occurs on the west side and only 29.1 per cent on the east. This division defines one street side as more associated with the formal rituals of the local community (east) and the other as involved with the everyday informal events. It also creates a strong alignment of shops, bars and restaurants on the west side which enhances visitors' journeys and 

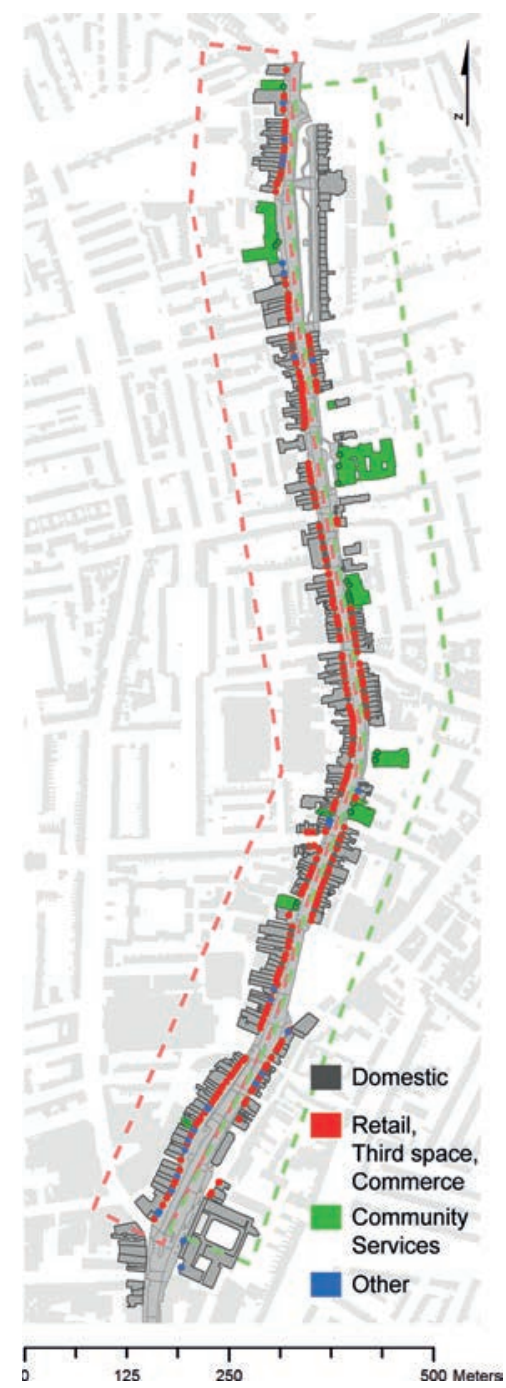

Figure 8.7

Upper Street - west and east street sides. Showing building entrances and associated land use, $c .2013$

Background map: (c) 2013 Crown Copyright. An Ordnance Survey/EDINA supplied service.

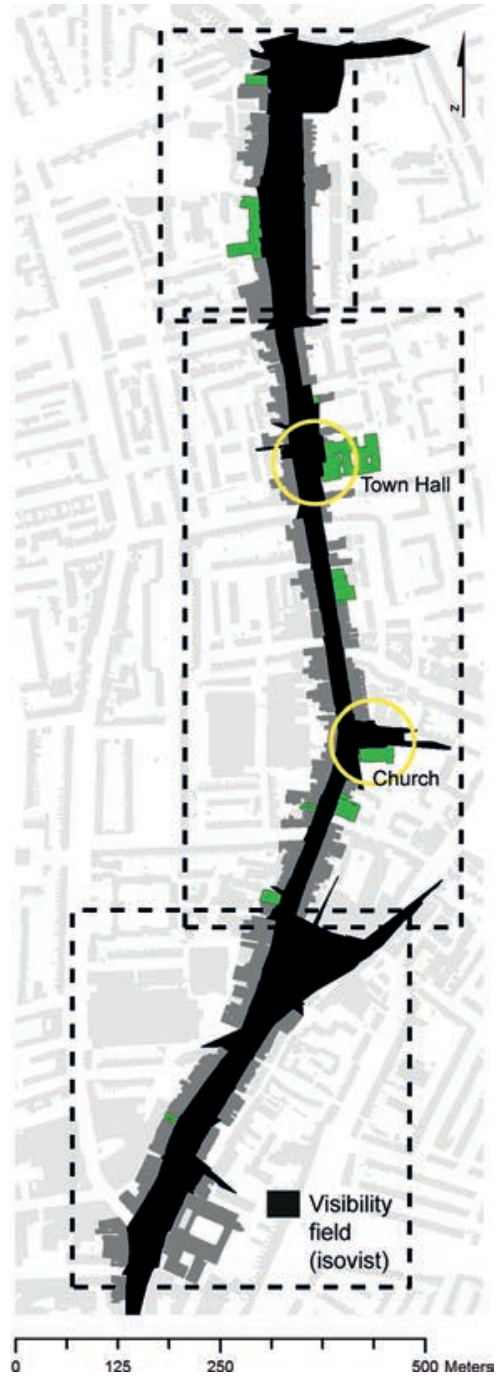

Figure 8.8

Upper Street - northern, middle and southern sections. Showing visibility fields and community buildings, $c .2013$ Background map: (c) 2013 Crown Copyright. An Ordnance Survey/EDINA supplied service. 
Table 8.3 Islington, London - Upper Street: door encounter rate (c.2013)

\begin{tabular}{lcllll}
\hline & Façades & Doors & $\begin{array}{l}\text { Mean façade } \\
\text { length } \mathbf{( m )}\end{array}$ & $\begin{array}{l}\text { Total façade } \\
\text { length } \mathbf{( k m})\end{array}$ & $\begin{array}{l}\text { Door encounter } \\
\text { rate }(\mathbf{m})\end{array}$ \\
\hline West street side & 180 & 288 & 7.2 & 1.3 & 4.5 \\
\hline East street side & 95 & 146 & 8.8 & 0.8 & 5.7 \\
\hline
\end{tabular}

Table 8.4 Islington, London - Upper Street: building entrances and land use (c.2013)

\begin{tabular}{|c|c|c|c|c|c|c|}
\hline & Façades & Doors & Domestic & Commercial & Community & Other \\
\hline \multirow{2}{*}{$\begin{array}{l}\text { West street } \\
\text { side }\end{array}$} & 180 & 288 & 64 & 197 & 7 & 20 \\
\hline & & & $\begin{array}{l}61.0 \% \text { (out } \\
\text { of total for } \\
\text { Upper St.) }\end{array}$ & $\begin{array}{l}70.9 \% \text { (out } \\
\text { of total for } \\
\text { Upper St.) }\end{array}$ & $\begin{array}{l}29.2 \% \text { (out } \\
\text { of total for } \\
\text { Upper St.) }\end{array}$ & $\begin{array}{l}74.1 \% \text { (out } \\
\text { of total for } \\
\text { Upper St.) }\end{array}$ \\
\hline \multirow{2}{*}{$\begin{array}{l}\text { East street } \\
\text { side }\end{array}$} & 92 & 146 & 41 & 383 & 17 & 7 \\
\hline & & & $\begin{array}{l}39.0 \% \text { (out } \\
\text { of total for } \\
\text { Upper St.) }\end{array}$ & $\begin{array}{l}29.1 \% \text { (out } \\
\text { of total for } \\
\text { Upper St.) }\end{array}$ & $\begin{array}{l}70.8 \% \text { (out } \\
\text { of total for } \\
\text { Upper St.) }\end{array}$ & $\begin{array}{l}25.9 \% \text { (out } \\
\text { of total for } \\
\text { Upper St.) }\end{array}$ \\
\hline
\end{tabular}

is likely to draw them to spend a longer time in the street than simply passing by. Indeed, the area is popular for social gathering.

Second, this time considering both sides together, the street presents a different overall morphology in its northern, middle and southern sections (Figure 8.8). More particularly, the street domain at the northern and southern ends is wider and buildings stand farther apart than in the middle part of the street. Moreover, in the latter part doorways are more evenly distributed along the two street sides. With the two sides closer together and the greater density of building entrances, this middle section defines the heart of the high street both spatially and morphologically, and, consequently, functionally. The curved geometry of the street alignment emphasises the central core further with the sequence of changing street vistas: wider visual field at the street edges to attract pedestrian traffic and open the street function to the city, in contrast to a picturesque, narrower middle section. The landmarks of the local community, the town hall and the church, lie in this section and are morphologically highlighted by their bigger building size and the areas of open space in front of and around them.

Overall, the patterns of diversity in the street's interface range in scale, from the micromorphological properties of the building scale to the block and the entire street side. The way uses are morphologically articulated creates a complex diversity pattern - one that addresses the dual role of the high street: to serve local life while being simultaneously 'urban'; in other words to manage the interface of the local community with the wider city. 
Upper Street is an example of the way diversity grows complex over time and is fed by longevity. The next section explores how the street's longevity has been spatially and morphologically enabled.

\section{High street transformations}

In order to contextualise processes of urbanisation, a consideration of the macro scale and the conceptualisation of cities as entities is essential. When analysing the workings of a whole city, the street system acts in two fundamental formative ways on urban structure: it shapes historicalmorphological processes (Hanson 1989a; Hillier 1989) and spatio-temporal phenomena (Hillier et al. 1993; Hillier 1996). The historical-morphological processes refer to a city's growth over time - to diachronic processes and study of the long-term transformation of settlements (Griffiths 2009). The spatio-temporal phenomena refer to the synchronic effects that emerge from the relational properties of the spatial configuration of the city grid - these effects are described by the theory of 'natural movement' (Hillier et al. 1993). The theory of 'natural movement' suggests that the structure of the urban street layout is a primary agent in distributing potential movement patterns and human encounter in the city by rendering some streets more prominent as routes or destinations than others. Taking the two together, the diachronic and synchronic descriptions of cities capture 'the mobilization of time-space' considering different dimensions of time (Giddens 1984: 72-3).

In its negotiation with urbanisation, Upper Street has undergone a substantial degree of change, but it has managed to maintain fundamental aspects of its past origins. A synergy of spatial and physical properties, along with the designation in the 1980s of the majority of the blocks along Upper Street as conservation areas, are factors which have contributed to the resilience of the high street. To better inform our understanding of the synchronic city and the role of Upper Street within it, this section considers the diachronic processes that have shaped the high street and describes its long-term transformation. The analysis builds a discussion around aspects of spatial and morphological longevity, change and adaptability, and the shifting local and city-wide requirements that the street has been supporting over time.

In order to undertake historical analysis of the wider area's street network, Ordnance Survey maps for $c .1910$ and $c .1965$ were used to draw street segment maps (based on axial maps which were drawn in ArcGIS software). These cover the same area as for the model created for the contemporary city (c.2013) and were drawn using the method of 'cartographic 
redrawing' introduced by Pinho and Oliveira in 2009 (see also Serra and Pinho 2011), whereby the mapping process begins with the most current map and, moving backwards in time, redraws lines from the preceding time period (through removal, addition or modification). Figure 8.9 shows the syntactical measure of the combined integration and choice for the historical
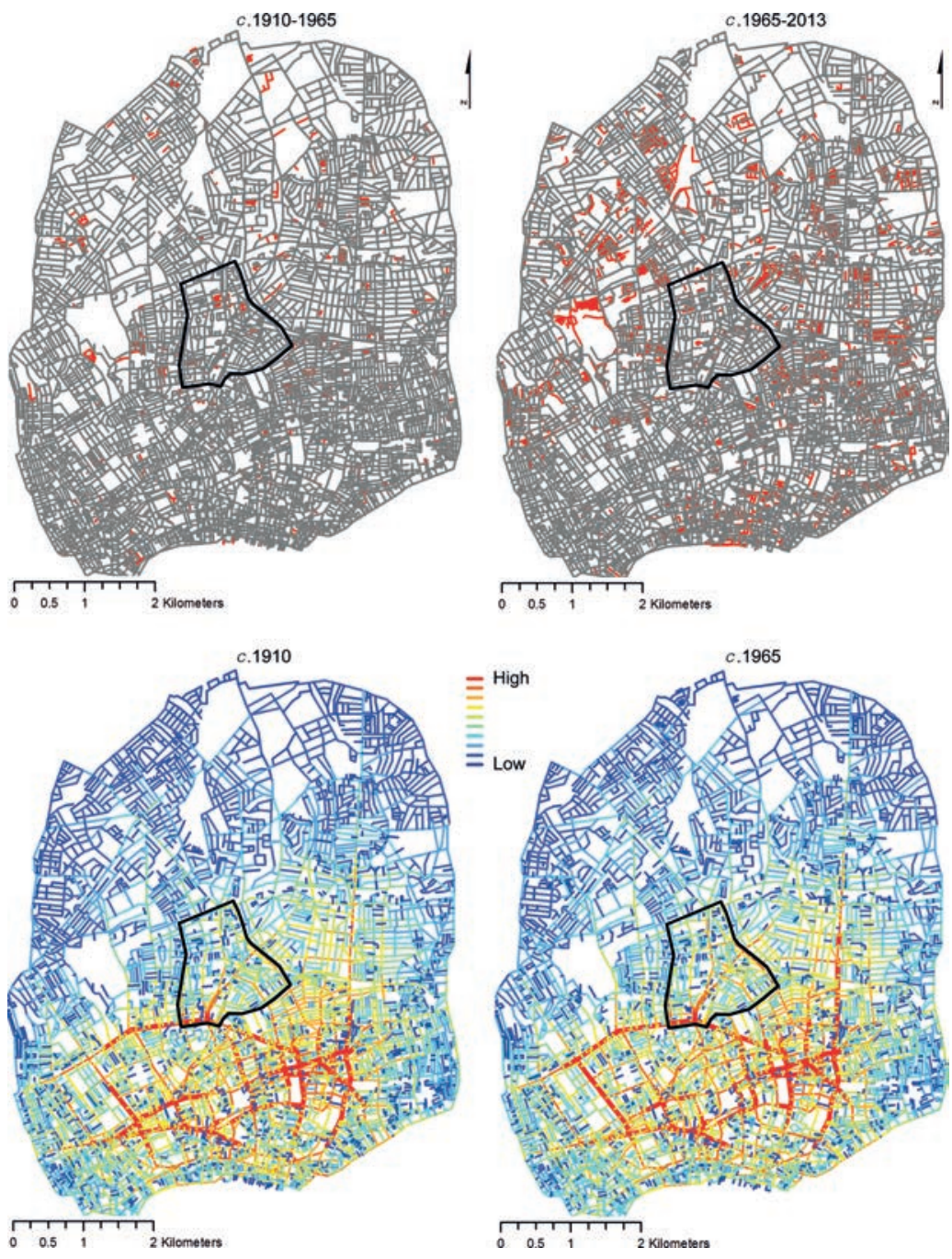

Figure 8.9

Islington, London: historical street network, c.1910, c.1965. Showing grid transformations (top) and segment angular analysis (below) for the measure of combined integration and choice, for radius $2500 \mathrm{~m}$

Garyfalia Palaiologou. 
networks. To explain this further, looking at the maps we can form an idea of changes in the combined street layout accessibility and permeability patterns. The measure is calculated for a radius of $2500 \mathrm{~m}$. An overall effect of urbanisation processes is that warmer colours 5 on the syntactical maps (red-orange-yellow colour range) - which represent higher space syntax values - take up a larger network area over time.

More particularly, the maps show that Upper Street is situated on the historically well-connected junction between the long arteries of Euston and Pentonville-City Roads ${ }^{6}$ and Islington High Street. As mentioned in the historical account of the area, this junction has been an important crossing for London since the early development of the city (and it is consistently prominent in the upper scales of accessibility, as can be seen in its red colouring in the maps). At the same time, the integrated (red) long lines of the (1) Euston-Pentonville-City Roads and (2) Oxford Street-High Holborn hold the integration core of the wider surroundings to the south and suggest a predominately east-west oriented organisation of the street network that dates back in time (see Hanson 1989a: 394). Effectively, these long lines comprise sections of the foreground city-wide network, keeping much of the longer-distance urban traffic to the south of the district and away from Upper Street itself. Still, for the immediate surroundings of Upper Street (the focus study area), the foreground-background distinction is historically clear and persistent (Tables 8.5, 8.6 and 8.7): the two main roads, Upper Street and Essex Road, maintain their configurational prominence as urban routes and stand out from their nearby street sections over time both for local trips (the walkable scale of $800 \mathrm{~m}$ ) as well as longer urban routes $(2500 \mathrm{~m})$. The mean values for the measure of combined integration

Table 8.5 Historical map: segment angular analysis showing mean values for the measure of combined integration and choice, for different radii (c.1910)

\begin{tabular}{lcccccc}
\hline & R800 & R1000 & R1600 & R2000 & R2500 & Rn \\
\hline Case study area & 512.84 & 773.47 & 1855.54 & 2788.53 & 4106.30 & 12100.60 \\
\hline Upper Street & 720.15 & 1121.230 & 2922.67 & 4514.54 & 6590.29 & 20292.70 \\
\hline Essex Road & 1007.37 & 1377.50 & 3401.39 & 5215.80 & 7743.06 & 22857.10 \\
\hline
\end{tabular}

Table 8.6 Historical map: segment angular analysis showing mean values for the measure of combined integration and choice, for different radii (c.1965)

\begin{tabular}{lcccccl}
\hline & $\mathbf{R 8 0 0}$ & $\mathbf{R 1 0 0 0}$ & $\mathbf{R 1 6 0 0}$ & $\mathbf{R 2 0 0 0}$ & $\mathbf{R 2 5 0 0}$ & Rn \\
\hline Case study area & 505.52 & 762.18 & 1803.01 & 2669.61 & 3898.74 & 11288.40 \\
\hline Upper Street & 785.51 & 1208.16 & 2955.16 & 4506.97 & 6563.84 & 19508.10 \\
\hline Essex Road & 950.40 & 1326.47 & 3299.68 & 5040.01 & 7483.75 & 22064.90 \\
\hline
\end{tabular}


Table 8.7 Contemporary map: segment angular analysis showing mean values for the measure of combined integration and choice, for different radii (c.2013)

\begin{tabular}{llcllll}
\hline & R800 & R1000 & R1600 & R2000 & R2500 & Rn \\
\hline Case study area & 423.24 & 640.46 & 1527.76 & 2300.20 & 3443.34 & 10599.70 \\
\hline Upper Street & 694.22 & 1043.27 & 2452.14 & 3770.29 & 5840.70 & 18981.70 \\
\hline Essex Road & 793.25 & 1113.24 & 2633.84 & 4199.14 & 6115.45 & 18752.70 \\
\hline
\end{tabular}

and choice shown in Tables 8.3-8.5 point to another important finding: Essex Road presents consistently higher values than Upper Street.

The greater prominence of Essex Road in comparison to Upper Street gives an important insight regarding the role of the structural properties of the wider street network in the resilient character of Upper Street. Recent developments in space syntax analytical techniques have introduced a way to take into account the size of the analysed spatial system when performing syntactical calculations - or in other words, to address the effect of the depth of the graph analysed (Hillier et al. 2012). In syntactical street network maps, depth refers to the number and size of the probabilistic routes within the street configuration. Recent methodological advancements in space syntax introduced normalised measures to allow for an effective mathematical comparison between street networks of different sizes (or depths), such as smaller and larger cities, as well as between a single city's different periods of growth. In their conclusion to a study comparing a sample of fifty cities, Hillier et al. (2012) suggested that the values of normalised choice that fall below the threshold of 1.4 reveal the street sections that work as structural elements of the local organisation, and values at the threshold of 1.5 and above pick up the global structure of the street network (Hillier et al. 2012: 180 ). With this finding in mind, Figure 8.10 shows the results of analysing normalised choice for the model of Islington and its wider surroundings in c.1910 and c.1965. Values above the threshold of 1.4 are marked in thicker red lines to visually clarify the grid structure. Comparing the three maps, it is evident how in both $c .1910$ and $c .1965$ Essex Road is included in the primary network structure with mean values close to 1.5, while Upper Street has a consistently important role locally (see Table 8.8 for a comparison of the mean normalised choice values across time). More particularly, the analysis picks up the southern part of Upper Street, indicating the impact of the Islington High Street junction.

These clues regarding the historical structural properties of the grid suggest that Upper Street, whilst being an important route, is not associated directly with the macro-scale spatial forces of urbanisation; rather it maintains some degree of spatial autonomy, participating in more local 

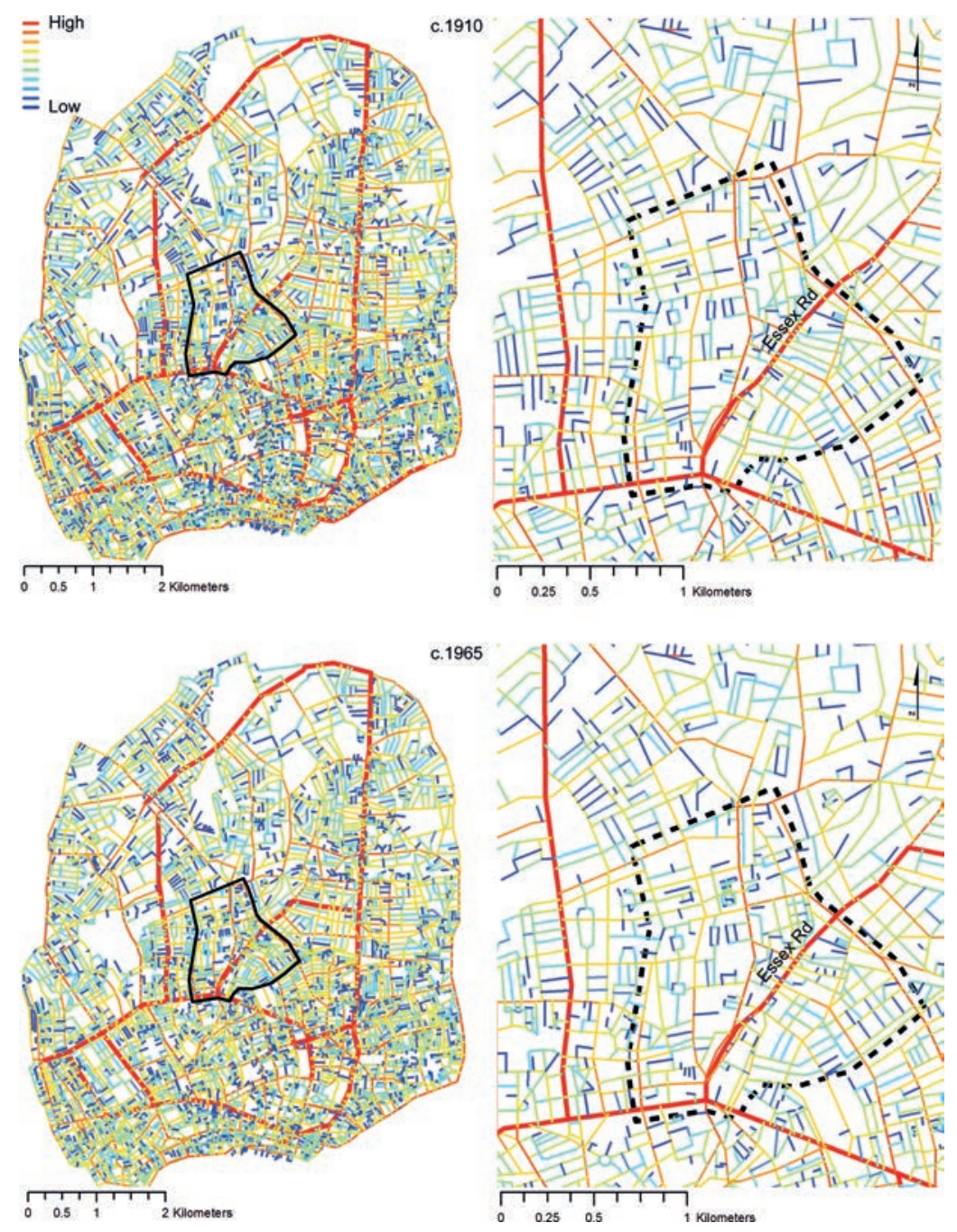

Figure 8.10

Islington, London: historical street network, c.1910, c.1965. Showing segment angular analysis for the measure of normalised choice, for radius $n$ Garyfalia Palaiologou.

processes. Jones et al. (2007) highlight that this is an observed phenomenon for UK high streets: they are protected from high-density city-wide pedestrian flows while at the same time attracting local life. Essex Road, on the other hand, participates more actively in city-wide processes, and thus, seems to be more directly affected by urbanisation. Islington's overall increases in centrality have brought changes to the character of the area in general, and 
Table 8.8 Temporal shifts in network, c.1910-2013; segment angular analysis showing mean values for the measure of normalised choice, calculated for the wider surroundings (radius $\mathrm{n}$ )

\begin{tabular}{llll}
\hline & $\boldsymbol{c . 1 9 1 0}$ & $\boldsymbol{c . 1 9 6 5}$ & $\boldsymbol{c . 2 0 1 3}$ \\
\hline Surroundings & 0.93 & 0.91 & 0.88 \\
\hline Upper Street & 1.38 & 1.38 & 1.38 \\
\hline Essex Road & 1.48 & 1.48 & 1.37 \\
\hline
\end{tabular}

to Upper Street in particular. These changes, however, do not appear to have compromised the socio-spatial integrity of the street to date.

High streets face a great challenge in trying to bridge the two scales of activity: local and city scale. High streets are unique points of reference for the local community. The diachronic processes of urbanisation, however, assign high streets a new role: that of participating in the synchronic structure of a greater urban whole. The latter is a strong counterweight which entails the possibility of absorbing the morphological and functional idiosyncrasy of the high street. Space syntax theory proposes that the random meeting and mixing of familiar and unfamiliar people is vital for the social essence of a city (Hillier and Hanson 1984: 17-20; Peponis 1989: 93). The co-presence and encounter of people of different social status, ethnicity and religion supports not only vibrant street activity, but also the exchange of information and the opportunity for socio-economic integration of the local people within the wider urban network (Legeby 2013; Marcus and Legeby 2012).

Originally a socially exclusive suburb, Islington gained the potential for greater numbers of encounters by merging with the city and by getting closer to London's expanding economic centre. At the same time, however, Upper Street had to accommodate denser and newly introduced patterns of activity, and consequently change aspects of its building use and morphology. This exemplifies a general process whereby forces of urbanisation make suburban urbanities accessible to a wider audience (not only to people living nearby, but also those commuting within the wider city) in a manner that socio-economically revitalises local life; or, on the other hand, expose local areas to major changes in order to match the macro-economic activities of the vast city. There lies the danger that a high street may lose its references to the past, and lose track of the unique diachronic processes that acted upon its physical form.

The long-term transformation of Upper Street shows that very early in the area's history the buildings adapted to the street's new role. In Figure 8.11 the building footprints of the blocks facing Upper Street are mapped 


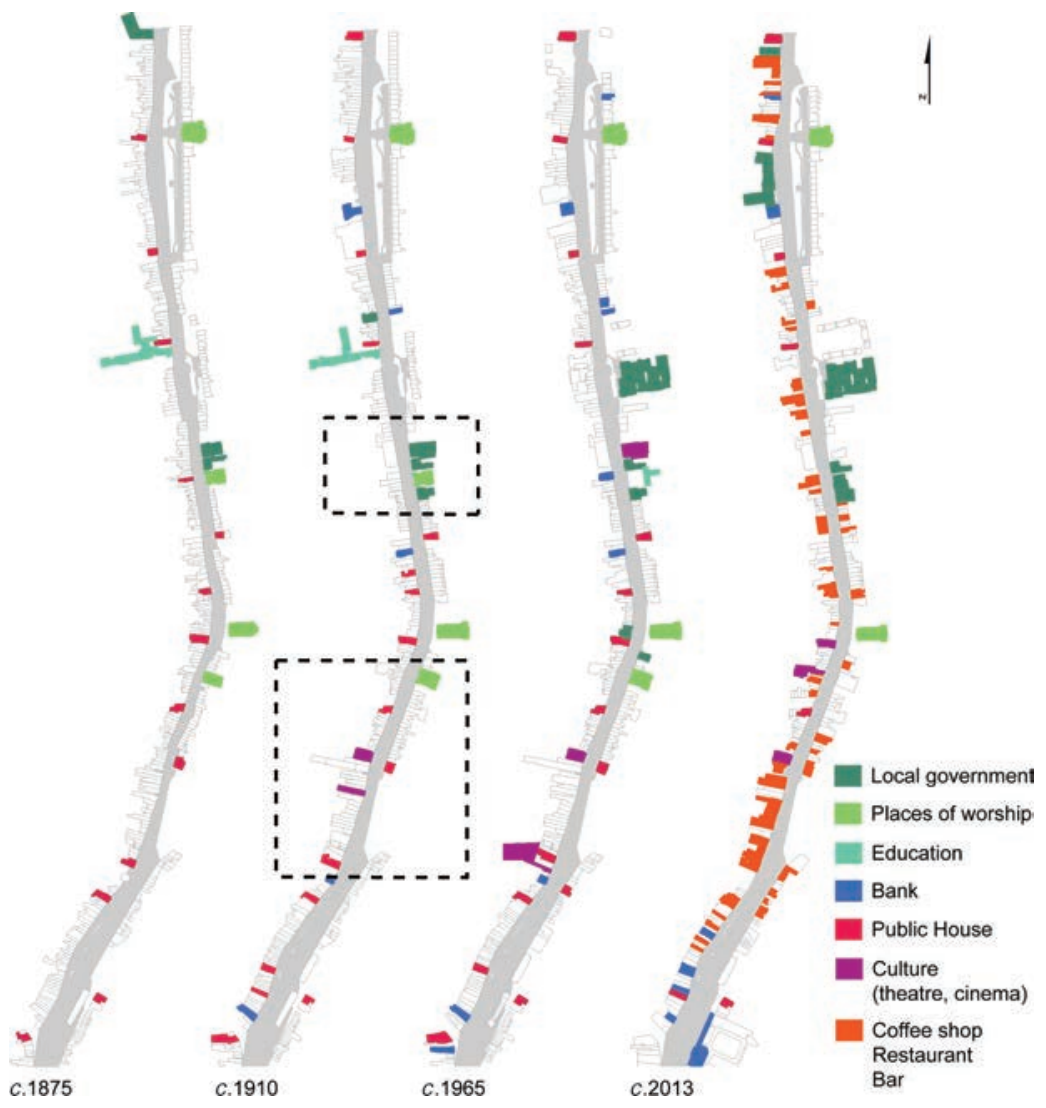

Figure 8.11

Upper Street - historical built form transformations. Showing building footprints for $c .1875, c .1910, c .1965$ and $c .2013$

Background map: (C) Ordnance Survey/EDINA supplied service.

for $c .1875, c .1910, c .1965$ and $c .2013$. The image also highlights the important establishments for the local community, such as the large institutional buildings, churches, schools, theatres, cinemas and public houses. An important change between $c .1875$ and $c .1910$ concerns the widening of Upper Street between Islington Green and Cross Street, and between Barnsbury Street and Waterloo Terrace. The Metropolitan Board of Works (MBW) - in charge of London's infrastructure between $c .1855$ and 1889 bought buildings on both sides for demolition to widen the street. These works finished in 1888 and, although they transformed the street morphology, the majority of uses were re-incorporated into the new buildings. The functional profile of the street did not remain intact for long. Comparing 
the maps of $c .1910, c .1965$ and $c .2013$, it can be seen how educational establishments have gradually lost ground from the high street. This is a by-product of increasing street traffic, not considered desirable for schools. Moreover, a second phase of big changes in the built form is noted (compare the $c .1910$ and $c .1965$ maps). This includes the demolition of sixteen buildings at the northern end of the street. Also, a whole block was cleared (fifteen buildings) for the new Islington Town Hall. In general, administrative and community buildings maintained their presence in Upper Street over time. A similar pattern is observed for theatres and cultural premises. Indeed, uses related to entertainment - theatres, cinemas, many restaurants, bars and public houses - are today the street's main attraction for a wide area of London. This is interesting when recalling that the area was renowned in the past for being a resort. In a way, Upper Street has kept the majority of its long-term established spatial bonds with the local community, as well as the transpatial bonds with the area's visitors.

The aforementioned changes in the built form entail building demolitions which imply that historical elements of the street are completely removed. There is another type of change and this refers to modification of the existing historical units (Törmä 2014). In this case, the historical pattern of building aggregation has contributed to the longevity of the built fabric in Upper Street. Laura Vaughan untangles the street morphology of 'the butcher, the baker, the candlestick maker' in the previous chapter and explains how the regular and narrow-fronted building units allow for a dense sequence of uses where functions are interchangeable. The underlying rhythm of the plot pattern creates in turn a template which ensured morphological unity (not to be confused here with 'uniformity' - as unity allows for architectural variability) and scalar modifications - namely, changes in building units from larger to smaller and vice versa. The outcome has been the ability to apply alterations that are 'fit-for-purpose' for whatever the scale of transformation required. In such urban complexes, urban change can be absorbed by the built form whilst maintaining a morphological consistency at various scales.

At 133 Upper Street we find an example of such a modification (Figure 8.12). The four-storey building, which was built originally as a school in the early nineteenth century, is occupied today by shops on the ground floor and offices on the upper floors. The wide five-window façade is marked with a central round-arched entrance (the former school entrance). At either side of the doorway pilasters, the altered commercial ground-floor interface is nowadays covered by large window displays which open up the stucco façade to allow visibility into the interiors. In other words, 133 Upper Street opened as an educational building, larger in size than a typical narrow 


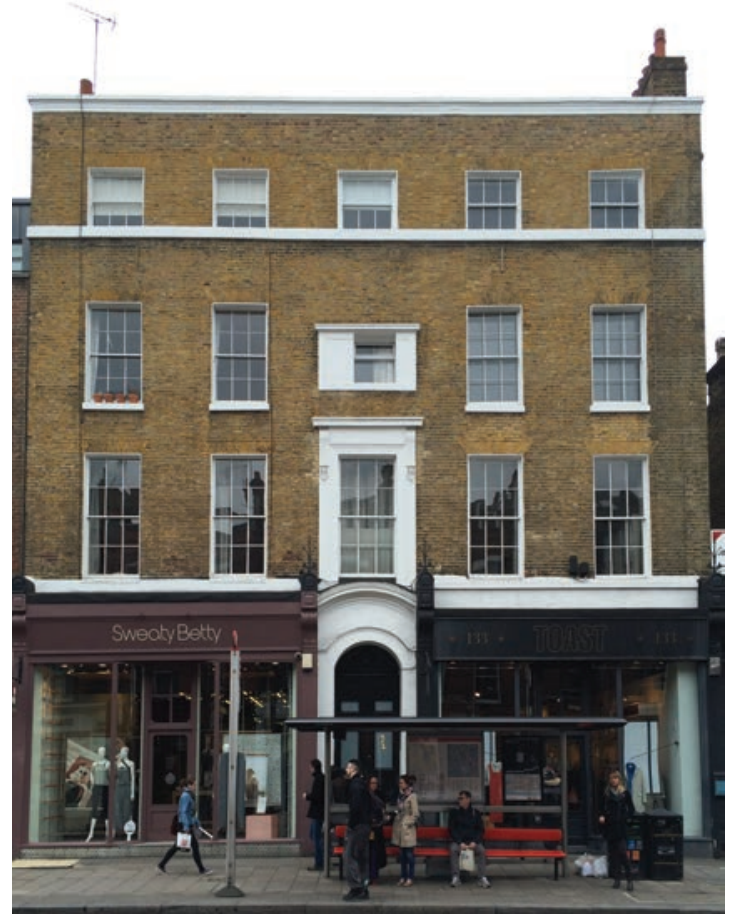

Figure 8.12

133 Upper Street

Garyfalia Palaiologou.

terraced unit, but was then subdivided at ground level to be similar in size to the adjacent smaller buildings. It was possible for subdivision to occur without losing the morphological references to the typical narrow plot width and building scale of the historical high street frontage.

A benefit of a long-standing building morphology is that the high street's urban history can be read in the built form properties (morphology and use). Building longevity acts in a conceptual manner with regards to high street identity. Shifting densities, uses and architectural styles have all left their mark on Upper Street, embedding cultural projections in the built materiality. Upper Street was divided into conservation areas in two phases: 'Angel' designated in 1981 and 'Upper Street North' in 1985. The London Borough of Islington's conservation policy (Islington Council 2015) specifies that the protection of an area involves the fostering of all those elements that contribute to its special character: the buildings, the historical street layout, the building and paving materials, the variety and mixture of building uses, landscape and tree cover, and in general all the 
features that compose the historical streetscape. In the context of Upper Street, these principles require its diachronic dynamic role in Islington, and the 'dialogue' with London via its vibrant high street interface, to be maintained.

\section{Conclusion}

This chapter has made a close examination of a long-standing, and once suburban, London high street: Upper Street, Islington. The discussion describes the street's contemporary role as part of the London network and the street's historical transformation. The intention has been to understand the evolving role of the high street over time.

Understanding suburban urbanities within an evolutionary scope requires attention to two important factors: the part-whole relationship and time. In order to understand relations between parts (in this case, suburbs) and whole (city), it is crucial to follow their interdependence over time. Clearly an historical study and a temporal analysis are suggested by the term 'evolution' itself, since this refers to longevity and therefore to historical processes of continuity and change (Griffiths et al. 2010). The part-whole relationship points first to inductive thinking (Jacobs 1961: 428-48) and second to holism (Kropf 2001: 33). Inductive thinking entails the retrieval of information concerning the complex 'whole' by studying its sub-components; namely, to a bottom-up philosophical approach. Holism implies thinking about the 'whole' while acknowledging a structural link between parts and the whole. This conjectures that the parts cannot be conceived independently of the whole but also that the whole is not simply considered as the agglomeration of the parts. Respectively, a suburb and its high street as a focus point cannot be understood without an equal appreciation of their (existing or growing) role as both local and urban components - especially in an urban configuration such as London where the city grows outwards, absorbing and displacing the fringes (Vaughan et al. 2010b).

Marshall suggests that the 'order of the whole arises from the interactions between the parts' (2009: 17-18). The London map appears as a random patchwork of urban parts. By parsing the street syntax, however, the two-dimensional city structure is understood. London's growth allows for spatial emergence in the street pattern based on a distinct foregroundbackground organisational logic. This emergence adjusts and assembles through diachronic morphological processes the parts within the whole (Hanson 1989a: 329). In this process, discrete suburban entities tangle with 
the city. The high street, as the most prominent spatial element of the suburban configuration, faces the challenge of sustaining its historical context and purpose and of managing city-wide forces. The challenge is for the high street to tackle the growing complexity of urban rhythms without alienating itself from its past and historical identity. This challenge can be better understood when considering Sam Griffiths' suggestion - discussed in the second chapter of this volume and using the suburb of South Norwood as an example - to acknowledge the high street as 'a dynamic agent of continuity'. In this context, it needs to be highlighted that the high street's agency refers to affiliating both spatial and time scales. Each high street essentially constitutes a unique urban 'choreography'7 as John Peponis (1997) calls it - a pattern of uses and of human encounter and co-presence situated within distinct morphologies. These choreographies are the outcome of the interaction between physical, temporal and social rhythms (Seamon 1980). It was the aim of this discussion to point out that the object of matter is a diachronic exchange between the high street and the urban configuration; one that embodies the synchronic city at a time situated within a temporal continuum of urban past and present. Namely, the high street is called to defend its individuality and at the same time claim its participation in the city. The analysis has shown how this has been the case for Upper Street. Protected initially by the London street network structure itself and later by conservation policies, Upper Street has maintained aspects of its historic suburban identity, updated to match the wider urban scope.

By building a case on the example of Upper Street, the discussion in this chapter suggests that the (sub) urban high street needs to be understood as a threshold between the local and the city scales. A threshold is a physical and/or notional space between two fields to which it is simultaneously adherent - both affecting those fields and being affected by them. The physical, spatial and functional history of Upper Street provides an example of the evolving transactions and interactions which overlap at the high street domain: between the local and the city-wide structure on the one hand, and the synchronic and diachronic city on the other. Most importantly, Upper Street as a living case study highlights how the socio-spatial transition from the city-wide scale to the local context, with the high street as the threshold, can serve a unique role in the urban context supporting the development of accessible 'spatial solidarities' (Hillier and Hanson 1984) - namely, of spatial references that enhance the concept of community on the one hand and citizenship on the other.

The author is grateful to the Engineering and Physical Sciences Research Council for financially supporting this research in the form of a PhD Studentship. 


\section{Notes}

1 Old Ordnance Survey Maps, Highbury \& Islington, The Godfrey Edition, c.1914.

2 See the Old Ordnance Survey Maps, Clerkenwell, King's Cross \& The Angel, The Godfrey Edition, c.1871; it is explained that deterioration was often the result of leasehold arrangements which did not prevent building at the back of the main roads.

3 See Glossary for a brief explanation of space syntax terminology. Broadly speaking, integration refers to a segment's potential to serve as destination and choice refers to a segment's potential to participate in trips through the area (the mathematical measure of betweenness). Segment lengthweighted measures normalise calculations by taking into account the effect of the segment length and are used to enable comparability across systems of different sizes (Hillier et al. 2012).

4 The combined measure for integration and choice estimates the way the street segment is generally situated within the grid, calculating each segment's potential for to- and through-movement. This analysis is used to form an overview of the potential spatial prominence of each segment within the street system. Higher values signify higher probabilities for the street segment to form part of a larger set of spatial relations within the street network.

5 The maps are coloured in ArcGIS, based on a classification of syntactical values in thirty bands from high (red) to low (blue). The syntactical calculations are performed in Depthmap software.

6 New Road opened in 1756-7 (today the Marylebone, Euston, Pentonville and City Roads altogether) (Inwood 1998: 260). In the Old Ordnance Survey Maps, Clerkenwell, King's Cross \& The Angel, The Godfrey Edition, c.1871, it is mentioned that the New Road worked as an 'arbitrary boundary of inner and outer London'.

7 With 'choreo-' standing for the Greek word $\chi \omega$ ós (namely, 'chóros', meaning 'space' in

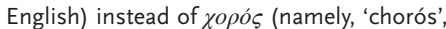
meaning 'dance' in English). 


\title{
Case Study 1 \\ High Street Productivity
}

\author{
Fiona Scott
}

\section{Introduction}

London is a vast network of high streets, from the dense pattern of diverse activities that characterises the very central zone, to a more dispersed and largely linear pattern of mixed-use streets outside this central area. These streets support a fantastic array of different activities on the street front and in the back streets and hinterlands, which also connect to trade and industrial estates. This chapter takes a look at the rich and varied life of these important areas of commercial activity in outer London, with an emphasis on their importance to local economies. A number of projects by Gort Scott Architects (of which the author is a director) including urban design research and strategy, and site-specific designed interventions, illustrate how a detailed understanding of these places is critical in order to nurture, strengthen and incorporate them meaningfully in regeneration plans.

The suburban setting has for centuries been the target of criticism for the supposed lack of diversity of suburban activity, people or places. The suburban high street is said to be reliant on shopping and therefore in an unsustainable journey towards decline. These high streets are typically thought of as shopping destinations, and as such, the increase in internet shopping and the impact of 'out-of-town' shopping are both widely seen as severe threats to high streets, leading to a potential terminal decline. But the reality is that a large part of the high street equation is not about shopping, and these other commercial functions tend to be overlooked, which has the effect of undermining both the robustness of high streets and their importance to London's broader economy.

In our work for the London Development Agency (LDA), we have identified and mapped over 600 distinct, named stretches of high street within the London Boroughs (Gort Scott and UCL Bartlett School of 


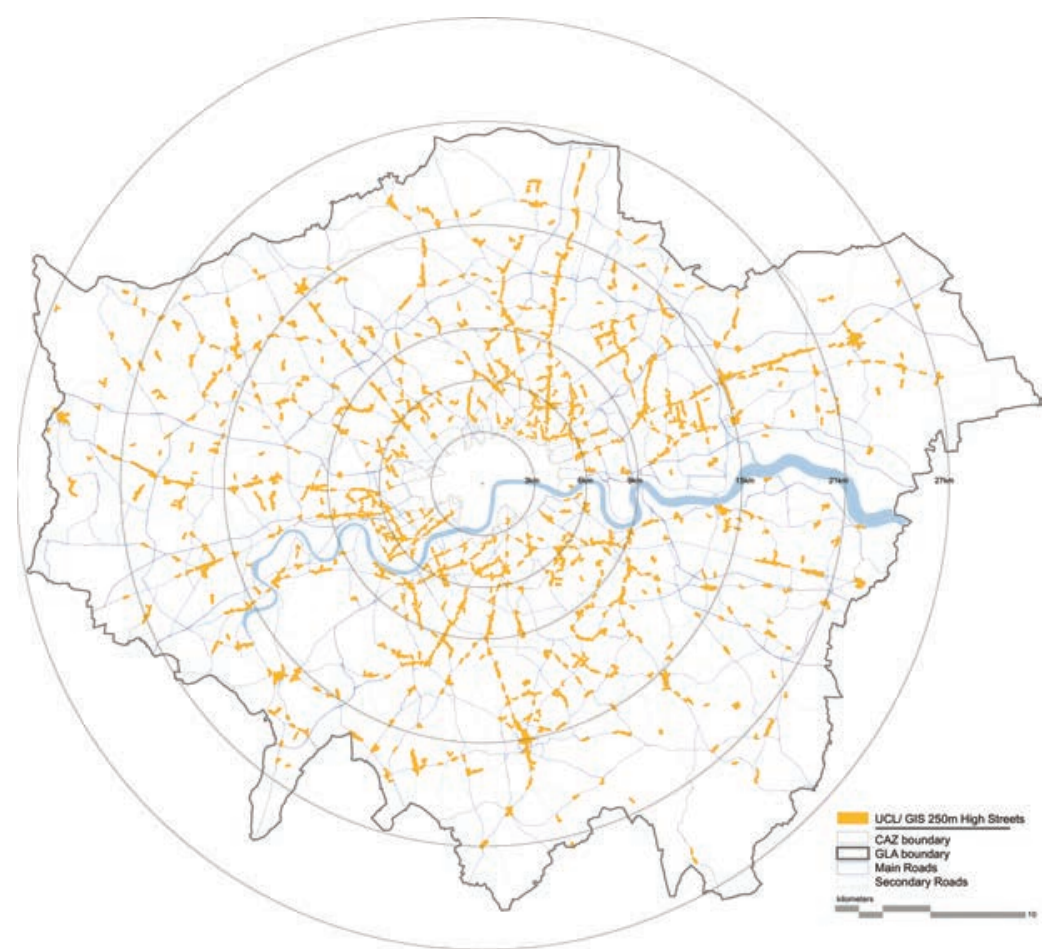

Plate 1.1

Map showing network of over 600 London high street locations

(c) Gort Scott Ltd and UCL.

Planning 2010) in order to understand their potential to accommodate London's continued growth by exploring their qualities, successes and challenges (see Plate 1.1). From the expensive boutiques of Hampstead High Street, to the sari shops of Southall, from the curated shopping experience of Marylebone High Street, to the diverse, free-for-all in Peckham, London's high street parades are the front windows that represent their localities.

\section{High street diversity}

Our investigations into high streets began with a detailed look at a low-key stretch of high street in Redbridge in outer London with the aim of understanding what these places are made of: their built form, character and use. Made in the Suburbs is a series of illustrations and analysis, which culminated in an exhibition (Gort Scott Architects 2009), revealing a suburban high 


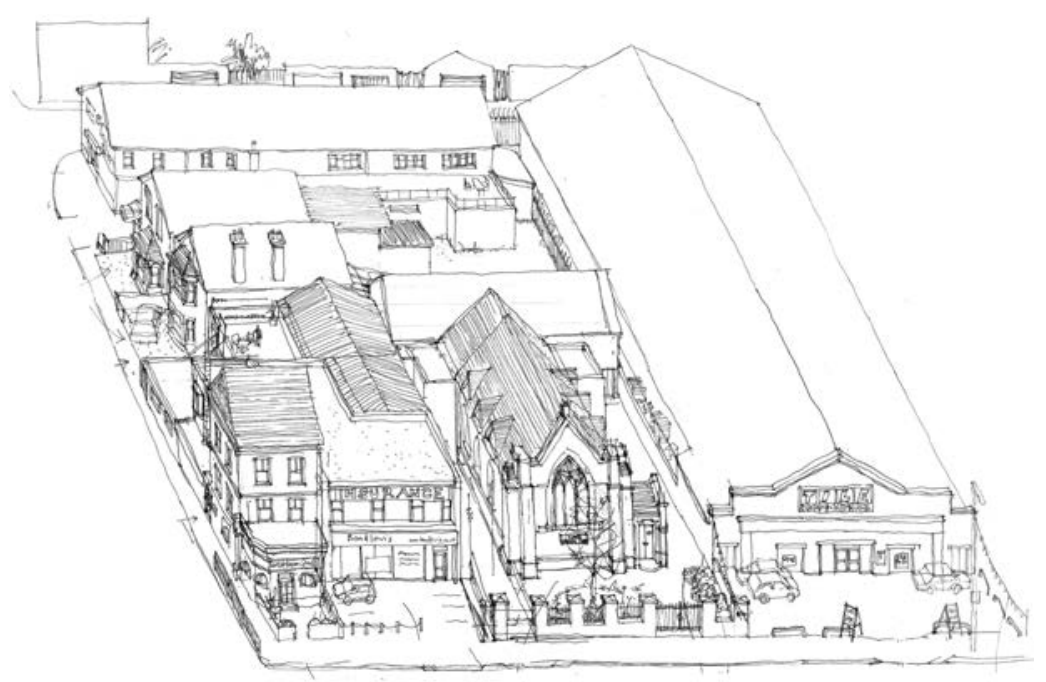

Plate 1.2

Hand sketch illustrating high street urban blocks on Roman Road (A1818)

Redbridge, London: a spiritualist church, a tile wholesaler, a Caribbean restaurant and a Punjabi bakery, amongst other uses

(c) Gort Scott Ltd.

street of mixed-use urban blocks with swimming pools, mosques, manufacturers of widgets, night-clubs, banqueting halls, churches, multi-use halls, higher education establishments, crèches, office complexes, garages, mechanics and aquariums (see Plates 1.2 and 1.3). There is an almost endless mix of different types of use, in which retail plays only a modest part. This mix extends into the depth of the block that fronts the high street, as well as above and behind high street frontages. Many of these activities take place in buildings that were originally designed for a different purpose, in particular the terraced house and the light industrial building. Both these building types, in their many forms, lend an extraordinary adaptability and flexibility to the high street, accommodating varied uses over time, and adapting to highly varied needs through extension and reconfiguration. In terraced houses we find everything from used car sales to fish aquaria and light industrial buildings have become banqueting halls, gyms, mosques and co-working spaces. These building types have allowed the high street to continually evolve over the last 150 years.

The uses at the rear of high street blocks also need to be thought of as part of the high street. One high street parade at Seven Kings in Redbridge (see Plate 1.4) is a handsome, if dishevelled, terrace of buildings that contains small shops, a post office, services and food establishments. But 


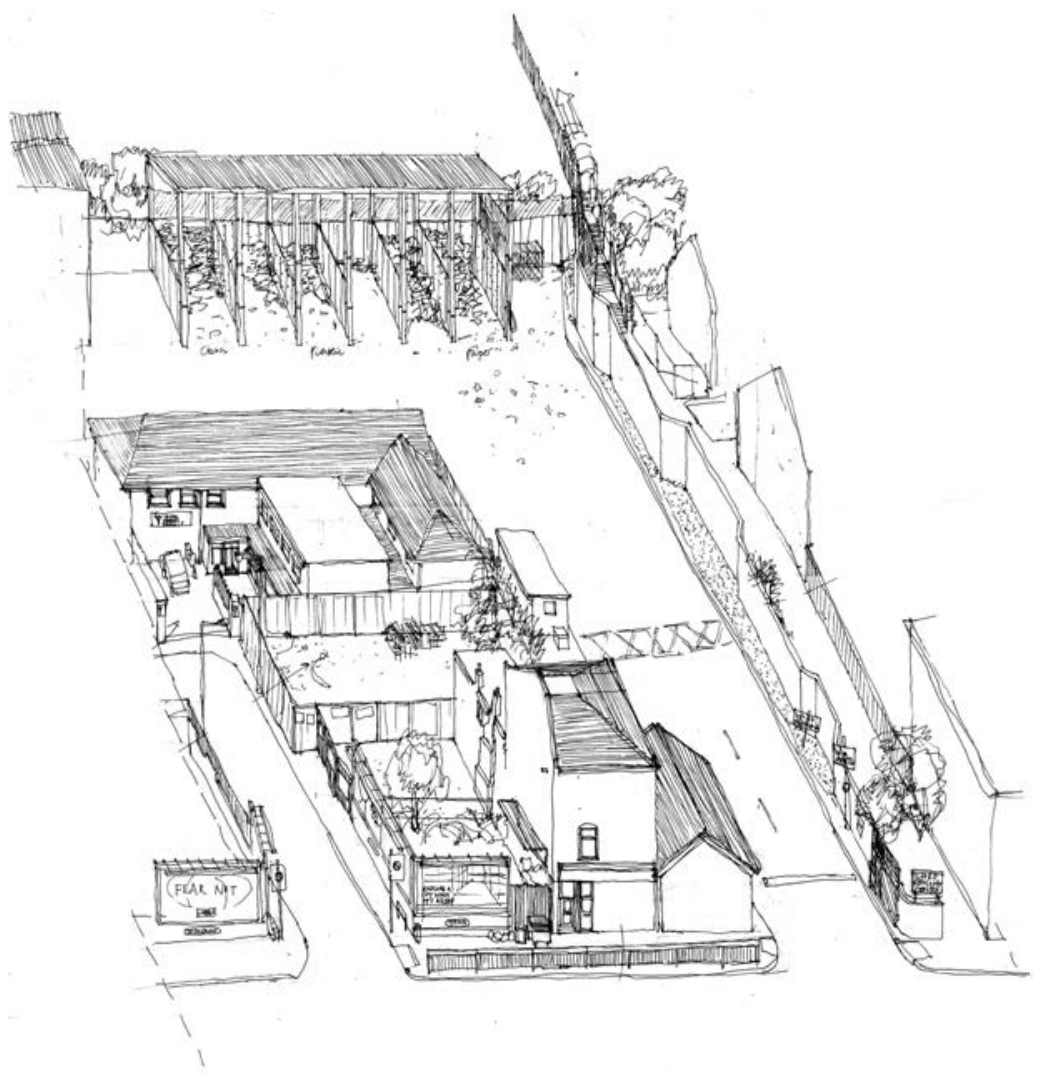

\section{Plate 1.3}

Hand sketch illustrating high street urban blocks on Roman Road (A1818), Redbridge, London: a recycling centre, learning centre and crèche, café, amongst other uses (c) Gort Scott Ltd.

down alleys into the depth of the block, accessed via the high street and side streets, there also exist a large mosque and teaching centre, nightclub and more business premises such as carpet fitters and printers, none of which is visible from the high street, but a clearly part of the life of the street.

\section{High street working life}

The Redbridge study (Gort Scott Architects 2009) led to Gort Scott Architects developing a new sensibility towards the high street - a wider appreciation of its true form and function from an urban design perspective that we had not encountered elsewhere. This type of sensibility for a place, despite its unassuming appearance, is very important in the context of regeneration, because in 


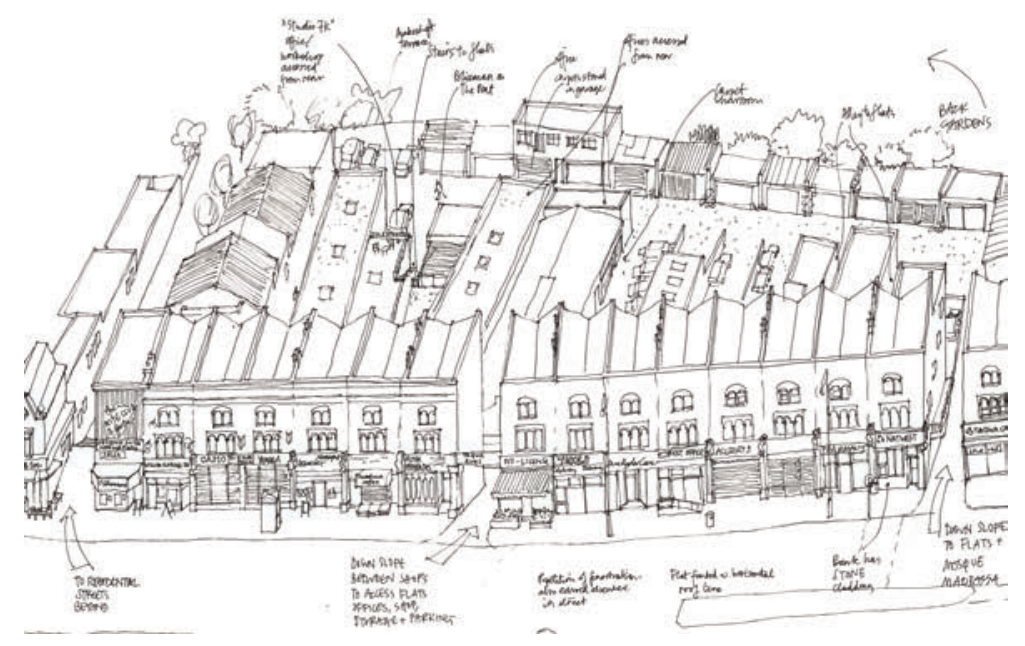

Plate 1.4

Hand sketch illustrating high street urban blocks on Roman Road (A1818), Redbridge, London: Seven Kings parade of shops including mosque, night-club and other uses

(c) Gort Scott Ltd.

redevelopment plans, the diversity and mix of existing buildings and uses on the high street are often belied by their appearance, and therefore not adequately valued.

The observational work in Redbridge led to a study of the whole of London. The High Street London report (Gort Scott Architects and UCL Bartlett School of Planning 2010) reveals in more analytical detail the importance of the employment and work functions of London's high streets. The study also reinforces the observations that high streets are much more than parades of shops. The study shows that in terms of floor area, shops and services can account for much less than half of the non-residential use on or adjacent to the high street. Of the high streets chosen for the study, both Redbridge and Tottenham had nearly 60 per cent of non-residential use for uses other than retail. In Peckham, 30 per cent of the floor area within $200 \mathrm{~m}$ of the high street was in industrial use. In Tottenham 42 per cent was industrial and in Redbridge it was as much as 45 per cent. By looking behind the façade, down alleys and side streets and mews, the study reveals places of work, culture and community, and every kind of activity that sustains the city.

The role of high streets in local economies is also reinforced by the study, which shows that 52 per cent of jobs outside the Central Activities Zone (CAZ) were on high streets, as were 55 per cent of workplaces outside the CAZ. This analysis of use and functions is also backed up in conversations with people working on and using the high streets. Similar to research undertaken by Vaughan and colleagues into three outer London suburbs 
(Vaughan et al. 2009b), our surveys found that typically two-thirds of trips to high streets were made for activities other than shopping: things like going to school, to work or to get somewhere else. This should also be seen in the context of the fact that contrary to a preconception of people travelling into the city to work, half of Londoners do not daily leave their local area (Gort Scott Architects and UCL Bartlett School of Planning 2010). So to understand high streets as purely a retail phenomenon is both to underestimate and to misunderstand them. High street retail is undoubtedly changing, and in some areas suffering. But our research shows that we cannot look at one use type in isolation: all of the other uses that were observed on the high street contribute to the sustainability of shop-front retail and services. Many different functions are woven together in a web of interdependency on a micro-level, and we need to reinforce all the varied business opportunities and amenities of the high street if we want to make places that thrive.

Many of London's high streets, especially the main arterial corridors such as the A1010 (Bishopsgate-Dalston-Tottenham-Edmonton) and the A 1818 (Aldgate-Stratford-Ilford-Romford), have, as historically important transportation corridors, close proximity with large pockets of land designated for employment and industry. These areas, with the many varied daily needs of their businesses and workers, can also be seen to be part of the high street ecology in those corridors. Strategic industrial land and local authority-designated employment land are still some of the largest areas of dense employment uses in suburban areas.

It is not just the working life of outer London high streets themselves that has been undervalued. Similarly, employment areas and industrial estates have been neglected in urban design discourse. With similar ambitions as the high streets research - to quantify the significance and characteristics of businesses and workplaces in outer London - we carried out an analytical study involving detailed observations of a number of Strategic Industrial Land (SIL) sites and Borough Employment Land areas in the Upper Lea Valley (see Plate 1.5) in north-east London. Historically, some of London's more important industrial areas were situated all along the edges of the Lea Valley, of which only small pockets now remain. As such, industry and manufacture are a very important part of this area's heritage. The projects were commissioned by the boroughs of Haringey and Waltham Forest and provided the opportunity to enquire into the type and scale of business uses and outputs in some key employment areas: trading estates understood as industrial estates (Gort Scott Architects 2013a, 2013b). It is worth understanding here that only one-third of industrial land in London is actually in uses classed as 'industrial', the rest being exceedingly varied in use, and 


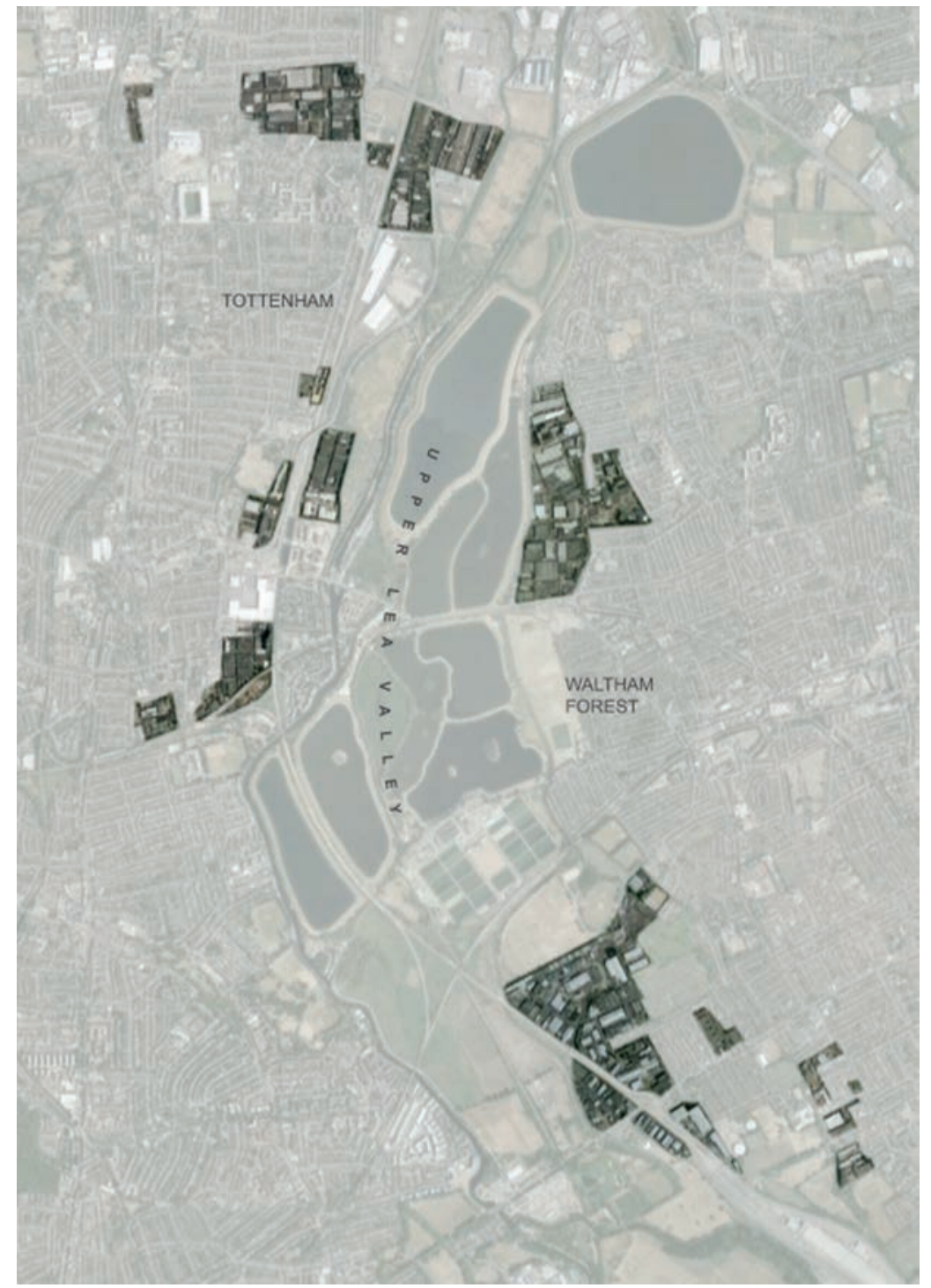

\section{Plate 1.5}

Aerial view showing extent of employment study areas in the Upper Lea Valley for the two studies, 'From Around Here' (Haringey) and 'Waltham Forest Employment Study' (Waltham Forest)

(c) Gort Scott Ltd. 
increasingly occupied by service sector and creative or artisanal manufacturing businesses, as convenient and affordable commercial space (Roger Tym and Partners 2011). The study areas on the western, Haringey, side of the Lea Valley are spatially and programmatically linked to the Aroro high street corridor - High Street Tottenham - which runs north-south up the valley. On the eastern edge of the valley in Waltham Forest, the study areas are connected with Blackhorse Road and Blackhorse Lane, a route that also runs north-south.

In the past, these trading estates were neither understood nor documented well. Statistical understanding within the boroughs of their scale and output has tended, if it existed at all, to be based on extrapolation of broad-brush statistics derived from a sample of only around 4 per cent of businesses (Office for National Statistics (ONS) 2014), and therefore did not give a good understanding of what happens in localities on a scale relevant to place-making. The aim of our study was to understand these trading estates through observation and enquiry at a fine grain, and explore the richness of the variety of different business activities there. The project also aimed to provide a better understanding of local links, specialities and co-dependencies, and establish new contacts between boroughs and businesses. The over-arching ambition was to provide the basis to help shift perceptions of the industrial areas in the boroughs, emphasising their positive contribution to the character and identity of the area through the outputs and cultures of the businesses and entrepreneurs, rather than focusing on the negative image of their often unkempt or unwelcoming appearance.

In most instances, the business or trading estates do not invite wandering through on foot, although they are publicly accessible. This is one of the practical reasons why many people have scant knowledge of the scale of these places and what happens there. The research methodology involved first visiting the industrial areas in person and mapping all of the individual units within the buildings in that area, through first-hand observation and conversation. It was important that the business survey was not performed as a formal questionnaire: most often the manager of the business was not present when the surveyor visited, so the ability to talk to foremen or employees and extract information in an easy manner that did not cause either suspicion or aggravation was very important. In the best cases, a rapport was established and the surveyor was invited into the premises to look around and hear more about the company.

Of the extrapolated number of over 1,200 businesses across the study areas, we found that the business types were very varied, although the largest number of businesses were 'Wholesale/Retail' and 'Distribution', with 
the largest subsector of both of these categories being 'Food and Beverage'. There were a large number of service sector businesses (11\%) and also automotive and repair sector businesses $(9 \%)$ in the Haringey areas. The 'rag trade' is also prominent in Haringey, with the manufacture and distribution of clothes, shoes, accessories and fabrics making up nearly 8 per cent of all businesses. However, a small but significant 'Artisanal Manufacturing' sector is also present in both areas (4 per cent in each, although there would also be some additional crossover with the separate 'Design and Creative' category). Although other business types employ more people and have higher production output, the specialist artisanal businesses are significant because they are typically successful and sustainable businesses producing high-value, high-quality outputs, which often require varied and particular skills. Many of them are unusual and intriguing businesses run by dynamic, motivated or entrepreneurial people, and are worthy of promotion and celebration by their borough.

Examples of such specialised businesses in the two study areas are: Dunhill, hand-made luxury men's leather goods and briar smoking pipes; Mandora and Gems Studios, mannequins and wax works; Cox Workshop, makers of luxury furniture and light fittings; Rosamanda Pleaters, one of the last remaining fabric pleaters in London; London Stone Conservation, stone carvers; Sands and Randall, wood carving and conservation; Gina, luxury hand-made women's shoes; and Louis Moreau Quilters, hand-made quilting, to give the flavour of just a few (see Plates 1.6 and 1.7).

As much information as possible was also gathered about the outputs of different businesses. For example, each year on average, Warren Evans makes around 18,000 beds, Best Bake makes over a million bread rolls, Gina makes 35,000 pairs of luxury hand-made shoes, San Amvrosia Health Foods makes 35,00okg of hummus and Redemption Brewers makes approximately 675,000 pints of craft beer. These kinds of figures, of which this list is a small sample, illustrate the scale of economic output in a way that can capture the imagination. They help to convey the varied characters of businesses, beyond the unremarkable and sometimes faceless or shabby appearance of the places they inhabit. Many of these businesses were featured in an exhibition on the high street in Tottenham as part of the project. The exhibition was called 'From Around Here' and was presented notionally as a 'shop', emphasising a direct link between the purchasing power of local people and the productive output of the local trading estates (see Plate 1.8).

Both the areas covered by the employment studies are currently undergoing change as part of regeneration initiatives, having received funding from the Greater London Authority, the Mayor's organisation. 


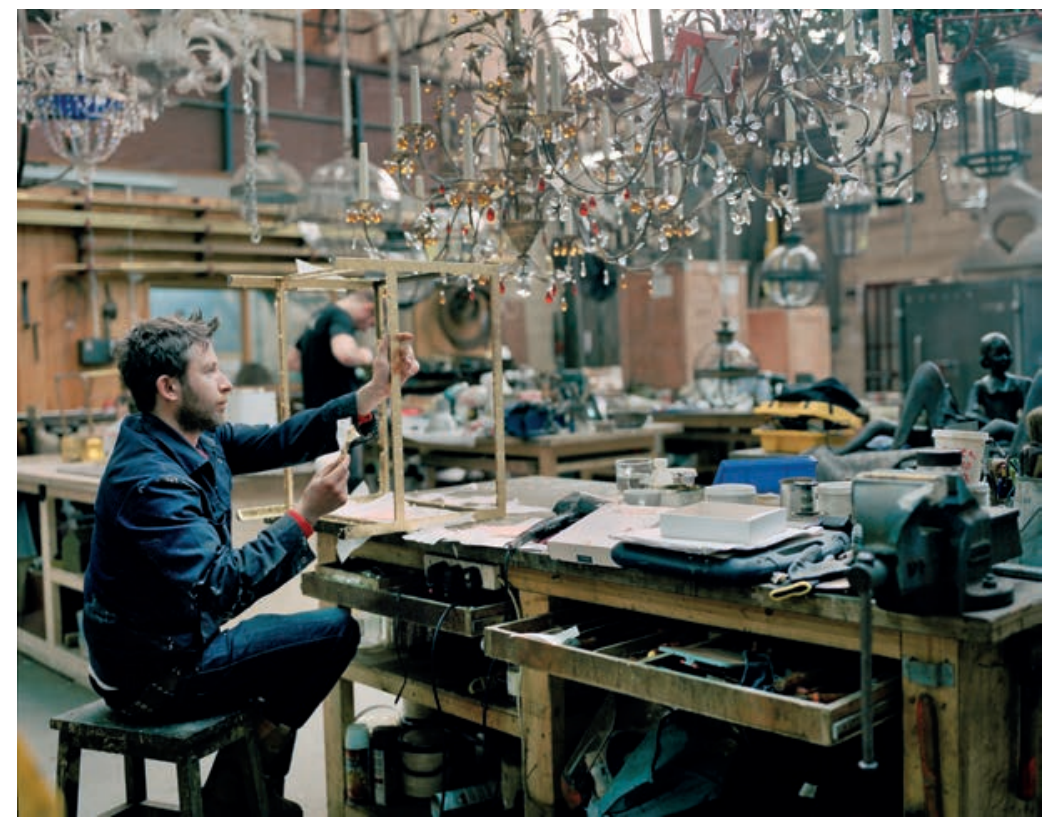

Plate 1.6

Cox Workshop, Tottenham

(c) Philipp Ebeling.

The work on the Tottenham side of the Lea Valley is very extensive, further to a series of master plans linked to the new Tottenham Hotspur stadium redevelopment. As a consequence, large areas of employment land and trading estates are being lost in Tottenham to make way for new mixed-use development. Indeed some of the businesses named above are likely to have been displaced by the time this goes to print. The employment study indicates that many businesses are viable but fragile, and although in theory it is possible for these businesses to relocate, many businesses depend on local supply chains, a local customer-base, and local employees to such an extent that being forced to move would, on balance, precipitate their closure. However, the more serious issue for thriving businesses is that there would need to be suitable premises available for relocation and adequate support offered. Between 2006 and 2012 , industrial land was released at a rate of 66 per cent more than the benchmark set by the London Plan for that period (Roger Tym and Partners 2011) and, in addition, vacancy rates are declining every year, so there is increasingly nowhere for these jobs to go. Many of the business owners understandably felt proud to be part of the industrial and 


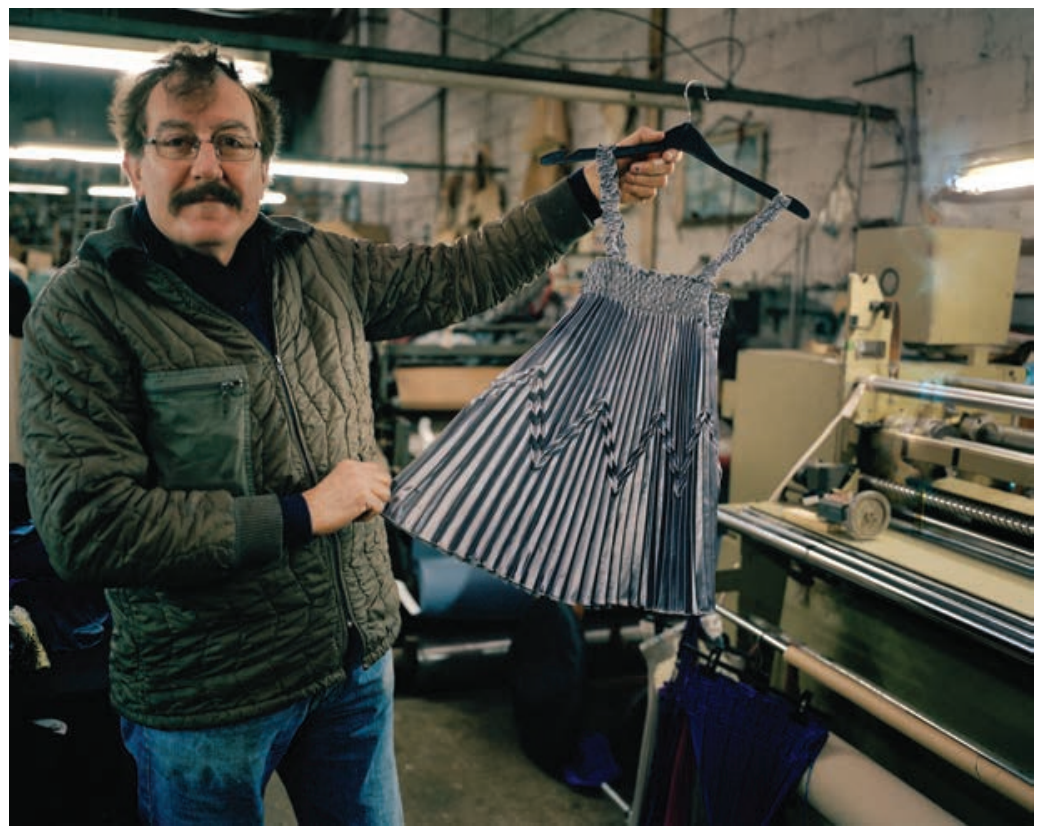

Plate 1.7

Rosamanda Pleaters, Tottenham

(C) Philipp Ebeling.

business heritage of the area - the cultural heritage of the Upper Lea Valley - that is valuable to many people, but were undervalued and misunderstood across the capital as a whole.

\section{High street design}

As in Tottenham, new housing and mixed-use developments are also under way on the other side of the Lea Valley in Blackhorse Lane, and some employment land will also be lost to such development, although the change is more modest than in Tottenham. Blackhorse Lane is an emerging high street and is identified as a key area for growth within the Upper Lea Valley Opportunity Area Planning framework. The area borders the eastern edge of Walthamstow Wetlands, an extraordinary landscape of Lea Valley reservoirs that is beautiful in its expanse and peacefulness. The Wetlands are also designated a Site of Special Scientific interest, with a large migratory bird population that lives in and alongside the man-made infrastructures of the reservoir system. 


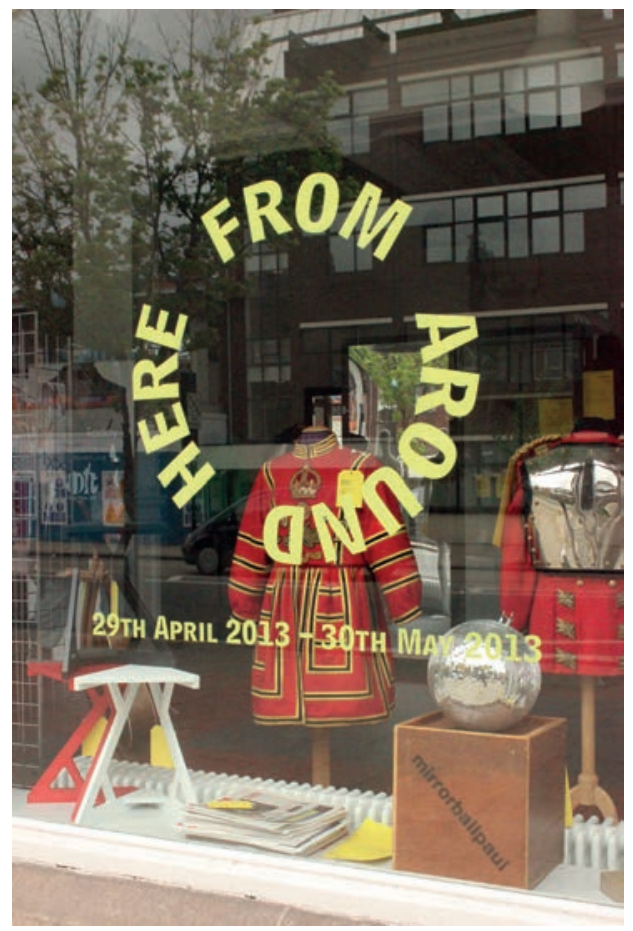

Plate 1.8

'From Around Here Shop' exhibition of locally produced goods, on High Street Tottenham

(c) Gort Scott Ltd.

Blackhorse Lane is an interesting case study to illustrate how an area of existing and historic manufacture might be integrated with a high street and its adjacent, existing residential neighbourhoods, as part of a master plan for new mixed-use neighbourhoods that celebrates rather than rejects the area's industry. Attempts have been made to actively build on the working heritage of the area. It is recognised that investment in regeneration that retains jobs is important to deliver growth in a borough where deprivation is high, although it remains to be seen whether the full ambitions survive the development process.

An urban design framework for Blackhorse Lane, carried out by Gort Scott Architects and a team led by Maccreanor Lavington Architects, focuses on the landscape and industry characteristics of the area (Maccreanor Lavington and Gort Scott Architects 2011). The trading estates within the regeneration area were viewed as important places with their own heritage, culture and character, and not as a blank canvas for development as is often the case. The area's 

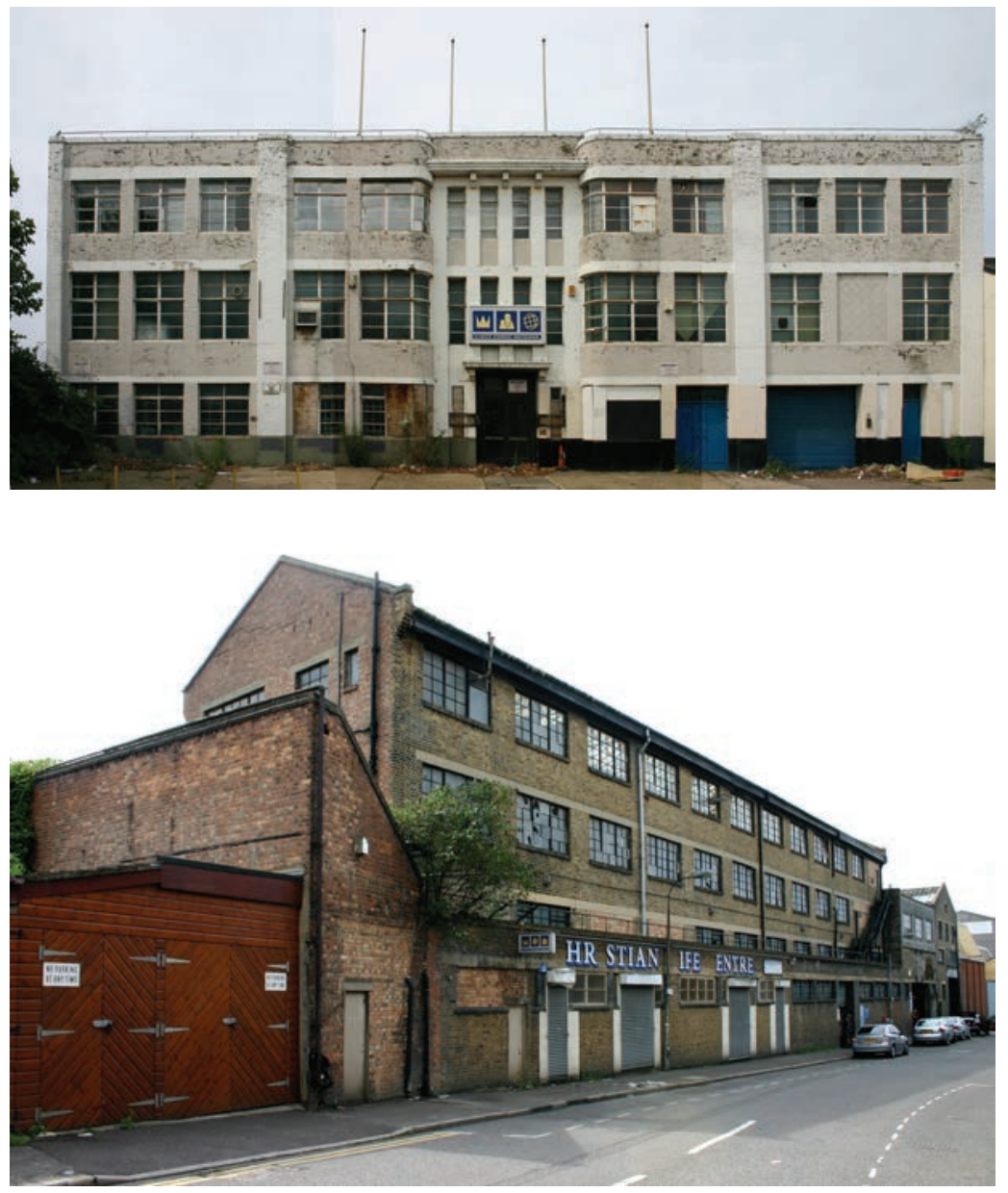

Plate 1.9

Existing industrial buildings, Blackhorse Lane, Waltham Forest

(c) Gort Scott Ltd.

heritage included both interesting industrial buildings and interesting productive activity. An important achievement of the study was to closely examine existing buildings within the trading estates, identifying both buildings and occupants of significant character that would otherwise be overlooked (see Plate 1.9).

Further to this 2011 urban design framework, funding was obtained from the Mayor of London as part of the Outer London Fund for high street regeneration, for a suite of projects in Blackhorse Lane (see Plate 1.10). Devised by Gort Scott Architects, these projects formed a strategy to reinforce the 


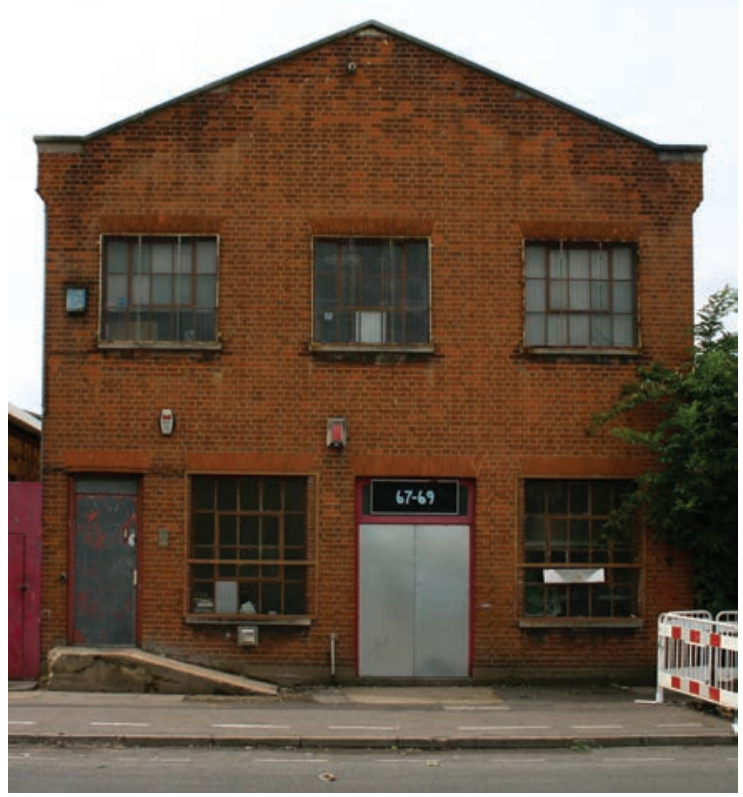

Plate 1.9

(Continued)

high street and neighbourhood centre, address the poor perception and degraded street frontages of the industrial estates, and improve the relationship of the area to the adjacent Wetlands (Gort Scott Architects 2011).

Many of these proposals were delivered by the borough in 2014 (see Plates 1.11, 1.12 and 1.13). New signage to the trading estates and improvements to the industrial frontages designed by architects We Made That and graphic designers Europa, are critical components in improving the interface between the industrial areas on the west of Blackhorse Lane and the residential areas to the east. The new 'Blackhorse Workshop' re-appropriates an existing two-storey industrial shed to create a fully equipped wood and metal workshop for use by all, alongside workspace for rent to designer-makers (see Plates 1.14 and 1.15). The valued and successful institution devised, designed, built and managed by Assemble creates an important link to the area's culture and business of making, also carrying out an extensive programme of events working with local schools and other organisations. A significant piece 


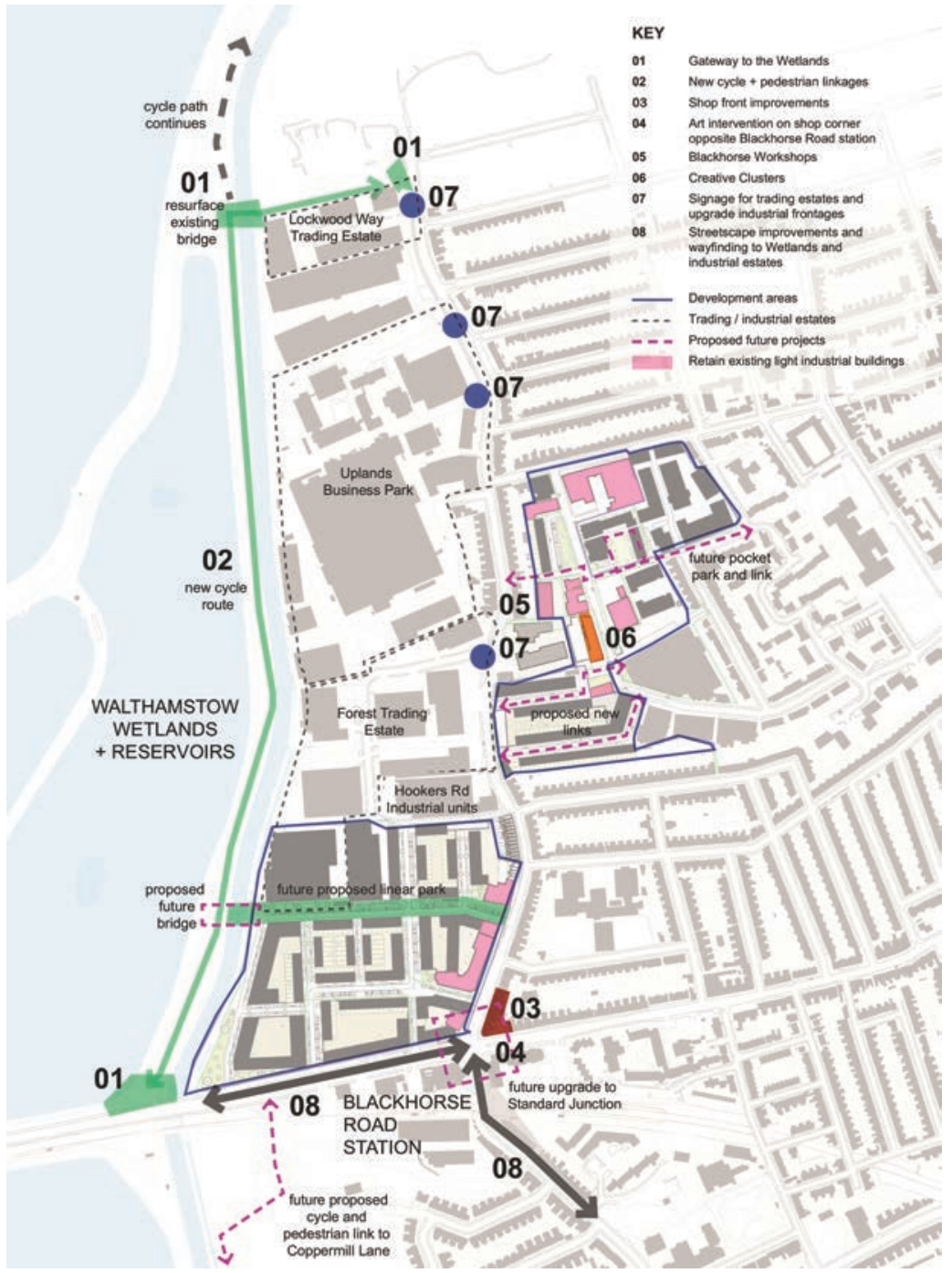

Plate 1.10

Plan showing suite of project proposals for Blackhorse Lane Outer London Fund (Round 2) bid

(c) Gort Scott Ltd.

of public art by sign artist and Walthamstow local Chris Bracey has also been completed (see Plate 1.16), as well as a series of more temporary photographic works on existing hoardings, advertising local businesses. Implemented projects also include local wayfinding signage and shopfront improvements. 


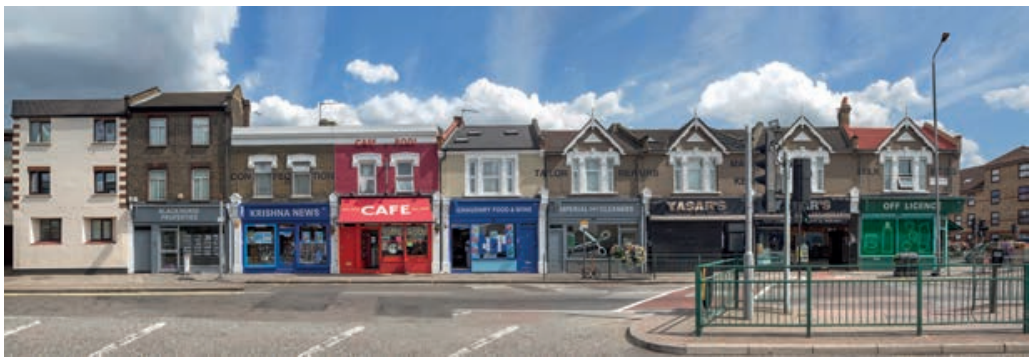

Plate 1.11

Blackhorse Lane shop-front improvements

(C) We Made That, Jakob Spriestersbach, Thomas Adank.

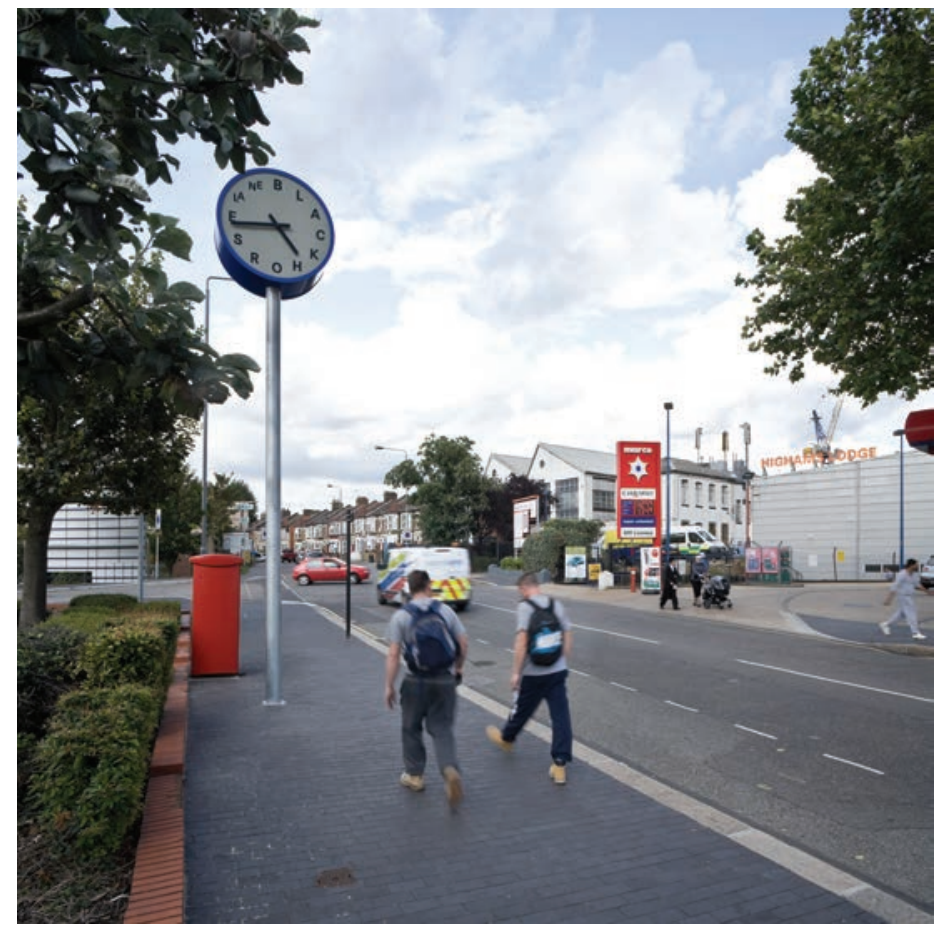

Plate 1.12

Blackhorse Lane public realm and trading estate improvements (C) We Made That, Jakob Spriestersbach, Thomas Adank.

These projects are significant in enhancing the distinctiveness of Blackhorse Lane and creating a diverse, mixed neighbourhood. They work alongside the emergence of more large-scale commercial development, while highlighting the importance of local businesses, and in particular local production. Blackhorse Lane provides an example of a sensitive 


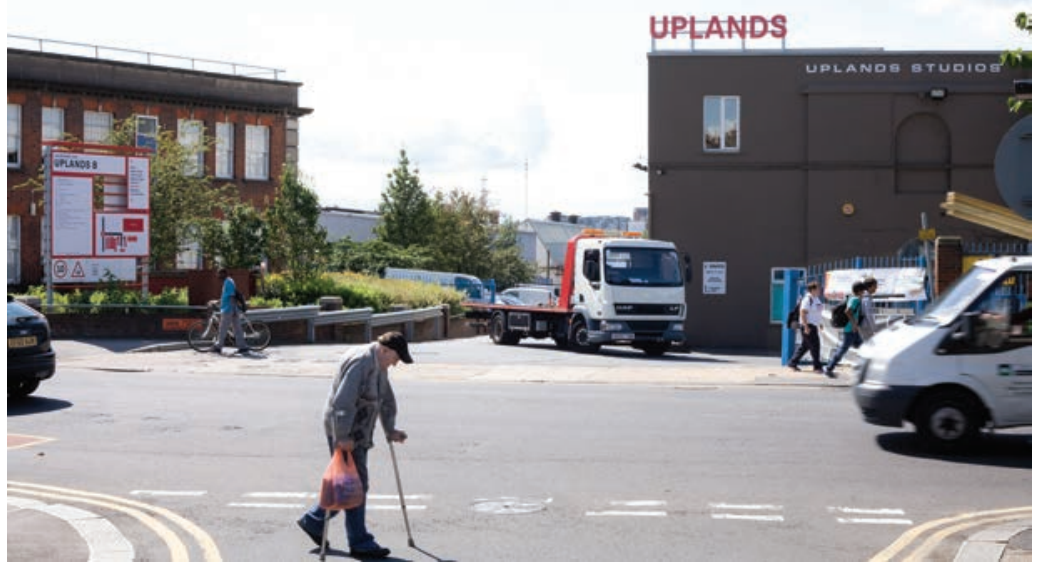

Plate 1.13

Blackhorse Lane public realm and trading estate improvements

(c) We Made That, Jakob Spriestersbach, Thomas Adank.

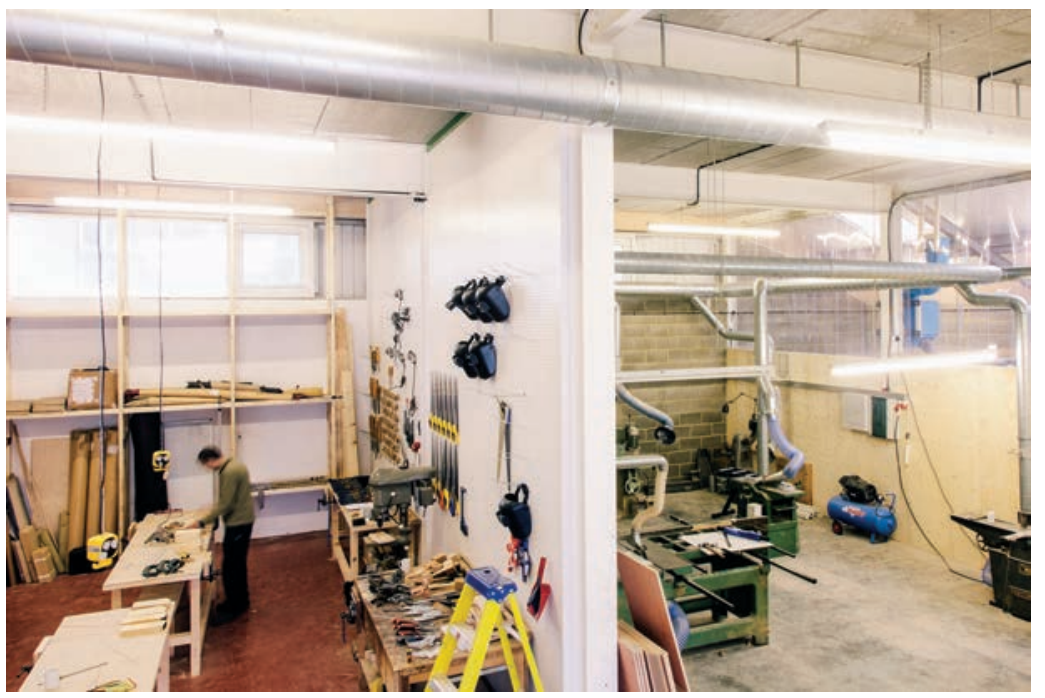

Plate 1.14

Blackhorse Workshop building devised, designed and implemented by Assemble and London Borough of Waltham Forest

(c) Ben Quinton and Blackhorse Workshop. 


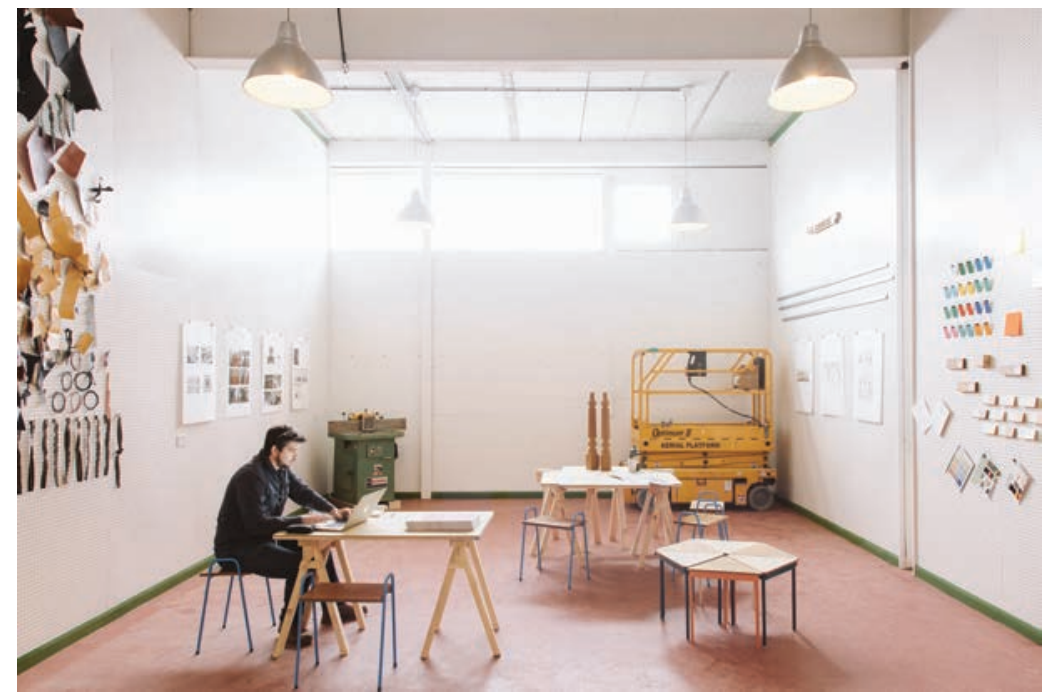

Plate 1.15

Blackhorse Workshop building devised, designed and implemented by Assemble and London Borough of Waltham Forest

(C) Ben Quinton and Blackhorse Workshop.

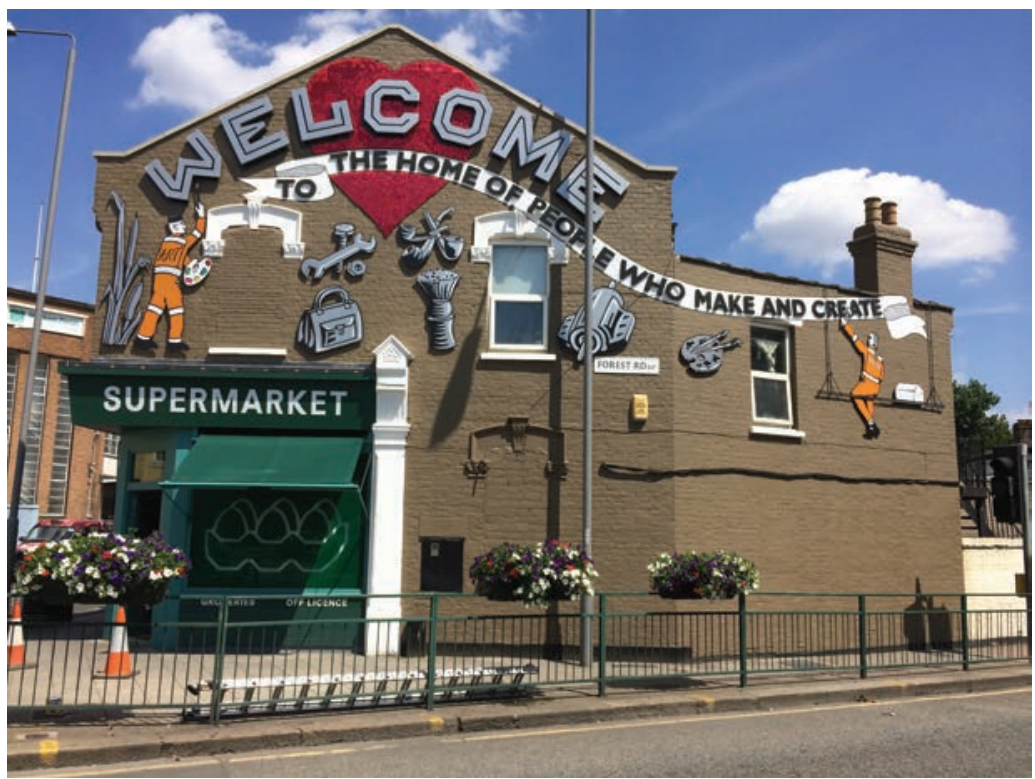

\section{Plate 1.16}

Artwork at Blackhorse Lane and Forest Road junction, by Chris Bracey (London Borough of Waltham Forest)

(C) LB Waltham Forest. 
response to the changing nature of the trading estates in London. This was achieved through a process that started with careful place-driven research into the character and culture of the area, setting the conceptual context for development.

I have tried to illustrate how London's high streets are much more than shopping streets. In Blackhorse Lane, as in many other parts of the capital, both the economy and its distinctive qualities rely on the varied uses in its adjacent trading estates. Retail is merely the most easily accessible, outermost face of most high streets, beyond which lie layers of commercial, creative and cultural and productive activity, which generate opportunities and make places where people can make lasting and meaningful connections. London's high streets are places that sustain and are sustained by the most diverse range of activities possible.

How we observe, analyse and ultimately draw or represent low-key but complex bits of the suburban city has a direct impact on what it is possible to achieve in terms of implementing change on the ground. Few would deny the value of local distinctiveness but it becomes a very fragile entity in the face of sweeping commercial redevelopment. The ability to retain and successfully build on the underlying qualities of specific places, however unassuming these places might appear, is not a romantic proposition, but one that is crucial to preserve valuable jobs, skills and local economies. 


\title{
Case Study 2
}

\section{High Streets and the Pedestrian Realm}

\author{
Yodan Rofè, Galit Yerushalmi, Moshe Margalith \\ and Ahuva Windsor
}

\section{Introduction}

The modernist solution to the conflict between vehicles and pedestrians on city streets was one of separation. Ideally, roads for vehicles were to be separated from paths for pedestrians, creating two networks running perpendicular to each other, and where they meet, the conflict was to be negotiated by level separation (Buchanan 1964). This solution, however, proved to be both impracticable on a large scale and difficult to implement in existing cities. What emerged instead as a planning and road engineering doctrine was the hierarchical classification of streets, categorising them according to the amount of through-traffic they allow, and limiting the level of access accordingly (Hebbert 2005a) (Plate 2.1).

The problem with this limitation of pedestrian access to major thoroughfares is that urban social and economic life is an outcome of the often casual and unplanned meeting between locals and strangers who are passing by. This is the essential insight of Jacobs in her famous and fundamental The Death and Life of Great American Cities (Jacobs 1961). Good major urban streets thus maximise both through-movement and access relative to other streets in the urban system. They do so not only by (usually) having more frequent intersections with connecting streets, but also by multiplying the number of doors and windows opening onto the street with shops and front-facing windows (Jacobs 1993; Hillier 1996). Moreover, there is now more than twenty years of accumulated research showing that most of the movement in the city - both pedestrian and vehicular - is concentrated in major urban streets, which also account for practically all of the city's social and economic activity (Porta et al. 2009; Porta et al. 2012; Carmona 2015). The use by planners of a functional hierarchy of streets, by forcing a reduction of 


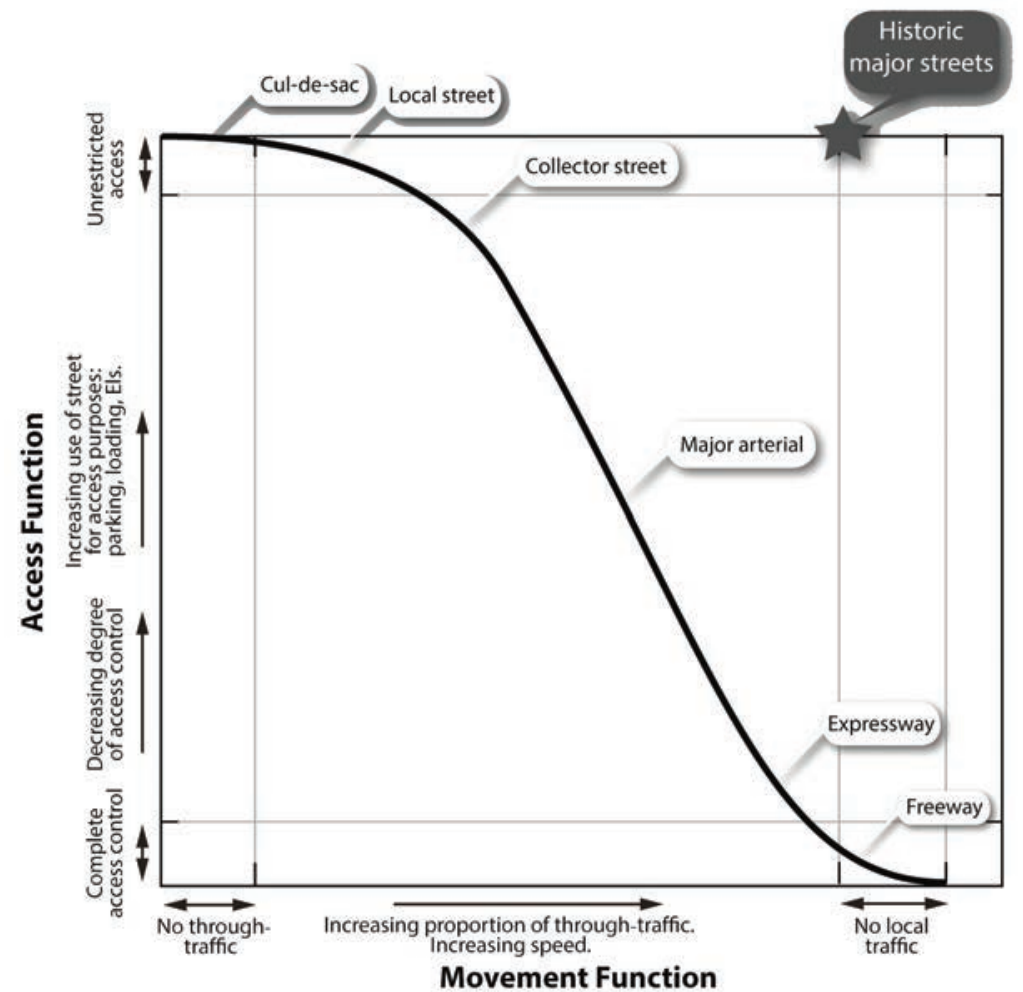

\section{Plate 2.1}

The modernist paradigm - the functional hierarchy of urban street design and its relationship to traditional major urban streets

Yodan Rofè et al.

access where through-movement is dominant, practically destroys the very mechanism that gives cities their life. As a result, this life emigrates to outof-town shopping and employment centres, accessible only by automobiles. While this may not have significant impact on a large metropolitan centre, like Tel-Aviv's central area, it does have a major impact on smaller suburban towns, where out-of-town shopping centres proliferate. This is exacerbated by political and professional attitudes that see the high streets of old suburban town centres as dead and encourage disinvestment in them as pedestrian-friendly environments. Instead, professionals and decision makers advocate that high streets will be dedicated to moving the increased amount of automobile traffic, which itself can be said to be partly the result of the dispersion of economic activities out of the centre towards the towns' periphery. 


\section{The pedestrian realm}

The research described here set out to evaluate whether suburban high streets in Israel were indeed 'dead', as so commonly thought, both in Israel and elsewhere in the world. Our initial observations showed that this was far from the case. Several of these high streets are still active commercial and social activity centres. By examining them in detail, we hoped to achieve three goals: first, to understand how they are able to combine both pedestrian and vehicular traffic in the same space; second, to connect the relative size and qualities of these streets' pedestrian realm to the way they are perceived by the people who spend time in them; and third, to learn, or develop from these examples, principles for combining both modes of movement and helping such streets to continue to flourish.

To examine the above questions in detail, we chose three suburban high streets, in relatively socio-economically similar and well-off communities north of Tel-Aviv (Plate 2.2). The three streets differ from each other in their level of centrality or arterial character within the metropolitan area road system, in the details of their organisation and design, in their dominant use patterns, in the characteristic movement patterns on them, and in the building and land use patterns surrounding them. In each of the streets we examined the pedestrian realm by documenting street and roadway

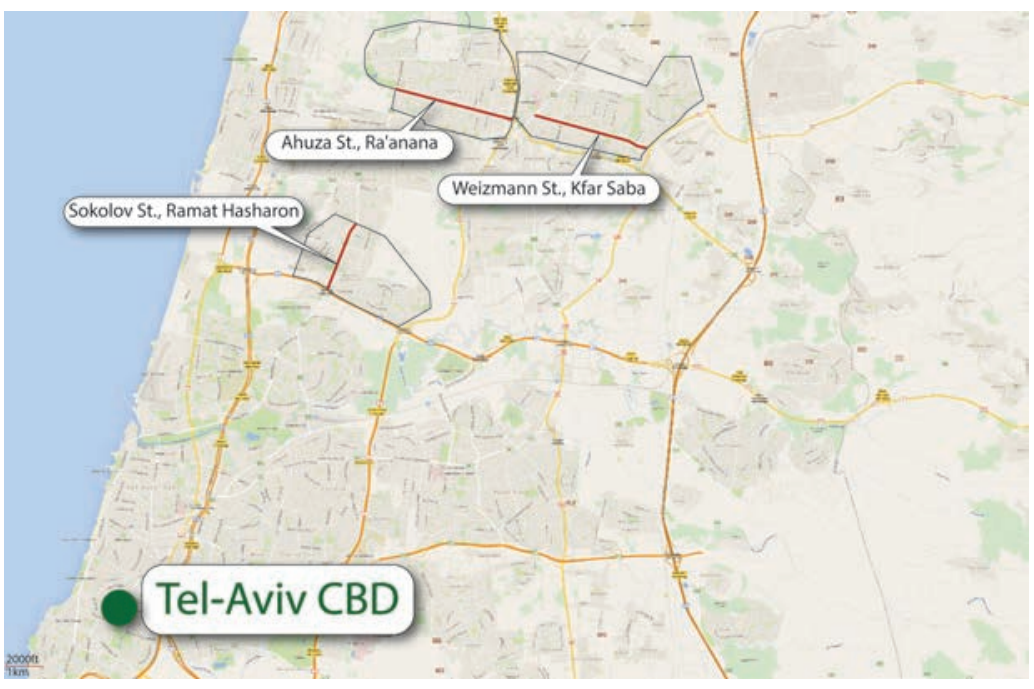

Plate $\mathbf{2 . 2}$

Case study streets in the metropolitan context

(c) OpenStreetMap contributors, and the GIS User Community. 
physical characteristics, automobile and pedestrian movement, building patterns, activity patterns and people's attitudes towards all of the above. These were elicited by three types of survey: (i) a physical survey, examining typical block plans and sections of a central length of each street; (ii) pedestrian movement counts and activity observation; and (iii) an attitude survey among street users.

The three case study streets are the high streets of what were originally three agricultural settlements founded north of Tel-Aviv at the beginning of the twentieth century. Together with Tel-Aviv, which was itself established only as recently as 1907 , they form part of the rapid growth of Jewish immigration and settlement in Palestine which took place in the decade after the First World War, following the establishment of the British Mandate in the region. As the metropolitan area around Tel-Aviv continued to grow in subsequent years, the three settlements joined the first and second rings of suburban towns surrounding Tel Aviv. Their original layout was influenced by Garden City planning, as practised by Unwin and Parker and Tel Aviv itself was laid out according to a plan drawn up by the influential Scottish planner Sir Patrick Geddes, though neither Tel Aviv nor its surroundings incorporated ideas of the hierarchical classification of streets which took hold in later evolutions of twentieth-century town planning.

Sokolov Street is the high street of Ramat Hasharon (Plate 2.3), a former garden suburb, founded in 1922 by a group of Jewish immigrants from Eastern Europe seeking an alternative to living in the crowded streets of Jaffa (Ramat Hasharon History 2014). Sokolov Street is a regional route (no. 482), and is one turn away from a national road, which is also part of the motorway system (route no. 5). The second street, Ahuza Street (Plate 2.4), is the high street of Ra'anana, founded as an agricultural settlement in 1922 by a group of American Jews intent on settling in Israel (Ra'anana Heritage 2014). It is also a regional route (no. 502) that is directly connected to another national road (route no. 4), which is, however, not a completely grade-separated motorway. The third street, Weizmann Street (Plate 2.5), is the high street of Kfar-Saba, another former agricultural colony founded early in the twentieth century, but finally established in 1922 (Kfar-Saba History 2014). Weizmann Street is not part of the national road system, but is a municipal high street connecting two regional roads (routes no. 55 and 554).

The arterial character of the streets is reflected in the intensity of the traffic, with Sokolov representing the highest level and Weizmann the lowest, in the connectivity of the street with its surroundings, as evidenced by the average distance between intersections $182 \mathrm{~m}$ in the case of Sokolov, 128m in Ahuza and 107m in Weizmann), and by the 


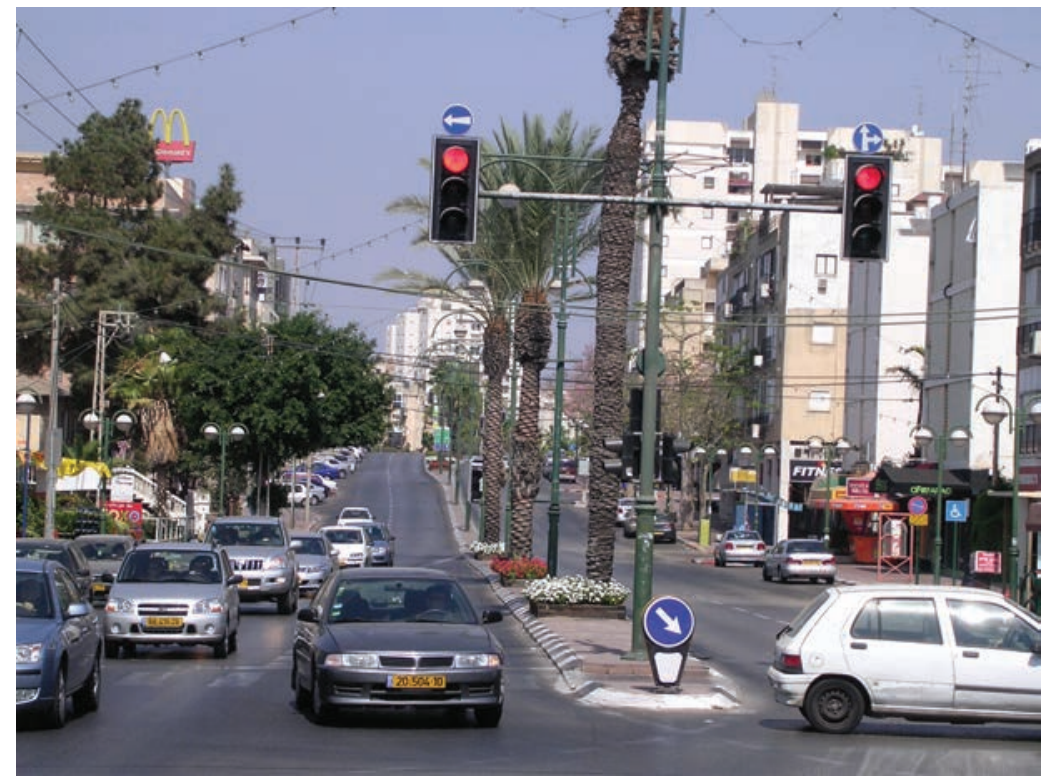

Plate 2.3

Typical view of Sokolov Street, Ramat Hasharon

Galit Yerushalmi.

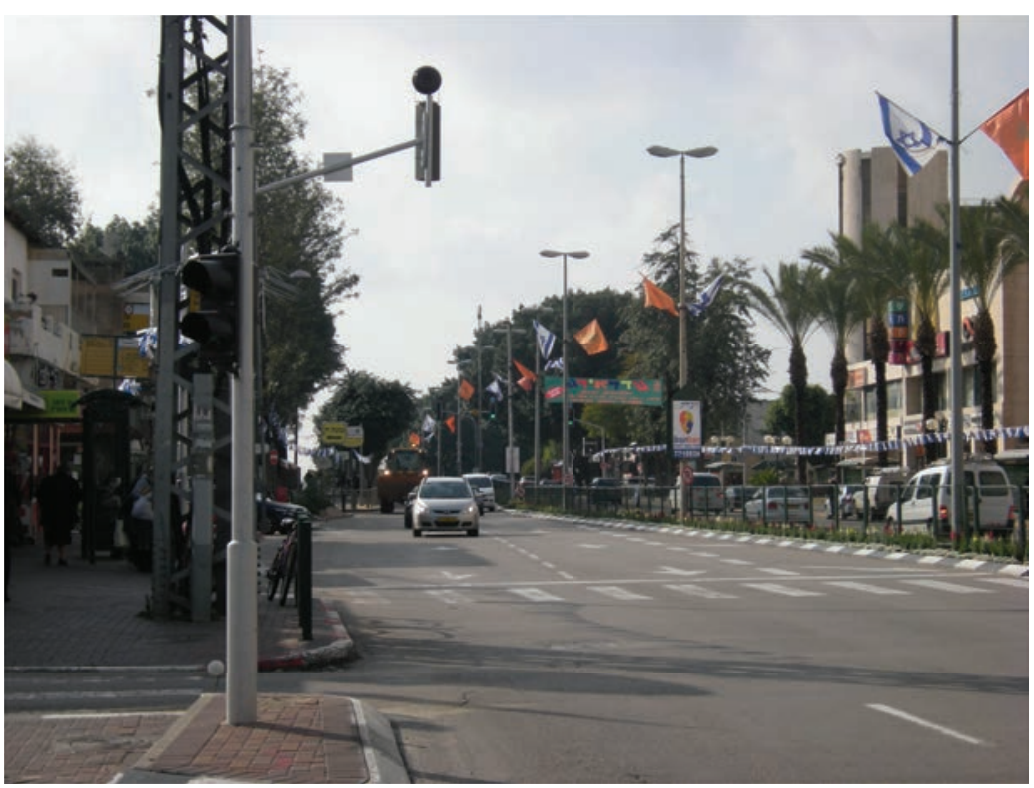

Plate $\mathbf{2 . 4}$

Typical view of Ahuza Street, Ra'anana

Galit Yerushalmi. 


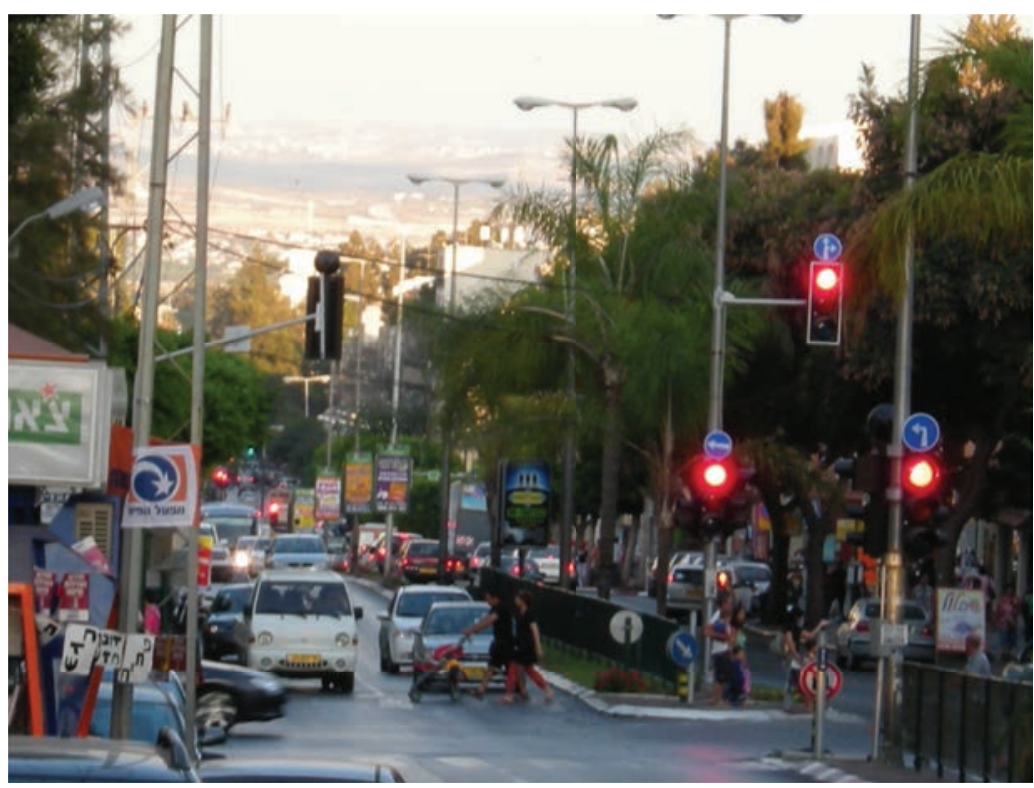

Plate 2.5

Typical view of Weizmann Street, Kfar-Saba

Galit Yerushalmi.

number of crossings. Oddly enough, it is not reflected in consistent restrictions on the ability of pedestrians to cross the streets at will between intersections. On Sokolov, there are no barriers to pedestrian crossings at all between intersections and designated crossings, but a raised planting area on the pavements near intersections directs pedestrian movement to the signed crossings (Plate 2.6). On Weizmann, 40 per cent of the surveyed area included a barrier preventing free crossings by pedestrians (Plate 2.7). On Ahuza Street, recently completed (at the time of the study) street 'improvements' eliminated free crossing for pedestrians completely except for designated crossings at intersections (see Plate 2.5). Also apparent is a slight impact of arterial traffic on the relative amount of local movement, as shown by the percentage of local pedestrians amongst the people interviewed on the street (local movement is 70 per cent on Sokolov, which is the most arterial of the streets, 74 per cent on Ahuza and 76 per cent on Weizmann, which is the most local). Another interesting difference between the streets, which also seems to be connected to their regional arterial importance, is the balance between men and women observed on the street, ranging from a predominantly female presence on Sokolov (62\%) to an only slightly lower female presence on Ahuza ( $56 \%$ women) and an 


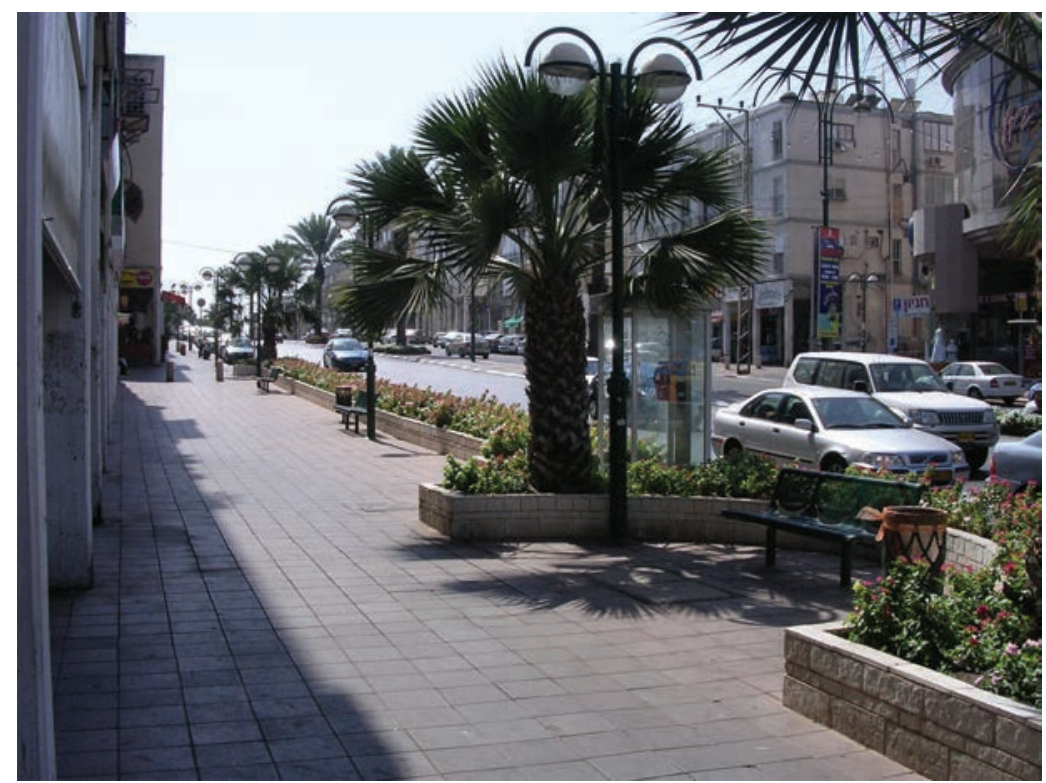

Plate 2.6

Pavement on Sokolov Street; note raised planting box meant to direct pedestrians to painted crossing at intersection

Galit Yerushalmi.

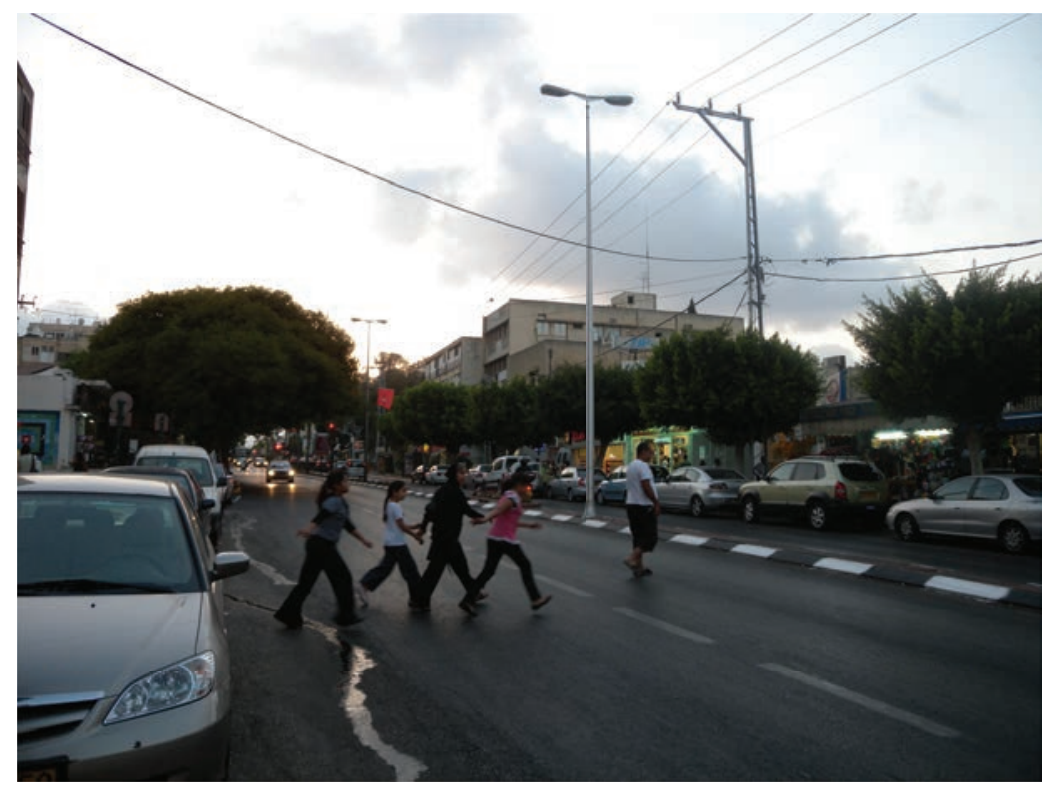

Plate 2.7

Crossing between intersections on Weizmann Street

Galit Yerushalmi. 
equality between the genders on Weizmann. We do not really have a good explanation for this difference except perhaps that more of the people surveyed on Sokolov (75\%) and Ahuza (73\%) were reported to have arrived on the street from home, whereas on Weizmann only $68 \%$ of the respondents did so. A higher percentage of visitors to the street on Weizmann also said that they were there on their way to another destination (38\%) as opposed to 30 per cent and 31 per cent on Sokolov and Ahuza, respectively. We know that in Israel, activity in public spaces around the home is still dominated by women, and perhaps this explains the somewhat larger presence of women on the latter two streets.

Despite their importance as part of the regional street system, these high streets are still predominantly local. On all of them the dominant mode of arrival to the street is on foot (mean of 54 per cent). About a quarter of the arrivals do so by private automobile, and a smaller percentage arrive by bus (mean of 18 per cent). The level of arrival by bus seems to be connected to the importance of the street as part of the regional bus network, and the number of buses passing through it. At the time of the research (in 2008-9), only a small percentage of those arriving did so using bicycles or scooters.

In our survey of street users, we asked them for what purpose they had come to the street. We allowed them to choose more than one answer, and many of them did so (Table A). The more diverse the activities that are reported on a street, the more that street can be said to be a successful place. Again it seems that the two arterial streets are lagging behind Weizmann, which is more local in character.

This is also apparent in another way of assessing the quality of urban space, following Gehl's analysis (Gehl 1987) - the amount of optional

Table A Frequency of activities along case study high streets

\begin{tabular}{lcccc}
\hline Activities & $\begin{array}{l}\text { Sokolov, Ramat } \\
\text { Hasharon }\end{array}$ & $\begin{array}{l}\text { Ahuza, } \\
\text { Ra'anana }\end{array}$ & $\begin{array}{l}\text { Weizmann, } \\
\text { Kfar-Saba }\end{array}$ & $\begin{array}{c}\text { \% of } \\
\text { responses }\end{array}$ \\
\hline Shopping & $31 \%$ & $33 \%$ & $41 \%$ & $35 \%$ \\
\hline Live/work in vicinity & $23 \%$ & $22 \%$ & $32 \%$ & $29 \%$ \\
\hline Services & $20 \%$ & $16 \%$ & $33 \%$ & $23 \%$ \\
\hline Got off bus & $2 \%$ & $1 \%$ & $8 \%$ & $4 \%$ \\
\hline Passing through & $14 \%$ & $29 \%$ & $8 \%$ & $17 \%$ \\
\hline Leisurely walk & $16 \%$ & $13 \%$ & $25 \%$ & $18 \%$ \\
\hline Sitting & $12 \%$ & $15 \%$ & $18 \%$ & $15 \%$ \\
\hline Total & $\mathbf{1 3 2} \%$ & $\mathbf{1 3 4 \%}$ & $\mathbf{1 6 6 \%}$ & $\mathbf{1 4 3 \%}$ \\
\hline Sum Optional & $28 \%$ & $28 \%$ & $43 \%$ & $33 \%$ \\
\hline No. of responses & 171 & 178 & 159 & 508 \\
\hline
\end{tabular}


Table B Relation between physical aspects of the streets and the sense of safety and well-being of people on them

\begin{tabular}{lccc}
\hline & $\begin{array}{l}\text { Sokolov, Ramat } \\
\text { Hasharon }\end{array}$ & $\begin{array}{l}\text { Ahuza, } \\
\text { Raanana }\end{array}$ & $\begin{array}{l}\text { Weizmann, } \\
\text { Kfar-Saba }\end{array}$ \\
\hline Pedestrian realm to roadway ratio & 0.69 & 0.89 & 0.82 \\
\hline $\begin{array}{l}\text { Connectivity - no. of intersections } \\
\text { and painted crossings per 100m }\end{array}$ & 0.85 & 1.94 & 2.14 \\
\hline $\begin{array}{l}\text { Sense of safety from automobile } \\
\text { movement }\end{array}$ & $63 \%$ & $74 \%$ & $73 \%$ \\
$\begin{array}{l}\text { Overall sense of well-being on } \\
\text { the street }\end{array}$ & $85 \%$ & $92 \%$ & $90 \%$ \\
\hline
\end{tabular}

activity (leisurely walking and sitting) occurring on it. We found significant optional activity on all three streets, but it is somewhat higher on Weizmann $(43 \%)$ than on the other two streets (28\% on Ahuza and on Sokolov).

We asked people to evaluate both their sense of safety and their overall sense of well-being on the street (on a scale of 1-5). We examined the correspondence between these two measures of people's sensations on the street and two objective measures of the street - the ratio between the pedestrian realm and the roadway, the ease of crossing and street connectivity. While the differences between the streets in the measures of safety and well-being are too small to allow for statistical significance, it seems that the ratio of the pedestrian realm to the roadway shows a more consistent relationship with the results of both measures, at least in terms of direction if not in magnitude (Table B). Interestingly the actual level of safety for all the streets is similar. All of them have been the location of 27 per cent of the pedestrian accidents in their respective cities.

\section{High street urbanity}

There are several lessons to be learned from these three case studies on the role of local high streets:

1. High streets in suburban towns are important generators of local urbanity. These streets, even when they serve as important regional arterials and carry heavy vehicular traffic, still draw a large local public. Over 70 per cent of visitors to these streets are local, and more than 80 per cent of the visitors surveyed claimed to be habitual users. The streets are used for a large variety of purposes, with a significant percentage of optional and leisurely activities and social encounters (Plate 2.8). 


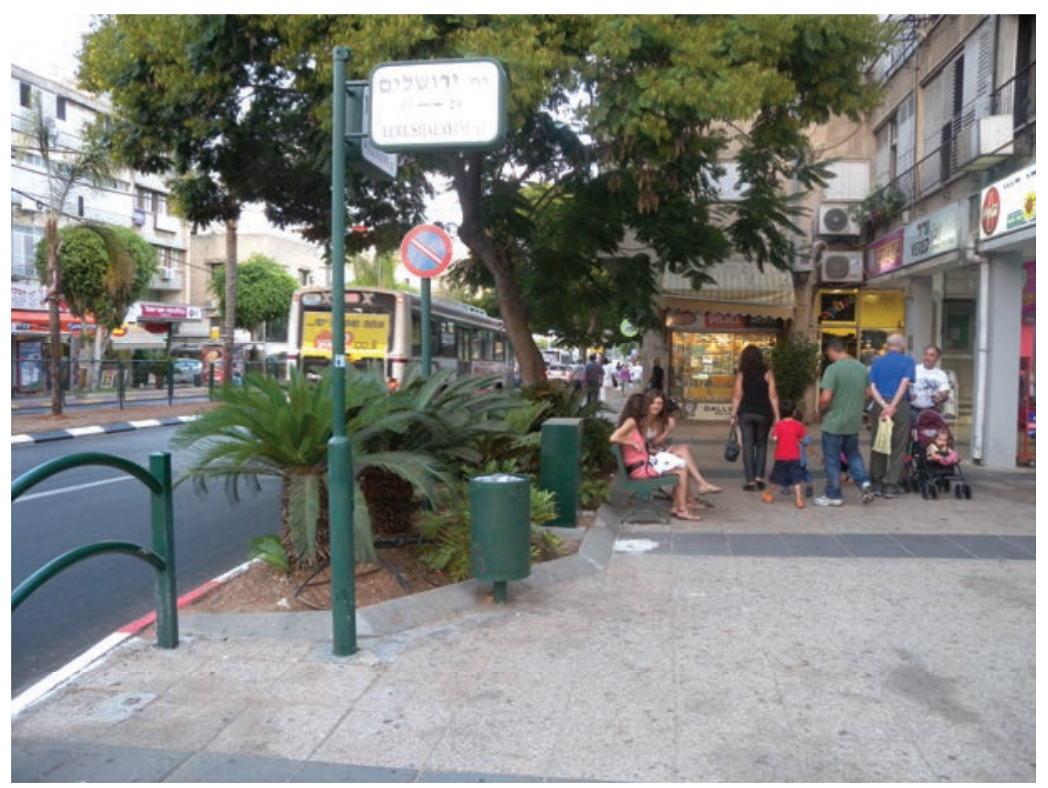

Plate 2.8

Lively pedestrian realm on Weizmann Street

Galit Yerushalmi.

2. Suburban high streets are a focus of local pedestrian activity. The majority of users arrive on foot, and do so from their homes nearby. They are more than twice the number of people who arrive by private automobile, even though the streets serve a significant amount of through-traffic. In many ways, the streets serve as the suburban town's 'living room'. They are lined with a continuous commercial front that invites shoppers and leisurely walkers, they contain other varied activities and almost half of their width is designed as a pedestrian realm (Plate 2.8).

3. The design of the street's physical space is associated with a sense of safety and well-being. Almost all the surveyed users reported generally positive feelings ( $89 \%)$, while 70 per cent reported feeling safe from vehicular traffic. The presence of 'interactive' street furniture (such as benches) was associated with a greater sense of well-being on the street, while on the other hand, an increase in the space given to the roadway, relative to the pedestrian realm, was correlated with a reduced sense of safety and well-being (Plate 2.9).

4. Combining modes of movement on high streets increases their viability. This is not to say that vehicles should be eliminated from 


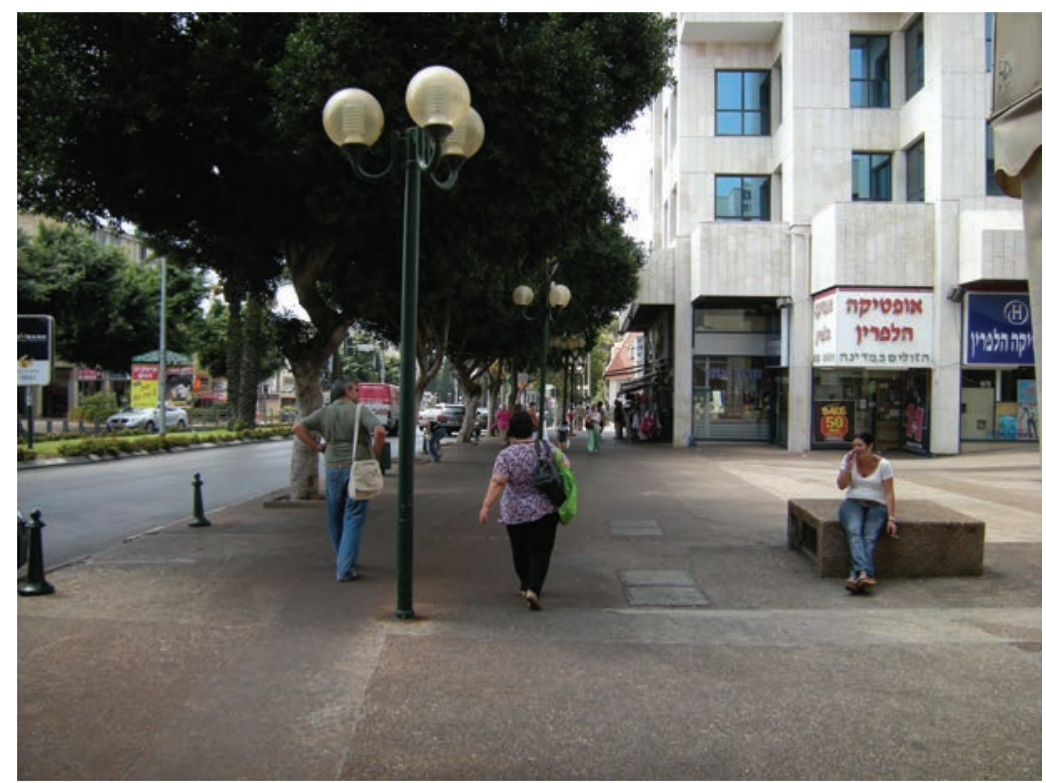

Plate 2.9

Extended and well-managed pedestrian realm on Ahuza Street

Galit Yerushalmi.

these streets. On the contrary, the presence of through car traffic increases the number of users on them, which improves the viability of commerce. That in turn improves the quality of the pedestrian realm by making it more interesting and attractive. The presence of vehicles does not immediately and necessarily translate to a reduced sense of safety or well-being. These are dependent on the strong presence of the pedestrian realm, and the frequency of intersections and crossings. They can be strengthened by creating a better balance between the pedestrian realm and the roadway by widening pavements, or by adding intersections and crossings and increasing visibility (Plate 2.10).

5. Improve pedestrian, bus and bicycle access; worry less about parking. Most often city authorities and shopkeeper associations are concerned about providing adequate parking on these streets in an attempt to rival the easy accessibility by car and the free and generous parking available at out-of-town commercial centres. This often comes at the expense of convenient pedestrian, bicycle and bus accessibility. Our study suggests that the dominant mode of arrival to these streets, even though they are all located in affluent suburbs, 


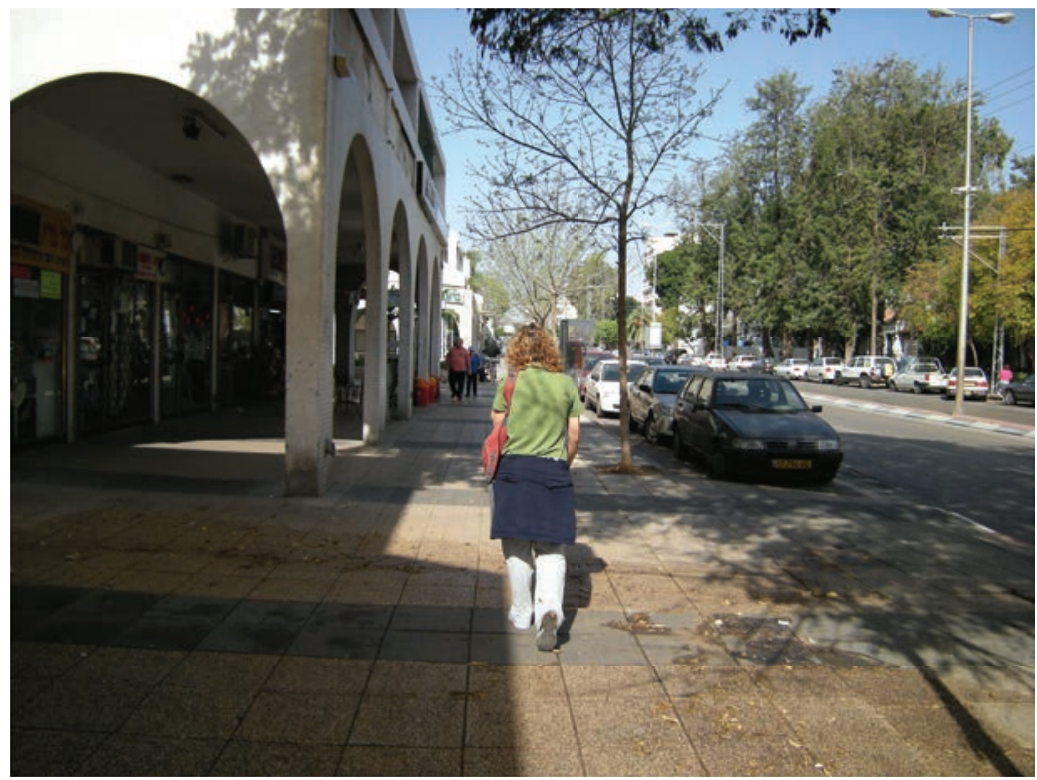

Plate 2.10

An arcade allows the extension of the pedestrian realm and creates a protected walking and sitting area on Weizmann Street

Galit Yerushalmi.

is not by car. Therefore, it makes more sense to allow pedestrians, public transit patrons and cyclists better conditions on the street, limiting on-street parking to a minimum, and providing for it along side streets, or in parking lots and garages located somewhat away, but within comfortable walking distance, from the high street - thus contributing further to pedestrian traffic around the street and along it (Plate 2.11).

\section{Conclusion}

The three high streets examined in this research were originally the major public thoroughfare and public space of self-sufficient agricultural settlements, economically related to Tel-Aviv, but not part of the daily commuting shed. As such, these streets carried out most of the regional traffic passing through the towns. The town centres have adapted and changed as the metropolitan area grew around them, and as the settlements themselves changed in character from predominantly agricultural to suburban towns. 


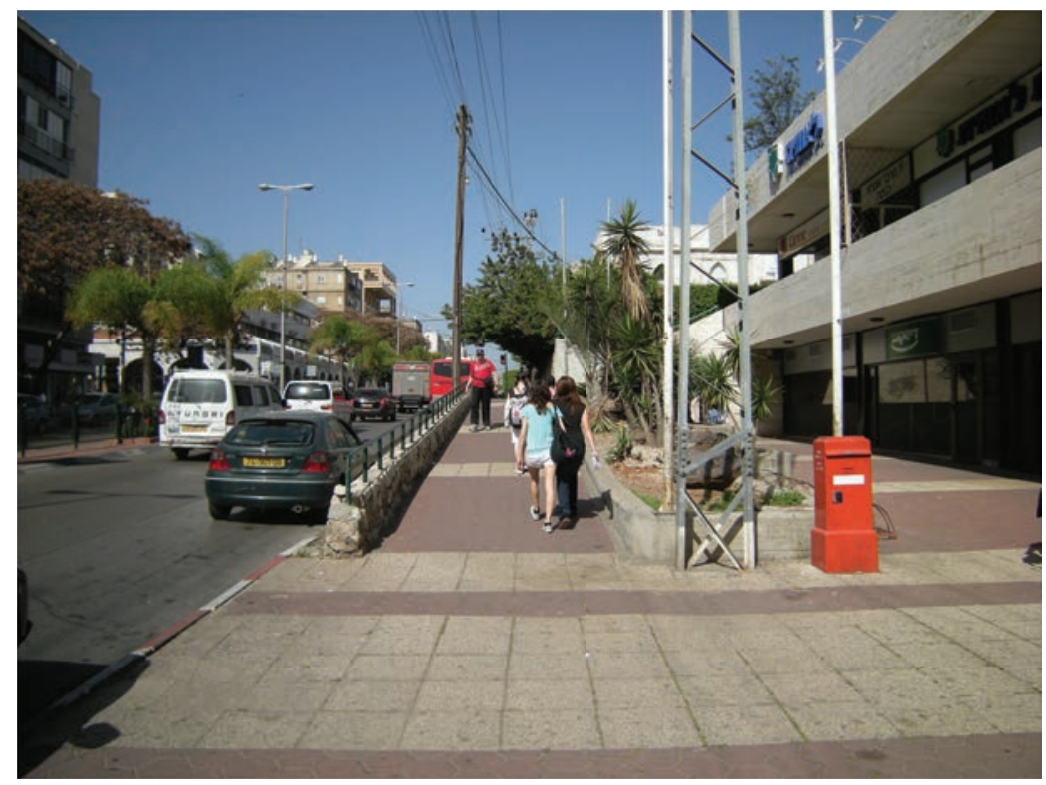

Plate 2.11

Combining modes of movement on suburban high streets increases their viability Galit Yerushalmi.

Part of this change was the construction of by-pass roads, which now carry the predominant share of through-traffic, relegating the high streets to a more secondary role as far as passing movement is concerned. The fact that they continue to thrive, as local hubs of community, as well as centres of local economic life, bears witness to their flexibility and adaptability to changing circumstances.

High street success is not merely a matter of economics. While the most common reason named for coming to these streets was shopping, it was definitely not the only one. Many of the users of the streets carried out more than one activity. Indeed, the more uses and activities that occur on these streets, the better they function as a local community hub.

Nor are these streets mainly a link to other places. The number of respondents who mentioned leisurely walking and sitting as the activity they came to the street for was double that of those saying they were only passing through. Our research suggests that the quality of the pedestrian realm itself plays an important role in making these streets places that are worthy of spending time in. Although they are not places of architectural distinction, and have a somewhat prosaic character, the detailed design of the public realm, the balance between arterial and local traffic, and between 
the pedestrian realm and overall street width, create that particular balance between link and place that make them work (Jones et al. 2007).

Suburban high streets still play an important role in building up the social and economic well-being of their towns. While through automobile traffic has an important function in them, it should not be allowed to dominate either spatially or functionally, and must be balanced with an adequate provision for public transit, alternative modes of transport and above all a, generous and well-designed pedestrian realm.

The research reported in this chapter was financed in part by a grant from the Ran Naor Foundation for the Advancement of Road Safety Research Ltd. It was carried out at the Tel-Aviv Institute of Architecture: Environment, Culture and Community, Azrieli School of Architecture, Tel-Aviv University. 


\section{PART D \\ Everyday Sociability}

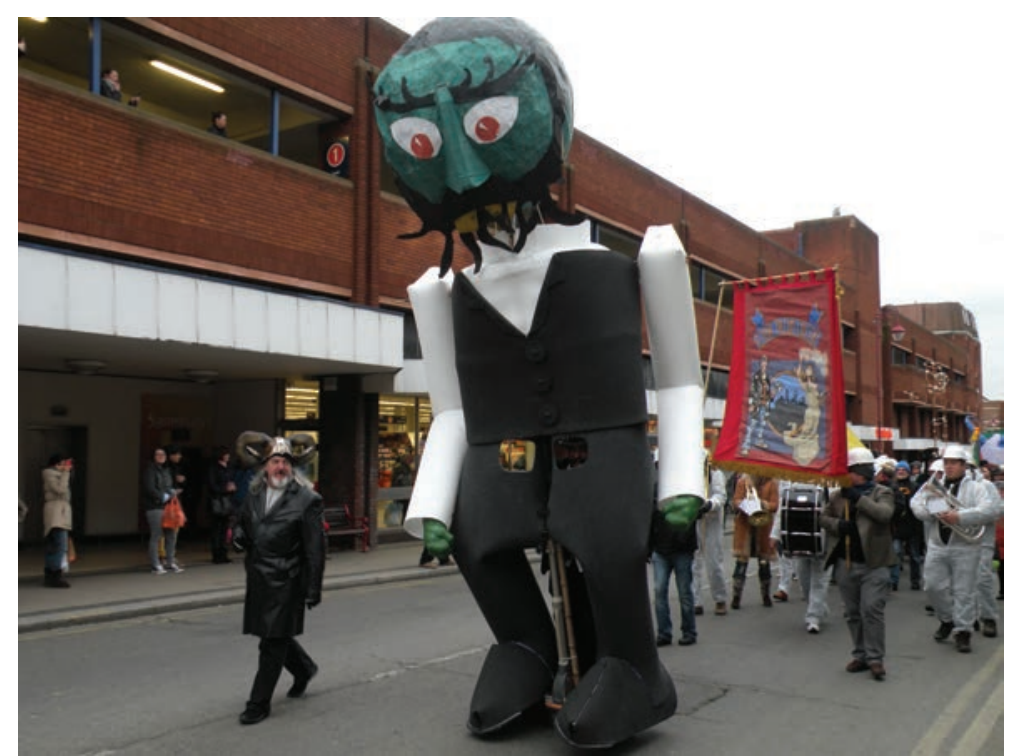

The Annual Lefi Parade fronted by Thamas Deeton, the giant of Seething 



\title{
Chapter 9
}

\section{Street Interaction and Social Inclusion}

\author{
Ann Legeby, Meta Berghauser Pont and Lars Marcus
}

\section{Introduction}

The Swedish history of massive post-war housing expansion has left a legacy of notoriously segregated suburbs. However, the situation is more complex with some suburbs suffering social problems much more than others. This chapter uses the case of Gothenburg, Sweden to illustrate how public spaces such as streets can become an important arena for interplay between incomers and local inhabitants in such suburbs. The research described here shows the role that spatial configuration plays in shaping the potential for social interaction. In particular, detailed analysis suggests that the design and configurational layout of public spaces such as streets, squares and parks contribute to day-to-day interaction and potentially to overcoming social exclusion. Urban form is thus found to play a critical role in such social processes.

The problems related to segregation and exclusion in Swedish cities are currently being discussed to an extent not experienced before. This is reflected in policy documents, municipal budgets and Comprehensive Development Plans, all of which have extensive formulations on social sustainability and social exclusion. More explicitly, the local government in Gothenburg has declared that segregation is to a large extent driven and reproduced by the unequal life chances found within the city. In particular, the relatively poorer conditions found in today's socially disadvantaged districts are of great concern, which is evident in their inclusion by the national government as part of the Urban Development Initiative (2008-14).In total, fifteen areas are included in the national initiative of which four are located in Gothenburg: Bergsjön, Hjällbo, Gårdsten and Norra Biskopsgården. ${ }^{1}$

Architecture and urban design are seen in this debate as playing a central role for counteracting segregation, confirmed by formulations found 
in policy documents. The critique of suburbs that were built as part of the great urban expansion from around 1940, especially estates built under the One Million Homes Programme ${ }^{2}$ has been extensive and, as a consequence, new urban design discourses have emerged. Frequently used buzzwords found in policy documents are 'densification', 'mixed use', 'social mix', 'fewer boundaries', 'public space as meeting place', 'connectivity' and 'permeability'. But how do we know that such urban design principles/ postulates lead to less segregation or will support social inclusion? What configurative properties of urban space will enable social processes that are desirable in this regard? As Julienne Hanson (2000) claims, there is an obvious risk that in time we may discover that we have 'got it wrong' once again. This can only be avoided by increasing our understanding of how different morphological layouts in different parts of the city support or inhibit social processes that are favourable to social sustainability.

During the last four decades, Sweden has seen a number of antisegregation initiatives carried out in suburbs defined as segregated or characterised by social exclusion. In spite of these far-reaching efforts, the situation remains highly problematic. The limited geographical focus of these initiatives, typically dealing with isolated areas where the population has the lowest income and the highest unemployment rates, and where many people are dependent on social welfare, is unfortunate. Urban research that focuses on how architecture and urban design can contribute to a less segregated city typically highlights the importance of the urban spaces that frame and support everyday life in the city - public spaces such as streets, squares, parks and so on - and is based on the idea that various social processes that are decisive for integration processes may take place here (Hanson 2000; Marcus and Legeby 2012). With whom we potentially share the street, it is argued, is of utmost importance for matters related to social exclusion, as are the resources, human and non-human, that are within easy access as we go about our daily routines. Thus, the street - along with other public urban spaces - becomes an important arena for interplay between citizens and for processes of recognition of 'the other'. The varying size of groups of co-present people in public spaces in these studies is found to be associated with certain configurational properties that streets and public spaces hold. Most importantly, however, this research has demonstrated that these variations are primarily the result of the interrelation between local and city-wide spatial properties, that is, on the systemic level, and far less to local properties of the individual spaces, meaning that spatial relations at the city level are important for the properties of local spaces (Hillier and Hanson 1984; Hillier 1996).

This chapter will develop and try to support these ideas about the role of public space for day-to-day interaction, interplay and exchange of 
information, which in extension may also contribute to the overcoming of social exclusion. The importance of the street and other urban public spaces is highlighted and it will be argued that many of the neighbourhoods studied have layouts with morphological properties that prove unfavourable from a social integration perspective, not only among those identified as characterised by exclusion. The street is thus not only seen as a transportation corridor but also as a potential social space and an arena for social interaction, provided that the urban layout is designed to support such processes. The empirical data from Gothenburg typically show how patterns of co-presence create unfavourable potential for social interaction in some of the squares and streets in its suburbs and that this is related to certain configurational properties of the urban layouts.

More specifically, two central aspects of the segregation debate will be highlighted. First, access to co-presence is analysed in order to establish what these neighbourhoods afford its users in terms of social interaction by measuring, on the one hand, the intensity and, on the other, the constitution of co-present people in public space, which, as we shall see, is deemed highly important for day-to-day interaction that may support social inclusion. Second, the level of access to various urban amenities and resources is analysed with the aim of carefully mapping their spatial distribution since, again, this is found to be decisive for matters of segregation and exclusion. As a background to this we will start with a brief account of recent developments in urban morphology and spatial analysis in regard to these issues, especially earlier work in space syntax. This will be followed with a report and brief review on work done in sociology and human geography in relation to the same issues, especially when it comes to understanding the role of co-presence for social processes. Following this we describe a relevant empirical study in Stockholm concerning the relation between urban form and segregation and present the approach and method chosen for the Gothenburg study, especially the approach to evaluating the relation between urban form and co-presence, on the one hand, and between urban form and urban amenities, on the other. The chapter will then present the results of the study and end with a discussion from the more general perspective of justice in regard to how human (co-presence) and material (amenities) resources are distributed in the urban landscape and how this conditions life opportunities.

\section{Urban life and co-presence}

In order to better understand social processes in urban space we will here start to discuss the critical role of spatial configuration and co-presence and 
the correspondence between these two aspects. Research in architecture within the field of space syntax points out that the design of many housing estates prone to poverty and exclusion poses an obstacle to integration processes in itself (Hanson and Hillier 1987; Hanson 2000; Vaughan 2005; Legeby 2010, 2013). Within space syntax theory, space is not seen as a neutral background for social and cultural processes; rather the opposite is argued and urban space is assumed to have an inherent social logic. According to Hillier and Hanson (1984), the spatial configuration of buildings and cities has a very direct influence on social life:

By giving shape and form to our material world, architecture structures the system of space in which we live and move. In that it does so, it has a direct relation - rather than a merely symbolic one - to social life, since it provides the material preconditions for the patterns of movement, encounter and avoidance which are the material realisation - as well as sometimes the generator - of social relations. In this sense, architecture pervades our everyday experience far more than a preoccupation with its visual properties would suggest. (Hillier and Hanson 1984: ix)

Co-presence as well as random encounters and awareness of others are here seen as fundamental for many social processes, but even if space has an inherent social logic of this kind it is stressed that this does not mean that there is something like a 'spatial determinism' in a 'cause and effect' sense (Hillier 2013: 75).

The design of many post-war urban layouts has been found to have an impact on behaviour that is disadvantageous for social life and cohesion: there is a ruptured interface between locals and non-locals, and hence, public space does not offer the potential for unplanned interactions such as bumping into people, dropping in or popping round (Hanson 2000; Hanson and Zako 2007). This means that casual and informal social arrangements are not supported through the spatial layout of the area but instead need to be replaced by pre-planned and formal arrangements. Furthermore - and highly relevant for the Swedish context - public space as an arena for the exchange of information is altered, in that the opportunity of personal experiences of other parts of the city, and hence other social groups, is limited on your home turf. Consequently, knowledge and opinions to a larger extent are shaped by media (Hanson 2000: 114-15).

Hanson has found that the lack of opportunity to participate in urban life was the result of changed properties in twentieth-century urban layouts, particularly in many post-war urban layouts, which were designed to 
minimise social contact, especially with 'strangers', which had the greatest effect on the people who are weakest and least powerful in social terms (Hanson 2000: 116-17). The typical pre-twentieth-century street-based 'all-neighbour' layout was replaced by the estate or what Hanson calls the 'no-neighbour' layout, a layout that does not encourage having 'strangers by the door' or a mix of locals and non-locals within the area. Hanson and Zako (2007) illustrate how varied housing morphologies of different historical periods give material form to different conceptions of movement, co-presence and surveillance. Their findings regarding how spatial configuration is associated with co-presence (including anti-social behaviour) are highly relevant for segregation, and they conclude that the community of the street is made up of a complex layering of anonymity, intimacy and social encounter.

Research has shown that urban safety is maintained by the copresence of locals and strangers on the street, the interface between local residents and passers-by on the doorstep and the informal surveillance of residents over street space from the privacy of their front window (Hanson and Zako 2007: 20). They argue that the panoptic models of modernism, the inward-facing housing groups, ruptured this spatial interface between inhabitants and passers-by. However, the degree to which such an interface among residents and between residents and passers-by will develop is dependent on the emergence and distribution of movement flows, which in turn depend to a large degree on the configurational properties of space, that is, the degree to which a specific place - a street or a square - is related to other places even at great distances away (Hanson and Zako 2007: 15; Hillier 1996: 17). This is something that is also referred to as being part of the foreground network, which according to Hillier (2009) is characterised by high accessibility and therefore captures movement flows from large parts of the city, which in extension facilitates socio-economic exchange and renewal through the co-presence of a variety of social groups. The background network in contrast is constituted by the parts of the street network that are least accessible from the system as a whole, and therefore capture distinctly less movement from other parts of the city.

The disabling effects of the urban transformation identified by Hanson (2000) have been highlighted in a Swedish context (e.g. Klasander 2003, 2005; Schulz et al. 2004; Olsson and Törnquist 2009; Legeby 2010, 2013), as well as in an international context (e.g. Hillier and Hanson 1984; Vaughan 2005, 2007; Vaughan and Arbaci 2011). In these studies it has been clearly demonstrated that the configuration of urban space can create either closeness or distance between citizens and between resources in a city. Public space is therefore seen to play a key role in the matter of segregation 
because it can be designed either to optimise processes that bring people together, supporting movement and co-presence, or to inhibit such processes (Legeby and Marcus 2011). In the Swedish context, the influence of architecture has been discussed in relation to anti-segregation initiatives and Shultz et al. (2004) argue that such unfavourable conditions have to do with the scale of the Swedish post-war estates, their profound enclave structure and differentiated traffic system, as well as land use zoning. Taken together, the spatial properties of the layouts in these areas cause many disadvantages for the local inhabitants, for example poor legibility and depopulation of public space. More specifically Klasander $(2001,2003)$ highlights the disrupted interface between buildings and streets/paths and argues that few entrances along public pathways (i.e. a weak constitution of the street in space syntax terms) is unfortunate. Schulz et al.'s evaluation report from 2004 called for urban design interventions such as increased density, in-fill development along strategic paths or streets that are desolate and unconstituted (namely, with blank walls, rather than doorways and windows), as well as better spatial integration with the surroundings and with the city as a whole (Schulz et al. 2004: 208-9).

Vaughan's extensive studies of morphological influences on poverty, deprivation and social exclusion find that spatial form can itself be considered a factor in the geography of poverty (Vaughan 2005: 409). There is a relationship between physical segregation and social marginalisation and some urban areas are especially prone to settlement by impoverished immigrants. Vaughan (2005) suggests that the physical separation of poverty-prone areas from the economic life of the city implies a lack of potential for the economically marginalised to integrate into society. By studying the relationship between spatial segregation and socio-economic segregation, Vaughan concludes that immigrant quarters have spatial attributes that make them more prone to poverty, for example spatially segregated from the rest of the city, London in her particular study, and that poverty persists over time (Vaughan et al. 2005: 403). Spatial segmentation is found to have a detrimental effect on the most vulnerable populations, especially those who are restricted to only local movement on a daily basis, which severely limits their opportunities for social exchange (Vaughan 2007: 248).

Empirical studies of the constitution of co-present people, meaning the social mix of these groupings, at squares in different neighbourhoods in Södertälje and Stockholm have found a correspondence between the inflow of non-locals and configurational properties of space (Legeby 2010, 2013). Many public spaces lacked spatial conditions that encouraged interaccessibility or circulation between neighbourhoods and have instead kept 
its inhabitants apart (Legeby 2013). Hence, an arena where local inhabitants can encounter or simply share space with non-locals has not been created. The configurational properties associated with such disadvantageous outcomes are a ruptured interface between local and global accessibility, weak spatial relations to neighbouring areas as well as a lack of good citywide connections that intersect with symbolically weighted meeting places such as neighbourhood squares or local main streets/paths. Streets (or paths) that link an area (typically by way of its high spatial accessibility) to its surrounding areas are of special importance in these neighbourhoods, thereby performing a function similar to that of the typical British 'high street'.

Vaughan et al. (2010b) indeed conclude that the configurational characteristics of suburban centres are bound up in how they have been shaped to take advantage of differing scales of movement and encounter over time and typically their high streets are very well connected to the wider city network. They found that the streets that are 'most effective' in capturing journeys of different lengths are those that are spatially integrated both locally and city-wide, and empirical evidence finds that these streets and their immediate surroundings are associated with large variations in non-residential activities (Vaughan et al. 2010b). Most critically, such streets (or paths) between areas in many Swedish suburban landscapes are not constituted by buildings.

If we turn to sociological research in this domain, it has been shown that everyday activities that take place in public spaces are a key factor for counteracting urban segregation. Franzén (2009) suggests that to better understand urban segregation, research needs to look beyond residential segregation and see if there are segregation patterns in the people's lives in a broader sense; a highly relevant question that is less studied is this: is life in the city being lived in parallel social worlds or not? (Franzén 2009: 1). How the city is used in everyday activities (not necessarily bound to where people live and become co-present) is here seen as an important prerequisite for a range of societal functions, that is, the development of social solidarity (Giddens 1984; Collins 2004), the development of weak or strong ties (Granovetter 1973, 1983), the potential to create spatial as well as transpatial solidarities (Hanson and Hillier 1987) or for different types of bridging or bonding processes (Putnam 2000). The structure and configuration of urban space furthermore directly influence the distribution of, and access to, human and material public and private resources.

Certain properties are associated with a greater diversity of groups in society sharing space, that is, they enable the experience of 'the other' in a daily situation as well as allowing for the participation in the formation of 
public culture (Zukin 1995). This may lead to an increased recognition of different groups in society that can trigger processes of solidarity (Collins 2004) or at least a 'civility of indifference' (Amin 2012). Co-presence, as a result of the routines of day-to-day life, is in this context argued to be fundamental to even the most elaborate forms of societal organisation (Giddens 1984: 64).

By being co-present in public streets, squares and parks we have, according to Zukin, the possibility of gaining insight into other people's life conditions. The street becomes a place for a constant ongoing process of creating different group solidarities and identities among those who share space, identities that may be further integrated into society at large (Zukin 1995: 11, 253). In a similar way Sennett (1992) contends that urban public life, the street life, is important in forming the unwritten rules of society and access to information. Olsson (1998) asserts that the interplay that occurs in public space is important for understanding 'the other', whilst Grannis (1998) emphasises the significance of who it is that shares public space, pointing out that the local street network affects the potential for neighbourly interaction not only among close neighbours but also between people who live further apart as a result of face-to-face interactions in the street.

The street structure can be changed and along connecting streets neighbourly relations are likely to increase; it is argued that micro-level phenomena produce macro-level outcomes (Grannis 1998: 1560). The mix of local inhabitants and non-locals is important since the information and knowledge that incomers may bring to an area are different from 'provincial news and views'. Such information from elsewhere is believed to be important, for example, in obtaining a job, which in the debate of social integration and exclusion is a critical issue (Granovetter 1983).

Giddens (1984) points out how patterns of co-presence in an urban environment are commonly the result of everyday practices that are highly routinised. Following Hägerstrand (2009), Giddens stresses how the trajectories of individuals to a large extent follow similar daily procedures, and how these trajectories may overlap or be superimposed - completely or in certain sequences - and cannot be characterised as completely random. This insight leads us to focus on the places where such everyday activities occur, namely in public space. The effect a street layout may have on keeping people apart, keeping strangers out of an area or enabling and allowing for inter-accessibility between people, will thus create conditions influencing the kind of social interaction that may take place in different locations. We therefore find substantial support for the contention that urban social processes can be influenced through various architectural design components, here expressed in space syntax terms, such as increased spatial integration, 
increased constitution, a densification of strategic public paths in terms of activities and entrances, and so on.

So how are configuration and co-presence interrelated, and what correspondences can be established? A study in Stockholm, based on extensive empirical data and space syntax methodology, has suggested a shift in focus in studies of urban segregation from residential segregation to segregation in public space, opening the way for anti-segregation initiatives to address the problem from the perspective of architecture and urban design in a new and theoretically solid way (Marcus 2007; Legeby 2013). The basis for this claim is that public spaces - streets, parks, squares - are shown to be extremely vital places for facilitating certain social processes, depending on their particular structure and configuration both locally and at the city level, and their subsequent influence on movement distributions and patterns of co-presence. Much empirical space syntax research highlights the particular correlation between spatial configuration and movement, but we want to point out that the essential thing here is how movement works as a mediator of co-presence and its critical role in social processes in cities (Marcus and Legeby 2012). This aligns closely with ideas originally set out in space syntax theory about the relation between spatial form and social processes (Hillier and Hanson 1984) and also is supported by the theories of Anthony Giddens (1984) and Erving Goffman (1966), as discussed above.

Apart from focusing on the relation between spatial configuration and co-presence (Legeby 2010, 2013; Marcus and Legeby 2012), our research also demonstrates how inequalities in terms of access to various urban amenities and resources may be analysed with great precision by the use of the Place Syntax Tool (Ståhle et al. 2005), which provides an opportunity to add geographical and social data to space syntax analysis, such as the location of urban services and amenities. This elucidates how urban form distributes the access to these resources in an uneven manner and how this, in extension, further contributes to the segregation of particular groups from society. More generally this approach makes use of the contribution of space syntax to new and original analyses of space, by extending traditional spatial analysis of distributions in space to analysis of distributions through space (see e.g. Koch 2004, 2007).

Concerning co-presence, research in this direction has more specifically looked into not only the relation between urban form and the distribution of co-present people in urban space, but also what, in this research, is called the intensity and constitution of co-presence. 'Intensity' refers to the size of the group of co-present people, whilst 'constitution' refers to the mix of people that comprise co-presence groups. In the Stockholm study 


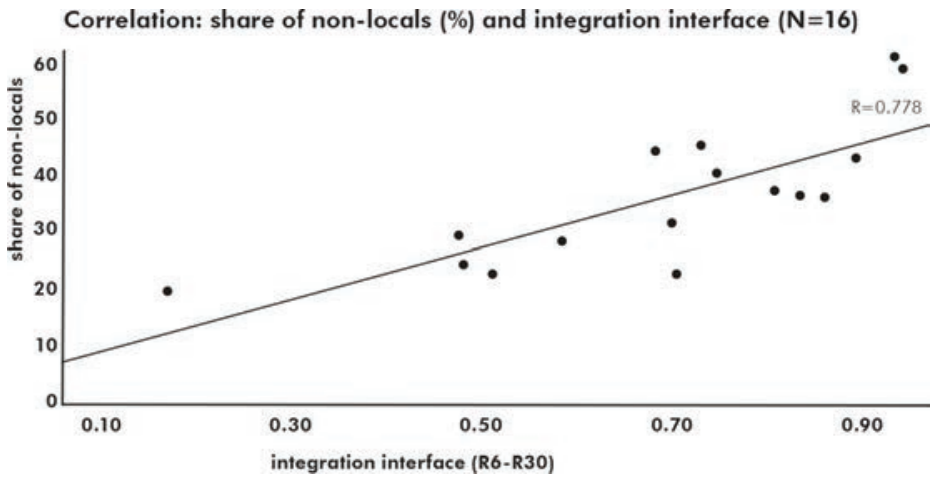

Figure 9.1

Correlation between degree of 'integration interface' and degree of incoming people to squares in Stockholm

Image by Ann Legeby: published in Patterns of co-presence, 2013.

(Legeby 2013) the intensity of co-presence was measured through repeated observations and constitution through questionnaires $(n=2,224)$. This established a study consisting of eighteen places in Stockholm with close descriptions of the typical character of co-presence in these places. These characteristics were shown to correlate with the particular configurational properties of these places. Of special relevance here were spatial centrality (integration), integration interface (high integration both locally and city-wide) and access to people (access to both inhabitants and working population).

A reasonably strong correlation was found between the integration interface and the degree of inflow of non-locals to the spaces $(R=0.577)$, though this included two outliers where major shopping mall increase the natural inflow of non-locals (Skärholmen and Farsta). Without these outliers the correlation rises to $\mathrm{R}=0.778$ (Figure 9.1).

\section{Co-presence and interaction}

The Gothenburg study builds on these findings, but aims to widen them to also include the unequal spatial distribution of urban resources as an important aspect of the discussion on segregation. Co-presence in this context can be seen as a resource for potential interaction and inclusion depending on its intensity and constitution that, as we have seen in the Stockholm study, is unequally distributed and typically found far less in socially disadvantaged areas. 
The four neighbourhoods that are the focus of the study are part of a national initiative called Urban Development designed to address problems related to social exclusion: Bergsjön, Hjällbo, Gårdsten and Norra Biskopsgården (Swedish Government 2007, 2009). The aim of the national initiative is to improve living conditions in areas characterised by exclusion and decrease socio-economic differences within cities and regions. These areas were constructed in a period characterised by extensive urban expansion (1945-75) and were part of a Swedish welfare-state initiative to meet the serious housing shortage at the time. Norra Biskopsgården was developed between 1956 and 1963, while the other three areas were part of the Million Homes Programme: Bergsjön between 1965 and 1972, Hjällbo between 1967 and 1969, and Gårdsten between 1969 and 1972. The design principles of these areas were strongly influenced by a Swedish interpretation of the neighbourhood-unit planning ideals (Klasander 2003). This means that these areas are organised as spatially demarcated enclaves dominated by housing and with differentiated traffic systems, that is, walking and cycling routes are in principle separated from those used by cars, and in some cases the tram system is also separated from streets and pedestrian paths. Traditional urban streets that unite the function of both circulation and public space and include built frontages with direct access to buildings are typically absent (Marshall 2005: 6). Besides these four neighbourhoods, three reference neighbourhoods were also included in the study: Högsbotorp, built 1949-52; Kyrkbyn, built 1950-5; and Björkekärr, built at the end of the 1950s (Figure 9.2).

Empirical data on co-presence was collected through observations in combination with a questionnaire in nine important squares located in the seven identified areas. The observations were made in April on a rather cold day (about 10 degrees) so few people were 'hanging out'. The intensity at the squares was measured as the total number of co-present people in the squares observed simultaneously at each square between nineteen and twenty-one times during a weekday. The mix of co-present people was assessed by asking randomly chosen people in the squares for their residential address. These two straightforward approaches gave a distinct image of the essential character of co-presence in public space in the different neighbourhoods. Of special interest here was the degree to which these spaces were dominated by locals or whether there was also an inflow of non-locals. The assumption was that depending on the mix of locals and non-locals, different settings are created in respect of potential social processes.

As explained earlier, integration is a measure of spatial centrality, which broadly speaking can be said to describe accessibility in the street network. Extensive research has repeatedly demonstrated how higher integration 


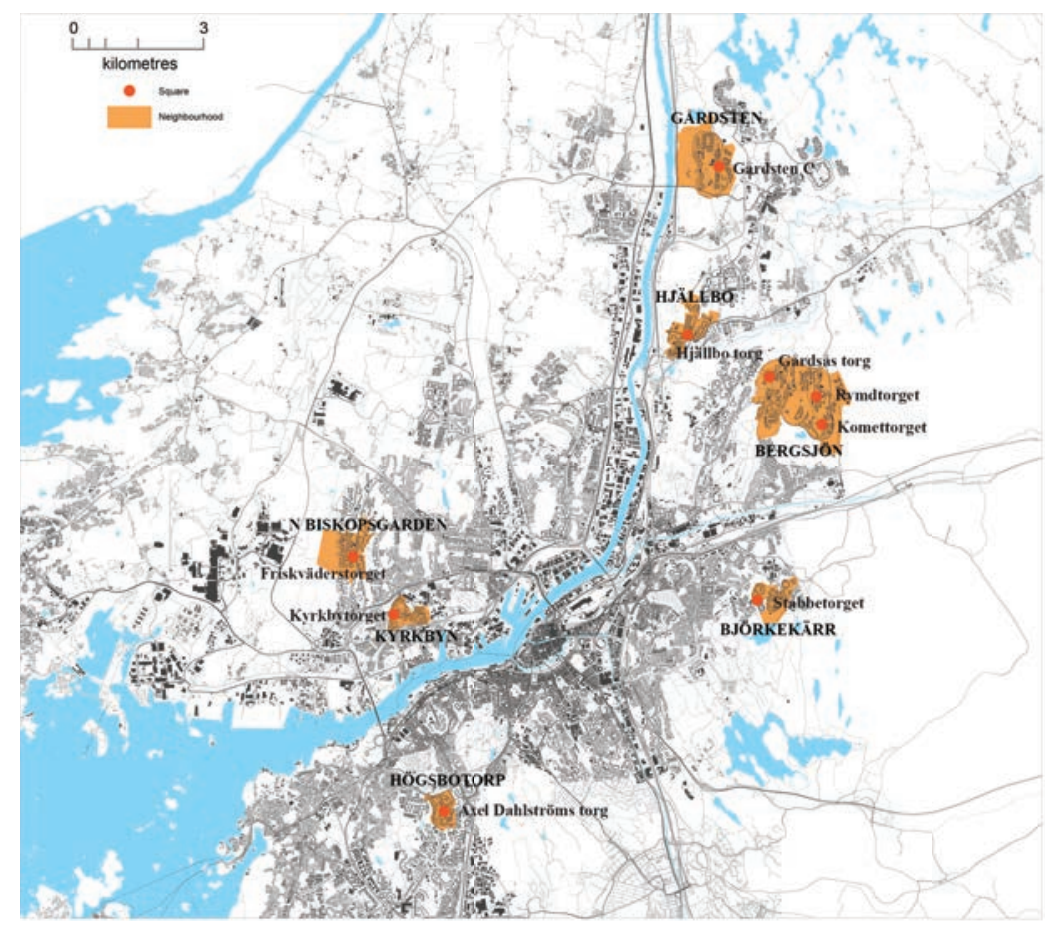

Figure 9.2

The location of the studied neighbourhoods and squares in Gothenburg

Based on maps provided by the City of Gothenburg, City Planning Authority, with permission.

typically captures pedestrian and vehicular movement (Hillier et al. 1993; Hillier and lida 2005), that is, a strong correlation between urban form and human behaviour. By extension, this strongly influences the distribution of co-presence in public space, which is why in our current context it also represents a powerful tool for detecting variations of social potential in public space and forms an essential part of the interpretation of our results. Access to various urban resources that are found to be relevant in relation to segregation and exclusion was analysed for the studied areas in Cothenburg by means of various spatial analyses using the Place Syntax Tool (Ståhle et al. 2005; Marcus 2010), which combines traditional space syntax analysis with a measure of access to resources from individual plots. The analyses highlight those conditions that are argued to be central from a social perspective. Results of the spatial analyses are presented using graphics particularly developed for the project with the aim of facilitating communication with non-professionals, for instance, polar diagrams, thematic maps, combined thematic maps and what we call a line analysis. 


\section{Segregation from urban life}

The spatial analysis of the areas reveals that only one out of nine squares is located in a neighbourhood that is highly integrated city-wide. Three neighbourhoods are, on the whole, spatially segregated on a city scale and only one square, Hjällbo torg, is more integrated than the neighbourhood for which it acts as a retail and service centre. The analysis shows further that, at a local level, most squares are integrated to a similar degree as their local context. Only three are more integrated compared to their surroundings Gårdsten centre, Hjällbo torg and Rymdtorget in Bergsjön - which is why according to space syntax research they would be expected to attract more movement than their surroundings (Figure 9.3).

When analysing to what extent local integration in an area correlates with integration city-wide (something that was found to correspond to the

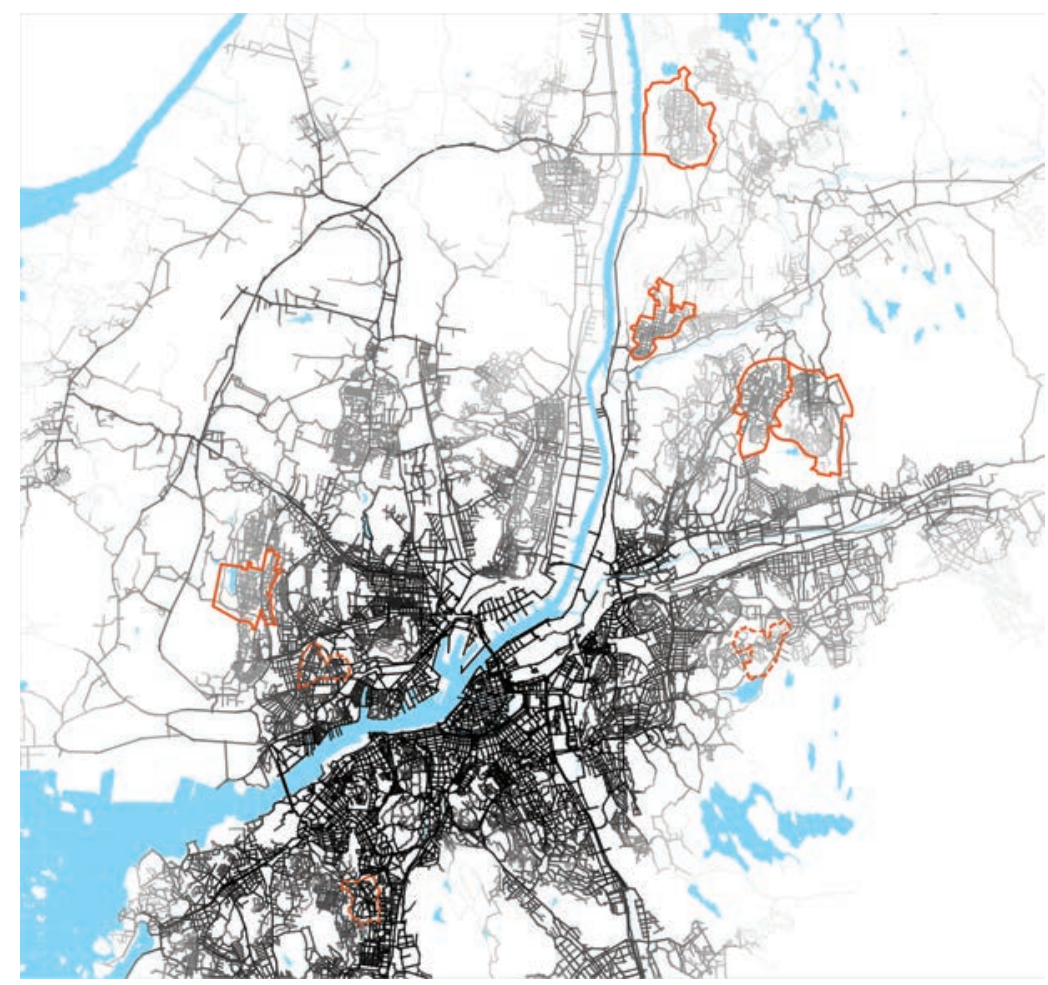

Figure 9.3

Network integration at city scale (radius 50)

Based on maps provided by the City of Gothenburg, City Planning Authority, with permission. 
inflow of non-locals in the Stockholm study), we see that three squares - Axel Dahlströms torg (Högsbotorp), Hjällbo torg and Rymdtorget (Bergsjön) have such correlations while the others do not. Hence, only three places out of nine have, in this respect, favourable configurational conditions for an inflow of non-locals.

The intensity of co-presence is, as already stated, highly dependent on different measures of centrality. However, when density and land -uses are very unevenly distributed, and this is typical for the Swedish suburban landscape, the correlation between spatial configuration and movement drops (Ståhle 2005). When geographical data such as residential and working populations are added to the analysis, the correlations have proven to be more robust (Ståhle 2005). In the current study we have therefore used, in addition to measures of centrality, accessibility to residential and working populations within a walking distance of $1000 \mathrm{~m}$ from each square. Table 9.1 shows the results of this analysis. Axel Dahlströms torg and Friskväderstorget (Norra Biskopsgården) have the highest access to the population, while Stabbetorget (Björkekärr) has less than half of that amount. The other areas are rather similar in this respect.

When it comes to the constitution of co-presence, the questionnaires tell us that the share of people living within a walking distance of 100om from each square ranges from 44 to 72 per cent. The lowest share of locals, 44 per cent, is found at Hjällbo torg, while at Friskväderstorget 72 per cent live within $1 \mathrm{~km}$. The 50 percentile reveals that the distance to the home addresses of co-present people is less than 1000m at eight out of nine squares (Figure 9.4 and Table 9.2). When this distance is compared with the number of axial turns, the squares located in Bergsjön stand out in comparison with the other squares: Komettorget, Gärdsås torg and Rymdtorget. The axial lines are much shorter in the proximity of these three squares in comparison to other squares within the sample: more turns are needed in urban space to walk the same actual distance.

Observations of intensity (Table 9.2) show that there are not many people on the move in public spaces adjacent to the squares, Hjällbo torg being the exception. However, this is a very large square, so even if it reaches its highest capacity it is far from being crowded. Knowing that the squares are places that belong to the more populated public spaces within their neighbourhoods (apart from schools) demonstrates the degree to which public space is used and this, as we know, affects not only potential exchange between people, but also the degree of retail and services that can be supported.

To clarify how people who visit different squares are distributed across the city, their home addresses were marked on a map (Figure 9.5). 


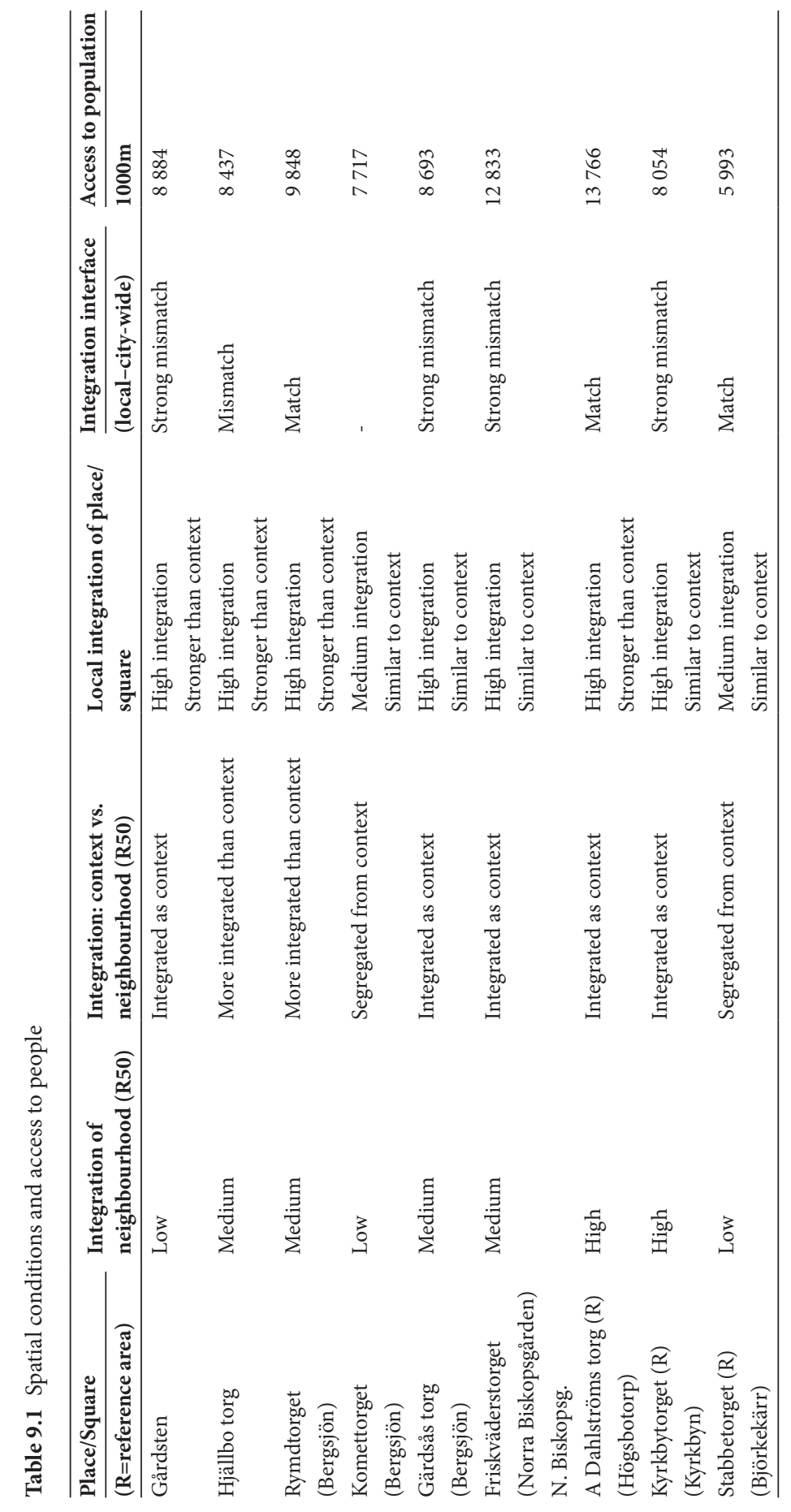




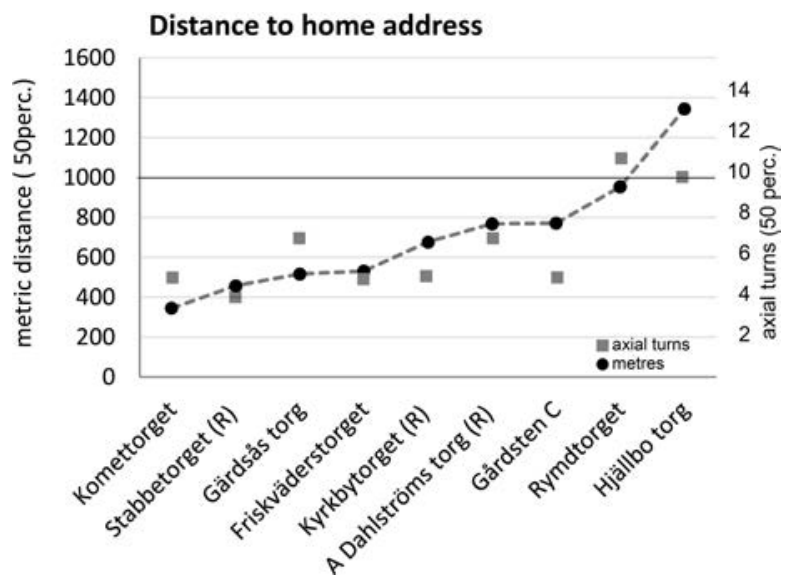

Figure 9.4

Distance to home addresses of co-present people Ann Legeby et al.

Table 9.2 Co-presence study: results from interviews and observations

\begin{tabular}{|c|c|c|c|c|c|c|}
\hline \multirow[b]{3}{*}{ Place/Square } & \multicolumn{4}{|c|}{$\begin{array}{l}\text { Distance from the square to home } \\
\text { address }\end{array}$} & \multirow{2}{*}{$\begin{array}{l}\text { Intensity } \\
\text { median value }\end{array}$} & \multirow{3}{*}{$\begin{array}{l}\text { Share living } \\
\text { within } \\
1000 \\
\text { metres }\end{array}$} \\
\hline & \multicolumn{2}{|c|}{50 percentile } & \multicolumn{2}{|c|}{75 percentile } & & \\
\hline & metres & $\begin{array}{l}\text { axial } \\
\text { turns }\end{array}$ & metres & $\begin{array}{l}\text { axial } \\
\text { turns }\end{array}$ & 19-21obsv. & \\
\hline Gårdsten & 770 & 5 & 7834 & 45 & 5 & 60 \\
\hline Hjällbo torg & 1343 & 10 & 5805 & 32 & 45 & 44 \\
\hline Rymdtorget & 953 & 11 & 2753 & 21 & 10 & 52 \\
\hline Komettorget & 345 & 5 & 2201 & 18 & 18 & 69 \\
\hline Gärdsås torg & 516 & 7 & 1695 & 13 & 7 & 64 \\
\hline Friskväderstorget & 531 & 5 & 1136 & 8 & 17 & 72 \\
\hline Axel Dahlströms torg & 768 & 7 & 1584 & 12 & 9 & 66 \\
\hline Kyrkbytorget & 676 & 5 & 1592 & 11 & 4 & 61 \\
\hline Stabbetorget & 457 & 4 & 1181 & 9 & 5 & 71 \\
\hline
\end{tabular}

The resulting pattern illustrates the origins of visitors to each square and reveals who is contributing to the local everyday life at each square: whether they are from the locality or from a wider catchment area across the city. Figure 9.5 effectively illustrates each square's social catchment area. The non-concentric shape of each catchment area indicates the uneven socio-spatial relationship between each square and its surroundings. In addition, the river is shown to constitute a barrier in several cases and indeed in one case none of the interviewed visitors to the square reported living on the opposite side of the river. 

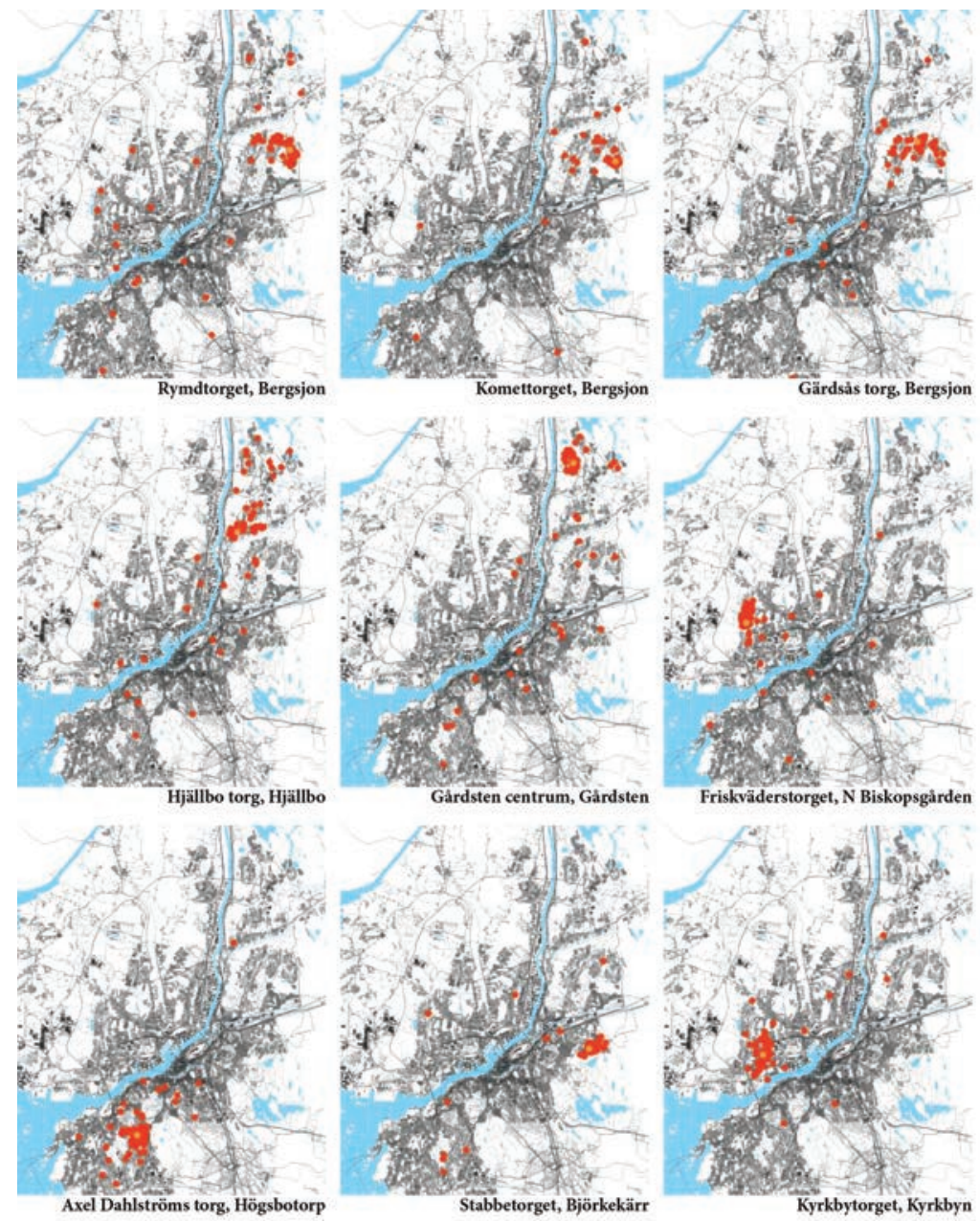

\section{Figure 9.5}

Catchment area of the squares: the home addresses of co-present people Ann Legeby et al.

Three squares, Rymdtorget, Gärdsåstorg and Komettorget, within the same neighbourhood, Bergsjön, provide very different opportunities for social interaction as a result of their configurational properties. The co-presence study confirms this: at Rymdtorget 52 per cent live within $1000 \mathrm{~m}$, at Gärdsåstorg 64 per cent and in Komettorget as many as 69 per cent. Hence, the inflow of non-locals is highest at Rymdtorget and lowest at Komettorget and this corresponds to their spatial potential described above. The intensity of people co-present, however, was found to be high at Komettorget (Table 9.2), but this was primarily the result of trams (or buses) arriving during the 
period of data capture. In between the arrivals of trams and buses, the place was quiet; people arriving by tram or bus populated the place for only a short time, before dispersing. At Gärdsåstorg and at Rymdtorget the intensity is, in comparison, much lower. At Rymdtorget, however, there is an indoor structure with shops that attract a lot of visitors at the expense of the outdoor public space. Moreover, the 50 percentile reveals that the catchment area of Komettorget is very limited, only $345 \mathrm{~m}$ (or 5 axial turns). In other words, half of the people observed live within a distance of $345 \mathrm{~m}$ from Komettorget. The catchment area of Gärdsåstorg is a little larger at this level, namely $516 \mathrm{~m}$, while Rymdtorget has a larger catchment area of $953 \mathrm{~m}$. This indicates that the urban life at Komettorget and Gärdsås torg has a more local character than at Rymdtorget, meaning that the potential for there to be citizens from other parts of Gothenburg is higher at Rymdtorget. Moreover, the length of the axial lines says something about orientation and visibility: on average each axial line adjacent to Komettorget is $6 \mathrm{gm}$ long, to Gärdsås torg $74 \mathrm{~m}$ and to Rymdtorget $87 \mathrm{~m}$. This indicates that people moving to and from these places are not within sight of others for a particularly long time.

We can conclude that Komettorget is a square for locals to reach out to other areas: they come and go using the tram, but not many people stay in the square and few visitors come here. In other words, it is a 'square for departures'. Rymdtorget, on the other hand, is less populated (although we know more people are in the indoor shopping mall), but the inflow of nonlocals is higher. Hence, this square has the character of a 'square of arrivals'.

\section{Segregation from urban functions}

A comparison of all nine analysed areas illustrates that they have similar access on an aggregated level to the most important daily services, such as elementary schools, grocery stores and medical care. Hence a kind of minimal level of service is provided: all have at least one school, one grocery store and one healthcare centre in relative proximity. However, the areas show considerable differences in terms of access to diversified urban resources, that is, how many shops and restaurants are accessible within a certain distance threshold (Figure 9.6). Hence, the neighbourhood planning ideals of satisfying so-called primary functions stand out in this respect, for example each neighbourhood was planned with certain basic services but not designed to favour secondary benefits that need a concentration of people to encourage urban life and provide access to information gained from other citizens' behaviour, or provide an arena for social interaction. 

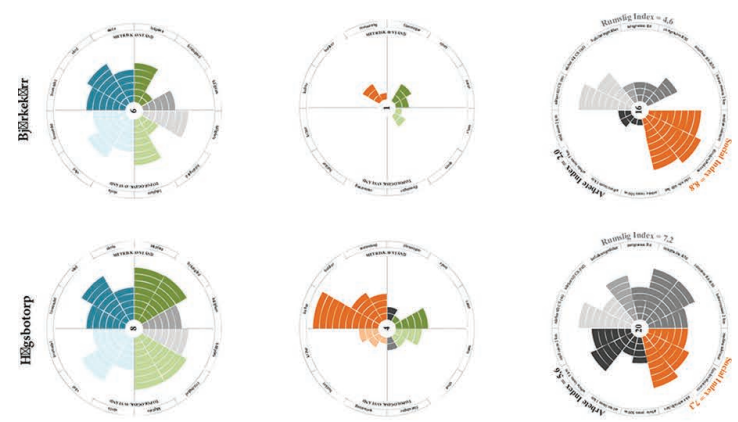

1
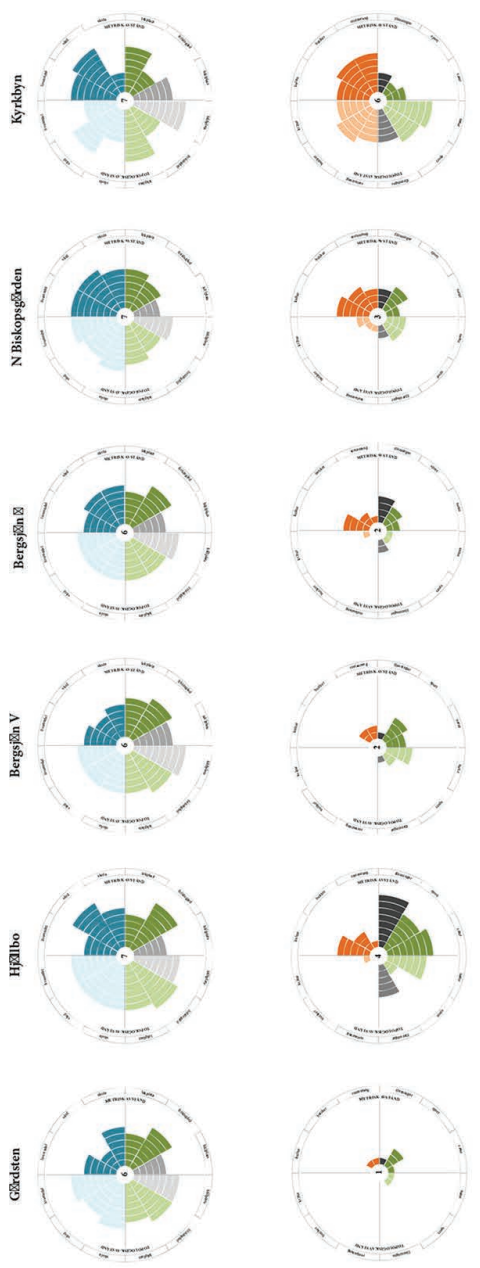

(2)
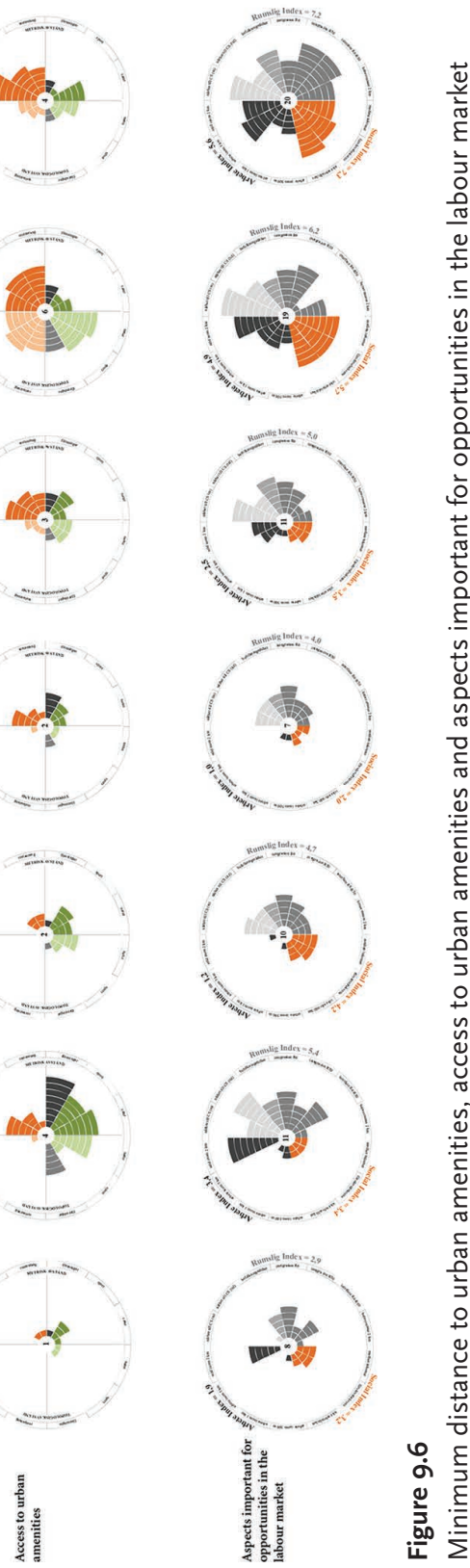

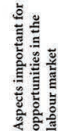

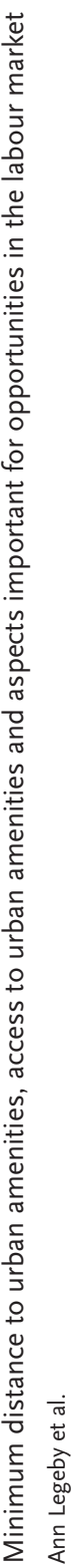


Besides the differences in access to diversified urban resources, the conditions important for opportunities in the labour market are unevenly distributed in the studied neighbourhoods, for example access to workplaces and access to non-locals in urban public spaces. Bergsjön, for instance, has low access to workplaces on all scales and proportionally poor access to the city centre by public transport. The situation in the three reference neighbourhoods is essentially more favourable. From the observation study we found that at least two of the three squares in Bergsjön had a low inflow of inhabitants from other parts of Gothenburg that could potentially contribute with another kind of information to that found locally. It is of great concern that the poorest conditions in terms of diversified urban resources, opportunities in the labour market and co-presence are found in those neighbourhoods where the residents are socio-economically most disadvantaged and where unemployment rates are high.

As part of the Gothenburg study we also made an in-depth study of Bergsjön in greater detail in order to understand how the spatial configuration contributes to unequal living conditions. The poor connection between the western and eastern parts of Bergsjön was studied in order to identify where the spatial interfaces were ruptured. The sequence of street segments that connects two of the main squares was analysed: Gärdsås torg in the west and Rymdtorget in the east. This connection proved to have the highest potential to be a 'main link' and improve internal relations, but orientation and constitution were generally very poor. The analysis was used to identify 'gaps' along this sequence of segments and the line analysis revealed a large variation from segment to segment for all four variables considered: variations in terrain (height), centrality (measured as betweenness), constitution, and the mix between night and day populations (Figure 9.7). By adding new connections, and buildings/address points in strategic locations,

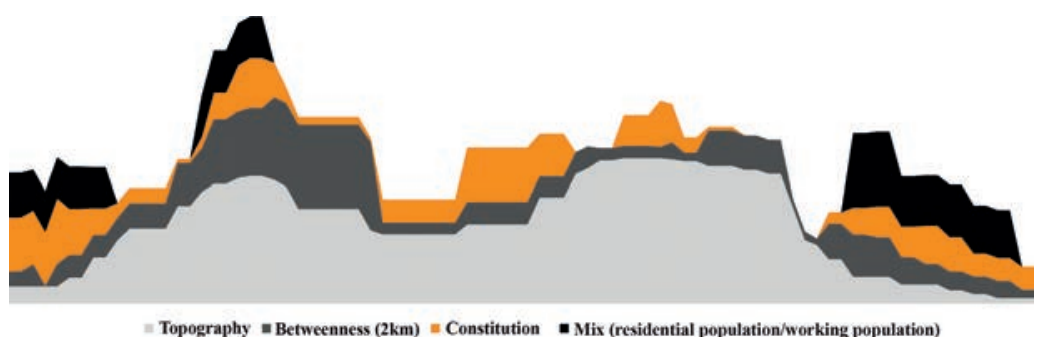

Figure 9.7

Line analysis - east-west section in Bergsjön illustrating topography, betweenness, constitution and mix between residents and non-residents

Ann Legeby et al. 
we wanted to test whether this could improve the continuity of the strip and heal gaps so that orientation and the potential for social interaction would improve.

Access to workplaces is important for the intensity of urban life, with a correspondence between people visible in public spaces and access to workplaces locally. Urban design interventions that improved the east-west connection in Bergsjön, in combination with new links between surrounding neighbourhoods and areas further away, were tested during the in-depth study (Figure 9.8). Rymdtorget in the eastern part of Bergsjön increased its access to workplaces by as much as 24 per cent, and accessibility from Gärdsås torg increased by 17 per cent, while Komettorget only increased by 5 per cent (Figure 9.9). However, we must also conclude that, in comparison to the reference neighbourhoods, these improvements represent only moderate advances when comparing absolute numbers. Axel Dahlströms torg has, for instance, more than three times as many workplaces within a walking distance of $1 \mathrm{~km}$ than the western part of Bergsjön. In other words, the spatial conditions in Bergsjön would, in spite of interventions, be much poorer than those found in the reference areas. It is important

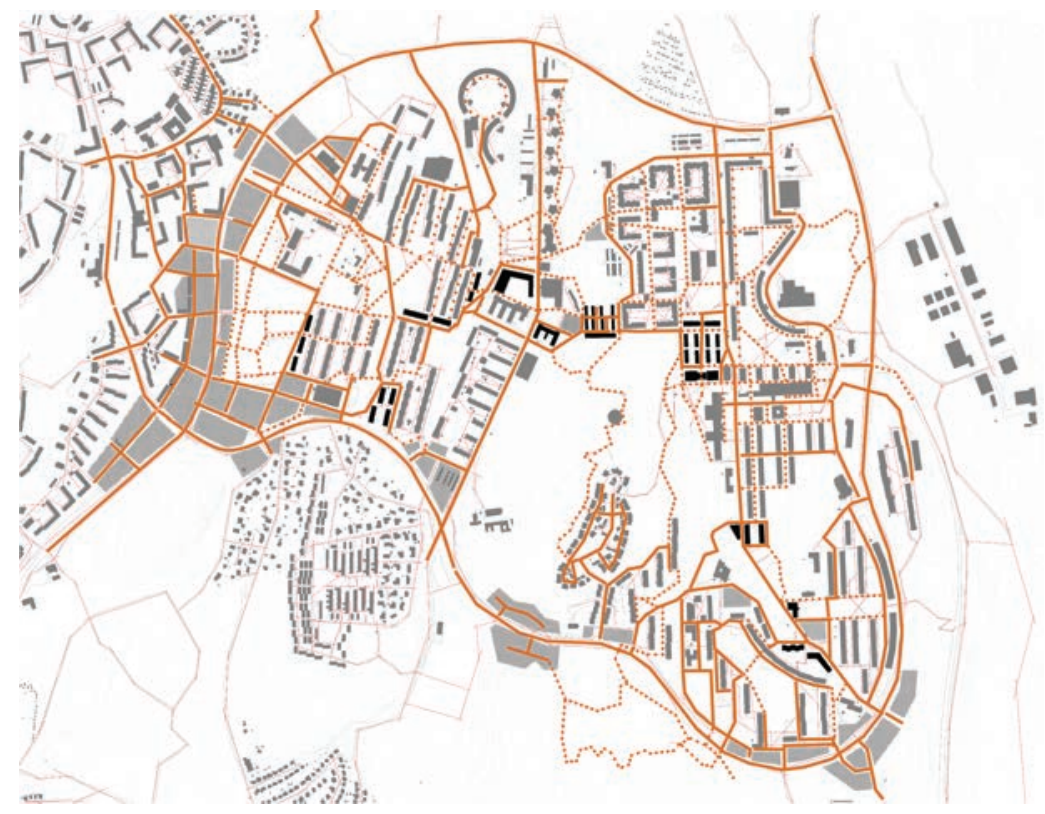

Figure 9.8

Proposed interventions in Bergsjön

Based on maps provided by the City of Gothenburg, City Planning Authority, with permission. 


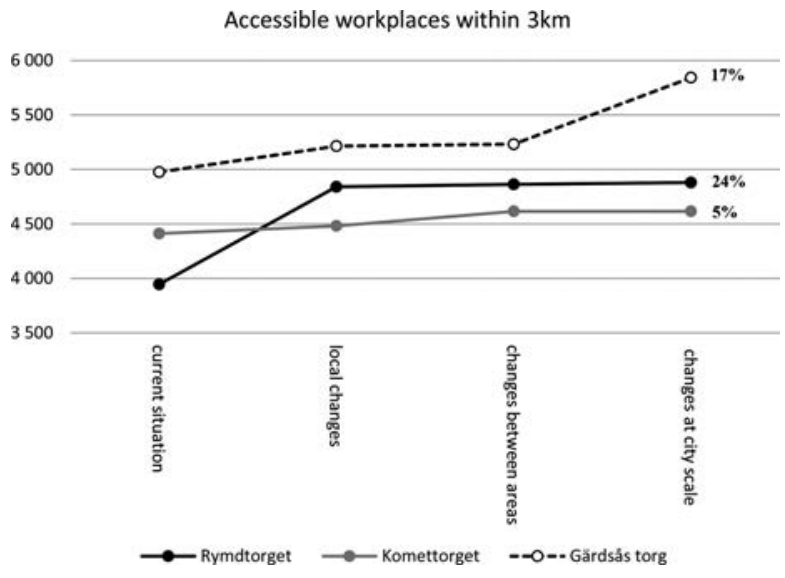

Figure 9.9

Increase of access to workplaces before and after the proposed interventions

Ann Legeby et al.

to stress that in the analysis no new workplaces or inhabitants have been added, so the change captured is solely due to a change in access to existing workplaces. This points to the principal finding that an increase in the resources in these areas can be created by adding new resources but also by increasing accessibility to the resources already present in the vicinity.

\section{Conclusion}

From an architectural perspective, we can identify public space as a key variable for facilitating important social processes in cities that can support long-term social inclusion. We furthermore conclude that it is especially important to investigate the configurational dimension of urban space, due to its proven ability to distribute movement and, in addition, to create a variety of situations of co-presence in public space - according to extensive sociological theory, this is critical to the development and maintenance of social inclusion and cohesion. We believe the Gothenburg study contributes to earlier research concerning the relation between spatial configuration and the intensity of co-presence. It continues earlier research in Stockholm which also considered the relation between spatial configuration and what has been called the constitution of co-presence, that is, the social mix of co-present people, in this case represented by the mix of locals and nonlocals. Finally, it also contributes to a better understanding of how spatial configuration distributes urban amenities and resources by creating varying 
degrees of accessibility to these. Naturally this accessibility depends on the location of such amenities but, by applying the place syntax approach, it can be clearly demonstrated the extent to which this also depends on the spatial configuration itself, increasing the toolbox of urban planning and design.

More specifically, we conclude that what is missing in many of these areas is a dense network, or web, of high-centrality spaces; a high street or something that performs in a similar way, that is, spaces that have the ability to distribute amenities through space in an efficient way and to connect the neighbourhood to its surrounding areas and to the city as a whole so that, on the larger scale, these neighbourhoods become part of or at least better connected to what Hillier calls the foreground network of the city. Many of the areas studied can be characterised as islands located in the background network (separated from the high-street network), most clearly in the cases of Gårdsten, Komettorget and Stabbetorget. Consequently, as the co-presence study shows, the intensity of co-presence is low in many of the areas while a few squares present a mix of locals and non-locals to a degree that is argued to create opportunities for broadening social interaction even though intensity is low. There is, furthermore, comparatively poor access to public institutions in many areas. Hence, 'society' is only visible (and thus represented) to a limited extent in the public space of these areas. This is a matter of great concern and reinforces the character of exclusion from the rest of society. Hence, our analyses show, in many respects, that the public space in many of these areas does not afford residents the conditions and opportunities central for a positive integration process, and that this is at least partly the result of the urban design of the areas as well as of their location in the urban network as a whole.

The analysis of access to urban resources is important for two reasons: first, the analysis establishes that there is an unequal distribution of resources in the city and that urban form plays an important role therein; second, the analysis has highlighted that there is, first and foremost, limited diversity of urban amenities that may be criticised in relation to the urban design ideals of which they are the product. The principles of neighbourhood unit planning included the provision of a high level of service for its inhabitants but not for a greater 'audience', meaning that non-locals and other 'strangers' were not encouraged to pass through or visit the area. Businesses and other activities and services established in many of these areas are often operating with very narrow margins. Hence, time has shown that this strategy has left many of these areas in a situation with very little development; the areas are prone to a kind of development impasse (except for publicly funded initiatives) and remain in a disadvantageous situation that risks aggravating the segregation problem. 
The empirical data from the co-presence study confirms that in most of the squares a large share of those co-present live very close to the square, and thus the inflow of people living elsewhere is low. The established inequalities in terms of living conditions are highly problematic, especially when people with fewer resources are affected. However, urban design interventions can change the configurational properties that affect the conditions for social interaction in areas where the spatial properties are found to be unfavourable. In such areas, access to resources may increase as a result of urban design interventions, creating easier access in terms of both human and material resources. The urban design interventions analysed in this study supported, on the one hand, the distribution of resources more effectively in space, increasing their likelihood of improving life chances locally. On the other hand, the analysis shows that more comprehensive urban design interventions are needed in order to actually achieve what may be defined as equal living conditions across the city and its suburbs.

The results presented in this chapter are part of a research project called Dela[d] Stad (Divided City) initiated by the city of Gothenburg, which aims to further develop how the matter of exclusion may be addressed from an urban design perspective. The project is financed by the Swedish National Board of Housing, Building and Planning through Mistra Urban Futures.

\section{Notes}

1 The criteria are an employment rate less than $52 \%$, more than $4.8 \%$ of the population living on social allowances (long-time dependency) and a qualification rate for secondary school lower than $70 \%$. In addition to this, there must be a population of 4,000 people or more.
2 The Million Homes Programme was an initiative to construct one million housing units within ten years between 1965 and 1974 in order to meet the extreme housing shortage that resulted from rapid urbanisation in Sweden. 


\title{
Chapter 10 \\ Sociability and Ethnic Identity
}

\author{
Angela Piragauta
}

\section{Introduction}

Historically the growth of cities such as London has been characterised by the emergence of centres and sub-centres spread across their spatial structure. Hillier (1999a) defines this phenomenon as 'centrality as a process', in which the spatial configuration of the city network influences movement flows, creating 'attraction inequalities' which in turn give rise to more intensive development of some areas. The centrality patterns generated by this process are influenced by the degree of integration of some locations in relation to the whole, and by local, particular grid conditions.

This process can also be seen in the UK's suburban development, which generally took place 'around pre-urban nucleated settlements that were favourably located in relation to road or railway transport links' (Rowley 2006; Whitehand and Carr 2001, cited in Griffiths et al. 2008: 3). In his analysis of Sheffield, Griffiths (2009) identifies how the city embedded the historical access roads of the rural parish, with a phase of suburban growth generated by concentrated connectivity along the roads, leading to processes of grid intensification that caused the emergence of localised centres, which in turn acquired a more urbanised character.

In this suburban development process the high street plays a key role. Typically evolving from main access roads, the high street 'embodies a degree of continuity in land use with the pre-urban settlement form' (Griffiths et al. 2009: 4), performing as a local centre where commercial and communal activities take place. The local centre is often associated with the presence of attractors, such as markets. In many cases, the high street developed around the site of regular markets which were typically held in the town centre (Watson 2009). Since then, high streets and markets have 
simultaneously been key commerce sites and public spaces where social connections and interactions between disparate groups can take place.

The social dimension these spaces acquire beyond economic purposes was explored by Jones et al. (2007), Watson (2009) and Hall (2012). Their studies highlighted the role of high streets and markets as places where encounters and informal interaction can bring a sense of community and local identity, while transforming them into places of social association and inclusion for marginalised groups.

This interaction acquires more relevance when ethnicity and cultural differences are considered. In contexts like London, terms such as 'superdiversity' are used to conceptualise urban places characterised by a multiplicity of ethnicities, migration stories and backgrounds (Wessendorf 2010, 2014), while an acknowledgement of a growing diversity in suburban spaces has challenged the idea of London suburbs as 'homogeneous, white, middle-class enclaves' (Saha and Watson 2013). In these diverse contexts, social interactions can promote cultural exchange and mediation of differences, although the depth of these encounters might vary according to where they are taking place.

For instance, in the public realm these encounters can be brief greetings or short conversations, marked by a sort of civility that leads people to learn intercultural skills (Wessendorf 2014). This behaviour also allows mediation of differences where diversity has brought tensions among groups, as reported by Wise (2005) in her description of social interactions taking place in the Sydney, Australia, suburb of Ashfield. Regular contact can evolve into deeper and more enduring exchanges, becoming a habitual engagement with the cultural other around shared interests. Although engagement can take place in the public realm, semi-public spaces such as clubs or community centres are the more usual scenarios (Amin 2002; Wise 2006; Wessendorf 2010).

The case of Seven Sisters Market, an indoor market located in a suburban area in the north of London, is consistent with the previously described association between high street and markets, and their roles as sites where everyday sociality promotes association, inclusion and the mediation of differences within a diverse context. While the surrounding high streets reflect the multi-ethnic composition of the area, the market performs as a singular piece in this mundane and diverse setting, due partly to its marked LatinAmerican identity. The market is a significant encounter point for the locals, who have given it diverse meanings: a social and cultural hub, a link with their homelands and the source of their livelihood. However, despite its significance, regeneration plans for the area are threatening its existence 
and, therefore, the interactions performed both in and between the market and the surrounding high streets.

The aim of this chapter is to discuss the role of the market as an encounter point in its locality, integrating its Latin-American identity with the contrasting and more diverse setting of the multicultural suburban high streets where it is located. It will also explore the ways in which the battle against the demolition of the market has brought local communities together to engage around a common interest: preventing the disappearance of the market.

\section{Immigrant clustering and suburbanisation}

For many years London has been influenced by high immigration flows coming from around the world. The city streets have been converted into the stage where multiple cultures and individuals converge, leading to a transformation where some areas have become highly ethnically diverse.

Immigrants tend to follow similar paths in their appropriation of the space. Indeed, immigrants who share the same origin tend to form spatial clusters, organising diverse enterprises to serve both their co-ethnics and the general population (Portes and Shafer 2006). The formation of these spatial clusters has been seen as one step in the process of acculturation and integration (Peach 2005; Vaughan 2007), since it allows cross-cultural contact and mediation of differences among diverse individuals and groups (Vaughan 2005). At the same time, it can protect the minorities from rejection of the dominant society by keeping them out of sight from it (Sibley 1995, cited in Vaughan 2011).

Despite being considered a rather 'invisible community' (RomanVelasquez 1998), Latin-Americans are steadily increasing their presence in London, having by 2008 reached a population comparable to the Chinese population living in the city at the time (Mcllwaine et al. 2011). As one of the 'London's new migrant groups', the majority of the population has arrived since 2000 . This migration process has been characterised by the emergence of Latino residential areas, principally in the boroughs of Lambeth and Southwark, south of the River Thames. Smaller Latino concentrations are located in the north-east of the city, in Hackney, Manor House, Stoke Newington and, more recently, in Haringey, Islington and Newham.

The settlement of Latin-Americans in these areas has been accompanied by the rise of thriving Latino commercial hubs such as Elephant and Castle in south London, and Seven Sisters Market in the north-east. Although Elephant and Castle Shopping Centre is the biggest and most 
recognised commercial area among the Latin-American community, Seven Sisters Market has also grown as an encounter point mainly for Latinos living in the north of London, particularly in the residential clusters in the borough of Haringey where it is located. The market has acquired an active role in this multicultural borough, recognised as one of the most ethnically diverse in the UK (URS 2012).

Seven Sisters Market is part of Wards Corner, a locally listed building located at the junction of Seven Sisters Road, West Green Road and High Road, sitting on the historic Roman road Ermine Street which connected London to the north of England, now known as the Aro. The road allowed the development of the area as a rural retreat for the aristocracy and upper-middle-classes until 1870, when the Great Eastern Railway opened new Enfield and Walthamstow branches and introduced special workman's trains and fares. This stimulated the transformation of the area into a London suburb, with the construction of houses for lower-middle and working classes, with cheaper fares enabling them to commute to inner London (David Lewis Associates 2012). The left-hand side of Figure 10.1 shows the area where, in 1894, the junction was already clearly defined, although suburbanisation had only just begun. On the right-hand side, the area is shown in its current, most urbanised condition. On both maps Seven Sisters Road and West Green Road are highlighted in yellow, whereas the former Ermine Street is highlighted in orange. The comparison between both maps shows how the configuration of these roads has barely changed over time. Wards Corner remains the convergence point of Seven Sisters Road and West Green Road.
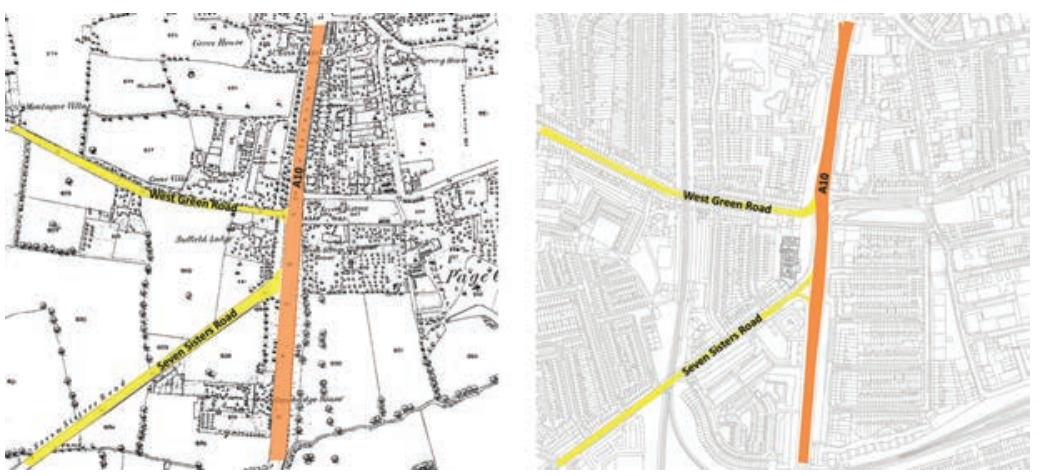

Figure 10.1

Ordnance Survey maps for Seven Sisters area, left, 1894, right, 2013

(C) Crown Copyright/database right 2013. An Ordnance Survey/EDINA supplied service. 
Wards Corner building is named after the Wards department store which opened its doors in that location in 1901, principally serving the suburban commuters who had moved to the new residential district. The store was closed in 1972, and after 1973, when London Underground bought the building, the London Borough of Haringey announced its intention to demolish it. However, the plans have been delayed for over thirty-five years, and in 2001 an individual took over the lease of the ground floor, setting it up as an indoor market. Since then, the leaseholder has sold licences for the use of the market's stall space, giving people the opportunity to start their own businesses with a relatively small investment.

The Latino influence on Seven Sisters Market began in 2001, when a Colombian trader set up his store there. At that time the market was mainly occupied by Afro-Caribbeans, and Latin-Americans constituted a minority. However, this trend soon changed. Attracted by low rent prices, and influenced by friends and acquaintances with businesses already there, LatinAmericans opened a diverse range of stores. Over time the market's relative ethnic diversity has shifted to its current situation, with a predominantly Latino pattern of business ownership.

Nowadays the market is comprised of forty-two shops offering a wide variety of services (Figure 10.2). By August of 2013, thirteen of the stores were leased by Black Africans, Black British, European, Indian and Iranian traders. The remaining twenty-nine were leased by Latin-American traders

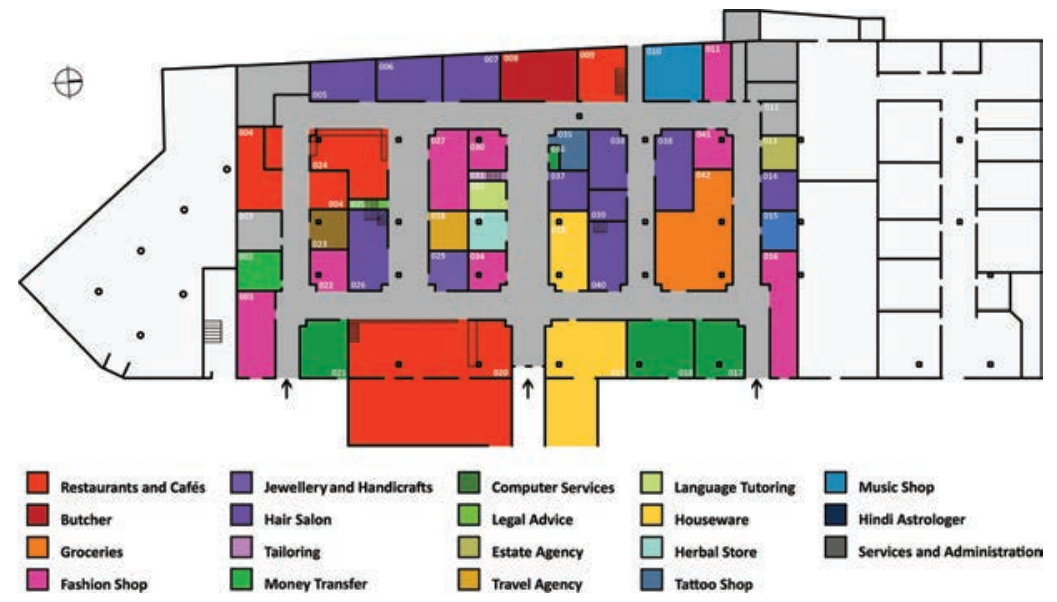

Figure 10.2

Land use map of Seven Sisters Market

Data plotted on plan redrawn by the author based on the Community Plan floor drawings. 


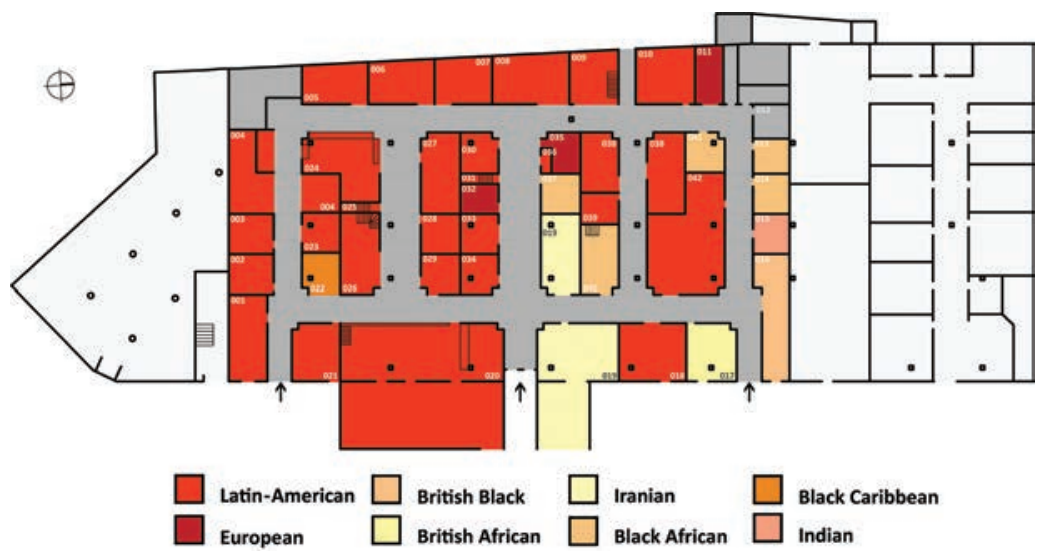

Figure 10.3

Ethnic ownership map of Seven Sisters Market

Data plotted on plan redrawn by the author based on the Community Plan floor drawings.

who therefore are the ethnic majority, occupying 73 per cent of the commercial floor space (Figure 10.3).

The following sections describe the results of a study undertaken during July and August of 2013, as part of fieldwork for an MSc dissertation in spatial design (Piragauta-Roldan 2013), in which the everyday sociality on Seven Sisters Market was analysed through ethnographic observation and space syntax techniques. A survey using a questionnaire' was conducted with fifty people, including twenty-one traders, ten employees and nineteen visitors to the market; twelve of the surveys led to extended interviews. The questionnaires were always introduced in English, although in many cases they were conducted in Spanish since the interviewees did not speak English. ${ }^{2}$

The results show the multidimensional performance of the market. First, it is demonstrated to be a space where tangible cultural elements are contributing to shaping the Latin-American atmosphere of the place. Second, it is shown to be the stage for multiple social interactions, where contrasting experiences are taking place: on the one hand, it can work as an amplifier for social distance between Latino and non-Latino in the market, when elements such as language are considered; on the other hand, it can be perceived as a sort of 'home-away-from-home', a safe place for those who find it difficult to integrate into the city and who therefore use the market as a source of support, knowledge or connections. ${ }^{3}$ Third, it is shown to be a space that has become the reason for the community to band together as a group, promoting negotiation with decision makers as well as community cohesion. 


\section{The Latino suburban hub}

As mentioned above, Seven Sisters Market is housed in what was once the Wards Furnishing Stores, which, in conjunction with small shops that developed along West Green Road and Seven Sisters Road, served the commuters who moved to this suburban area. Over the years, the area became more urbanised, but the strategic role of the two roads and the market persists.

Nowadays, the two high streets have distinctive characteristics. West Green Road is the liveliest high street, with highly mixed independent businesses on both sides of the road. Supermarkets, bakeries, hair salons and restaurants and cafés are just a sample of the shops that locals find there. Seven Sisters Road has a weaker commercial profile, although the presence of varied community services complements the vibrant setting of West Green Road.

The diversity of the area is perceived just by observing the shop fronts: a Brazilian centre, a Polish delicatessen, a Chinese herbal store, butchers offering halal meat, supermarkets with Afro-Caribbean products, African fabrics. Stores of all these kinds can be seen by walking along both high streets to the point where they converge at the market site.

The presence of the market is not apparent to those who do not know the area. With a modest sign announcing it (Figure 10.4), Wards Corner seems to blend with the stores common to the surrounding diverse high streets. However, this lively commercial hub is almost hidden just one turning away from the busy Seven Sisters Road and West Green Road, and small glimpses of what is going on beyond its doors can be caught: people speaking Spanish on the street, and sounds of Latin-American rhythms coming from Pueblito Paisa Café (Figure 10.5), a Latin-American restaurant, situated on the ground floor of the market building with direct access from the street, which seems to be a main point of encounter and orientation in the area.

Once inside the market, the Latin-American atmosphere is dramatically amplified. The sounds of the street are left behind, masked by the beats of varied Latin-American musical genres. Colombian radio stations are played in many stores, and it is possible to watch Colombian soap operas while sitting on the chairs randomly scattered around the space. The smells of food coming from the different restaurants reinforce the impression of being in a Latin quarter in the heart of London.

The physical setting for these sights, sounds and smells has been constructed by the traders over several years. The building interior has been adapted over time with reproductions of the ornamentation most typical to 


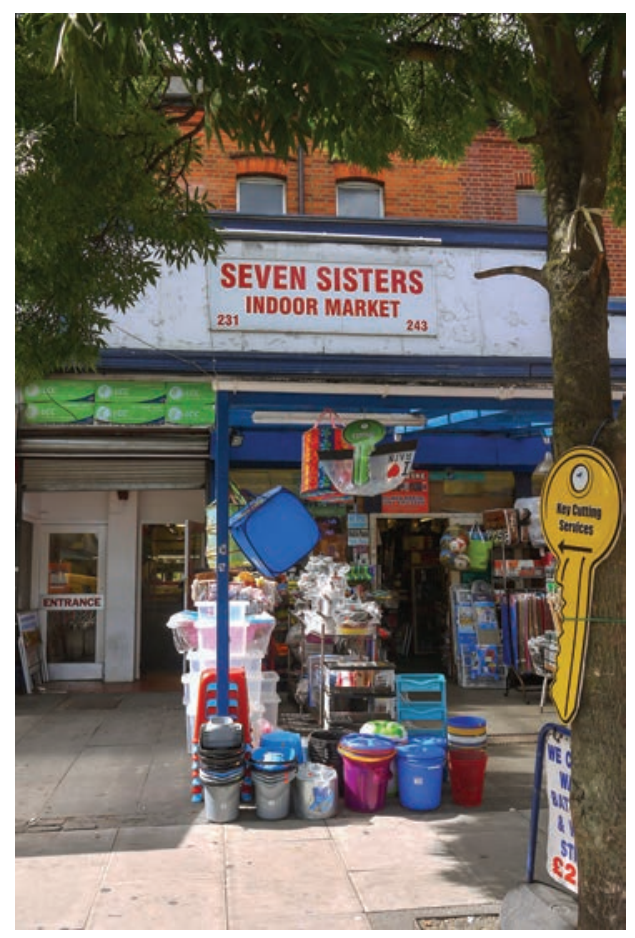

Figure 10.4

Seven Sisters Market, entrance from High Road Angela Piragauta.

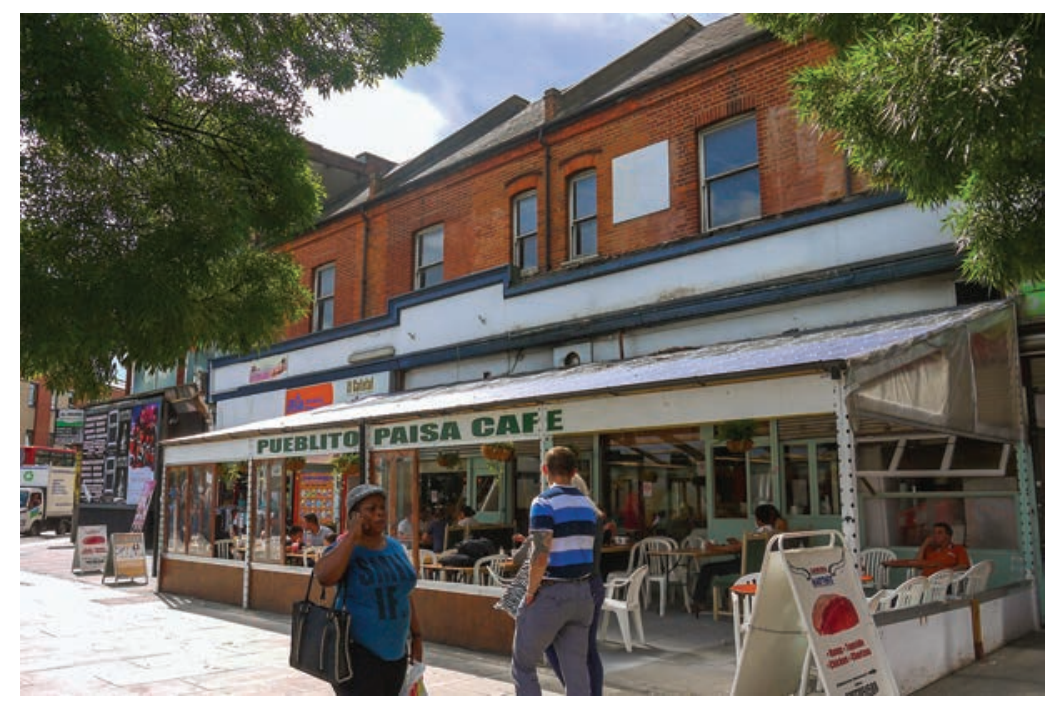

Figure 10.5

Seven Sisters Market, Pueblito Paisa Café

Angela Piragauta. 


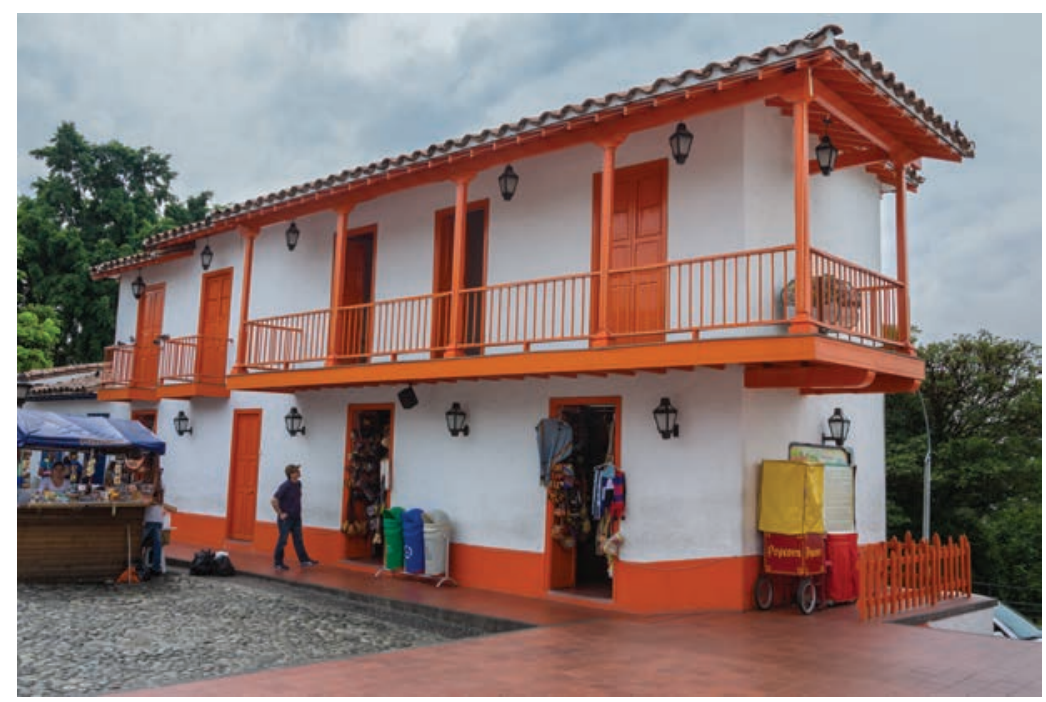

Figure 10.6

House in Pueblito Paisa, Medellín, Colombia

Angela Piragauta.

village houses in Colombia's coffee zone (Figure 10.6). This has earned the market the name of 'Pueblito Paisa', a colloquialism used by Colombians when they refer to these villages. Wooden balconies and clay roofs have been recreated in an attempt to build a place which resembles the traders' homeland. In this sense, their effort has gone beyond the architectural elements, paying attention to decorative details. As in the village houses, flowers or lamps hanging from roofs and balconies of the market stalls are recognisable features (Figure 10.7).

Some of the references to Latin America are more literal, relying on national identities. A number of the traders have decked out their stalls with distinctive elements of their own countries. This is the case for 'Studio Gortázar', a photography studio and gallery adorned by the Cuban flag and a portrait of Ernesto 'Che' Guevara, or a hair salon where the Brazilian flag over the entrance is its most remarkable feature (Figure 10.8).

Ethnic goods sold in the market also play a key role in the construction of its identity as a Latin quarter. Of the thirty stores owned by Latin-American traders, twelve of them offer a wide range of Latin products. From Colombian handicrafts and souvenirs, to the most sought-after Latin-American groceries and dishes, Latin-Americans can find products typical of their countries in the market and which are not normally available in the UK.

When the fieldwork for this research was conducted, many respondents commented that something they miss about being in a foreign country 


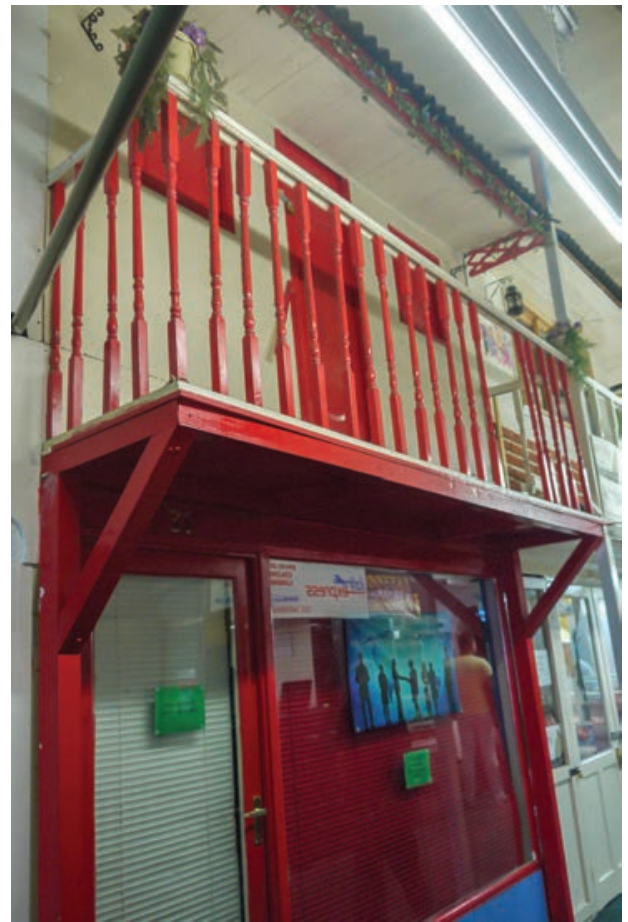

Figure 10.7

Stalls decoration inside the market Angela Piragauta.

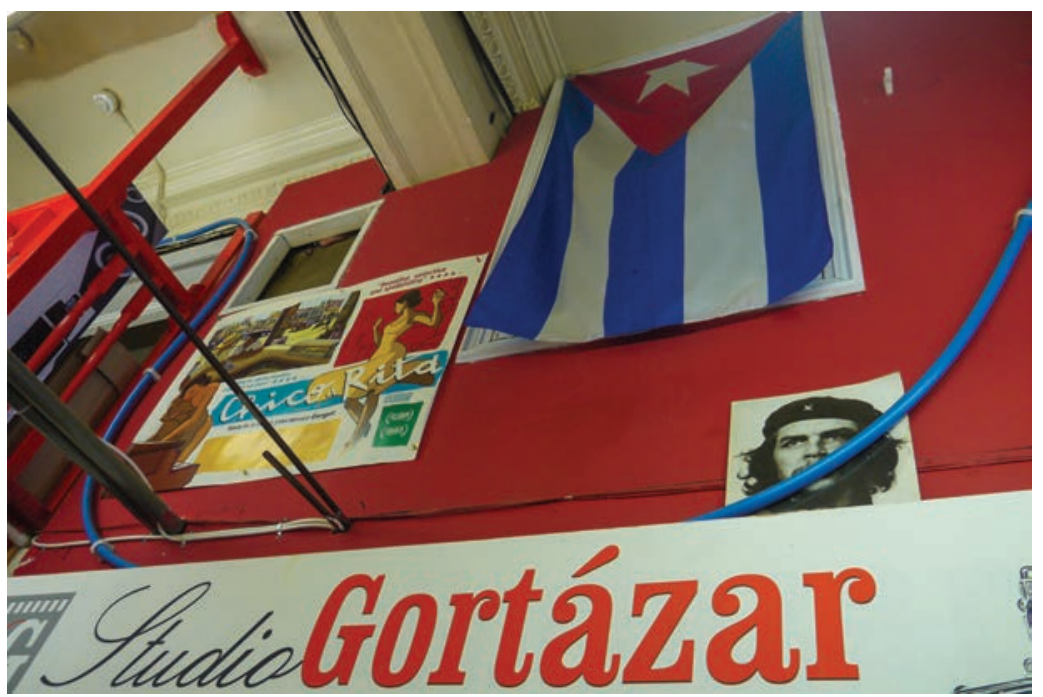

\section{Figure 10.8}

Direct references to Latin-America

Angela Piragauta. 
is the food. In this sense, the restaurants and the supermarket were identified as the most popular stalls among customers. Therefore, a large number of the market's visitors are the diverse spectrum of the restaurant's customers; from individuals to entire families, they come on a regular basis to enjoy typical Latin dishes (Figure 10.9), or to buy groceries and ingredients to prepare those dishes at home. In both cases, through ordinary practices such as eating, Latin-Americans reconnect with their culture and family history, preserving the associated traditions in spite of being away from their homelands.

These reconnection strategies have been also actively encouraged by the traders, promoting ethnic cultural performances within the market. This is the case for Pueblo Paisa Café, which showcases live Latin music sessions every Saturday. Although the primary role of these performances is to attract larger numbers of customers and increase sales, their character has transcended these aspects. They provide an opportunity for Latinos to engage with manifestations of their culture, as witnessed during the observations of this research. That Saturday, the musical number was 'Los niños vallenatos',

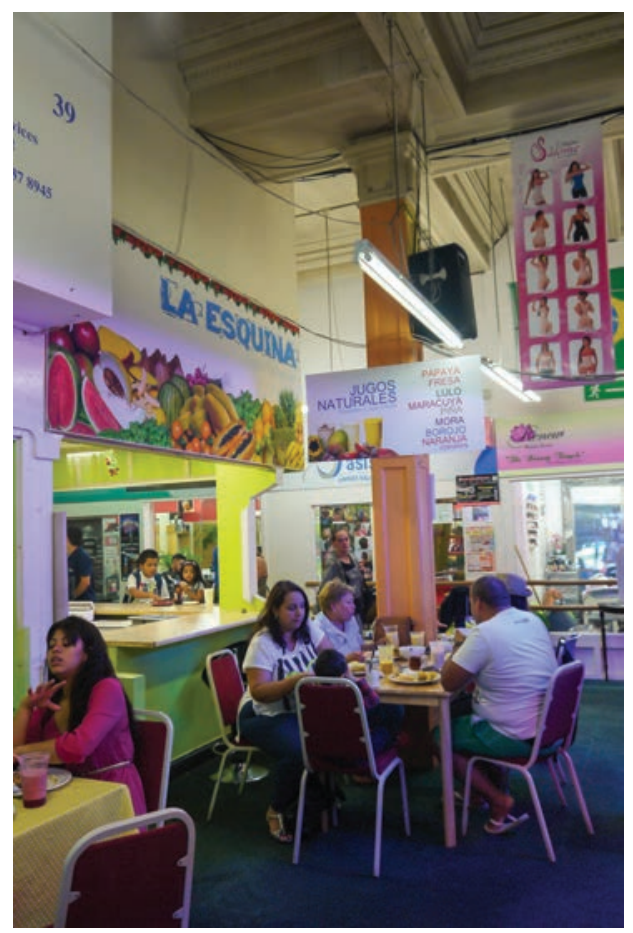

Figure 10.9

Restaurant inside the market Angela Piragauta. 
performed by children from a vallenato music school in Colombia, who were on tour in the UK promoting Colombian Caribbean folklore. Their performance was eagerly awaited by Latin-American visitors, who engaged with it as soon as it started, interacting with the musicians by dancing and singing along to the popular folk songs.

These tangible and intangible representations of culture have shaped a sort of Latin-American experience with profound and varied meanings for both visitors and traders. For some, they are regarded as elements contributing to the construction of a Latin-American identity that must be preserved:

The market is an important place to relate with the Latin-American culture. Especially for the second generation who has an identity problem: they don't know whether they're British or Latin-American. Through the market, the second generation establish a sense of identity with their roots and create emotional links with the country of their parents. (Colombian trader)

For some others, the representation of culture present in the market triggers a sense of belonging with their homeland. That was the case for one of the extended interviewees. Having lived in Spain for eighteen years, she moved to London after losing her business in Spain due to the recession. With few contacts and poor English language skills, the city seemed rather hostile. Nevertheless, she decided to try her luck in Seven Sisters, aware that it was a recognised Latin quarter. Her first impression when she arrived at the market after being away from her country for so many years was that she 'felt in Colombia'. She felt 'at home'.

\section{Market sociality}

In her research into the sociality of markets in England, Watson argued that for a market to find success as a social space, it has first to be sustainable as a place of trade and consumption. Fulfilling this condition ensures the market is visited regularly, and once this happens the sociality can be constituted in different ways. One of them is explained by the notion of 'rubbing along', an easy sociality enacted in markets, where diverse behaviours such as glances of recognition, brief greetings or long conversations among traders and between traders and shoppers constitute 'a kind of social glue holding the sociality of the market in place' (Watson 2009: 1582). In Seven Sisters, this sociality acquires cultural and ethnic 
connotations, being consciously recognised and becoming one of the main reasons for Latin-Americans to visit the market. Respondents to the visitor questionnaire emphasised this issue, commenting that they go to the market to share time with traders and other visitors, since in the market 'everybody knows each other' (Latin-American trader). One Colombian visitor highlighted Seven Sisters as an alternative to Elephant and Castle as a place to meet with fellow Latin-Americans, pointing out that although he uses the market for shopping and eating, sometimes he goes there just to socialise and talk 'with everybody'.

The market also serves as a setting for friends and families to come together. Some of the visitors interviewed have included the market in their everyday routines, going regularly to pay visits to friends or family who work there. This was the case for an habitual customer of 'La Fonda de Juancho', a Colombian restaurant inside the market. He comes regularly to the restaurant since he knows the owner. When the interview took place the man stated: 'After lunch I'll go home, but I plan to come back to the market later because I will meet a friend and have a coffee at Pueblo Paisa Café'.

A similar answer was given by a Colombian woman who happened to be the sister of one of the stall owners, who goes to the market regularly to visit her brother: 'I come with my husband and my son, and we use to spend the whole day here. My son comes to play. ... This market is a place where people from different parts of the city come to gather together. People come to taste the Latin food, for instance.'

These testimonies give an account of the role played by Seven Sisters as a meeting point, a role confirmed by the observations of social interactions within the market. Visitors arrange to meet there to have drinks, eat or discuss business. This is particularly noticeable on Saturdays, the busiest and most lively day in the market. Restaurants are busier than usual, having customers all day long. It is common to see families eating together, and then walking around the market taking a look at the different stalls. Women come to the hair salons, and while they are having their hair cut or manicure done, they have animated chats with stylists and fellow customers. In the meantime, their children get together and play in the corridors, which also get full of groups of adults, chatting informally, having drinks or playing board games.

The events taking place at the market play a key role in the promotion of social interactions. For instance, the live Latin music numbers on Saturdays at Pueblo Paisa Café have become widely known by the community, who start to gather in the café after 6.00 p.m. in anticipation. Around 8.00 p.m., the café and its surroundings are full of people partying, chatting and having drinks, coming together to see the performances. 


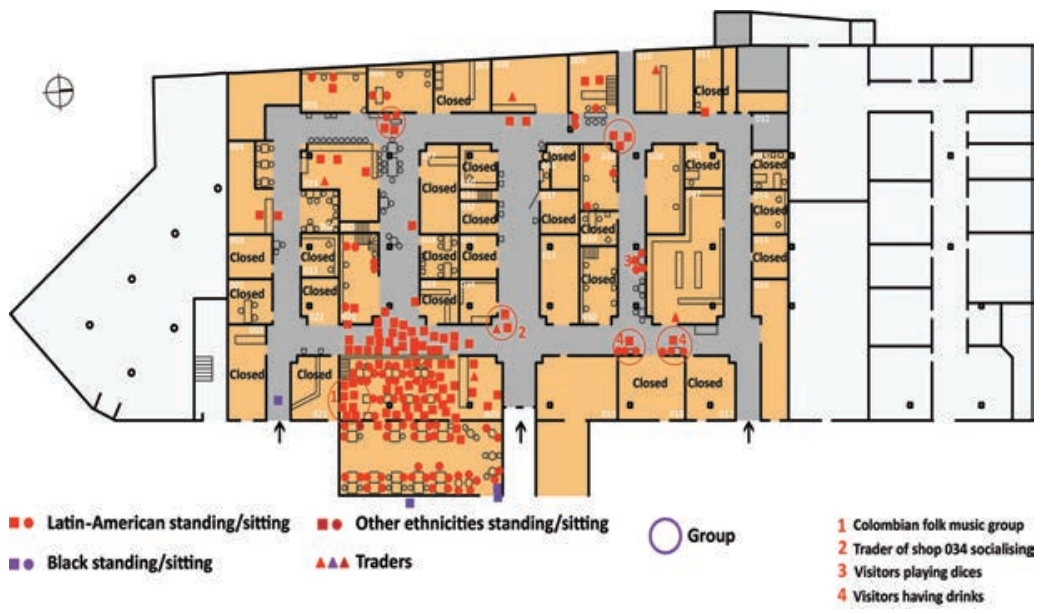

Figure 10.10

Stationary activities in Seven Sisters Market on a Saturday, from 8:00 to 9:00 p.m.

Data plotted on plan redrawn by the author based on the Community Plan floor drawings.

This can be seen in Figure 10.10, which draws over the market floor plan various behaviours and social interaction among people in the hour from 8.00 p.m. to 9.00 p.m. on one observations day, classified according to ethnicity and activity.

Social interactions sometimes lead to people spending long periods of time inside the market. A high number of the visitors interviewed on Saturday were spending more than five hours there, even staying until closing time (10.00 p.m.). Moreover, the frequency of their visits to the market is considerably high, since 75 per cent of the visitor respondents claimed to go there at least once a week.

The length and frequency of the visits to Seven Sisters have an impact on the constitution of social networks. By regularly spending long hours in the market, visitors become closely acquainted with both traders and other regular visitors, frequently developing friendship ties that have their spatial realisation in the market, through the repetition of planned and unplanned encounters.

\section{Constituting social networks}

Previous research has shown how spatial clustering and the inclination of immigrants towards entrepreneurship can reinforce social networks 
and reciprocal support (Body-Gendrot et al. 2000), constituting a source of social capital which creates social structures that facilitate action, reduce risks and become an effective way for finding jobs or transmitting skills (Waldinger 2003). Previous research has shown that for Latin-Americans, the constitution of social networks has played a key role in their making a life in London. Family and friendship networks indeed facilitate migration, provide help in finding jobs, give informal financial assistance with small-scale borrowing and even provide emotional support, helping to 'ameliorate economic and emotional hardships' (Mcllwaine et al. 2011: 107).

Seven Sisters Market as a Latino hub is itself a live outcome of these support networks. As stated before, Latin-Americans first set up their shops in the market following friends and family who were already there. This tendency has not changed. Many of the stores are family businesses and the owner or other family members will commonly be those running the store on a daily basis. On some occasions, the same family owns more than one shop, as in the case of the restaurant 'La Esquina de Blanca' and the hair salon 'Peluquerías Hollywood' whose owners happened to be a couple and their adult son.

Friendship networks also play a key role when it comes to finding employees, or someone to cover temporary leave. A high number of employees reported that they were working there because they were friends of the owner. In these cases, the work relationship seems to be one of mutual exchange: the owner supports the friend by providing a job, and the employee can offer trustworthy labour.

Family and friendship also add valuable support on a daily basis for the workers in the market, which it would not be easy to get from other people. This can be illustrated by the words of two women, who work occasionally there: 'The store is not mine. It is my daughter's. But today she had to go with my other son for an interview in a new school, so I came to take care of the store in the meantime.' The second woman happened also to be helping the same trader, though on a different day:

I do not usually work here, but sometimes my friend has to go and she calls me to help her. This was what happened today. She had an emergency, so she called and asked me the favour to stay in the store while she is away. I am not currently working, so I have no problems to come and help her when she needs it.

In addition to the above, networking in the market is recognised by visitors as a way to find a job, accommodation or even legal advice. Some 
regular visitors are unemployed people who go to the market since they see in this an opportunity to change their circumstances. This was the case for one interviewee, who stated: 'Since I lost my job I'm coming every day to the market, and I stay until closing time. I do this for not being alone at home the whole day, and in the meantime maybe somebody can tell me about a vacancy.'

Some of the traders have spotted an opportunity to build a business around consultancy services for Latin-Americans. This is the case for stalls such as 'Swan Legal Consultant Services', which provide legal and immigration advice. However, according to its proprietor, a Colombian lawyer who focuses on immigration and human rights issues, due to his field of expertise he has witnessed difficult cases where the legal circumstances of the clients affect other spheres of their personal lives. In this sense, although fellow Latin-Americans come to him looking for expert advice, sometimes the support he provides goes beyond his professional services and becomes more personal and emotional.

This need for emotional support rather than professional advice was commonly manifested in the extended interviews. A regular visitor of the market described how 'many Colombians have lonely existences. The divisions of the country are mirrored here in London. Therefore, lots of people come here looking for a bit of company, support and solidarity'. Indeed, one of the interviewees stated that this is the main reason that he visits the market. In spite of having lived in the UK for seventeen years, he does not have many friends or close relationships, partly due to the long hours he spends at work. He stated: 'I live alone here in London. I feel the solitude of living alone, therefore, I come to the market to meet people and have a nice time.'

These testimonies give an account of the market as a place which provides a supporting hand for those going through some sort of hardship. However, this perception is not shared by everybody. Among a number of Latin-American traders, it was stated that social interaction is limited to courtesy greetings, or to discuss topics exclusively related to the market. The reasons for them maintaining a more distant contact with their fellow Latin-American traders have to do with concerns about envy of their relative success, or issues of competition between traders.

One woman who owns a hair salon argued: 'I do not sympathise with the Colombians in the market, because they feel envious when somebody else progresses and therefore they attack them.' Another trader stated that he does not have too much contact with the other Latin-Americans in the market, since he feels they are not 'too friendly', whilst a different respondent stated that although people gather together in the market, there is a 
strong tendency among Latin-Americans to reach economic success by exploiting people from their own community.

These voices recall the findings made by Mcllwaine (2009), who highlighted how mistrust underpins relationships among Latin-Americans, and the conflicting perception they have about themselves as a community. In the market these contradictions are amplified: Latin-Americans working in Seven Sisters are sharing the same enclosed space on a daily basis. Therefore, conflicts and friendships, which in other circumstances might become faded over distance, in the market are more likely to be intensified, more frequent and persistent.

\section{Language barriers}

As mentioned above, the surveys for this study were always introduced in English. However, with the majority of Latin-Americans the conversations shifted to Spanish, either because the respondents do not speak English or because they speak it poorly (although it should be noted that the author speaking Spanish as a native may have encouraged the respondents to speak in that language partly as a means of enhancing communication). Indeed, the lack of knowledge of English has been identified as a main problem for Latin-Americans (Mcllwaine et al. 2011), since it prevents them from effectively settling in the UK.

However, this lack of language skills is one of the reasons why the market is successful. Latin-Americans know that in Seven Sisters the language barrier is non-existent. Indeed, some of the traders identified the possibility of speaking in Spanish as a main attraction for their visit, arguing that a majority of those who go to the market do not know how to explain themselves in other languages. Therefore, they feel comfortable going to the market since there they will find people who can understand them. The owner of a computer repair stall pointed out this issue as the main reason for the sustainability of his business:

Sometimes Latino customers have gone to repair their computers to English speaking stalls. Since they do not know the language, there are misunderstandings when they try to say what is going wrong. Therefore, they prefer to come to my stall because I speak Spanish and they are sure they will get what they want.

A shared language is seen by Latin-Americans as one of the factors that define them as a community. However, it is also a factor that reduces the chances of social mobility and keeps them apart from other ethnicities. The fieldwork study found cases of people who have been in the UK for many years who are working and living exclusively among Latin-Americans 
on a day-to-day basis. With no actual need to learn, no time to go to English lessons and a sense of isolation produced by their lack of ability in the language, the market becomes for many a familiar place where they feel comfortable and acts as a haven from the seemingly hostile world outside.

Nevertheless, with comfort come contrasting fears, particularly among Latin-Americans who have recently started to work in the market:

When I arrived to England I felt the language was a barrier. Because of that I think that learning English is very important. I started a course in Holborn, but the lack of money didn't allow me to continue. Then I started to work here and I felt like I was in Colombia. But then, being in the market every day is not helping me to learn the language, because I'm cooped up here just speaking Spanish. And like me there are many others. New people coming to Seven Sisters are afraid of getting used to working in the market because they are aware that some people here have lived in London for many years without even trying to learn English. (Colombian woman, temporary worker at one of the stalls)

This is a common issue in the market. Some traders reported having lived in the UK for as much as twenty years without learning English. Moreover, when asked what they do if they have a customer who only speaks English, some of them replied that in some cases repeat customers will actually learn some Spanish in order to be able to buy in the market. In this sense, the owner of the music shop answered: 'Customers who are not Latin-American come the first time speaking English, but through listening and watching movies and music in Spanish they learn the language and start to speak in Spanish every time they come back.'

Traders for whom Spanish is not their mother tongue have also learned, or started to learn, this language as a way to fit in at the market. Brazilian traders were found to speak Spanish, and two traders from Uganda and Romania are in the process of learning it, since they recognise it to be a necessity.

Nevertheless, social interactions between Latin-American traders and their neighbours from other ethnicities remain low, due principally to this lack of a common language. This is reinforced by patterns of spatial clustering, with the stalls of Black African, British Black, Black Caribbean and Indian (ethnicities self-defined by respondents to the questionnaire) mostly located on the north corridor of the market (Figure 10.8). Clustering has an impact on social activity patterns and the observations 
found that traders from other ethnicities tend to stay inside their own shops without going to the areas that are predominantly Latin-American. Latin-Americans also tend to cluster near the shops owned by people of their own ethnicity.

The obstacles created by language between Latin-Americans and other ethnicities are not always seen as problematic. Sometimes they use their poor knowledge of English as a conscious way to avoid unwanted contact. For instance, during the observations it was witnessed how occasional sellers come to the market offering their services, and some Latin-American traders use language as a way to build a barrier between them: instead of stating clearly their lack of interest, they reinforce their lack of knowledge, pretending to know less English than they actually do as a way to cut off any possibility of communication.

These findings suggest that language is performing a dual role in the market: on the one hand, it is becoming a major reason for Latin-Americans to visit Seven Sisters, strengthening a sense of identification with the community through the shared language. The market becomes a place where Latin-Americans can find relief from the sense of isolation caused by not speaking English, finding out that the barriers they face on a daily basis for their lack of knowledge disappear, enabling them to state clearly their needs and wishes without any risk of misunderstandings.

On the other hand, language is becoming a major factor of social distance, keeping apart the various groups of traders inside the market, and to an extent also keeps the market apart from its immediate surroundings. This situation is reinforced by a cycle that is rather difficult to break: Latin-Americans in Seven Sisters are surrounded every day by fellow LatinAmericans. Few or non-existent contacts with English speakers reduce their opportunites to learn the language and acquire the skills that would allow them to cope with everyday interactions with the host society.

\section{Navigating space, bridging difference}

Space can provide opportunities for navigating different cultures and their own system of meanings, bringing a physical sphere where diverse ethnic groups can bridge their differences (Hall 2012). It can also reflect or be the outcome of negotiations such as 'belonging to a territorial community, in participating in local decisions, and navigating the political landscape at multiple scales' (Rios 2013: 177).

In the market both aspects are taking place simultaneously. First, despite the barriers set by language and spatial clustering as mentioned above, the 
fieldwork found that the co-presence of different ethnicities in the same space is promoting cultural exchange and mutual cordiality on a daily basis:

It is a funny feeling having my business in this shopping centre, I enjoy the environment because I'm surrounded by Latin-Americans who use to be shaking and dancing. Now I do not imagine working somewhere else, since it would be rather boring. When friends come around they feel surprised by the loud environment and the way people dress - particularly the women, who can be a bit uncovered. Women from my country envy that because it reveals a freedom we don't have in our country. There's a strong sense of community and I have been welcomed in that community: I'm feeling like a Colombian. (African trader)

We don't talk too much with the Jamaican,4 but in spite of that we keep an eye on each other, we take care of each other. If something happened to one of them, we are there to help and the same thing happens the other way around. We are like a family. (Latin-American trader)

A second aspect of bridging difference has been the unforeseen consequences of the redevelopment plans for the market site that have meant that a variety of local groups, including the market traders themselves, have made common cause to defend Wards Corner building against plans for its demolition and redevelopment as part of a regeneration plan for the area. The challenge between the community and the local Borough Council of Haringey dates back to 2007, when the latter chose Grainger PLC as a development partner. In 2008 the council granted permission for a regeneration scheme, including the demolition of Wards Corner building, to be replaced by 197 new flats and retail space. Reading through the campaign documents as well as speaking to campaigners at the time shows that it was both a sense of association with the building, as well as the concerns raised by the possibility of losing it, that brought together local residents, community leaders and traders under the banner of the Wards Corner Coalition. Their purpose was to block the redevelopment plans, since it was felt they would result in a 'loss of customers, local identity, diversity and community contact with friends and family' (URS 2012). The cause achieved support beyond the market, engaging large numbers of people in actions such as the site 'hug', when people formed a human chain surrounding the building, to demonstrate their support for their own alternative community-led plan. Following a judicial review, the planning permission was reversed in 2012. 
A reading of this short history of a local campaign shows how the local community appreciated the building as an important place beyond its architectural value and role in Tottenham's history. What was clear was their recognition of the market as the source for the livelihoods and employment for many people, regarding it as 'an area of congregation and socialising for Latin-American and other ethnic groups, with strong links to cultural identity' (URS 2012: 55). The threat of demolition raised fears among local residents and traders: fear they would lose community cohesion and cultural connections for the wide ethnic diversity of the area, since the market is a place where interactions between different racial groups are taking place; fear of the loss of a social and commercial hub, particularly by Latino traders, employees and visitors; whilst market traders were concerned their businesses would lose customers if they had to relocate whilst the rebuilding was taking place; as well as concerns of traders that once the site was redeveloped, they would not be able to afford its rental rates, or to compete with larger and more stable businesses such as national chains.

Nowadays, the stand-off between community and developer remains. With a revised version of the plan, the developer gained new planning permission in July 2012. In April 2013 the council also granted permission for the alternative community plan. Although the granting of permission was an important step forward for the community, Grainger still holds their own permission, and an agreement with the council to use compulsory purchase orders to clear the regeneration area. Therefore, the threat of demolition persists.

In spite of this, the years of activism have raised awareness among the various local communities of what they can achieve by working together. They have enlarged and enriched the support to their cause, developing a variety of strategies to reinforce informed communal participation. Workshop consultations, weekly meetings and consultation in the form of posting planning proposals on the walls of the market for people to make their comments, have been the means by which local people from different backgrounds, community leaders and local project consultants exchange their ideas and negotiate their visions for the regeneration of the area.

The community has also started to work on the means by which they expect to build this vision. Guided and supported by a variety of organisations, the community has founded the West Green and Seven Sisters Development Trust, to ensure the long-term financial and political sustainability of their activities. 5

This cooperative work to protect Wards Corner is evidence of how the community is taking ownership over the future of their locality. They are 
building an alternative for the development of the area, envisaging a project which would embody the values, aspirations and needs of the diverse groups among the community. Throughout the process, they have negotiated their differences whilst founding a political space from which they have claimed, together, their right to build a place that radically differs from the authority's and planners' vision.

\section{Conclusion}

Previous research has identified concepts such as a 'sense of belonging' and 'place-making' as key points in the settling process of migrants. In her research on Brazilian restaurants in Tokyo, Zambonelli (2013) identified how place-making is associated with two kinds of activities: first, place as product, as the activities which by means of design produce a tangible site with particular characteristics. This might influence the second activity, place as process, which is related to reiterative activities such as inhabitancy, naming and discourse practices, and everyday routines, which happens in existing locations, transforming them into 'places of significance, memory, and attachment' (Zambonelli 2013: 50).

Retail spaces such as markets are some of the urban scenarios where these practices occur on a daily basis. Kershman (1994, cited in Botticello 2007: 13) suggested that local markets are a good way to see a different side of the city because each one reflects a different community ... [with each varying] greatly depending upon the communities which give them life'.

In this sense, it is possible to see how the spatial characteristics and daily sociality of Seven Sisters Market are a reflection of the cultural values that the Latin-American people working and visiting the market have brought with them. What Zambonelli has identified as a 'place as product' activity is perceivable in the ways Latin-American traders have appropriated the market's physical space, transforming its appearance with distinctive elements of their culture. Resemblances of their architecture, direct national references and the offer of ethnic products have contributed to creating a space where one can for a minute forget that the market is actually located in London.

These aspects have contributed to the transformation of the market into a major destination for many Latin-Americans across London, who see in it the possibility to engage with their culture on a regular basis. Through elements such as food, music and language, the market provides an immediate sense of familiarity, an emotional connection with the homeland. 
Simultaneously, it has become a social space where Latin-Americans can interact with their co-ethnics and find several sources of informal support, which helps them to ameliorate the struggles that life in British society implies for many of them.

In this sense, the market has acquired a significance that goes beyond its commercial role. The conjunction of cultural elements, networks of everyday sociality and support has influenced the multiple social dimensions taking place in Seven Sisters, transforming it into a sort of 'home away from home' cherished by many Latin-Americans. Indeed, some of them regard the market as a key piece in the construction of a Latin-American identity in London, since the richness, contrasts and contradictions of this community give the market a unique atmosphere.

In addition to the major significance Seven Sisters has acquired for the Latin-American community, the market, and the building housing it, have become a place of encounter for different groups and ethnicities, Latin-Americans included. On the one hand, the market has created an environment where, despite barriers set by language and spatial clustering, the co-presence of different ethnicities in the same space is promoting cultural exchange and mutual cordiality. On the other hand, the market has become a reason for the community to bridge and negotiate their differences with a common cause: defend it against demolition, due to its importance as a social hub and as the source of livelihoods and employment for traders and employees. To achieve this goal, the community has put in motion a variety of mechanisms, challenging the local authority's plans with their own vision of redevelopment.

The confrontation between the community, local authorities and planners happening in Seven Sisters Market offers an account of how the significance that the market has for the community is not recognised or even understood in planning terms, an aspect highlighted by Hall (2012, 2014) when she argues for alternative measures to quantify the value of ethnically diverse high streets. Indeed, community and planners totally differ about their appreciation of the Wards Corner building. While planners see it as a 'symptom and cause of the area's decline' (Seven Sisters Regeneration), the community see it as part of their history, as the home for small retail practices that give life to a vital local economy and to a diverse and vibrant cultural hub. Less visible aspects such as the attachment of the community with the building, or the emotional investment undertaken by Latin-American retailers in the construction of the market as a cherished destination for their community, are values quite difficult to measure but, still, they contribute to the creation of an already successful place, although it might not be what the planners have in mind. 
It is indeed a combination of aspects working at different levels that defines the success of the market. It has to do with the diverse identities and 'social milieus' converging in the market on a daily basis, but also with the multiple meanings these identities attach to it. Borrowing Hiebert et al.'s (2014) conceptualisation, it could be said that the market is being shaped by the diversity of its suburban locality; at the same time it is shaping this diversity and contributing to the configuration of the local social life. This two-way process is linked with the market's multidimensional character as a public and semi-public space. Whereas a person who goes there for the first time can experience it as a public space (Wessendorf 2010), for those who interact and engage within and with the market experience it is a semi-public space, a contact zone that creates a space for attachment and belonging.

\section{Notes}

1 The answers to the questionnaire were entirely confidential and anonymous. No individuals were identified from the answers given as part of the ethical approval obtained.

2 In these cases, the answers given by the interviewees were translated into English by the author.

3 The term 'Latino' is generally accepted amongst the Latin-American community in Great Britain. See e.g. their Spanish language newspaper, the bi-lingual Latino Times.

4 The term is the exact word used by one of the traders. It should be noted that 'Jamaican' seems to be the way this person refers to any of the Black African, Black Caribbean and British Black traders located in the market.
5 The Trust has four objectives: First, the promotion of the area as the gateway to the multicultural diversity of Tottenham. Second, the financial viability of the project, by acquiring, holding and managing assets, and looking for partnerships with investors and funders to finance the market. Third, the provision of support and training to the local businesses to improve their trade, as well as the provision of incubation spaces at the interior of the market for local startups. Fourth, the management of the indoor market and the public realm around it, providing spaces for the community and local artists to boost the market as a cultural destination. 


\title{
Chapter 11 \\ Being Suburban
}

\author{
David Jeevendrampillai
}

\section{Introduction}

Drive down to South London from the centre, through Dulwich and Crystal Palace, and suddenly you're leaving behind the cosy signifiers of middleclassdom in the shop names (Yak and Yeti Nepalese restaurant, Milkhouse Candle Co.) and cruising down South Norwood Hill, London SE25. It is not an attractive neighbourhood. The bank is boarded up. The Conservative Club has seen better days. At a Visitors Centre you find brochures that urge you, 'Walk Croydon into the Great Green Yonder' and 'Help Police Get Your Stolen Mobile Phone Back.' We're close to the vast cat's-cradle of train tracks that men call Norwood Junction - But the hill offers splendid views of London - you can imagine people coming here for a glimpse of the sublime, 150 years ago.

(Independent 5 March 2013)

This piece from a national newspaper is not atypical of the sort of coverage given in the press for suburbs. But something else is going on in the prosaic suburbs of London. I am not talking about getting your phone stolen, or the twitching of net curtains but something that is quite frankly rather absurd and, as I will show, quite nonsensical. In South Norwood, an area of south-east London, the self-proclaimed 'South Norwood Tourist Board' (SNTB) has declared that they are the true inheritors to the title of 'The Lake District' (an important tourist area in northern England) and have written to the Lake District Authority to tell them so (SNTB 2013). In recent years they have had parties for tunnels, festivals for Pickles the dog and a referendum on whether they should join an independent Scotland.

The use of nonsensical behaviour and practice is not isolated to a single corner of 'forgotten London'; move from the south-east to the southwest of London and you will find yourself in Surbiton where, over the course 
of the year, you can experience nearly a dozen events celebrating Lefi, a half-goat-half-boy creature from a mythical past. Events include the annual Lefi Day remembering 'the spirit of Lefi', a parade celebrating fresh-water sardines involving the ritual fishing of said sardines from the River Thames and their pulling to shore by four giant Guinea Pigs of the Apocalypse, a Suburban Skiing event and other wonderfully bizarre happenings. Whilst in Walthamstow in north London, otherwise known as 'Awesomestow', Walthamstow's Unofficial Tourist Board regularly update a Facebook profile with images of the lives of the area's 'matri' (the plural of mattress) - which, of course, have their own lives - and encourage others to post images of matri getting up to no good on their site. The Unofficial Tourist Board has released calendars which compare images of the matri in Walthamstow's alleys and back streets with the fashion choices of celebrities such as the Duchess of Cornwall and Lily Allen, the celebrities supposedly being influenced by the matri (Walthamstow Tourism 2014).

So what is going on? Over the course of this chapter I argue that this silliness is more than 'just a bit of fun': through being daft or nonsensical these groups are in fact showing a deep love for where they live. I will show that these groups are aiming, in some of the most creative and nonsensical ways imaginable, to re-conceptualise what it means to be in the suburbs, re-casting them as fun, creative and enlivening places to be. In doing so there is a lot of silliness, play and nonsense reminiscent of the satirical styles of Lewis Carroll or Edward Lear. This nonsense, however, is productive; it produces new forms of relations in terms of how people relate to each other and towards the suburbs themselves. By highlighting the distinctiveness of particular suburbs in this playful way they focus attention on the particularity of places that goes beyond the socio-spatial imaginary of suburbs, which typically views them as a place on the edge, in between and everywhere the same.

I begin by outlining the common 'cultural imaginary' of the suburbs as a dull, lifeless and soul-destroying realm which sets the context for the activities of these suburban groups. This context is what Wagner (1975) might call a 'controlling context' in that the dominant discursive frames of what the suburbs are and what life can be found there set the tone of the conversation which the enthusiasts enter into in order to both develop and change common perceptions of the suburbs. Further, the cultural imaginary is understood and used as a toolset through which the creative interventions of local enthusiasts reflect back an image of the suburbs where life not only survives but thrives, where communities are strong and where 'local' comes to mean something. I argue that activities such as the crafting of fish puppets, the re-imagining of the lives of matri and the making of outlandish claims of independence bring 
people together and re-arrange relationships of people-to-people and peopleto-place. In so doing they actively draw out new potentials from the social and material landscape of the suburbs, re-imagining not only what it means to dwell there but also articulating a new form of socio-economic being. I will suggest that the use of nonsense is part of a 'not this, not that' position (Jeevendrampillai 2015'), where these local enthusiasts not only reject the common cultural imaginary, the monadic 'good worker' stereotype and the suburbs as cultural wasteland ('not this'), but further reject the abject liminal position of rebel or revolutionary that comes with discourses of refusal ('not that'). Rather they take a 'not this, not that, but this' position where the common sense of what should happen in suburbs is played with so that it makes no sense (is nonsensical) and in so doing produces a new, or renewed, sense of local. This local is based on play, fun, trust and familiarity and through relationships of a personal - more than economic - nature. I suggest that through the use of nonsense local enthusiasts are taking ownership of both the image of their locality and the process of producing localness and local selves through local relations, thereby laying new possibilities for alternative, but recognisable, forms of society and economy. In this sense the local enthusiasts assert their own vision of being suburban that neither accepts the dominant ideas of what a suburb is or what happens there, nor radically differs from it. Rather they adjust the narrative, play with stories, histories and ideas and suggest new possibilities for what a suburb is on their own terms.

The economic value of the material spaces of the suburbs stems from spatial as well as non-spatial characteristics of place. The high street might still be the best place to locate a coffee shop for example, but if the shop owner wishes to be socially as well as spatially integrated locally, they need to provide different forms of social value to those of a non-local coffee shop. The act of buying a coffee from a socially integrated coffee shop helps to form trust, familiarity and reciprocal social purchases within the locality by virtue of its providing local social connectivity. A recent rise in local currency apps such as the Kingston Pound ${ }^{2}$ are the most clear example of how localism can manifest in particular forms of economic exchange, but I want to suggest that it goes much deeper than that. Being local is not simply a spatial action, but makes the most of spatial opportunities and further allows those spatial forms to endure.

\section{The image of the suburbs}

Parades about mythical creatures, a culture of matri and suburban skiing all sound like a lot of fun, and they are, but at their heart they belie the 
popular cultural imaginary that goes with being in a suburb. This common perception would state that the suburbs are boring; the heart of middle England where nothing happens. Despite the fact that around 84 per cent of the UK population live in suburbs (Vaughan et al. 2009a), they are still seen as places 'where the life of the mind curls up in front of the fire in a comfy pair of M\&S [Marks and Spencer, the stereotypical middle-class chain store] slippers' (The Big Issue 1999, 22 February: 16-17). They are places with an interstitial identity, neither escaping the crush of the city nor thriving in the idyllic green openness of the English countryside, they are a mundane blend, and with their archetypal mock Tudor vernacular they are everywhere and nowhere at the same time (Mace 2013).

Surbiton, where I did the majority of my eighteen-month ethnographic research, is perhaps the pinnacle of the suburban image; it even sounds like suburb - 'Suburbaton' (London Evening Standard 2012, also The Big Issue 1999). In 1995 Liverpool City Council 'seriously considered adopting "Liverpool - it's not Surbiton" as a marketing slogan' (Statham 1996: xiii cited in Wickstead 2013). The ordinariness of Surbiton, which stands as a synecdoche for 'suburbs', can be harnessed and politically deployed as an image of middle England, the home of the ordinary 'good worker'. As Helen Wickstead highlights, the 1967-8 'I'm Backing Britain' campaign, where 'five girl typists at a factory in Surbiton' worked 'an extra half-hour a day without extra pay' (The Times 1968: 1 cited in Wickstead 2013), rolled into a national campaign dubbed 'the Surbiton Revolution' (Economist 1968: 12 cited in Wickstead 2013) and provided an alternative image of an ordinary worker to the public in an era of unionisation. It is this idea of the detached worker ideal removed from the community, loyal to family and employer, fitting neatly into a dominant socio-economic paradigm and void of creative rebellion that plays into the notion of a suburban death. It is this threat that forms the imaginary of the suburbs. When 'The Good Life' sitcom was written in the 1970s, to portray the apparent absurdity of a middle-class couple deciding to go back to basics in their back garden, it was perhaps inevitable that Surbiton would be its chosen setting.

In 1999 The Big Issue magazine ran an editorial feature, 'I Want the Good Life', with the sub-title 'Bland. Boring. Banal. Everything You Think You Know about Suburbia is Wrong says Jim McClellan and to prove it, he's moving to Surbiton'. The magazine professed to be surprised that there was actually 'life' in the suburbs. The assertion of life in the face of the cultural image of suburbs came across again and again in my fieldwork, as Rani explained to me whilst we got to know each other during the crafting of a giant wicker lamp ... 
I'm Surbiton born and bred, I've been away for a few years and I moved back again. ... I used to think the place was a boring middle-class, middle England conservative town. ... When I came back I heard about all these strange happenings ... people skiing down the road and all that.

The suburbs then, with Surbiton their imagined ideal, have a firm place in the cultural lexicon as the home of middle England. As Benedict Anderson (1991) notes, the imagination can be a powerful cohesive device in the formation of collective identities. Against the background of the events in Surbiton, a cultural imaginary of a dystopian suburban subject frequently emerged during conversations. People talked of 'never having expected to live here', meaning they never expected to live in a boring commuter town. But then they would paint a new picture with a tone of 'but ...', saying 'we have great friends here' and describing 'a real sense of community'. Underlying such conversations was a sense of the idea that, if left alone, the suburbs would fulfil a media-fuelled, culturally imagined, prophecy of being void of character and life. The suburbs are understood as a cultural terra nullius, an anthropological desert.

The suburban imaginary (see Silverstone 1997) provides a background against which an analogy of the exotic, rich anthropological 'other' - as in over there and interesting - can be imagined in order to highlight the position of suburbs - as here and banal. These two 'worlds' were juxtaposed in a sketch by the famous English comedians Monty Python (episode 28, BBC1, 1972) who recreated the anthropological investigations of the Norwegian explorer Thor Heyerdahl. Recreating a journey by the Kon Tiki raft that Heyerdahl sailed across the Pacific Ocean in order to test a hypothesis that people from South America could have settled in Polynesia, Python satirically parodied the journey made by the characters of Mr and Mrs Norris.

Moving from Surbiton to Hounslow, Mr Norris finds similar mock-Tudor vernacular housing and common lawnmower technology, decreeing that the 'identical cultural background' must mean the areas are linked through a historical movement of populations, but that people moved not from Surbiton to Hounslow but rather Hounslow to Surbiton. The sketch is funny due to the silliness of the claim, which makes an analogical connection between the movements of the distant, unknown and historically rich South Pacific islanders and the known, close, historically vacuous London suburbs. It is funny because what could be less adventurous, less exotic, than the suburbs?

The suburbs are portrayed as being without history, without heritage. As Wickstead (2013) notes, this is their heritage, and this non-heritage as heritage is recognised and played with by the groups described above. Whereas mainstream TV comedy and satire play on the notion of a suburban terra 
nullius at the expense of the lives in those suburbs, in the events I witnessed in South London people take ownership of these cultural imaginaries, build on them and change them by showing what it is that they are and, importantly, what they are not. In so doing they create a suburban world that takes its dullness and pushes its discursive limits to the edge of sense. It plays with histories, stories and 'that which you expect to find' until you get that which lacks the common sensibility of what a suburb is. It makes it nonsensical.

\section{Re-imagining suburbs}

Walthamstow will never be a hot-bed of celebrity spotting, but it is full of mattresses, or 'matri'. South Norwood will never be the lynchpin in a collective identity to the extent that it can claim independence, but by inverting the relation, a nonsensical claim arises which draws attention to the particulars of place and re-frames the banal in a celebratory way. If suburbs are imagined as a cultural desert, void of history, then that is their history, and furthermore, the banal stories, freshly created legends and myths prosper in the gap left between the cultural imaginary of suburbs and the potential of re-imagining place. As Jon, a key member of the SNTB, explained when I asked him about the name 'Tourist Board':

We booked a room in this pub near the Tower of London. When we got there at half seven at night they had put little signs on the tables saying 'reserved for South Norwood Tourist Board' and it's one of those pubs that lots of bankers go to before going home you know ... they had hung around to see us and they were like 'that's a laugh isn't it, there's nothing to see there, it's Croydon and all that' and they got into a really animated discussion with us. If we hadn't of used the word tourist board well ... it's a hook to bring people in you know, because you know they are going to say there is nothing to f---ing see there is there!

We show people that [refers to the story of Pickles the dog] and they think, 'f---ing hell how did you make a story out of that?' It's about making the common place uncommon ... getting people to see things they don't normally see. See things they walk past a hundred times a day and getting them to see something they don't usually see, getting them to see things in a new light which makes them feel differently about the area, it's about people taking pride in it like ... it's not like 'look at this, this is a shithole like'. 
By playing with the common imaginary of suburbs, the historical authority to narrate place and the idea of officious tourist boards, local enthusiasts are taking possession of the image of their suburbs. These groups take ownership of assertions of what the suburbs are like: South Norwood might not be 'an attractive neighbourhood' to a reporter, but it is a fun one to the SNTB. Surbiton might not be Liverpool, but maybe Surbiton's Lefi and Liverpool's own mythical Liver bird know each other? In their assertions through nonsense stories and fun events, people in the suburbs demonstrate a humble pride in the suburbs.

This playing with common images of suburbs, governance and myths work to remake alignments of emotion, fun, excitement, pride and joy with the very real corporeal being within the suburbs. These alignments are a form of what Yael Navaro-Yashin (2012: 11) calls 'conceptual crafting', where the imagination is put to work through the circulation of images, the ways relationships are formed, how spaces are understood and used and a wide range of material everyday practices that go towards building both a lived experience and a popular idea of the suburban place through new associations and links.

In his work on urban exploring, Bradley Garrett (2013) uses the term 'Edgework' (see also Lyng 1990) to describe the ways in which the urban explorers he follows push at the boundaries of what they think their bodies are capable of doing, where they can go and how they can interact with the city. He then describes the ways in which new relations between bodies, buildings, streets, the city and its rhythms are forged. In so doing the constellations of power, subject, personhood, rights and the sense of belonging are reworked. He calls this reworking of relations and of the self a process through which subjects become 'the meld'. In a similar but less dramatic way, a comparable reworking of relations occurs in the suburbs through the events described, creating a particular suburban, local, sense of being and melding new places and new subjectivities. However, where Garrett's subjects are self-declared liminal subjects working at the edges of the city, the law and themselves, the suburban enthusiasts are working in a slower, less dramatic arena, but nonetheless are involved in the process of 'melding'. That is, in suburbs such as Surbiton, South Norwood and Walthamstow, through puppets, parades and other such activities, a reworking occurs where a particular sense of local person and local place co-emerge. These activities and events, I suggest, are more than nonsense but are a key part of the reworking of relations between suburban spaces, people and businesses that create new forms of being local.

Borrowing from Navaro-Yashin, the next section will work through how 'conceptual crafting emerges from the tangibility of the field' (2012: 11) in 
that through crafting nonsensical events, relations are opened up to be developed, and this process is inherently material. That is, through aesthetic interventions of puppets, by using public spaces in new ways, or merely cloaking them in a discourse of mythical history of political significance, new affective experiences can occur, laying the way for new feelings, emotions and relations to flow from people-to-people and people-to-place. Affect here is understood as a bodily capacity prior to cognition or emotion, is always interpersonal and is un-representational (see Pile 2010). According to Gilles Deleuze and Félix Guattari (1987: xvi) affect differs from emotion in that it is more the capacity to be affected, to be moved, to be influenced in your state of being for a change to occur as opposed to the production of a specific, emotional state which is able to be represented. In this sense the capacity of nonsense to produce a disposition, a change in a person in that which is considered possible, is what I wish to draw attention to. Through nonsense events and creative playfulness, these groups break the normative habits of the suburbs. They break the rhythm of the streets, the things that are seen and heard, the relationships that are made and the very notion of what a suburb is, giving an opportunity for new states of being suburban to emerge. Through dancing in parks or parading down streets, new ways of thinking, feeling and relating are opened up. An ability to 'conceptually craft' the suburbs emerges with the forms of what it means to be suburban radically reworked. It is this process of suburban 'melding', of breaking down common perceptions of what suburbs are, what happens there and who lives in them which is described in the next section.

\section{Living in Seething, a place that is not a place}

I once heard it said in the corridors of the UCL Anthropology Department that most of an anthropologist's career is spent trying to understand the first two days of fieldwork. In my case, the suburban London field site was, I thought, a familiar one both from experience and in the memory bank of my imagination. As part of the Adaptable Suburbs project, both South Norwood and Surbiton were predetermined field sites for my anthropological enquiries - they had been randomly selected as part of a wider spatial/morphological study of London's suburban evolution. In trying to find people in Surbiton to talk to about the changing landscape of the high street, I heard of a group of people putting on a series of events, parades and festivals. At the local archives I found a flyer which told me the date, time and the occasion of a parade to remember the 'legend of Lefi Ganderson'. 
I later discovered that Lefi Ganderson was the central figure in the Seething stories (Hutchinson 2010a, 2010b, 2011, 2012). Emanating from a cheese club in the local pub, over time his story had evolved, changed and branched out into all aspects of Surbiton/Seething life. The core of the Seething story was based around Lefi, who being half-boy-half-goat was ostracised from a village called Seething. Lefi lived in a cave at the base of a mountain on the top of which a giant, the nasty Thamas Deeton, lived. Nobody would talk to Lefi other than the Children of Seething, who would bring him food and play with him. Every year Thamas would come into Seething and terrorise the Seething Villagers until one year, Lefi, seeing how frightened this made the Villagers, tricked the Giant into leaving. By passing milk through a ring again and again, Lefi was able to make cheese and fulfil the bet he had made with Thamas that he could live for a whole month on only the food that would pass through that ring. Keeping his promise, Thamas fled from Seething, destroying the mountain as he left.

Every year Lefi, who 'taught the Seethingers how to love and the spirit of doing things for others', is remembered by people who call themselves the Seething Villagers (Figure 11.1). The term Seething has origins in the history of the area of Surbiton relating to a name found around a spring area near the river in Surbiton. However, the term had largely fallen out of common usage. Using Seething rather than Surbiton as a collective name for events and the community allows a sense of belonging beyond traditional residential or kin links to being local. This is where we find the origins of the Surbiton/Seething divide in this chapter. Seething, as the T-shirt seen in Figure 11.1 states, is a 'state of mind' which is based around togetherness, fun and happiness. This state of mind brings about the Seething events through which it is spread, shared and enjoyed.

Through this 'state of mind', ethical commitments to others, love, trust and time are shared in ways that allow new potentials to emerge from existing relations. The spaces of the suburbs, the streets, the parks in Surbiton, the lake in South Norwood, the abandoned mattress in Walthamstow can, through this 'state of mind', function as places of festival, produce smiles, humble pride and allow a fun walk down the street. During my ethnographic fieldwork in Surbiton I saw people mingle, meet and forge friendships; I saw people try new crafts, foods and hobbies; I saw others turn hobby crafts to occasional trade and small trade to business; I saw new businesses establish themselves in the community; I saw people choosing to support local shop owners who they met at the events and I saw people say 'hi' to others they passed on the high street. People were remaking place, which was remaking people. These observations point to the fact that being local is more than being co-present on a spatially integrated local high street. Rather than 


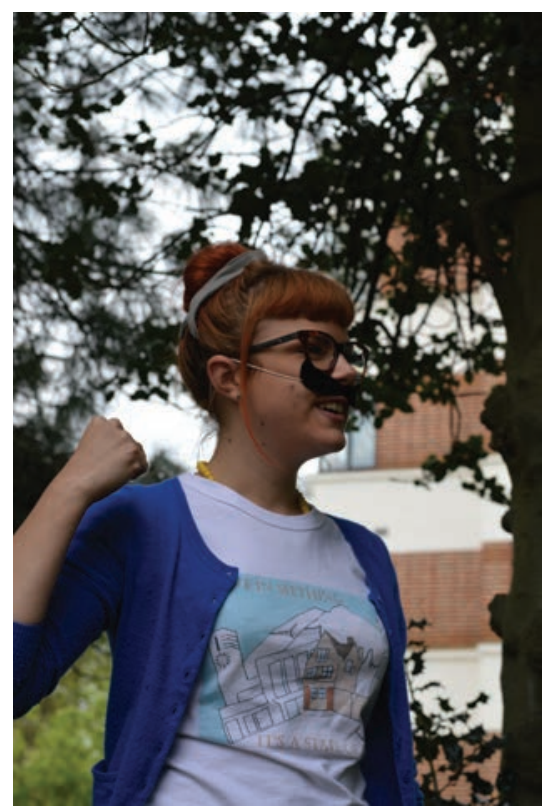

Figure 11.1

Seethinger wearing an 'I live in Seething'

T-shirt. Her own design

David Jeevendrampillai.

constituting the 'possibility of social interaction', as space syntax notions of co-presence suggest (Chapter 2 in this volume; Hillier 1996: 212-14), being co-present on a socially integrated high street means that the pattern of everyday interactions reinforces a sense of being local and sharing community values so the spatial and social patterns effectively strengthen community ties over time.

\section{The Seething events}

Let us return to the pub and these first few hours of fieldwork. After getting no response from an e-mail I had sent to the address on the flyer, I ventured to a pub a couple of weeks before the main event to attend a 'craft day'. I made my way to the back of the almost-empty beautiful old pub and into the garden, which was thronging with people sticking paper to wicker and wicker to other bits of wicker. Basking in the February sun, giant lamps (see Figure 11.2), cheese sculptures, giant heads and other Seething symbols were taking shape. I had not been stood there long when Rani thrust some glue and crêpe paper into my hand and before any of the usual questions, 
such as 'hello' or 'what's your name?', asked 'ever made a giant wicker lamp before?' - I had not, but by the end of the day, I had.

Over the course of the two weeks leading up to the event not only had I helped build giant lamps, I had built a stage, helped set up a sound system and met a huge number of friendly Seethingers in doing so. On the day of the parade I asked Steve about the history of the guild banners that were lying against a wall ready to be taken on the parade. He explained: 'Well there is the Cheese makers, the Couriers who aren't here yet, the Sardines, the Water Bearers, the Talcum Men and the Bats.' I asked 'are they based on happenings in Surbiton, I mean are they based on historical fact ... or'; Steve responded 'well ... the fact that the first cheese made in Britain was made in Surbiton, that might not be based in truth, but the bats - well there are endangered bats in the wetlands so we hope to bring attention to that. The talcum men, well ... the sardines .... I interjected: '... there is a river here ...'; 'you're getting it' said Steve before walking off, and I was not sure if I had just hit upon historical fact or made myth.

The guild banners are funny, daft or nonsensical, as they resemble the symbols of unionised labour, or more accurately for this part of London, the traditional workers' guilds such as those found in Kingston, the regional centre of government; however, they could never be those things. Surbiton

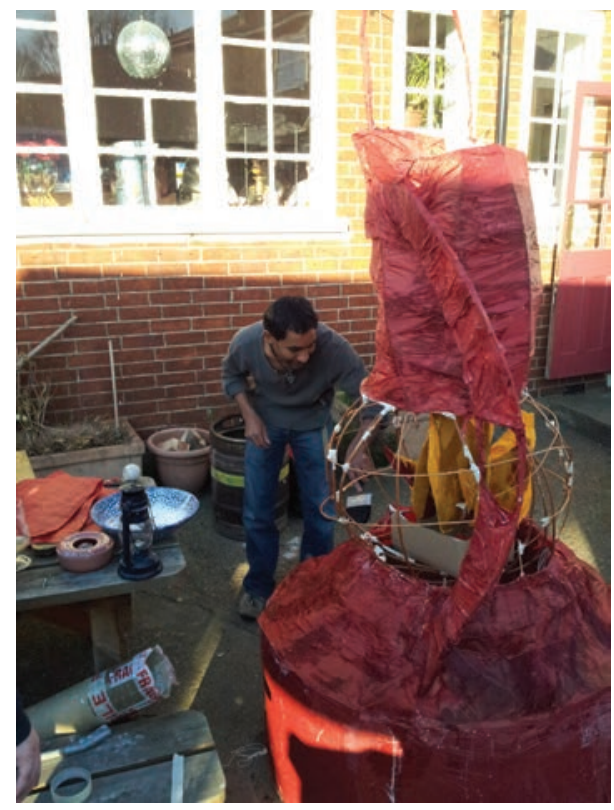

Figure 11.2

Making a giant wicker lamp

David Jeevendrampillai. 
is too small, too provincial, too ... well ... suburban. Having the banners, or a referendum on independence (in the case of South Norwood), or a deep mythical history, highlights that which they could never be. By bringing these things into relation with themselves, these groups of suburban enthusiasts show what they are not trying to be, but through the spectacle, the humour and the self-declaration of their suburban position they take possession of the symbol, of the suburb and of themselves. They are neither the culturally imagined suburban figure set up for ridicule in mass media and mainstream intellectual comedy, nor are they the self-declared separatists or rebels living on the outside of society's limits; they are neither this nor that. In fact they are something else, and this something else is a different idea of how interaction, economy and being together in suburbs should and could work.

Where they could, people pulled on their resources to help, from sticking bits of paper, handing out flyers or working alongside the council and local businesses to get space and facilities. Over the course of my fieldwork I saw all sorts of businesses and people help in various ways. The local branch of the supermarket chain Waitrose froze the blocks of ice for Suburban Skiing; the Council loaned fences to use in the parks; and local coffee shops and pubs provided space for meetings. The meetings were always open and advertised for all to attend on Facebook. They took on a positive and creative spirit in which everyone could have a role and equal say. People were encouraged to get involved in any way they wished, the events would always happen one way or another and were always, in the words of Steve, 'brilliant'. Brilliance was the word chosen by Steve during an interview for a local television company, where he stressed the fun and energising nature of the events and further the way in which the organising, partaking and involvement in the events gave space for people to shine.

The many Seething events took different shapes and forms but they would often involve a parade and/or a small festival in a local park. During the Lefi parade the procession was led by a $12 \mathrm{ft}$ tall Thamas placed on a Segway, which would be manoeuvred at speed towards passers-by and car drivers (see Figure 11.3), radically disrupting the everyday rhythms and aesthetics of suburban streets (see Lefebvre 2004; see also Hubbard and Lilley 2004). These moments of aesthetic and material intervention display the hours of craft and care that have gone into the symbols of Seething; the guild banners, giant wicker cheeses, man-size sardine tins, music that fills the air as talc miners parade their 'traditional colliery band', drawing on the history of the UK's mining movement. Volunteers ensure the crowd stay safe, halting cars and thanking the confused onlookers for waiting (see Figure 11.4) - though few complain. Some ask as to 'what's going on?' 


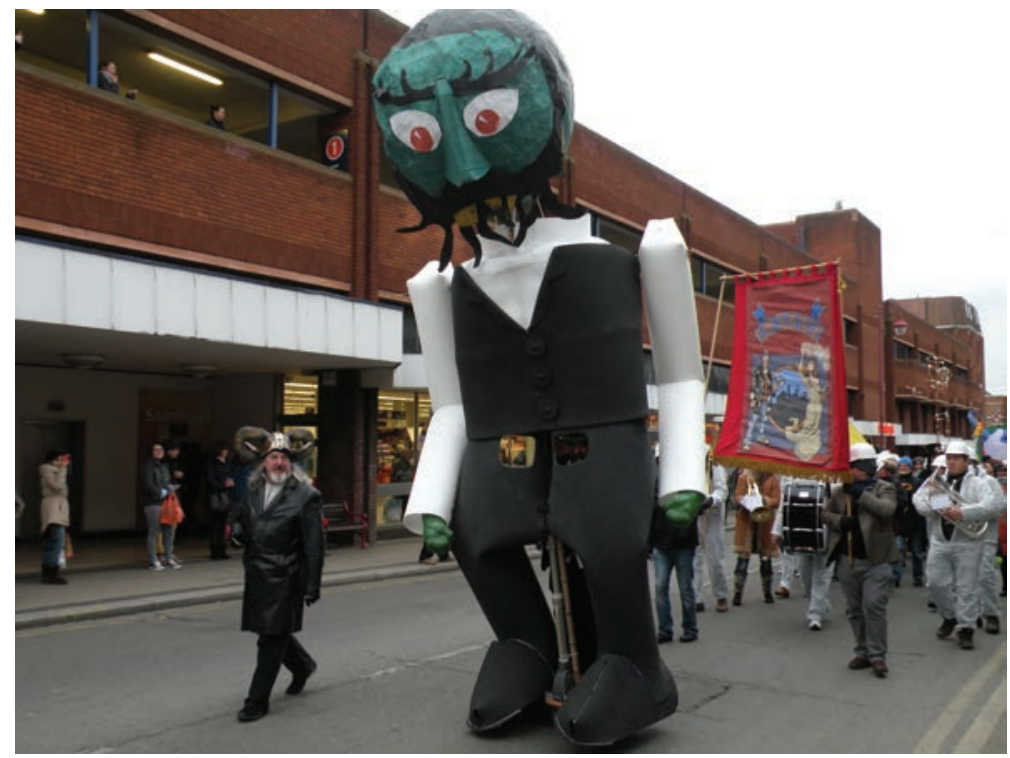

Figure 11.3

The Annual Lefi Parade fronted by Thamas Deeton, the giant of Seething David Jeevendrampillai.

and others sound their horns or boo the Giant, clearly already in the know. The tale is well established in the area, not just through such events but also through book readings in schools and local stores. As we walked, the Deputy Mayor commented on how nice it was to walk through the centre of the street, traffic slowing, with music and banter allowing a very different experience of place, momentarily turning the order of relations between people, streets and traffic 'upside down' in a carnivalesque moment (see Bakhtin 1984; Strathern 1991; Povinelli 2011).

During the parade Bret and Alton discussed if they should hand out flyers to explain Lefi, Seething and the parade to people. On the one hand, they wanted to bring people in and explain the origin of Lefi, Thamas and the giant sculptures, but on the other hand, they both agreed that a flyer would leave people looking down at a simple answer on a piece of paper. What they wanted was an unfinished answer - Seething could be whatever you wanted. Here relationships were to be built: the acts of discussing, enquiring, researching or joining the parade were the start of this process. Quite simply you had to get in there, talk to people, in person. I was starting to see why my e-mail had gone unanswered.

In the parks where processions end, local bands perform, a bar provides drinks and food and craftsmen and small traders set up their stalls. 


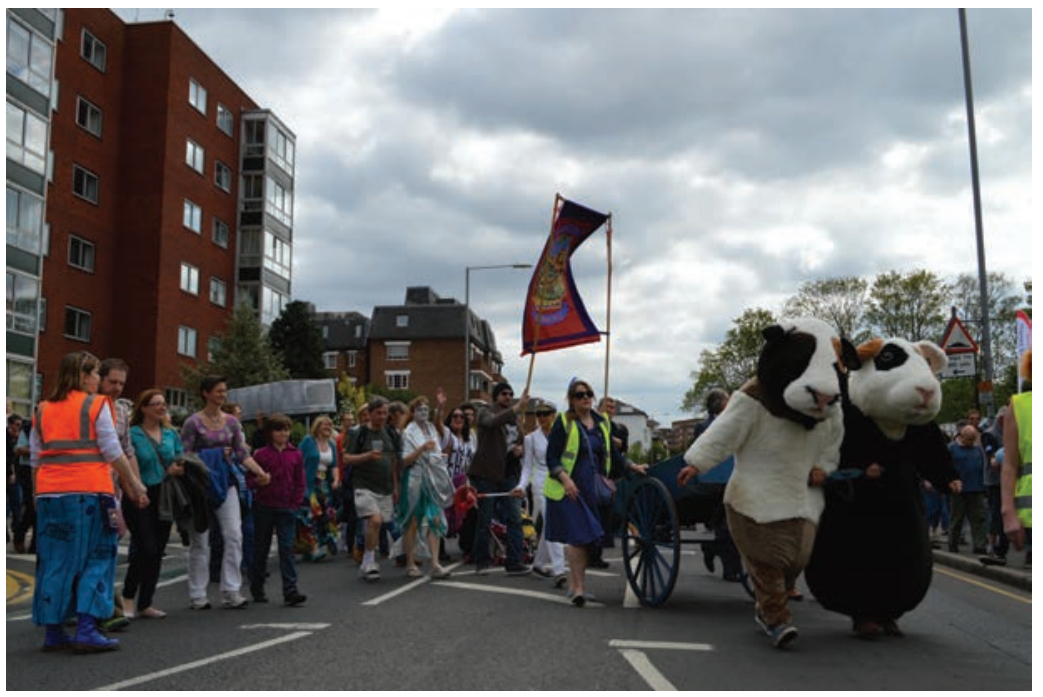

Figure 11.4

The Sardine Parade stopping traffic whilst moving from the river to a local park David Jeevendrampillai.

Dancing and drinking go on until late afternoon when the numbers dwindle and a large crew stays behind to clean and pack up. It is during these moments that people ask each other's names and why they are here and get to know each other. Notably people do not focus on if you are local or not, it's taking part that counts here. The cleaning and caring of the spaces in which the events occur affirms the spirit of togetherness, and bonds of trust and familiarity that are formed by working together. In so doing a moral position of 'community' - of co-commitment to each other and, further, to the spaces themselves - is produced. New assemblages of people, place and emotion are being crafted, shared and experienced, or as Garrett might say, 'melded'.

These melds shape not just people, but also places in how they are used, understood, remembered and valued. As the Mayoress of Kingston stated at an event staged at a local park called Claremont Gardens: 'Claremont Gardens' moment has arrived ... it has been waiting to have its moment for around 100 years and it has become a new home for Lefi'. A conscious effort had been made to meld with the underused spaces of the suburb; grass is worn thin and memories, attachments and emotional bonds made. Well after the event, Zoe, a Seething regular and keen volunteer, told me that she would often take a longer route through the park so 
she could remember being there. 'Until that event' she says 'I hadn't walked through that park, now I walk through it every day ... it's one of my favourite places now'. The shortest or most spatially integrated route is not the most desired in this instance. Instead, the social significance of place comes to be a factor in choosing which way to walk through the area.

\section{After the event}

Towards the end of my fieldwork I met with Rachael, also a regular Seething Villager, for a long lunch. Having recently been made redundant from her job in the arts and subsequently becoming self-employed, she explained to me that the sense of trust and familiarity the Seething community provides gives a base from which people feel that there is 'support' and opportunity to try new things. In her consideration of what to do next she 'refused to get a job she was bored with' and felt if she did not set up her own business now she would never do it. Because of the Seething attitude of doing and the support of the Villagers she was able to ask herself if she had 'really given it a go yet or am I just sat there scared?'.

For Rachael, she was at a point in her life where she wanted to try making a living spending her time doing what she wanted. For her 'doing what she wanted' was curating art events, developing craft skills and teaching others. The Seething events had allowed her, in her own words, to 'discover I am good at stuff', such as organising and running events. She states 'for me getting involved in Seething is the first time I have felt like I belong for probably the first time in my life ... I have been able to be myself and become a part of that group'. Seething enabled a flexible arena of being suburban where skills can be used to maintain a lifestyle that in itself shapes the nature of what 'work' is. In moving away from a notion of 'work' as antilife, as monadic commuter, as suburban and exploitative, Seethingers move towards a notion of work which is productive of the self, of an ethical plane and of others.

Trying and failing is seen as a part of the condition of expanding beyond what you think is possible. The conditions for this involve re-arranging ethical commitments from the imagined dull and lifeless world of a suburban commuter to the more life-giving commitments of the local and corporeal Seethinger. This commitment to a network of trust and familiarity provides the resources 'to give things a go'. The invention of nonsensical events, stories and so on is a demonstration, a showing, a bringing-to-the-fore of that which is possible, and a commitment to each other. It might not be immediately measureable in the traditional sense of what walking down a 
high street may produce in terms of spending, shop footfall, how busy the high street is and so on, but in doing things for the fun of it a community 'that allows people to be brilliant' is developed - one where new 'meldings', new possibilities, can occur.

\section{Local communities}

The ability to 'try things out' manifests at a variety of scales and locations; people can try crafts, play music, expand a hobby into a small business or a small business into a larger business, all the while drawing on and responding to community support. During the course of my fieldwork, a huge range of local businesses became involved in the events, from a pub that regularly lends space for storage, meetings, activities and after parties through to the person working from home who started setting up stalls at an event. All manner of businesses would get involved, but where profit is the usual barometer of business activity here the main motivation was commitment to a form of work that promotes a happy lifestyle and to businesses that contribute to a sense of well-being in the community. However, whilst present indicators of high street success, such as building occupancy, may struggle to show it, 'successful businesses' and ones that contribute to the community are not mutually exclusive. As a prominent local business leader explained to me during the Seething Community Sports Day whilst chatting about traditional high street traders:

They don't see the benefit of doing things like this, they have to get the marquee, invest in the banner, spend a day down here so get someone to cover their shop ... what they don't realise is that whilst they are sitting there they might get one or two people walk in off the high street but you can't run businesses like that anymore, you have to get out there, engage with people, make the market for yourself ... we see this as networking really ... not only that but getting involved in the community, knowing the customers, we live around here too, we want it to be a nice place to live.

At the Sports Day a huge range of traders would set up a stall; many would be regulars, such as Amanda and Anna who sell beauty products and gift cards, both of whom usually work from home. Often there would be new stalls such as Pickled Pantry who set up at the Sports Day in order to have a presence in the community before they opened their shop near the train station. Over the course of the fieldwork Pickled Pantry would be involved in 
many events, from arranging picnics after cycle rides to providing space for meetings. Traders would enter into a symbiotic relationship with the area or rather the lines between being local and running a business were blurring. They are the area, they are local. Throughout my time in the suburbs my informants and I shopped local, that is through the people and in the places they get a good feeling from, where relationships mattered, where buying a coffee was more than a mere transaction, it was local.

In recent years in Surbiton a local food festival has established itself with the aim of promoting Surbiton as a place to eat, source and grow food. In promoting Surbiton in its own right, against the backdrop of its bigger neighbour Kingston, local enthusiasts have spent many hours volunteering, working with local businesses and developing networks of traders, volunteers and friends (Surrey Comet, 12 May 2014). Whilst many of the volunteers are the same as those involved in the Seething events, the name Seething was dropped from the food festival as the emphasis moved towards a more outward-facing advertisement of place and an inclusive celebration of 'what Surbiton has to offer'. The inventive stories still featured, as in the Sardine Parade and the 'vegetable that looks like a celebrity' competition, but my point here is to draw attention to the way in which large-scale events, which promote all range of business, are able to come together because of the development of a community with strong networks based on familiarity and trust that have been harnessed through creative, fun and playful interventions. These acts have no prior condition of needing to produce something useful in any way that might be immediately recognisable or measurable, such as an economic output; it is nonsensical and fun, it just is what it is. In this sense it allows a way of being together which is open to new meldings of people and place occuring, it allows a new enactment of what a suburb is or might be to emerge. Further, it does so through playing on the cultural imaginary of suburbs as mundane and boring that so often clouds the suburbs, taking them to their limits (see Boyer and Yurchak 2010), suggesting independence or re-creating ancient myths, and as such undermining those very ideas and images, allowing new ones to be built up.

Through events such as those in Seething/Surbiton new spaces of the suburb are brought into use, people meet each other, businesses change their orientation, as do local shoppers, but all this takes work. These spaces, this work, may not always be visible or understood in terms of the value they produce - not just in economic terms but in the way they produce a way of life, a sense of community and particular ethical sense of being. In the concluding parts of this chapter I want to show how the bright picture painted above hides behind it a whole body of hard work, stresses and strains, and I suggest that this tension may become less 
harmful if the recognition of the complexity of suburbs and what people want from them is brought to the fore of thinking of how these places are made and could be made.

\section{Conclusion}

Surbiton has a well-used and active high street, and Steve, a Seething regular and active volunteer, would frequently engage with projects to support the high street as a locus of local economy. Steve told me of the ambitions he had to 'get hold' of a shop for community use and how he had talked to the local council, local business leaders and landlords. Steve and other Seethingers wanted to take over a shop on a temporary basis and use it as a base to promote Seething events, small businesses, craft workshops, local traders and so on. This is a common idea in urban regeneration and examples of success stories are easily found on social media and in London news (see also Rietveld and Rietveld 2014 for inventive space re-use.) This idea of re-use came up repeatedly during my fieldwork and almost every time I walked past one of the few empty units on the high street people would ask 'why can't we just get in there ... even for a few months?'. During my fieldwork this never came to fruition; Steve told me how he had made 'great efforts', but bureaucratic restrictions 'got in the way'. He kept much of this knowledge to himself, or at least aimed to minimise the negative or draining aspects of the conversations, only passing on positive and productive information in Seething meetings.

Steve's commitment to the 'local' as a place of inclusivity, positivity and fun meant the stresses and strains of the effort needed to acquire resources would often stay with him or at least not disseminate outwards to other Seethingers. Only towards the later stages of fieldwork, when we got to know each other better, did he explain the ways in which he struggled with aspects of the conversations with other locals: he talked of his trouble with 'the way some people are'. Steve was trying to make a better world, but having to sacrifice aspects of himself; it was tiring, but worth it. Rachael and Zoe had also mentioned similar things. In a sense the care of the self for the self (following Foucault, see Rabinow 1986) was being sacrificed for the self for the local in order to produce a self as local. This self as local is maintained through a commitment to the creative acts which produce positive relations of trust, familiarity and a particular local 'meld' of local people and local places.

Frequently the productive aspects of these commitments are hard to measure, falling outside of the traditional metrics of a healthy 
economy - such as high street occupancy rates, or the number of flagship stores on the one hand or charity shops on the other (see Portas 2011), which have been the focus of numerous headlines announcing 'the Death of the High Street' (see The Guardian 27 April 2014). The temporary stalls of home traders, hobbyists and new coffee shops doing some community work may seem frivolous or of little economic consequence - just the local 'village fête' (festival) - but I want to suggest there is more going on.

From the acts of silliness described above emerges an arena through which people are able to 'conceptually craft' themselves and form new relations to others and to place, as well as forge, new types and understandings of exchange. Radical interruptions to the aesthetics and rhythms of the everyday disrupt the non-event (of suburban banality) and reveal the potential for other relations, commitments and possibilities. New relations are built, friends and contacts are made, skills are gained, opportunities open up and confidence blooms. Buying a coffee, then, is also a commitment to a sense of being local, and with it comes a bundle of new potentials that are subtly, but powerfully, re-shaping what the 'socio-economic' function of suburbs are. Not only does the panoply of inventive silliness produce a type of local place that is familiar, friendly and fun but this in itself produces a sense of support, a regular and encouraging network of transactions, skill sharing and new potential for socio-economic growth and adaptability. What this chapter suggests, informed through long-term, deep, ethnographic fieldwork, is that if we can take being silly a little more seriously, then we might find ways to allow people to live the life they want to lead (see Surrey Comet 25 October 2014).

I suggest that the suburbs are not just a soulless retreat, a place to curl up, but rather, if understood differently, are potentially a place to uncurl, to live. Not a retreat, but - as numerous Seethingers told me - 'an exciting playground!' One in which work, home, economy and the high street can be radically re-imagined outside existing parameters of measurement. In this sense this chapter adds a social layer to the overarching spatial understanding of suburbs as a place with particular forms of 'high street' which are integrated into particular values of movement and that have a distinct spatial relation to the rest of the city. I have shown how Seethingers focus overtly on their social capacities, which I argue are particularly suburban in themselves. By creating a sense of distinct localness through cultural practice, they allow the high street and the particular social spaces of parks or paths to thrive under defined socio-economic conditions. The suburban practices undertaken by Seethingers shape a high street that has a much broader conception even than the 'active centre' proposed by Laura Vaughan (Vaughan et al. 2009b): this is a centre reinforced by invented myths of 
place as well as physical realisations of local sociality. I suggest that further research should look at the creative acts and expressions of groups such as those described in this chapter as examples of self-organising place-makers where what it means to be local, to be suburban, is crafted on their own particular terms. Work is needed to further understand what these creative acts do in terms of making places that work as well as what can be done to support and encourage these acts in different local contexts.

Thank you to Lefi and to the Seething Villagers for their unrelenting support for this work (IWLWHW). Thank you to the Adaptable Suburbs Project and to UCL Anthropology, particularly Timothy Carroll, Gill Conquest and Dominik Hoehn who all kindly read earlier versions of this chapter. The ethnographic research described here formed part of a PhD studentship on the UCL Adaptable Suburbs Project, funded by the UK Engineering and Physical Sciences Research Council (EPSRC: project reference EP/ loo1212/1). Names of informants have been changed and identities have been aggregated in this work to protect anonymity. Any omissions or errors remain my own.

\section{Notes}

1 This 'not that, not this' position is developed in Jeevendrampillai (2015) as a position that purposefully plays with the limits of the discursively possible. That is, in pushing an image of a suburb to the point of absurdity it exposes the socially contingent nature of that image and allows room for new suburban imaginaries to form from the performance of nonsense, or being 'stupid', as described in the thesis.

2 See e.g. http://kingstonpound.org/ [accessed 9 June 2015]. 


\section{Glossary of Space Syntax}

Space syntax is a theory of space and a set of analytical, quantitative and descriptive tools for analysing the layout of space in buildings and cities.' Space syntax methods are independent of social parameters so overcome the problem of analysing spatial concepts with social data, since it is possible to measure the accessibility patterns of streets or street systems without relying on social data. Originating in the Bartlett School of Architecture, University College London in the 1970s, the research field aims to answer key architectural and urban design questions, starting with whether the layout of cities has an impact on how people use streets. Methods were developed in order to control the spatial variable at the level of the complex patterns of space that make up the city, from which it was then possible to gain insight into both the social antecedents and consequences of spatial form in the physical city or in buildings ranging from houses to any complex building. The ability of space syntax methods to objectively measure the physical and spatial attributes of cities in relation to patterns of human activity has led to hundreds of research projects (as well as architectural and urban design projects), covering subjects as diverse as the relationship between burglary and housing layout, the architecture of Inuit snow houses and visitor movement in museum layouts.

Space syntax began from the observation that space is the common ground of the physical and social cities. In syntax terms, spatial configuration means relations between spaces which take into account other relations, and so in effect relations between all the various spaces of a system. Space syntax, in effect, takes certain common measures of relationality from graph mathematics, and first theorises them in terms of their potential to embody or transmit social ideas, and then turns them into mathematical measures and computerised representations of spatial structure. It does this by creating geometric representations of buildings or settlements that are being studied (Hillier and Hanson 1984). The representations are 
converted into mathematical measures which are essentially formal interpretations of the notion of spatial integration and segregation - which space syntax sees as the core of the understanding of how built systems work socially. Providing a measurable scale from segregation to integration has enabled statistical comparison of different spatial forms across cultures, and so provides a platform from which social origins and consequences of spatial forms might be investigated. From these beginnings, space syntax has evolved into a set of tools linked to a set of theories, the two together giving rise to a set of interpretative models for different socio-spatial phenomena.

Space Syntax analysis examines the spatial configuration of settlements by defining all external spaces as a continuous network of space, so streets, paths, squares, etc. are seen as voids shaped by the buildings, walls and other obstructions that surround them. Space syntax is built on the idea that we should think of space not as the background to human activity, as we think of it as the background to objects, but as an intrinsic aspect of everything human beings do in the sense that moving through space, interacting with other people in space or even just seeing ambient space from a point in it, all have a natural and necessary spatial geometry: movement is essentially linear, interaction requires a convex space in which all points can see all others, and from any point in space we see a variably shaped, often spiky, visual field we call an isovist.

This glossary provides a brief overview of some space syntax concepts in order to enhance the reading of this book. Readers are encouraged to follow links to other research articles in the field where full mathematical exposition of the terms used is provided. In the following list we have extracted some of the terms used in this book that readers may not be familiar with outside of the field of space syntax.

- Attractor refers to buildings or urban features having the potential of generating trips to and from them (such as a football stadia or shopping centres).

- Axial analysis is a way of analysing the open space structure of a spatial layout by drawing an axial map. 'An axial map of the open space structure of the settlement will be the least set of [axial] lines which pass through each convex space and makes all axial links' (Hillier and Hanson 1984: 91-2). The axial map of a settlement is constructed by taking an accurate basemap and drawing a set of intersecting lines through all the open public space (streets, squares and so on) so that all rings of circulation are completed. In recent 
times this has been somewhat superseded by segment analysis (see below).

- The measure of space constitution is simply the number of building entrances opening onto an axial line or convex space (Hillier and Hanson 1984: 105). We therefore refer to a space being constituted.

- Depth exists wherever it is necessary to go through intervening spaces to get from one space to another. A space is one step deep if it is one turning away and so on.

- A gate is a conceptual line drawn across a street and used for counting movement flows in observation studies.

- Global analysis refers to system-wide analysis, sometimes referred to as radius $n$. In axial analysis this is typically contrasted with local analysis which takes account only of a system within a few turnings away from each and every street (this will normally be radius 3 in axial analysis and 8oom in segment analysis).

- Grid intensification refers to a process that is typical of town centres where street blocks become smaller over time (and so the number of junctions increases) in order to reduce local trips. It is typically found where commercial activity has grown to the extent that it starts to spread around the block (see Hillier 1999a).

- Integration is a normalised measure of distance from any space of origin to all others in a system. In general, it calculates how close the origin space is to all other spaces, and can be seen as the measure of relative asymmetry (or relative depth). See: segment angular integration.

- Intelligibility, used in axial analysis, indexes the degree to which the number of immediate connections an axial line has is a reliable guide to the importance of that line in the system as a whole (namely, it is a correlation between axial connectivity and axial global integration). A strong correlation, or 'high intelligibility' in a non-orthogonal street system suggests that well-connected streets are also well integrated within the wider street network (see Hillier 1996: 124 et seq.).

- The movement economy theory builds on the theory of natural movement (Hillier et al. 1993) and postulates that the spatial distribution of movement is part of a powerful mechanism by which cities organise their movement-seeking land uses such as shops in relatively integrated locations and uses which have lower requirements for movement, such as housing, in relatively segregated locations. Accordingly, 
in the long run the local grid itself adapts to carry more (or less) intensive development following this spatial/social process.

- The (street) segment is the section of axial line or street or path lying between two intersections. The segment map is commonly constructed from an axial map, where axial lines are broken at their intersections and short stubs (formed at the ends of axial line overlaps) are removed. An alternative method takes the road centrelines from a pre-drawn transport network and simplifies and cleans it up to reduce over-articulated curves and to remove extraneous road traffic features.

- Segment analysis is any analysis of a segment map, including topological, angular and metric analyses. It is normally carried out in DepthMap software, although other packages, including add-ons to standard GIS software have been developed in recent times.

- Segment angular choice is calculated by counting the number of times each street segment falls on the shortest path between all pairs of segments within a selected distance (termed 'radius'). The 'shortest path' refers to the path of least angular deviation (namely, the straightest route) through the system. The normalised version of this measure allows for a comparison between street networks of different sizes and is referred to as ' $N A C H$ ' - see Hillier et al. 2012 for the mathematical definition.

- Segment angular integration measures how close each segment is to all others in terms of the sum of angular changes that are made on each route. It is measured as the reciprocal of the normalised angular total depth, allowing it to be compared across systems. The normalised version of segment angular integration is referred to as 'NAIN' see Hillier et al. 2012 for a full explanation of normalisation.

- Segregation in space syntax theory refers to a state where spaces are more remote or cut off from all other spaces within a settlement. More segregated spaces have higher mean depth values.

- Static activities refer to activities within a space such as a street or square, such as sitting, standing and talking (and in some studies, these will be set in comparison with the pattern of small, localised movements).

- The virtual community in a given area is the pattern of natural copresence brought about through the influence of spatial design on movement and other related aspects of space use. Spatial configuration influences patterns of movement in space, and movement is by far the dominant form of space use. Through its effects on movement, 
spatial configuration tends naturally to define certain patterns of co-presence and therefore co-awareness amongst the individuals living in and passing through an area. These are referred to as the virtual community.

\section{Note}

1 This glossary draws on material from 'The City as One Thing' (Hillier and Vaughan 2007) as well as the Space Syntax Online Training Platform created and hosted by University College London and Space Syntax

Limited. For a full explanation of space syntax methods and to obtain the free open source DepthMap software, readers should visit http://www.spacesyntax.net. 



\section{References}

Abercrombie, P. 1943. Some aspects of the county of London plan. The Geographical Journal 102 (5/6): 227-38.

Abercrombie, P. 1945. Greater London Plan 1944. London: HM Stationery Office.

Ackroyd, P. 2000. London: The biography. London: Chatto \& Windus.

Adburgham, A. 1964. Shops and shopping, 1800-1914: Where and in what matter the well-dressed Englishwoman bought her clothes. London: George Allen \& Unwin.

Al-Naim, M. A. 2006. The home environment in Saudi Arabia and Gulf States: The dilemma of cultural resistance identity in transition. Vol. 2. Milano: Largo Gemelli, Catholic University.

Al-Sayed, K., A. Turner and S. Hanna. 2012. Generative structures in cities. In 8th International Space Syntax Symposium, edited by M. Greene, J. Reyes and A. Castro. Santiago: Pontificia Universidad Católica de Chile.

Alexander, C. 1966. A city is not a tree. Design Magazine 206: 46-55.

Amin, A. 2002. Ethnicity and the multicultural city: Living with diversity. Environment and Planning A 34 (6): 959-80.

Amin, A. 2012. Land of strangers. Cambridge: Polity.

Anderson, B. R. 1991. Imagined communities: Reflections on the origin and spread of nationalism. Rev. and extended ed. London: Verso.

Anderson, K. 2006. Introduction: after sprawl: Post-suburban Sydney. In Post-suburban Sydney: The city in transformation, edited by K. Anderson, R. Dobson, F. Allon and B. Neilson. Parramatta, Sydney: Centre for Cultural Research, University of Western Sydney.

Anderson, S. 1986. On Streets. Cambridge, MA: The MIT Press.

Appleyard, D. 1969. Why buildings are known: A predictive tool for architects and planners. Environment and Behavior 1 (2): 131-56.

Appleyard, D. 1981. Liveable streets. Berkeley, CA: University of California Press.

Archer, J. 2005. Architecture and suburbia, from English villa to American dream house 1690-2000. Minneapolis: University of Minnesota Press. 
Arnaiz, M., B. Ruiz-Apilánez and J. M. D. Ureña. 2013. Spatial network analysis based on space syntax methodologies. The evolution of integration in the history of Toledo [in Spanish: El análisis de la traza mediante space syntax. Evolución de la accesibilidad configuracional de las ciudades históricas de toledo y alacalá de henares]. ZARCH Journal of Interdisciplinary Studies in Architecture and Urbanism 1: 128-40.

Arthur, W. B. 1988. Urban systems and historical path-dependence. Stanford Institute for Population and Resource Studies. Working Paper Series: Paper No. 0012 .

Åslund, O., J. Östh and Y. Zenou. 2010. How important is access to jobs? Old question - improved answer. Journal of Economic Geography $10(3): 389-422$.

Augé, M. 1995. Non-places: Introduction to an anthropology of supermodernity (trans. J. Howe). London: Verso Books.

Azzuz, I. 2000. Contemporary Libyan architecture: Possibilities vs. realities. Cambridge, MA: The Aga Khan Programme for Islamic Architecture, The MIT Press.

Baker, T. F. T. and C. R. Elrington, eds. 1985. A history of the county of Middlesex: Volume 8: Islington and Stoke Newington Parishes. London: Victoria County History.

Bakhtin, M. 1984. Rabelais and his world. Bloomington, IN: Indiana University Press.

Barker, P. 1999. Non-plan revisited: Or the real way cities grow: The tenth Reyner Banham memorial lecture. Journal of Design History 12 (2): 95-110.

Barratt, N. 2013. Greater London: The story of the suburbs. London: Random House.

Barthelemy, M. 2011. Spatial networks. Physics Reports 499 (1-3): 1-101.

Batty, M. 2007. Complexity in city systems: Understanding, evolution, and design. CASA Working Paper, UCL.

BBC. 2010 BBC Turn Back Time: Flickr group on the British high street. Available from https://www.flickr.com/groups/bbcturnbacktime/ [accessed 26 January 2015].

Bentley, I., A. Alcock, P. Murrain, S. McGlynn and G. Smith. 1985. Responsive Environments: A manual for designers. London: Architectural Press.

Bentley, M. 2006. Past and presence: Revisiting historical ontology. History and Theory 45: 349-61.

Berger, B. M. 1968. Suburbia and the American dream. In Urbanism in World Perspective: A reader, edited by S. F. Fava. New York: Cromwell.

Bernard, A. 2014. Lifted: A cultural history of the elevator. New York: NYU Press.

Body-Gendrot, S., M. Martiniello and Centre for Research in Ethnic Relations. 2000. Minorities in European Cities: The dynamics of social 
integration and social exclusion at the neighbourhood level. Basingstoke: Macmillan.

Booth, C. Poverty series survey notebooks (online archive). British Library of Political and Economic Science archive 1886-1903. Available from http://booth.Ise.ac.uk/ [accessed 23 June 2007].

Booth, C. Maps descriptive of London poverty, digital version (London School of Economics, 2000). London School of Economics 1898-9. Available from http://booth.Ise.ac.uk/ [accessed 30 July 2014].

Botticello, J. 2007. Lagos in London: Finding the space of home. Home Cultures 4: 7-23.

Bourne, L. S. 1996. Reinventing the suburbs: Old myths and new realities. Progress in Planning 46 (3): 163-84.

Boyd, S. 2010. Content, context, conduit: It's not who you know, but where you know. Available from http://stoweboyd.com/post/2093344403/ content-context-conduit-its-not-who-you-know [accessed 1 August 2014].

Boyer, D. and A. Yurchak. 2010. American stiob: Or, what late-socialist aesthetics of parody reveal about contemporary political culture in the west. Cultural Anthropology 25 (2): 179-221.

Braudel, F. 1975. The Mediterranean and the Mediterranean world in the age of Philip II (trans. Siân Reynolds). New York; London: Harper \& Row.

Bressey, C. and E. L. Lutyens. 1938. Highway development survey, 1937. London: HM Stationery Office.

Brueckner, J. K. and A. G. Largey. 2008. Social interaction and urban sprawl. Journal of Urban Economics 64 (1): 18-34.

Buchanan, C. 1964. Traffic in towns, the specially shortened edition of the Buchanan Report. Harmondsworth, Middlesex: Penguin Books (Report first published by HMSO, 1963).

Bullard, R. D., G. S. Johnson and A. O. Torres, eds. 2000. Sprawl city: Race, politics, and planning in Atlanta. Washington, DC: Island Press.

Bullman, J., N. Hegarty and B. Hill. 2012. The secret history of our streets London: A social history through the houses and streets we live in. London: BBC Books and Random House.

Burgess, E. W. 1967 (original 1925). The growth of the city: An introduction to a research project. In The city, edited by R. E. Park, E. W. Burgess and R. D. McKenzie. Chicago: University of Chicago Press.

Busquets, J. 2000. Toledo and its future. The special plan for the historic centre of Toledo [in Spanish Toledo y su futuro. El plan especial del casco historico]. Toledo: City of Toledo, Castilla-La Mancha Regional Savings Bank, and Toledo Municipal Housing Company.

Calthorpe, P. 1993. The next American metropolis: Ecology, community and the American dream. New York: Princeton Architectural Press. 
Campbell, J. 2008. Strange fiction: J. G. Ballard talks to James Campbell. The Guardian, 14 June.

Caniggia, G. and G. L. Maffei. 2001. Architectural composition and building typology: Interpreting basic building. Florence: ALINEA.

Cannadine, D. 1977. Victorian cities: How different? Social History 2: 457-82.

Carmona, M. 2014. Explorations in urban design: An urban design research primer. Surrey; Burlington, VT: Ashgate.

Carmona, M. 2015. London's local high streets: The problems, potential and complexities of mixed street corridors. Progress in Planning 100: 1-84.

Carter, H. 1983. An introduction to urban historical geography (1989 edition). London: Edward Arnold.

Casey, E. S. 1997. The fate of place: A philosophical history. Berkeley, CA: University of California Press.

Castells, M. 1989. The informational city: Information technology, economic restructuring, and the urban-regional process. Oxford: Blackwell.

Castells, M. 1996. The rise of the network society. Cambridge, MA: Blackwell.

Chang, D. 2002. Spatial choice and preference in multilevel movement networks. Environment and Behavior 34 (5): 582-615.

Channel 4. 2013. The fried chicken shop. Available from http://www.channel4. com/programmes/the-fried-chicken-shop [accessed 26 January 2015].

Clapson, M. 1998. Invincible green suburbs, brave new towns: Social change and urban dispersal in postwar England. Manchester: Manchester University Press.

Clapson, M. 2003. Suburban century: Social change and urban growth in England and the USA. Oxford; New York: Berg.

Clapson, M. 2012. Working-class suburb: Social change on an English council estate, 1930-2010. Manchester: Manchester University Press.

Collins, R. 2004. Interaction ritual chains. Princeton, N): Princeton University Press.

Connell, J. 1974. The metropolitan village: Spatial and social processes in discontinuous suburbs. In Suburban Growth: Geographical processes at the edge of the western city, edited by J. $\mathrm{H}$. Johnson. Chichester: Wiley.

Connerton, P. 2009. How modernity forgets. Cambridge: Cambridge University Press.

Conzen, M. 1960. Alnwick, Northumberland: A study in town-plan analysis. Transactions and Papers (Institute of British Geographers) 27: 3-122.

Corfield, P. J. 2007. Time and the shape of history. New Haven; London: Yale University Press.

Couch, C. and J. Karecha. 2006. Controlling urban sprawl: Some experiences from Liverpool. Cities 23 (5): 353-63. 
Crang, M. and P. S. Travlou. 2001. The city and topologies of memory. Environment and Planning $D 19(2): 161-78$.

Cromwell, T. 1835. Walks through Islington. London: Sherwood, Gilbert \& Piper. Cullen, G. 1961. The concise townscape. London: Architectural Press.

Cutler, K.-M. 2015. East of Palo Alto's Eden: Race and the formation of Silicon Valley. TechCrunch.com. Available from http://techcrunch. com/2015/01/10/east-of-palo-altos-eden/ [accessed 21 January 2014].

Darke, J. 1982. The design of public housing: Architects' intentions and users' reactions. Vol. 1. University of Sheffield.

David Lewis Associates. Seven Sisters heritage statement, 2012 http://www. sevensistersregeneration.co.uk/downloads/Heritage_Statement_ May-2012.pdf [accessed 1 December 2014].

Davies, L. 2007. Urban design compendium. London: Urban Design Alliance.

Davis, H. 2009. The commercial-residential building and local urban form. Urban Morphology 13 (2): 89-104.

Dawson, J. A. 1988. Futures for the high street. The Geographical Journal 154: 1-12.

de Certeau, M. 1984. The practice of everyday life (trans. Steven Rendall). Berkeley, CA: University of California Press.

de Terán, M. 1961. Two Madrilenian streets: Alcalá Street and Toledo Street. [in Spanish: Dos calles madrileñas: Las de alcalá y Toledo]. Estudios Geográficos XXII: 375-476.

Deleuze, G. and F. Guattari. 1987. A Thousand Plateaus: Capitalism and schizophrenia. Minneapolis: University of Minnesota Press.

Dennis, R. 2008. Cities in modernity: Representations and productions of metropolitan space, 1840-1930. Cambridge: Cambridge University Press.

Department for Business Innovation and Skills, Genecon LLP and Partners, and Urban Pollinators. 2011. Understanding high street performance. London: BIS.

Dhanani, A. 2014. Street network centrality and built form evolution in the spatial development of London's periphery 1880-2013. Unpublished PhD thesis, Bartlett School of Graduate Studies, University College London, London.

Dhanani, A., L. Vaughan, C. Ellul and S. Griffiths. 2012. From the axial line to the walked line: Evaluating the utility of commercial and usergenerated street network datasets in space syntax analysis. In 8th International Space Syntax Symposium, edited by M. Greene, J. Reyes and A. Castro. Santiago: Pontificia Universidad Católica de Chile.

Dhanani, A. and L. Vaughan. 2013. A porous urban fabric: The structures and scales of London's peri-urban development from 1880-2013. In 9th 
International Space Syntax Symposium, edited by Y. O. Kim, H. T. Park and K. W. Seo. Seoul: Sejong University.

Dickens, C. 1837-9. Oliver Twist; or, the parish boy's progress. London: Richard Bentley.

Dines, M. and T. Vermeulen, eds. 2013. New suburban stories. New York: Bloomsbury.

Duany, A., E. Plater-Zyberk and J. Speck. 2000. Suburban nation: The rise of sprawl and the decline of the American dream. New York: North Point Press.

Duncan, E. 2014. Death of the high street? Hurrah ... The Guardian, 27 April 2014.

Dyos, H. J. 1961. Victorian suburb: A study of the growth of Camberwell (1977 edition). Leicester: Leicester University Press.

Equipo de Técnicos en Transporte y Territorio. 1994. Study for the rearrangement of the street network and the mobility in the historic centre of Toledo. A pilot experience. Vol. 2 [in Spanish: Estudio de reordenación viaria y del transporte en el casco histórico de Toledo. Una experiencia piloto. Tomo 2: Diagnóstico].

Esteban, Á., D. Martín-Consuegra, A. Molina and E. Díaz. 2005. Tourism quality and consumer perception in Toledo [in Spanish: Calidad del turismo y percepción del consumidor en Toledo]. Study prepared for the Centre for Consumer Studies \& University of Castilla-La Mancha and the Government of Castilla La Mancha.

Ethington, P. 2000. Los Angeles and the problem of historical knowledge: A multimedia essay to accompany the December issue of the American historical review. Available from http://www.usc.edu/dept/LAS/history/ historylab/LAPUHK/Text/LAPUHK.pdf [accessed 18 February 2015].

Ethington, P. J. 2007. Placing the past: 'groundwork' for a spatial theory of history. Rethinking History 11 (4): 465-93.

Evans, G. and P. J. Larkham. 2004. Designing and living in a new industrial suburb: Experiences in the Cannock Chase coalfield from the 1950 s to the 1970s. Environment and Planning B 31: 673-91.

Fishman, R. 1987. Bourgeois utopias: The rise and fall of suburbia. New York: Basic Books.

Florida, R. 2013. The fading differentiation between city and suburb. Urban Land: The magazine of the Urban Land Institute, 31 January 2013.

Francescato, G. 1979. Residents' satisfaction in HUD-assisted housing: Design and management factors. USA: Office of Policy Development and Research.

Franzén, M. 2009. Matters of urban segregation. In 7th International Space Syntax Symposium, edited by D. Koch, L. Marcus and J. Steen. Stockholm: Royal Institute of Technology. 
Gans, H. 1967. The Levittowners. New York: Pantheon Books.

Garreau, J. 1992. Edge City: Life on the new frontier. Vol. xxiii. New York; London: Anchor Books.

Garrett, B. 2013. Explore Everything: Place hacking the city. London: Verso.

Geddes, I. 2014. From "A miserable town of 150 mud houses" to "The city that never sleeps": the transformation of Limassol's urban form over the past 200 years. In 21st International Seminar on Urban Form. Porto.

Gehl Architects. 2004. Towards a fine city for people. In Public Spaces and Public Life. London.

Gehl, J. 1987. Life between buildings: Using public space. New York: Van Nostrand Reinhold.

Gehl, J. 1994. Public spaces, public life in Perth. City of Perth: State of Western Australia.

Gehl, J. 2002. Public spaces and public life in Adelaide. Adelaide: Adelaide City Council.

Gehl, J. 2004. Public for people. Australia: City of Melbourne.

Gehl, J. 2010. Cities for people. Washington; Covelo; London: Island Press.

Gehl, J. and B. Svarre. 2013. How to study public life. Washington, DC: Island Press.

Gerasimou, S. and M. Georgoudis. 2011. Sustainable mobility in Cyprus: The city of Limassol. In Urban Transport xvii: Urban transport and the environment in the 21st century, edited by A. Pratelli and C. A. Brebbia. Southampton: Wit Press.

Gibson, J. J. 1950. The perception of the visual world. Boston: Houghton Mifflin Press.

Giddens, A. 1984. The constitution of society: Outline of the theory of structuration. Cambridge: Polity Press.

Giles, J. 2004. The parlour and the suburb: Domestic identities, class, femininity and modernity. Oxford: Berg.

Gilliland, J. A., S. H. Olson, and D. Gauvreau. 2011. Did segregation increase as the city expanded? Social Science History 35 (4): 465-503.

Giuliani, F. and E. Wiesenfeld. 2003. Promoting sustainable communities: Theory, research, and action. Community, Work Q Family 6 (2): 159-223.

Glaeser, E. L. and J. Shapiro. 2001. Is there a new urbanism? The growth of US cities in the 1990s. Cambridge, MA: National Bureau of Economic Research.

Glass, R. 1989. Urban sociology. In clichés of urban doom and other essays, edited by R. Glass. Oxford: Blackwell.

Goffman, E. 1966. Behaviour in public places: Notes on the social organization of gatherings. New York: Free Press.

Goldberger, P. 1987. When suburban sprawl meets upward mobility. New York Times, 26 July. 
Goldsworthy, V. 2004. The love that dares not speak its name: Englishness and suburbia. In Revisions of Englishness, edited by D. Rogers and J. MacLeod. Manchester: Manchester University Press.

Gordon, P. and H. W. Richardson. 2000. Critiquing sprawl's critics. Cato Institute of Policy Analysis No. 365. Washington, DC: Cato Institute.

Gort Scott Architects. 2009. Made in the suburbs: An outer London high road (exhibition at London Metropolitan University and accompanying articles sponsored by Architects Journal and London Development Agency).

Gort Scott Architects. 2011. Blackhorse Lane: Going for growth. London: London Borough of Waltham Forest.

Gort Scott Architects. 2013a. From around here. London: Haringey Council.

Gort Scott Architects. 2013b. Waltham Forest employment study. London: London Borough of Waltham Forest and Greater London Authority.

Gort Scott Architects and UCL Bartlett School of Planning. 2010. High street London. London: Design for London, Greater London Authority.

Grannis, R. 1998. The importance of trivial streets: Residential streets and residential segregation. American Journal of Sociology 103 (6), $1530-64$.

Granovetter, M. 1973. The strength of weak ties. American Journal of Sociology $78(6)$ : 1360-80.

Granovetter, M. 1983. The strength of weak ties: A network theory revisited. Sociological Theory 1: 201-33.

Griffiths, S. 2005. Historical space and the practice of 'spatial history': The spatio-functional transformation of Sheffield 1770-1850. In 5th International Space Syntax Symposium, edited by A. van Nes. Amsterdam: Techne Press.

Griffiths, S. 2009. Persistence and change in the spatio-temporal description of Sheffield parish 1770-1910. In 7th International Space Syntax Symposium, edited by D. Koch, L. Marcus and J. Steen. Stockholm: Royal Institute of Technology.

Griffiths, S. 2011. Temporality in Hillier and Hanson's theory of spatial description: Some implications of historical research for space syntax. The Journal of Space Syntax 2 (1): 73-96.

Griffiths, S. 2012. The use of space syntax in historical research: Current practice and future possibilities. In 8th International Space Syntax Symposium, edited by M. Greene, J. Reyes and A. Castro. Santiago: Pontificia Universidad Católica de Chile.

Griffiths, S., L. Vaughan, M. Haklay and C. E. Jones. 2008. The sustainable suburban high street: A review of themes and approaches. Geography Compass 2: 1155-88. 
Griffiths, S., C. E. Jones, L. Vaughan and M. Haklay. 2009. A morphological approach to the persistence of socio-economic activity in three suburbs of greater London. In $16^{\text {th }}$ International Seminar on Urban Form. Guangzhou, China.

Griffiths, S., C. E. Jones, L. Vaughan and M. Haklay. 2010. The persistence of suburban centres in greater London: Combining Conzenian and space syntax approaches. Urban Morphology 14 (2): 85-99.

Griffiths, S., A. Dhanani, C. Ellul, M. Haklay, D. Jeevendrampillai, N. Nikolova, P. Rickles and L. Vaughan. 2013. Using space syntax and historical land-use data to interrogate narratives of high street 'decline' in two greater London suburbs. In gth International Space Syntax Symposium, edited by Y. O. Kim, H. T. Park and K. W. Seo. Seoul: Sejong University.

Gwilliam, M., C. Bourne, C. Swain and A. Prat. 1999. Sustainable renewal of suburban areas. York: Joseph Rowntree Foundation.

Habitat, U. 2013. Streets as public spaces and drivers of urban prosperity. Nairobi, Kenya: United Nations Human Settlements Programme.

Hägerstrand, T. 1967. Innovation diffusion as a spatial process (trans. Allan Pred and Greta Haag). Chicago: University of Chicago Press.

Hägerstrand, T. 1982. The impact of social organization and environment upon the time-use of individuals and households. In Internal structure of the city: Readings on urban form, growth and policy, edited by L. S. Bourne. Oxford and New York: Oxford University Press.

Hägerstrand, T. 2009. The fabric of life [in Swedish: Tillvaroväven]. Stockholm: Forskningsrådet Formas.

Halbwachs, M. 1992. On collective memory (ed. and trans. Lewis A. Coser). Chicago: University of Chicago Press.

Hall, P. and K. Pain. 2006. The polycentric metropolis: Learning from mega-city regions in Europe. London: Earthscan.

Hall, S. 2012. City, street and citizen: The measure of the ordinary. London and New York: Routledge.

Hall, S. 2013. Super-diverse street: A 'trans-ethnography' across migrant localities. Ethnic and Racial Studies: 38(1): 1-14.

Hall, S. 2014. Emotion, location and urban regeneration: The resonance of marginalised cosmopolitanisms. In Stories of Cosmopolitan Belonging: Emotion and location, edited by $\mathrm{H}$. Jones and $\mathrm{E}$. Jackson. Abingdon: Routledge.

Hallowell, G. D. and P. K. Baran. 2013. Suburban change: A time series approach to measuring form and spatial configuration. The Journal of Space Syntax 4 (1): 74-91.

Hanson, J. 1989a. Order and structure in urban space: A morphological history of the city of London. Unpublished PhD thesis, Bartlett School of Architecture and Planning, University of London, London. 
Hanson, J. 1989b. Order and structure in urban design: The plans for the rebuilding of London after the great fire of 1666. Ekistics 56 (Special Issue on Space Syntax, Number 334/335): 22-42.

Hanson, J. 2000. Urban transformations: A history of design ideas. Urban Design International 5: 97-122.

Hanson, J. and B. Hillier. 1987. The architecture of community: Some new proposals on the social consequences of architectural and planning decisions. Architecture et Comportement / Architecture and Behaviour 3 (3): $251-73$.

Hanson, J. and R. Zako. 2007. Communities of co-presence and surveillance: How public open space shapes awareness and behaviour in residential developments. In 6th International Space Syntax Symposium, edited by A. S. Kubat. Istanbul: Technical University of Istanbul. Hapgood, L. 2005. Margins of desire: The suburbs in fiction and culture 18801925. Manchester: Manchester University Press.

Harris, R. 1996. Unplanned suburbs : Toronto's American tragedy, 1900 to 1950. Baltimore; London: Johns Hopkins University Press.

Harris, R. 2004. Creeping conformity: How Canada became suburban, 1900196o. Toronto: University of Toronto Press.

Harris, R. 2010. Meaningful types in a world of suburbs. Research in Urban Sociology 10: 15-47.

Harris, R. 2015. Using Toronto to explore three suburban stereotypes, and vice versa. Environment and Planning A 47 (1): 30-49.

Harris, R. and P. J. Larkham, eds. 1999. Changing suburbs: Foundation, form and function. London: Routledge.

Harris, R. and R. Lewis. 2001. The geography of north American cities and suburbs, 1900-1950: A new synthesis. Journal of Urban History 27: 262-92.

Hartley, L. P. 1953. The Go-Between. London: Hamish Hamilton.

Harvey, D. 1989. The urban experience. Baltimore; London: Johns Hopkins University Press.

Hayden, D. 2004. A field guide to sprawl (with aerial photographs by Jim Wark). New York; London: W. W. Norton and Company.

Hebbert, M. 1998. London: More by fortune than design. Chichester: John Wiley \& Sons.

Hebbert, M. 2005a. Engineering, urbanism and the struggle for street design. Journal of Urban Design 10: 39.

Hebbert, M. 2005b. The street as locus of collective memory. Environment and Planning D: Society and Space 23 (4): 581-96.

Hebbert, M. 2014. Historical exploration/explanation in urban design. In Explorations in urban design: An urban design research primer, edited by M. Carmona. Surrey; Burlington, VT: Ashgate. 
Hecht, A. 2001. Home sweet home: Tangible memories of an uprooted childhood. In Home possessions: Material culture behind closed doors, edited by Daniel Miller. Oxford: Berg Publishers.

Hershberger, R. G. 1969. A study of meaning and architecture. Review of Research in Visual and Environmental Education 1 (1): 75-82.

Hewstone, M. 2009. Living apart, living together? The role of intergroup contact in social integration. Proceedings of the British Academy 162: 243-300.

Hiebert, D., J. Rath and S. Vertovec. 2014. Urban markets and diversity: Towards a research agenda. Ethnic and Racial Studies 38 (1): 5-21.

Hillier, B. 1989. The architecture of the urban object. Ekistics 334 \& 335 (January/February 1989 \& March/April 1989): 5-21.

Hillier, B. 1996. Space is the machine: A configurational theory of architecture (2006 ebook version). Cambridge: Cambridge University Press.

Hillier, B. 1999a. Centrality as a process: Accounting for attraction inequalities in deformed grids. Urban Design International 4 (3-4): 107-27.

Hillier, B. 1999b. The hidden geometry of deformed grids: Or, why space syntax works, when it looks as though it shouldn't. Environment and Planning B: Planning Q Design 26 (Theme Issue on Space Syntax): 169-91.

Hillier, B. 2002. A theory of the city as object: Or, how spatial laws mediate the social construction of urban space. Urban Design International 3-4 (127): 153-79.

Hillier, B. 2004. Can streets be made safe? Urban Design International 1 (9): $31-45$.

Hillier, B. 2008. Space and spatiality: What the built environment needs from social theory. Building Research Q Information 36 (3): 216-30.

Hillier, B. 2009a. The city as a socio-technical system: A spatial reformulation in the light of the levels problem and the parallel problem. In Digital Urban Planning and Modelling, edited by S. Müller, P. W. Arisona, G. Aschwanden and J. Halatsch. Berlin: Springer Communications in Computer and Information Science (CCIS).

Hillier, B. 200gb. Spatial sustainability in cities: Organic patterns and sustainable forms. In 7 th International Space Syntax Symposium, edited by D. Koch, L. Marcus and J. Steen. Stockholm: Royal Institute of Technology.

Hillier, B. 2013. Credible mechanisms or spatial determinism. Cities 34: 75-77.

Hillier, B. and J. Hanson. 1984. The social logic of space. 1990 ed. Cambridge: Cambridge University Press.

Hillier, B. and S. lida. 2005. Network and psychological effects in urban movement. In Lecture Notes in Computer Science, edited by A. G. Cohn and D. M. Mark, Vol. 3693 (Springer: Springer Berlin Heidelberg). 
Hillier, B. and L. Vaughan. 2007. The city as one thing. Progress in Planning 67 (3): 205-30.

Hillier, B., R. Burdett, J. Peponis and A. Penn. 1987. Creating life: Or, does architecture determine anything? Architecture Q Behaviour 3 (3): 233-50.

Hillier, B., A. Penn, J. Hanson, T. Grajewski and J. Xu. 1993. Natural movement: Or configuration and attraction in urban pedestrian movement. Environment and Planning B: Planning and Design 20: 29-66.

Hillier, B., T. Young and A. Turner. 2012. Normalising least angle choice in depthmap and how it opens up new perspectives on the global and local analysis of city space. The Journal of Space Syntax 3 (2): 155-93.

Hinchcliffe, T. 2005. Elusive suburbs, endless variation. Journal of Urban History 31 (6): 899-906.

Hooper, M. 1970. Dating hedges. Area 2 (4): 63-5.

Hubbard, P. J. 2006. The city. London; New York: Routledge.

Hubbard, P. and K. Lilley. 2004. Pacemaking the modern city: The urban politics of speed and slowness. Environment and Planning D: Society and Space 2 (22): 273-94.

Hughes, M. V. 1977 (1934). A London child of the 1870s. Oxford: Oxford University Press.

Hutchinson, R. 2010a. The king's soup. Seething: Homage Publishing.

Hutchinson, R. 2010b. The legend of Lefi Ganderson. Seething: Homage Publishing.

Hutchinson, R. 2011. Jack and the golden egg, or, how the Seething community sports day started. Seething: Homage Publishing.

Hutchinson, R. 2012. The last sardines. Seething: Homage Publishing.

Hunt, T. 2005. The rise and fall of the Victorian city: Lessons for contemporary urban renewal. London: CABE (Commission for Architecture and the Built Environment).

I Want the Good Life. 1999. The Big Issue Magazine, 16-17.

Inwood, S. 1998. A history of London. London: Macmillan.

Islington Council. Conservation area designation 2015 [accessed February 2015].

ITC (Independent Transport Commission). 2004. Suburban future. London: ITC.

Jackson, A. A. 1973. Semi-detached London: Suburban development, life and transport, 1900-39. London: Allen and Unwin.

Jackson, A. A. 1978. London's local railways. London: David and Charles.

Jackson, K. T. 1985. Crabgrass frontier: The suburbanization of the United States. New York: Oxford University Press. 
Jacobs, A. B. 1985. Looking at cities. Cambridge, MA: Harvard University Press.

Jacobs, A. B. 1993. Great Streets. Cambridge, MA: The MIT Press.

Jacobs, J. 1961. The death and life of great American cities. Harmondsworth, Middlesex: Penguin.

Jeevendrampillai, D. 2015. Making the local: Anthropology and the suburban citizen. Unpublished PhD thesis, Department of Anthropology, University College London.

Jones, P., M. Roberts and L. Morris. 2007. Rediscovering mixed-use streets: The contribution of local high streets to sustainable communities. London: Joseph Rowntree Foundation \& Polity Press.

Kaplan, R., S. Kaplan and R. L. Ryan. 1998. With people in mind: Design and management of everyday nature. USA: Island Press.

Karimi, K. 1997. The spatial logic of organic cities in Iran and the United Kingdom. In 1st International Space Syntax Symposium, edited by M. D. Major, L. Amorim and F. Dufaux. London: University College London.

Karimi, K. 2000. Urban conservation and spatial transformation: Preserving the fragments or maintaining the 'spatial spirit'. Urban Design International 5: 221-31.

Karimi, K. 2012. Special issue: Evidence-informed and analytical methods in urban design. Urban Design International 17 (4): 253-6.

Katziaounis, R. 1996. Labour, society and politics in Cyprus during the second half of the nineteenth century. Texts and studies in the history of Cyprus. Nicosia: Cyprus Research Centre.

Keil, R., ed. 2013. Suburban constellations: Governance, land and infrastructure in the 21st century. Berlin: Jovis Verlag GmbH.

Keil, R. and R. Shields. 2013. Suburban boundaries: Beyond greenbelts and edges. In Suburban constellations: Governance, land and infrastructure in the 21st century, edited by R. Keil. Berlin: Jovis Verlag $\mathrm{GmbH}$.

Kelly, B. M. 1993. Expanding the American dream: Building and rebuilding Levittown. New York: New York State University of New York Press.

Kelly's London suburban directory for 1901 (with a map engraved expressly for the work). 1901. Holborn, London: Kelly's Directories Limited.

Kfar-Saba History. Available from http://www.kfar-saba.muni.il/?Categoryid= 312. Kfar-Saba Municipality 2014 [accessed 19 December 2014].

Kirby, K. M. 1996. Indifferent boundaries: Spatial concepts of human subjectivity. New York; London: Guilford Press.

Klasander, A.-J. 2001. Urban parts. The suburb as urban design [in Swedish: Stads-delar: förorter som stadsbyggnadsfråga]. Licentiate Thesis. Chalmers Tekniska Högskola, Sektionen för Arkitektur. Göteborg: Chalmers. 
Klasander, A.-J. 2003. Suburban navigation: Structural coherence and visual appearance in urban design. Unpublished PhD thesis, Chalmers University of Technology, Gothenburg.

Klasander, A.-J. 2005. Challenges of the modernist urban landscape. Nordisk Arkitekturforskning 18(1): 37-46.

Koch, D. 2004. Spatial systems as producers of meaning: The idea of knowledge in three public libraries. School of Architecture, KTH Stockholm.

Koch, D. 2007. Structuring fashion department stores as situating spatial practice. Stockholm: KTH, Arkitektur; axlbooks.

Kritioti, M. 1988. Limassol, a town in transition. Unpublished MSc Advanced Architectural Studies dissertation. Bartlett School of Graduate Studies, University College London.

Kropf, K. 2001. Conceptions of change in the built environment. Urban Morphology 5 (1): 29-42.

Kroplick, H. and A. Velocci. 2008. The Long Island motor parkway. Mount Pleasant, SC: Arcadia Publishing.

Kruse, K. M. 2005. White flight: Atlanta and the making of modern conservatism. New Jersey; Oxford: Princeton University Press.

Lang, R. E. 2003. Edgeless Cities: Exploring the elusive metropolis. Washington, DC: Brookings Institution.

Lang, R. E., A. C. Nelson and R. R. Sohmer. 2008. Boomburb downtowns: The next generation of urban centers. Journal of Urbanism: International Research on Placemaking and Urban Sustainability, 1 (1): 77-90.

Lefebvre, H. 1991. The production of space (originally in French, 1974 as La production de l'espace), trans D. Nicholson-Smith. Oxford: Basil Blackwell.

Lefebvre, H. 2004. Rhythmanalysis: Space, time and everyday life, trans. Stuart Elden and Gerald Moore; with an introduction by Stuart Elden. London: Continuum.

Legeby, A. 2010. From housing segregation to integration in public space: A space syntax approach applied on the city of Södertälje. The Journal of Space Syntax 1 (1): 92-107.

Legeby, A. 2013. Patterns of co-presence: Spatial configuration and social segregation, School of Architecture and the Built Environment, KTH Royal Institute of Technology, Stockholm.

Legeby, A. and L. Marcus. 2011. Does the urban structure of Swedish cities inhibit the sharing of public space? Built Environment 37 (2): 155-69.

Li, W. 1998. Anatomy of a new ethnic settlement: The Chinese ethnoburb in Los Angeles. Urban Studies 35 (3): 479-501.

Liebst, L. 2014. Staged, yet unstaged sociological inquiries into space and micro-interaction. Unpublished PhD thesis, Department of Sociology, University of Copenhagen. 
Lyng, S. 1990. Edgework: A social psychological analysis of voluntary risk taking. American Journal of Sociology 95 (4): 851-86.

MacCormac, R. 1996. An anatomy of London. Built Environment 22 (4): 306-11.

Maccreanor Lavington and Gort Scott. 2011. Blackhorse Lane Urban Design Framework. London: London Borough of Waltham Forest.

Mace, A. 2013. City Suburbs: Placing suburbia in a post-suburban world. New York: Routledge.

Mcllwaine, C. 2009. Legal Latins? Webs of (ir) regularity among Latin American migrants in London. Identity, Citizenship and Migration Centre Working Paper No. 4, University of Nottingham. Available from http:// www.geog.qmul.ac.uk/docs/staff/48201.pdf [accessed 1 December 2014].

Mcllwaine, C., J. C. Cock and B. Linneker. 2011. No longer invisible: The Latin American community in London. London: Queen Mary University of London, Latin American Women's Rights Service (LAWRS), Trust for London.

McKellar, E. 1999. The birth of modern London: The development and design of the city, 1660-1720. Manchester: Manchester University Press.

McLaren, B. 2006. Architecture and tourism in Italian colonial Libya: An ambivalent modernism. Washington, DC: University of Washington Press.

McLuhan, H. M. 1951. The mechanical bride: Folklore of industrial man (2002 edition). California: Corte Madera Ginko Press.

McManus, R. and P. Ethington. 2007. Suburbs in transition: New approaches to suburban history. Urban History 34 (2): 317-37.

Mangoian, L. and H. A. Mangoian. 1947. The island of Cyprus. An illustrated guide and handbook. Nicosia: Mangoian Bros.

Marcus, C. C. and W. Sarkissian. 1986. Housing as if people mattered: Site design guidelines for medium-density family housing (California series in urban development). Berkeley CA: University of California Press.

Marcus, C. C. and Francis, C. 1998. People places: Design guidelines for urban open spaces. New York: John Wiley \& Sons.

Marcus, L. 2007. Social housing and segregation in Sweden - from residential segregation to social integration in public space. Progress in Planning: special issue on The Syntax of Segregation, edited by L. Vaughan, 67 (3): $251-63$.

Marcus, L. 2010. Spatial capital: A proposal for an extension of space syntax into a more general urban morphology. The Journal of Space Syntax 1 (1): $30-40$.

Marcus, L. 2012. Towards a spatial morphology of urban social-ecological systems. 18th International Seminar on Urban Form. Montréal. 
Marcus, L. and A. Legeby. 2012. The need for co-presence in urban complexitymeasuring social capital using space syntax. In 8th International Space Syntax Symposium, edited by M. Greene, J. Reyes and A. Castro. Santiago: Pontificia Universidad Católica de Chile.

Marcus, L. and A. Ståhle. 2005. Place syntax - geographic accessibility with axial lines in GIS. In 5 th International Space Syntax Symposium, edited by A. van Nes. Amsterdam: Techne Press.

Marshall, S. 2005. Streets and patterns: The structure of urban geometry. London: Spon Press.

Marshall, S. 2006. The emerging 'Silicon Savanna': From old urbanism to new suburbanism. Built Environment: special issue on sustainable suburbs, edited by Nicholas Falk, 32 (3): 267-80.

Marshall, S. 2009. Cities design and evolution. Abingdon: Routledge.

Massey, D. 2005. For space. London: Sage.

Massey, D., J. Allen and S. Pile. 1999. City worlds. London and New York: Routledge (in association with the Open University).

Massey, D. and R. Denton. 1993. American apartheid: Segregation and the making of the underclass. Cambridge, MA: Harvard University Press.

Masucci, A. and G. J. Rodgers. 2008. The network of commuters in London. Physica A: Statistical Mechanics and its Applications 387 (14): 3781-8.

Merriman, P. 2009. Automobility and the geographies of the car. Geography Compass 3 (2): 586-99.

Miller, M. 1992. Raymond Unwin: Garden cities and town planning. Leicester: Continuum International Publishing Group - Leicester University Press.

Monteiro, C. 2008. Enclaves, condominiums, and favelas: Where are the ghettos in Brazil? City a Community 7 (4): 378-83.

Monty Python's Flying Circus. 1978. Mr and Mrs Brian Norris' Ford Popular: Series 3, Episode 28.

Mumford, L. 1940. The culture of cities. London: Secker and Warburg.

Mumford, L. 1961. The city in history: Its origins, its transformations and its prospects. London: Secker \& Warburg.

Muzzio, D. and T. Halper. 2002. Pleasantville? The suburb and its representation in American movies. Urban Affairs Review 37 (4): 543-74.

Nairn, I. 1955. Outrage. Architectural Review CXVII (702). (Reprinted London: Architectural Press, 1956.)

Nairn, I. 1956. Counter-attack against subtopia. London: Architectural Press. Nasar, J. L. 1998. The evaluative image of the city. USA: Sage Publications.

Navaro-Yashin, Y. 2012. The make-believe space: Affective geography in a postwar polity. Durham, NC: Duke University Press.

NEF (New Economics Foundation). 2005. Clone Town Britain: The loss of local identity on the nation's high streets. London: NEF. 
Newman, P. and J. Kenworthy. 1999. Sustainability and cities: Overcoming automobile dependence. Washington, DC: Island Press.

Nicolaides, B. 2002. My blue heaven, life and politics in working-class suburbs of Los Angeles, 1920-1965. Chicago; London: University of Chicago Press.

Nicolaides, B. and A. Wiese. 2006. The suburb reader. New York: Routledge.

Office for National Statistics. 2014. Business register and employment survey. Available from http://www.ons.gov.uk/ons/about-ons/get-involved/taking-part-in-a-survey/information-for-businesses/a-to-z-ofbusiness-surveys/business-register-and-employment-survey--bres-/ index.html [accessed 7 November 2014].

Office of the Deputy Prime Minister. 2004. Statistics for retail planning for London's town centres. Original edition, ISBN 0-11-753573-7.

Oldenburg, R. 1997. The great good place: Cafés, coffee shops, bookstores, bars, hair salons, and other hangouts at the heart of a community. Boston: Da Capo Press.

Oliver, P., I. Davis and I. Bentley. 1981. Dunroamin: The suburban semi and its enemies. London: Pimlico.

Olsson, S. 1998. The transformations of urban public life [in Swedish: Det offentliga stadslivets förändringar]. Gothenburg: Chalmers University of Technology.

Olsson, S. and A. Törnquist. 2009. The suburb: Interventions and development during 40 years [in Swedish: Förorten: Insatser och utveckling under 40 år]. Stockholm: Arkitekternas forum för forskning och utveckling Arkus.

Pacione, M. 2005. Urban geography, a global perspective (2nd edition). London: Routledge.

Page, S. E. 2006. Path dependence. Quarterly Journal of Political Science 1 (1): 87-115.

Palaiologou, G. and L. Vaughan. 2012. Urban rhythms: Historic housing evolution and socio-spatial boundaries. In 8th International Space Syntax Symposium, edited by M. Greene, J. Reyes and A. Castro. Santiago: Pontificia Universidad Católica de Chile

Patria, R.-V. 1998. The making of Latin London: Salsa music, place and identity. London: Ashgate.

Peach, C. 2005. The ghetto and the ethnic enclave. In Desegregating the city: Ghettos, enclaves and inequality, edited by D. P. Varady. Albany: State University of New York Press.

Pellow, D. N. and L. Sun-Hee Park. 2002. The Silicon Valley of dreams: Environmental injustice, immigrant workers, and the high-tech global economy. New York: New York University Press. 
Pendlebury, J., M. Short and A. While. 2009. Urban world heritage sites and the problem of authenticity. Cities 26: 349-58.

Penn, A., I. Perdikogianni and C. Mottram. 2009. The generation of diversity. In Designing Sustainable Cities: Decision-making tools and resources for design, edited by R. Cooper, G. Evans and C. Boyko. Chichester: Wiley Blackwell.

Peponis, J. 1989. Space, culture and urban design in late modernism and after. Ekistics 334-5: 93-108.

Peponis, J. 1997. Topography - the architectural design of meaning [in Greek:

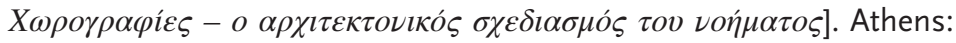
Alexandria.

Perdikogianni, I. 2003. Heraklion and Chania: A study of the evolution of their spatial and functional patterns. In 4 th International Space Syntax Symposium, edited by J. Hanson. London: University College London.

Phelps, N. A., N. Parsons, D. Ballas and N. Dowling. 2006. Post-suburban Europe: Planning and politics at the margins of Europe's capital cities. Basingstoke: Palgrave-Macmillan.

Phillips, D., C. Davis and P. Ratcliffe. 2007. British Asian narratives of urban space. Transactions of the Institute of British Geographers 32 (2): 217-35.

Pile, S. 2010. Emotions and affect in recent human geography. Transactions of the Institute of British Geographers 35 (1): 5-20.

Pinho, P. and V. Oliveira. 2009. Cartographic analysis in urban morphology. Environment and Planning B: Planning and Design 36 (1): 107-27.

Piragauta-Roldan, A. 2013. Seven Sisters market: Local market or the place where Latin-American identities are expressed in space, Unpublished MSc Advanced Architectural Studies dissertation, Bartlett School of Graduate Studies, University College London.

Pivlakis, C. 1977. Limassol in another age. Limassol: Onisilos Publications.

Polasky, J. 2001. Transplanting and rooting workers in London and Brussels: A comparative history. The Journal of Modern History 73 (3): 528-60.

Pollins, H. 1964. Transport lines and social divisions. In London: Aspects of change, edited by Ruth Glass. Centre for Urban Studies, London: MacGibbon and Kee.

Porta, S. and J. L. Renne. 2005. Linking urban design to sustainability: Formal indicators of social urban sustainability field research in Perth, Western Australia. Urban Design International 10 (1): 51-64.

Porta, S. and O. Romice. 2014. Plot-based urbanism: Towards time consciousness in place making. In Dortmunder: Vörtrage zur Stadtbaukunst [Dortmunder Lectures on Civic Art], edited by C. Mäckler and W. Sonne, Vol. 4. Sulgen, DE.

Porta, S., P. Crucitti and V. Latora. 2006. The network analysis of urban streets: A primal approach. Environment and Planning B: Planning and Design 33 (5): 705-25. 
Porta, S., V. Latora, F. Wang, E. Strano, A. Cardillo, S. Scellato, V. Iacoviello and R. Messora. 2009. Street centrality and densities of retail and services in Bologna, Italy. Environment and Planning B: Planning and Design 36(3): 450-65.

Porta, S., V. Latora and E. Strano. 2010. Networks in urban design. Six years of research in multiple centrality assessment. In Network science: Complexity in nature and technology, edited by E. Estrada, M. Fox, D. Higham and G. Oppo. London: Springer (107-30).

Porta, S., V. Latora, F. Wang, S. Rueda, E. Strano, S. Scellato, A. Cardillo, E. Belli, F. Cardenas and B. Cormenzana. 2012. Street centrality and the location of economic activities in Barcelona. Urban Studies 49 (7): 1471-88.

Portas, M. 2011. The Portas Review: An independent review into the future of our high streets. London: Department for Business, Innovation and Skills.

Portes, A. and S. Shafer. 2006. Revisiting the enclave hypothesis: Miami twenty-five years later. CMD Working Paper \#06-10, Princeton University. Available from http://www.princeton.edu/cmd/working-papers/ papers/wpo610.pdf [accessed 1 December 2014].

Potschin, M. 2009. Land use and the state of the natural environment. Land Use Policy 26(1): 170-7.

Povinelli, E. A. 2011. Economies of abandonment: Social belonging and endurance in late liberalism. Durham, NC: Duke University Press.

Pred, A. 1990. Making histories and constructing human geographies. Boulder, CO: Westview Press.

Project for Public Spaces. 2000. How to turn a place around: A handbook for creating successful public spaces. New York: Project for Public Spaces.

Putnam, R. D. 2000. Bowling alone: The collapse and revival of American community. London; New York: Simon and Schuster.

Ra'anana Heritage: Milestones. Available from http://moreshet.raanana. muni.il/web/story/milestones/hachozaa/default.Aspx [accessed 1 December 2014].

Rabinow, P., ed. 1986. The Foucault Reader. London: Penguin.

Ramat Hasharon History. Available from http://ramat-hasharon.muni.il/ en/?Page_id=464 [accessed 1 December 2014].

Relph, E. 1976. Place and placelessness. London: Pion Ltd.

Riesman, D., R. Denney and N. Glazer. 1950. The lonely crowd: A study of the changing American character. New Haven, CT: Yale University Press.

Rietveld, R. and E. Rietveld. 2014. Vacancy studies: Experiments and strategic interventions in architecture. Rotterdam, Netherlands: Naioro Publishers.

Rifkind, H. 2014. Don't mourn for the old high street. It was awful. The Times, 11 October. 
Rios, M. 2013. From a neighbourhood of strangers to a community of fate: The village at Market Creek Plaza. In Transcultural Cities: Border-crossing and placemaking, edited by $\mathrm{H}$. Jeffrey. New York; London: Routledge (176-88).

Rodney, S. 2001. Kitchener's survey of Cyprus 1878-1883. The first full triangulated survey and mapping of the island. Nicosia: The Bank of Cyprus Cultural Foundation.

Roger Tym and Partners. 2011. Industrial land demand and release benchmarks in London. London: Greater London Authority.

Roman-Velasquez, P. 1998. The making of Latin London: Salsa music, place and identity. London: Ashgate.

Rose-Redwood, R., D. Alderman and M. Azaryahu. 2008. Collective memory and the politics of urban space: An introduction. Geojournal 73 (3): $161-4$.

Rowley, T. 2006. The English landscape in the twentieth century. London and New York: Hambledon Continuum.

Rubinstein, D. 1977. Cycling in the 1890s. Victorian Studies 21 (1): 47-71.

Ruiz-Apilánez, B., J. M. de Ureña and E. Solís. 2014. Revitalising the street: Redesign strategies [in Spanish: La revitalización de la calle: Estrategias basadas en la remodelación]. Ciudad y Territorio Estudios Territoriales XLVI: 1-19.

Saha, A. and S. Watson. 2013. Suburban drifts: Mundane multiculturalism in outer London. In RC21 Resourceful Cities conference. Berlin: Humboldt-University.

Schulz, S., G. Jivén, I. Malmqvist, J. Stenberg and L. Särnbratt, eds. 2004. Architecture matters: About safety and overall satisfaction in four neighbourhoods [in Swedish: Arkitektur betyder om trygghet och trivsel i fyra stadsdelar]. Gothenburg: Chalmers University of Technology.

Seamon, D. 1980. Body-subject, time-space routines and place ballets. In The human experience of space and place, edited by A. Buttimer and D. Seamon. London: Croom Helm (148-65).

Seamon, D. 2004. Grasping the dynamism of urban place: Contributions from the work of Christopher Alexander, Bill Hillier and Daniel Kemmis. In Reanimating Places: A geography of rhythms, edited by T. Mels. London: Ashgate.

Seamon, D. 2013. Lived bodies, place, and phenomenology: Insights from Edmund Husserl, Maurice Merleau-Ponty, Edward Casey, Jane Jacobs, and Eric Klinenberg. Journal of Human Rights and the Environment (special issue on human bodies and material space) 4 (2): 143-66.

SELAS. 2011. Road map of Limassol (town \& district). Nicosia, Cyprus: SELAS Publications Ltd. 
Sennett, R. 1992 [1990]. The conscience of the eye: The design and social life of cities. New York: W. W. Norton.

Serra, M. and P. Pinho. 2011. Dynamics of periurban spatial structures: Investigating differentiated patterns of change on Oporto's urban fringe. Environment and Planning B: Planning and Design 38 (2): 359-82.

Serra, M. and P. Pinho. 2012. Emergent configurational effects of differentiated growth patterns at Oporto's urban fringe. In 8th International Space Syntax Symposium, edited by M. Greene, J. Reyes and A. Castro. Santiago: Pontificia Universidad Católica de Chile.

Severis, R. C. 2006. Limassol, a town of visionaries. Limassol: Hellenic Bank.

Sevtsuk, A. and M. Mekonnen. 2012. Urban network analysis. Revue internationale de géomatique no. 2: 287-305.

Sharman, J. 2014a. Food festival saved my business. Surrey Comet. Available from http://www.surreycomet.co.uk/news/11206636._ Food_festival_saved_my_business__Surbiton_village_fete_return_ for_trader/?ref=ms [accessed 1 August 2014].

Sharman, J. 2014b. Seriously silly: How events like Surbiton Ski Sunday can teach new life skills. Surrey Comet. Available from http://www.thenorthernecho.co.uk/news/11557806.Seriously_silly__How_events_ like_Surbiton_Ski_Sunday_can_teach_new_life_skills/ [accessed 1 August 2014].

Shaviro, S. 2012. Without criteria: Kant, Whitehead, Deleuze, and Aesthetics. Cambridge, MA: The MIT Press.

Sheller, M. and J. Urry. 2000. The city and the car. International Journal of Urban and Regional Research 24 (4): 737-57.

Shpuza, E. 2009. Evolution of street networks in Adriatic and Ionian coastal cities. In 7th International Space Syntax Symposium, edited by D. Koch, L. Marcus and J. Steen. Stockholm: Royal Institute of Technology.

Sibley, D. 1995. Geographies of exclusion: Society and difference in the West. London; New York: Routledge.

Sieverts, T. 2003. Cities without cities: An interpretation of the zwischenstadt (originally in German, 1997: 'Zwischenstadt. Zwischen ort und welt'). London and New York: Spon Press.

Silverstone, R. 1997. Visions of suburbia. London: Routledge.

Simon, D. 2008. Urban environments: Issues on the peri-urban fringe. Annual Review of Environment and Resources 33: 167-85.

Sinclair, I. 2002. London orbital: A walk around the M25. London: Granta Books.

Soja, E. W. 1990. Postmodern geographies: The reassertion of space in critical social theory. London: Verso.

Soja, E. W. 2000. Postmetropolis: Critical studies of cities and regions. Oxford: Blackwell. 
Soja, E. W. 2002. Restructuring the industrial capitalist city. In Transurbanism, edited by J. Brouwer and A. Mulder. Rotterdam: v2 Publishing/Nai Uitgevers Pub (89-102).

Soja, E. 2010. Seeking spatial justice. Minneapolis: University of Minnesota Press.

South Norwood Tourist Board. Available from www.southnorwoodtourist board.com [accessed 1 August 2014].

Spiers, M. 1976. Victoria Park, Manchester: A nineteenth-century suburb in its social and administrative context. Manchester: Chetham Society.

Ståhle, A. 2005. Place syntax-geographic accessibility with axial lines in GIS. In Stockholm, Sweden, edited by L. Marcus, A. Karlström and D. Koch.

Stanilov, K. and B. C. Scheer. 2004. Suburban form: An international perspective. London: Routledge.

Statham, R. 1996. Surbiton past. Guildford: Phillimore.

Stilgoe, J. R. 1989. Borderland: Origins of the American suburb, 1820-1939. New Haven, CT: Yale University Press.

Stobart, J., A. Hann and V. Morgan. 2007. Spaces of consumption: Leisure and shopping in the English town, c. 1680-1830. London: Routledge.

Strathern, M. 1991. Partial connections. Lanham, MD: Rowman and Littlefield.

Spotlight on Surbiton. 2012. Homes and property supplement. London Evening Standard.

Swedish Government. 2007. National Policy of Urban Development: The Government Budget Proposal 2007/08:1. Stockholm: Ministry of Integration and Gender Equality.

Swedish Government. 2009. Urban Development-Annual Report of 2009 (in Swedish: Urbant Utvecklingsarbete. Årsredovisning 2009). Stockholm: Ministry of Integration and Gender Equality.

Thornbury, W. 1878. Old and new London. London: Cassell, Petter \& Galpin.

Thorns, D. 1972. Suburbia. In Sociology and the modern world, edited by J. Rex. London: MacGibbon \& Kee.

Thrift, N. 2004. Movement-space: The changing domain of thinking resulting from the development of new kinds of spatial awareness. Economy and Society 33 (4): 582-604.

Tiesdell, S. 2002. The new urbanism and English residential design guidance: A review. Journal of Urban Design 7 (3): 353-76.

Törmä, I. 2014. Morphology and adaptation: Case studies on demolition, modification and use change, MRes dissertation, Bartlett School of Graduate Studies, University College London.

Town Planning Department. 2013. Limassol local plan, edited by Town Planning Department. Nicosia: Ministry of Interior and Town Planning Department. 
Troitiño, M. Á., D. Brandis, I. del Río, M. De la Calle, J. Gutiérrez Puebla, P. Lobo and F. Martín. 1998. Toledo: Urban issues and implications for tourism [in Spanish: Toledo: Problemáticas e implicaciones urbanas en el turismo]. Ería 47: 229-325.

Turner, W. 1820. Journal of a tour in the Levant. I-III vols. Vol. II. London: John Murray.

Urban Design. 2013. Mixed Streets (Issue 125-Winter 2013). London: Nuffield Press.

Urban Task Force. 1999. The social life of small urban spaces. Abingdon: Routledge.

Urry, J. 2002. Mobility and proximity. Sociology 36 (2): 255-74.

URS Infrastructure \& Environment UK Limited. 2012. Seven Sisters regeneration at Wards Corner. Equality Impact Assessment. London. Available from http://www.minutes.haringey.gov.uk/Published/ Coooo0728/Moooo6093/Aloo030127/150612SevenSistersEQIAfinal. pdf [accessed 1 December 2014].

Van der Laan, L. 1998. Changing urban systems: An empirical analysis at two spatial levels. Regional Studies 32 (3): 235-47.

Van Nes, A. 2001. Road building and urban change: A morphological and configurative explanation of how ring roads change the pattern of distribution of shops in city and town centres. In 3rd International Space Syntax Symposium, edited by J. Peponis, J. Wineman and S. Bafna. Atlanta: Georgia Institute of Technology.

Vaughan, L. 2005. The relationship between physical segregation and social marginalisation in the urban environment. World Architecture, Special issue on space syntax 185: 88-96.

Vaughan, L. 2006. Making connections: The case of Borehamwood. Built Environment, special issue on sustainable suburbs, edited by N. Falk 32 (3): 281-97.

Vaughan, L. 2007. The spatial foundations of community construction: The future of pluralism in Britain's 'multi-cultural' society. Global Built Environment Review 6 (2): 3-17.

Vaughan, L. 2011. Beyond the ghetto: An interdisciplinary perspective on patterns of ethnicity in the built environment. UCL Sustainable Cities Report. London: University College London. Available from http://discovery.ucl.ac.uk/141063/1/BeyondtheGhetto_report.pdf [accessed 10 September 2013].

Vaughan, L. and S. Arbaci. 2011. The challenges of understanding urban segregation. Built Environment 37 (2): 128-38.

Vaughan, L. and S. Griffiths. 2013. A suburb is not a tree. Urban Design 125 (Winter): 17-19. 
Vaughan, L., D. C. Clark, O. Sahbaz and M. Haklay. 2005. Space and exclusion: Does urban morphology play a part in social deprivation? Area $37(4): 402-12$.

Vaughan, L., S. Griffiths, M. Haklay and C. E. Jones. 2009a. Do the suburbs exist? Discovering complexity and specificity in suburban built form. Transactions of the Institute of British Geographers 34 (3): 475-88.

Vaughan, L., C. E. Jones, S. Griffiths and M. Haklay. 2009b. The spatial signature of suburban 'active' centres. In 7 th International Space Syntax Symposium, edited by D. Koch, L. Marcus and J. Steen. Stockholm: Royal Institute of Technology.

Vaughan, L., M. Haklay, S. Griffiths and C. E. Jones. 2010a. The shape of belonging in the outer London suburbs: Beyond a discourse of alienation. In PLiC - Public Life in the in-between-City International Conference, edited by I. Aravot. Faculty of Architecture and Town Planning, Technion: Technion, Israeli Institute of Technology.

Vaughan, L., C. E. Jones, S. Griffiths and M. Haklay. 2010b. The spatial signature of suburban town centres. Journal of Space Syntax 1 (1): 77-91.

Vaughan, L., A. Dhanani and S. Griffiths. 2013. Beyond the suburban high street cliché - a study of adaptation to change in London's street network: 1880-2013. Journal of Space Syntax 4 (2): 221-41.

Vaughan, L., I. Törmä, A. Dhanani and S. Griffiths. 2015. An ecology of the suburban hedgerow, or: how high streets foster diversity over time. In 10th International Space Syntax Symposium, edited by K. Karimi, L. Vaughan and K. Sailer. London: University College London.

Vázquez, A. 2000. Report on the state of Toledo's historic city [in Spanish: Informe sobre la situación del casco historico de Toledo]. Añil: Cuadernos de Castilla-La Mancha 21 (Autumn): 62-5.

Vázquez, A., P. Morollón, E. Llorente and J. Blanco. 2000. Study of the evolution of Toledo's historic centre (1995-1998) [in Spanish: Estudio de la evolución del casco histórico de Toledo (1995-1998)]. Toledo: Universided de Castilla-La Mandra.

Verburg, P. H., J. R. R. van Eck, T. C. M. de Nijs, M. J. Dijst and P. Schot. 2004. Determinants of land-use change patterns in The Netherlands. Environment and Planning B: Planning and Design 31 (1): 125-50.

Versluis, L. 2013. Towards a multi-scale description of choice. In 9th International Space Syntax Symposium, edited by Y. O. Kim, H. T. Park and K. W. Seo. Seoul: Sejong University.

Vidler, A. 2011. The scenes of the street, and other essays. New York: Monacelli Press.

Wagner, R. 1975. The invention of culture. Englewood Cliffs: Prentice-Hall. 
Waldinger, R. 2003. Networks and niches: The continuing significance of ethnic connections. In Race, ethnicity and social mobility in the US and UK, edited by G. Loury, T. Moodod and S. Teles. New York: Cambridge University Press.

Walsh, J. 2013. The true Lake District? The day I wandered lonely as a cloud ... in South Norwood. The Independent, 5 April 2013. Available from http:// www.independent.co.uk/news/uk/home-news/the-true-lake-districtthe-day-i-wanderedlonely-as-a-cloud-in-south-norwood-8562620.html [accessed 1 August 2014].

Walthamstow Tourism. Available from http://www.walthamstowtourism. co.uk/index.html [accessed 1 August 2014].

Warner, S. B. 1962 (1978 edition). Streetcar suburbs: The process of growth in Boston 1870-1900. London: Harvard University Press.

Watson, S. 2009. The magic of the marketplace: Sociality in a neglected public space. Urban Studies 46 (8): 1577-91.

Webber, M. 1963. Order in diversity: Community without propinquity. In Cities and Space, edited by L. Wingo. Baltimore, MD: The John Hopkins Press.

Weber, R. 1995. On the aesthetics of architecture: A psychological approach to the structure and the order of perceived architectural space. Aldershot, UK: Avebury.

Webster, R. 2000. Expanding suburbia: Reviewing suburban narratives. New York: Bergahn Books.

Weightman, G. and S. Humphries. 1984. The making of modern London, 1914-1939. Vol. 2. London: Sidgwick \& Jackson.

Wessendorf, S. 2010. Commonplace diversity: Social interactions in a superdiverse context. Göttingen: Max Planck Institute for the Study of Religious and Ethnic Diversity. Working Paper Series: Paper 10-11. Available from http://www.mmg.mpg.de/?id=25\#c11425 [accessed 7 January 2015].

Wessendorf, S. 2013. Commonplace diversity and the 'ethos of mixing': Perceptions of difference in a London neighbourhood. Identities 20 (4): 407-22.

Wessendorf, S. 2014. Researching social relations in super-diverse neighbourhoods: Mapping the field. Birmingham: University of Birmingham.

Whitehand, J. W. R. 1967. Fringe belts: A neglected aspect of urban geography. Transactions of the Institute of British Geographers 41: 223-33.

Whitehand, J. W. R. 1975. Building activity and intensity of development at the urban fringe: The case of a London suburb in the nineteenth century. Journal of Historical Geography 1 (2): 211-24.

Whitehand, J. W. R. 2001a. British urban morphology: The Conzenian tradition. Urban Morphology 5 (2): 103-9. 
Whitehand, J. W. R. 2001b. Changing suburban landscapes at the microscale. Tijdschrift voor Economische en Sociale Geografie 92 (2): 164-84.

Whitehand, J. W. R. and C. Carr. 1999a. The changing fabrics of ordinary residential areas. Urban Studies 36 (10): 1661-77.

Whitehand, J. W. R. and C. Carr. 1999b. England's interwar suburban landscapes: Myth and reality. Journal of Historical Geography 25 (4): 483-501.

Whitehand, J. W. R. and C. M. Carr. 1999c. England's garden suburbs: Development and change. In Changing suburbs: Foundation, form and function, edited by R. Harris and P. Larkham. London: E\&F Spon.

Whitehand, J. W. R. and C. M. H. Carr. 2001. Twentieth-century suburbs: A morphological approach. London: Routledge.

Whitehand, J. W. R. and P. J. Larkham. 1991. Housebuilding in the back garden: Reshaping suburban townscapes in the midlands and south east England. Area 23 (1): 57-65.

Whitehand, J. W. R., P. J. Larkham and A. N. Jones. 1992. The changing suburban landscape in post-war England. In Urban landscapes: International perspectives, edited by J. Whitehand and P. J. Larkham. London; New York: Routledge.

Whitehand, J. W. R., N. J. Morton, and C. M. H. Carr. 1999. Urban morphogenesis at the micro-scale: How houses change. Environment and Planning B: Planning and Design 26 (4): 503-15.

Whitehand, J. W. R., K. Gu, M. P. Conzen and S. M. Whitehand. 2014. The typological process and the morphological period: A cross-cultural assessment. Environment and Planning B: Planning and Design 41 (3): 512-33.

Whitehead, A. N. 2006. The concept of nature. The Tarner Lectures delivered in Trinity College Cambridge November 1919. Teddington: The Echo Library.

Wickstead, H. 2013. The goat boy of Mount Seething: Heritage and the English suburbs. In New Suburban Stories, edited by M. Dines and T. Vermeulen. London; New York: Continuum. London: Bloomsbury Press.

Whyte, W. H. 1956. The organization man. New York: Simon and Schuster.

Whyte, W. H. 1980. The social life of small urban spaces. USA: Project for Public Spaces Inc.

Whyte, W. H. 1988. City: Rediscovering the centre. New York: Doubleday.

Whyte, W. H., ed. 1993 (1957). The exploding metropolis. Berkeley and Los Angeles, CA: University of California Press.

Wiese, A. 2004. Places of their own: African American suburbanization in the twentieth century. Chicago; London: University of Chicago Press.

Williams, R. 1975. The country and the city. St Albans: Paladin. 
Willmott, P. and M. Young. 1960. Family and class in a London suburb. London: Routledge and Kegan Paul.

Wise, A. 2005. Hope and belonging in a multicultural suburb. Journal of Intercultural Studies 26 (1-2): 171-86.

Wise, A. 2006. Multiculturalism from below: Transversal crossings and working class cosmopolitans. In Everyday Multiculturalism Conference Proceedings, edited by S. Velayutham and A. Wise. Macquarie University, 28-29 September 2006. Sydney: Centre for Research on Social Inclusion, Macquarie University.

Wolmar, C. 2013. To the edge of the world: The story of the trans-Siberian railway. London: Atlantic Books Ltd.

Wunsch, J. L. 1995. The suburban cliché. Journal of Social History 28 (3): 643-58.

Young, M. and P. Willmott. 1957 (1962 edition). Family and kinship in East London. Harmondsworth, Middlesex: Penguin (Pelican Books).

Zambonelli, V. 2013. Brazilian restaurants and the transcultural making of place in Tokyo. In Transcultural cities: Border-crossing and placemaking, edited by $\mathrm{H}$. Jeffrey. New York; London: Routledge.

Zárate, M. A. 2007. Tourist strategies and practices in a world heritage city, Toledo [in Spanish: Estrategias y prácticas turísticas en una ciudad patrimonio de la humanidad, Toledo]. Geographicalia 51: 81-106.

Zárate, M. A. and A. Vázquez. 1983. The historic centre of Toledo: A living urban space? [in Spanish: El casco histórico de Toledo: ¿un espacio urbano vivo?]. Toledo: Editorial Zocodover.

Zhang, J. 2005. Shaping the pattern: A historical perspective on the interaction between space and function in Clerkenwell. In 5th International Space Syntax Symposium, edited by A. van Nes. Amsterdam: Techne Press.

Zukin, S. 1995. The cultures of cities. Cambridge, MA: Blackwell. 



\section{Index}

A

active centre, 7, 100, 305

active frontage, 126; see also street

frontage

adaptability

of buildings, $4,56,168,170-2$

of high streets or centres, 7,21 ,

102-3, 104, 153, 167, 192, 206,

235,305

of cities, 79

anti-suburbanism, 26

artists

graphic, 28, 218

John Constable, 5

local, 218, 286

William Logsdail 36

axial map see space syntax methods

Australia, 12, 26, 264

\section{B}

background network, 114, 182-3, 193,

$$
\text { 201, 243, } 261
$$

see also foreground network

bakers, 112, 206, 269

Barnet, see High Barnet

BBC

Monty Python (TV), 291

Turn Back Time (Flickr group), 36

Birmingham, 18, 20

Birmingham University, 56

Brussels, Belgium, 4, 17

built form

continuity and change, $37,58,77,85$,

155 et seq, 189, 199-200, 205 suburban, 18-9

see also Urban Morphology

butcher, baker, candle-stick maker

(nursery rhyme), 153, 199

\section{C}

Canada, 21

carnival parades, 85, 288, 293-4, 297

Central Place theory, 21

centrality

Centrality as a Process theory, 78-9, $150,156,263$

and diversity, 105

modelling method, 105

suburban, 53, 162 et seq, 225, 248

urban, 14, 134

see also space syntax theory

charity shops (as sign of decline), 41,

153, 305

children, 37, 90, 274-5

children's stories, 32

childhood memories, 23, 177

Children of Seething, 295

choreography of movement, 202

see also street ballet

churches

as suburban land use, 160, 188, 191,

198, 206

conversion to other uses, 39

Katholiki, Nicosia, 82

St John the Baptist, Barnet, 59

St Martin-in-the-Fields, London

36

Union Church, Islington, 184 
cinemas, 188,198

decline as suburban land use

94-95

cities see urban

clone towns, 33, 153

coffee shops, 111, 275, 298

as social place $35,188,289$

Colombia, 267 et seq

community

and co-presence, 39-42, 48-49

and suburban identity, 15, 104, 264,

291

demise of, 25

everyday practice of, 32,36

facilities or activities, 23, 33, 41, 142,

184, 208, 264

memory, 46

presence in the high street, 105, 109,

$187,235,243$

common culture, 279

commuting

and dynamics of suburban activity,

55, 154, 197, 267, 291

and urban growth, 58, 234

as aspect of transport evolution, 5 ,

$17,58,180,266$

contributing to demise of suburban

life, 25,125

configuration

and continuity and change over time,

79-80, 105, 130 et seq, 171, 176

and land use distribution, 78

and movement flows, 78, 102,

$156-8,263$

and social interaction, 239, 286

of built form, 19

of spatial networks, 42 et seq, 72,

155

constituted space, 105, 244-5, 247

consumption, 25,27

co-presence

and movement flows, 161-2, 197

as outcome of spatial configuration

or diversity, 78, 168, 173, 202 as potential for interaction, 241,282 , 296

as source of social energy, 40

countryside see rural

crafting, 153, 212, 271, 288 et seq

conceptual crafting 293-4

cultural images, 27, 32, 53

cycling (bicycles), 97, 230, 233

D

deformed wheel theory, 182-3

see also space syntax theory

demographic change, 16, 101, 131-3,

$$
144-50
$$

density

inner-city, 64, 179

of high street activities, 108, 157, 185

of population, 252

of suburban buildings, 26-7, 33, 189, 191, 244

of suburban networks, 64-7

diachromesh, 41, 45

diachronic analysis see temporal analysis

diversity

economic or land-use, 105, 154

et seq, 188-9, 204, 208, 261, 269

social or ethnic, $26,83,245,264,267$

superdiversity, 264

Durkheim, Émile (Durkheimian ideas),

$$
\text { 40-1 }
$$

\section{E}

ecological conceptions, 19, 155-6, 171-3, 209

economy

edge city, 12, 16, 33, 73, 78

local, $82,130,204,222,285$ et seq

night-time, 39, 149, 206-8, 258

tourist, 132

see also movement economy theory

edge effect, 61,185

eighteenth century, 5, 16, 34, 58, 155, 178 
employment, 22, 55, 83, 209

unemployment 258

ethnicity, 24, 197, 264

and multiculturalism 26

cross-cultural interaction 26, 264-5

see also race and immigrants

ethnography, 23, 26, 157, 268, 290

et seq

$\mathbf{F}$

fieldwork see ethnography

film

as cultural signifier, $272-3$

fast food, 39

film studios, 29

food, 35, 206, 295

local, 303

suburban depiction in, $14,27-28$

foreground network, 182, 243, 261

see also background network

fringe belt see Urban Morphology

G

\section{Garden City}

Garden City movement, 27

garden suburbs, 27, 226

in Tel Aviv area, 226 et seq

in Tripoli, 106 et seq

gardens, 290, 296

see also public gardens

geography

human, 18, 241

suburban, 16

urban, 15, 105

see also psychogeography

Gothenburg, Sweden, 239 et seq

grid intensification, 74, 100, 263

$\mathrm{H}$

heritage, 41, 215

absence in the suburbs, 291

presence in the suburbs, 215-6

Toledo as World Heritage site, 131

et seq high streets

death of, 36, 153,290, 305

employment in, 208, 224, 283, 285

high-technology see Silicon Valley

history

case studies, 20

local, 44

morphological, 40-1

of events, 42

of the high street, 36-7

the past as a foreign country, 34

see also heritage and topoi

I

immigrants, 17, 226, 244 et seq

see also ethnicity

industry

causing move to the suburbs, 27

high-technology, 29

in the city, 16

in the suburbs, 20, 209, 212, 215

intelligibility, 156, 173

L

land uses

attractors, 49, 78, 263

secondary, 84, 104, 167

landscape, 214

urban, 154, 184, 241

see also ecological conceptions

language skills, 268, 274, 279-81

Levittown, 18, 23

Limassol, Cyprus, 77 et seq

London Plan (The), 60, 213

London Underground, 59, 267

London

Barnsbury, 179 et seq

Blackhorse Lane, 211 et seq

Camberwell, 4, 16, 20

Canonbury, 177, 179-80

City of, $5,42-3,45,58,178$

Clapham, 39

Hampton Court Palace, 61

High Barnet, 57 et seq, 157 et seq 
London (continued)

Islington, 175 et seq

Loughton, 58 et seq

Peckham, 205, 208

'Seething' (Surbiton), 294 et seq

Seven Sisters Market, 264 et seq

South Norwood, 37, 39, 58 et seq, 157 et seq, 287, 292 et seq

Surbiton 57 et seq, 157 et seq

287 et seq

Redbridge, 205-8

Tottenham, 208-15, 283

Walthamstow, 214, 218, 266, 288

longitudinal study see temporal analysis

Los Angeles, 20, 48

\section{M}

markets

as home away from home, 268

indoor, 264

street, 2, 35, 102, 133, 174n, 182, 302

material culture, 23, 155

middle-class, 17, 23, 39, 179-80, 264, 266, 287, 290-1

Million Homes Programme, 240, 249

mixed-use see diversity

morphological event, 32 et seq

morphology see Urban Morphology

movement economy theory, 75, 158, 182

see also space syntax theory

Multiple Centrality Assessment method, 106

mundanity, 28, 156, 264, 290, 303

municipality offices or town halls, 85 , 94, 133, 191, 199

\section{N}

narratives, $12,20-1,33,43-4,46,289$

natural movement theory, 192

see also space syntax theory

neighbourhood unit principles, 249,

$$
\text { 256, } 261
$$

New Urbanism, 27

nightlife see economy nineteenth century

as golden age of suburbia, 20

social decline, 24-25, 27

suburban trade, 34

suburban commercial activity, 159

suburban manufacturing in, 16, 22,

58

suburban growth, $16,35,81,179-180$

see also railways

non-domestic land uses, 2, 129, 159-62, 185

Non-Plan, 33-4

nonsense, 288 et seq

North America see USA

O

offices, 149, 155, 188, 199

out-of-town shopping, 50n, 204, 224,

233

see also shopping

$\mathbf{P}$

parades see carnival parades

path-dependency, 6, 75, 159

peri-urban see urban periphery

Persia, 1

persistence, 21, 30, 75 et seq, 171, 175

photography, 271

Halley Docherty method 36, 39, 48, 5on

Place Syntax Tool, 247, 250-1

planning

battles, 282

studies, 4

town planning, 81,84

utopian ideas, 42, 53

polycentricity, 22

post offices, 94-5, 188, 206

poverty, 29

Charles Booth poverty map, 173, 180 see also segregation, economic

pride

civic, 25

suburban, 292 
psychogeography, 28

public gardens, 87, 94

Sadler's Wells, 178

public houses see pubs

public space, $85,109,136,240-50,261$, 294

public squares, 180, 308

public transport see railways and London Underground

pubs, $39,188,198-9,298$

R

race, 17

see also ethnicity

railways, 5, 16, 22, 34

retail see shopping

rhythms

musical, 269

spatial, 110, 199, 202, 294, 298

temporal, 31, 37, 43-4, 154, 293, 305

see also street ballet

rivers, $43,85,131,159$

as barrier, 82, 254

as source of imaginary history 288 et seq

Roman

London, 42

Toledo, 131

Tripoli, 111-2

rural

suburban growth into countryside, 157,263

retreat, 266

past or nostalgia for, 15, 24, 73

in contrast to suburbs, 22,24

segment map see space syntax

methods

\section{S}

segregation

economic, 242, 244

ethnic, 17, 29, 239 et seq

spatial, 12

semiology, 46,48 servants, 23

Sheffield, 35, 263

shopping, 91

high street, 180, 204-5, 230

internet shopping, 33, 56

shopping malls, 33-4, 248, 265, 275

et seq.

window-shopping, 139

See also out-of-town shopping

Silicon Valley, 25, 29

slums, 17, 27

social encounter and interaction, 39,

109, 128

amongst neighbours, 246

in high streets, 130, 163, 241

reinforcing a sense of belonging

locally, 296

within markets, 275

see also co-presence

social isolation, $23-4,280-1$

space syntax measures

changes in values over time, 78 ,

162,193

choice and integration correlations,

$159,161,164$

combined integration and choice, 185

equivalence to Multiple Centrality

Assessment, 107

normalisation, 88

space syntax methods, 80, 88, 134, 247

space syntax theory, $78,156,197,242$,

247

spatial culture, 175, 177

spatial determinism, 26, 242

sprawl, 22, 29, 33, 55, 102

Zwichenstadt, 22

Stockholm, Sweden, 241 et seq

street ballet, 37, 154

street frontage, 107-108, 116-117,

$$
122-123,125-126,132,141
$$

suburban concepts, 29, 26

as terra nullius, 291

as 'The Good Life', 20, 27 
suburban studies, 11-2, 15-6, 24

supermarkets, $163,269,273,298$

see also shopping

T

take-away restaurants, 39, 41, 85

Tel Aviv, Israel, 224 et seq

television

suburban depiction in, 27, 39, 290-1

television companies, 298

temporal analysis, 42-4, 48, 88, 103,

192, 197, 201-2

temporal intelligibility, $45-6$

temporal processes, 3-4, 34 et seq, 64, $94,156,192$

theatres, 86, 188, 198-9

Toledo, Spain, 130 et seq

topoi, 45-9

tourists, 84, 90, 131, 287-8, 292-3

transport see London Underground and railways

Tripoli, Libya, 112 et seq

twentieth century

motor cars, 5

social change, 23

social decline, 131

suburban growth, 78, 158, 226

\section{U}

urban periphery, 12, 15, 18, 28, 54-7,

$72-5,201,224$

as tabula rasa, 12, 55

favelas, 12
Urban Morphology

burgage plots, 155, 174n

fringe belt, 18

micromorphology, 189

urban grain, $44-5$

urban

compactness, 113

in contrast with suburban, 22 et seq, 73

USA, 5, 11-12, 15-6, 21-2, 27-8, 153

V

villages

'Seething', 295

as origins of suburb, 178

Colombian, 271

'executive', 28

historical, 21, 34, 92

metropolitan, 21

urban, 22, 35, 81

village greens, 27

virtual community theory, 40, 44, 161 see also space syntax theory

W

women

domestic sphere, 23

dominance on high street, 228, 230

engagement with modernity, 23

working from home, 2, 302

working-class, 20, 25-6

Z

zoning, 33, 81, 244 
Suburban space has traditionally been understood as a formless remnant of physical city expansion,

without a dynamic or logic of its own. Suburban Urbanities challenges this view by defining the suburb as a temporally evolving feature of urban growth. Anchored in the architectural research discipline of space syntax, this book offers a comprehensive understanding of urban change, touching on the history of the suburb as well as its current development challenges, with a particular focus on suburban centres. Studies of the high street as a centre for social, economic and cultural exchange provide evidence for its critical role in sustaining local centres over time. Contributors from the architecture, urban design, geography, history and anthropology disciplines examine cases spanning Europe and around the Mediterranean. By linking large-scale city mapping, urban design scale expositions of high street activity and local-scale ethnographies, the book underscores the need to consider suburban space on its own terms as a specific and complex field of social practice.

LAURA VAUGHAN is Professor of Urban Form and Society at the Bartlett School of Architecture, University College London. In addition to her longstanding research into London's suburban evolution, she has written on many other critical aspects of urbanism.

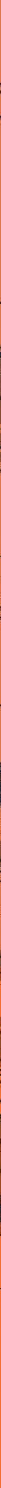

